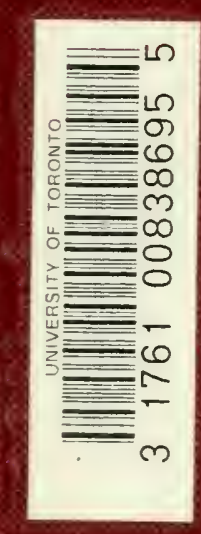


Digitized by the Internet Archive in 2008 with funding from Microsoft Corporation 


READINGS IN EVOLUTION, GENETICS, AND EUGENICS 
THE UNIVERSITY OF CHICAGO PRESS CHICAGO, ILLINOIS

THE BAKER \& TAYLOR COMPANY

NEW YORK

THE CAMBRIDGE UNIVERSITY PRESS

LONDON

THE MARUZEN-KABUSHIKI-KAISHA

TOKYO, OSAKA, KYOTO, FUEUOKA, SENDAI

THE MISSION BOOK COMPANY

SHANGHAI 


\title{
READINGS IN EVOLUTION, GENETICS, AND EUGENICS
}

\author{
By \\ HORATIO HACKETT NEWMAN \\ Professor of Zoollogy in the \\ University of Chicago
}

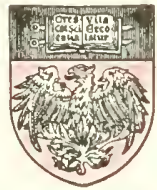

$\frac{169763}{10.3 .22}$

THE UNIVERSITY OF CHICAGO PRESS

CHICAGO, ILLINOIS 
Copyright ro2i By

The University of Chicago

All Rights Reserved

Published October 1921

Second Impression December 1921

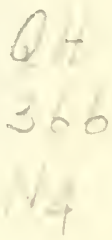

Composed and Printed By The University of Chicago Press Cricago, Illinois, U.S.A. 
THIS VOLUME

IS AFFECTIONATELY DEDICATED

TO

MY MOTHER 



\section{PREFACE}

This book has been prepared to meet a specific demand, long felt here and elsewhere, for an account of the various phases of evolutionary biology condensed within the scope of one volume of moderate size. The present writer has now for sixteen successive years presented in lecture form to large classes of students the subjects of evolution, genetics, and eugenics. Never have we been able to find a single book that would cover the required ground. In fact it has been necessary to require, or at least to recommend, as many as three books. It is believed that the present book will furnish adequate reading material for a major or a semester course in evolutionary biology. Some supplementary reading may be necessary in case an instructor wishes to emphasize one or more phases of the subject; but for a first course in the subject we believe that all of the essential reading material will be found within the text itself.

An effort has been made to present the subject in the best perlagogical order. After a general introduction, a rather long chapter appears in which the whole history of the development of evolutionary science is outlined, together with the names and contributions of the leading evolutionists. Part II is a presentation of the evidences of organic evolution, beginning with the bodies of evidence most definite and direct, and ending with the less definite and more controversial. Part III deals with causo-mechanical theories of evolution with Darwinism as the central topic. Part IV concerns itself with genetics or modern experimental evolution, and Part $Y$ with eugenics, or genetics as applied to human improvement.

The book consists largely of excerpts, some long and some short, from both the older classical evolutionary writers and the modern writers. Our aim has been to select the most significant or characteristic passages from each author. In most cases this ideal has been attained, but it has sometimes happened that we have had to make our selection of material to meet a real need in the book, and accordingly have selected from an author a passage he himself might not consider particularly characteristic of his work. We have succeeded, nevertheless, in welding together out of a collection of isolated chapters and passages what seems to us to be a close approach to a coherent unit. Unification has been accomplished by the aid of editorial connecting passages, introductory, statements, criticisms, and summaries. In certain cases it became necessary, for a variety of reasons, 
for the editor to write short chapters on certain topics that were not presented in the available literature in sufficiently brief compass or in sufficiently non-technical language.

The one-man textbook is only too often written to emphasize the author's pet theories and is likely to be unduly biased. The present work is completely non-partisan. It consists of the writings of many authors and presents many diverse theories. The student is left to balance the various views one against another and to form his own judgment.

It is very unfortunate, but none the less true, that even in these scientific days, the subject of evolution has a bad name in many communities and in many educational institutions with religious affiliations. The mistake is made of supposing that evolution and religion are diametrically opposed. The present writer has been at some pains to make it clear that evolution and religion are strictly compatible. We teachers of evolution in the colleges have no sinister designs upon the religious faith of our students.

While this book is intended primarily for a college textbook, we have also had in mind the general reader. Apart from a few of the more technical details, the text seems to us very readable. The language of the great classic writers-Darwin, Wallace, Romanes, De Vries, Le Conte-is simple and lucid. Among recent biological books few are written so freshly and vividly as those of Professor J. Arthur Thomson. The clearness and scientific accuracy of Conklin, Saleeby, Guyer, Walter, Lull, Osborn, the Coulters, Downing, Shull, Tayler, Popenoe, Johnson, and others, are familiar to American biologists.

Scrupulous care has been taken to verify all passages quoted, but it is hardly likely that, in so large a mass of material, all errors shall have been avoided. The author and the publishers would welcome as a favor any suggestions or corrections submitted by interested readers.

A list of fifty books from which material has been quoted is given on pages 510-512. To the authors and publishers of these books and monographs we wish herewith to tender our grateful acknowledgments for their generosity and co-operation. A considerable amount of material for which permission to reprint had been granted fails to appear in the present volume. It is hoped to incorporate this material in an appendix to a later edition, or else to use it in the form of a small volume of supplementary readings.

August 15, 1921

H. H. N. 


\section{TABLE OF CONTENTS}

List of Illustrations . . . . . . . . . . . . . xV-XViii

\section{PART I. INTRODUCTORY AND HISTORICAL}

Chapter I. Introduction

What Organic Evolution Is-Definitions . . . . . . . 3

The Modern Attitude as to the Truth of the Evolution Doctrine . 5

What Organic Evolution Is Not . . . . . . . . . 8

Chapter II. Historical Account of the Development of the Evolution Theory. H. H. . . . . . . . . . . . IO

Evolution among the Greeks . . . . . . . . . . . II

Post-Aristotelians . . . . . . . . . . . I4

The Early Theologians . . . . . . . . . . . I4

The Revival of Science . . . . . . . . . . I5

The Great Naturalists of the Eighteenth Century . . . . . 16

Lamarck . . . . . . . . . . . . I8

Cuvier and Geoffroy St. Hilaire. . . . . . . . . 21

Catastrophism and Uniformitarianism . . . . . . . 22

The Reawakening of the Evolution Idea . . . . . . . $23=$

Charles Darwin . . . . . . . . . . . . . 24

Summary of Darwin's Theories . . . . . . . . 25

Contemporary Opinion Regarding the Validity of Darwin's Views 27

Isolation Theories. . . . . . . . . . . . . . 32

Orthogenesis Theories . . . . . . . . . . . . . 33

Mutation or Heterogenesis Theories . . . . . • . . 36

The Rise and Vogue of Biometry . . . . . . . . . 38

Modern Experimental Evolution . • • . • . . • . . 39

Mendel's Laws . . . . . . . . . . . . . . . 4 I

Hybridization and the Origin of Species . . . . . . . 43

Neo-Mendelian Developments . . . . . . . . . 43

Heredity and Sex . . . . . . . . . . . 44

Chapter III. The Relation of Evolution to Materialism.

Joseph Le Conte. . . . . . . . . . . . . . . 46

\section{PART II. EVIDENCES OF ORGANIC EVOLUTION}

Chapter IV. Is Organic Evolution an Established Principle?

H.H.N. . . . . . . . . . . . . . . . . 57

Chapter V. Evidences from Palaeontology • . • • . . 6 I

Strength and Weakness of the Evidence . . . . . . . 6I 
Other Opinions as to the Adequacy of the Evidences from Palaeontology . . . . . . . . . . . . . . . 62

What Fossils Are and How They Have Been Preserved. . . . 63

Fossils Classified . . . . . . . . . . . . 63

On the Conditions Necessary for Fossilization . . . . . . 64

On the Lapse of Time during Which Evolution Is Believed to Have Taken Place.

On the Principal General Facts Revealed by a Study of the Fossils Fossil Pedigrees of Some W'ell-known Vertebrates . . . . . 70 Pedigree of the Horse . . . . . . . . . . 70

Pedigree of the Camels. H. B. Scoll . . . . . . . . 73

Evolution of the Elephants. A. Franklin Shull . . . . . 76

Chapter VT. The Evolution of Man: Palaeontology. Richard

Swann Lull . . . . . . . . . . . . . . . 8I

Origin of Primates . . . . . . . . . . 8 I

Origin of Man. . . . . . . . . . . . 82

Fossil Man. . . . . . . . . . . . . 84

Evidences of Human Antiquity . . . . . . . . • • . 94

Future of Humanity . . . . . . . . . . • • • 95

Chapter ViI. Evidences from Geographic Distribution • 97

Some of the More Significant Facts about the Distribution of

Animals . . . . . . . . . . . . . . IOI

The Fauna of Oceanic Islands. George John Romanes . . . IoI

The Fauna of Madagascar and New Zealand. A. R. IV allace.. I Io

The Distribution of Marsupials. A. R. Hallace . . . . . II I

The Distribution of Birds. A. R. IVallace. . . . . . . II 2

Summary of Mammalian Dispersal. Hans Gadow . . . . II4

Summary of the Argument for Evolution as Based on Geographic

Distribution. . . . . . . . . . . . . . II5

Chapter V'tit. Evidences from Classification. • • • - II7

The Principles of Classification. A. F. Shull . . . . . . II7

The Method of Classification. Charles Darwin . . . . . I20

What Is a Species? . . . . . . . . . . . . I2I

Cilapter IX. Evidence from Blood Tests. W. B. Scott . . I 24

Chapter X. Evidences from Morphology (Comparative Anat-

omi). George John Romanes . . . . . . . . . . 129

Citapter XI. Evidences from Embryology . . . . . . . I64

The Facts of Reproduction and Development . . . . . . I64

Outline of Animal Development. D. S. Jordan and V. L. Kellogg . ${ }_{1} 65$

Cijapter xit. Critique of the Recapitulation Theory. W. $B$.

Scolt. . . . . . . . . . . . . . . $\mathbf{1} 73$ 


\section{PART III. THE CAUSAL FACTORS OF ORGANIC EVOLUTION}

Chapter XiII. Introductory Statement ........ I85 What We Owe to Darwin . . . . . . . . . . r 86

Citapter XiV. The Background of Darwinism-

Adaptations. H. H.N. . . . . . . • • • • . 188

Laws of Adaptation . . . . . . . . . . . . I92

Adaptations Classified . . . . . • . . • . . I95

Some Special Adaptations . . . . . . . . . . 196

Parasitism and Degeneration . . . . . . . . . 197

Color in Animals . . . . . . . . . . . . . 200

Chapter XV. Tiie Background of Darwintsm-Continued • 206

The Web of Life. J. Arthur Thomson . . . . . . . 206

Chapter XVi. Natural Selection. Charles Darwin ¿ . . . 219

Foundation Stones of Natural Selection . . . . . . . 2 I9

Darwin's Own Estimate as to the Rôle of Natural Selection in Evolution . . . . . . . . . . . . . . 2 I9

Effects of Habits and the Use or Disuse of Parts; Correlated Variation; Inheritance. . . . . . . . . . 220

Darwin's Idea of the Causes Responsible for the Origin of Domes-

tic Races . . . . . . . . . . . . . . . $22 \mathrm{I}$

Darwin's Idea of the Origin of Varieties, Species, and Genera in

Nature . . . . . . . . . . . . 22 I

The Term "Struggle for Existence" Used in a Large Sense . . 222

Geometrical Ratio of Increase . . . . . . . . . 223

Natural Selection; Or the Survival of the Fittest . . . . . 223

Sexual Selection . . . . . . . . . . 230

Illustrations of the Action of Natural Selection, or the Survival of the Fittest. . . . . . . . . . . . 232

Summary of Chapter on Natural Selection . . . . . . 233

Difficulties and Objections to Natural Selection as Seen by Darwin 236

Chapter XViI. Critique of Darwinism . . . . . . . 245

Summary of Darwin's Natural-Selection Theory. Vernon $L$.

Kellogg . . . . . . . . . . . . . . . . . 245

Objections to Darwinism. . . . . . . . . . 247

Defense of Darwinism . . . . . . . . . 252

General Defense of Darwinism. J. L. Tayler . . . . . 253

Experimental Support of the Effectiveness of Natural Selection . ${ }_{256}$

The Present Status of Natural Selection . . . . . . . 258

The Relation of Mendelism and the Mutation Theory to Natural

Selection. C. C. Nutting . . . . . . . . . . 258 
Chapter XVIII. Other Thisories of Species-Forming • . 263

Theories Auxiliary to Natural Selection . . . . . . . $26_{3}$

Wcismann's Theory of Panmixia . . . . . . . . ${ }_{2} 63$

Weismann's Theory of Germinal Selection . . . . . . 265

Roux's Theory of Intraselection or the Battle of the Parts . . 268

Coincident Selection or Organic Selection . . . . . . 268

Isolation Theories . . . . . . . . . . . . . 269

Theories Alternative to Natural Selection . . . . . . . 273

Chapter Xix. A New Composite Causo-Mechanical Theory of Evolution (the Tetrakinetic Theory). Henry Fairfield Osborn . . . . . . . . . . . . . . 275 The Energy Concept of Life. . . . . . • • . . 275 The Four Complexes of Energy . . . . . . . . . 280

\section{PART IV. GENETICS}

Chapter XX. The Scope and Methods of Genetics . • • $\quad 287$ Definitions. . . . . . . . . . . . . 287

The Scope and Methods of Genetics . . . . . . . 287

The Importance of the Cell Theory in Genetics . . . . . . 289

Chapter XXi. The Bearers of the Heritage (an Account of the Cellular Basis of Heredity). Michael F. Guyer . . . . . 290

Cifapter XXII. Variation. Emest Brown Babcock and Roy Elwood Clausen . . . . . . . . . . . . . 307

Chapter XXili. Are Acquired Characters (Modifications) Hereditary? . . . . . . . . . . . . . . 323

Misunderstandings as to the Question at Issue. J. Arthur Thomson . . . . . . . . . . . . . . . .

The Inheritance or Non-Inheritance of Acquired Characters. Edwin Grant Conklin . . . . . . . . . . . . 330

The Other Side to the Question . . . . . . . . . 336

A Possible Mechanism for the Transmission of Acquired Characters. Michael F. Guyer . . . . . . . . . . . . . . 338

Cilapter XXiv. The Mutation Theory . . . . . . 346

New Species (MIutants) of Oenothera. Hugo De Vries . . . . 348

Summary of De Vries's Mutation Theory. Thomas II unt Morgan . 355

Criticisms . . . . . . . . . . . . . . 359

Causes of Mutations . . . . . . . . . . . . . . 360

Chapter XXV. Bionetry (the Statistical Study of Variation and Heredty). H. H.N . . . . . . . . . . 365

The Statistical Study of Variation . . . . . . . . 365

Bimodal and Multimodal Curves . . . . . . . 368

The Coefficient of Correlation . . . . . . . . . 369

Statistical Study of Inheritance. Edwin Grant Conklin . . 370 
CHAPTER XXVI. HEREDITY

Chapter XXVi. Heredity in Pure Lines. H.H.N. • • • 376

Are Determiners (Genes) Constant or Variable? . . . . . 378

Chapter XXvil. Mendel's Laws of Heredity . • . • : 380

Mendel's Life and Character. J. Arthur Thomson . . . . . 380

Mendel's Discoveries. J. Arthur Thomson . . . . . . 380

Mendel's Explanations. J. M. Coulter and M. C. Coulter . . . 386

Illustrations of Simple Mendelian Inheritance in Both Animals and

Plants. J. Arthur Thomson . . . . . . . . . . . 393

Chapter XXViII. The Physical Basis of Mendelism. Ernest B. Babcock and Roy E. Clausen . . . . . . . . . . $40 \mathrm{I}$

Chapter XXIX. Neo-Mendelism in Plants. John M. Couller and Merle C. Coulter . . . . . . . . . . . . . 4I 3

Presence and Absence Hypothesis . . . . . . . . . 4I 3

Blends . . . . . . . . . . . . . . . 415

The Factor Hypothesis . . . . . . . . . . . . . $4 \mathrm{I} 7$

Chapter XXX. Neo-Mendelian Heredity in Animals. H. H.N. 429

Illustrations of the Factor Hypothesis . . . . . . . . 429

The Factorial Analysis of Color in Mice . . . . . . . 429

Different Kinds of Albinos . . . . . . . . . . . 430

Castle's Guinea Pigs . . . . . . . . . . . . $43 \mathrm{I}$

Chapter XXXI. SeX-linked and Other Kinds of Linked Inheritance in Drosophila and Other Species. William E. Castle

Drosophila Type and Poultry Type of . • • 433

Drosophila Type and Poultry Type of Sex-linked Inheritance • 436

Chapter XXXII. Linkage and Crossing-Over. William $E$. Castle. . . . . . . . . . . . . . . . 44I

Chapter XXXili. Sex Determination. H.H.N. . . . . 449

Various Theories of Sex Determination . . . . . . . . 449

The Chromosomal Mechanism of Sex Determination . . . 450

Sex Determination in Parthenogenetic Species. . . . . . $45 \mathrm{I}$

The Poultry Type of Sex Determination . . . . . . 452

Sex Differentiation . . . . . . . . . . . 453

\section{PART V. EUGENICS}

Chapter XXXiV. The Inheritance of Human Characters, Physical and Mental. Elliol $R$. Downing . . . . . 459

Chapter XXXV. Human Conservation. Herbert E. Walter . 473

How Mankind May Be Improved . . . . . . . . . . 473

More Facts Needed . . . . . . . . . . . . . 473

Further Application of What We Know Necessary . . . . . 474

The Restriction of Undesirable Germplasm . . . . . . . 475

Control of Immigration . . . . . . . . . . . 475 
More Discriminating Marriage Laws . . . . . . 477 An Educated Sentiment . . . . . • • • . • 477

Segregation of Defectives . . . . • • • • 4778

Drastic Measures . . . . . . . . . . . . 479

The Conservation of Desirable Germplasm . . . . . 480

By Subsidizing the Fit. . . . . . . . . . . 480

By Enlarging Individual Opportunity . . . . . . . 48 I

By Preventing-Germinal Waste . . . . . . . . . 48 r

Who Shall Sit in Judgment? . . . . . . . . . 482

Chapter XXXvi. Eugenics and Euthenics. Paul Popenoe and

Roswell H. Johnson. . . . . . . . . . . . . . 484

Chapter XXXviI. The Promise of Race Culture. Caleb

Williams Saleeby . . . . . . . . . . . . 497

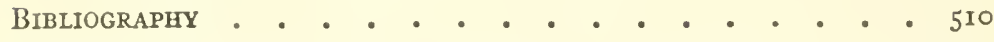

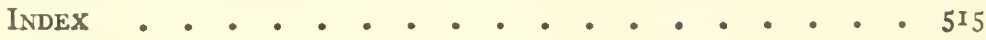




\section{LIST OF ILLUSTRATIONS}

I. Total Geologic Time Scale . . . . . . . . . 68

2. Feet and Teeth in Fossil Pedigree of the Horse . . . 72

3. Four Stages in the Evolution of the Cameline Skull . . 74

4. Four Stages in the Evolution of the Cameline Fore Foot • 75

5. Evolution of IIead and Molar Teeth of Mastodons and Elephants . . . . . . . . . . . . 77

6. Skull of Java Ape-Man, Pithecanthropus erectus . . . . 87

7. Jaws of Man and of the Apes. . . . . . . . 88

8. Restoration of Prehistoric Mien . . . . . . . . 9 90

9. Neanderthaloid Skull of La Chapelle-aux-Saints . • . 9 I

io. Skeleton of Neanderthal Man . . . . . . . . . 92

i i. Skeleton of Seal . . . . . . . . . . . . I3O

I2. Sheleton of Greenland Whale . . . . . . . . 132

I3. Paddle of Whale Compared with Hand of Man . . . I33

I4. Wing of Reptile, Mamial, And Bird . . . • • . . $\mathrm{r}_{34}$

I5. Skeleton of Dinornis gravis. . . . . . . . . . . 137

i6. Hermit Crabs Compared with Cocoa-nut Crab . . . . r39

I7. Rudimentary or Vestiglal Hind Limbs of Python • • . I4i

I8. A pteryx australis . . . . . . . . . . . . . . $\mathrm{I}_{42}$

19. Illustrations of the Nictitating Membrane in the Various

ANimals . . . . . . . . . . . . . I47

20. Rudinentary, or Vestigial and Useless, Muscles of the HuMan EAR . . . . . . . . . . . . ${ }_{4} 48$

21. Portrait of a Young Gorilla. . . . . . . . . . I49

22. Lower Extremities of a Young Child . . . . . . . I50

23. An Infant, Three Weeks Old, Supporting Its Own Weight for Over Two Minutes . . . . . . . . . . I5I

24. Sacrum of Gorilla Compared with That of Man . . . I52

25. Diagramimatic Outline of the Human Embryo When about Seven Weeks Old . . . . . . . . . . . . . I53

26. Front and Back View of Adult Human Sacrum . . . . I53

27. Appendix vermiformis in Orang and in Man . . . . . . I54

28. Appendix vermiformis IN Orang and Man, Showing Variation IN THE ORANG . . . . . . . . . . . . . . I54 
Page

29. Human Ear Modeled and Drawn by Mr. Woolner • • - 155

30. Foetus of an Orang . . . . . . . . . . . . I 56

3i. Vestigial Characters of Human Ears . . . . . . I57

32. Hair Tracts on the Aris and Hands of Man . • . . $\quad$ i59

33. Molar Teeth of Lower Jaw in Gorilla, Orang, and Man . i6 i

34. Perforations of the Humerus in Three Species of QuadRUMLANA . . . . . . . . . . . . 162

35. First Stages in the Embryonic Development of the Pond SNAIL, Lymnaeus . . . . . . . . . . . . . . I66

36. Stages in the Development of tile Prawn, Peneus potimirium i 70

37. Later Stages in the Development of the Prawn, Peneus potimirium . . . . . . . . . . . . . . . I70

38. Metaliorphosis of a Barnacle, Lepas . . . . . . . I7I

39. Embryos in Corresponding Stage of Development of SHARK, Fowl, AND MAN . . . . . . . . . . $~ I 77$

40. Three Aquatic Types of Vertebrate, to Illustrate ConVERgENT ADAPTATION . . . . . . . . . . . . I93

41. Fierasfer acus, penetrating the Anal Openings of HoloTHURLANS . . . . . . . . . . . . . . . . 199

42. Kallima, the "Dead-Leaf Butterfly" . . . . . . 202

43. Dlagram of a Cell, Showing Various Parts . . . . . 29 I

44. Diagram Showing Representative Stages in Mitotic or INDiRect Cell-Division . . . . . . . . . . . 292

45. Germ Cell Set Apart in the Eight-Celled Stage of CleavAGE IN Miastor americana. . . . . . . . . . 295

46. Chromosomes of the Mosquito and of the Fruit Fly • 297

47. Diagram to Illustrate Spermatogenesis . . . . . . 298

48. Diagram to Illustrate Oögenesis . . . . . . . . 299

49. Diagram Showing the Parallel between Maturation of the Sperm Cell and Maturation of the Ovum . . . . 300

50. Diagram to Illustrate Fertilization . . . . . . . 302

5I. Variation in Sedum speciabile Due to Differences in Color of Light . . . . . . . . . . . . . 313

52. Temperature Phases of the Diurnal Peacock-Butterfly . 314

53. Morphological Cycle of Head Height in Hyalodaphnia. 315

54. Schematic Curves of Head Height in Hyalodaphnia as Grown in Media of Three Different Food Values . . 316

55. Climatic Effects upon Plumage in Pigeons . . . . 317

56. Effects of Injections into OVary of Scrophularia. . . 319 
57. Oenothera lamarckiana.

58. A Series Showing Oenothera lamarckiana And Several of ITs

Mutants Growing Side by Side . . . . . . . . 352

59. Dlagram Showing in Condensed Form the Genealogy of rHE Oenothera lamarckiana FaMILy ANd Its V'aRIous Mutants

6o. Some Divergent Types (Mutations) of Beetles Produced by Subjecting the Germ Cells to External Influences

6r. Two Plants of Onagra biennis, Showlng the Effect of Injections of Zinc Sulphate into the Ovule . . . . 362

62. Polygon of Variation for the Total Number of Scutes in the Nine Bands of the Armadillo . . . . . . . 366

63. Bimodal Polygon Plotted from Data on the Earwig . . 369

64. Correlation Table of 400 Plants of Sixty-Day Oats * 370

65. Diagrail of Galton's "Law of Ancestral Inheritance" . 372

66. Scheme to Illustrate Galton's "Law of Filial Regression" 374

67. Diagram Illustrating Behavior of Chromosomes in Mendel's Cross of Tall and Dwarf Peas . . . . . 388

68. Diagram Illustrativg Behavior of First Hybrid GeneraTiON When INBred . . . . . . . . . . . 389

69. Diagrair Illustrating Dihybrid Ratio . . . . . . . 392

70. Diagrair Showing the Characteristic Pairing, Size Relations, AND Shapes of the Chromosomes of Drosophila ampelophila . . . . . . . . . . . . . 402

71. Diagram of Mitosis in a Species Having Four ChromoSOMES IN ITS CELlS . . . . . . . . . . . 404

72. The Reduction Division as Represented for a Species Whose Diploid Number Is Four . . . . . . . 406

73. Diagrair of Chromatin Interchange between Homologous Mejibers of a Pair of Chromosomes . . . . . 408

74. Diagram Showing Consequences of Independent Segregatron of CHromosomes in Drosophila ampelophila . . . . 409

75. Diagram to Show Chromosome Relations in the InheritANCE of Sex in Drosophila ampelophila. . . . . . 4II

76. Diagrair Showing How the Original Scheje Must Be Modified to Satisfy the Presence and Absence HypotheSIS

77. Diagram Showing How Presence and Absence Scheme Is Actually USED. . . . . . . . . . . . . 4 4I5

78. Dlagram Illustrating Blending Inheritance . . • . . 4i6 
79. Diagram Illustratixg Complementary Factors . . . 4 id

80. Diagram Illustrativg Behavior of Inhibitory Factor . . 421

81. Diagram Silowing Some Possible Combinations in F $F_{2}$ When $\mathrm{F}_{1}$ OF Figure SO Is INBRED . . . . . . . . . 422

82. Diagram Showing the Heterozygote Situation . . . . 422

83. Diagram Illustrating the Action of a Supplementary FACTOR . . . . . . . . . . . . . .

84. Diagram Illustrativg Nilsson-Ehle's Explanation of the I5: I Ratio in $F_{2}$ OF Hybrid Between Red- AND WhiteGRALNED WHEAT . . . . . . . . . . . . 425

85. Axother Method of Visualizing Nilsson-Ehle's i 5: i Ratio 426

86. Diagrair of Nilsson-Ehle's 63: r Ratio . . . . . . . 427

87. Sex-Linked Inheritance of White and Red Eyes in Drosophila. . . . . . . . . . . . . . 434

88. Reciprocal Cross to That Shown in Figure 87 • . . 435

89. Drawing Showing the Four Pairs of Chromosomes Seen in the Dividing Egg of Drosophila. . . . . . . . 436

90. Diagram Showing the Location in the Four Paired Chromosomes of Drosophila, of the Genes for Various Mendelizing Characters, as Determined by Morgan. . . . . 437

91. Sex-Linked Inheritance of Barred and Unbarked (Black) Plumage in Poultry . . . . . . . . . . 438

92. Reciprocal Cross to That Shown in Figure 9i . . . 439

93. Diagram to Show the Mechanism of Crossing Over. . . 440

94. An Armadillo Egg about SlX Weeks after Fertillzation," Showing the Quadruplet Foetuses . . . . . . . 45I

95. A Typical Opposite-Sexed Pair of Cattle Twins. . . 455

96. A Pedigree of Brachydactylism . . . . . . . . . 460

97. A Pedigree Showing Transmission of Cataract . . . . 46i

98. A Pedigree Showing Heredity of Feeble-Mindedness . $\quad 463$

99. Another Pedigree Showing Heredity of Feeble-MindedNESS . . . . . . . . . . . . . . . . 464

io0. Pedigree Showing Heredity of Insanity . . . . . 4465

ioi. Pedigree Siowing Heredity of Insanity and Neurotic Tendency . . . . . . . . . . . . 465 


\section{PART I}

INTRODUCTORY AND HISTORICAL 



\section{CHAPTER I}

\section{INTRODUCTION}

\section{WHAT ORGANIC EVOLUTION IS-DEFINITIONS}

[The following selections are representative both of the older and of the newer'attitudes of thinkers on the subject of organic evolution. The earlier writers were greatly impressed with the sublimity of the idea and found it in full accord with their religious faith. The later writers are less awed by the vastness of the process and hence adopt a more completely materialistic attitude. It is not necessary, however, to discard one's religious beliefs in order to adopt a scientific attitude toward the problems of organic evolution. ${ }^{\mathrm{I}}$ These points of view are well expressed in the following quotations.-ED.]

"The world has been evolved, not created; it has arisen little by little from a small beginning, and has increased through the activity of the elemental forces embodied in itself, and so has rather grown than suddenly come into being at an almighty word. What a sublime idea of the infinite might of the great Architect! the Cause of all causes, the Father of all fathers, the Ens entium! For if we could compare the Infinite it would surely require a greater Infinite to cause the causes of effects than to produce the effects themselves.

"All that happens in the world depends on the forces that prevail in it, and results according to law; but where these forces and their substratum, Matter, come from, we know not, and here we have room for faith. "-Erasmus Darwin, ${ }^{2}$ as interpreted by Weismann.

"When I first came to the notion, . . . . of a succession of extinction of species, and creation of new ones, going on perpetually now, and through an indefinite period of the past, and to continue for ages to come, all in accommodation to the changes which must continue in the inanimate and habitable earth, the idea struck me as the grandest which I had ever conceived, so far as regards the attributes of the Presiding Mind." -From a letter of Sir Charles Lyell to Sir John Herschel, $\mathbf{2 8} 36$.

× See Joseph Le Conte, Relation of Evolution to Materialism, chap. iii.

${ }^{2}$ From R. S. Lull, Organic Evolution (The Macmillan Company. Reprinted by permission). 
"It is interesting to contemplate a tangled bank, clothed with many plants of many kinds, with birds singing on the bushes, with various insects flitting about, and with worms crawling through the damp earth, and to reflect that these elaborately constructed forms, so different from each other, and dependent upon each other in so complex a manner, have all been produced by laws acting around us. These laws, taken in the largest sense, being Growth with Reproduction; Inheritance which is almost implied by reproduction; Variability from the indirect and direct action of the condition of life, and from use and disuse; a Ratio of Increase so high as to lead to a struggle for Life, and as a consequence to Natural Selection, entailing Divergence of Character and the Extinction of less-improved forms. Thus, from the war of nature, from famine and death, the most exalted object which we are capable of conceiving, namely, the production of the higher animals, directly follows. There is a grandeur in this view of life, with its several powers, having been originally breathed by the Creator into a few forms or into one; and that, while this planet has gone cycling on according to the fixed law of gravity, from so simple a beginning endless forms most beautiful and most wonderful have been, and are being evolved."-Charles Darwin, Origin of Species, concluding paragraph.

"Speaking broadly we find as a fact that transmutation of species through the geologic ages has been accompanied by increasing divergence of type, by the increased specialization of certain forms, and by the closer and closer adaptation to conditions of life on the part of the forms most highly specialized, the more perfect adaptation and the more elaborate specialization being associated with the greatest variety or variation in the environment. Accepting for this process the name organic evolution, Herbert Spencer has deduced from it the general law, that as life endures generation after generation, its character, as shown in structure and function, undergoes constant differentiation and specialization. In this view, the transmutation of species is not merely an observed process, but a primitive necessity involved in the very organization of life itself."-D. S. Jordan and V. L. Kellogg, Evolution and Animal Life (1908), p. 4.

"The Doctrine of Evolution is a body of principles and facts concerning the present condition and past history of the living and lifeless things that make up the universe. It teaches that natural processes 
have gone on in the earlier ages of the world as they do to-day, and that natural forces have ordered the production of all things about which we know." - Henry Edward Crampton, The Doctrine of Evoluiion (I9II), P. I.

"Evolution is the gradual development from the simple unorganized condition of primal matter to the complex structure of the physical universe; and in like manner, from the beginning of organic life on the habitable planet, a gradual unfolding and branching out into all the varied forms of beings which constitute the animal and plant kingdoms. The first is called Inorganic, the last Organic Evolution." -Richard Swann Lull, Organic Evolution (I9I7), p. 6.

THE MODERN ATTITUDE AS TO THE TRUTH OF THE EVOLUTION DOCTRINE

"Among that public which, though educated and intelligent, is not yet professionally scientific, there has been, of late, a widespread belief that naturalists have become very doubtful as to the truth of the theory of evolution and are casting about for some more satisfactory substitute, which shall better explain the infinitely varied and manifold character of the organic world. This belief is an altogether mistaken one, for never before liave the students of animals and plants been so nearly unanimous in their acceptance of the theory as they are to-day. It is true that there are still some dissentient voices, as there have been ever since the publication of Darwin's 'Origin of Species,' but the whole trend of scientific opinion is strongly in favor of the evolutionary hypothesis.'-William Berryman Scott, The Theory of Evolution, p. I.

"But the biological sciences were still slower [than the physical sciences] to come to their true position as dignified science. Here was the last stronghold of tile supernaturalist. Thrust out from the field of 'physical science' it was in the phenomena of life that the last stand was made by those who claim that supernatural agency intervenes in nature in such a way as to modify the natural order of events. When Darwin came to dislodge them from this, their last intrenchment, there was a fight, intense and bitter, but, like all attempts to stay the progress of human knowledge, this final struggle of the supernaturalists was foredoomed to failure. The theory of evolution has taken its place beside the other great conceptions of natural relations, and largely through its establishment biology has become truly a science 
with a large group of phenomena consistently arranged and properly classified. The discussion which followed the publication of Darwin's 'Origin of Species' lasted for nearly a generation, but it is now practically closed, so far as any attempt to discredit evolution as a true scientific generalization is concerned. Scientists are no longer questioning the fact of crolution; they are busied rather with the attempt to further explore and more perfectly understand the operation of the factors that are at work to produce that development of animals and plants which we call organic evolution. "-Maynard M. Metcalf, An Outline of the Theory of Organic Evolution (r9I I), pp. xxii-xxiii.

"Biologists turned aside from general theories of evolution and their deductive application to special problems of descent, in order to take up objective experiments on variation and heredity for their own sake. This was not due to any doubts concerning the reality of erolution or to any lack of interest in its problems. It was a policy of masterly inactivity deliberately adopted; for further discussions concerning the causes of evolution had clearly become futile until a more adequate and critical vicw of existing genetic phenomena had been attained."-E. B. Wilson (address as president of the American Association for the Advancement of Science, I9I4).

"The theory of development, as it was revived by Darwin nearly half a century ago, is in its modern form prevailingly unhistorical. True, it has forced beneath its sceptre the methods of investigation of all the sciences which deal with the living world and to-day almost completely controls scientific thought. . . . And yet science does not sincerely rejoice in its conquests. Only a few incorrigible and uncritically disposed optimists stcadfastly proclaim what glorious progress we have made; otherwise, in scientific as in lay circles, there prevails a widespread feeling of uncertainty and doubt. Not as though the correctness of the principle of descent were seriously questioned; rather does the conviction steadily grow that it is indispensable for the comprehension of living nature, indeed selfevident."-Gustav Stcinmann (translated by W. B. Scott from Die Abstammungslehre [1908], pp. I-2).

"The many converging lines of evidence point so clearly to the central fact of the origin of forms of life by an evolutionary process that we are compelled to accept this deduction, but as to almost all the essential featurcs, whether of cause or of mode, by which specific 
diversity has become what we perceive it to be, we have to confess an ignorance nearly total."-William Bateson, Problems of Genetics (I9I3), p. 248 .

"The demonstration of evolution as a universal law of living nature is the great intellectual achievement of the nineteenth century. Evolution has outgrown the rank of a theory, for it has won a place in natural law beside Newton's law of gravitation, and in one sense holds a still higher rank, because evolution is the universal master, while gravitation is among its many agents. Nor is the law of evolution any longer to be associated with any single name, not even with that of Darwin, who was its greatest exponent. It is natural that evolution and Darwinism should be closely connected in many minds, but we must keep clear the distinction that evolution is a law, while Darwinism is merely one of the several ways of interpreting the workings of this law.

"In contrast to the unity of opinion on the law of evolution is the wide diversity of opinion on the causes of evolution. In fact, the causes of the evolution of life are as mysterious as the law of evolution is certain. Some contend that we already know the chief causes of evolution, others contend that we know little or nothing of them. In this open court of conjecture, of hypothesis, of more or less heated controversy the names of Lamarck, of Darwin, of Weismann figure prominently as leaders of different schools of opinion; while there are others, like myself, who for various reasons belong to no school, and are as agnostic about Lamarckism, as they are about Darwinism or Weismannism, or the more recent form of Darwinism, termed Mutation by De Tries.

"In truth, from the period of the earlier stages of Greek thought man has been eager to discover some natural cause of evolution, and to abandon the idea of supernatural intervention in the order of nature. Between the appearance of The Origin of Species, in 1859 , and the present time there have been great waves of faith in one explanation and then in another: each of these waves of confidence has ended in disappointment, until finally we have reached a stage of very general scepticism. Thus the long period of evolution, experiment, and reasoning which began with the French natural philosopher, Buffon, one hundred and fifty years ago, ends in I9I6 with the general feeling that our search for causes, far from being near completion, has only just begun. 
"Our present state of opinion is this: we know to some extent how plants and animals and man evolve; we do not know why they evolve. We know, for example, that there has existed a more or less complete chain of beings from nomad to man, that the one-toed horse had a four-toed ancestor, that man has descended from an unknown ape-like form somewhere in the Tertiary. We know not only those larger chains of descent, but many of the minute details of these transformations. We do not know their internal causes, for none of the explanations which have in turn been offered during the last hundred years satisfies the demands of observation, of experiment, of reason. It is best frankly to acknowledge that the chief causes of the orderly evolution of the germ are still entirely unknown, and that our search must take an entirely fresh start."-H. F. Osborn, The Origin and Evolution of Life (Charles Scribner's Sons), I9I8, pp. viii-x.

\section{WHAT ORGANIC EVOLUTION IS NOT}

[I. The evolution doctrine is not a creed to be accepted on faith, as are religious faiths or creeds. It appeals entirely to the logical faculties, not to the spiritual, and is not to be accepted until proved.

2. It does not teach that man is a direct descendant of the apes and monkeys, but that both man and the modern apes and monkeys have been derived from some as yet unknown generalized primate ancestor possessing the common attributes of all three groups and lacking their specializations.

3. It is not synonymous with Darwinism, for the latter is merely one man's attempt to explain how evolution has occurred.

4. Contrary to a very widespread idea, evolution is by no means incompatible with religion. Witness the fact that the early Christian Theologians, Augustine and Thomas Aquinas, were evolutionists, and the majority of thoughtful theologians of all creeds are today in accord with the evolution idea, many of them even applying the principle to their studies of religion; for religious ideas and ideals, like other human characters, have evolved from crude beginnings and are still undergoing processes of refinement.

5. The evolution idea is not degrading. Quite the contrary; it is ennobling as is well brought out by the classic statement of Darwin on page 4 and by that of Lyell, on page 3 .

6. The evolution doctrine does not teach that man is the goal of all evolutionary process, but that man is merely the present end product of one particular series of evolutionary changes. The goal 
of evolution in general is perfection of adaptation to the conditions of life as they happen to be at any particular time. Many a highly perfected creature has reached the goal of its evolutionary course only to perish because it was too highly perfected for a particular environment and could not withstand the hardships incident to radically changed world-conditions. Many evolutions therefore have been completed, while others are still awaiting the opportunity to speed up toward a new goal.

7. Evolution is therefore not entirely a thing of the past. Obviously some species, inciuding Man perhaps, are nearly at the end of their physical evolution, but there are always certain generalized plastic types awaiting the next great opportunity for adaptive specialization.-ED.] 


\section{CHAPTER II}

\section{HISTORICAL ACCOUNT OF THE DEVELOPMENT OF THE EVOLUTION THEORY}

\section{H. H. NEWMAN}

The chief sources of material for the present chapters are: Osborn's From the Greeks to Darwin ${ }^{\mathrm{I}}$ and Judd's The Coming of Evolution. ${ }^{2}$

Professor Osborn studies the evolution of the evolution idea as a biologist would investigate the evolution of a group of species, using all of the available sources of evidence at his disposal. The fragments of ancient writing and the crude imaginings of early natural philosophers are the fossils of the evolution idea, many of them ancestors of modern principles; fragnents of ancient or discarded ideas that still persist, though irrelevant to modern thought, are the vestigial structures that proclaim kinship between the past and the present; parallelisms between the development of ideas in the minds of independent thinkers do not prove plagiarism, but indicate common descent from the same ancestral ideas.

This whole history is an important chapter in the story of human evolution in general, for it deals with the evolution of a characteristic human faculty-that of appreciating the broad relations that exist between the past and the present. This faculty has evolved as truly as has an organic system such as the nervous system, and is unquestionably closely bound up with the latter.

The evolution theory is a vast fabric of interrelated and interdependent facts and principles. The fabric has been gradually woven out of separate threads and now stands strong though flexible, with strands reaching into all sciences and tending to unify all science.

It was only after the lesser ideas came to be cleatly apprehended that it was possible for the master minds of Lamarck and of Darwin to weave them together into a consistent fabric and to bring the facts together under the ne great conception, that of organic evolution. Classification was a cience, comparative anatomy had made much progress, the principies of embryology were fairly well understood,

"I. F. Osborn, Fr the Greeks to Darwin (The Macmillan Company, I908).-"

: John W. Judd, The 'oming of Evolution (Cambridge University Press, I9II). 
(much palaeontological discovery had been made, before it was found that the facts from these sources all pointed to one general principle, and only one, that master-principle "organic evolution."

We shall now trace the development of the evolution idea from its inception among the Greeks to its present status, and shall first give a brief account of Greek evolution.

\section{EVOLUTION AMONG THE GREEKS}

The early Greek thinkers were sea people. "Along the shores and in the waters of the blue Aegean," says Osborn, "teeming with what we now know to be the earliest and simplest forms of animals and plants, they founded their hypotheses as to the origin and succession of life.... The spirit of the Greeks was vigorous and hopeful. Not pausing to test their theories by research, they did not suffer the disappointments and delays which come from one's own efforts to wrest truths from Nature."

The Greeks were anticipators of Nature. Their speculations outstripped the facts; in fact were usually made with "eyes closed to the facts." (Their theories were inextricably bound up with current mythology, were naïve, vague, and, from our modern point of view, ridiculous; yet they contained many grains of truth and were the germs out of which grew the saner ideas of subsequent thinkers.

Thales $(624-548$ B.c.) was the first of the Greeks to theorize about the origin of life. "He looked upon the great expanse of mother ocean and declared water to be the mother from which all things arose, and out of which they exist." This idea anticipates the modern idea of the aquatic or marine origin of life and also the present idea as to the indispensability of water in all vital processes.

Anaximander (6II-547 B.C.) has been called the prophet of Lamarck and of Darwin. While his theories were highly mythical in character, he conceived the idea of a gradual folution from a formless or chaotic condition to one of organic coherence. He saw vaguely the idea of transformation of aquatic species into terrestrial, even deriving man from aquatic fishlike men (mythical mermen) who were able to emerge from the water only after they had undergone the necessary changes required for land life. This idea involves that of adaptatidn, one of the cornerstones of the modern evolutionary structure.

Anaximenes (588-524 B.c.), a pupil of Anaximander, "found in air the cause of all things. Air, taking the form of soul, imparts life, motion, and thought to animals." It is questionable whether $t \mathrm{t}$ is is a 
prophecy of the importance of oxygen and oxidation in vital processes. Anaximenes also introduced the idea of abiogenesis (spontaneous generation of living substance), his idea being that animals and plants $>$ arose out of a primordial terrestrial slime wakened in to life by the sun's heat. This primordial terrestrial slime is perhaps a prophecy of Oken's "Urschleim" or of protoplasm.

Xenophanes (576-480 B.C.), probably another pupil of Anaximander, "agreed with his master so far as to trace the origin of man back to the transition period between the fluid or water and solid or land stages of the development of the earth." He was the first to recognize fossils as the remains of animals once alive, and to see in them proof that once the seas covered the entire surface of the earth.

Heraclitus ( $535-475$ B.C.), the first of a group of physicists, was the great proponent of the philosophy of change. He was imbued with the idea that all was motion, that nothing was fixed. "Everything "was perpetually transposed into new shapes." Although Heraclitus did not apply his ideas to living creatures and their cvolutions, his philosophy was influential in molding the ideas of his successors.

Empedocles (495-435 B.c.) "took a great stride beyond his predecessors, and may justly be called the father of the Evolution idea. . . . Hebelieved in Abiogenesis, or spontaneous generation, as the explanation of the origin of life, but that Nature does not produce the lower and higher forms simultaneously or without an effort. Plant life comes first, and animal life developed only after a long series of trials." He thought that all creatures arose through the fortuitous combination of scattered and miscellaneous parts which were attracted or repelled by the forces of love or hate (the two great forces in Nature). Thus arose every sort of combination of parts, some more or less harmonious and complete, others with ill-assorted organization, lacking in some parts, double or triple in others. Some of these combinations could not survive, because of their incompleteness and incongruity, but "other forms arose which were able to support themselves and multiply." This is a sort of vague prophecy of the survival of the fittest or of natural selection. Four sparks of truth may be found in Empedocles' philosophy, "first, that the development of life was a gradual process; second, that plants were evolved before animals; third, that imperfect forms were gradually replaced (not succeeded) by perfect forms; fourth, that the natural cause of the production of perfect forms was the extinction of the imperfect." 
Democritus (b. $45^{\circ}$ B.c.), said to have been the first comparative anatomist, contributed to the substructure of evolution the idea of the "adaptation of single structures and organs to certain purposes."

Anaxagoras (500-428 B.C.) was the first of the Greeks "to attribute the adaptations of Nature to Intelligent Design, and was thus the founder of Teleology, "an idea that has played a retarding function in the history of evolution.

"With Aristotle (384-322 B.c.) we enter a new world," says Osborn. "He towered above his predecessors, and by the force of his genius created Natural History." The evolution idea took a great step forward with Aristotle and reached a stage beyond which it did not go for many centuries. He covered nearly the whole field, touching upon most of the foundation stones of the complex problem. His ideas, like those of all the Greeks, were often vague and, in the light of present knowledge, incoherent; but, considering the meager factual background with which he had to work he had a surprising grasp of the whole situation. Some of his principal ideas were:

I. He had a clear idea of laws of Nature ("Necessity"), and. attributed all evolutionary changes to natural causes.

2. He opposed the ideas of Empedocles as to the fortuitous origin * of adaptive characters, and favored the idea of intelligent design in nature. He was therefore a teleologist.

3. Hence he rejected the hypothesis of the survival of the fittest,. because it was based on chance.

4. He "had substantially the modern conception of the Evolution . of life, from a primordial soft mass of living matter.'

5. He had an idea of a linear phylogenetic series, beginning ' with plants, then plant-animals, such as sponges and sea anemones, then animals with sensibility, and thence by graded stages up to Man.

6. "He perceived the unity of type in certain classes of animals, " and considered rudimentary organs as tokens whereby Nature sustains this unity.'

7. "He anticipated-Harvey's doctrine of Epigenesis in embryonic development."

8. "He fully perceived the forces of hereditary transmission, of the prepotency of one parent or stock, and of Atavism and Reve:sion."

9. He is the father of that ancient fallacy called "prenatal intluences," and selieved in the inheritance of acquired characters. \& is shown in the following passage: 
"Children resemble their parents not only in congenital characters, but in those acquired later in life. For cases are known where parents have been marked by scars and children have shown traces of these scars at the same points; a case is also reported from Chalcedon in which a father had been branded with a letter, and the same letter somewhat blurred and not sharply defined appeared upon the arm of the cliild."

\section{POST-ARISTOTELIANS}

With Aristotle the evolution idea reached a high watermark and thereafter the tide steadily declined. Pliny, Epicurus, Lucretius, and others kept the idea alive, but added nothing of importance to Aristotle's contribution.

Lucretius (99-55 B.C.) appears to have been chiefly a follower of Empedocles in so far as his ideas as to the origin of animals are concerned. He ignored Aristotle and his much more advanced philosophy of Nature, finding the earlier, more mythical conceptions better suited to poetic expression. He was not truly an evolutionist, for he believed that all animals and plants arose fully formed from the earth. Lucretius is of importance chiefly as a retarding factor, for his ideas were accepted and admired even up to the eighteenth century; witness Milton's immortal verse:

"The Earth obey'd, and straight, Op'ning her fertile womb, teem'd at a birth Innumerous living creatures, perfect forms, Limb'd and full grown."

THE EARLY THEOLOGIANS

The evolution idea made no progress from the time of Aristotle until the revival of learning in the Middle Ages. The chief inhibiting factor was the church, which favored traditional knowledge and the special-creation idea in its most literaI form. Yet the early theclogians, such as Gregory, Augustine, and Thomas Aquinas, were openminded about the evolution idea and attempted to reconcile it with the scriptural account of creation.

"Gregory of Nyssa (33I-396 A.D.) taught," says Osborn, "that Creation was potential. God imparted to matter its fundamental properties and laws. Theobjects and completed forms of the Universe developed gradually out of chaotic material." 
Augustine (353-430 A.D.) conceived the idea, now so generally adopted by theologians, that the biblical account of creation is allegorical. "In explaining the passage 'In the beginning God created heaven and the earth,' he says:

"In the beginning God made the heaven and the earth, as if this were the seed of the heaven and the earth, although as yet all the matter of heaven and of earth was in confusion, but because it was certain that from this the heaven and the earth would be, therefore the material itself is called by that name."

Thomas Aquinas ( $1225-74$ ), who wrote much later and was one of the leading cliurch authorities, satisfied himself with merely expounding Augustine: "As to the production of plants, Augustine holds a different view, .... for some say that on the third day plants were actually produced, each in its kind-a view favoured by the superficial reading of Scripture. But Augustine says that the earth is then said to have brought forth grass and trees causaliter; that is, it then received the power to produce them. For in those first days . . . . God made creation primarily or causaliter, and then rested from His work."

\section{THE REVIVAL OF SCIENCE}

During the long centuries until the awakening of science in the Middle Ages the evolution idea smouldered along in the minds of a few thinkers, but it was only when a few daring spirits broke the trammets of scholasticism and began once more to give free rein to observation and speculation that the idea once more burst into flame and began its second great period of advance.

A small group of natural philosophers, scarcely more scientific in their methods than the Greeks, were the first to revive interest in the evolution idea. Of these the names of Bacon, Descartes, Leibnitz, and Kant are the most famous.

Francis Bacon (1561-1626) did much to revive the vogue of Arist totelian ideas. He also added some new ideas: (r) that the mutability of species was the result of the accumulation of variations; (2) that variations of an extreme kind, equivalent to "mutations," sometimes occur; (3) that new species might arise by a degenerative process from old species.

Emmanuel Kant (1724-I804) was purely a philosopher, not an observing naturalist, but he profited by the writing of the contemporary naturalists, especially those of Buffon ad $\mathrm{I}$ aupertius. His 
general ideas of evolution were comprehensive and summed up the best features of all preceding writers, but he did not contribute anything new to the pressing problem of the causes of evolution.

Real progress was not to be made through further speculation. II hat was most needed was facis, and it was the task of the naturalists to furnish these. The earliest of the eighteenth-century naturalists were still anticipators of Nature in that their theories outran their facts. Of these the names of Bonnet and Oken are the best known.

Bonne (1720-93) was an evolutionist only in the sense that he believed that the adult organism is present in the egg and evolves from it by a process of unfolding or expansion. He was a zoölogical observer of some note, however, and made some of the most important contributions of his time to the general subject. He believed "that the globe had been the scene of great revolutions, and that the chaos described by MIoses was the closing chapter of one of these; thus the Creation described in Genesis may be only a resurrection of animals previously existing." This theory admits of no progress and is scarcely worthy of the name evolution.

Oken (I776-I85I) is known chiefly for his "Urschleim" doctrine and his ideas of cells as vesicular units of life. According to him, "Every organic thing has arisen out of slime and is nothing but slime in various forms. This primitive slime originated in the sea from inorganic matter." These ideas are purely speculative, but suggest our modern ideas of protoplasm and cells.

THE GREAT NATURALISTS OF THE EIGHTEENTH CENTURY

Three great names stand out above all the rest during this period: those of Linnaeus, Buffon, and Erasmus Darwin.

Limnaeus ( $\mathrm{I} 707-78)$ was the father of taxonomy. He contributed facts rather than theories; he invented our present system of binomial nomenclature of both animals and plants, and a great many of his generic and specific names still persist. Unfortunately he was an ardent advocate of the special-creation idea, holding that all of the true species were creatcd as they are known today, except that new combinations may have arisen through hybridization or through degeneration. His influence was great, but was reactionary and proved a serious hindrance to the progress of the evolution idea.

Buffon (I707-S8), bom the same year as Linnaeus, has been recognized as the father of the modern applied form of the evolution idea. He attempted to explain particular cases on an evolutionary 
basis. He lived at a time when it was dangerous to express views that might be interpreted as unorthodox, and this may account for the apparent lack of conviction in his own ideas; for he wavered between special creation and evolution. His chief contribution is the idea of the direct influence of the environment in the modification of the structure of animals and plants and the conservation of these modifications through heredity. OThis seems to imply that he believed in the inheritance of acquired characters. He expressed himself as believing that-climate has had a direct effect in the production of various races of man that new varieties of animals have been formed through human intervention (an idea implying artificial selection), that similar results are produced by geographic migration and through isolation. He expressed the view that there is a great struggle for existence among animals and plants to prevent overcrowding and to maintain the balance of Nature. This appears to be an anticipation of Malthus' ideas on population, which were so influential in shaping the theories of Charles Darwin and of Wallace.

While many of his ideas appear to be highly advanced for his time, his special applications are open to serious criticism. He reasons, for example, that the pig as it exists at present could not have been formed on any original complete and perfect plan, but seems to have been formed as a compound from other animals. It has useless parts which could hardly have been a part of a perfect plan as originally conceived. He thought that "the ass is a degenerate horse, and the ape a degenerate man."

On the whole Buffon was not a strong advocate of evolution and his influence was far from being as important as some recent writers appear to believe.

Erasmus Darwin (I73I-I802), grandfather of Charles Darwin, was a physician, a naturalist, and a minor poet. Undoubtedly he transmitted to his grandson his thoughtful habit and love of science and was influential in shaping his ideas on evolution. The elder Darwin's theories as to the causes of evolution closely paralleled those of Lamarck, his distinguished contemporary in France, but it is now very generally conceded that the ideas of the two men were independently derived from similar materials. Erasmus Darwin laid little emphasis on the direct action of the environment, which had been Buffon's main dependence, and dwelt on the internal origin of adaptive characters. "All animals," he said, "undergo transformations which are in part produced by their own exertions, in response to, 
pleasures and pains, and many of these acquired forms or propensities are transmitted to their posterity." One could ask for no clearer statement of the idea that acquired characters are inherited.

The fierceness of the struggle for existence was clearly recognized by Dr. Darwin. He considers that this struggle is beneficiat to Nature as a whole because it checks the too rapid increase of life. One step farther in the argument, and he would he arrived at the idea of the survival of the fittest, but he never took that step. He agreed with the early Christian fathers in his belief that the powers of development were implanted within the first organisms by the Creator and that subsequent evolution of adaptive characters went on without further divine intervention. The power of improvement rests within the creature's own organizations and is due to his own efforts. The effects of these efforts, he believes, are transmitted to offspring so that there might be a cumulative effect throughout many generations of the results of effort.

Erasmus Darwin was perhaps the first to express clearly the ideas that millions of years have been required for the processes of organic evolution and that all life arose from one primordial protoplasmic mass. He writes as follows:

"From thus meditating upon the minute portion of time in which many of the above changes have been produced, would it be too bold to imagine, in the great length of time since the earth began to exist, perhaps millions of ages before the commencement of the history of mankind, that all warm-blooded animals have arisen from one living filament, which the first great Cause imbued with animality, with the power of acquiring new parts, attended with new propensities, directed by irritations, sensations, volitions, and associations, and thus possessing the faculty of continuing to improve by its own inherent activity, and of delivering down these improvements by generation to posterity, world without end?"

\section{LAMARCK}

Lamarck (I744-1829), the greatest of French evolutionists, is now looked upon as "the founder of the complete modern "Theory of Descent." Osborn considers him "the most prominent figure between Aristotle and Darwin. One cannot compare his Philosophie zoölogique with all previous and contemporary contributions to the evolution theory or learn the extraordinary difficulties under which he laboured, and that his work was put forth only a few years after he had turned 
from Botany to Zoölogy, without gaining the greatest admiration for his genius. No one has been more misunderstood, or judged with more partiality by over or under praise. The stigma placed upon his writings by Cuvier, who greeted every fresh edition of his words as a 'nouvelle folie,' and the disdainful illusions to him by Charles Darwin (the only writer of whom Darwin ever spoke in this tone) long placed him in the light of a purely extravagant, speculative thinker. Yet, as a fresh instance of the certainty with which men of science finally obtain recognition, it is gratifying to note the admiration which has been accorded to him in Germany by Haeckel and others, by his countrymen, and by a large school of American and English writers of the present day; to note, further, that his theory was finally taken up and defended by Charles Darwin himself, and that it forms the very heart of the system of Herbert Spencer."

Lamarck's main theory of evolution was expressed by him in the form of his four "laws":

I. "Life, by its proper forces, continually tends to increase the volume of every body which possesses it, and to increase the size of its parts, up to a limit which brings it about:

II. "The production of a new organ in the animal body results from the supervention of a new want which continues to make itself felt, and new movement which this want gives rise to and maintains.

III. "The development of organs and their powers of action are constantly in ratio to the employment of these organs.

IV. "Everything which has been acquired, impressed upon, or changed in the organization of individuals during the course of their life is preserved by generation and transmitted to new individuals which have descended from those which have undergone these changes."

It is about the last "law" that the controversy rages, for it upholds the idea that acquired iharacters are inherited, now known as the "Lamarckian doctrine."

A somewhat more specific statement of Lamarck's theory of evolution may be summed up in the following list of factors which he considered as playing an essential rôle in evolution.

i. "Favorable circumstances attending changés of environment, soil, food, temperature, etc., supposed to act directly in the case of plants, indirectly in the case of animals and man.'

2. "Needs, new physical wants or necessities induced by the changed conditions of life. Lamarck believed that change of habits 
may lead to the origination or modification of organs; that changes of function also modify or create new organs. By changes of environment animals become subjected to new surroundings, involving new ways and means of living. Thus, certain land birds, driven by necessity to obtain their food in the water, gradually assumed characters adapting them for swimming, wading, or for searching for food in the shallow water, as in the case of the long-necked kinds."

3. "Use and disuse. To use an organ is to develop it; not to use it is toreventually lose it. The anterior limbs of birds became capable of sustained flight through use; the hind limbs of whales are lost through disuse, etc."

4. "Competition- Nature takes precautions not to overcrowd the earth. The stronger and larger-living things destroy the smaller and "weaker. The smaller multiply very rapidly, the larger slowly. A physiological balance is maintained."

5. "The transmission of acquired characters- The advantages gained by every individual as the result of the structural changes resulting from use or disuse are handed down to its descendants who begin where the parent leaves off, and so are able to continue the progression or retrogression of the character."

6. "Cross-breeding. "If when any peculiarity of form or any defects whatsoever are acquired, the individuals in this case, always pairing, they will produce the same peculiarities, and if for successive generations confined to such unions, a special distinct race will then be formed. But perpetual crosses between individuals which have not the same peculiarities of form result in the disappearance of all the peculiarities acquired by the particular circumstances."

7. "Isolation. "Were not man separated by distances of habitation, the mixtures resulting from crossing would obliterate the general characters which distinguish different nations.' This thought is expressed in his account of the origin of men from apes, and is not applied to living things in general."

In addition to his theories as to the causes of evolution, Lamarck was the first to present the idea of the tree of life, or phylogenic as a mode of representing animal relationships. All previous classifications had been based on the idea of a single linear phylogenetic series, each lower group being supposedly ancestral to a higher group, and all in a single chain.

We may best sum up Lamarck's work and influence in the words of Osborn: 
"Lamarck, as a naturalist, exhibited exceptional powers of definition and description, while in his philosophical writings upon Evolution, his speculation far outran his observations, and his theory suffered from the absurd illustrations which he brought forward in support of it. . . . His critics spread the impression that he believed animals acquired new organs simply by wishing for them. His really sound speculation in Zoölogy was also injured by his earlier thoroughly worthless speculation in Chemistry and other branches of science. Another marked defect was, that Lamarck was completely carried away with the belief that his theory of the transmission of acquired characters was adequate to explain all the phenomena. He did not, like his contemporaries, Erasmus Darwin and Goethe, perceive and point out, that certain problems in the origin of adaptations were still left wholly untouched and unsolved. ... His arguments are, in most cases, not inductive, but deductive, and are frequently found not to support his law but to postulate it.

"It is now a question whether Lamarck's factor is a factor in Evolution at all! If it prove to be no factor, Lamarck will sink gradually into obscurity as one great figure in the history of opinion. If it prove to be a real factor, he will rise into a more eminent position than he now holds,-into a rank not far below Darwin."

CUVIER AND GEOFFROY ST. HILAIRE

Georges Cuvier ( $1769-1832$ ) deserves especial mention as one of the strongest negative factors in the development of the evolution idea. He was, first of all, an opponent of Lamarck, and, second, of evolution in general. He ranged himself with Linnaeus as a special creationist. and advocated the idea of fixity of species. "All the beings," said he, "belonging to one of these forms (perpetual since the beginning of all things, that is, the Creation) constitute what we call species." So able was Cuvier and so much in favor at the French court that he succeeded in throwing Lamarck's views into disrepute and thus greatly retarded the progress of evolution. He was brilliant as a comparative anatomist and palaeontologist and will long be known for his discoveries in these fields.

E. Geoffroy St. Hilaire (I772-1844) did his best to defeat the retarding influence of Cuvier. The two engaged in a long and bitter controversy over the evolution idea. While not a supporter of Lamarckism proper, he was a thoroughgoing evolutionist, favoring 
the doctrine of Buffon, that the direct action of the environment was the sole cause of evolution. He also, in a sense, anticipated De Vries, in that he believed that new species might be formed by transmutation or sudden large variations occurring in one generation. "Hence the underlying causes of transformations," he said, "were profound changes induced in the egg by external influences, accidents as it were, regulated by law." The controversy between Cuvier and St. Hilaire was a losing one for the latter. The cards were stacked against him and after him the evolution idea was retired to comparative obscurity until revived by Charles Darwin.

\section{CATASTROPHISM AND UNIFORMITARIANISM}

The development of the science of geology had a profound influence upon that of erolution. The prevailing theories as to historical geology during the Middle Ages involved the idea of "catastrophism." According to this view all important changes in the earth's crust represented sudden radical transformations, involving earthquakes, volcanic outbursts, floods, sudden upliftings of submerged areas, or equally sudden submergence of land bodies. From these ideas naturally grew the related idea of great, world-wide destructions of animals and plants, followed by re-creation of new faunas and floras. Cuvier, for example, interpreted the more or less distinct fossil strata as being the result of a series of tremendous cataclysms, the last of which had been the great deluge of Scripture, in which Noah figured prominently. He thought that at each cataclysm great floods of water had covered the earth, that the existing animals had been buried in mud and thus preserved as fossils, and that a new creation followed each cataclysm. The great strength of this conception was that it appeared to give scientific support to both special creation and the Mosaic account of the "Flood." As compared with the pure evolutionary conception, this alternative was highly acceptable to the chuch and was proclaimed as orthodox. The Scotch philosopher and geologist, Hutton, who lived during the last half of the eighteenth century, combated the idea of catastrophism by advocating the doctrine of "uniformitarianism," a view involving the idea that past changes on the earth were the result of the same sort of gradual changes as are observed to be taking place today-in brief, that there has been a strict uniformity of change throughout the entire period of geologic history. There may have been, according to this view, local catastrophes, 
such as rolcanic outbursts, earthquakes, and floods, but the main trend of change lias been slow and constant, due largely to erosion and allied phenomena. This view had practically no influence on the ideas of the time and for a long period the idea of catastrophism triumphed over the more truly evolutionary view of uniformitarianism; thus the evolution idea was destined to lie dormant till revived by Charles Darwin.

\section{THE REAWAKENING OF THE EVOLUTION IDEA}

A number of important influences paved the way for the rehabilitation of the evolution idea at the hands of the younger Darwin. Which of these was the most important it is difficult to say. Probably Charles Lyell's Principles of Geology and Malthus' On Population were the most suggestive works that Darwin encountered. He was also doubtless influenced by Robert Chambers' Vestiges of Natural History of Creation which appeared in $\mathrm{I} 844$.

Charles Lyell (I797-I875) so successfully rehabilitated the doctrine of uniformitarianism in geology that it became very generally accepted, thus paving the way for a more favorable consideration of the idea of organic evolution. Charles Darwin as a very young man took Lyell's Principles of Geology with him on his voyage on the "Beagle" and read it with the greatest devotion, as is evidenced by his dedication of the journal of his voyage: "To Charles Lyell, Esq., F.R.S., this second edition is dedicated with grateful pleasure, as an acknowledgment that the chief part of whatever scientific merit this Journal and other works of the author may possess, has been derived from studying the well-known, admirable Principles of Geology."

Malthus' influence on Darwin's ideas is well expressed by Judd as follows:

"Fifteen months after this 'systematic inquiry' began [referring to Darwin's exhaustive working over of his notes taken during his voyage on the 'Beagle'], Darwin happened to read the celebrated work of Malthus 'On Population' for amusement, and this served as a spark falling on a long prepared train of thought. The idea that as animals and plants multiply in geometrical progression, while the supplies of food and space to be occupied remain nearly constant, and that this must lead to a struggle for existence of the most desperate kind, was by no means new to Darwin, for the elder De Candolle, Lyell, and others had enlarged upon it; yet the facts with regard to 
the human race, so strikingly presented by Malthus, brought the whole question with such vividness before him that the idea of 'Natural Selection ' flashed upon Darwin's mind."

\section{CHARLES DARWTX (ISOg-S2)}

Charles Darin is without question the foremost figure in the development of the evolution idea and probably in the development of science in general. The publication of his book, The Origin of Species, in IS 5 , was the most important event in biological history. As has been already shown, Darwin's chief ideas had been anticipated not $5 y$ one but by several of his predecessors. Nevertheless, he was the first to furnish a really adequate proof of the fact of evolution and his causo-mechanical theory to explain the method of evolution was supported by a mass of systematically arranged data such as has been paralleled neither before nor since. Darwin was the first evolutionist effectively to employ the inductive method, that of everywhere seeking facts first and then devising theories to fit the facts. He never allowed speculation to outstrip observation, as nearly all of his predecessors had done, but made theory await the amassing of facts in its support, until the accumulation of the latter seemed almost to speak out the theory of themselves. Our greatest debt to Darwin is due to his establishment of the factual basis of erolution; his selection theory was relatively of minor significance in so far as its value in the development of the evolution idea was concerned. Fet this latter theory gained the widest acceptance among the scientifically inclined during the entire post-Darwinian period. It has been viciously assailed on all sides and has tottered repeatedly under the attacks of well-trained adversaries. Some of the weaker elements of the theory have given way under stress, and the whole selection factor as a primary causal factor in evolution has been seriously called into question; but since Darwin's time the fact of evolution has been almost universally accepted.

The story of Darwin's life is almost a romance. "Born in I8og," says Lull, "this emancipator of human minds from the shackles of slavery to tradition saw the light of day upon the very day that ushered in the life of Abraham Lincoln, the emancipator of human bodies from ano more real physical bondage. Darwin studied first at Edinburgh, but finding medicine unsuited to his tastes, entered Christ's College, Cambridge, as a candidate for the church. His love

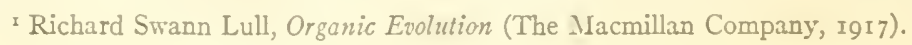


of Nature, however, dominated all other interests and shortly after graduation an opportunity came to join the ship 'Beagle' as naturalist in a voyage of exploration around the world. The five years spent upon this memorable journey, the narrative of which is so admirably set forth in the book, A Vaturalist's Voyage around the World, resulted in the accumulation of the first of Darwin's great series of observations, the final decision to devote his life to zoölogical research, and the beginning of that illness which made him a life-long invalid. This last factor necessitated a retired life and thus proved of indirect benefit, as it enabled him to accomplish the immense amount of work which he did without being impeded by the distractions of a public - career."

SUMAMARY OF DARWIN'S THEORIES

Since two subsequent chapters are to be devoted to Darwinism, only an outline of Darwin's theories need be presented in the present historical account.

Although Darwin was an all-round biologist and gave attention to practically every phase of evolutionary biology, he is known especially for his selection theories. There are three of these: the theory of artificial selection, the theory of natural selection, and the theory of sexual selection.

a) Artificial selection.-According to Darwin the commonest method of producing, under human culture, new races of animals and plants is that of selection. The breeder selects from among the highly variable individuals of a parent-race those which possess the beginnings of desired modifications, and he breeds them together, expecting that the offspring will show the desired character, some in a more highly perfected condition, others in a less. The ones that vary favorably are again selected for breeding stock, and the same process is carried on until thr desired character has been perfected.

Although we now know that this is far from being a typical experience among breeders, it appeared to Darwin to be so typical that he transferred the selection idea from the breeder to Nature, making Nature the selecting agency responsible for the production of natural wild species. His argument is as follows:

b) Natural selection.--The following factors are involved:

I. All animals and plants tend to multiply in geometrical ratio.

2. There is not food or room for a much larger number of animals and plants than now exist. 
3. All members of a species vary in many if not all directions.

4. Those that vary in the more farorable directions, so as better to fit them to meet the conditions of life, survive in larger numbers than those varying in less favorable directions. 'This is Spencer's "survival of the fittest."

5. The survivors of one generation become the parents of the next and, therefore, the more favorable characters are passed on more largely than the less favorable.

6. There is in each generation a slow but definite approach toward complete adaptation to life-conditions.

7. Variations neither useful nor harmful would not be affected by natural selection, and would be left either as fluctuating variations or as polymorphic characters.

c) Sexual selection.-This theory was offered to supplement that of natural selection, because Darwin considered the latter as inadequate to explain the facts of sexual dimorphism, or secondary sexual characters. The theory is as follows: There is always a contest among males for possession of females, in which the inferior males are eliminated either because they are, on the one hand, less courageous or weaker or less well equipped with weapons of combat, or because, on the other hand, the more attractive males, whether on account of colors, odors, phosphorescence, behavior, etc., would succeed in winning mates from those less endowed. Thus would be enhanced the sexual dimorphism until it reaches extremes in many cases that are truly remarkable.

The name of Alfred Russell Wallace (I822-I9I3) will always be associated with that of Charles Darwin as co-author of the theory of natural selection. Wallace at the age of twenty-six went on a naturalistic expedition, primarily for collecting specimens from new regions. He covered almost the same ground as did Darwin in his voyage on the "Beagle." Wallace had read Lyell's Principles of Geology, Malthus' On Population, Chambers' I'estiges of Creation. While in Sarawak he tells us: "I was quite alone with one Malay boy as cook, and during the evenings and wet days, I had nothing to do but to look over my hooks and ponder over the problem which was rarely absent from my thoughts." While thus engaged the idea of natural selection came to him as though by a sudden flash of insight. When the idea was still in process of formation he wrote it out on thin paper and mailed it to Darwin, stating that he considered the idea new and asking Darwin to show it to Lyell, who had expressed interest in a 
former paper of Wallace. The ideas were expressed under the title On the Tendency of Varieties to Depart Indefinitely from the Original Type, and it proved to be an unusually concise and lucid statement of the main points of the natural-selection theory. Darwin at once wrote to Lyell as follows:

"I never saw a more striking coincidence; if Wallace had my MS sketch, written in $184^{2}$, he could not have made a better short abstract! Even his terms now stand as heads of my chapters. Please return to me the MS which he does not say he wishes me to publish but I shall, of course, at once write and offer to send it to any journal. So all my originality, whatever it may amount to, will be smashed, though my book, if it ever have any value, will not be deteriorated, as all the labour consists in the application of the theory. I hope you will approve of Wallace's sketch, that I may tell him what to say."

Lyell insisted that Darwin publish an abstract of his own work simultaneously with that of Wallace, and this course was carried out. Darwin's generosity was equaled by that of Wallace who wrote, in I870:

"I have felt all my life and still feel the most sincere satisfaction that Mr. Darwin had been at work long before me, and that it was not left for me to attempt to write The Origin of Species. I have long since measured my own strength and know well that it would be quite unequal to the task."

Still later he wrote: "I was then (and often since) the 'young man in a hurry,' he [Darwin] the painstaking student, seeking ever the full demonstration of the truth he had discovered, rather than to achieve immediate personal fame."

One must perforce admit the nobility of character of both men; but there can be no serious competition between the two for the honor of being called the originator of the natural-selection theory.

\section{CONTEMPORARY OPINION REGARDING THE VALIDITY OF DARIVIN'S VIEWS}

At first Darwin was inclined to believe that the selection factor was all-sufficient to account for the origin of species, as well as that of adaptations; but as time passed he modified his earlier more sanguine views and came to the conclusion "that natural selection has been the main but not the exclusive means of modification." Many of his followers went to such extremes in their advocacy of the all-sufficiency of natural selection as would not have met with Darwin's approval. 
"The first effect of Darwin's works," says McFarland, ", "was to carry the world of science by storm, but at the same time to arouse intense hostility on the part of the theologians who found the theory of descent .... incompatible with the doctrines of Creation. In this conflict Darwin took no part, but was championed by Huxley, while Bishop Wilberforce led the opposition. The battle was long and bitter, there was much acrimonious writing on both sides, but the theory of descent-the doctrine of evolution-was found to be invulnerable and at present the theologians themselves have accepted it and even make use of it in their own work.

"But as the years flew by the Darwinian doctrines began to meet with assaults from the scientists themselves, who, having endeavored to prove their validity, began to find them inadequate to the requirements of expanding knowledge. The question was asked, 'What is the origin of the fittest?' Given the fittest, we easily understand how it is perpetuated, but how does it arise? In the striking phrase of someone: 'Natural selection might explain the surviral of the fittest but fails to account for the arrival of the fittest!"'

Darwin's main supporters during the most trying controversial period were Herbert Spencer and Thomas H. Huxley.

Herbert Spencer (I820-I903) was an extremely able supporter of the general theory of evolution, but was more definitely an advocate of Lamarckism than of natural selection. His rôle was that of a champion of the whole philosophy of evolution as opposed to special creation, and it was largely due to his forceful writings that Darwinism won the battle against dogmatism. Spencer tried to explain the structure of protoplasm (living substance) on a physicochemical basis. He thought of the structural units of protoplasm as comparable with the molecules of chemical compounds, each local region of the protoplasm in the organism being made up of different kinds of units, which he called "physiological units." This conception of the physical basis of organic structure had a considerable influence in shaping Darwin's ideas and was probably the basis of the latter's provisional theory of "pangenesis." This theory was probably the first consistently worked out theory of the mechanics of heredity. It was thought that every part of the body is continually giving off its particular kind of units ("gemmules") into the blood. These gemmules are transported by the blood stream to all parts of the body and Igr8).

I. McFarland, Biology, General and MIedical (The Macmillan Company, 
collect in the germ cells. This was supposed to account for the fact that from the germ cell will develop an organism like the parent in various details. If a part of the body was modified through functioning or through changed environment, it would have modified gemmules, which, in turn, would go to the germ cells and carry over the modification to the next generation. This theory was not satisfactory even to Darwin and is now only of historical interest.

Spencer is best known in the history of the evolution theory as an ardent neo-Lamarckian. He states his belief as follows: "Change of function produces change of structure; it is a tenable hypothesis that changes of structure so produced are inherited." This idea prevailed until it was cast down by Weismann.

Thomas Henry Huxley (I825-95), one of the keenest, most analytical thinkers of the nineteenth century, not only defended the general doctrine of evolution against Bishop Wilberforce and his aids, but was an able investigator in the fields of comparative anatomy and embryology. "At the British Association at Oxford in I860," says Judd, "after an American professor had indignantly asked 'Are we a fortuitous concourse of atoms?' as a comment on Darwin's views, Dr. Samuel Wilberforce, the Bishop of Oxford, ended a clever but flippant attack on the Origin by enquiring of Huxley, who was present as Darwin's champion, if it 'was through his grandfather or his grandmother that he claimed his descent from a monkey?'

"Huxley made the famous and well-deserved retort: 'I assertedand I repeat - that a man has no reason to be ashamed of having an ape for his grandfather. If there were an ancestor whom I should feel ashamed of recalling, it would rather be a man-a man of restless and versatile intellect - who not content with success in his own sphere of activity, plunges into scientific questions with which he has no real acquaintance, only to obscure them by aimless rhetoric, and distract the attention of his hearers from the real point at issue by eloquent digressions and skilled appeals to religious prejudice!'

"Huxley himself accepted the theory of Natural Selection-but not without some important reservations-these, however, did not prevent him from becoming its most ardent and successful champion. Darwin used to acknowledge Huxley's great service to him in undertaking the defense of the theory - a defense which his own hatred of controversy and state of health made him unwilling to undertakeby laughingly calling him 'my general agent' while Huxley himself in replying to the critics, declared he was 'Darwin's bulldog.' "' 
Ernst Hacckel (1834-r9ig) was one of the earliest and most influential followers of Darwin in Germany. In his Generelle Morphologie, published in I866, seven years after the Origin of Species first appeared, he applied the doctrine of evolution, and especially the theory of natural selection, to the whole field of vertebrate morphology. Beyond question Haeckel overapplied the theory and in a sense weakened its influence by his rather uncritical use of materials. His writings have been translated into most languages and "are popularly believed to represent the best scientific thought on the matter." Biologists today, however, are apt to look askance at Haeckel's works and to consider that they did more harm than good to Darwinism.

August Weismann (I834-I9I4) was the first really original evolutionist after Darwin. Like other thinkers of his time, he realized that further progress in the knowledge of the causal basis of evolution lay in further investigation of the causes of variation and the physical basis of heredity. Weismann has been classed as a neo-Darwinian because he was a strong advocate of some form of selection, but his "selection" was not the selection of Darwin. URealizing that the greatest weakness of the natural-selection theory lay in its inadequacy as an originator of variations, he proposed the "germinal-selection" theory 4 He contended that all heritable variations have their origin in the germ cell, and therefore that a new type of organism arises only from a changed type of germ cell. The germinal-selection theory stands out in striking contrast with Darwin's "pangenesis" theory. The former is centrifugal, the latter centripetal. "Determiners" of new characters, according to Weismann, arise in the germ plasm and work outward to all parts of the developing body; while the "gemmules," Darwin's equivalent of determiners, originate in the body tissues and are carried to the germ cells in each generation. According to Weismann, there is a struggle among the determiners for the available food and favorable positions in the germ cell, and those that receive the most food and the best positions gain an initial advantage, so that they are able to initiate the development of langer or more perfectly adapted organs. The descendants through cell division of these favored determiners are in a position to compete with other determiners on a more favorable footing in each succeeding generation, so that the character represented by them steadily increases in a linear or definitely directed fashion until it reaches the state of complete adaptation or fitness. Such a character may even continue its direct line of advance beyond the point of maximum fitness and result in 
what are known as overspecializations. The theory therefore would, if well founded, account not only for the initial stages of new adaptive characters, but also for overspecializations, two phenomena that natural selection was unable to account for. Not only were progressive evolutionary changes explained by germinal selection, but regressive changes seemed to be even more readily accounted for on this basis. In the struggle among determiners in the germ cell some of the less favored units would be handicapped at the outset by insufficient food or winfavorable position and would produce smaller or less effective structures. Progressively, from generation to generation, these weakened determiners would lose ground and become less and less successful in competition until they were weaklings among determiners and would be able to initiate only degenerate or vestigial structures, or else would die out and lose their place altogether, thus accounting for total losses of structures.

This theory does not exclude natural selection, but rather increases its importance, for every structure that arises to the threshold of utility or disutility meets the winnowing process of natural selection. The fitter individuals survive in the long run and these perpetuate the germ cells in which the successful determiners reside.

A slightly different explanation of degenerating structures involves the principle of "panmixia." According to this idea, changing environmental conditions may render certain adaptive organs of lessened value or of no value, as would be the case in the eyes of cave animals. In different individuals the eye determiners would vary in their success in competition with other determiners, and since natural selection would no longer put a premium on perfect eyes, all grades of eyes would be equally inherited and gradually the poorer or degenerate eyes would become more numerous, till finally there would be no good eyes in the race. Thus it will be seen that the germinal-selection theory was auxiliary to natural selection and tended to support the latter at two of its weakest points. But the supporting theory itself has the fundamental weakness of lacking a factual basis. It is purely hypothetical and cannot be put to an experimental test. Every time an objection to the theory was raised an auxiliary hypothesis was added to explain away the difficulty, till finally it fell to the ground -through sheer top-heaviness, unable further to support its intricate structure of interrelated hypotheses.

A much more valuable and lasting contribution of Weismann was his theory of "germinal continuity"-and of the "apartness of the germ plasm." The whole theory has come to be known as the "germ-plasm 
theory," which forms the framework of nearly all of our modern genetics. According to this view the germ plasm is immortal in that it is perpetuated from generation to generation through the instrumentality of mitotic cell division, each germ cell being the product of the division of a previous germ cell back to the first germ cell that arose at the dawn of life. Thus a germ cell cannot be a product of the soma, but the soma is the product of germ cells. The soma loses its generalized characters and specializes in various ways. Once specialized, soma cells are believed to have lost their capacity to play a germinal rôle. Specialization means mortality. Thus the relationship between parent and offspring is not that the parent gives rise to the offspring, but that the same germ plasm gives rise to both parent and offspring.

The logical conclusion to which this line of reasoning leads is that the changes in the soma, no matter how produced, are helpless to produce any effect upon the germ plasm since germ cells come only from germ cells and not from soma cells. Consequently Weismann led the assault against Lamarckism and won the day so conclusively that even in these modern times few biologists have the temerity to express aloud any definite belief in the inheritance of acquired characters. Weismann's germ-plasm idea is the cornerstone of modern genetics, though there are some forward-looking biologists who, looking at things with a physiological bias, cannot make themselves believe in the total independence of any tissue--even the sacred germ plasm.

Weismann's influence was very great, especially during the last decade of the nineteenth century, and his theories gave rise to an immense amount of research, chiefly of a cytological and embryological character.

\section{ISOLATION THEORIES}

Among the theories subsidiary to natural selection as an aid to species forming are the various isolation theories. One of the weaknesses inherent in natural selection lrad to do with the probable swamping out of new types by promiscuous breeding with the more numerous individuals of the older types. "Anything," says Metcalf, "which divides a species into groups, which do not freely interbreed, is said to segregate (isolate) the members of the species into these subdivisions."

Some American writers, especially Jordan and Kellogg, Gulick, and Crampton, have dealt with the isolation factor in evolution and believe 
that it is a major factor of as great importance in species forming, or nearly so, as natural selection. But the prevailing opinion seems to be that isolation is really a kind of selection, more like artificial selection than anything else, which separates out certain pure lines and prevents promiscuous interbreeding. Various agents are known to produce isolation by erecting barriers to interbreeding between groups of individuals within a species. These segregative factors may be geographical, climatic, reproductive, physiological, or, in plants, the result of soil diversity. Thus a mountain range, on the two sides of which a species migrates, effectively separates the species into two independent groups. Heat, cold, moisture, etc., separate others. Reproductive incompatibility between new and older types is equally effective, as is assortative mating of like with like. Like natural selection, isolation has nothing to do with the origin of new types, but merely aids in the preservation of types when once formed. Were there not spontaneous variations among animals and plants, there would be nothing to isolate. Therefore isolation plays only an auxiliary rôle, helping to preserve new races once they are formed.

\section{ORTHOGENĖSIS THEORIES}

"The orthogenetic evolution theories of various authors, based upon the assumed occurrence of variations in determinate lines or directions (a restricted and determinate variation as compared with the nearly infinite, fortuitous, and indeterminate variation assumed in the selection theories), are of several types. The mention of two will reveal pretty well the more important characters of all. Not a few biologists have always believed in the existence of a sort of mystic, special vitalistic force or principle by virtue of which determination and general progress in evolution is chiefly fixed. Such a capacity, inherent in living matter, seems to include at once possibility of progressive or truly evolutionary change. Not all evolution is in a single direct line, to be sure; ascent is not up a single ladder or along a single geological branch, but these branches are few (as indeed we actually know them to be, howerer the restriction may be brought about) and the evolution is always progressive, that is, toward what we, from an anthropocentric point of view, are constrained to call higher and higher or more ideal life stages and conditions.

"Other naturalists also seeming to see this source of determinate or orthogenetic evolution, but not inclined to surrender their disbelief in vitalism, in forces over and beyond the familiar ones of the 
physicochemical world, have tried to adduce a definite causomechanical explanation of orthogenesis. The best and most comprehensive types of this explanation are those essentially Lamarckian in principle, in which the direct influence of environmental conditions, the direct reactions of the life stuff to stimuli and influences from the world outside, are the causal factors in such an explanation. But while every naturalist will grant that such factors do change and control in a considerable degree the life of the individual, most see no mechanism or means of extending this control directly to the species."

The above-quoted paragraphs from Jordan and Kellogg will serve to place before the reader the general ideas involved in the orthogenesis conception. A brief account of the various special theories of orthogenesis follows:

Carl von Nägeli's ideas of orthogenesis involve a belief in a sort of mystical principle of progressive development, a something, quite intangible, that exists in organic nature, which causes each organism, to strive for or at least make for specialization or perfect adaptation. This idea of an inner driving and directing force reminds one of the "entelechy" of Driesch, or Bergson's "creative evolution." Nägeli believed that animals and plants would have developed essentially as they have without any struggle for existence or natural selection. This form of orthogenesis theory, then, is alternative to natural selection.

Theodore Eimer's theory of orthogenesis is more scientific and less mystical than Nägeli's. He believed that lines of evolution were not miscellaneous and haphazard, but were confined to a few definite directions, determined at their initial stages not by natural selection but by the laws of organic growth, aided by the inheritance of acquired characters. A new character makes a beginning as would the first step in a slow chemical change, or series of such changes, and it must go through to a fixed end, under given conditions, just as surely as does the chemical process. Only when a given character or line of evolution results in the production of a very positive advantage or disadvantage to the species does natural selection siep in to interfere with orthogenesis. The causes of orthogenesis are said "to lie in the effects of external influeices, climate, nutrition, or the given constitution of the organism."

Actual species-forming, or the breaking-up into specific units of the orthogenetic lines of change, depends, according to Eimer, upon

${ }^{x}$ Jordan and Kellogg, Evolution and A nimal Life (D. Appleton and Company). 
three factors: a standstill or cessation of development on the part of some lines; sudden development by leaps (practically mutations); and hindrance or difficulty of reproduction (the type of thing that Romanes emphasized as physiological isolation ten years later). Eimer illustrated his theories by the evolution of color patterns in lizards and those on the wings of butterflies. In both he believed that longitudinal stripes were primitive, that rows of dots followed these which were in turn followed by crossbands, reticular patterns, and finally by solid coloration. This hypothetical phylogenetic order is more or less closely paralleled by the ontogenetic order, in the lizards at least.

It will be noted that Eimer's theory places natural selection in a subordinate position, but does not dismiss it altogether, as is done by Nägeli. It aids natural selection in explaining adaptations in that it furnishes for natural selection various characters of selective value, which may be either perpetuated or eliminated according to their utility.

E. D. Cope, a leading American palaeontologist of the past century, had an orthogenetic theory involving his ideas of "bathmism" (growth force), "kinetogenesis" (direct effect of use and disuse and environmental influence), and "archaesthetism" (influence of primitive consciousness). It may be said that his ideas were Lamarckian throughout. In common with the majority of palaeontologists of later date-Osborn, Williston, Hyatt, Smith, and others-Cope felt the need of some factor other than natural selection to explain the apparent steady progress of characters in definitely directed lines as seen in the fossils. It is natural therefore that palaeontologists almost universally lay hold of both Lamarckian and orthogenesis ideas.

Charles Otis Whitman, who, until his death over ten years ago, was considered the leading American zoölogist, had strong leanings toward orthogenesis. In one of his few publications he says:

"Natural selection, orthogenesis, and mutation appear to present fundamental contradictions; but I believe that each stands for truth, and reconciliation is not far distant. The so-called mutations of Oenothera are indubitable facts; but two leading questions remain to be answered. First, are these mutations now appearing, as is agreed, independently of variation, nevertheless the products of variations that took place at an earlier period in the history of these plants? Secondly, if species can spring into existence at a single leap, without the assistance of cumulative variations, may they not also originate with such 
assistance? That variation does issue a new species, and that natural selection is factor, though not the only factor, in determining results, is, in my opinion, as certain as that grass grows although we cannot see it grow. Furthermore, I believe I have found indubitable cvidence of -species-forming variation advancing in a definite direction (orthogenesis), and likewise of variations in various directions (amphigenesis). If I am not mistaken in this, the reconciliation for natural selection, and orthogenesis is at hand."

In concluding this brief account of orthogenesis, it should be said that definitely directed evolution is now believed to be one of the laws of organic evolution, but that we have no clear ideas as yet as to what are its underlying causes. Therefore orthogenesis is not a causomechanical theory of evolution at all.

\section{MUTATION OR HETEROGENESIS THEORIES}

The theory of "mutations" is associated with the name of $B$ ugo De Vries, the well-known Dutch botanist; that of "heterogenesis," with the name of $H$. Korchinsky, a Russian.

Though Korchinsky anticipated De Vries by several years, his work was not supported by the large amount of experimental data that characterized that of the great Dutch worker. The relative claims for recognition as the founder of the mutation theory are almost on a par with those of Darwin and Wallace for the naturalselection theory. Both Darwin and De Vries held back their theories until they appeared to be adequately supported by personally collected facts.

There is a striking parallelism between the ideas and conclusions of De V'ries and those of Korchinsky, and since this is true a résumé of De Vries's better-known work will serve to give the essentials of the whole conception.

De Tries began his genetic experiments by a study of the variations of plants in the field. After learning their normal variability in nature, he transferred them to the experimental garden and there attempted to improve them by selection. He found that the improved living conditions due to better soil and cultivation induced a wider range of variability in size, luxuriance, and fecundity. Such variations were plus or minus in their character, fluctuating about a mean or average. It was exactly this type of variability that Darwin emphasized as the raw material of evolution; but De Vries found by experiment that selection had no permanent hereditary effect when based 
to fluctuating variations, since the latter were merely somatic responses on variable growth conditions. This negative finding led him to renewed interest in discontinuous or saltatory variations as the only alternative to fluctuating or continuous variations.

He looked far and wide among species of wild plants for a species that might exhibit a significant amount of saltatory variation and finally discovered in the evening primrose (Oenothera lamarckiana) what seemed to exhibit exactly the hoped-for characteristics. This large, stately plant with conspicuous yellow blooms had escaped from cultivation and was growing wild in the fields. In addition to a large number of plants that showed only minor differences among themselves, De Vries found several individuals growing among the typical individuals which differed not merely in degree but in kind. These were as different as distinct varieties, and, when the seeds were planted in the garden they bred true to their kind. The only question now was whether they had actually arisen from typical parents. To test this possibility, seeds of several typical plants were planted in the garden; the result being not only a repetition of the peculiar types observed in the field, but of about a dozen other true breeding types with well-marked differences from the parent-species and among themselves.

These new types De Vries considered as new elementary species and he called them "mutants." They came into existence suddenly in one generation and, as a rule, bred true. Whatever factors were responsible for mutations, the seat of origin must have been in the germ cell and not in the soma. Consequently they were inherited fully from the start. The same mutations occurred in considerable numbers and in successive years. In one case a given mutation occurred only once in eight years of observation. Some mutants were robust and successful, others were weak and incapable of living under natural conditions, wthers were sterile. On the basis of these results, which are reported in detail in chapter xxiv, De Vries came to the conclusion that evolution was based upon the sudden appearance of new varieties or elementary species and not upon the natural selection of fluctuating variations.

The mutation theory compared and contrasted with the natural selection theory. - It will be recalled that the raw material upon which natural selection works is the minute individual or continuous variation that is universal in all living forms and is known to be largely somatic in character and due to differences in environment. Darwin 
did not distinguish between somatic and germinal variations. The essential feature of mutations is that they are germinal in origin and therefore come forth full-fledged in the first generation arising from the changed germ. Darwin recognized "saltatory variations" or "sports," which are mutations, but did not consider them of suffciently frequent occurrence to furnish an adequate material for selection.

De Vries, on his side, did not discard the principle of selection, but showed that selection acted as between mutants, serving to eliminate those which are unfit and allowing the sufficiently fit to survive alongside the parent-types. According to Darwin's view, the netr types arose only at the expense of the old, for only through the elimination of the old (less fit) types could the new types progress toward further fitness. Darwin's view was ill suited to explain the origin of new distinct types, because the process of selection proceeded by imperceptible steps. De Vries's view gives us distinctly different, pure breeding types at once that, if isolated, would be new elementary species from the first.

In conclusion it may be said that the mutation theory was at first intended as a substitute for natural selection, but that later the selection idea was adopted as a directive principle, guiding mutations toward adaptiveness.

\section{THE RISE AND VOGUE OF BIOMETRY}

No historical account of the development of the evolution idea would be complete without a statement of the rôle played by biometry in the study of evolutionary data. Biometry is the statistical study of variation and heredity. During the last decade of the nineteenth century it became obvious to those who had followed the progress of the suljject that farther advance toward the solution of the problem of the causes of evolution must come from a better understanding of variation and heredity, the two fundamental factors involved. Three main modes of attack were developed during these years: the statistical (biometry), the experimental (chiefly breeding work), and the microscopical (cytology or the study of the minute structure of the germ cells).

Sir Francis Galton, a cousin of Charles Darwin, was the founder of biometry. He applied certain already understood principles that had been developerl mainly in the study of the laws of chance to the study of variations, and, by comparing the boiled-down formulas 
resulting from his computations of parental generations with those of offspring, he arrived at two laws of heredity: the law of filial regression, and that of ancestral shares of inheritance. The essence of the first was that the offspring of exceptional parents tend to regress toward mediocrity in proportion to the degree of parental exceptionalness. The second law was really explanatory of the first, for it was found that the offspring inherit not only from parents, but from the various grades of ancestors, and it was the pulldown of a miscellaneous ancestry that made for regression toward mediocrity. It appeared that half of the hereditary influence could be assigned to parents, half of the remainder to grandparents, half of the remaining remainder to great-grandparents, and so on down the line.

Karl Pearson, a pupil and follower of Galton, has carried the study of biometry to a more highly refined state. His attempt has been to apply to the study of evolution the precise quantitative methods which are used in physics and in chemistry. While much of Pearson's work is far beyond the range of the average professional biologist today, it is extremely useful as a tool in handling data in which great accuracy is demanded. Frequently, however, the methods are far too refined for the material, and much time is wasted in handling crude data by means of highly refined instruments of measurement and ultraaccurate mathematical methods.

On the whole the contributions of biometry to our understanding of the causes of evolution are rather disappointing. About the only clean-cut finding has been the discovery that some variations are continuous and others discontinuous. The former are capable of being expressed in a single curve with a single mode, while the latter are expressed in bimodal or polymodal curves. If material is homogeneous to start with it is likely to give monomodal curves, but if it is heterogeneous, its heterogeneity will be revealed by the plural modes. In a subsequent connection (chapter xxv) some further account of the details of biometry will be presented. We must for the present be content with having placed biometry in its setting as one step in the advance of the evolution idea.

\section{MODERN EXPERIMENTAL EVOLUTION}

"While De Vries," says Castle, " was engaged in his studies of the evening primrose he hit upon an idea far more important, as most biologists now believe, than the idea of mutation, though De Vries

I W. E. Castle, Genetics and Eugenics (Harvard University Press, I920), p. 82. 
himself, both before and since, has seemed to regard it as of minor importance. He called this the 'law of splitting of hybrids.' The same law, it is claimed, was independently discovered about the same time by two other botanists, Correns in Germany, and Tschermak. in Austria. Further, historical investigations made by De Vries showed that the same law had been discovered and clearly stated many years previously by an obscure naturalist of Brünn, Austria, named Gregor Mendel, and we have now come to call this law by his name, Mendel's Law. Mendel was so little known when his discovery was published that it attracted little attention from scientists and was soon forgotten, only to be unearthed and duly honored years after the death of its author. Had Mendel lived forty years later than he did, he would doubtless have been a devotee of biometry, for he had a mathematical type of mind and his discovery of a law of hybridization was due to the fact that he applied to his biological studies methods of numerical exactness which he had learned from algebra and physics. In biology he was an amateur, being a teacher of the physical and natural sciences in a monastic school at Brünn. Later he became head of the monastery and gave up scientific work, partly because of other duties, partly because of failing eyesight."

There had been plant-hybridizers before Mendel, but their lack of exactness in technique had prevented them from discovering the law of segregation or splitting of hybrids.

Joseph Gotilieb Kölreuter (I733-1806), who really belonged to the period of Lamarck, barely missed making the discovery that was afterward made by Mendel. The salient features of his work are according to Castle: ${ }^{x}$

"I. Kolreuter established the occurrence of sexual reproduction in plants by showing that hybrid offspring inherit equally from the pollen plant and the seed plant.

" 2 . He showed that hybrids are commonly intermediate between their parents in nearly all characters observed, such for example as size and shape of parts.

"3. Many hybrids are partially or wholly sterile, especially when the parents are very dissimilar (belong to widely distinct species). Such hybrids often exceed either parent in size and vigor of growth.

"4. Kolreuter did not observe the regular splitting of hybrids which Mendel and De Vries record, but some of his successors did, particularly 'Thomas Knight (I799) and John Goss (1822) in England,

sOp. cit., p. 86. 
who were engaged in crossing the garden peas with a view to producing more vigorous and productive varicties, and Naudin (I862) in France, who made a comprehensive survey of the facts of hybridization in plants and came very near to expressing the generalization which Mendel reached four years later."

\section{MENDEL'S LAW}

"The earliest experimental investigations of heredity," says Locy $^{\mathrm{I}}$ in a concise summary of Mendel's work, "were conducted with plants, and the first epoch-making results were those of Gregor Mendel (I822-I884), a monk and later abbot, of an Augustinian monastery at Brünn, Austria. In the garden of the monastery, for eight years before publishing his results, he made experiments on the inheritance of individual (or unit) characters in twenty-two varieties of garden peas. Selecting certain constant and obvious characters, as color, and form of seed, length of stem, etc., he proceeded to cross these pure races, thus producing hybrids, and thereafter, to observe the results of self-fertilization among the hybrids.

"The hybrids were produced by removing the unripe stamens of certain flowers and later fertilizing them by ripe pollen from another pure breed having a contrasting character. - The results showed that only one of a pair of unit characters appeared in the hybrid of the next generation, while the other contrasting character lay dormant. Thus, in crossing a yellow-seeded with a green-seeded pea, the hybrid generation showed only yellow seeds. The character thus impressing itself on the entire progeny was called dominant, while the other that was held in abeyance was designated recessive.

"That the recessive color was not blotted out was clearly demonstrated by allowing the hybrid generation to develop by self-fertilization. Under these circumstances a most interesting result was attained. The filial generation, derived by self-fertilization among the hybrids, produced plants with yellow and green seeds, but in the ratio of three yellow to one green. All green-seeded individuals and one-third of the yellow proved to breed true, while the remaining two thirds of the yellow-seeded plants, when self-fertilized, produced yellow and green seeds in the ratio of three to one.

"Subsequent breedings gave an unending series of results similar to those obtained with the first filial generation.

I William A. Locy, The Main Currents of Zoölogy (Henry Holt \& Company, I918), pp. 37-39. 
"This great principle of alternative inheritance was exhibited throughout the extensive experiments of Mendel, and it is now recognized as one of the great biological discoveries of the nineteenth century."

The essential feature of Mendel's discovery was not the phenomenon of dominance, for relatively few instances of pure dominance have been discovered; but it was the phenomenon of segregation, By segregation is meant that although determiners for opposed hereditary characters derived from. diverse parental sources may unite in a common germ plasm-for-one generation, they segregate out pure, or unmodified by their association together, in the next and subsequent generations. This law of segregation depends on the idea that the germ cell is composed of bundles of separately inheritable unit characters, which may be paired or grouped, shuffled and redealt like cards, so as to give an infinite number of permutations and combinations without affecting the unit determiners themselves.

From the evolutionary standpoint it is supposed that new unit characters arise by mutations and are fully hereditary. They cannot be swamped out by interbreeding unless they are recessive, for they will dominate the old characters. Even recessive characters could be perpetuated by segregation, or by the union of two individuals possessing the determiner in the recessive condition as well as the dominant. Thus a knowledge of the behavior of unit characters in heredity reveals part of the mechanism for conserving new characters if they are advantageous or even sufficiently fit to survive.

New types or species might arise through processes of hybridization and the survival of individuals possessing the most favorable combinations of characters.

"Evolution from this point of view," says Morgan, ${ }^{\mathrm{r}}$ "has consisted largely in introducing (by mutations) new factors that influence characters already present in the animal or plant.

"Such a view gives us a somewhat different picture of evolution from the old idea of a ferocious struggle between the individuals of a species with the survival of the fittest and the annihilation of the less fit. Evolution assumes a more peaceful aspect. New advantageous characters survive by incorporating themselves into the race, improving it and opening to it new opportunities. In other words, the emphasis may be placed less on the competition between the indi-

I T. H. Morgan, A Critique of the Theory of Evolution (Princeton University Press, 1916), pp. $87,88$. 
viduals of a species (because the destruction of the less fit does not in itself lead to anything that is new) than on the appearance of new characters and modifications of old characters that become incorporated in the species, for on these depends the evolution of the race."

\section{HYBRIDIZATION AND THE ORIGIN" OF SPECIES}

As a consequence of the great interest aroused by Mendel's hybridization experiments the question has arisen as to the rôle of hybridization in organic evolution. Certain it is that a vast number of animal and plant races now existing are mixed or hybrid in nature and are continually splitting up into various Mendelian segregates. How many pure races are there today? Some authors think that no variable races today are pure. Lotsy' goes so far as to claim and attempt to prove that unit characters are fixed and that the only source of variation is hybridization, or amphimixis. Biologists today would not be willing to go thus far with Lotsy, but it seems beyond question that hybridization has played an important rôle in the production of very many groups now living. It is of interest to recall that Linnaeus, though a special creationist, admitted the possibility of the origin of new species by hybridization.

\section{NEO-MENDELIAN DEVELOPMENTS}

Since the rediscovery of Mendel's paper by De Vries and its perusal by thousands of biologists the world over, Mendelian breeding experiments with all manner of animals and plants has been the ruling passion of geneticists. Among the leading neo-Mendelians are Bateson, Morgan, Castle, Correns, East, Hurst, Shull, Tschermak, and the pupils of these.

Perhaps the first two mentioned, Bateson and Morgan, have contributed most largely to an understanding of the intricacies of the Mendelian operations. Bateson has become so imbued with the idea that all mutations are the result of the loss of factors that he proposes the hypothesis that "evolution has taken place through the steady loss of inhibiting factors," as Morgan puts it. "Living matter was stopped down, so to speak, at the beginning of the world. As the stops are lost, new things emerge. Living matter has changed only in that it becomes simpler." It is quite probable that Bateson, in proposing so radical a view, intended to be taken only half-seriously. Apart from this, his best-known expression of opinion, Bateson is the 
author of a large amount of fine work in genetics and will rank high in the history of the subject.

T. H. Morgan, our leading American geneticist, is best known for his researches into the mechanism of Mendelian inheritance. Through the statistical study of ratios and linkages of characters in the fruit fly Drosophila, it has been.possible to chart the localities of the determiners or genes of at least I50 mutant characters. . He has shown that four linked groups of genes exist, corresponding to the four kinds of chromosomes of the germ cells; one of these groups is sex-linked and is therefore to be assigned to the X-chromosome of the mutant male. Two other large groups are to be located in the two large autosomes, and one very small group is assumed to be located in the microsome. Not only have characters, or their determiners, been assigned to given chromosomes, but they have been lacated in a linear series on a given chromosome. So accurately have these loci been determined that they may be used to predict unknown breeding ratios. It would seem that when a theory serves so well that it may be used to predict the results of experiments, such a theory must be founded on facts. Morgan and his collaborators in genetics are now convinced that they have discovered the actual mechanism of heredity in the behavior of the chromosomes in maturation and fertilization and that it is unexpectedly simple. Their views have aroused considerable opposition, but they have apparently met successfully all attacks up to the present. If it be true that the actual machinery of variation and heredity has been discovered, we are farther along in our understanding of the causo-mechanical basis of evolution than we could have hoped to be at so early a date.

\section{HEREDITY AND SEX}

Since Darwin's theory of sexual selection, sex has been a complicating factor in evolutionary theories, and one of the chief advances of the present century has been in connection with the factors controlling sex determination and sex differentiation. The evolution of sex has also been a subject for considerable research.

It now appears that sex is an inherited Mendelian character, the determiner of which is carried in a definite chromosome or group of chromosomes. Cytological examination of germ cells, under the able leadership of E. B. Wilson, has now made it certain that sex, if not directly the result of the presence or absence of specific chromosomes, at least is absolutely correlated with such chromosomes. It appears, however, that the sex which is settled by the chromosome 
mechanism at the time of fertilization may or may not realize its normal somatic differentiation, depending upon the presence or absence of the proper environment. Cases are on record in which an individual germinally determined as a female may be caused to develop the secondary sexual characters of the male, or even to produce sperms instead of eggs. A great deal of extremely interesting work on sex control and sex reversats has been done within the last half-dozen years and new discoveries are being marle almost daily. In fact, it might be said that the genetic study of sex marks the high-tide level of modern genetic advance.

\section{CONCLUDING REMARKS}

Now that we have traced the evolution of the science of organic evolution from its crude beginnings among the Greeks up to the present, we are in a position to go back and make a systematic study of some of the more important phases of evolutionary science. Charles Darwin found it necessary to prove the fact of organic evolution before attempting to cliscover its causes. His method of proof was to marshal a great array of facts which agree with the idea of descent with modification; and we shall follow Darwin's method in the subsequent chapters dealing with the evidences of evolution.

NoTe.-In the first half of the present historical account many short passages are presented in quotation marks without mentioning the source of the quotation. In all such cases it will be understood that these passages are from H. F. Osborn's book, From the Greeks to Darwin (The Macmillan Company). 


\title{
CHAPTER III
}

\section{THE RELATION OF EVOLUTION TO MATERIALISM ${ }^{\mathrm{I}}$}

\author{
Joseph Le CoNte
}

It is seen in the sketch given in the previous chapter that, after every struggle between theology and science, there has been a readjustment of some beliefs, a giving up of some notions which really had nothing to do with religion in a proper sense, but which had become so associated with religious belief as to be confounded with the lattera giving up of some line of defense which ought never to have been held because not within the rightful domain of theology at all. Until the present the whole difficulty has been the result of misconception, and Christianity has emerged from every struggle only strengthened and purified, by casting off an obstructing shell which hindered its growth. But the present struggle seems to many an entirely different and far more serious matter. To many it seems no longer a struggle of theology, but of essential religion itself - a deadly life-and-death struggle between religion and materialism. To many, both skeptics and Christians, evolution seems to be synonymous with blank materialism, and therefore cuts up by the roots every form of religion by denying the existence of God and the fact of immortality. That the enemies of religion, if there be any such, should assume and insist on this identity, and thus carry over the whole accumulated evidence of evolution as a demonstration of materialism, although wholly unwarranted, is not so surprising; but what shall we say of the incredible folly of her friends in admitting the same identity!

A little reflection will explain this. There can be no doubt that there is at present a strong and to many an overwhelming tendency toward materialism. The amazing achievements of modern science; the absorption of intellectual energy in the investigation of external nature and the laws of matter have created a current in that direction so strong that of those who feel its influence- of those who do not stay at home, shut up in their creeds, but walk abroad in the light of modern thought-it sweeps away and bears on its bosom all

I From J. Le Conte, Evolution (copyright I888). Used by special permission of the publishers, D. Appleton \& Company. 
but the strongest and most reflective minds. Materialism has thus become a fashion of thought; and, like all fashions, must be guarded against. This tendency has been created and is now guided by science. Just at this time it is strongest in the department of biology, and especially is evolution its stronghold. This theory is supposed by many to be simply demonstrative of materialism. Once it was the theory of gravitation which seemed demonstrative of materialism. The sustentation of the universe by law seemed to imply that Nature operates itself and needs no God. That time is passed. Now it is evolution and creation by law. This will also pass. The theory seems to many the most materialistic of all scientific doctrines only because it is the last which is claimed by materialism, and the absurdity of the claim is not yet made clear to many.

The truth is, there is no such necessary connection between evolution and materialism as is imagined by some. There is no difference in this respect between evolution and any other law of Nature. In evolution, it is true, the last barrier is broken down, and the whole domain of Nature is now subject to law; but it is only the last; the march of science has been in the same direction all the time. In a word, evolution is not only not identical with materialism, but, to the deep thinker, it has not added a feather's weight to its probability or reasonableness. Evolution is one thing and materialism quite another. The one is an established law of Nature, the other an unwarranted and hasty inference from that law. Let no one imagine, as he is conducted by the materialistic scientist in the paths of evolution from the inorganic to the organic, from the organic to the animate, from the animate to the rational and moral, until he lands, as it seems to him, logically and inevitably, in universal materialism-let no such one imagine that he has walked all the way in the domain of science. He has stepped across the boundary into the domain of philosoph. But, on account of the strong tendency to materialism and the skilful guidance of his leaders, there seems to be no such boundary; he does not distinguish between the inductions of science and the inferences of a shallow philosophy; the whole is accredited to science, and the final conclusion seems to carry with it all the certainty which belongs to scientific results. The fact that these materialistic conclusions are reached by some of the foremost scientists of the present day adds nothing to their probability. In a question of science, viz., the law of evolution, their authority is deservedly high, but in a question of philosophy, viz., 
materialism, it is far otherwise. If the pure scientists smile when theological philosophers, unacquainted with the methods of science, undertake to dogmatize on the subject of evolution, they must pardon the philosophers if they also smile when the pure scientists imagine that they can at once solve questions in philosophy which have agitated the human mind from the earliest times. I am anxious to show the absurdity of this materialistic conclusion, but I shall try to do so, not by any labored argument, but by a few simple illustrations.

I. It is curious to observe how, when the question is concerning a work of Nature, we no sooner find out how a thing is made than we immediately exclaim: "It is not made at all, it became so of itself!" So long as we knew not how worlds were made, we of course concluded they must have been created, but so soon as science showed how it was probably done, immediately we say we were mistakenthey were not made at all. So also, as long as we could not imagine how new organic forms originated, we were willing to believe they were created, but, so soon as we find that they originated by evolution, many at once say: "We were mistaken; no creator is necessary at all." Is this so when the question is concerning a work of man? Yes, of one kind-riz., the work of the magician. Here, indeed, we believe in him, and are delighted with his work, until we know how it is done, and then all our faith and wonder cease. But in any honest work it is not so; but on the contrary, when we understand how it is done, stupid wonder is changed into intellectual delight. Does it not seem, then, that to most people God is a mere wonder-worker, a chief magician? But the mission of science is to show us how things are done. Is it any wonder, then, that to such persons science is constantly destroying their superstitious illusions? But if God is an honest worker, according to reason-i.e., according to law-ought not science rather to change gaping wonder into intelligent delight, superstition into rational worship?

2. Again, it is curious to observe how an old truth, if it come only in a new form, often strikes us as something unheard of, and even as paradoxical and almost impossible. A little over thirty years ago a little philosophical toy, the gyroscope, was introduced and became very common. At first sight, it seems to violate all mechanical laws and set at naught the law of gravitation itself. A heavy brass wheel, four to five inches in diameter, at the end of a horizontal axle, six or eight inches long, is set rotating rapidly, and then the free end of the 
axis is supported by a string or otherwise. The wheel remains suspended in the air white slowly gyrating. What mysterious force sustains the wheel when its only point of support is at the end of the axle, six or cight inches away? Scientific and popular literature were flooded with explanations of this seeming paralox. And yet it was nothing new. 'The boy's top, that spins and leans and will not fall, although solicited by gravity, so long as it spins, which we have seen all our lives without special woncler, is precisely the same thing.

Now, evolution is no new thing, but an old familiar truth; but, coming now in a new and questionable shape, lo, how it startles us out of our propriety! Origin of forms lyy evolution is going on everywhere about us, both in the inorganic and the organic world. In its more faniliar forms, it had never occurred to most of us that it was a scientific refutation of the existence of God, that it was a demonstration of nuaterialism. But now it is pushed one step farther in the direction it has always been going--it is made to include also the origin of species-only a little change in its form, and lo, how we start! 'To the deep thinker, now and always, there is and has been the alternative-materialism or theism. God operates Nature or Nature operates itself; but evolution puts no new phase on this old question. For example, the origin of the individual by evolution. Everybody knows that every one of us individually became what we now are lyy a slow process of evolution from a microscopic spherule of protoplasm, and yet this did not interfere with the idea of God as our individual maker. Why; then, should the discovery that the species (or first individuals of each kind) originated by evolution destroy our belief in God as the creator of species?

3. It is curious and very interesting to observe the manner in which vexed questions are always finally settled, if settled at all. All vexed questions-i.e., questions which have taxed the powers of the greatest minds age aiter age-are such only because there is a real truth on both sides. Pure, unmixed error does not live to plague us long. Error, when it continues to live, does so by virtue of a germ of truth contained. Great questions, therefore, continue to be argued pro and con from age to age, because each side is in a sense-i.e., from its own point of view-true, but wrong in excluding the other point of view; and a true solution, a true rational philosophy, will always be found in a view which combines and reconciles the two partial, mutually excluding views, showing in what they are true and in what they are false-explaining their differences by transcending 
them. This is so universal and far-reaching a principle that I am sure I will be pardoned for illustrating it in the homeliest and tritest fashion. I will do so by means of the shield with the diverse sides, giving the story and construing it, however, in my own way. There is, apparently, no limit to the amount of rich marrow of truth that may be extracted from these dry bones of popular proverbs and fables by patient turning and gnawing.

We all remember, then, the famous dispute concerning the shield, with its sides of different colors, which we shall here call white and black. We all remember how, after vain attempts to discover the truth by dispute, it was agreed to try the scientific method of investigation. We all remember the surprising result. Both parties to the dispute were right and both were wrong. Each was right from his point of view, but wrong in excluding the other point of view. Each was right in what he asserted, and each wrong in what he denied. And the complete truth was the combination of the partial truths and the elimination of the partial errors. But we must not make the mistake of supposing that truth consists in compromise. There is an old adage that truth lies in the middle between antagonistic extremes. But it seems to us that this is the place of safety, not of truth. This is the favorite adage, therefore, of the timid man, the time-server, the fence-man, not the truth-seeker. Suppose there had been on the occasion mentioned above one of these fence-philosophers. He would have said: "These disputants are equally intelligent and equally valiant. One side says the shield is white, the other that it is black; now truth lies in the middle; therefore, I conclude the shield is gray or neutral tint, or a sort of pepper-and-salt." Do we not see that he is the only man who has no truth in him? No; truth is no heterogeneous mixture of opposite extremes, but a stereoscopic combination of two surface views into one solid reality.

Now, the same is true of all vexed questions, and I have given this trite fable again only to apply it to the case in hand.

There are three possible views concerning the origin of organic forms whether individual or specific. Two of these are opposite and mutually excluding; the third combining and reconciling. For example, take the individual. There are three theories concerning the origin of the individual. 'The first is that of the pious child who thinks that he was made very much as he himself makes his dirt-pies; the second is that of the street-gamin, or of Topsy, who says: "I was not made at all, I growed "; the third is that of most intelligent 
Christians-i.e., that we were made by a process of evolution. Olsserve that this latter combines and reconciles the other two, and is thus the more rational and philosophical. Now, there are also three exactly corresponding theories concerning the origin of species. The first is that of many pious persons and many intelligent clergymen, who say that species were made at once by the Divine hand without natural process. The second is that of the materialists, who say that species were not made at all, they were derived, "they growed." The third is that of the theistic erolutionists, who think that they were created by a process of evolution-who believe that making is not inconsistent with growing. The one asserts the divine agency, but denies natural process; the second asserts the natural process, but denies divine agency; the third asserts divine agency by natural process. Of the first two, observe, both are right and both wrong; each view is right in what it asserts, and wrong in what it denies - each is right from its own point of view, but wrong in excluding the other point of view. The third is the only true rational solution, for it includes, combines, and reconciles the other two; showing wherein each is right and wherein wrong. It is the combination of the two partial truths, and the elimination of the partial errors. But let us not fail to do perfect justice. The first two views of origin, whether of the individual or of the species, are indeed both partly wrong as well as partly right; but the view of the pious child and of the Christian contains by far the more essential truth. Of the two sides of the shield, theirs is at least the whiter and more beautiful.

But, alas! the great bar to a speedy settlement of this question and the adoption of a rational philosophy is not in the head, but in the heart-is not in the reason, but in pride of opinion, self-conceit, dogmatism. The rarest of all gifts is a truly tolerant, rational spirit. 1 In all our gettings let us strive to get this, for $i t$ alone is true wisdom. But we must not imagine that all the dogmatism is on one side, and that the theological. Many seem to think that theology has a "preemptive right" to dogmatism. If so, then modern materialistic science has " jumped the claim." Dogmatism has its roots deep-bedded in the human heart. It showed itself first in the domain of theology, because there was the seat of power. In modern times it has gone over to the side of science, because here now is the place of power and fashion. There are two dogmatisms, both equally opposed to the true rational spirit, viz., the old theological and the new scientific. The old clings fondly to old things, only because they are old; the new grasps eagerly 
after new things, only because they are new. True wisdom and true philosophy, on the contrary, tries all things both old and new, and holds fast only to that which is good and true. The new dogmatism taunts the old for credulity and superstition; the old reproaches the new for levity and skepticism. But true wisdom perceives that they are both equally credulous and equally skeptical. The old is credulous of old ideas and skeptical of new; the new is skeptical of old ideas and credulous of new. Both deserve the unsparing rebuke of all rightminded men. The appropriate rebuke for the old dogmatism has been already put in the mouth of Job in the form of a bitter sneer: "No doubt ye are the people, and wisdom shall die with you." The appropriate rebuke for the new dogmatism, though not put into the mouth of any ancient prophet, ought to be uttered - I will undertake to utter it here. I would say to these modern materialists, "No doubt ye are the men, and wisdom and true philosophy were born with you."

Let it be observed that we are not here touching the general question of the personal agency of God in operating Nature. This we shall take up hereafter. All that we wish to insist on now is that the process and the law of evolution does not differ in its relation to materialism from all other processes and laws of Nature. If the sustentation of the universe by the law of gravitation does not disturb our belief in God as the sustainer of the universe, there is no reason why the origin of the universe by the law of evolution should disturb our faith in God as the creator of the universe. If the law of gravitation be regarded as the Divine mode of sustentation, there is no reason why we should not regard the law of evolution as the Divine process of creation. It is evident that if evolution be materialism, then is gravitation also materialism; then is every law of Nature and all science materialism. If there be any difference at all, it consists only in this: that, as already said, here is the last line of defense of the supporters of supernaturalism in the realm of Nature. But being the last line of defensethe last ditch-it is evident that a yielding here implies not a mere shifting of line, but a change of base; not a readjustment of details only, but a reconstruction of Christian theology. This, I believe, is indeed necessary. There can be little doubt in the mind of the thoughtful observer that we are even now on the eve of the greatest change in traditional views that has taken place since the birth of Christianity. But let no one be greatly disturbed thereby. For then, so now, change comes not to destroy but to fulfil all our dearest 
hopes and aspirations; as then, so now, the germ of living truth has, in the course of ages, become so encrusted with meaningless traditions which stifle its growth that it is necessary to break the shell to set it free; as then, so now, it has become necessary to purge religious belief of dross in the form of trivialities and superstitions. This has ever been and ever will be the function of science. The essentials of religious faith it does not, it cannot, touch, but it purifies and ennobles our conceptions of Deity, and thus elevates the whole plane of religious thought. 

PART II

EVIDENCES OF ORGANIC EVOLUTION 



\section{CHAPTER IV}

\section{IS ORGANIC EVOLUTION AN ESTABLISHED PRINCIPLE?}

\section{H. H. NewMaN}

r. Is there definite proof of organic evolution?

2. If so, what is the nature of the proof?

3. What are the evidences of evolution, and in what ways do these bear witness that evolution has occurred and is still occurring?

Before presenting in any detail the several bodies of data that constitute the "evidences of evolution," let us anticipate a little by attempting to answer the three questions just propounded.

I. Reluctant as he may be to admit it, honesty compels the evolutionist to admit that there is no absolute proof of organic evolution. But, for that matter, there is no absolute proof of anything that depends on records of past events. We have no absolute proof that Caesar or Napoleon once lived, or fought, or conquered. All we have are the accounts left by the historians which we accept without question because they are the products of human thought and imagination. There is no absolute proof for either of the more or less directly opposed theories of the origin of the material universe: the "nebular hypothesis" of Laplace, and the "planetesimal hypothesis" of Chamberlin and Moulton. Both of these theories rest upon exactly the same types of evidences as does the theory of organic evolution, viz., the amassing of facts which appear to be explicable on the assumption that the one or the other theory is true. If all of the facts are in accord with it, and none are found that are incapable of being reconciled with it, a working hypothesis is said to have been advanced to the rank of a proved theory. As yet it is impossible to say that either of these theories as to the origin of the universe has been proved. Yet there is much less popular opposition to the acceptance of these theories as facts than there is to the general theory of organic evolution. Similarly, there are certain widely accepted theories of the origin of the present conditions of the earth's crust, and its liquid and gaseous envelopes. The accepted theory, as given us by Hutton and especially by Lyell, is essentially an evolutionary theory and depends for its proof on almost exactly the same types of eridence as does that 
of organic evolution. The basis of the accepter theory of geological evolution is the "uniformitarian doctrine" of Lyell, which assumes that the key to the past lies in the present, that the changes that are going on today are of the same order and kind as those of the past, and, finally, that there is neither beginning nor end to the earth's evolutionary history, lut that a slow and orderly development has gone on and will continue indefinitely. The proof of this conception consists of an array of facts derived from a study of the earth's crust, including its stratified structure, of traces of animal and plant life preserved in the rocks, of observed changes in continental contours going on today, of erosion going on in coasts and streams, and of a considerable array of facts derived from a study of other worlds than ours in the making. The theory of geologic evolution meets with scarcely any opposition today, although its foundations are no more securely based than are those of organic evolution.

In a sense the proofs of the atomic, ionic, and electron theories are eren less absolutely established than is that of organic evolution, because no one has ever seen nor ever can see an atom, an ion, or an electron. Chemical and physical fact : are rationalized by assuming the existence of these units with their various properties. The only evidences of the existence of atoms, ions, and electrons appear in the facts that, on the assumption that they exist, the whole array of observed chemical and physical phenomena are rationalized and bound together into a coherent, consistent, and intelligible system. In other words, with the atomic, ionic, and electron theories chemistry and physics are highly rational sciences; without these theories the phenomena of physics and chemistry would be a hopeless hodgepodge. Yet who would say that these fundamental theories are absolutely proved?

The only type of proof of phenomena that cannot be directly observed or that pertain to the remote past is circumstantial proof. By analogy we conclude that certain changes took place thus and so in the past because we observe similar changes going on today. Every past erent has left a trace, and it is the task of the historian, antiquarian, or evolutionist to discover and to interpret these traces. Sometimes the traces exist as vestiges in modern life and are meaningless unless related to their origin in the past. The task of the student of organic evolution is to gather all of the traces of past changes both in living creatures today and in the preserved remains of creatures of the remote past. A collection of traces of evolution involves many 
apparently unrelated bodies of phenomena. There are eviclences of evolution in the grouping of animals into phyla, classes, orters, families, genera, species, varieties, and races; in the homologies that exist in general structure and in particular organs between different groups of animals and plants; in the orderly process of ontogeny or embryonic development of the individual; in actual blood relationship, based upon chemical reactions: on the succession of extinct animals and plants found as fossils imbedded in the geoloric strata: in the present geographical distribution of the various groups of animals and plants, in the light of data clerived from a study of geological changes; and finally, in experimental evolution, which involves the observation under experimental control of changes in organisms and the origin of new varieties or elementary species.

2. The nature of the proof of organic evolution, then, is this: that, using the concept of organic evolution as a working hypothesis it has been possible to rationalize and render intelligible a vast array of observed phenomena, the real facts upon which evolution rests. Thus classification (taxonomy), comparative anatomy, embryology, palaeontology, zoögeography and phỹtogeography, serology, genetics. become consistent and orderly sciences when based upon evolutionary foundations, and when riewed in any other way they are thrown into the utmost confusion. There is no other generalization known to man which is of the least value in giving these bodies of fact any sort of scientific coherence and unity. In other words, the working hypothesis works and is therefore acceptable as truth until overthrown by a more workable hypothesis. Not only does the hypothesis work, but, with the steady accumulation of further fact: I the weight of evidence is now so great that it overcomes all intelligent opposition by its sheer mass. There are no rival hypotheses except the outworn and completely refuted idea of special creation, now retained only by the ignorant, the dogmatic, and the prejudiced.

3. In answer to the question, "What are the evidences of evolution and in what ways do these bear witness that evolution has occurred and is still occurring?" we may present an ordered list of subjects that are to be taken up serially in detail. In connection with each of these bodies of evidence the character of their witness-bearing will be discussed.

Some of the evidences are more direct and freer from purely interpretative construction than others. Some evidences are primary and foundational; some are in themselves rather inconclusive, but serve 
to confirm other facts, and, when reinforced by other evidences, are themselves strongly substantiated. Perhaps the crowning evidence of the truth of evolution is that all of these diverse bodies of phenomena invariably support one another and all point in the same direction and to the same conclusion, viz., that organic evolution is a fact.

In presenting the evidences of evolution, those evidences that are believed to furnish the most direct proof are discussed first and those whose evidence is subsidiary and confirmatory are dealt with later. 'The order of treatment, therefore, will be as follows:

I. Palacontology-the evidence afforded by a study of the distribution in time (vertical distribution in the earth's strata) of the fossil remains of extinct animals and plants.

II. Geographic distribution-the evidence afforded by present (also, to some extent, past) horizontal distribution of contemporaneous animals and plants.

III. Classifucation-the evidence that the present groups of animals and plants have arisen by "descent with modification," which is an evolutionary conception.

IV. Comparative anatomy (homologies and vestigial structures)the evidence derived from the fact that structures in unlike organisms have a common plan and mode of origin; that changes have occurred which are in some way related to changes of habit or of environment.

V. Serology (blood-transfusion tests) - the evidence that the chemical specificity of the blood parallels taxonomic specificity.

VI. Embryology (the doctrine of recapitulation) - the evidence that the embryonic development of the individual follows the main outlines of the evolutionary history of its ancestors.

VII. Experimental cvolution (genetics)-evidences that heritable variations can be produced experimentally and that these are of the same general character as those which occur spontaneously in Nature. (This material will be presented in some detail in Part IV of this book.) 


\title{
CHAPTER V
}

\section{EVIDENCES FROM PALAEONTOLOGY}

\author{
STRENGTH AND WEAKNESS OF THE EVIDENCE
}

[The word palaeontology means literally the science of ancient life. Practically, it is the study of the fossil remains of extinct animals and plants, including any traces of their existence, such as footprints, impressions in slate, clay, or coal. The evidence from the fossils has definite elements of strength in that it deals with actual organisms that formerly inhabited the earth's surface. Many of these species must have left descendants, some of which are doubtless living in a modified condition today. Palaeontology should be able either strongly to support or to contradict the idea of evolution. If its data accord with the evolution idea and are opposed to the special creation idea, the fossils may be said to be evidences of evolution.

The weakness of the study of fossils lies in the fact that extremely few samples of the living forms that have existed in the past have been preserved, and of those that have been preserved only a very small percentage have been dug up and studied by capable scientists. Many types of animals and plants, moreover, are soft and capable of preservation only under such exceptiona! conditions that but a rare specimen here and there over the world, scattered through various widely separated strata, has been found. Only very common or abundant types are likely to have been preserved and discovered, for the chances of an uncommon form being preserved would be small and the further chances of these infrequently preserved specimens being found would be infinitely smaller.

The great majority of fossil remains are fragmentary or preserved very incompletely, so that only the hard parts have come down to us. There are, of course, many important exceptions to this rule, and these are our chief reliance in interpreting ancient life.

That Darwin fully realized the vulnerable points in the palaeontological record is shown by the following quotation from the Origin of Species:-ED.]

"I look at the geological record as a history of the world imperfectly kept and written in a changing dialect; of this history we possess 
the last volume alone, relating only to two or three countries. Of this volume only here and there a short chapter has been preserved; and of each page only here and there a few lines. Each word of the slowly changing language, more or less different in the successive chapters, may represent the forms of life which are entombed in our successive formations and which falsely appear to us to have been abruptly introduced."

\section{OTHER OPINIONS AS TO THE ADEQUACY OF THE EVIDENCES OF PALAEONTOLOGY}

"The primary and direct evidence in favour of evolution can be furnished only by palaeontology. The geological record, so soon as it approaches completeness, must, when properly questioned, yield either an affirmative or a negative answer: if Evolution has taken place there will its mark be left; if it has not taken place there will lie its refutation."-T. H. Huxley.

"The geological record is not so hopelessly incomplete as Darwin believed it to be. Since The Origin of Species was written our knowledge of that record has been enormously extended, and we now possess no complete volumes, it is true, but some remarkably full and illuminating chapters. The main significance of the whole lies in the fact that, just in proportion to the completeness of the record is the unequivocal character of its testimony to the truth of the evolutionary theory." W. B. Scott.

"On the other hand, matters have greatly improved since Darwin wrote his oft-cited Chapter X; many lands then geologically unknown have been explored and many of the missing chapters and paragraphs in the history of life have been brought to light. The most ancient biologically intelligible period of the earth's history is called the Cambrian and, compared with the succeeding periods, the Cambrian has always been poor in fossils, great areas and thicknesses of rocks being entirely barren. No one could doubt that our knowledge of Cambrian life was most incomplete and inadequate. A few years ago Dr. C. D. Walcott, Secretary of the Smithsonian Institution, discovered in the Canadian Rockies a most marvelous series of Cambrian fossils of an incredible delicacy and beauty of preservation, which have thrown a flood of new and unexpected light into very dark places. It is clear that the Cambrian seas swarmed with a great variety and profusion of life, but that in only a few places, so far known to us, 
were conditions such that these delicate creatures could be preserverl. It is not possible to saly how far the difficulty caused by the imperfection of the geological record will be removed by the progress of cliscovery. Even as matters stand to-day, the astonishing fact is that so much has been preserved, rather than that the story is so incomplete. Notwithstanding all the difficulties, the palaeontological method remains one of the most viluable means of testing the theory of evolution, because certain chapters in the history of life have been recorded with a minuteness that is really very surprising." W. B. Scott, Theory of Evolution. (The Macmillan Company. Reprinted by permission).

WHAT FOSSILS ARE AND HOW THEX HAVE BEEN PRESERVED

"Fossils are only animals and plants which have been dead rather longer than those which died yesterday."-T. H. Huxley.

"Fossils are either actual remains of bones or other parts preserved intact in soil or rocks, or else, and more commonly, parts of animals which have been turned into stone, or of which stony casts have been made. All such remains buried by natural causes are called fossils." Jordan and Kellogg.

\section{FOSSILS CLASSIFIED}

[Class 1 . The actual remains of recently extinct animals and plants which have been buried or surrounded by some sort of preserving material constitute the first type under consideration. Such remains have undergone little or no change of the original organic matter into inorganic. Thus we find the complete bodies of great hairy mammoths frozen in the arctic ice. These are so well preserved that dogs have fed upon their flesh. Nearly a thousand species of extinct insects, including many ants, have been obtained practically intact from amber, a fo, $m$ of petrified resin. Innumerable mollusk shells, teeth of sharks, pieces of buried logs, bones of animals buried in asphalt lakes and bogs, have been found in a well-preserver condition.

Class 2. Petrified fossils.-The process of petrification involves the replacement, particle for particle, of the organic matter of a deacl animal or plant by mineral matter. So completely is the finer structure preserved that microscopic sections of preserverl tissues, especially of plants, have practically the same appearance as sections made from living organisms. Various mineral materials have been employed in petrification; such as quartz, limestone, or iron pyrites. 
Class 3. Casts and impressions. - Very frequently the animal or plant has been buried in mud or has lain on a sof $i$ murl flat only long enough to have left its impress in the plastic material. Suhsequently the entire organism has decayed and been dissolved away, and its place has been taken by a mineral deposit. Thus only the external appearance has been preserved, as would be the case in making plaster-of-paris casts. Sometimes traceries of soft-bodied animals have been left upon forming slate or coal that are almost as accurate in detail as a lithograph.

Perhaps the most remarkable fossils known are those found by Professor Charles D. Walcott in the marine oily shales of British Columbia. A large number of soft-bodied invertebrates of Cambrian age have been found so wonderfully preserved that not only are the external features revealed, but sometimes even the details of the internal organs may be seen through the transparent integument.

Some authorities include among fossils such traces of extinct life as footprints, utensils and tools of extinct man, and even the vestiges of archaic sea beaches. Perhaps this is' stretching the definition of the term "fossil" too far.-ED.]

\section{ON THE CONDITIONS NECESSARY FOR FOSSILIZATION}

"Examination and study of the rocks of the earth reveal the fact that fossils or the remains of animals and plants are found in certain kinds of rocks only. They are not found in lava, because lava comes from volcanoes and rifts in the earth's crust, as a red-hot, viscous liquid, which cools to form a hard rock. No animal or plant caught in a lava stream will leave any trace. Furthermore, fossils are not found in granite, nor in ores of metals, nor in certain other of the common rocks. Many rocks are, like lava, of igneous origin; others, like granite, although not originally in the melted condition, have been so heated subsequent to their formation, that any traces of animal or plant remains in them have been obliterated. Fossils are found almost exclusively in rocks which have been formed by the slow deposition in water of sand, clay, mud, or lime. The sediment which is carried into a lake or ocean by the streams opening into it sinks slowly to the bottom of the lake or ocean and forms there a layer which gradually hardens under pressure to become rock. This is called sedimentary rock, or stratified rock, because it is composed of sedi- 
ment, and sediment always arranges itself in layers or strata. In sedimentary or stratified rocks fossils are found. The commonest rocks of this sort are limestone, sandstone, and shales. Limestone is formed chiefly of carbonate of lime; sandstone is cemented sand, and shales, or slaty rocks, are formed chiefly of clay.

"The formation of sedimentary rocks has been going on since land first rose from the level of the sea; for water has always been wearing away rock and carrying it as sediment into rivers, and rivers have always been carrying the worn-off lime and sand and clay downward to lakes and oceans, at the bottoms of which the particles have been piled up in layers and have formed new rock strata. But geologists have shown that in the course of the earth's history there have been great changes in the position and extent of land and sea. Sea bottoms have been folded or upheaved to form dry land, while regions once land have sunk and been covered by lakes and seas. Again, through great foldings in the cooling crust of the earth, which resulted in depression at one point and elevation at another, land has become ocean and ocean land. And in the almost unimaginable period of time which has passed since the earth first shrank from its hypothetical condition of nebulous vapor to be a ball of land covered with water, such changes have occurred over and over again. They have, however, mostly taken place slowly and gradually. The principal seat of great change is in the regions of mountain chains, which, in most cases, are simply the remains of old folds or wrinkles in the crust of the earth.

"When an aquatic animal dies, it sinks to the bottom of the lake or ocean, unless, of course, its flesh is eaten by some other animal. Even then its hard parts will probably find their way to the bottom. There the remains will soon be covered by the always dropping sediment. They are on the way to become fossils. Some land animals also might, after death, get carried by a river to the lake or ocean, and find their way to the bottom, where they, too, will become fossils, or they may die on the banks of the lake or ocean and their bodies may get buried in the soft mud of the shores. Or, again, they are often trodden in the mire about salt springs or submerged in quicksand. It is obvious that aquatic animals are far more likely to be preserved as fossils than land animals. This inference is strikingly proved by fossil remains. Of all the thousands and thousands of kinds of extinct insects, mostly land animals, comparatively few specimens are known as fossils. On the other hand, the shell-bearing 
mollusks and crustaceans are represented in almost all rock deposits which contain any kind of fossil remains. "-Jordan and Kellogg.

[The study of geology teaches us that the earth's outer zones have undergone within the period of vertebrate history numerous profound changes which in general we may term climatic changes. There have been periods of continental subsidence, accompanied by ocean-floor elevations, during which great continental plains have been covered with comparatively shallow seas. The marine faunas of the seas have migrated into these shallows and representatives of them have been buried in sediment. When the reverse change has occurred and the continental plain has been again elevated, the sedimentation of the shallow-sea period forms a great rocky stratum laden with marine fossils. Between periods of subsidence millions of years elapsed, and therefore a break in the continuity of the entombed fossils is to be expected. Discontinuity between the fossil faunas in adjacent strata is the invariable rule. Were it not for this periodicity of subsidence and elevation there would be no boundaries between consecutive geologic strata.

In addition to the methods of fossilization mentioned, a few others deserve notice. Many animals of the arid plains have been fossilized by becoming imbedded in dust or sand drifts which have piled up against rocky outcrops or have filled in dried-up arroyos. Some very valuable fossils have been recovered from asphaltic deposits as the result of animals falling into liquid or semiliquid lakes or pools of asphalt.

Not only are external organs preserved with precision, but even delicate internal structures, such as the brains or the viscera of vertebrates, have been found in such a perfectly natural shape that the comparative anatomy could be worked out with confidence.

On the whole, then, we must conclude that the earlier pessimism regarding the inadequacy and insufficiency of fossil data is giving way before a steadily increasing optimism, due to the very rapid advance in technique and the surprisingly abundant discoveries of the modern palaeontologist. The more enthusiastic of the new school of fossilhunters do not despair of ultimately bringing to light all of the really essential links in the chain of evidence necessary to place the evolution theory beyond the reach of controversy.-ED.]

${ }^{x}$ From D. S. Jordan and V. L. Kellogg, Evolution and A nimal Life (copyright 1907). Used by special permission of the publishers, D. Appleton \& Company. 
ON THE LAPSE OF TIME DURING WHICH EVOLUTION IS BELIEVED

TO HAVE TAKEN PLACE

"Independently of our not finding fossil remains of such infinitely numerous connecting links [referring to the objection that all steps in the evolution of modern types should be revealed in the fossils], it may be objected that time cannot have sufficed for so great an amount of organic change, all changes having been effected slowly. It is hardly possible for me to recall to the reader who is not a practical geologist, the facts leading the mind feebly to comprehend the lapse of time. He who has read Sir Charles Lyell's grand work on the Principles of Geology, which the future historian will recognize as having produced a revolution in natural science, and yet does not admit how vast have been the past periods of time, may at once close this volume. Not that it suffices to study the Principles of Geology, or to read special treatises by different observers on separate formations, and to mark how each author attempts to give an inadequate idea of the duration of each formation, or even of each stratum. We can best gain some idea of past time by knowing the agencies at work, and learning how deeply the surface of the land has been denuded, and how much sediment has been deposited. As Lyell has well remarked, the extent and thickness of our sedimentary formations are the result and the measure of the denudation which the earth's crust has elsewhere undergone. Therefore a man should examine for himself the great piles of superimposed strata, and watch the rivulets bringing down the mud, and the waves wearing away the sea-cliffs, in order to comprehend something about the duration of past time, the monuments of which we see all around us."-Charles Darwin, Origin of Species.

"In I862," says Schuchert, ${ }^{\mathrm{r}}$ "the physicist, Lord Kelvin . . . . held that as our planet was continually losing energy in the form of heat, the globe was a molten mass somewhere between $20,000,000$ and $400,000,000$ years ago, with a probability of this state occurring about $98,000,000$ years ago. Finally in 1897 he concurred in Clarence King's conclusion that the globe was a molten mass about $24,000,000$ years ago. Both of these conclusions, however, were wrought out under the Lap lacian hypothesis, and now many geologists hold that the earth never was molten. While geologists have not been able to fit their evidence into so short a time, they have ever since been trying to keep their

C. Schuchert, Text-Book of Geology, Part II, II istorical Geology (19r5). 


\begin{tabular}{|c|c|c|c|c|c|c|}
\hline \multirow{2}{*}{$\begin{array}{l}\text { MILLIONS } \\
\text { OF } \\
\text { YEARS }\end{array}$} & \multirow{2}{*}{ 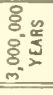 } & \multirow{2}{*}{$\begin{array}{c}\text { AGE OF MAN } \\
\text { AGE } \\
\text { OF } \\
\text { MAMMALS } \\
\end{array}$} & \multirow{2}{*}{ 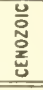 } & & \multirow{2}{*}{$\begin{array}{l}\text { OUARTERNARY } \\
\text { TERTIARY }\end{array}$} & \multirow{13}{*}{ 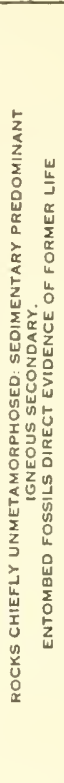 } \\
\hline & & & & & & \\
\hline & \multirow{4}{*}{ 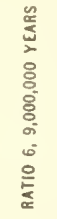 } & \multirow{4}{*}{$\begin{array}{c}\text { AGE } \\
\text { OF } \\
\text { REPTILES }\end{array}$} & \multirow{4}{*}{$\begin{array}{l}u \\
0 \\
N \\
O \\
W \\
w \\
\Sigma\end{array}$} & & $\begin{array}{l}\text { UPPER } \\
\text { CRETACEEOUS }\end{array}$ & \\
\hline & & & & & $\begin{array}{l}\text { LOWER } \\
\text { CRETACEOUS } \\
\text { (COMANGEEAN) } \\
\end{array}$ & \\
\hline & & & & & JURASSIC & \\
\hline & & & & & TRIASSIC & \\
\hline & \multirow{7}{*}{ 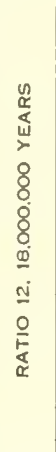 } & \multirow{7}{*}{$\begin{array}{c}\text { AGE } \\
\text { OF } \\
\text { INVERTEERATES }\end{array}$} & \multirow{7}{*}{ 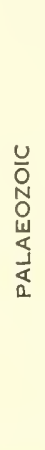 } & & PERMIAN & \\
\hline & & & & 产 & $\begin{array}{l}\text { PENNSYLVANIAN } \\
\text { CUPPER } \\
\text { CARBONIFEROUS) }\end{array}$ & \\
\hline & & & & $\breve{s}$ & $\begin{array}{l}\text { MISSISSIPPIAN } \\
\text { (LOWER } \\
\text { CARBONIFEROUS) }\end{array}$ & \\
\hline & & & & 产 & DEVONIAN & \\
\hline & & & & 产 & SILURIAN & \\
\hline & & & & 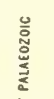 & ORDOVICIAN & \\
\hline & & & & $\frac{\vec{E}}{u}$ & CAMBRIAN & \\
\hline \multirow[t]{7}{*}{$\begin{array}{l}\text { MILLIONS } \\
\text { OF } \\
\text { YEARS }\end{array}$} & \multirow{8}{*}{ 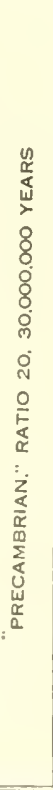 } & \multirow{5}{*}{$\begin{array}{c}\text { EVOLUTION } \\
\text { OF } \\
\text { INVERTEERATES }\end{array}$} & \multirow{5}{*}{ 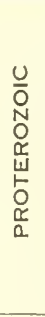 } & \multirow{3}{*}{ 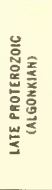 } & KEWEENAWAN & \multirow{8}{*}{ 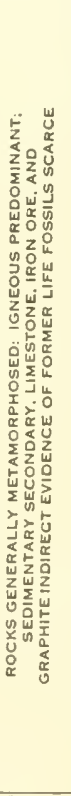 } \\
\hline & & & & & ANIMIKIAN & \\
\hline & & & & & HURONIAN & \\
\hline & & & & 总 & ALGOMIAN & \\
\hline & & & & \% & SUDBURIAN & \\
\hline & & \multirow[t]{3}{*}{$\begin{array}{l}\text { EVOLUTION } \\
\text { UNICELLULAR } \\
\text { LIFE }\end{array}$} & \multirow{3}{*}{ 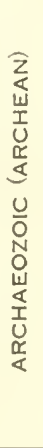 } & & LAURENTIAN & \\
\hline & & & & & $\begin{array}{l}\text { GRENVILLE } \\
\text { (KEEWATIN) } \\
\text { (COUTCHICHING) }\end{array}$ & \\
\hline 60 & & & & & & \\
\hline
\end{tabular}

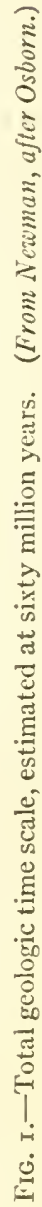


estimates within the bounds of Lord Kelvin's older calculations. Walcott, in 1893 , on the basis of the stratigraphic record and the known discharge of sediment by rivers, concluded that 70,000,000 years had elapsed since sedimentation began in the Archeozoic. Sir Archibald Giekie places the time at 100,000,000 years, and most geologists have tried, although with difficulty, to fit the record within these estimates.

"Since the discovery of radium, all of the calculations previously made have been set aside by the new school of physicists, and now the geologists are told they can have $\mathrm{r}, 000,000,000$ or more years as the time since the earth attained its present diameter. . . . Even if finally it shall turn out that the physicists have to reduce their estimates as to the age of certain minerals and rocks, geologists nevertheless appear to be on safer ground in accepting their estimates than those based either on sedimentation, chemical denudation, or los of heat by the earth."

[The last decade has seen the demise of the outworn objection to evolution based on the idea that there has not been time enough for the great changes that are believed by evolutionists to have occurred. Given I00,000,000 or I,000,000,000 years since life began, we can then allow $\mathrm{I}, \infty 00,000$ years for each important change to arise and establish itself. We can also understand why it is that so little change can be noted in the majority of wild animals and plants within the historic period. A thousand years in the development of the race is like a second in the derelopment of an individual and, though no one can notice any change in a growing creature in a second or a minute, very radical changes can be noted in an hour or a day or a year. We cannot see any movement in an hour hand of a clock, but it moves with certainty around the dial in a relatively short time. There is therefore no shortage of time. Evolution may have been infinitely slow, but time has been infinitely long. The accompanying time scale shows the lapse of time an.l the distribution in time of the main groups of animals (Fig. I).-ED.]

ON THE PRINCIPAL GENERAL FACTS REVEALED BY A STUDY OF THE FOSSILS

[I. None of the animals or plants of the past are identical with those of the present. The nearest relationship is between a few species of the past and some living species which have been placed in the same families. 
2. The animals and plants of each geologic stratum are at least generically different from those of any other stratum, though belonging in some cases to the same families or orders.

3. The animals and plants of the oldest (lowest) geologic strata represent all of the existing phyla, except the Chordata, but the representatives of the various phyla are relatively generalized as compared with the existing types.

4. The animals and plants of the newest (highest) geolog:c strata are most like those of the present and help to link the present with the past.

5. There is, in general, a gradual progression toward higher types as one proceeds from the lower to the higher strata.

6. Many groups of animals and plants reached the climax of specialization at relatively early geologic periods and became extinct.

7. Only the less specialized relatives of the most highly specialized types survived to become the progenitors of the modern representatives of their group.

8. It is very common to find a new group arising near the end of some geologic period during which vast climatic changes were taking place. Such an incipient group almost regularly becomes the dominant group of the next period, because it developed under the changed conditions which ushered in the new period and was therefore especially favored by the new environment.

9. The evolution of the vertebrate classes is more satisfactorily shown than that of any other group, probably because they represent the latest phylum to evolve, and most of their history coincides with the period within which fossils are known.

IO. Most of the invertebrate phyla had already undergone more than half of their evolution at the time when the earliest fossil remains were deposited.-Ev.]

FOSSIL PEDIGREES OF SOME WELL-KNOWN VERTEBRATES,

PEDIGREE OF THE HORSE

[Of all fossil pedigrees that of the horse is most often mentioned in evolutionary literature. The main facts have been known for about fort years, and there is a rather general consensus of opinion as to the history as a whole. It appears practically certain that the horse family (Equidae) arose from a group of primitive five-toed ungulates or hoofed mammals called Condylarthra that lived in Eocene times. 
No particular member of this extinct group has been found that fulfils all the requirements of a primitive horse ancestor, so the chances are that the real ancestral condylarthran has not been discovered.-ED.]

"The course of their [Equidae] evolution," says Dendy, "has evidently been determined by the development of extensive, dry, grass-covered, open plains on the American continent. In adaptation to life on such areas structural modification has proceeded chiefly in two directions. The limbs have becone greatly elongaterl and the foot uplifted from the ground, and thus adapted for rapid flight from pursuing enemies, while the middle digit has become more and more important and the others, together with the una and the fibula, have gradually disappeared or become reduced to mere vestiges. At the same time the grazing mechanism has been gradually perfected. The neck and head have become elongated so that the animal is able to reach the ground without bending its legs, and the cheek teeth have acquired complex grinding surfaces and have greatly increased in length to compensate for the increased rate of wear. As in so many other groups, the evolution of these special characters has been accompanied by gradual increase in size. Thus Eohippus, of Lower Eocene times, appears to have been not more than eleven inches high at the shoulder, while existing horses measure about sixty-four inches, and the numerous intermediate genera for the most part show a regular progress in this respect.

"All these changes have taken place gradually, and a beautiful series of intermediate forms indicating the different stages from Eohippus to the modern horse [Equus] have been discovered. The sequence of these stages in geological time exactly fits in with the theory that each one has been derived from the one next below it by more perfect adaptation to the conditions of life. Numerous genera have been described, but it is not necessary to mention more than a few."

["The first indisputably sorselike animal appears to have been Hyracotherium," of the Lower Eocene of Europe. Another Lower Eocene form is Eoluippus, which lived in North America, probably having migrated across from Asia by the Alaskan land connection which was in existence at that time. In Eohippus the fore foot had four completely developed hoofed digits and a "thumb" reduced to a splint bone; in the hind foot the great toe had entirely disappeared and the little toe is represented by a vestigial structure or splint bone. 1916).

I Arthur Dendy, Outlines of Evolutionary Biology (D. Appleton \& Company; 
Then came in succession Orohippus, of the Upper Eocene, Mesohippus of the Lower Oligocene, Pliohippus of the Upper Pliocene, and finally

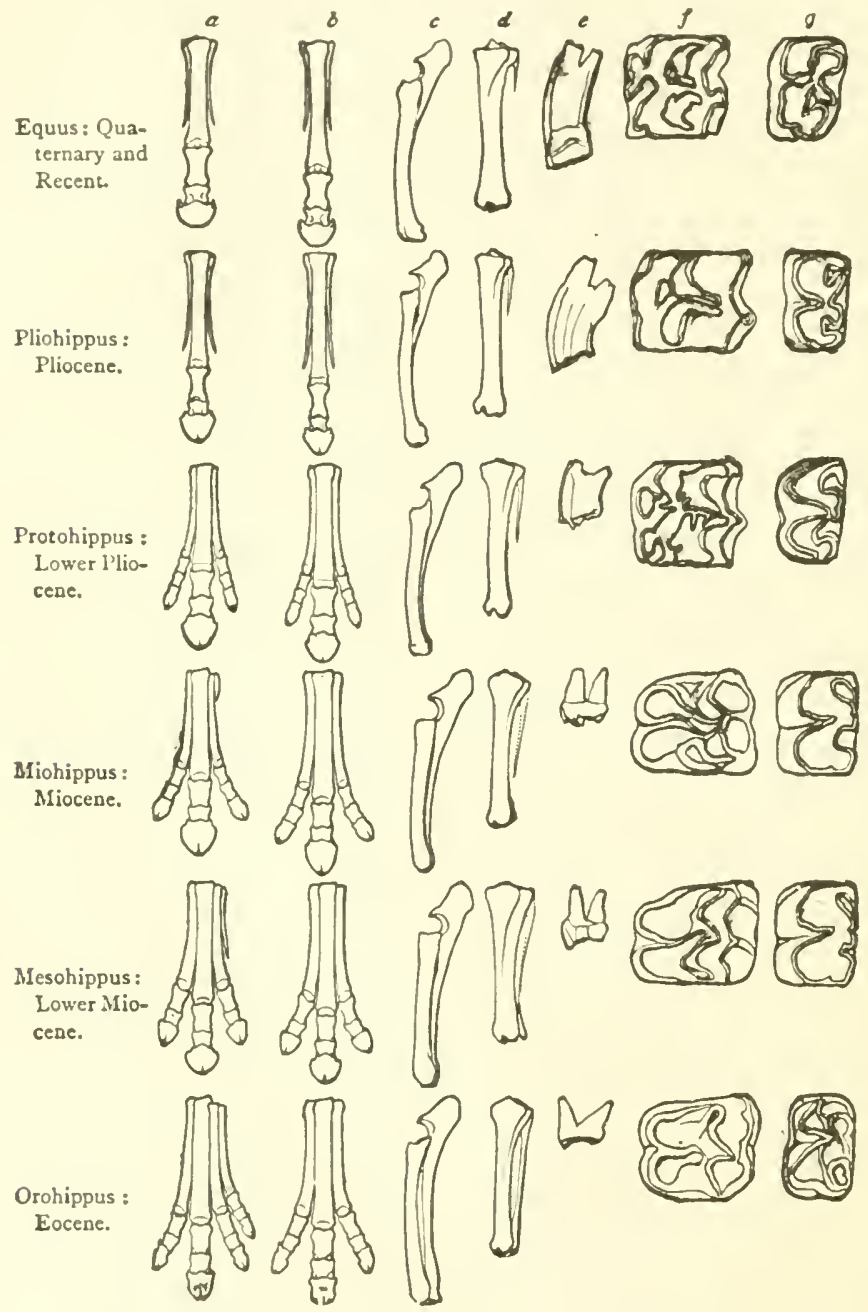

FIG, 2.-Feet and teeth in fossil pedigree of the horse. (Afler Marsh.) $a$, Bones of the fore foot; $b$, bones of the hind foot; $c$, radius and ulna; $d$, fibula and tibia; $e$, roots of a tooth; $f$ and $g$, crowns of upper and lower teeth.

Equus of the Quaternary and Recent. Other genera might be mentioned, but the history of this series has been pictured in a classic 
diagram by Marsh, and in this (Fig. 2) the reader may trace upward from Orohippus to Equus the steady changes in fore and hind feet, bones of the forearm, bones of the lower leg, and the grinding teeth of upper and lower jaws.

So definitely and clearly has the horse pedigree been worked out that, according to Dendy, "the palaeontological evidence amounts to a clear demonstration of the evolution of the horse from a five-toed ancestor along the lines indicated above."

For a long time the palaeontological series of the horse was unrivaled by other vertebrate types, but now we have almost equally complete series for several other modern types, notably the camels and the elephants. We shall present herewith accounts of the pedigree of the camels by Professor Scott, and that of the elephants by Professor Shull. And, to conclude the vertebrate pedigrees, we shall present in the next chapter that of man as given by Professor Lull.

In extenuation of the use of vertebrate material to the exclusion of invertebrate, the present writer has only this to offer, that vertebrate material is more intelligible to the non-biological reader and is more in his own field of knowledge and interest.-ED.]

PEDIGREE OF THE CAMELS

W. B. ScotT

There remains one family of mammals with which it is necessary to deal and that is the camel tribe. This family has two well-defined subdivisions, the camels of the Old World and the llamas, guanacos, etc., of South America. For a very long time, the family was entirely confined to North America and did not reach its present homes until the Pliocene epoch of the Tertiary period. The skeleton of a Patagonian guanaco may be taken as the starting point of our inquiry. In this animal the third incisor and the canine are retained in the upper jaw, all the incisors and the ranine in the lower. The anterior two grinding teeth have been lost and the others are moderately highcrowned. The skull is broad and capacious behind, narrow and tapering in front. The neck is long and its vertebrae very curiously modified. The limbs are long and slender and have undergone nearly the same modifications as in the horses; the ulna is greatly reduced, interrupted in the middle and its separated portions are fused with the radius. In the hind leg the shaft of the fibula has been completely

I From W. B. Scott, The Theory of Evolution (copyright 1917). Used by special permission of the publishers, The Macmillan Company. 
suppressed; the upper end fuses with the tibia, while the lower remains as a small separate bone, wedged in between the tibia and the heelbone. The feet are very long and slender, with two toes in each; the
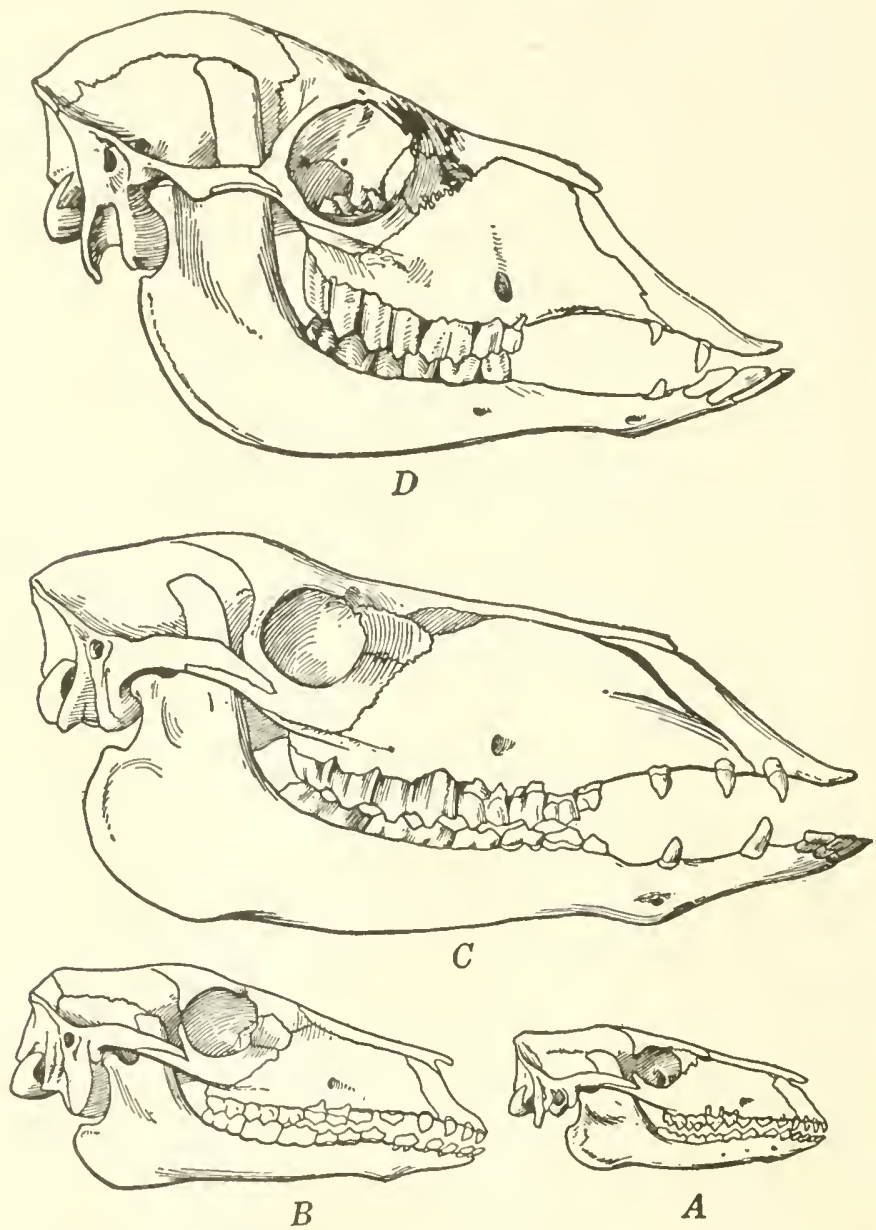

FIG. 3.-Four stages in the evolution of the cameline skull. A, Protylopus, Upper Eocene; B, Poëbrotherium, Lower Oligocene; C, Procamelus, Upper Miocene; D. guanaco, Recent. (From Scott.)

long bones of the foot are co-ossified to form a "cannon-bone," the very young skeleton showing that this co-ossification does actually take place. The toes proper are free, giving the "cloven hoof," but the hoofs are very small and the weight is carried upon a soft, thick pad. 

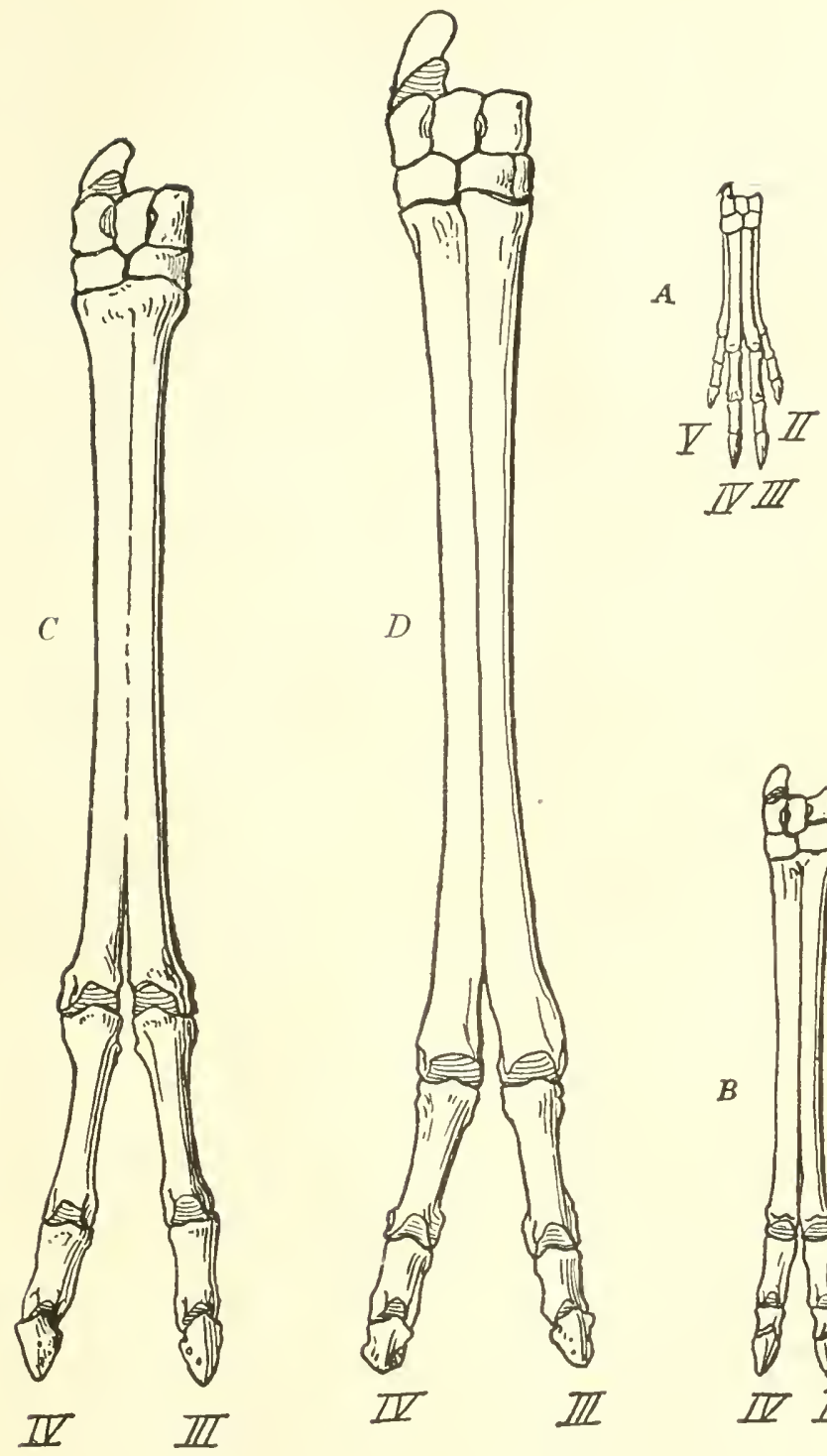

FIG. 4.-Four stages in the evolution of the cameline fore foot. A, Protylopus, Upper Eocene; B, Poëbrotherium, Lower Oligocene; C, Procamelus, Upper Miocene; $D$, guanaco, Recent. (From Scott.) 
Were there time enough to do so, we might trace the development of this family backward, step by step, through all the many stages between the Pleistocene and the Upper Eocene in quite as unbroken sequence and in as full detail as can be clone for the horses. We must, however, pass over all the intermediate steps and consider the ancestral camels of the Upper Eocene. These were very little animals, hardly larger than a jack rabbit, which had the full complement of teeth, 44 in total number, and all with very low crowns. The limbs, and especially the feet, are relatively short, the ulna is complete and separate, as is also the fibula; there are four toes in each foot, though the lateral pair of the hind foot are extremely slender, and there is no co-ossification to form cannon-bones. 'The hoofs are well developed, in form like those of an antelope, so that there can have been no pad. For the present, the line cannot be carried back of the Upper Eocene, the probable ancestors from the middle and Lower Eocene being, as yet, represented only by fragmentary specimens.

In addition to this main stem of cameline descent which resulted in the modern species, there were two short-lived side branches which should be mentioned. One, ending in the Lower Miocene, was the series descriptively called "gazelle-camels," small animals with very" long and slender legs, evidently swift runners. The other series, the so-called "giraffe-camels," terminated in the Upper Miocene; these were browsers and display an increasing stature, especially in the length of the neck and fore limbs. They adapted themselves to the growing aridity of the western plains.

\section{EVOLUTION OF THE ELEPHANTS ${ }^{x}$}

\section{A. FRANKLIN SHULL}

The mastodon-elephant series shows a larger number of obvious changes than most of the other series named, all of these changes except that of the body having to do with features of the head. From the numerous specimens of elephant-like forms available, the following are selected (following Lull) as probably representing a direct line of evolution: Moeritherium from the Upper Eocene of Egypt; Palacomastodon from the Lower Oliogocene of Egypt, also from India; Trilophodon from the Miocene of Europe, Africa, and North America; Mastodon from the Pliocene and Pleistocene of

"From A. F. Shull, Principles of A nimal Biology (copyright 1920). Used by' special permission of the publishers, The McGraw-Hill Book Company. 
North America, Lurope and Asia; Stegodon from the Pliocene of southern Asia; and Elephas from the Pleistocene of the Americas, Europe, and Asia, as well as the living elephants of Asia and Africa.
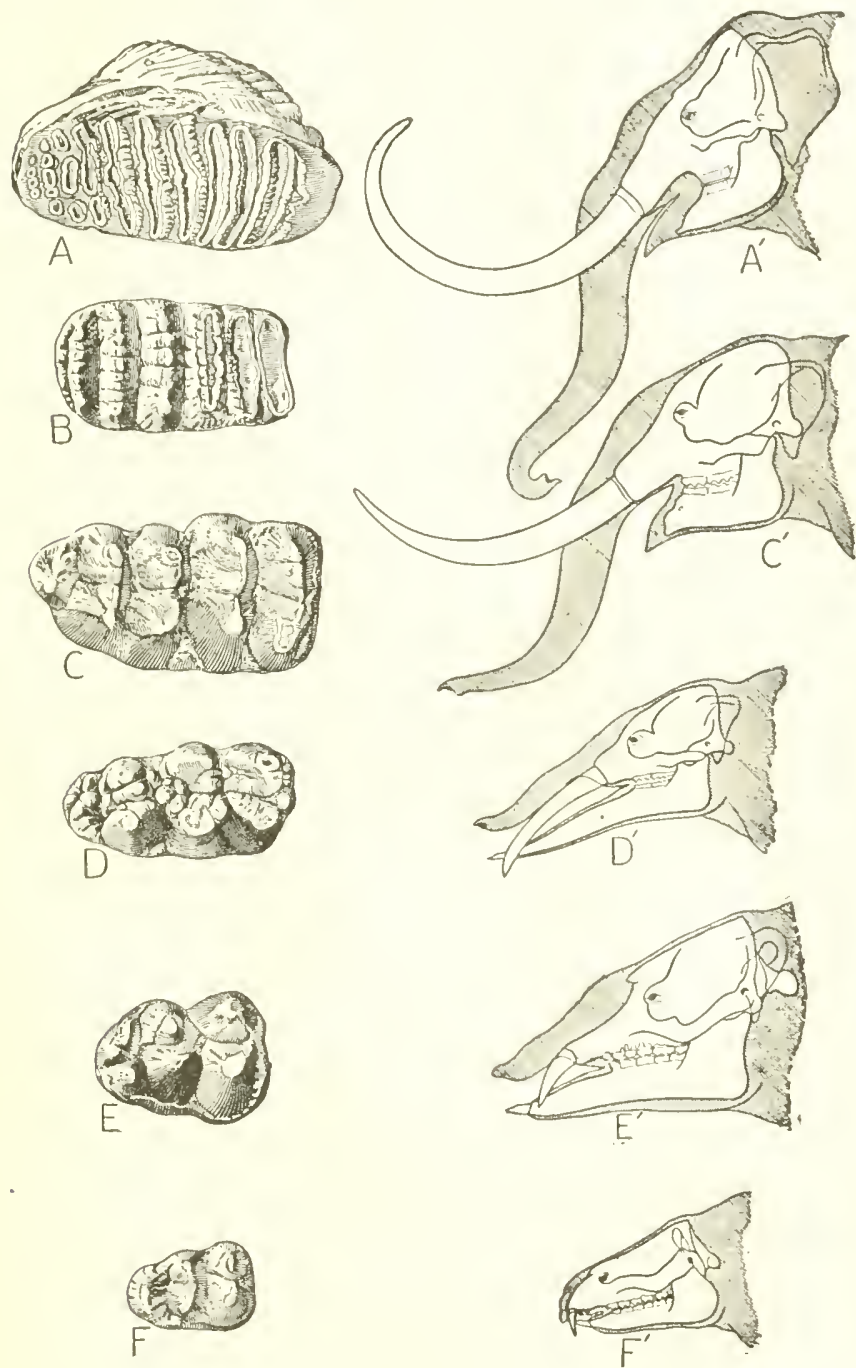

FIG. 5.-Evolution of head and molar teeth of mastodons and elephants. $A, A^{\prime}$, Elephas, Pleistocene; B, Stegodon, Pliocene; $C, C^{\prime}$, Mastodon, Pleistocene; $D, D^{\prime}$, Trilophodon, Miocene; $E, E^{\prime}$, Palacomastodon, Oligocene; $F, F^{\prime}$, Hoeritherium, Eocene. (From Lull.) 
A study of Figure 5 in connection with the following account will disclose the more striking steps of evolution. These forms differed from one another in a number of features, but the differences between any member of the series and the one that precedes or that which follows were so small that the series is obviously a continuous one. Mocritherium was very different from the modern elephant, but the intermediate forms completely bridged the gap. The series exhibits an enormous increase in size of body, changes in the form and size of the teeth, a reduction in the number of teeth, an alteration in the method of tooth succession, the enlargement of certain teeth to lecome tusks, the elongation and subsequent shortening of the lower jaw, the development of the upper lip and nose into a proboscis, and an increase in the height of the skull through the development of large cavities in the substance of the bone. These features are described in the several forms seriatim.

Moeritherium.- The earliest animal recognized as belonging to the elephant series, Mocritherium by name, was recovered from the late Eocene and early Oligocene deposits of northern Egypt. It was slightly over three feet. in height. The features suggesting elephantine affinities are the high posterior portion of the skull (Fig. $5, F)$; composed of somewhat cancellate bone, that is, bone containing open spaces; the elongation of the second pair of incisors in each jaw to form short tusks; the indication of transverse ridges on the molar teeth (Fig. 5, F); and the position of the nasal openings some distance back of the tip of the upper jaw, indicating probably a prehensile upper lip. There were 24 teeth, and the neck was long enough to enable the animal to put its head to the ground. It probably fed upon tender shoots and swamp regetation.

Palaeomastodon.-This form also lived in Egypt, but has recently been found in India. It dates from early Oligocene time. Palacomastodon was of somewhat larger size than the preceding form, the posterior part of the skull was distinctly higher (Fig. 5, $E^{\prime}$ )-with a greater development of cancellate bone, and the neck was somewhat shortened. The upper incisors of the second pair were more elongated as tusks and bore a band of enamel on their front surfaces. The lower second incisors were present, but not enlarged. All other incisors and the canines had disappeared. The molar teeth $(E)$ resembled those of Mocritherium but were larger. The lower jaw was considerably elongated, and the total number of teeth was still high (26). The nasal openings had receded until they were just in front of the eyes, 
which is believed to indicate the existence of a short proboscis extending at least to the tips of the tusks.

Trilophodon.-Trilophodon, a great migrant and consequently wide-spread over several continents as stated above, exhibited in several respects a striking advance over Palaeomastodon; but this advance was in the main in the same direction as was indicated by the change from Woeritherium to Palaeomastodon. Trilophodon was a huge animal, nearly as large as modern Indian elephants. The tusks were considerably longer (Fig. $5, D^{\prime}$ ) and still bore a band of enamel. The molar teeth were large and greatly reduced in number, so that only two were present at any one time on each side of each jaw. The surface of these teeth bore a somewhat larger number of transverse crests (Fig. 5, D) than were present in the earlier forms. The lower jaw was enormously elongated, so that it projected as far forward as the tusks. The great weight of the lower jaw and tusks was associated with a considerable development of cancellate bone in the skull, to which the supporting muscles of the neck were attached. Presumably there was a proboscis which extended to or beyond the tips of the tusks and lower jaw.

Mastodon.-The mastodons on the whole represent a line of development which became extinct; but in their incipient stages they appear to have given rise to the succeeding forms leading to the elephants. The body was somewhat larger than that of Trilophodon, being about the size of the Indian elephant. The tusks $\left(C^{\prime}\right)$ were much elongated ( 9 feet or more), but the lower jaw was greatly shortened and the lower incisor teeth were reduced or wanting. The molar teeth (Fig. 5, C) were scarcely more complex than earlier forms, and numbered two on each side of each jaw. They were still crushing teeth, and the food must have been tender twigs and succulent plants; indeed, remains of such objects have been found in the region of the stomach of the fossil mastodons.

Stegodon.-This animal is of interest chiefly because the molar teeth bore five or six well-defined transverse ridges (Fig. 5, B). These ridges were due to plates of enamel extending up through the tooth, and inclosing a substance known as dentinc. Over the enamel in an unworn tooth was a thin coat of a third substance called cement, but there was not much of this substance between the ridges. In the latter respect Stegodon differed, as is pointed out below, from the elephants and mammoths. On the whole, Stegodon was intermediate between the mastodons and elephants. 
Elephas.-In this genus are included a number of extinct forms (the mammoths) from three or four continents, and the living elephants. The extinct forms, though called mammoths, were not large animals, being no larger than the Indian elephant of today, and not so large as the living African species. Some of the features of the elephants, their size, the short neck, the long proboscis, and the heavy tusks are matters of common observation. The skull is very high and short (Fig. 5, $A^{\prime}$ ). The height is due chiefly to the development of cancellate bone, not to the enlargement of the brain, which is still quite small. As stated ahore, the high skull affords the necessary leverage for the muscles that support the weight of the tusks. The molar teeth are distinctly grinding teeth (Fir. 5, A). Each tooth bears a number of transverse ridges, about ten in the African elephant and two dozen or more in the Indian species. These ridges are worn down by the chewing of harsh food, so that the upper surface displays a number of flattened tubular plates of enamel inclosing dentine and bound together by cement. A tooth is completely worn out by use, and is replaced by another. The method of replacement, however, is peculiar. While the tusks (incisors) are of two sets, one following the other like milk and permanent teeth of other mammals, the grinders succeed one another in continuous fashion. There are never more than two visible grinders on each side of each jaw. As they wear out they move forward in the jaw, and are replaced by new teeth appearing behind. New molars thus enter at intervals of two to four years in young elephants, and at intervals of $I_{5}$ to 30 years in later life. If an elephant lives long enough ( 60 years or more) it develops a total of 28 teeth, including tusks, but has not more than ten (often less) at any one time.

Correlated with the nature of the teeth of the elephants are their food and chewing habits. Whereas the ancestral forms whose molars bore prominent elevations lived on twigs and tender herbage which they crushed in mastication, the mammoths with their flattened tooth surfaces deroured grasses, sedges, and other harsh regetation which ther ground with lateral motion of the teeth upon one another. In this respect modern elephants are like the mammoths.

In the changes described above is found one of the most beautiful and best established evolutionary series with which the palaeontologist is acquainted. Only a few others equal or approach it in clearness and completeness. 


\section{CHAPTER II \\ THE ETOLUTION OF MAI: PALAEONTOLOGY:

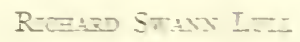

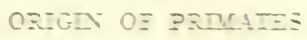

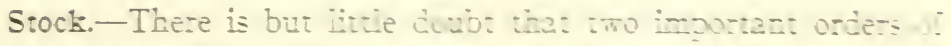
moder mammale, the Carnivora and the Primures haj a commou origin, diveging minly along lines determind by a dietary contrast. as the former have become more stricty fiesh-eating on potatavus.

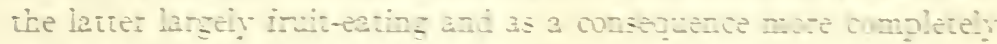
arboreal. Bacis of excic group lie as ancectant forms the Instctiroza. not perhaps such as are alive co-iay, as all these are highy sperialie i along diverse lines, but generalized insectivores possessing, berzus of their primitiveness. a wiber range di potential adapaztion. Mat-

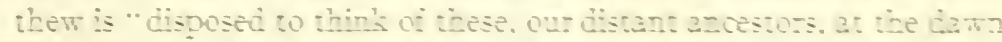
of ihe Tertiary. as a sort of hyorit besween a lemur and a mongovee. rether cutholic in their tastes. living among and party in the :xts. with sharp nose. oright eyes, and a shrewd little boain behind them. looking out, if rou will, from a perce among the brancines. upon a world tha: was to he singulary hind to inem and their cescentants

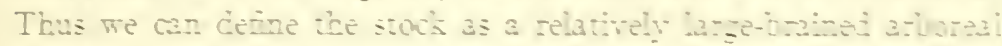
insectivore of primitive but adapatle centition, and espetialy of progressive mentality.

Time. - The time of primate origin must have been not late:

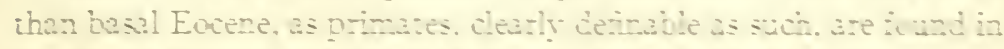
ine Inmer Eocene rocks of both Europe and North America.

Place.-The simuitaneous appeanuce of the poimate in the Old World and the New gives rise to the same concicenons as to cheiplace of origin and their mitrations thence as with cithe modermined mammals. It suffices now to say that iheir ancestral tome was boreal Holarctica. poobably within the limits ot the prestut cutinenof Asia. whence they mizrated southmat a'ong ine throe great continemtal radit. The impelling cawse of his migntin wa the increasing northerz oold. betore which the boresl limications ot the tropical torests retreated. carying with then the primutes whith. in

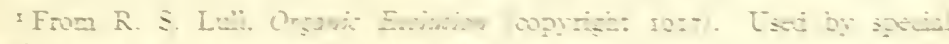
permission of the pubisters, The Macmillan Compang: 
general, are utterly dependent upon such an environment for their sustenance.

Geologic record.-Primates are found in the North American sediments from Lower to Upper Eocene time, when they became extinct. Thus, while their remains constitute a relatively large percentage of the total fauna of the Eocene, primates are utterly unknown on this continent from that time until the coming of man. In Europe the record is similar except that the extinction occurred at a somewhat later date, the Oligocene. Furthermore, they reappear in Europe in the Lower Miocene, at the time of the proboscidean migration out of Africa, whence these primates may also have come. Their second European extinction was in the Upper Pliocene shortly before the first appearance of mankind.

But in southern Asia, Africa, and South America the evolution of primates seems to have been continuous since the first great southward migration. The evidence, however, is not so much the historical documents as the presence of primates in those places at the present time, the fossil record is not entirely lacking although highly inconplete. The South American monkeys may have had their origin in the ancient North American primates, or more doubtfully, the stock may have come by way of Africa. Scott inclines toward the latter view although he says the evidence is by no means conclusive.

\section{ORIGIN OF MAAN}

Stock.-According to IV. K. Gregory, the stock from which man arose was some big-brained anthropoid related most nearly to the chimpanzce-gorilla group, an assumption based upon anatomical evidences, in spite of wide differences in habitus and consequent adaptation.

Place.-Evidences point to central Asia as the place of descent from the trees of the human precursor, the reasons for this belief being several. First, it was central for migrations elsewhere; Europe, on the other hand, where the most conclusive, in fact almost the exclusive evidence for fossil man is found, is too small an area for the divergent evolution of the several human species. Second, Asia is contiguous to the oldest known human remains, which, as we shall see, were found in Java. Third, it was the seat of the oldest civilizations, not only of the existing nations which, like the Chinese, trace their recorded history back to a hoary antiquity, but of nations which preceded them by thousands of years, and whose records have not yet come to light. 
This antiquity vastly exceeds that of the nations of Europe or of the Americans or of Africa. Fourth, central Asia is the source of almost all of our domestic animals, many of which have been subjected to human will and control for thousands of years, and this is equally true of many of our domestic plants. This is not due to the fact that man first reached civilization in Asia, but rather that he chose for his companions the highest and best of their several evolutionary lines, and Asia was the place of all others upon earth where the evolution in general of organic life reached its highest development in late Cenozoic time (Williston). Fifth, climatic conditions in Asia in the Miocene or early Pliocene were such as to compel the descent of the prehuman ancestor from the trees, a step which was absolutely essential to further human development.

Impelling cause.-We look for a geologic cause back of this most momentous crisis in the evolution of humanity and we find it in continental elevation and consequent increasing aridity of climate, especially to the northward of the Himalayas. With this increased aridity and tempering of tropical heat came the dwindling of the forested areas suitable to primate occupancy. Barrell has suggested that this diminution left residual forests comparable to the diminishing lakes and ponds of the Devonian, which upon final desiccation compelled their denizens to become terrestrial or perish. The dwindling of the residual forests would have an effect upon the tree-dwellers which may be expressed in precisely the same words. Once upon the ground the effect upon even a conservative type - and the primates in general, where constant conditions prevail, are slow of change--would be the rapid acquisition of such adaptations as were necessary to insure survival under the new conditions. The other man-like apes had, unfortunately for their further evolution, reached a region where tropical forests continued to be available and hence have retained their arboreal life and with it a stagnation of progress. The result has been, at any rate on the part of the three larger forms, a degeneracy from the estate of their common ancestry with mankind; the gibbons seem to have deteriorated less, while terrestrial man has risen to the summit of primate evolution.

Time.-The time of the descent is not later than early Pliocene nor earlier than Miocene time; when the terrestrial ape-man became what we would call human was perhaps later, but certainly during the Pliocene, which makes the age of man as such measurable in terms of hundreds of thousands of years! 
Significance of the descent from trees.-As a result of the descent from the trees, certain definite factors were called into play, each of which had its effect on the further evolution. Briefly enumerated, these are: (r) Assumption of the erect posture; (2) liberation of the hands from their ancient locomotor function to become organs of the mind; (3) loss of the easily obtainable food of the tropical forests, necessitating the search for sustenance, both plant and animal, and mar became a hunter; (4) need of clothing with increasing inclemency of the weather, especially during the long winters; (5) freedom from climatic restrictions - when an omnivorous diet and clothing were acquired man was no longer limited to one definite habitat and the result was dispersal; (6) the development of communal life, rendered possible by the terrestrial habitat. Primates are at best gregarious, submitting, as in the gorilla, to the leadership of the strongest male, but it is only by communal life with its attendant division of labor that man can rise above the level of utter savagery.

Evolutionary changes.-Human evolutionary changes which are recorded are: more erect posture, shorter arms, perfection of thumb opposability, reduction of muzzle and of size of teeth, loss of jaw power, development of chin prominence, increase in skull capacity, diminution of brow-ridges, diminution in strength of zygomatic or temporal arch, increase in size and complexity of brain, especially frontal lobes, development of articulate speech.

\section{FOSSIL MAN}

Fossil remains of man are found under two conditions, in river valley deposits and in limestone caverns which served first as a dwelling-place and later as a sepulture. Of these the caverns have been by far the most productive, but they contain only the remains of the later races, as the caverns according to Penck did not become arailable for human occupancy before middle Pleistocenc time.

The rarity of human fossils may be explained, first, by the various burial customs which seldom are sufficiently perfect to preclude the possibility of alternate wetting and drying or of rapid oxidation, both of which are prohibitive of fossilization. If man lived and died in the forests the chances for his fossilization, in common with other forest creatures, was very remote, for the remains of such are almost invariably destroyed by other animals, by dampness, or by fungi, and rarely attain a natural burial in sediment. If, on the other hand, he dwelt 
in the open, the chances of so shrewd a creature being caught in the flood waters and thus buried in sediment were not very great. However we account for it, the fact remains that relics of ancient man are rare and are valued accordingly.

In North America.-Repeated instances of seemingly ancient man have been brought to light in North America, such as the "Caleveras skull" of the California gold-bearing gravels, which was satirized by Bret Harte; the Nebraska "Loess man," and those of the Trenton gravels; none of which, with the possible exception of the last-mentioned, has proved to be really old in the geologic sense. Indirect evidence of human antiquity, that is, the association of North American man with animals which are now extinct, while very rare, has been reported in at least two highly authentic instances. The first of these was at Attica, New York, and is attested by Doctor John M. Clarke, the New York state geologist. Four feet below the surface of the ground, in a black muck, he found the bones of the mastodon (Mastodon americanus), and $\mathrm{I} 2$ inches below this, in undisturbed clay, pieces of pottery and thirty fragments of charcoal. The charcoal may have been of natural origin, but the presence of the pottery seems conclusive. The other instance was that of the remains of a herd of extinct bison (Bison antiquus) found near Smoky Hill River, Logan County, Kansas, and thus described by Professor Williston: An "arrow-head was found underneath the right scapula of the largest skeleton, embedded in the matrix, but touching the bone itself. The skeleton was lying upon the right side. . . . The bone bed when cleared off ... contained the skeletons of five or six adult animals, and two or three younger ones, together with a foetal skeleton within the pelvis of one of the adult skeletons. The animals had evidently all perished together, during the winter. There was no possibility of the accidental intrusion of the arrow-head in the place where found. . . . It must have been within the body oi the animal at the time of death, or have been lying on the surface beneath its body."

What at this writing is claimed to be another genuine case of such an association, this time of the actual human bones, has just been announced from Florida. This find, which has been reported by State Geologist Sellards, was made at Vero, eastern Florida, in I9I 3. The fossil human bones are from two incomplete skeletons and are found in strata which also contain remains of the following extinct species: Elephas columbi, Equus leidyi, a fox, a deer, the ground-sloth, Megalonyx jeffersoni, and the American mastodon. 
In South America.-A number of finds have been recorded from South America, notably by the late Florentino Ameghino of Buenos Aires, who contributed so largely to our knowledge of South American prehistoric life. An expert from Washington, Doctor Ales Hrdlicka, has sturtied with the utmost care the locality and character of each of these finds in the Western World, and has expressed the opinion that none is of an antiquity greater than that of the pre-Columbian Indians.

Further evidence lies in the uniformity of type, except for minor distinctions, of all native American peoples. There is no such racial differentiation as that seen in the Old World, and the argument is that there has not been time for such a deployment. The area and conditions as an adaptive radiation center are surely ample.

In Africa.-The only African relics thus far reported are those of prehistoric cultures, comparable to those of Southern Europe, in certain caverns of the Barbary States. There has also been reported from Oldoway ravine, German East Africa, a human skeleton of undoubted antiquity. It is described, however, as being neither a very early nor a primitive type.

In Asia.-Asia has given us in Pithecanthropus the oldest known relic of the Hominidae, found at Trinil in the island of Java. Osborn says: "It is possible that within the next decade one or more of the Tertiary ancestors of man may be discovered in northern India among the foothills known as the Siwaliks. Such discoveries have been heralded, but none have thus far been actually made. Yet Asia will probably prove to be the center of the human race. We have now discovered in southern Asia primitive representatives or relatives of the four existing types of anthropoid apes, namely, the gibbon, the orang, the chimpanzee, and the gorilla, and since the extinct Indian apes are related to those of Africa and of Europe, it appears probable that southern Asia is near the center of the evolution of the higher primates and that we may look there for the ancestors not only of prehuman stages like the Trinil race but of the higher and truly human types."

In Europe.-It is in Europe, however, that the tale of human prehistory is the most complete, not only through the happy accident of preserval, but because it has been much more thoroughly explored than has the Asiatic evolutionary center. 'The latter, however, holds the greatest hopes for future exploration since, as we have emphasized, Europe is too small to be an adaptive radiation center and European 
prehistoric man represents waves of migration from the greater continent.

Nevertheless the European record has enabled us to name and define a number of distinct human species, and here the record of the cultural evolution of man is also unusually complete. Hence European chronology is taken as a standard in describing discoveries from any portion of the world.

\section{CHRONOLOGICAL 'TABLE}

(Adapted from Osborn, ig I5)

Postglachal Time...................... 25,000 years Upper Palaeolithic culture

Crô-Magnon man

Fourth Glacial Stige (Würm, Wisconsin)...... 50,000 years Close of Lower Palaeolithic culture

Neanderthal man

Third Interglacial Stage................. I 50,000 years Beginning of Lower Palaeolithic culture

Piltdown and pre-Neanderthaloid men

Third Glacial Stage (Riss, Illinoian)......... I 75,000 years

Second Interglacial Stage. . . . . . . . . . . 375,000 years

Heidelberg man

Second Glacial Stage (Mindel, Kansas). . . . . . . 400,000 years

First Interglacial Stage. . . . . . . . . . . . . 475,000 years Pithecanthropus, ape-man

First Glacial Stage (Günz, Nebraskan)....... 500,000 years

Pithecanthropus.-The Java ape-man, Pithecanthropus erectus (Figs. 6 and $7, A$ ), was discorered in Trinil, on the Solo or Bengawan River in central Java, in I894. The type consists of a calvarium or skull cap, a left thigh bone, and two upper molar teeth. The skull is characterized by its limited capacity, about twothirds that of man; and by the low flat forehead and beetling brows. Hence not only was the brain limited in its total size, but this was especially true of the

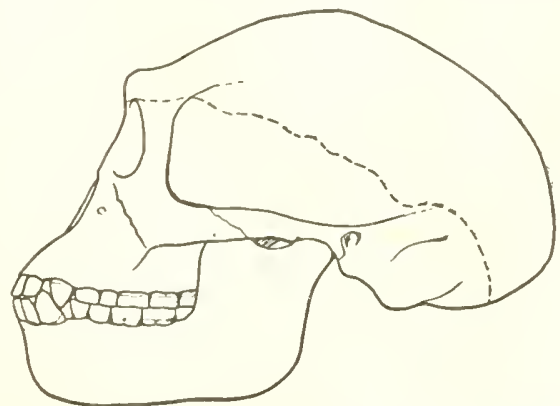

FIg. 6.-Skull of Java ape-man, Pithecanthropus crectus. (From Lull, after Dubois.) frontal lobes, which, as we have seen, are the seat of the higher intellectual faculties. Thus, as Osborn says, although touch, taste, and 
vision were well developed there was a limited faculty for profiting by experience and accumulated tradition. The femur associated with

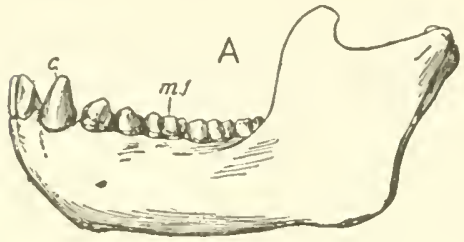
the skull is remarkable for its length and slight curvature as compared with the primitive Neanderthal race of Europe and indicates a creature fully as erect and nearly as tall as the average European of today, the height being estimated at 5

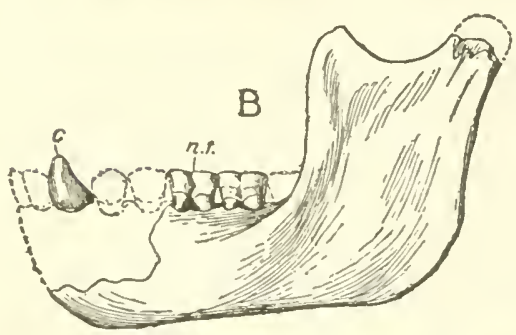
feet 7 inches as compared with 5 feet 3 inches for the Neanderthals and 5 feet 8 inches, the average height of modem males. The erect posture of course implies the liberation of the hands from any part in the locomotor function. The teeth are somewhat ape-like,

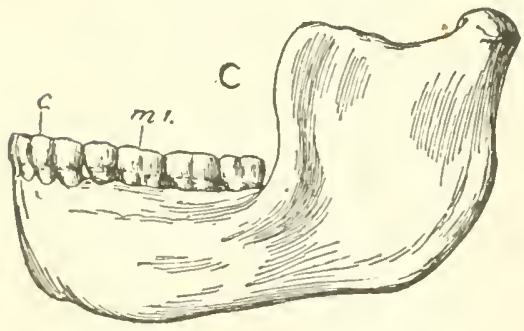
but are more human than are those of the gibbon, and the human mode of mastication has been acquired. Certain authorities have tried to prove that Pithecanthropus is nothing but a large gibbon, but the weight of authority considers it prehuman, though not in

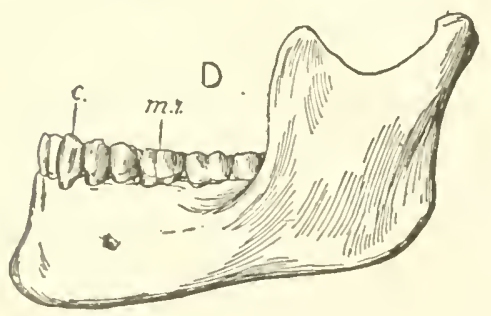

FIg. 7.-Jaws, left outer aspect, of $A$, chimpanzee, $P$ an, sp.; $B$, fossil chimpanzee, Pan velus, found in association with Piltdown man; $C$, Heidelberg man, Homo heidelbergensis; $D$, modern man, $I I$. sapiens. (From Lull, after Woodward.) the line of direct development into humanity. It is nevertheless a highly important transitional form.

Associated with the Pithecanthropus remains are those of a number of the contemporary animals which fix the date as either of the Upper Pliocene or lowermost Pleistocene period, which being rendered in terms of years gives an estimated age of about 500,000! 
Heidelberg man.-Ilomo heidelbergensis, the Heidelberg man, represents the oldest recorded European race, geologically speaking. The type was discorered in 1907 in river sands, 79 feet below the surface, at Mauer, near Heidellerg, South Germany. The relic consists of a perfect lower jaw with the dentition (Fig. 7, C). The description by the discoverer, Doctor Schoetensack, follows (from Osborn):

"The mandible shows a combination of features never before found in any fossil or recent man. The protrusion of the lower jaw just below the front teeth (the chin prominence) which gives shape to the human chin is entirely lacking. Had the teeth been absent it would have been impossible to diagnose it as human. From a fragment of the symphysis of the jaw it might well have been classed as some gorilla-like anthropoid, while the ascending ramus resembles that of some large variety of gibbon. The absolute certainty that these remains are human is based on the form of the teeth--molars, premolars, canines, and incisors are all essentially human and although somewhat primitive in form, show no trace of being intermediate between man and the anthropoid apes but rather of being derived from some older common ancestor. The teeth, however, are small for the jaw; the size of the border would allow for the development of nuch larger teeth. We can only conclude that no great strain was put on the teeth, and therefore the powerful development of the bones of the jaw was not designed for their benefit. The conclusion is that the jaw, regarded as unquestionably human from the nature of the teeth, ranks not far from the point of separation between man and the anthropoid apes. In comparison with the jaws of the Neanderthal races .... we may consider the Heidelberg jaw as pre-Neanderthaloid; it is, in fact, a generalized type."

Associated with the Heidelberg jaw is an extensive warm-climate fauna: straight-tusked elep', ant (E. antiquus), Etruscan rhinoceros, primitive horse, bison, wild cattle (urus), bear, lion, and so on, all of which aid in establishing the date of the jaw as Second Interglacial and its age, conservatively estimated, at from 300,000 to 375,000 years. The cultural evolution of Heidelberg man is indicated by the presence of eoliths, flint implements of the crudest workmanship, if indeed their apparent fashioning is not merely the result of use.

Neanderthal man.- The original specimen of the Neanderthal man, Homo neanderthalensis or primigenius (Figs. 8, 9, 10) was discovered in 1856 not far from Düsseldorf in Rhenish Prussia. Here the valley of the Düssel forms the deep Neanderthal ravine, whose 
limestone walls are penetrated by caverns, in one of which the remains were found. What was doubtless a perfect skeleton at the time of its
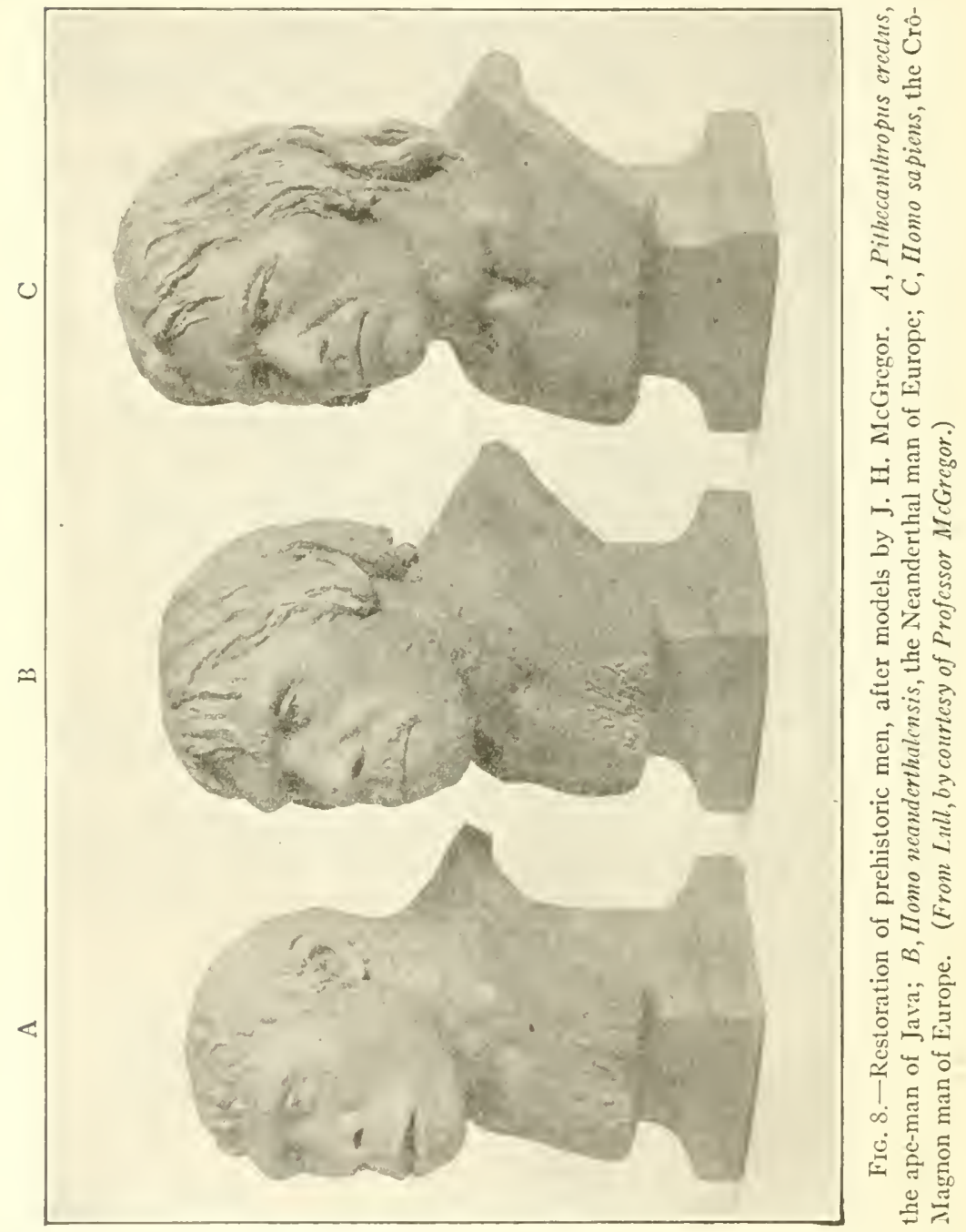

discovery was so injured by its finders that only a portion of it, which is now preserved in the Provincial Museum at Bonn, was saved. "This prophet of an unknown race was for a time utterly without honor 
though of course the subject of a most heated controversy, leing considered as non-human, or, as Virchow believed, owing its distinctive characters to disease. The sagacity of Huxley threw true light upon the problem, though it was not until the mute testimony of other representatives of the race (the men of Spy) was offered that even Huxley's masterful conception of the Neanderthal characters was taken as an accepted fact. Professor Huxley's description of the Neanderthal type is classic. He says:

"The anatomical characters of the skeletons bear out conclusions which are not flattering to the appearance of the owners. They were short of stature but powerfully built, with strong, curiously curved thigh bones, the lower ends of which are so fashioned that they must have walked with a bend at the knees.

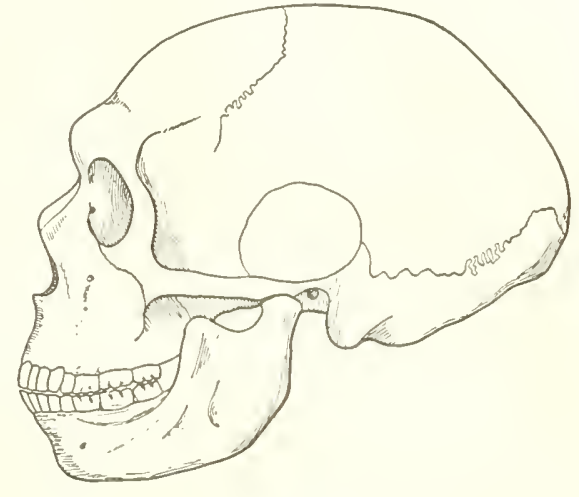

FIG, 9.-Neanderthaloid skull of La Chapelle-aux-Saints (Homo neanderthalensis). (From Lull, after Boulc.)

Their long depressed skulls had very strong brow-ridges; their lower jaws, of brutal depth and solidity, sloped away from the teeth downwards and backwards in consequence of the absence of that especially characteristic feature of the higher type of man, the chin prominence."

Subsequently several more specimens have come to light, at Spy in Belgium, at Krapina in Croatia, at Le Moustier, La Chapelle-auxSaints and La Ferrassie in France, and at Gibraltar, which, while differing in various details, effectually serve to establish the race, whose main characteristics are: Heavy, overhanging brows, retreating forehead, long upper lip; jaw less powerful than that of the Heidelberg man but very thick and massive; chin generally strongly receding but in process of forming; dentition extraordinarily massive in the La Chapelle specimen, whereas in those of Spy the teeth are small. The skull in many characteristics is nearer to the anthropoids than to modern man.

The brain is large and its volume is surely human, but the proportions are again less like those of recent man than like the anthropoids. The chest is large and robust, the shoulders broad, and 
the hand large, but the fingers are relatively short, the thumb lacking the range of movement seen in modern man. The knce was somewhat bent, the leg powerful, with a short shin and clumsy foot, clearly

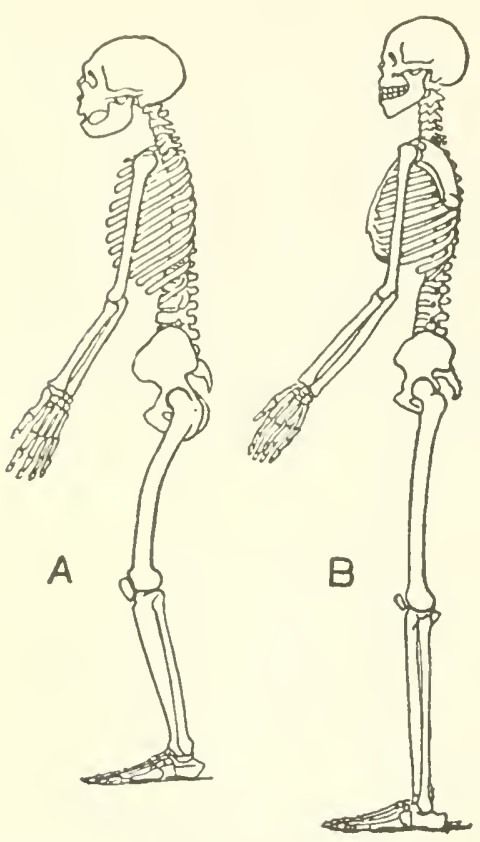

Fig. I0.-Skeleton of Neanderthal man. A, Homo neanderthalensis, compared with that of a living native Australian; B, Homo sapicns, the latter the lowest existing race. (From Lull, after $\mathrm{IHoodward}^{\text {) }}$ not of cursorial adaptation. The curve of the bent leg was correlated with a similar curvature of the spine, so that the man could not stand fully crect, as he lacked the fourth or cervical curvature of Homo sapiens. The average stature was 5 feet 3 inches, with a range from 4 feet Io. 3 inches to 5 feet 5.2 inches, partly sex differences.

Neanderthal man lived in Europe from the Third Interglacial stage through the Fourth Glacial, a duration of thousands of years, and then became extinct, from twenty to twenty-five millenniums ago. He seems to have been an actual lineal successor of the man of Heidelberg, but was throughout his long career an unprogressive static race. One of the most remarkable features in connection with this race, however, was the very reverent way in which the dead were buried, with an abundance of ornaments and finely worked flints. This can have but one interpretation, the awakening within this ancient type of the instinctive belief in immortality!

Piltdown man.-In I9I 2 was announced the discovery of a very ancient man from the Thames gravels at Piltdown, Sussex, England. Here again the skull was injured and partly lost, so that the question of its proper restoration has been the subject of considerable controversy. The material consists of portions of the cranial walls, nasal bones, a canine tooth, and part of a lower jaw. The brain-case in this instance is typically human, except for the remarkably thick cranial walls. The forehead is high and lacks the superorbital ridges of Neanderthal man and Pithecanthropus. While the skull is of com- 
paratively high human type, the associated jaw and canine tooth clearly are not, and some difficulty was met in explaining their evolutionary discrepancy. That has apparently been answered, however, by the conclusion that the association of the material is purely accidental and that the jaw not only does not belong with the skull, but that it is not even human but is that of a fossil chimpanzee. That being the case, there seems to be no reason for the exclusion of the Piltdown man, who has been named Eoanthropus dawsoni, from the direct line of human ancestry. The specimen is not, perhaps, so surely dated as are those of the other European races, but it is associated with a warm-climate fauna and is generally considered to belong to the Third Interglacial stage-from 100,000 to 150,000 years old, and hence vastly more ancient than the more primitive Homo neanderthalensis. (See Fig. 7, B.)

Crô-Magnon man.-The original finds of the men of the CrôMagnon race, Homo sapiens, were made at Gower, Wales, and at Aurignac, France. In the latter place seventeen skeletons came to light in $18_{52}$, but were buried in the village cemetery and thus lost to science, and not until I868, when five more skeletons were discovered at Crô-Magnon, France, was the race established. These individuals, an old man, two young men, a woman and a child, are thus the types of the race. This magnificent race is thus characterized:

Skull large but narrow, with a broad face, hence disharmonic. Facial angle equalling the highest type of Homo sapiens. Jaw thick and strong, with a narrow but very prominent chin. Forehead high and orbital ridges reduced. Brain not only of high type but very large, that of the women exceeding the average male of to-day.

The stature of the old man was 6 feet 4.5 inches; the average for males being 6 feet I. 5 inches, for women 5 feet 5 inches, a great disparity. The lower segments of the limbs were long, in contrast with the Neanderthal type, hence the men of Crô-Magnon were swiftfooted, while those of Neanderthal were slow. Osborn says: "The wide, short face, the extremely prominent cheekbones, the spread of the palate and a tendency of the upper cutting teeth and incisors to project forward, and the narrow, pointed chin recall a facial type which is best seen to-day in tribes living in Asia to the north and to the south of the Himalayas. As regards their stature the Crô-Magnon race recall the Sikhs living to the south of the Himalayas. In the disharmonic proportions of the face, that is, the combination of broad cheekbones and narrow skull, they resemble the Eskimo. The 
sum of the Crô-Magnon characters is certainly Asiatic rather than African, whereas in the Grimaldis (of which specimens have been founci in association with Crô-Magnons at the Grotte des Enfants, Mentone) the sum of the characters is decidedly negroid or African."

The Crô-Magnons again show by their elaborate burial customs how old and well founded is the belief in life after death. They are supposed to be the people who left on the walls of the caverns of France and Spain the marvelous examples of Upper Palaeolithic art of which Professor Osborn's book gives so adequate a description. They lived for a while contemporaneously with the men of Neanderthal and may have contributed somewhat to the final extinction of the latter. In the course of time, however, they too declined, although to this day survivors of the race may be seen in Dordogne, at Landes, near the Garonne in Southern France, and at Lannion in Brittany. Osborn says:

The decline of the Crô-Magnons, with their artistic culture, "may have been partly due to environmental causes and the abandonment of their vigorous nomadic mode of life, or it may be that they had reached the end of a long cycle of psychic development. . . . We know as a parallel that in the history of many civilized races a period of great artistic and industrial development may be followed by a period of stagnation and decline without any apparent environmental cause."

Europe was repopulated after Crô-Magnon decline by later invaders from the Asiatic realm, the so-called Mediterranean narrowheaded and the Alpine broad-headed types, etc., probably differentiated in Asia in early Palaeolithic times. The repopulation took place in the Upper Palaeolithic.

\section{EVIDENCES OF HUMAN ANTIQUITY}

Great variation.-These, briefly summarized, are, first, great variation. If man is monophyletic, that is, derived from a single prehuman species, and there is no reason to believe otherwise, he must be old, for while the adaptations to ground-dwelling after the descent from the trees were doubtless relatively rapidly acquired, the differentiation into the various races, due perhaps largely to climatic influences rather than to any notable environmental change, must have been slowly attained. As corroborative evidence we have but to point to the mural paintings on Egyptian monuments, dating back 
several thousand years, in which are depicted the Ethiopian, Caucasian, and the like, which are in some instances striking likenesses of the present-day Egyptians.

Universal distribution is, in animals, another mark of antiquity: in man, it is probably less so because of his greater intelligence. And yet before transportation had become a science man's spread over land and sea was extremely slow.

High intelligence as compared with that of the anthropoids is also a mark of antiquity, for the brain, especially the type of brain found in the higher human races, must have been very slow of development. Our study of fossil man shows this.

Communal life, division of labor and all of the complicated interactions which it brings about, and the development of law and religions all have taken time. When we realize that Babylonian texts, twice as remote as the patriarch Abraham, give evidence of highly perfect laws and of a civilization which must have antedated their production by centuries, we gain another yet more emphatic impression of human antiquity. Add to all this the palaeontological evidence of man's association with various genera and numerous successive species of prehistoric animals of which he alone survives, and the evidence is complete.

\section{FUTURE OF HUMANITY}

Because of his intelligence and communal co-operation man is no longer subject to the laws which govern the adaptation of animals to their environment. Osborn's law of adaptive radiation, which, as we have seen, applies equally well to the insects, reptiles, and mammals, fails in its application to mankind; and yet man has become as thoroughly adapted to speed, flight, to the fossorial and aquatic as they; but his adaptation is artificial and to a very small extent only affects his physical frame, while theirs is natural and the stamp of environment is deeply impressed upon the organism.

Man's physical evolution has virtually ceased, but in so far as any change is being effected, it is largely retrogressive. Such changes are: Reduction of hair and teeth, and of hand skill; and dulling of the senses of sight, smell, and hearing upon which active creatures depend so largely for safety. That sort of charity which fosters the physically, mentally, and morally feeble, and is thus contrary to the law of natural selection, must also in the long run have an adverse effect upon? the race. 
Man is hardly as yet subject to Malthus' law, for while he is increasing more rapidly than any other animal, owing largely to the care of the young which makes the expectation of life of the new-born relatively very high, his migratory ability, but above all his intelligence, save him from the application of the law. A single new discovery such as that of electricity may increase his food supply and other life necessities several fold. His future evolution, in so far as it is progressive, will be mental and spiritual rather than physical, and as such will be the logical conclusion of the marvelous results of organic evolution. 


\section{CHAPTER VII}

\section{EVIDENCES FRON GEOGRAPHIC DISTRIBUTION}

[Just as palacontology may be said to be a study of the vertical distribution (distribution in time) of organisms, so geographic distribution may be called a study of the horizontal distribution of organisms, on the earth's surface at any given time (spatial distribution). We are chiefly to be concerned with the prescnt spatial distribution of animal and plant species, but equally interesting studies have been and still may be made of the horizontal or contemporaneous existence of extinct forms. Much new knowledge has been gained by combining the data of palacontology with those of geographic distribution. In fact, neither field can be studied profitably without recourse to the other. This fact was clearly perceived by J. A. Thomson in his little manual on Evolution when he combined the two types of evidence in one chapter under the title "Evidences of Evolution from Explorer and Palaeontologist."

It was a consideration of the present and of the past distribution of Edentates that led Charles Darwin to his first clear concept of descent with modification. In his voyage on the "Beagle" he found that present-day Eclentates (armadillos, sloths, anteaters), a very peculiar group of archaic mammals, are practically confined to South America. When he also found that the only fossil Edentates, resembling but also differing from the existing types, are also confined to South America, he easily arrived at the only inference permitted by the facts: that the present Edentates are the modified descendants of the Edentates of the past.

The following quotations from both an older and a recent writer will give the reader a clear idea of the ways in which the general facts of geographic distribution bear witness to the truth of the evolutionary principle.-ED.]

"The theory," says Wallace, "which we may now take as established - that all the existing forms of life have been derived from other forms by a natural process of descent with modification, and that this same process has been in action during past geological time-should

${ }^{x}$ From A. R. Wallace, Darwinism (I889). Used by special permission of the publishers, The Macmillan Company. 
enable us to give a rational account not only of the peculiarities of form and structure presented by animals and plants, but also of their grouping together in certain areas, and their general distribution over the earth's surface.

"In the absence of any exact knowledge of the facts of distribution, a student of the theory of evolution might naturally anticipate that all groups of allied organisms would be found in the same region, and that, as he travelled farther and farther from any given centre, the forms of life would differ more and more from those which prevailed at the starting-point, till, in the remotest regions to which he could penetrate, he would find an entirely new assemblage of animals and plants, altogether unlike those with which he was familiar. He would also anticipate that diversities of climate would always be associated with a corresponding diversity in the forms of life.

"Now these anticipations are to a considerable extent justified. Remoteness on the earth's surface is usually an indication of diversity in the fauna and flora, while strongly contrasted climates are always accompanied by a considerable contrast in the forms of life. But this correspondence is by no means exact or proportionate, and the converse propositions are often quite untrue. Countries which are near to each other often differ radically in their animal and vegetable productions; while similarity of climate, together with moderate geographical proximity, are often accompanied by marked diversitiss in the prevailing forms of life. Again, while many groups of animals-genera, families, and sometimes even orders-are confined to limited regions, most of the families, many genera, and even some species are found in every part of the earth. An enumeration of a few of these anomalies will better illustrate the nature of the problem we have to solve.

"As examples of extreme diversity, notwithstanding geographical proximity, we may adduce Madagascar and Africa, whose animal and vergetable productions are far less alike than are those of Great Britain and Japan at the remotest extremities of the great northern continent; while an equal, or perhaps even a still greater, diversity exists between Australia and New Zealand. On the other hand, Northern Africa and South Europe, though separated by the Mediterranean Sea, have faunas and floras which do not differ from each other more than do the various countries of Europe. As a proof that similarity of climate and general adaptability have had but a small part in determining the forms of life in each country, we have the fact of the enormous increase 
of rabbits and pigs in Australia and New Zealand, of horses and cat tle in South America, and of the common sparrow in North America, though in none of these cases are the animals natives of the countries in which they thrive so well. And lastly, in illustration of the fact that allied forms are not always found in adjacent regions, we have the tapirs, which are found only on opposite sides of the globe, in tropical America and the Malayan Islands; the camels of the Asiatic deserts, whose nearest allies are the llamas and alpacas of the Andes; and the marsupials, only found in Australia and on the opposite side of the globe in America. Yet, again, although mammalia may be said to be universally distributed over the globe, being found abundantly on all the continents and on a great many of the larger islands, yet they are entirely wanting in New Zealand, and in a considerable number of other islands which are, nevertheless, perfectly able to support them when introduced.

"Now most of these difficulties can be solved by means of wellknown geographical and geological facts. When the productions of remote countries resemble each other, there is almost always continuity of land with similarity of climate between them. When adjacent countries differ greatly in their productions, we find them separated by a sea or strait whose great depth is an indication of its antiquity or permanence. When a group of animals inhabits two countries or regions separated by wide oceans, it is found that in past geological times the same group was much more widely distributed, and may have reached the countries it inhabits from an intermediate region in which it is now extinct. We know, also, that countries now united by land were divided by arms of the sea at a not very remote epoch, while there is good reason to believe that others now entirely isolated by a broad expanse of sea were formerly united and formed a single land area. There is also another important factor to be taken account of in considering how animals and plants have acquired their present peculiarities of distribution,--changes of climate. We know that quite recently a glacial epoch extended over much of what are now the temperate regions of the northern hemisphere, and that consequently the organisms which inhabit those parts must be, comparatively. speaking, recent immigranis from more southern lands. But it is a yet more important fact that, down to middle Tertiary times at all events, an equable temperate climate, with a luxuriant vegetation, extended to far within the Arctic circle, over what are now barren wastes, covered for ten months of the year with snow and ice. The 
Arctic zone has, therefore, been in past times capable of supporting almost all of the forms of life of our temperate regions; and we must take account of this condition of things whenever we have to speculate on the possible migration of organisms between the old and new continents."

"Many of the facts of distribution," says Shull. "are capable of interpretation by the assumption that evolution has operated with the other factors. If each kind of animal has arisen from a pre-existing kind, then each group of related animals must have had an ancestral form, and if the component parts of the groups are widespread the range of the ancestral form may be considered to be the center of dispersal of the group. The facts of distribution can apparently be interpreted only on this basis.

"Accepting erolution, along with the other factors which can be recognized, the method of distribution is generally conceived to be as follows. The ancestral form tends to spread in all directions. In some directions it is limited by unfavourable conditions either throughout its life or for some time. In other directions it extends its range. Anywhere within its range new types of individuals may arise through the process of evolution. These new types may be fitted to occupy new regions, and if they are formed near the limits of the range they may find opportunity to spread into areas which are inaccessible to the unaltered members of the species. Thus may arise recognizably distinct forms coincident in range with certain entironmental conditions. If particular forms, or the individuals of a single form, are accidentally or possibly by sporadic migration transferred across barriers the distribution of the group becomes discontinuous. If these processes have been going on for a long time, that is, if the common ancestors of a group of forms existed long ago, the range mayhave had time to become very extensive, or its discontinuity very marked. If, contrariwise, the ancestors were comparatively recent. the range is likely to be much smaller. For this reason, groups that have diverged far enough to have attained the rank of families are on the whole more widespread than those so nearly allied as to be considered genera. Should the environment become altered within a given range, the occupying form might be driven from it or destroyed.

I From A. F. Shull, Principles of A nimul Biology icopyright 1920. Used by special permission of the publishers, The McGraw-Hill Book Company. 
If the enviromment in a region adjoining a range should change in a favourable manner, the range might be extended at that point without any alteration on the part of the animals.

"The distribution of animals is inferred to be in harmony with this method, which involves, it will be noted, the factors of migration, evolution, physiological and morphological dependence upon the enviromment, the diversity and changeableness of the earth's surface, and extinction: and in this mamner are explained the difierences in greographical position, differences in size of range, differences in the continuity of range and the fact that ranges are at first continuous, differences in physical and biological conditions which characterize the ranges of different forms, and the geographical proximity of apparently related forms."

\section{SOME OF THE MORE SIGNIFICANT FACTS ABOUT THE DISTRIBLTIOX OF ANIMALS}

THE FAUNA OF OCEAXIC ISLANDSI

GEORGE JOHXI ROMANES

Turning now from aquatic organisms to terrestrial, the body of facts from which to draw is so large, that I think the space at my disposal may be best utilized by confining attention to a single division of them-that, namely, which is furnished by the zoölogical sturly of oceanic islands.

In the comparatively limited--but in itself extensive-class of facts thus presented, we have a particularly fair and cogent test as between the alternative theories of evolution and creation. For where we meet with a volcanic island, hundreds of miles from any other land, and rising abruptly from an ocean of enormous depth, we may be quite sure that such an island can never have formed part of a now submerged continent. In other words, we may be quite sure that it always has been what it $n \cdot w$ is - an oceanic peak, separated from all other land by hundreds of miles of sea, and therefore an area supplied by nature for the purpose, as it were, of testing the rival theories of creation and evolution. For, let us ask, upon these tiny insular specks of land what kind of life should we expect to find? To this question the theories of special creation and of gradual evolution would agree in giving the same answer up to a certain point. For both theories would agree in supposing that these islands would, at all

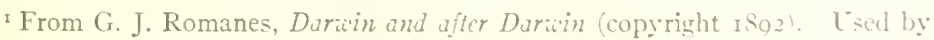
special permission of The Open Court Publishing Company. 
events in large part, derive their inhabitants from accidental or occasional arrivals of wind-blown or water-floated organisms from other countries-especially, of course, from the countries least remote. But, after agreeing upon this point, the two theories must part company in their anticipations. The special-creation theory can have no reason to suppose that a small volcanic island in the midst of a great ocean should be chosen as the theatre of any extraordinary creative activity, or for any particularly rich manufacture of peculiar species to be found nowhere else in the world. On the other hand, the evolution theory would expect to find that such habitats are stocked with more or less peculiar species. For it would expect that when any organisms chanced to reach a wholly isolated refuge of this kind, their descendants should forthwith have started upon an independent course of evolutionary history. Protected from intercrossing with any members of their parent species elsewhere, and exposed to considerable changes in their conditions of life, it would indeed be fatal to the general theory of evolution if these descendants, during the course of many generations, were not to undergo appreciable change. It has happened on two or three occasions that European rats have been accidentally imported by ships upon some of these islands, and even already it is observed that their descendants have undergone a slight change of appearance, so as to constitute them what naturalists call local varieties. The change, of course, is but slight, because the time allowed for it has been so short. But the longer the time that a colony of a species is thus completely isolated under changed conditions of life the greater, according to the evolution theory, should we expect the change to become. Therefore, in all cases where we happen to know, from independent evidence of a geological kind, that an oceanic island is of very ancient formation, the evolution theory would expect to encounter a great wealth of peculiar species. On the other hand, as I have just observed, the special-creation theory can have no reason to suppose that there should be any correlation between the age of an oceanic island and the number of peculiar species which it may be found to contain.

Therefore, having considered the principles of geographical distribution from the widest or most general point of view, we shall pass to the oppesite extreme, and consider exhaustively, or in the utmost possible detail, the facts of such distribution where the conditions are best suited to this purpose - that is, as I have already said, upon oceanic islands, which may be metaphorically regarded as having been 
formed by nature for the particular purpose of supplying naturalists with a crucial test between the theories of creation and evolution. The material upon which my analysis is to be based will be derived from the most recent works upon geographical distribution-especially from the magnificent contributions to this department of science which we owe to the labours of Mr. Wallace. Indeed, all that follows may be regarded as a condensed filtrate of the facts which he has collected. Even as thus restricted, however, our subject matter would be too extensive to be dealt with on the present occasion, were we to attempt an exhaustive analysis of the floras and faunas of all oceanic islands upon the face of the globe. Therefore, what I propose to do is to select for such exhaustive analysis a few of what may be termed the most oceanic of oceanic islands - that is to say, those oceanic islands which are most widely separated from mainlands, and which, therefore, furnish the most unquestionable of test cases as between the theories of special creation and genetic descent.

Azores.-A group of volcanic islands, nine in number, about 900 miles from the coast of Portugal, and surrounded by ocean depths of I, 800 to 2,500 fathoms. There is geological evidence that the origin of the group dates back at least as far as Miocene times. There is a total absence of all terrestrial Vertebrata, other than those which are known to have been introduced by man. Flying animals, on the other hand, are abundant: namely, 53 species of birds, one species of bat, a few species of butterflies, moths and hymenoptera, with 74 species of indigenous beetles. All these animals are unmodified European species, with the exception of one bird and many of the beetles. Of the 74 indigenous species of the latter, 36 are not found in Europe; but 19 are natives of Madeira or the Canaries, and 3 are American, doubtless transplanted by drift-wood. The remaining I4 species occur nowhere else in the world, though for the most part they are allied to other European species. There are 69 known species of land-shells, of which 37 are European, and 32 peculiar, though all allied to European forms. Lastly, there are 480 known species of plants of which 40 are peculiar, though allied to European species.

Bermudas.-A small volcanic group of islands, 700 miles from North Carolina. Athough there are about Ioo islands in the group, their total area does not exceed 50 square miles. The group is surrounded by water varying in depth from 2,500 to 3,800 fathoms. The 
only terrestrial Vertebrate (unless the rats and mice are indigenous) is a lizard allied to an American form, but specifically distinct from it, and therefore a solitary species which does not occur anywhere else in the world. None of the birds or bats are peculiar, any more than in the case of the Azores; but, as in that case, a large percentage of the land-shells are so-namely, at least one quarter of the whole. Neither the botany nor the entomology of this group has been worked out; but I have said enough to show how remarkably parallel are the cases of these two volcanic groups of islands situated in different hemispheres but at about the same distance from large continents. In both there is an extraordinary paucity of terrestrial Vertebrata, and of any peculiar species of bird or beast. On the other hand, there is in both a marvellous wealth of peculiar species of insects and land-shells. Now these correlations are all abundantly intelligible. It is a difficult matter for any terrestrial animal to cross 900, or even 700 miles of ocean: therefore only one lizard has succeeded in doing so in one of the two parallel cases; and living cut off from intercrossing with its parent form, the descendants of that lizard have become modified so as to constitute a peculiar species. But it is more easy for large flying animals to cross those distances of ocean: consequently, there is only one instance of a peculiar species of bird or bat-namely, a bull-finch in the Azores, which, being a small land-bird, is not likely ever to have had any other visitors from its original parent species coming over from Europe to keep up the original breed. Lastly, it is very much more easy for insects and land-mollusca to be conveyed to such islands by wind and floating timber than it is for terrestrial mammals, or even than it is for small birds and bats; but yet such means of transit are not sufficiently sure to admit of much recruiting from the mainland for the purpose of keeping up the specific types. Consequently, the insects and the land-shells present a much greater proportion of peculiar species-namely, one half and one fourth of the land-shells in the one case, and one eighth of the beetles in the other. All these correlations, I say, are abundantly intelligible on the theory of evolution; but who shall explain, on the opposite theory, why orders of beetles and land-mollusca should have been chosen from among all other animals for such superabundant creation on oceanic islands, so that in the Azores alone we find no less than 32 of the one and $\mathrm{I}_{4}$ of the other? And, in this connection, I may again allude to the peculiar species of beetles in the island of Madeira. Here there are an enormous number of peculiar species, though they are nearly all related to, 
or included under the same genera, as beetles on the neighboring continent. Now, as we have previously seen, no less than 200 of these species have lost the use of their wings. Evolutionists explain this remarkable fact by their general laws of degeneration under disuse, and the operation of natural sclection, as will be shown later on; but it is not so easy for special creationists to explain why this cnormous number of peculiar species of beetles should have been deposited on Madeira, all allied to beetles on the nearest continent, and nearly all deprived of the use of their wings. And similarly, of course, with all the peculiar species of the Bermudas and the Azores. For who will explain, on the theory of independent creation, why all the peculiar species, both of animals and plants, which occur on the Bermudas should so unmistakably present American affinities, while those which occur on the Azores no less unmistakably present European affinities? But to proceed to other, and still more remarkable, cases.

The Galapagos Islands. - This archipelago is of volcanic origin, situated under the equator between 500 and 600 miles from the West Coast of South America. The depth of the ocean around them varies from 2,000 to 3,000 fathoms or more. This group is of peculiar interest, from the fact that it was the study of its fauna which first suggested to Darwin's mind the theory of evolution. I will, therefore, begin by quoting a short passage from his writings upon the zoölogical relations of this particular fauna.

"Here almost every product of the land and of the water bears the unmistakable stamp of the American continent. There are twenty-six land birds; of these, twenty-one, or perhaps twenty-three, are ranked as distinct species, and would commonly be assumed to have been here created; yet the close affinity of most of these birds to American species is manifest in every character, in their habits, gestures, and tones of voice. So it is with the other animals, and with a large proportion of the plants, as shown by Dr. Hooker in his admirable Flora of this archipelago. The naturalist, looking at the inhabitants of these volcanic islands in the Pacific, distant several hundred miles from the continent, feels that he is standing on American land. Why should this be so? Why should the species which are supposer to have been created in the Galapagos Archipelago, and nowhere else. bear so plainly the stamp of affinity to those created in America? There is nothing in the conditions of life, in the geological nature of the islands, in their height or climate, or in the proportions in which the several classes are associated together, which closely resembles the 
conditions of the South American coast; in fact, there is a considerable dissimilarity in all these respects. On the other hand, there is a considerable degree of resemblance in the volcanic nature of the soil, in the climate, height, and size of the islands, between the Galapagos an i rape de Verde Archipelagoes; but what an entire and absolute difference in their inhabitants! The inhabitants of the Cape de Verde Islands are related to those of Africa, like those of the Galapagos to America. Facts such as these admit of no sort of explanation on the ordinary view of independent creation; whereas in the view here maintained it is obvious that the Galapagos Islands would be likely to receive colonists from America, and the Cape de Verde Islands from Africa; such colonists would be liable to modification- the principle of inheritance still betraying their original birthplace."

The following is a synopsis of the fauna and flora of this archipelago, so far as at present known. The only terrestrial vertebrates are two peculiar species of land-tortoise, and one extinct.species; five species of lizards, all peculiar - two of them so much so as to constitute a peculiar genus; - and two species of snakes, both closely allied to South American forms. Of birds there are 57 species, of which no less than 38 are peculiar; and all the non-peculiar species, except one, belong to aquatic tribes. The true land-birds are represented by 3 I species, of which all, except one, are peculiar; while more than half of them go to constitute peculiar genera. Moreover, while they are all unquestionably allied to South American forms, they present a beautiful series of gradations, "from perfect identity with the continental species, to genera so distinct that it is difficult to determine with what forms they are most nearly allied; and it is interesting to note that this diversity hears a distinct relation to the probabilities of, and facilities for, migration to the islands. The excessively abundant rice-bird, which breeds in Canada, and swarms over the whole United States, migrating to the West Indies and South America, visiting the distant Bermudas almost every year, and extending its range as far as Paraguay, is the only species of land-bird which remains completely unchanged in the Galapagos; and we may therefore conclude that some stragglers of the migrating host reach the islands sufficiently often to keep up the purity of the breed" [Wallace]. Again, of the thirty peculiar land-birds, it is observable that the more they differ from any other species or genera on the South American continent, the more certainly are they found to have their nearest relations among those South American forms which have the 
more restricted range, and therefore the least likely to have found their way to the islan.ls with any frequency.

The insect fauna of the Galapagos Islands is scanty, and chicfly composed of beetles. These number 35 species, which are nearly all peculiar, and in some cases go to constitute peculiar genera. The same remarks apply to the twenty species of land-shells. Lastly, of the total number of flowering plants $(332$ species) more than one half ( 74 species) are peculiar. It is observable in the case of these peculiar species of plants-as also of the peculiar species of birds - that many of them are restricted to single islands. It is also observable that with regard both to the fauna and flora, the Galapagos Islands as a whole are very much richer in peculiar species than either the Azores or Bermudas, notwithstanding that both the latter are considerably more remote from the nearest continents. This difference, which at first sight appears to make against the evolutionary interpretation, really tends to confirm it. For the Galapagos Islands are situated in a calm region of the globe, unvisited by those periodic storms and hurricanes which sweep over the North Atlantic, and which every year convey some straggling birds, insects, seeds, etc., to the Azores and Bermudas. Notwithstanding their somewhat greater isolation geographically, therefore, the Azores and Bermudas are really less isolated biologically than are the Galapagos Islands; and hence the less degree of peculiarity on the part of their endemic species. But, on the theory of special creation, it is impossible to understand why there should be any such correlation between the prevalence of gales and a comparative inertness of creative activity. And, as we have seen, it is equally impossible on this theory to understand why there should be a further correlation between the degree of peculiarity on the part of the isolated species, and the degree in which their nearest allies on the mainland are there confined to narrow ranges, and therefore less likely to keep up any biological communication with the islands.

St. Helena.-A small volcanic island, ten miles long by eight wide, situated in mid-ocean, I, I00 miles from Africa, and I, 800 from South America. It is very mountainous and rugged, bounded for the most part by precipices, rising from ocean depths of I7,000 feet, to a height above the sea-level of nearly 3,000. When first discovered it was richly clothed with forests; but these were all destroyed by human agency during the $\mathrm{I} 6 \mathrm{th}, \mathrm{I} 7 \mathrm{th}$, and I 8 th centuries. The records of civilization present no more lamentable instance of this kind of destruction. 
From a merely pecuniary point of view the abolition of these primeval forests has proved an irreparable loss; but from a scientific point of view the loss is incalculable. These forests served to harbour countless forms of life, which extended at least from the Miocene age, and which, having found there an ocean refuge, survived as the last remnants of a remote geological epoch. In those days, as Mr. Wallace observes, St. Helena must have formed a kind of natural museum or vivarium of archaic species of all classes, the interest of which we can now only surmise from the few remnants of those remnants, which are still left among the more inaccessible portions of the mountain peaks and crater edges. These remnants of remnants are as follows:

There is a total absence of all indigenous mammals, reptiles, fresh-water fish, and true land-birds. There is, however, a species of plover, allied to one in South Africa; but it is specifically distinct, and therefore peculiar to the island. 'The insect life, on the other hand, is abundant. Of beetles, no less than $\mathrm{x} 29$ species are believed to be aboriginal, and, with one single exception, the whole number are peculiar to the island. "But in addition to this large amount of specific peculiarity (perhaps unequalled anywhere else in the world) the beetles of this island are remarkable for their generic isolation, and for the altogether exceptional proportion in which the great divisions of the order are represented. The species belong to 39 genera, of which no less than 25 are peculiar to the island; and many of these are such isolated forms that it is impossible to find their allies in any particular country" [Wallace]. More than two-thirds of all the species belong to one group of weevils-a circumstance which serves to explain the great wealth of beetle-population, the weevils being beetles which live in wood, and St. Helena having been originally a densely wooded island. This circumstance is also in accordance with the view that the peculiar insect fauna has been in large part evolved from ancestors which reached the island by means of floating timber; for, of course, no explanation can be suggested why special creation of this highly peculiar insect fauna should have run so disproportionately into the production of weevils. About two-thirds of the whole number of beetles, or over 80 species, show no close affinity with any existing insects, while the remaining third have some relations, though often very remote, with European and African forms. That this high degree of peculiarity is due to high antiquity is further indicated, according to our theory, by the large number of species which some of the types comprise. Thus, the 54 species of Cossonidae may be 
referred to three types; the I I species of Bembidium form a group by themselves; and the IIeleromera form two groups. "Now, each of these types may well be descended from a single species, which originally reached the island from some other land; and the great variety of generic and specific forms into which some of them have diverged is an indication, and to some extent a measure, of the remoteness of their origin" [Wallace]. But, on the counter-supposition that all these I 28 peculiar species were separately created to occupy this particular island, it is surely unaccountable that they should thus present such an arborescence of naturai affinities amongst themselves.

Passing over the rest of the insect fauna, which has not yet been sufficiently worked out, we next find that there are only 20 species of indigenous land-shells - which is not surprising when we remember by what enormous reaches of ocean the land is surrounded. Of these 20 species no less than ${ }_{3}$ have become extinct, three are allied to European species, while the rest are so highly peculiar as to have no near allies in any other part of the globe. So that the land-shells tell exactly the same story as the insects.

Lastly, the plants likewise tell the same story. The truly indigenous flowering plants are about 50 in number, besides 26 ferns. Forty of the former and ten of the latter are peculiar to the island, and, as Sir Joseph Hooker tells us, "cannot be regarded as very close specific allies of any other plants at all." Seventeen of them belong to peculiar genera, and the others all differ so markedly as species from their congeners, that not one comes under the category of being an insular form of a continental species. So that with respect to its plants, no less than with respect to its animals, we find that the island of St. Helena constitutes a little world of unique species, allied among themselves, but diverging so much from all other known forms that in many cases they constitute unique genera.

Sandwich Islands.-These are an extensive group of islands, larger than any we have hitherto considered--the largest of the group being about the size of Devonshire. The entire archipelago is volcanic, with mountains rising to a height of nearly i4,000 feet. The group is situated in the middle of the North Pacific, at a distance of considerably over 2,000 miles from any other land, and surrounded by enormous ocean depths. The only terrestrial vertebrates are two lizards, one of which constitutes a peculiar genus. There are 24 aquatic birds, five of which are peculiar; four birds of prey, two of which are peculiar; and I6 land-birds, all of which are peculiar. 
Moreover, these r6 land-birds constitute no less than ro peculiar genera, and even one peculiar family of five genera. This is an amount of peculiarity far exceeding that of any other islands, and, of course, corresponds with the great isolation of this archipelago. The only other animals which have here been carefully studied are the landshells, and these tell the same story as the birds. For there are no less than 400 species which are all, without any exception, peculiar; while about three-quarters of them go to constitute peculiar genera. Again, of the plants, 620 species are believed to be endemic; and of these 377 are peculiar, yielding no less than 39 peculiar genera.

THE FAUNA OF MADAGASCAR AND NEW ZEALAND

\section{A. R. WALLACE}

The two exceptions just referred to are Madagascar and New Zealand, and all the evidence goes to show that in these cases the land connection with the nearest continental area was very remote in time. The extraordinary isolation of the productions of Madagascar-almost all the most characteristic forms of mammalia, birds, and reptiles of Africa being absent from it-renders it certain that it must have been separated from that continent very early in the Tertiary, if not as far back as the latter part of the Secondary period; and this extreme antiquity is indicated by a depth of considerably more than a thousand fathoms in the Mozambique Channel, though this deep portion is less than a hundred miles wide between the Comoro Islands and the mainland. Madagascar is the only island on the globe with a fairly rich mammalian fauna which is separated from a continent by a depth greater than a thousand fathoms; and no other island presents so many peculiarities in these animals, or has preserved so many lowly organised and archaic forms. The exceptional character of its productions agrees exactly with its exceptional isolation by means of a very deep arm of the sea.

New Zcaland possesses no known mammals and only a single species of batrachian; but its geological structure is perfectly continental. There is also much evidence that it does possess one mammal, although no specimens have been yet obtained. Its reptiles and birds are highly peculiar and more numerous than in any truly oceanic island. Now the sea which directly separates New Zealand from Australia is more than 2,000 fathoms deep, but in a north-west direc-

${ }^{1}$ From A. R. Wallace, Darwinism (copyright $\mathrm{I} 889$ ). Used by special permission of the publishers, The Macmillan Company. 
tion there is an extensive bank under $\mathrm{I}, 000$ fathoms, extending to and including Lord Howe's Island, while north of this are other banks of the same depth, approaching towards a submarine extension of Queensland on the one hand, and New Caledonia on the other, and altogether suggestive of a land union with Australia at some very remote period. Now the peculiar relations of the New Zealand fauna and flora with those of Australia and of the tropical Pacific Islands to the northward indicate such a connection, probably during the Cretaceous period; and here, again, we have the exceptional depth of the dividing sea and the form of the ocean bottom according well with the altogether exceptional isolation of New Zealand, an isolation which has been held by some naturalists to be great enough to justify its claim to be one of the primary Zoölogical Regions.

\section{THE DISTRIBUTION OF MARSUPIALS}

A. R. WALLACE

This singular and lowly organised type of mammals constitutes almost the sole representative of the class in Australia and New Guinea, while it is entirely unknown in Asia, Africa, or Europe. It reappears in America, where several species of epossums are found; and it was long thought necessary to postulate a direct southern connection of these distant countries, in order to account for this curious fact of distribution. When, however, we look to what is known of the geological history of the marsupials the difficulty vanishes. In the Upper Eocene deposits of Western Europe the remains of several animals closely allied to the American opossums have been found; and as, at this period, a very mild climate prevailed far up into the arctic regions, there is no difficulty in supposing that the ancestors of the group entered America from Europe or Northern Asia during early Tertiary times.

But we must go much further back for the origin of the Australian marsupials. All the chief types of the higher mammalia were in existence in the Eocene, if not in the preceding Cretaceous period, and as we find none of these in Australia, that country must have been finally separated from the Asiatic continent during the Secondary or Mesozoic period. Now during that period, in the Upper and the Lower Oölite and in the still older Trias, the jaw-bones of numerous small mammalia have been found, forming eight distinct genera, which

${ }^{x}$ From A. R. Wallace, Darwinism (copyright I889). Used by special permission of the publishers, The Macmillan Company. 
are believed to have been either marsupials or some allied lowly forms. In North America also, in beds of the Jurassic and Triassic formations, the remains of an equally great variety of these small mammalia have been discovered; and from the examination of more than sixty specimens, belonging to at least six distinct genera, Professor Marsh is of the opinion that they represent a generalised type, from which the more specialised marsupials and insectivora were developed.

From the fact that very similar mammals occur both in Europe and America at corresponding periods, and in beds which represent a long succession of geological time, and that during the whole of this time no fragments of any higher forms have been discovered, it seems probable that both the northern continents (or the larger portion of their area) were then inhabited by no other mammalia than these, with perhaps other equally low types. It was, probably, not later than the Jurassic age when some of these primitive marsupials were able to enter Australia, where they have since remained almost completely isolated; and, being free from the competition of higher forms, they have developed into the great variety of types we now behold there. These occupy the place, and have to some extent acquired the form and structure of distinct orders of the higher mammals- the rodents, the insectivora, and the carnivora-while still preserving the essential characteristics and lowly organisation of the marsupials. At a much later period-probably in late Tertiary times-the ancestors of the various species of rats and mice which now abound in Australia, and which, with the aerial bats, constitute its only forms of placental mammals, entered the country from some of the adjacent islands. For this purpose a land connection was not necessary, as these small creatures might easily be conveyed among the branches or in the crevices of trees uprooted by floods and carried down to the sea, and then floated to a shore many miles distant. That no actual land connection with, or very close approximation to, an Asiatic island had occurred in recent times, is sufficiently proved by the faci that no squirrel, pig, civet, or other widespread mammal of the Eastern hemisphere has been able to reach the Australian continent.

THE DISTRIBUTION OF BIRDS ${ }^{\mathrm{T}}$

A. R. WALLACE

These vary much in their powers of flight, and their capability of traversing wide seas and oceans. Many swimming and wading birds

${ }^{2}$ From A. R. Wallace, Darwinism (copyright I8gI). Used by special permission of the publishers, The Macmillan Company. 
can continue long on the wing, fly swiftly, and have, besides, the power of resting safely on the surface of the water. These would hardly be limiterl by any width of ocean, except for the need of food; and many of them, as the gulls, petrels, and divers, find abundance of food on the surface of the sea itself. These groups have a wide distribution across the occans; while waters-especially plovers, sandpipers, snipes, and herons-are equally cosmopolitan, travelling along the coasts of all the continents, and across the narrow seas which separate them. Hany of these birds seem unaffected by climate, and as the organisms on which they feed are especially abundant on arctic, temperate, and tropical shores, there is hardly any limit to the range even of some of the species.

Land-birds are much more restricted in their range, owing to their usually limited powers of flight, their inability to rest on the surface of the sea or to obtain food from it, and their greater specialisation, which renders them less able to maintain themselves in the new countries they may occasionally reach. Nany of them are adapted to live only in woods, or in marshes, or in deserts; they need particular kinds of food or a limited range of temperature; and they are adapted to cope only with the special enemies or the particular group of competitors among which they have been developed. Such birds as these may pass again and again to a new country, but are never able to establish themselves in it; and it is this organic barrier, as it is termed, rather than any physical barrier, which, in many cases, determines the presence of a species in one area and its absence from another. We must always remember, therefore, that, although the presence of a species in a remote oceanic island clearly proves that its ancestors must at one time have found their way there, the absence of a species does not prove the contrary, since it also may have reached the island, but have been unable to maintain itself, owing to the inorganic or organic conditions not being suitable to it. This general principle applies to all classes of organiums, and there are many striking illustrations of it. In the Azores there are eighteen species of land-birds which are permanent residents, but there are also several others which reach the islands almost every year after great storms, but have never been able to establish themselves. In Bermuda the facts are still more striking, since there are only ten species of resident birds, while no less than twenty other species of land-birds, and more than a hundred species of waders and aquatics are frequent visitors, often in great numbers, but are never able to establish themselves. 


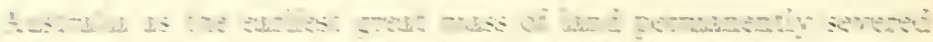

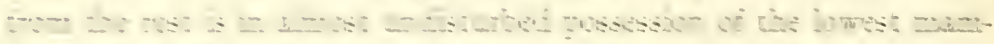

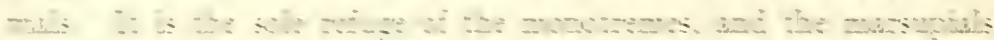

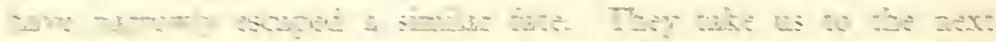

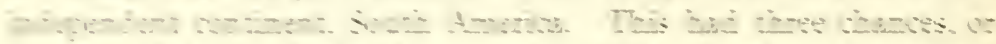

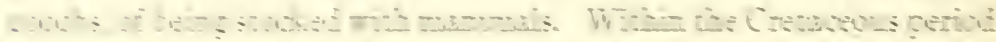

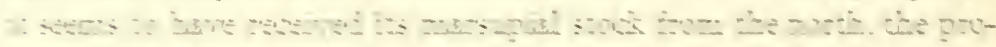

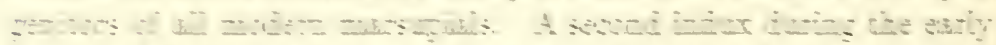

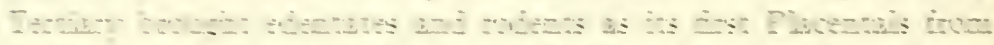

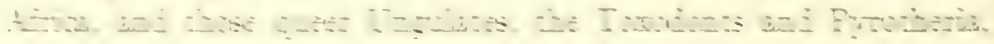
z L

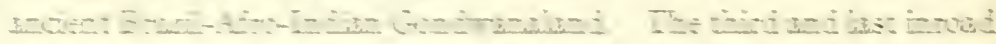

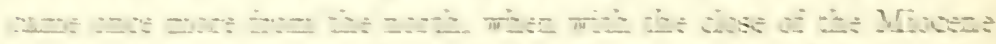
From

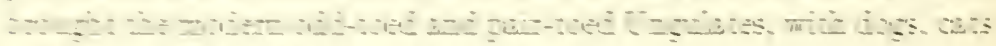

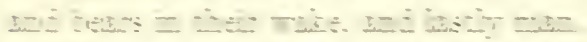

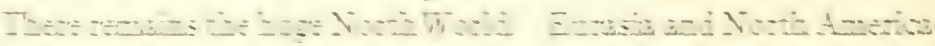

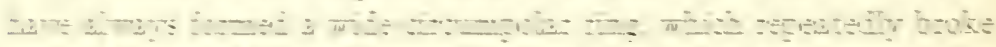

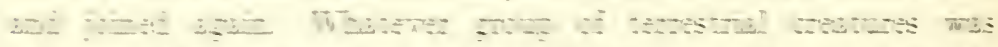

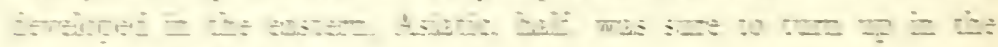

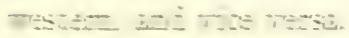

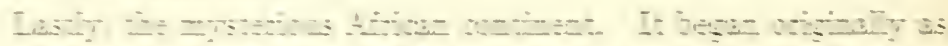

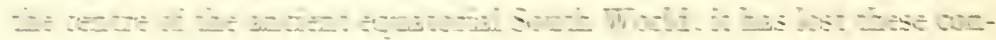

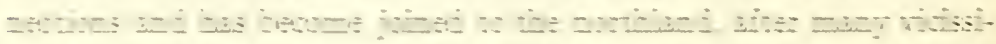
wis. I: I =атin

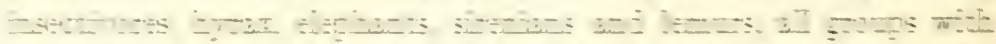

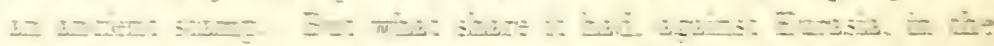
准

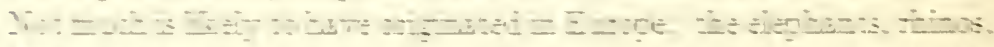

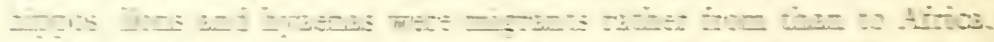
-

$\exists-\div$ -

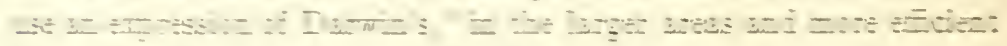

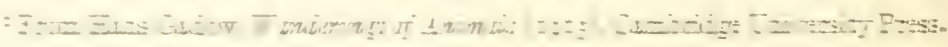




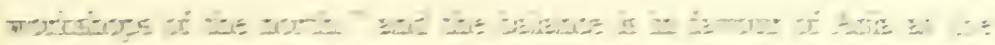

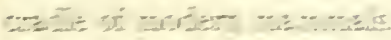

Is

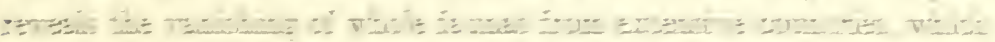
мा

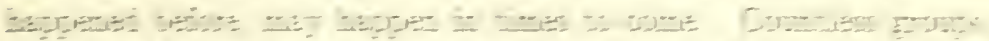

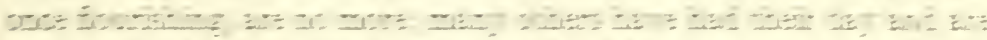
בу

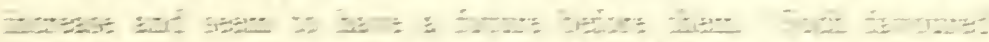

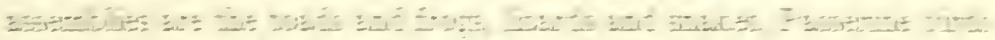

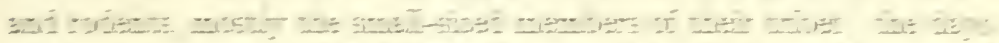

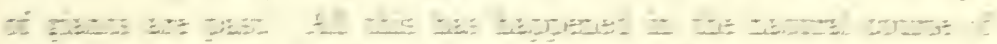

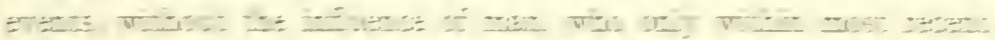
-

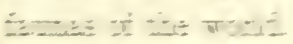

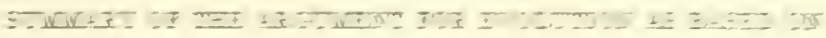

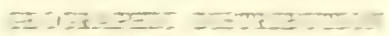

Ya

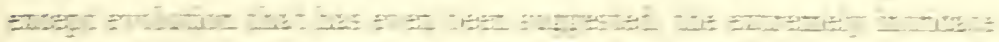

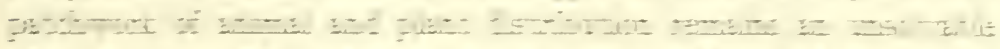
prim...

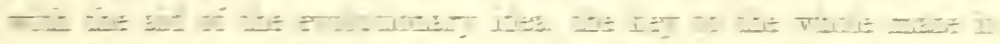

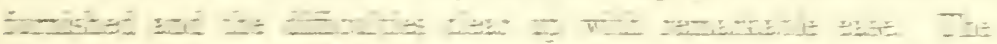
míle

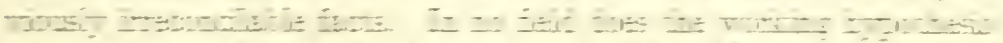
of

10 드 I

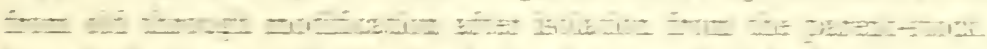

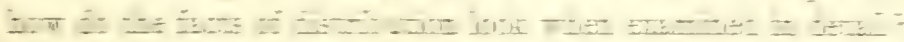

2. Cosur $\therefore$ -

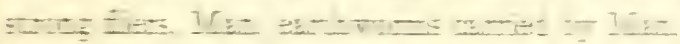

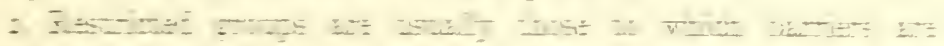

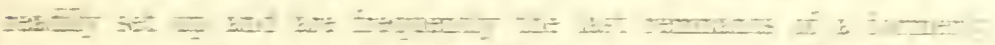

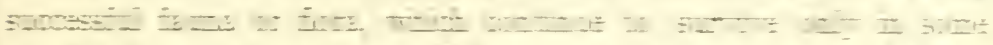

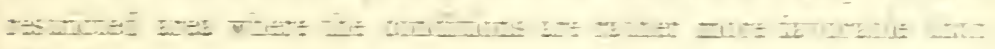

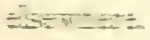


3. The study of the distribution of species belonging to a single genus reveals that the more primitive or generalized species occupy a central position and the most specialized species are at the outer boundaries of the distributional area.

4. The faunas and floras of continental islands are just what we should expect on the basis that there was at one time a land connection with the nearest continent; that at this time the faunas and floras were the same on both island and continent; that, later, the continent and island were separated by an impassable barrier of ocean; and that the inhabitants of the two bodies evolved separately.

5. The faunas and floras of oceanic islands are like those of the nearest mainland and are of those types, for the most part, that might most readily have been blown there by the wind or carried on floating débris.

6. The conclusions arrived at by students of geographic distribution, past and present, as to the existence of former land connections, now broken, are borne out by the independent findings of geologists and geogranhers.--ED.] 


\section{CHAPTER VIII \\ EVIDENCES FROM CLASSIFICATION}

TIIE PRINCIPLES OF CLASSIFICATION ${ }^{I}$

A. F. SHULL

The International Code.-Some of the essential features of the International Code are as follows. The first name proposed for a genus or species prevails on the condition that it was published and accompanied by an adequate description, definition or indication, and that the author has applied the principles of binomial nomenclature. This is the so-called law of priority. The tenth edition of the Sytema Naturae of Linnaeus is the basis of the nomenclature. The author of a genus or species is the person who first publishes the same in connection with a definition, indication or description, and his name in full or abbreviated is given with the name; thus, Bascanian anthonyi Stejneger. In citations the generic name of an animal is written with a capital letter, the specific and subspecific name without initial capital letter. The name of the author follows the specific name (or subspecific name if there is one) without intervening punctuation. If a species is transferred to a genus other than the one under which it was first described, or if the name of a genus is changed, the author's name is included in parentheses. For example, Bascanion anthonyi Stejneger should now be written Coluber anthonyi (Stejneger), the generic name of this snake having been changed. One species constitutes the type of the genus; that is, it is formally designated as typical of the genus. One genus constitutes the type of the subfamily (when a subfamily exists), and one genus forms the type of the family. The type is indicated by the descr.ber or if not indicated by him is fixed by another author. The name of a subfamily is formed by adding the ending -inae, and the name of a family by adding -idae to the root of the name of the type genus. For example, Colubrinae and Colubridae are the subfamily and family of snakes of which Coluber is the type genus.

The basis of classification.-Early systematists largely employed superficial characters to differentiate and classify animals, and their

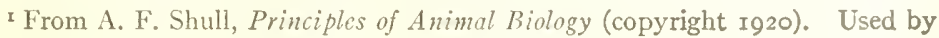
special permission of The McGraw-Hill Book Company. 


\section{I18}

classifications were thus largely artificial and served principally as convenient methols of arrangement, description and cataloging. Since the time of the development of the theory of descent with modifications by Lamarck (1809) and I)arwin (1859), there has been an attempt to base the classification on relationships. Very nearly related animals are jut into the same species. 'They are related because they descend from a commen ancestry, and that common ancestry could not in most cases have been very ancient, otherwise evolution within the group would have occurred and the species would have been split into two or more species. Species that are much alike are includer in one gents, being thus marked off from the species of another genus. The similarity of the species of a genus is held to indicate kinship, but since there is greater diversity among the individuals of a genus than among the members of a species, the common stock from which the species of a genus have sprung must have exister at an earlier time, in order that evolution could bring about the degree of divergence now observed. In like manner, a family is made up of genera, and their likeness is again a sign of affinity. But to account for the greater difference between the extreme individuals belonging to a family, evolution must have had more time, that is, the common source of the members of a family must have antedated the common source of the individuals of a genus. Orders, classes, and phyla are similarly regarded as having sprung from successively more remote ancestors, the time differences being necessary to allow for the differences in the amount of evolution. 'This statement is in general correct. However, since evolution has probably not proceeded at the same rate at all periods, nor in all branches of the animal kingdom at any one time, the time relations of the groups of high or low rank must not be too rigidly assigned. Thus certain genera, in which evolution has been slow, are probably much older than some families in which evolution has been rapirl. It is not improbable, also, that some genera are quite as old as the families which include them; lut in no case can they be older. Furthermore, different groups are classified by taxonomists of different temperaments, so that groups of a given nominal rank may be much more inclusive (and hence older) in one branch of the animal kingdom than in another. On the whole, nevertheless, the groups of higher rank have sprung from ancestry more remote than that of the groups of lower rank.

The means of recognizing the kinship implied in classification permit some differences of opinion. It is recognized that likeness in 
structural characters is the chiei clue to affinities. However, the evidential ralue of similarity in one or several structures unaccompanied by the similarity of all parts is to be distrusted, since animals widely separated and dissimilar in most characters may have certain other features in common. Thus, the coots, phalaropes and gretes among birds have lobate feet but, as indicated by other features, they are not closely relaied: and there are certain lizards (Amphistuenidae which closely resemble certain snakes (Typholopidae) in being blind, limbless, and hariug a short tail. The early systematists vere very liable to bring together in their classification analogous forms, that is, those which are functionally similar; or animals which are superficially similar. In contrast with the early practice, the aim of taxonomists at the present time is to group forms according to homol$0 \%$, wich is corsidered an indication of actual relationship. Since a genetic classification must tale into consideration the entire animal, the search for affnities becomes an attempt to eraluate the results of all morphological lnowledge, and it is also becoming evident that other things beside structure ma: throw light upon relationships. The fossil records. georraphical distribution. ecology and experimental breeding may all assist in establishing afinities.

The method of taronomy.-It is evident that beiore the relationships of animals can be determined the forms must be known, for unlnown forms constitute breaks in the pedigrees of the groups to which they belong. Moreover. as printed out abore, the structural characters, variation and distrifution must be known beiore a form can be placed in the proper place in a genetic system. For these reasons an improtant part of systematic work is the description of forms and an analysis of their differences. Aiter the Linnaean system vas adopted zoölogists attaci:ed this rirgin field and ior many years "species ma"-ing" predominated. Even at the present time when other aspects of zoolog have come to receive relatively more attention it is an interesing fact that the analytical method prevails in systematic studies, and tamonomy suffers irom, and in part merits, the criticism that it is a mere cataloging of forms and ignores the higher goal of investigation, namely, the discovery of the course oi evolution. Many systematists, however, recognize that the ultimate purpose of taronomic work is to discover the relationships as well a: the differences between the descrited forms in order that the course of evolution may be determined. In other mords, it is apfreciated that while aralytical studies are recessar: they are only preliminary, and 
that upon their results must be built synthetic studies, if taxonomy is to fulfil its purpose.

\section{THE METHOD OF CLASSIFICATION}

CHARLES DARWIN

Naturalists, as we have seen, try to arrange the species, genera, and families in each class, on what is called the Natural System. But what is meant by this system? Some authors look at it merely as a scheme for arranging together those living objects which are most alike, and for separating those which are most unlike; or as an artificial method of enunciating, as briefly as possible, general propositions,that is, by one sentence to give the characiers common, for instance, to all mammals, by another those common to all carnivora, by another those,common to the dog-genus, and then, by adding a single sentence, a full description is given of each kind of dog. The ingenuity and utility of this system are indisputable. But many naturalists think that something more is meant by the Natural System; they believe that it reveals the plan of the Creator; but unless it be specified whether order in time or space, or both, or what else is meant by the plan of the Creator, it seems to me that nothing is thus added to our knowledge. Expressions such as that famous one by Linnaeus, which we often meet with in a more or less concealed form, namely, that the characters do not make the genus, but that the genus gives the characters, seem to imply that some deeper bond is included in our classifications than mere resemblance. I believe that this is the case, and that community of descent-the one known cause of close similarity in organic beings-is the bond which, though observed by various degrees of modification, is partially revealed to us by our classifications.

Let us now consider the rules followed in classification, and the difficulties which are encountered on the view that classification either gives some unknown plan of creation, or is simply a scheme for cnunciating general propositions and of placing together the forms most like each other. It might have been thought (and was in ancient times thought) that those parts of the structure which determined the habits of life, and the general place of each being in the economy of nature, would be of very high importance in classification. Nothing can be more false. No one regards the external similarity of a mouse to a shrew, of a dugong to a whale, of a whale to a fish, as of any

${ }^{x}$ From The Origin of Specics. 
importance. These resemblances, though so intimately connected with the whole life of the being, are ranked as merely "adaptive or analogical characters": lout to the consideration of these resemblances we shall recur. It may even be given, as a general rule, that the less any part of the organisation is concerned with special habits, the more important it becomes for classification. As an instance: Owen, in speaking of the dugong, says, "The generative organs, being those which are most remotely related to the habits and food of an animal, I have always regarded as affording very clear indications of its true affinities. We are least likely in the modifications of these organs to mistake a merely adaptive for an essential character." With plants how remarkable it is that the organs of vegetation, on which their nutrition and life depend, are of little signification; whereas the organs of reproduction, with their product the sced and embryo, are of paramount importance! So again in formerly discussing certain morphological characters which are not functionally important, we have seen that they are often of the highest service in classification. This depends on their constancy throughout many allied groups; and their constancy chiefly depends on any slight deviations not having been preserved and accumulated by natural selection, which acts only on serviceable characters.

\section{WHAT IS A SPECIES?}

"Each kind of animal or plant, that is, each set of forms which in the changes of the ages has diverged tangibly from its neighbors, is called a species. There is no absolute definition for the word species. The word kind represents it exactly in common language, and is just as susceptible to exact definition. The scientific idea of species does not differ materially from the popular notion. A kind of tree or bird or squirrel is a species. Those individuals which agree very closely in structure anc' function belong to the same species. There is no absolute test, other than the common judgment of men competent to decide. Naturalists recognize certain formal rules as assisting in such a decision. A series of fully intergrading forms, however varied at the extremes, is usually regarded as forming a single species. There are certain recognized effects of climate, of climatic isolation, and of the isolation of domestication. 'These do not usually' make it necessary to regard as distinct species the extreme forms of a series concerned." $x$

${ }^{I}$ From D. S. Jordan and V. L. Kellogg, Evolution and Animal Life. 
"The term 'species' was thus defined by the celebrated botanist De Canciolle: 'A species is a collection of all the individuals which resemble each other more than they resemble anything else, which can by mutual fecundation produce fertile individuals, and which reproduce themselves by generation, in such a manner that we may from analogy suppose them all to have sprung from one single individual.' And the zoölogist Swainson gives a somewhat similar definition: 'A species, in the usual acceptation of the term, is an animal which, in a state of nature, is distinguished by certain peculiarities of form, size, colour, or other circumstances, from another animal. It propagates, after its kind, individuals perfectly resembling the parent; its peculiarities, therefore, are permanent." "x

[As will have become apparent, the significant assumption underlying classification is that the closest fundamental similarities between animals (or plants) are found in the forms most closely related and that the greatest differences are found in those forms which are unrelated or at best very distantly related. The assumption implies the idea of descent with modification, which is no more nor less than evolution. Using this evolutionary basis, we can arrive at an extremely satisfactory classification both of living and of extinct forms; and there is no other basis of classification that works.

The question might well be asked whether it is possible to test the validity of the assumption that degrees of resemblance vary directly with closeness of blood relationship? Two direct tests of this may be and have been made. The closest of blood relatives possible are individuals that have been derived by the dividing of a single egg. Armadillo ${ }^{2}$ quadruplets have been shown to be thus derived, and detailed studies of the closeness of resemblance existing between members of a given set indicate that they are vastly more alike than are the simultaneously born offspring of animals which give birth to several young, but in which each young is derived from a separate egg. If we use the index of correlation to indicate the degree of similarity between individuals we find that ordinary brothers or sisters are only about 50 per cent alike, while armadillo quadruplets are over 90 per cent alike. Identical or duplicate twins in human beings are believed to have an origin from one egg, after the fashion of the armadillo,

From A. R. Wallace, Darwinism.

${ }^{2}$ See H. H. Newman, The Biology of Twins (Igr7), University of Chicago Press. 
though the proof has not been forthcoming. Everyone is familiar with the remarkable similarity, amounting almost to identity, between such twins. Thus we are able to show that the closest blood relationship known is associated with the closest resemblance. The next degree of resemblance is between members of the same family, brothers, sisters, cousins, etc., and we do not hesitate to explain this resemblance as due to blood relationship. In this we merely accept the known principles of heredity.

The second direct test of the validity of the assumption that degrees of resemblance run parallel with degrees of blood relationship is found in connection with "blood-transfusion tests." This evidence, as presented by Professor Scott, forms the substance of the next chapter.-ED.] 


\title{
CHAPTER IX
}

\section{EVIDENCE FROM BLOOD TESTS ${ }^{x}$}

\author{
IV. B. ScotT
}

Here may be conveniently considered the very interesting and significant blood tests which have been made in the last fifteen years by various physiologists and especially by Dr. George H. F. Nuttall, of the University of Cambridge. Though there are several methods of making these tests, the "precipitation method" employed by Dr. Nuttall will be quite sufficient for the ends sought in these lectures. The method and significance of the tests can best be explained by taking as an example human blood, which, of course, has been most extensively and minutely studied, because of its legal importance as well as its scientific interest. Ordinary chemical analysis is unable to determine the differences in blood-composition between various animals, but that there were important differences had long been understood. This was shown by the fact that, in performing the operation for the transfusion of blood, it was not practicable to substitute animal for human blood, since the former might cause serious injury to the patient.

The precipitation method of making blood tests is as follows: Freshly drawn human blood is allowed to coagulate or clot, which it will do in a few minutes, if left standing in a dish, and then the serum is drained away from the clot. Blood-serum is the watery, almost colourless part of the blood, which remains after coagulation. Small quantities of this serum are injected, at intervals of one or two days, into the veins of a rabbit and cause the formation in the rabbit's blood of an anti-body, analogous to the anti-toxin which is produced in the blood of a horse by the injection of diphtheria virus. After the last injection the rabbit is allowed to live for several days and is then killed and bled, the blood is left until it clots and the serum drained off and preserved. The serum obtained thus from a rabbit is called "anti-human" serum and is an exceedingly delicate test for human blood, not only when the latter is fresh, but also when it is in the form of old and dried blood-stains, or even when the blood is

s From W. B. Scott, The Theory of Evolution (copyright 1917). Used by special permission of the publishers, The Macmillan Company. 
putric. Stains, for example, are soaked in a very weak solution of common salt and, if necessary, the blood solution is filtered until it is quite limpid and clear. Into the blood solution a few drops of the anti-human serum are conveyed and, if the stains are of human blood, a white precipitate is formed and thrown down, but if the stains are of the blood of some domestic animal, such as a pig, sheep, or fowl, no such reaction follows. In the same manner as above described, we may prepare anti-pig, anti-horse, anti-fowl, etc., etc., sera by injecting the fresh-drawn serum of a pig, horse, fowl, or any other animal into the rabljit, instead of human blood-serum. In some countries, notably in Germany and Austria, this test has already been adopted by the courts of justice and has been found extremely useful in the detection of crime.

Further investigation showed that these blood tests might be employed to determine the degrees of relationship between different animals, for, although a prompt and strong reaction is usually obtained only from the blood of the same species as that from which the original injection into the rabbit was taken, the blood of nearly allied species, such as the horse and donkey, for example, gives a weaker and slower precipitation. By using stronger solutions and allowing more time, quite distant relationships may be brought out. Nuttall and his collaborator, Graham-Smith, made many thousands of such experiments bearing upon the problems of relationship and classification and it is of great significance to note that their highly interesting and important results contain few surprises, but, in almost all cases, merely serve to confirm the conclusions previously reached by other methods, such as comparative anatomy and palaeontology. It will be instructive to quote some of these results, the quotations being taken from "Blood Immunity and Blood Relationship, by G. H. F. Nuttall, including Original Researches by G. L. Graham-Smith and T. S. P. Strangeways," Cambridge, I904.

"In the absence of palaeontological evidence the question of the interrelationship amongst animals is based upon similarities of structure in existing forms. In judging of these similarities, the subjective element may largely enter." "The very interesting observations upon the eye made by Johnson also demonstrate the close relationships between the Old World forms and man, the macula lutea tending to disappear as we descend in the scale of New World Monkeys and being absent in the Lemurs. The results which I published upon my tests with precipitins directly supported this evidence, for the reactions 
obtained with the bloods of Simiidae (i.e., Man-like Apes) closely resemble those obtained with human blood, the bloods of Cercopithecidae (Old World Monkeys) came next, followed by those of Cebidae and Hapalidae (New World Monkeys and Marmosets) which gave but slight reactions with anti-human serum, whilst the blood of Lemuroidea gave no indication of blood-relationship." "A perusal of the pages relating to the tests made upon the many bloods I have examined by means of precipitating anti-sera, will very clearly show that this method of investigation permits of our drawing certain definite conclusions. It is a remarkable fact . . . . that a common property has persisted in the bloods of certain groups of animals throughout the ages which have elapsed during their evolution from a common ancestor, and this in spite of differences of food and habits of life. The persistence of the chemical blood-relationship between the various groups of animals serves to carry us back into geological times, and I believe we have but begun the work along these lines, and that it will lead to valuable results in the study of various problems of evolution."

The general conclusions on interrelationships, so far as they are of particular interest for our purpose, reached by Nuttall and GrahamSmith as the result of many thousands of blood tests, may be summarized as follows:

I. If sufficiently strong solutions be used and time enough be allowed, a relationship between the bloods of all mammals is made evident.

2. The degrees of relationship between man, apes and monkeys have already been noted.

3. Anti-carnivore sera show "a preponderance of large reactions amongst the bloods of Carnivora, as distinguished from other Mammalia; the maximum reactions usually take place amongst the more closely related forms in the sense of descriptive zoölogy."

4. Anti-pig serum gives maximum reactions only with the bloods of other species of the same family, moderate reactions those of ruminants and camels, and moderate or slight reactions with those of whales. Anti-llama serum gives a moderate reaction with the blood of the camel, and the close relationship between the deer family and the great host of antelopes, sheep, goats and oxen is clearly demonstrated.

5. Anti-whale serum gives maximum reactions only with the bloods of other whales and slight reactions with those of pigs and ruminants. 
6. A close relationship is shown to exist between all marsupials, with the exception of the Thylacine, or so-called Tasmanian IVolf.

7. Strong anti-turtle serum gives maximum reactions only with the bloods of turtles and crocodiles; with those of lizards and snakes the results are almost negative. With the egg-albumins of reptiles and birds a moderate reaction is given.

8. Anti-lizard serum produces maximum results with the bloods of lizards and reacts well with those of snakes.

9. These experiments indicate that there is a close relationship between lizards and snakes, on the one hand, turtles and crocodiles on the other. They further indicate that birds are more nearly allied with the turtle-crocodile series than with the lizard-snake series, results for which palaeontological studies had already prepared us.

10. "Tests were made by means of anti-sera for the fowl and ostrich upon 792 and 649 bloods respectively. They demonstrate a similarity in blood constitution of all birds, which was in sharp contrast to what had been observed with mammalian bloods, when acted upon by anti-mammalian sera. Differences in the degree of reaction were observed, but did not permit of drawing any conclusions."

II. I have already called attention to the fact that the problematical Horseshoe-crab is indicated by its embryology to be related to the air-breathing spiders and scorpions rather than to the marine Crustacea. It is of exceptional interest to learn that embryology is supported by the results of the blood tests.

It must not be supposed that there is any exact mathematical ratio between the degrees of relationship indicated by the blood tests and those which are shown by anatomical and palaeontological evidence. Any supposition of the kind would be immediately negatived by the contrast between the blood of mammals and that of birds. It could hardly be maintained that an ostrich and a parrot are more nearly allied than a woif and a hyena and yet that would be the inference from the blood tests. Like all other anatomical and physiological characters, the chemical composition of the blood is subject to change in the course of evolution and these developmental changes do not keep equal pace in all parts of the organism. It is the rule rather than the exception to find that one part of the structure advances much more rapidly than other parts, such as the teeth, the skull, or the feet. The human body is, fortunately for us, of rather a primitive kind, while the development of the brain is far superior to that of any other mammal and this great brain development has 
necessitated a remodeling of the skull. On the other hand, the skeleton, limbs, hands and feet are but slightly specialized. In the clephant tribe, so far as we can trace them back in time, there has been little change, save in size, in the structure of the body or limbs, while the teeth and skull have passed through a series of remarkable changes. It is for this reason that it is unsafe to found a scheme of classification, which is meant to be a brief expression of relationship, upon a single character, for the result is almost invariably misleading. The results of blood tests must be critically examined and checked by a comparison with the results obtained by other methods of investigation, but after every allowance has been made, these tests are very remarkable.

The blood tests have brought very strong confirmation to the theory of evolution and from an entirely unexpected quarter; they come as near to giving a definite demonstration of the theory as we are likely to find, until experimental zoölogy and botany shall have been improved and perfected far beyond their present state. 


\section{CHAPTER X \\ EVIDENCES FROM MORPHOLOGY \\ (COMPARATIVE ANATOMY)}

GEORGE JOHN ROMANES

The theory of evolution supposes that hereditary characters admit of being slowly modified wherever their modification will render an organism better suited to- change in its conditions of life. Let us, then, observe the evidence which we have of such adaptive modifications of structure, in cases where the need of such modification is apparent. We may begin by again taking the case of the whales and porpoises. The theory of evolution infers, from the whole structure of these animals, that their progenit must have been terrestrial quadrupeds of some kind, which gradually became more and more aquatic in their habits. Now the change in the conditions of their life thus brought about would have rendered desirable great modifications of structure. These changes would have begun by affecting the least typical-that is, the least strongly inherited-structures, such as the skin, claws, and teeth. But, as time went on, the adaptations would have extended to more typical structures, until the shape of the body would have become affected by the bones and muscles required for terrestrial locomotion becoming better adapted for aquatic locomotion, and the whole outline of the animal more fish-like in shape. This is the stage which we actually observe in the seals, where the hind legs, although retaining all their typical bones, have become shortened up almost to rudiments, and directed backwards, so as to be of no use for walking, while serving to complete the fish-like taper of the body (Fig. I I). But in the whales the modification has gone further than this so that the hind legs have ceased to be apparent externally, and are only represented internally-and even this only in some species-by remnants so rudimentary that it is difficult to make out with certainty the homologies of the bones; moreover, the head and the whole body have become completely fish-like in shape (Fig. 12). But profound as are these alterations, they affect only

s From G. J. Romanes, Darwin and after Darwin (copyright IS92). Used by special permission of the publishers, The Open Court Publishing Company. 
I30 READINGS IN EVOLUTION, GENETICS, AND EUGENICS

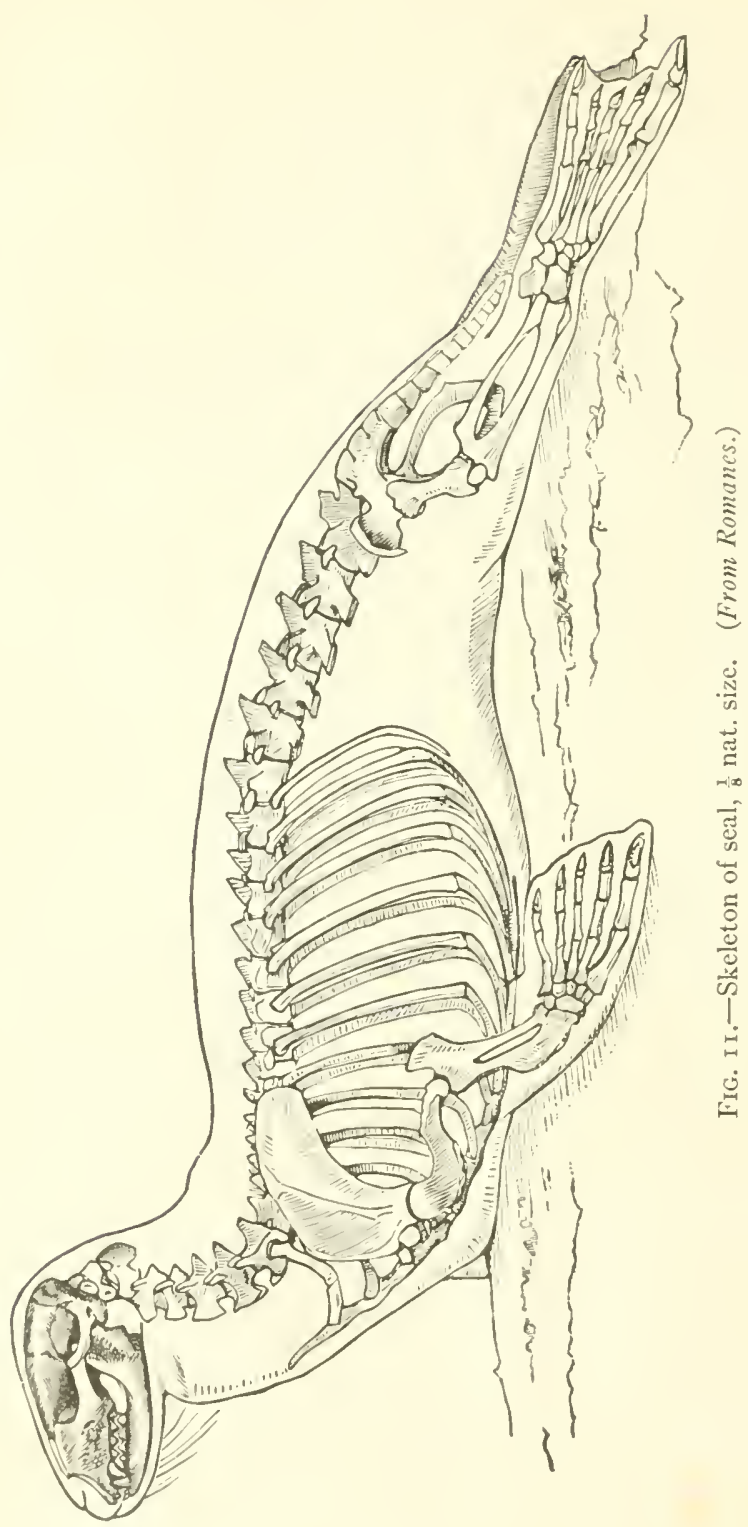


those parts of the organism which it was for the benefit of the organism to have altered, so that it might be adapted to an aquatic mode of existence. Thus the arm, which is used as a fin, still retains the bones of the shoulder, fore-arm, wrist, and fingers, although they are all enclosed in a fin-shaped sack, so as to render them useless for any purpose other than swimming (Fig. I3). Similarly, the head, although it so closely resembles the head of a fish in shape, still retains the bones of the mammalian skull in their proper anatomical relations to one another; but modified in form so as to offer the least possible resistance to the water. In short, it may be said that all the modifications have been effected with the least possible divergence from the typical mammalian type, which is compatible with securing so perfect an adaptation to a purely aquatic mode of life.

Now I have chosen the case of the whale and porpoise group, because they offer so extreme an example of profound modification of structure in adaptation to changed conditions of life. But the same thing may be seen in hundreds and hundreds of other cases. For instance, to confine our attention to the arm, not only is the limb, modified in the whale for swimming, but in another mammal-the bat-it is modified for flying, by. having the fingers enormously elongated and overspread with a membranous web.

In birds, again, the arm is modified for flight in a wholly different way - the fingers here being very short and all run together, while the chief expanse of the wing is composed of the shoulder and forearm. In frogs and lizards, again, we find hands more like our own; but in an extinct species of flying reptile the modification was extreme, the wing having been formed by a prodigious elongation of the fifth finger, and a membrane spread over it and the rest of the han! (Fig. $\mathrm{I}_{4}$ ). Lastly, in serpents the hand and arm have disappeared altogether.

Thus, even if we confine our attention to a single organ, how wonderful are the modification: which it is seen to undergo, aithwugì never losing its typical character. Everywhere we find the distinction between homology and analogy which was explainer in the last chapter-the distinction, that is, between correspondence of structure and correspondence of function. On the one hand, we meet with structures which are perfectly homologous and yet in no way analogous; the structural elements remain, but are profoundly modified so as to perform wholly different functions. On the other hand, we meet with structures which are perfectly analogous, and yet in no way homologous; totally different structures are modified 
I32 READINGS IN EVOLUTION, GENETICS, AND EUGENICS

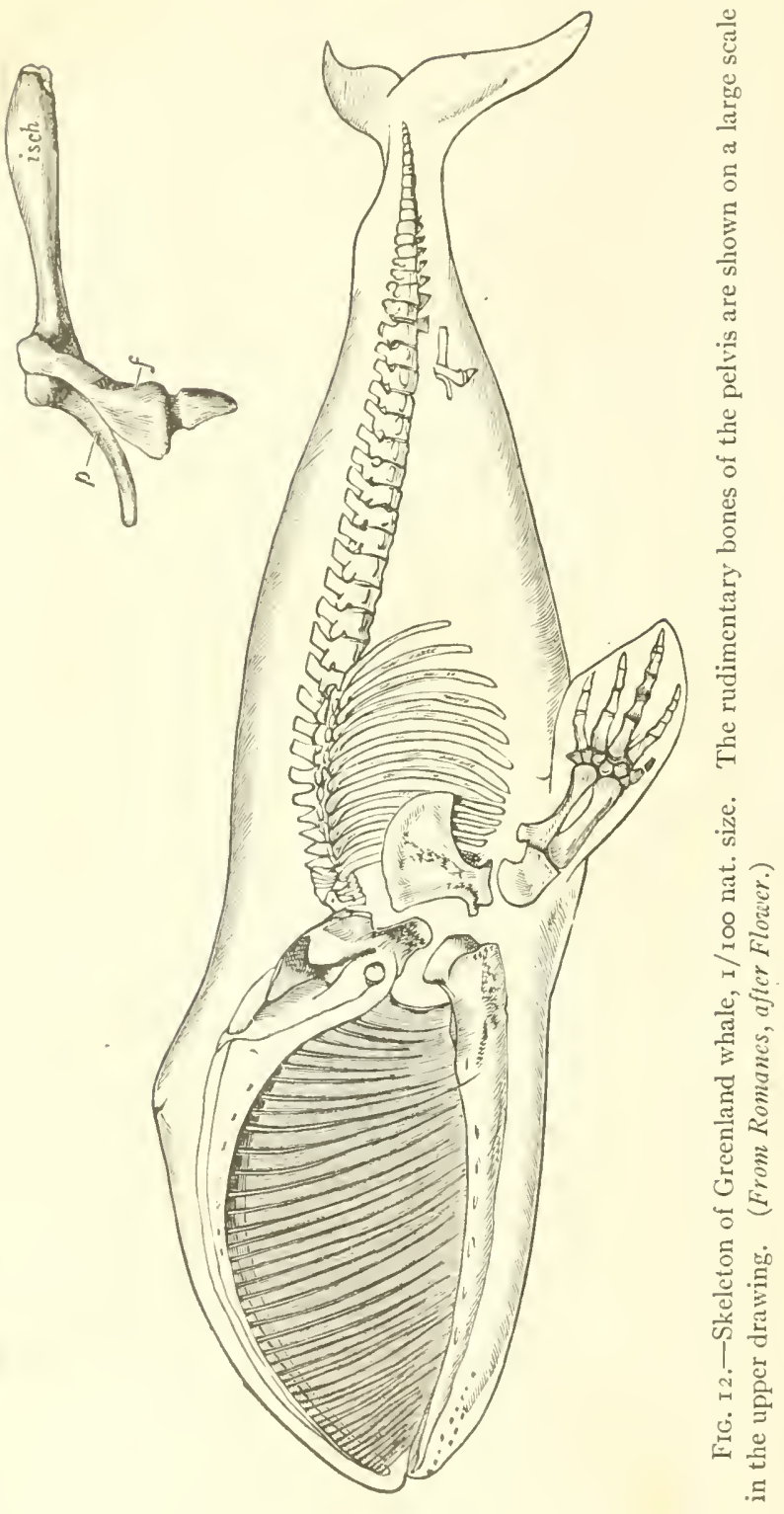


to perform the same functions. How, then, are we to explain these things? By design manifested in special creation, or by descent with adaptive modification? If it is said by design manifested in special creation, we must suppose that the Deity formed an archetypal plan of certain structures, and that he determined to adhere to this plan through all the modifications which those structures exhibit. But, if so, why is it that some structures are selected as typical and not others? Why should the vertebral skeleton, for instance, be tortured
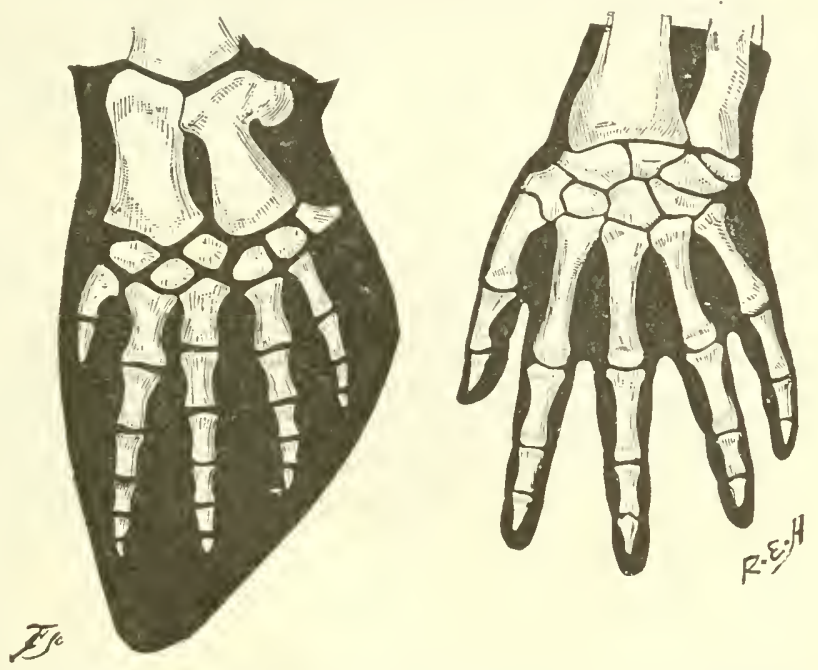

FIG. I3.-Paddle of whale compared with hand of man. (From Romanes.)

into every conceivable variety of modification in order to subserve as great a variety of functions; while another structure, such as the eye, is made in different sub-kingdums on fundamentally different plans, notwithstanding that it has throughout to perform the same function? Will any one have the hardihood to assert that in the case of the skeleton the Deity has endeavored to show his ingenuity, by the manifold functions to which he has made the same structure subservient; while in the case of the eye he has endeavored to show his resources, by the manifold structures which he has adapted to serve the same function? If so, it becomes a most unfortunate circumstance that, throughout both the vegetable and animal kingdoms, all cases which can be pointed to as showing ingenious adaptation of the 
I34 READINGS IN EVOLUTION, GENETICS, AND EUGENICS

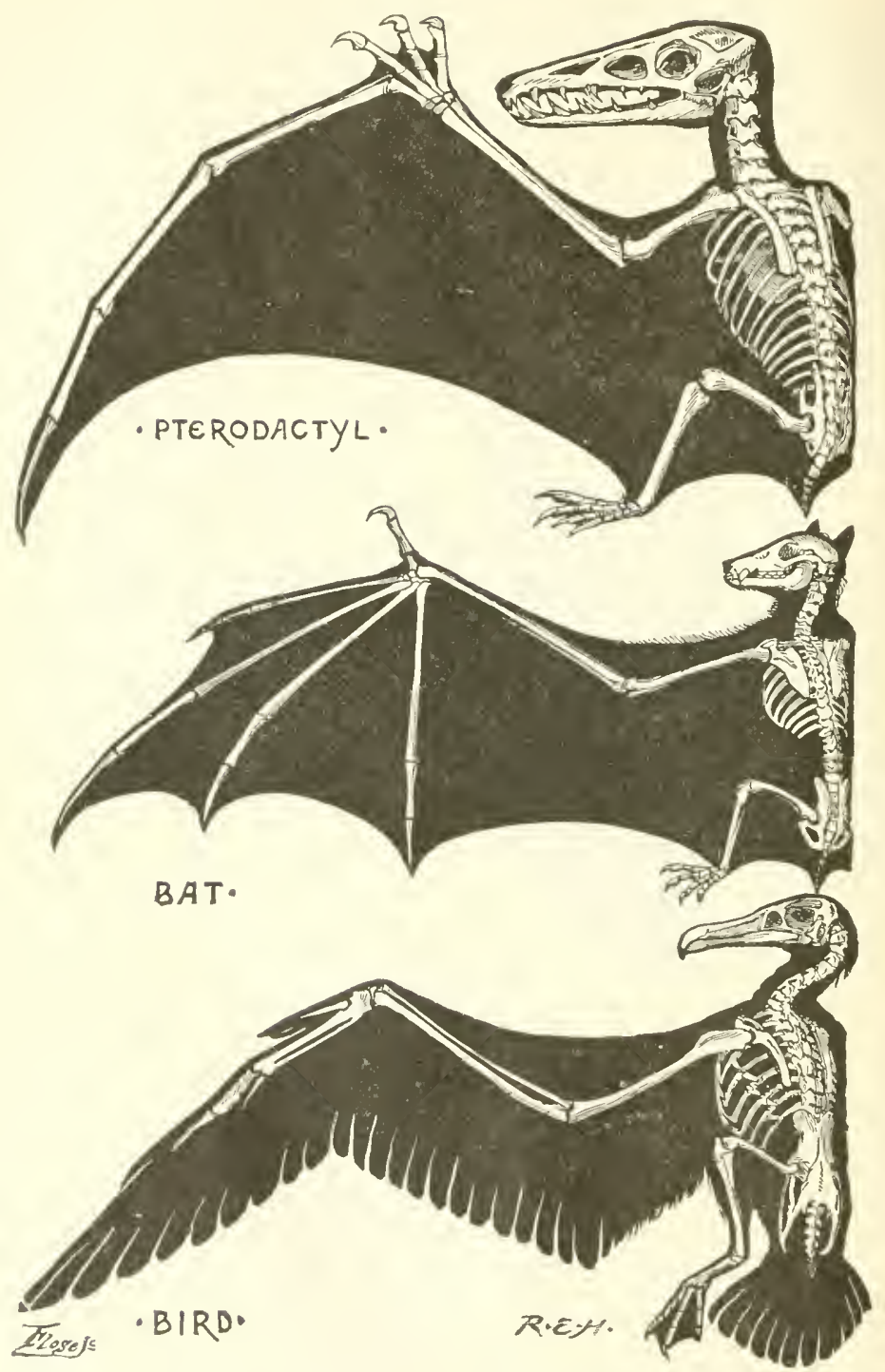

FIG. I4.-Wing of reptile, mammal, and bird. (From Romanes.) 
ame typical structure to the performance of widely different funcions-or cases of homology without analogy-are cases which come vithin the limits of the same natural group of plants and animals, and herefore admit of being equally well explained by descent from a :ommon ancestry; while all cases of widely different structures perorming the same function-or cases of analogy without homology, tre to be found in different groups of plants or animals, and are herefore suggestive of independent variations arising in the different ines of hereditary descent.

To take a specific illustration. The octopus, or devil-fish, belongs o a widely different class of animals from a true fish; and yet its eye, $n$ general appearance, looks wonderfully like the eye of a true fish. Now, Mr. Mivart pointed to this fact as a great difficulty in the wav if the theory of evolution by natural selection, because it must clearly se a most improbable thing that so complicated a structure as the eye if a fish should happen to be arrived at through each of two totally lifferent lines of descent. And this difficulty would, indeed, be a ormidable one to the theory of evolution, if the similarity were not mly analogical but homological. Unfortunately for the objection, sowever, Darwin clearly showed in his reply that in no one anatomical or homologous feature do the two structures resemble one another; ;o that, in point of fact, the two organs do not resemble one another $\mathrm{n}$ any particular further than it is necessary that they should, if both ire to be analogous, or to serve the same function as organs of sight. But now, suppose that this had not been the case, and that the two itructures, besides presenting the necessary superficial or analogical esemblance, had also presented an anatomical or homologous resemlance, with what force might it have then been urged,--your hypohesis of hereditary descent with progressive modification being here excluded by the fact that the animals compared belong to two widely lifferent branches of the tree of liie, how are we to explain the identity of type manifested by these two complicated organs of vision? The only hypothesis open to us is intelligent adherence to an ideal plan or nechanism. But as this cannot now be urged in any comparable case throughout the whole organic world, we may, on the other hand, rresent it as a most significant fact, that while within the limits of the same large branch of the tree of life we constantly find the same typical structures modified so as to perform very different functions we never find any of these particular types of structure in other large pranches of the tree. That is to say, we never find typical structures 
appearing except in cases where their presence may be explained by the hypothesis of hereditary descent; while in thousands of such cases we find these structures undergoing every conceivable variety of adaptive modification.

Consequently, special creationists must fall back upon another position and say,- Well, but it may have pleased the Deity to form a certain number of ideal types, and never to have allowed the structures occurring in one type to appear in any of the others. We answer,-Undoubtedly such may have been the case; but, if so, it is a most unfortunate thing for your theory, because the fact implies that the Deity has planned his types in such a way as to suggest the counter-theory of descent. For instance, it would seem most capricious on the part of the Deity to have made the eyes of an innumerable number of fish on exactly the same ideal type, and then to have made the eye of the octopus so exactly like these other eyes in superficial appearance as to deceive so accomplished a naturalist as Mr. Mivart, and yet to have taken scrupulous care that in no one ideal particular, should the one type resemble the other. However, adopting for the sake of argument this great assumption, let us suppose that God did lay down these arbitrary rules for his own guidance in creation, and then let us see to what the assumption leads. If the Deity formed a certain number of ideal types, and determined that on no account should he allow any part of one type to appear in any part of another, surely we should expect that within the limits of the same type the same typical structures should always be present. Thus, remember what efforts, so to speak, have been made to maintain the uniformity of type in the case of the fore-limb as previously explained, and should we not expect that in other and similar cases a similar method should have been followed? Yet we repeatedly find that this is not the case. Even in the whale, as we have seen, the hind-limbs are either altogether absent or dwindled almost to nothing; and it is impossible to see in what respects the hind-limbs are of any less ideal value than the fore-limbs-which are carefully preserved in all vertebrated animals except the snake, and the extinct Dinornis, where again we meet in this particular with a sudden and sublime indifference to the maintenance of a typical structure (Fig. I5). Now I say that if the theory of ideal types is true, we have in these facts evidence of a most unreasonable inconsistency. But the theory of descent with continued adaptive modification fully explains all the known cases; for in every case the degree of divergence from the typical structure which an 
rganism presents corresponds, in a general way, with the length of me during which the divergence has been going on. Thus we

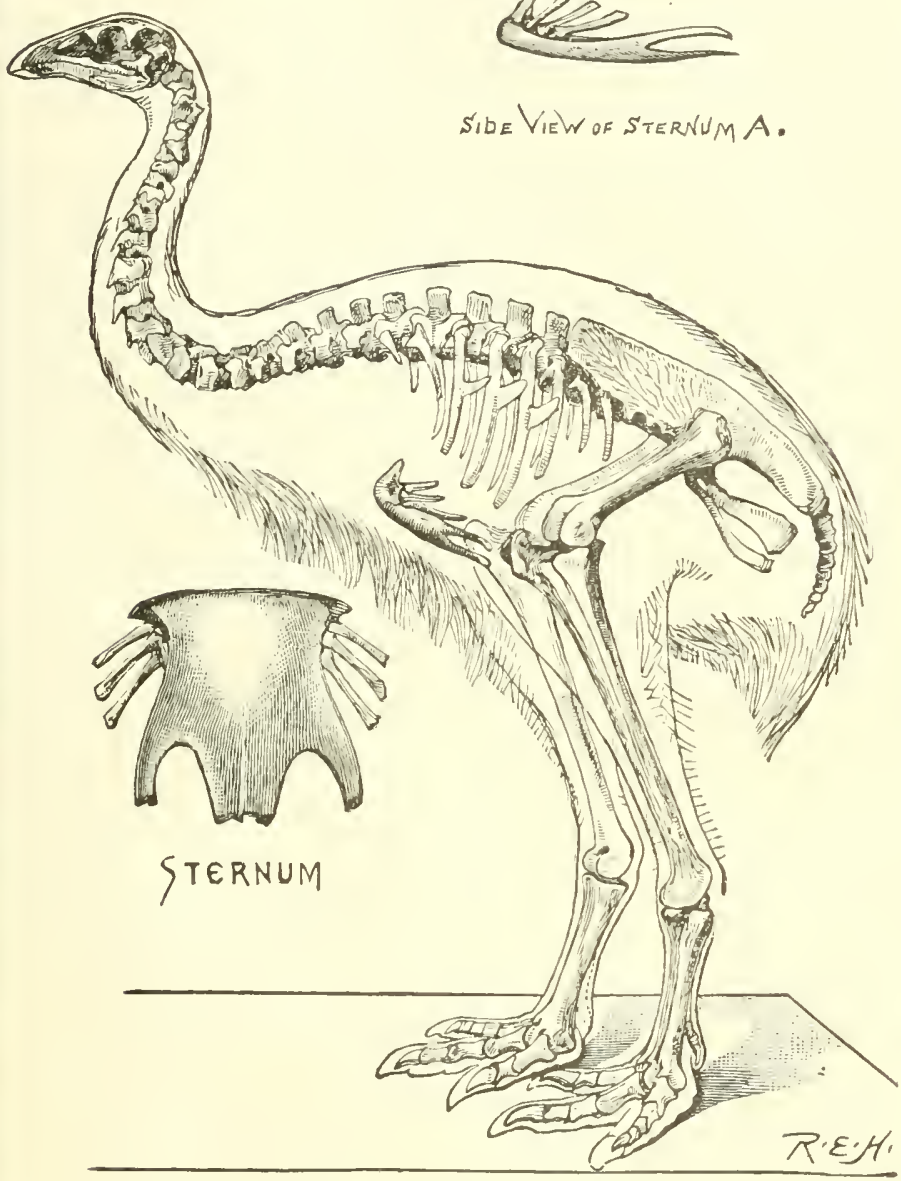

Fig. I5.-Skeleton of Dinornis gravis, $\frac{1}{16}$ nat. size. Drawn from nature British Museum). As separate cuts on a larger scale are shown, (I) the sternum $\mathrm{s}$ this appears in mounted specimens, and (2) the same in profile, with its hypothetical) scapulo-coracoid attached. (From Romanes.)

carcely ever meet with any great departure from the typical form vith respect to one of the organs, without some of the other organs eing so far modified as of themselves to indicate, on the supposition 


\section{I38 READINGS IN EVOLUTION, GENETICS, AND EUGENICS}

of descent with modification that the animal or plant must have been subject to the modifying influences for an enormously long series of generations. And this combined testimony of a number of organs in the same organism is what the theory of descent would lead us to expect, while the rival theory of design can offer no explanation of the fact, that when one organ shows a conspicuous departure from the supposed ideal type, some of the other organs in the same organism should tend to keep it company by doing likewise.

As an illustration both of this and of other points which have been mentioned, I may draw attention to what seems to me a particularly suggestive case. So-called soldier- or hermit-crabs are crabs which have adopted the habit of appropriating the empty shells of mollusks. In association with this peculiar habit, the structure of these animals differs very greatly from that of all other crabs. In particular, the hinder part of the body, which occupies the mollusk-shell, and which therefore has ceased to require any hard covering of its own, has been suffered to lose its calcareous integument, and presents a soft fleshy character, quite unlike that of the most exposed parts of the animal. Moreover, this soft fleshy part of the creature is especially adapted to the particular requirements of the creature by having its lateral appendages - i.e., appendages which in other crustacea perform the function of legs - modified so as to act as claspers to the inside of the mollusk-shell; while the tail-end of the part in question is twisted into the form of a spiral, which fits into the spiral of the mollusk-shell. Now, in Keeling Island there is a large kind of crab called Birgus latro, which lives upon land and there feeds upon cocoa-nuts. The whole structure of this crab, it seems to me, unmistakably resembles the structure of a hermit-crab (Fig. I6). Yet this crab neither lives in the shell of a mollusk, nor is the hinder part of its body in the soft and fleshy condition just described; on the contrary, it is covered with a hard integument like all the other parts of the animal. Consequently, I think we may infer that the ancestors of Birgus were hermit-crabs living in mollusk-shells; but that their descendants gradually relinquished this habit as they gradually became more and more terrestrial, while, concurrently with these changes in habit, the originally soft posterior parts acquired a hard protective covering to take the place of that which was formerly supplied by a mollusk-shell. So that, if so, we now have, within the limits of a single organism evidence of a whole series of morphological changes in the past history of its species. First, there must have been the great change from an 


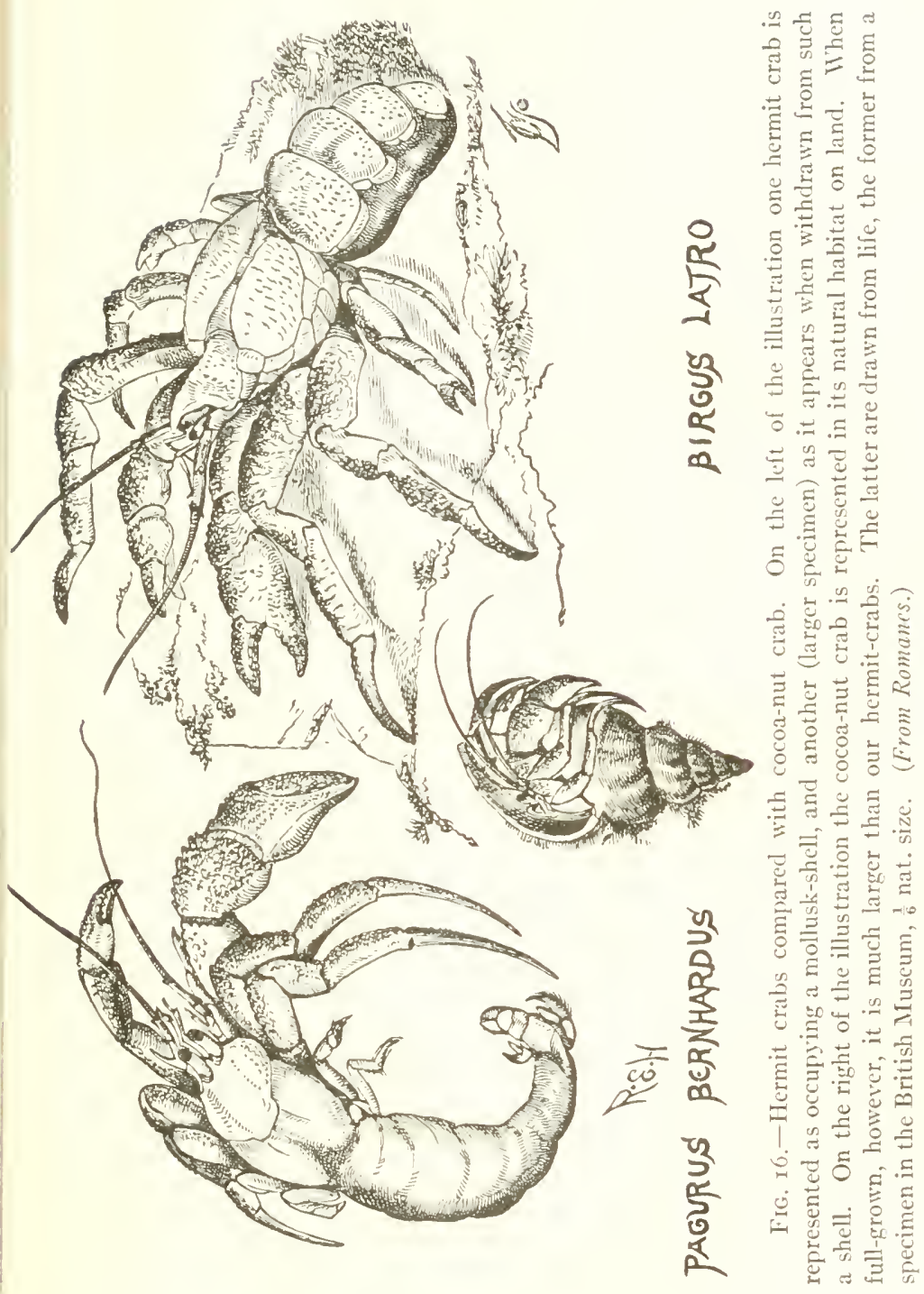


ordinary crab to a hermit-crab in all the respects previously pointed out. Next, there must have been the change back again from a hermit-crab to an ordinary crab, so far as living without the necessity of a mollusk-shell is concerned. From an evolutionary point of view, therefore, we appear to have in the existing structure of Birgus a morphological record of all these changes, and one which gives us a reasonable explanation of why the animal presents the extraordinary appearance which it does. But, on the theory of special creation, it is inexplicable why this land-crab should have been formed on the pattern of a hermit-crab, when it never has need to enter the shell of a mollusk. In other words, its peculiar structure is not especially in keeping with its present habits, although so curiously allied to the similar structure of certain other crabs of totally different habits, in relation to which the peculiarities are of plain and obvious significance.

I will derote the remainder of this chapter to considering another branch of the argument from morphology, to which the case of Birgus serves as a suitable introduction: I mean the argument from rudimentary structures.

Throughout both the animal and vegetable kingdoms we constantly meet with dwarfed and useless representatives of organs, which . in other and allied kinds of animals and plants are of large size and functional utility. Thus, for instance, the unborn whale has rudimentary teeth, which are never destined to cut the gums; and throughout its life this animal retains, in a similarly rudimentary condition, a number of organs which never could have been of use to any kind of creature save a terrestrial quadruped. The whole anatomy of its internal ear, for example, has reference to hearing in air, as Hunter long ago remarked, "is constructed upon the same principle as in the quadruped"; yet, as Owen says, "the outer opening and passage leading therefrom to the tympanum can rarely be affected by sonorous vibrations of the atmosphere, and indeed they are reduced, or have degenerated, to a degree which makes it difficult to conceive how such vibrations can be propagated to the ear-drum during the brief moments in which the opening may be raised above the water."

Now, rudimentary organs of this kind are of such frequent occurrence, that almost every species presents one or more of themusually, indeed, a considerable number. How, then, are they to be accounted for? Of course the theory of descent with adaptive modification has a simple answer to supply-namely, that when, from 
changed conditions of life, an organ which was previously useful becomes useless, it will be suffered to dwindle away in successive generations, under the influence of certain natural causes which we shall have to consider in future chapters. On the other hand, the theory of special creation can only maintain that these rudiments are formed for the sake of adhering to an ideal type. Now, here again the former theory appears to be triumphant over the latter; for, without waiting to dispute the wisdom of making dwarfed and useless structures merely for the whimsical motive assigned, surely if such a

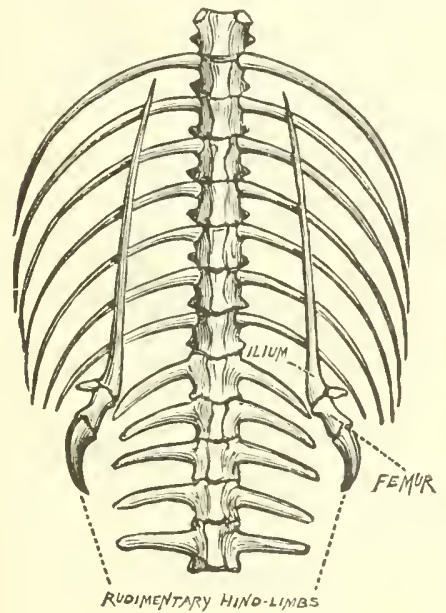

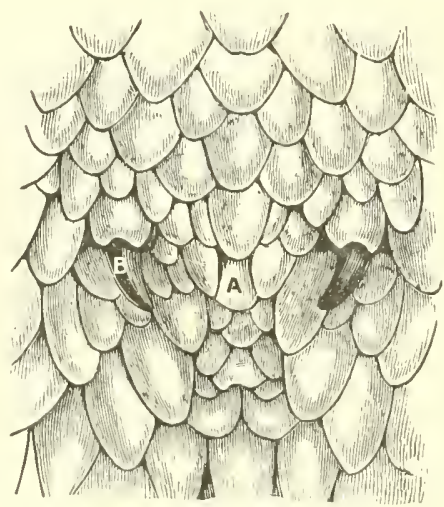

A. VENT,

B. HORNY TERMINATION OF

FIG, I 7.-Rudimentary or vestigial hind limbs of python, as exhibited in the skeleton and on the externai surface of the animal. Drawn from nature, $\frac{1}{4}$ nat. size. (From Romanes.)

method were adopted in so many cases, we should expect that in consistency it would be adopted in all cases. This reasonable expectation, however, is far from being realized. We have already seen that in numberless cases, such as that of the fore-limbs of serpents, no vestige of a rudiment is present. But the vacillating policy in the matter of rudiments does not end here; for it is shown in a still more aggravated form where within the limits of the same natural groups of organisms a rudiment is sometimes present and sometimes absent. For instance, although in nearly all the numerous species of snakes there are no vestiges of limbs, in the Python we find very tiny rudiments of the hind-limbs (Fig. I7). Now, is it a worthy conception of Deity that, while neglecting to maintain his unity of ideal in the case of 
nearly all the numerous species of snakes, he should have addled a tiny rudiment in the case of the Python - and even in that case should have maintained his ideal very inefficiently, inasmuch as only two limbs, instead of four, are represented? How much more reasonable is the naturalistic interpretation; for here the very irregularity of their appearance in different species, which constitutes rudimentary structures one of the crowning difficulties to the theory of special design, furnishes the best possible evidence in favour of hereditary

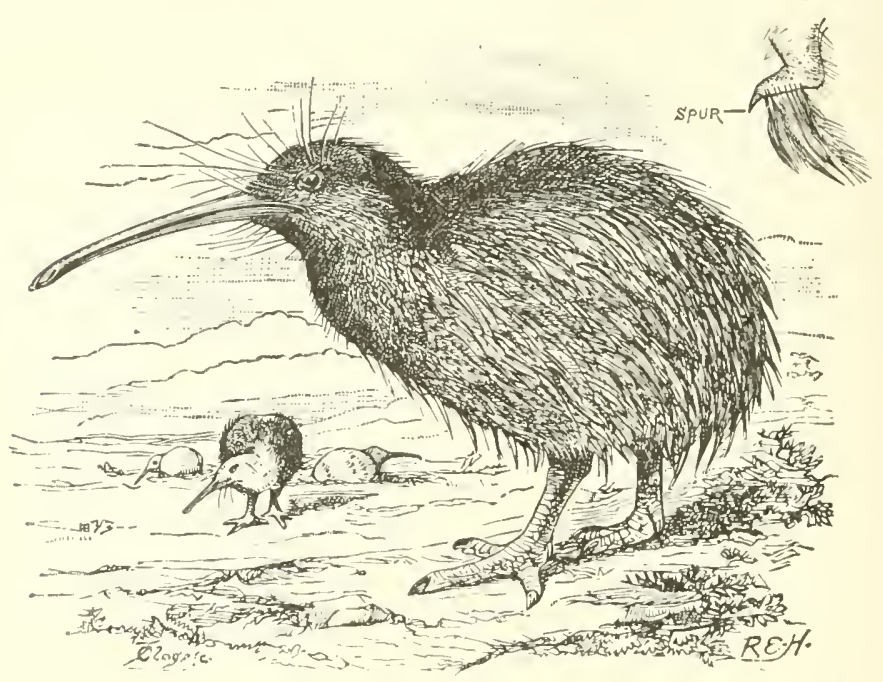

FIG. I8. - Apleryx australis. Drawn from life in the Zoölogical Gardens, $\frac{1}{6}$ nat. size. The external wing is drawn to a scale in the upper part of the cut. The surroundings are supplied from the most recent descriptions. (From Romanes.)

descent; seeing that this irregularity then becomes what may be termed the anticipated expression of progressive dwindling due to inutility. Thus, for example, to return to the case of wings, we have already seen that in an extinct genus of bird, Dinornis, these organs were reduced to such an extent as to leave it still doubtful whether so much as the tiny rudiment hypothetically supplied to Figure I5 was present in all the species. And here is another well-known case of another genus of still existing bird, which, as was the case with Dinornis, occurs only in New Zealand (Fig. I8). Upon this island there are no four-footed enemies-either existing or extinct-to escape from which the wings of birds would be of any service. Conse- 
quently we can understand why on this island we should meet with such a remarkable dwindling away of wings.

Similarly, the logger-headed duck of South America can only flap along the surface of the water, having its wings considerably reduced though less so than the Apteryx of New Zealand. But here the interesting fact is that the young birds are able to fly perfectly well. Now, in accordance with a general law to be considered in a future chapter, the life-history of an individual organism is a kind of condensed recapitulation of the life-history of its species. Consequently, we can understand why the little chickens of the logger-headed duck are able to fly like all other ducks, while their parents are only able to flap along the surface of the water.

Facts analogous to this reduction of wings in birds which have no further use for them, are to be met with also in insects under similar circumstances. Thus, there are on the island of Madeira somewhere between 500 and 600 species of beetles, which are in large part peculiar to that island, though related to other-and therefore presumably parent-species on the neighboring continent. Now, no less than 200 species-or nearly half the whole number-are so far deficient in wings that they cannot fly. And, if we disregard the species which are not peculiar to the island-that is to say, all the species which likewise occur on the neighboring continent, and therefore, as evolutionists conclude, have but recently migrated to the island,-we find this very remarkable proportion. There are altogether 29 peculiar genera, and out of these no less than 23 have all their species in this condition.

Similar facts have been recently observed by the Rev. A. E. Eaton with respect to insects inhabiting Kerguelen Island. All the species which he found on the island-viz., a moth, several flies, and numerous beetles - he found to be incapable of flight; and therefore, as Wallace observes, "as these insects could hardly have reached the islands in a wingless state, even if there were any other known land inhabited by them, which there is not, we must assume that, like the Madeiran insects, they were originally winged, and lost their power of flight because its possession was injurious to them"-Kerguelen Island being "one of the stormiest places on the globe," and therefore a place where insects could rarely afford to fly without incurring the danger of being blown out to sea.

Here is another and perhaps an even more suggestive class of facts. 
It is now many years ago since the editors of Silliman's Journal requested the late Professor Agassiz to give them his opinion on the following question. In a certain clark subterranean cave, called the Mammoth Cave, there are found some peculiar species of blind fishes. Now the editors of Silliman's Journal wished to know whether Professor Agassiz would hold that these fish had been specially created in these caves, and purposely devoided of eyes which could never be of any use to them; or whether he would allow that these fish had probably descended from other species, but, having got into the dark cave, gradually lost their eyes through disuse. Professor Agassiz, who was a believer in special creation, allowed that this ought to constitute a crucial test as between the two theories of special design and hereditary descent. "If physical circumstances," he said, "ever modified organised human beings, it should be easily ascertained here." And eventually he gave it as his opinion, that these fish "were created under the circumstances in which they now live, within the limits oved which they now range, and with the structural peculiarities which now characterise them."

Since then a great deal of attention has been paid to the fauna of this Mammoth care, and also to the faunas of other dark caverns, not only in the New, but also in the Old World. In the result, the following general facts have been fully established.

I. Not only fish, but many representatives of other classes, have been found in dark caves.

2. Wherever the caves are totally dark, all the animals are blind.

3. If the animals live near enough to the entrance to receive some degree of light, they may have large and lustrous eyes.

4. In all cases the species of blind animals are closely allied to species inhabiting the district where the caves occur; so that the b)ind species inhabiting the American caves are closely allied to American species, while those inhabiting European caves are closely allied to European species.

5. In nearly all cases structural remnants of eyes admit of being detected, in various degrees of obsolescence. In the case of some of the crustaceans of the Mammoth cave the foot-stalks of the eyes are present, although the eyes themselves are entirely absent.

Now, it is evident that all these general facts are in full agreement with the theory of crolution, while they offer serious difficulties to the theory of special creation. As Darwin remarks, it is hard to imagine conditions of life more similar than those furnished by deep 
limestone caverns under nearly the same climate in the two continents of America and Europe; so that, in accordance with the theory of special creation, very close similarity in the organizations of the two sets of faunas might have been expected. But, instead of this, the affinities of these two sets of famas are with those of their respective continents - as of course they ought to be on the theory of evolution. Again, what rould have been the sense of creating the useless footstalks for the imaginary support of absent eyes, not to mention all the other various grades of degeneration in other cases? So that, upon the whole, if we agree with the late Professor Agassiz in regarding these cave animals as furnishing a crucial test between the rival theories of creation and evolution, we must further conclude that the whole body of evidence which they now furnish is weighing on the side of evolution.

So much, then, for a few special instances of what Darwin called rudimentary structures, but what may be more descriptively designated-in accordance with the theory of descent-obsolescent or restigial structures. It is, however, of great importance to add that these structures are of such general occurrence throughout both the vegetable and animal kingdoms that, as Darwin has observed, it is almost impossible to point to a single species which does not present one or more of them. In other words, it is almost impossible to find a single species which does not in this way bear some record of its own descent from other species; and the more closely the structure of any specics is exanined anatomically, the more numerous are such records found to be. Thus, for example, of all organisms that of man has been n:os! miutely investigated by anatomists; and therefore I think it will be instructive to conclude this chapter by giving a list of the more nolewortiy vestigial structures which are known to occur in the htunan borty. I will take only those which are found in adult man, reserving for the next chapter those which occur in a transitory manner during carlier periods of his life. But, even as thus restricted, the number of obsolescent structures which we all present in our own persor is so remarkable, that their combined testimony to our descent from \& fialurumanous ancestry appears to me in itself conclusive. I mean, thit even if these structures stood alone, or apart from any more geineral eviclences of our family relationships, they would be sufficient to prove our parentage. Nevertheless, it is desirable to remark that of course these special evidences which I am about to detail do not stand alone. Not only is there the general analogy 


\section{I46 READINGS IN EVOLUTION, GENETICS, AND EUGENICS}

furnished by the general proof of evolution elsewhere, but there is likewise the more special correspondence between the whole of our anatomy and that of our nearest zoölogical allies. Now the force of this latter consideration is so enormous that no one who has not studied human anatomy can be in a position to appreciate it. For without special study it is impossible to form any adequate idea of the intricacy of structure which is presented by the human form. Yet it is found that this enormously intricate organisation is repeated in all its details in the bodies of the higher apes. There is no bone, muscle, nerve, or vessel of any importance in the one which is not answered to by the other. Hence there are hundreds of thousands of instances of the most detailed correspondence, without there being any instances to the contrary, if we pay due regard to vestigial characters. 'The entire corporeal structure of man is an exact anatomical copy of that which we find in the ape.

My object, then, here is to limit attention to those features of our corporcal structure which, having become useless on account of our change in attitude and habits, are in the process of becoming obsolete, and therefore occur as mere vestigial records of a former state of things. For example, throughout the vertebrated series, from fish to mammals, there occurs in the inner corner of the eye a semitransparent eyc-lid, which is called the nictitating membrane. The object of this structure is to sweep rapidly, every now and then, over the external surface of the eye, apparently in order to keep the surface clean. But although the membrane occurs in all classes of the sub-kingdom, it is more prevalent in some than in others-e.g., 1 in birds than in mammals. Even, however, where it does not occur of a size and mobility to be of any use, it is usually represented, in animals above fishes, by a functionless rudiment, as here depicted in the case of man (Fig. I9).

Now the organisation of man presents so many vestigial structures thus referring to various stages of his long ancestral history, that it would be tedious so much as to enumerate them. Therefore I will yet further limit the list of vestigial structures to be given as examples, by not only restricting these to cases which occur in our own organisation; but of them I shall mention only such as refer us to the very last stage of our ancestral history-viz., structures which have become obsolescent since the time when our distinctively human branch of the family tree diverged from that of our immediate forcfathers, the Quadrumana. 


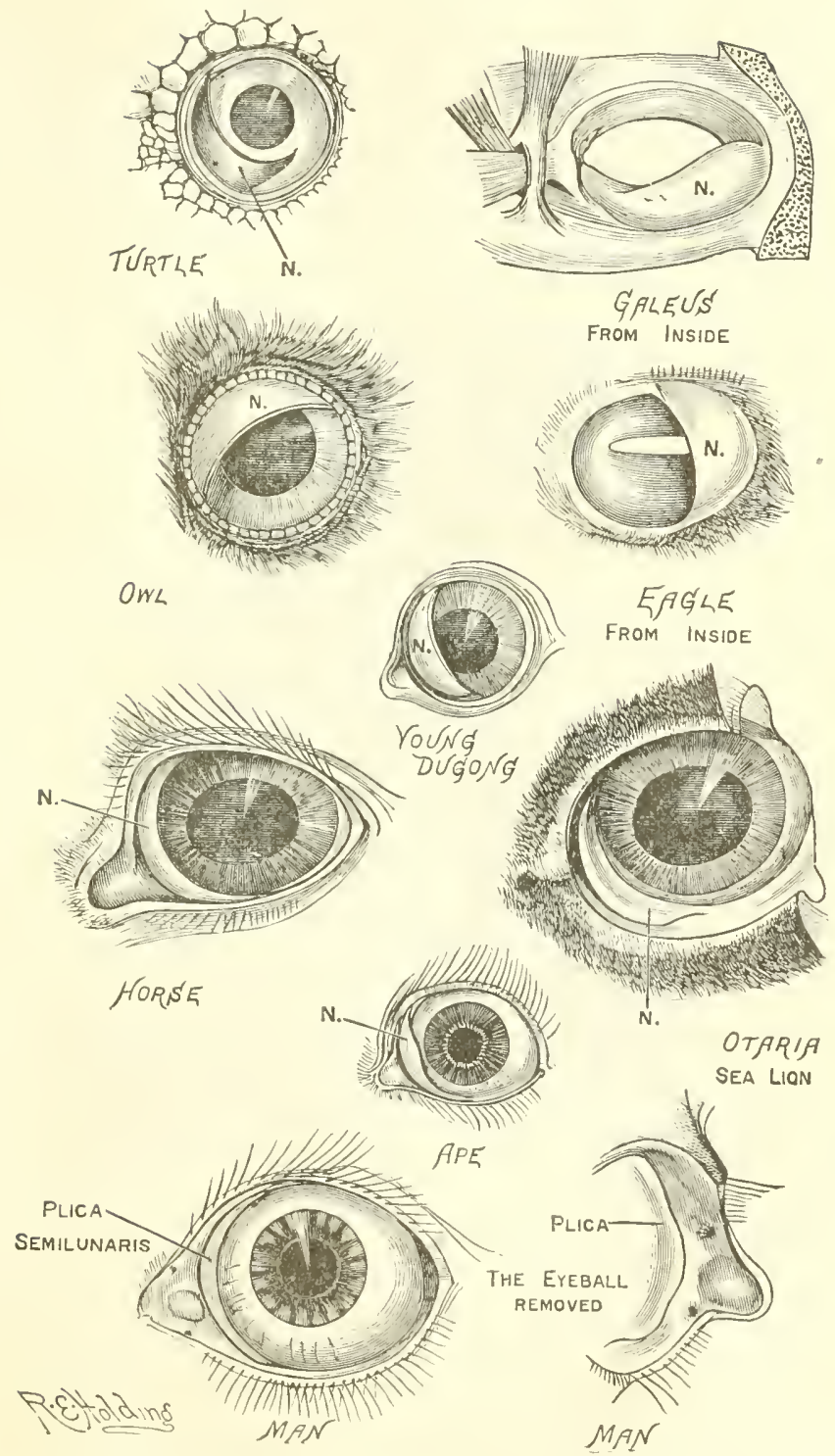

FIG. I9.-Illustrations of the nictitating membrane in the various animals named, drawn from nature. The letter $N$ indicates the membrane in each case. In man it is called the plica scmilunaris and is represented in the two lower drawings : under this name. In the case of the shark (Galeus), the muscular membrane is shown as dissected. (From Romanes.) 


\section{I48 READINGS IN EVOLUTION, GENETICS, AND EUGENICS}

I. Muscles of the external ear.- These, which are of large size and functional use in quadrupeds, we retain in a dwindled and useless condition (Fig. 20). This is likewise the case in anthropoid apes; but in not a few other Quadrumana (e.g., baboons, macacus, magots, etc.) degeneration has not proceeded so far, and the ears are voluntarily movable.

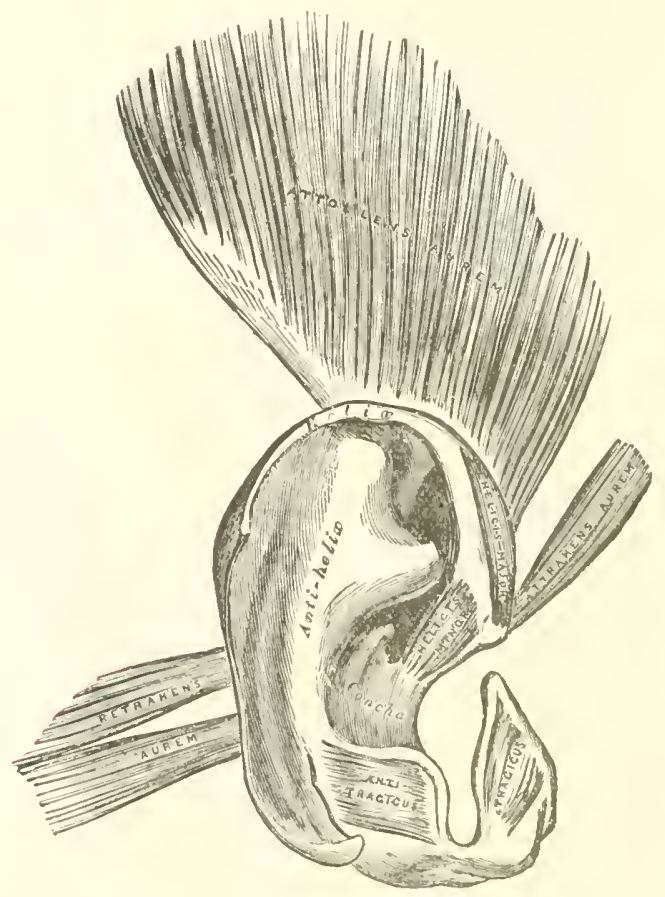

F1. 20.--Rudimentary, or vestigial and uscless, muscles of the human car. (From Romanes, afler Gray.)

2. Panniculus carnosis. $-A$ large number of the mammalia are able to moxe their skin by means of subcutaneous muscle, as we see, for instance, in a horse, when thus protecting himself against the sucking of flies. We, in common with the Quadrumana, possess an active remnant of such a muscle in the skin of the forehead, whereby we draw up the eyebrows; but we are no longer able to use other considerable remnants of it, in the scalp and elsewhere,-or more correctly it is rarely that we meet with persons who can. But most of the Quadrumana (including the anthropoids) are still able to do so. 
There are also many other vestigial muscles, which occur only in a small percentage of human beings, but which, when they do occur, present unmistakable homologies with normal muscles in some of the Quadrumana and still lower animals.

3. Feet.-It is observable that in the infant the feet have a strong reflection inwards, so that the soles in considerable measure face one another. This peculiarity, which is even more marked in the embryo than in the infant, and which becomes gradually less and

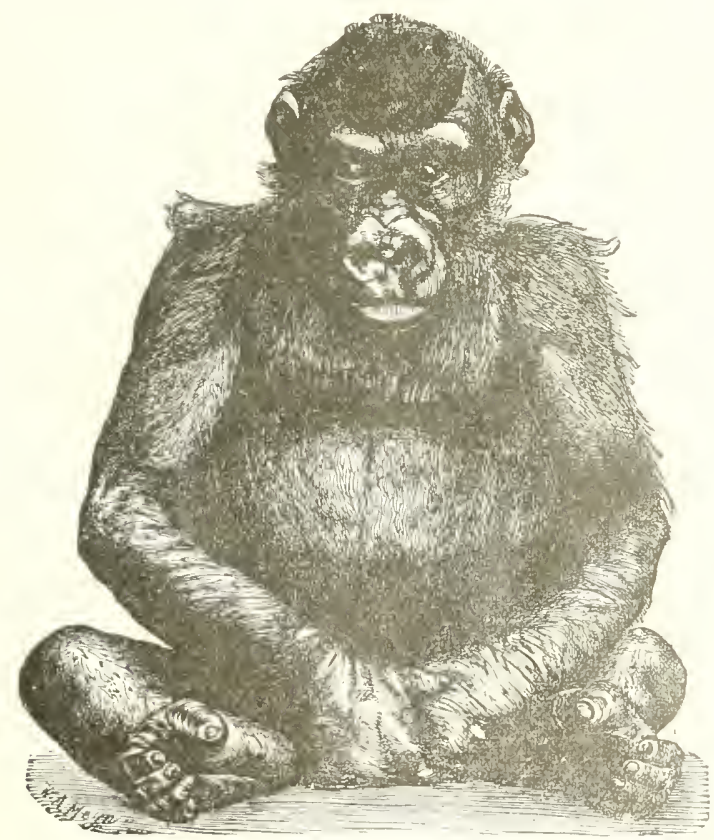

FIg. 21,-Portrait of a young gorilla. (From Romanes, after IIartmann.)

less conspicuous even before the child begins to walk, appears to me a highly suggestive peculiarity. For it plainly refers to the condition of things in the Quadrumana, seeing that in all these animals the feet are similarly curved inwards, to facilitate the grasping of branches. And even when walking on the ground apes and monkeys employ to a great extent the outside edges of their feet, as does also a child when learning to walk. The feet of a young child are also extraordinarily mobile in all directions, as are those of apes. In order to show these points, I here introduce comparative drawings of a young ape and the 
lower extremities of a still younger child. These drawings, moreover, serve at the same time to illustrate two other vestigial characters, which have often been previously noticed with regard to the infant's foot. I allude to the incurved form of the legs and the lateral extension of the great toe, whereby it approaches the thumb-like character of this organ in the Quadrumana. As in the case of the incurved position of the legs and feet, so in this case of the lateral extensibility of the great toc, the peculiarity is even more marked in embryonic

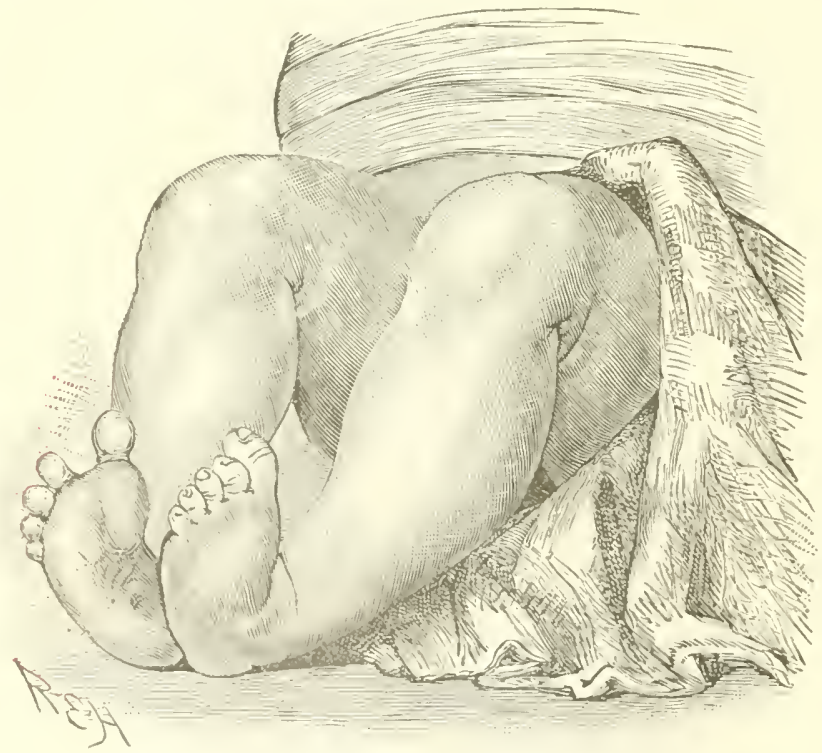

FIG. 22.-Lower extremities of a young child. Drawn from life, when the mobile feet were for a short time at rest in a position of extreme inflection. (From Romanes.)

than in infant life. For, as Professor Wyman has remarked with regard to the foctus when about an inch in length, "The great toe is shorter than the others; and, instead of being parallel to them, is projected at an angle from the side of the foot, thus corresponding with the permanent condition of this part in the Quadrumana." So that this organ, which, according to Owen, "is perhaps the most characteristic peculiarity of the human structure, "when traced back to the early stages of its development, is found to present a notably less degree of peculiarity. 
4. Hands.-Dr. Louis Robinson has recently observed that the grasping power of the whole human hand is so surprisingly great at birth, and during the first few weeks of infancy, as to be far in excess of present requirements on the part of a young child. Hence he concludes that it refers us to our quadrumanous ancestry-the young of anthropoid apes being endowed with similar powers of grasping, in order to hold on to the hair of the mother when she is using her arms for the purposes of locomotion. This inference appears to me justifiable,

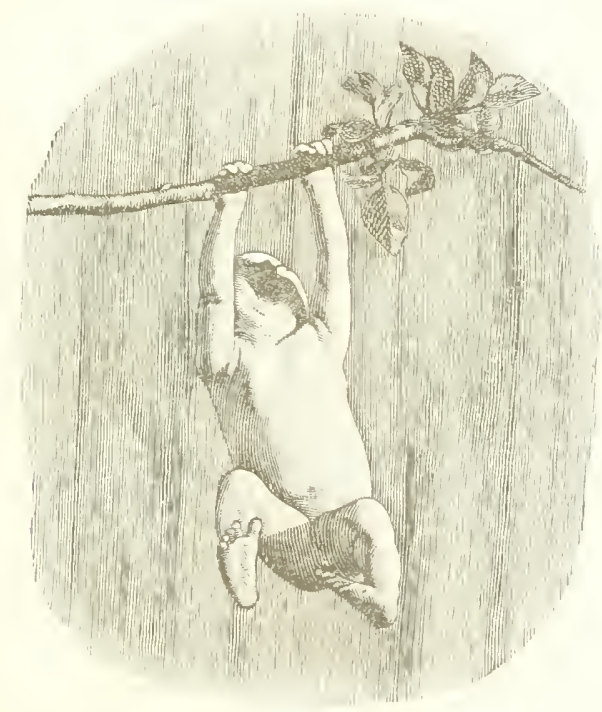

Fig. 23.- An infant, three weeks old, supporting its own weight for over two minutes. The attitude of the lomer limbs, feet, toes, is strikingly simian. Reproduced from an instantaneous photograph, kindly given for the purpose by Dr. L. Robinson. (From Romanes.)

inasmuch as no other explanation can be given of the comparatively inordinate muscular force of an infant's grip. For experiments showed that very young babies are able to support their own weight, by holding on to a horizontal bar, for a period varying from one half to more than two minutes. With his kind permission, I here reproduce one of Dr. Robinson's instantaneous, and hitherto unpublished, photographs of a very young infant. This photograph was taken after the above paragraph (3) was written, and I introduce it here because it serves to show incidentally-and perhaps even better than the preceding figure-the points there mentioned with regard 
to the feet and great toes. Again, as Dr. Robinson observes, the attitude, and the disproportionately large development of the arms as compared with the legs give all the photographs a striking resemblance to a picture of the chimpanzee "Sally" at the Zoölogical Gardens. For "invariably the thighs are bent nearly at right angles to the body, and in no case did the lower limbs hang down and take the attitude of the erect position." He adds, "In many cases no sign of distress is evinced, and no cry uttered, until the grasp begins to give way."
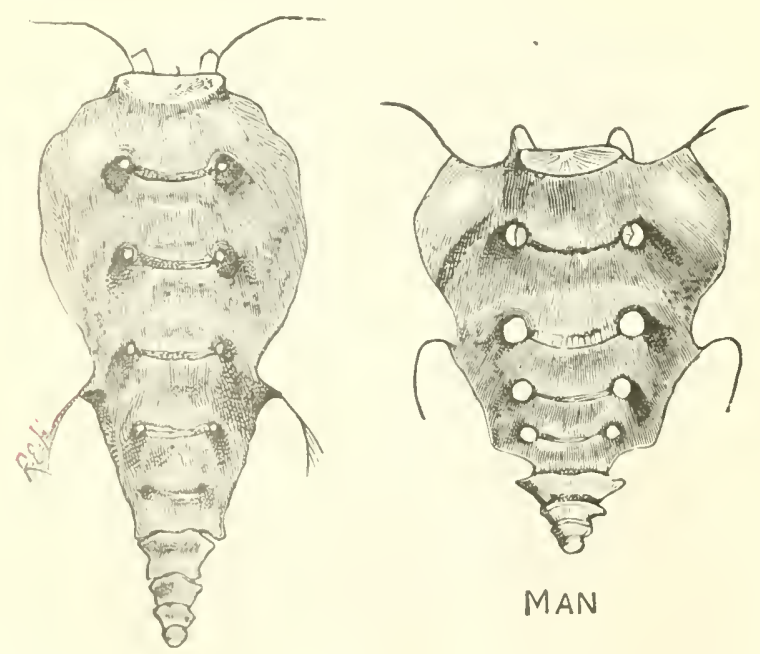

MAN

GORILLA

FIr. 24.- Sacrum of gorilla compared with that of man, showing rudimentary tail bones of each. I)rawn from nature. (From Romanes.)

5. Tail.-The alsence of a tail in man is popularly supposed to constitute a difficulty against the doctrine of his quadrumanous descent. As a matter of fact, however, the absence of an external tail in man is precisely what this doctrine would expect, seeing that the nearest allies of man in the quadrumanous series are likewise destitute of an external tail. Far, then, from this deficiency in man constituting any difliculty to be accounted for, if the case were not so-i.e., if man did possess an external tail,- the difficulty would be to understand how he had managed to retain an organ which had been renounced by his most recent ancestors. Nevertheless, as the anthro- 
poid apes continue to present the rudimentary vestiges of a tail in a few caudal vertebrae below the integuments, we might well expect to find a similar state of matters in the case of man. And this is just

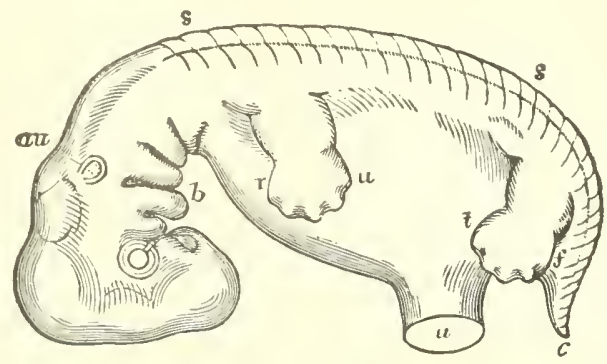

Fig. 25.-Diagrammatic outline of the human embryo when about seven weeks old, showing the relations of the limbs and tail to the trunk. (After Allen Thompson.) $r$, the radial, and $u$, the ulnar, border of the hand and forearm; $t$, the tibial, and $f$ the fibular, border of the foot and lower leg; $a u$, ear; $s$, spinal cord; $v$, umbilical cord; $b$, bronchial gill slits; $c$, tail. (From Romanes.)
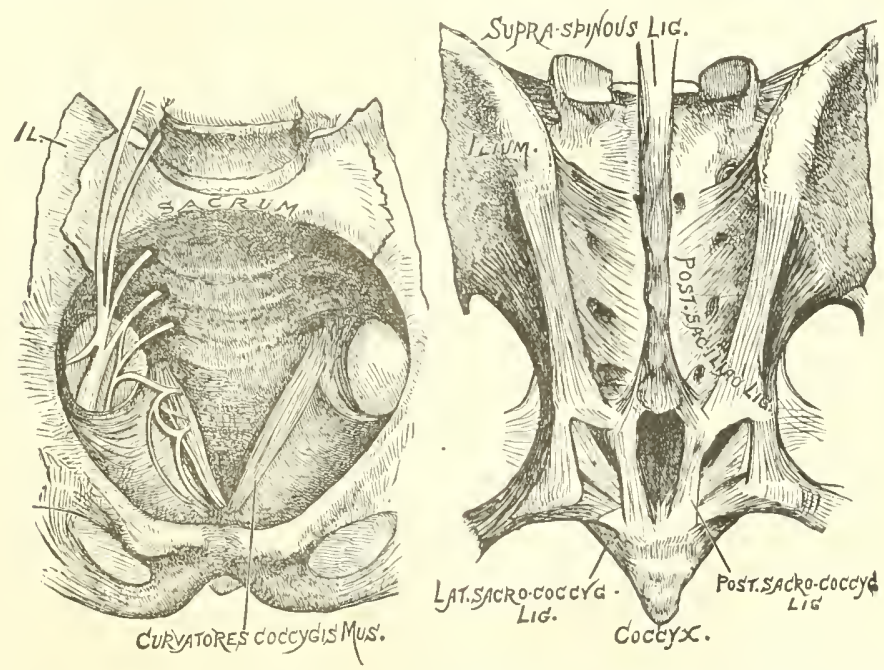

Fig. 26.-Front and back view of arlult human sacrum, showing abnormal persistence of vestigial tail muscles. (From Romanes.)

what we do find, as a glance at these two comparative illustrations will show (Fig. 24). Moreover, during embryonic life, both of the anthropoid apes and of man, the tail much more closely resembles 


\section{I54 READINGS IN EVOLUTION, GENETICS, AND EUGENICS}

that of the lower kinds of quadrumanous animals from which these higher representatives of the group have descended. For at a certain stage of embryonic life the tail, both of apes and of human beings, is
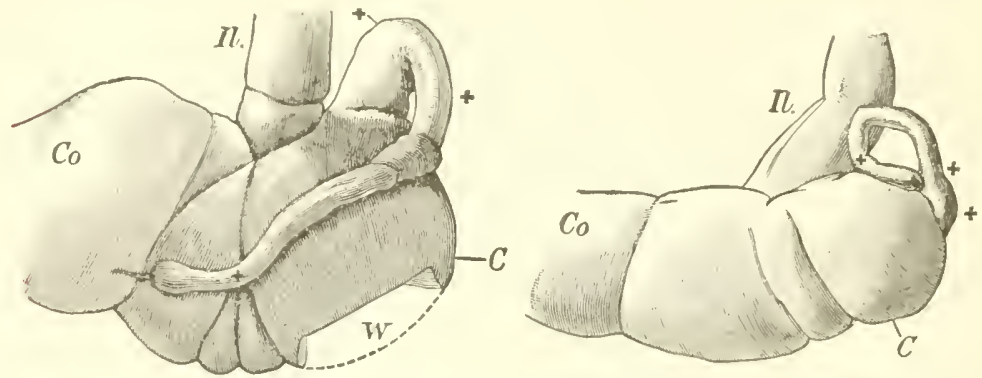

FIG. 27.-Appendix vermiformis in orang and in man. $I l$, ilium; Co, colon; $C$, coecum; W, a window cut in the wall of the coecum; $x x x$, the appendix. (From Romancs.)

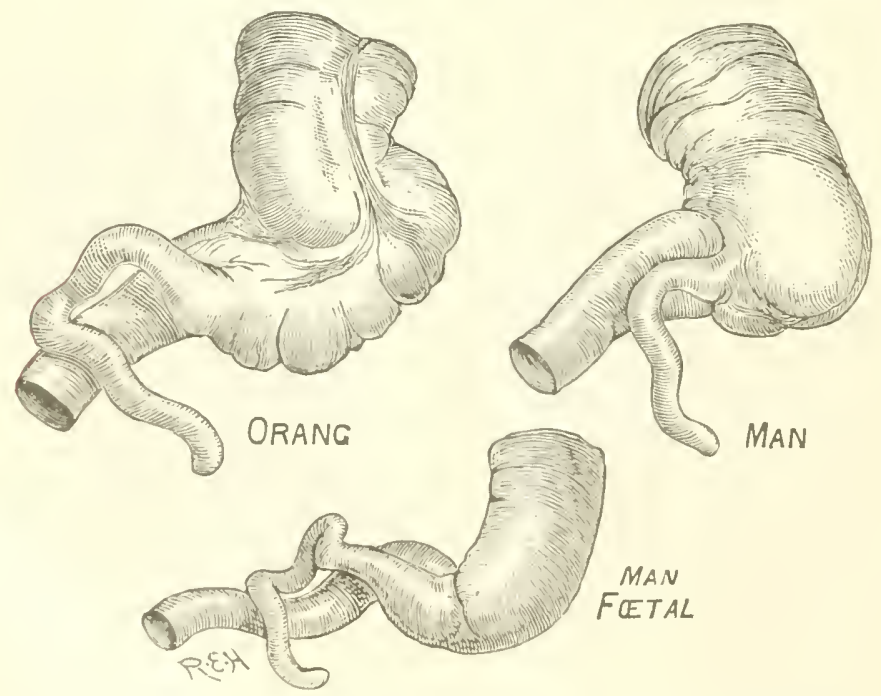

FIG. 28.--The same, showing variation in the orang. (From Romanes.)

actually longer than the legs (see Fig. 25). And at this stage of development, also, the tail admits of being moved by muscles which later on dwindle away. Occasionally, however, these muscles persist, and are then described by anatomists as abnormalities. The illustra- 
tions on page 153 (Fig. 26) serve to show the muscles in question, when thus found in adult man.

6. Vermiform appendix of the coecum.-This is of large size and functional use in the process of digestion among many herbivorous animals; while in man it is not only too small to serve any such purpose, but is even a source of danger to life-many persons dying every year from inflammation set up by the lodgement in this blind tube of fruit-stones, etc.

In the orang it is longer than in man (Fig. 27), as it is also in the human foetus proportionally compared with the adult (Fig. 28). In some of the lower herbivorous animals it is longer than the entire body.

Like the vestigial structures in general, however, this one is highly variable. Thus Figure $2 S$ serves to show that it may sometimes be almost as short in the orang as it normally is in man-both the human subjects of this illustration having been normal.

7. Ear.-Mr. Darwin writes:

"The celebrated sculptor, Mr. Woolner, informs me of one little peculiarity in the extemal ear, which he has often observed both in men and women.... The peculiarity consists in a little blunt point, projecting from the inwardly folded margin, or helix. When present, it is developed at birth, and according to Professor Ludwig Meycr, more frequent iy man than in woman. Mr. Woolner made an exact model of one such case, and sent me the accompanying drawing [Fig. 29]. . . . The helix obviously consists of the extreme margin of the ear folded inwards; and the folding appears to be in some manner connected with the whole external ear being permanently pressed backwards. In many monkeys, which do not stand high in the order as baboons and some species of macacus, the upper portion of the ear is slightly pointed, and the margin is not at all folded inwards; but if the margin were to be thus folded, a slight point would necessarily project towards the centre. . . In Figure 30 is shown an accurate copy of a photograph

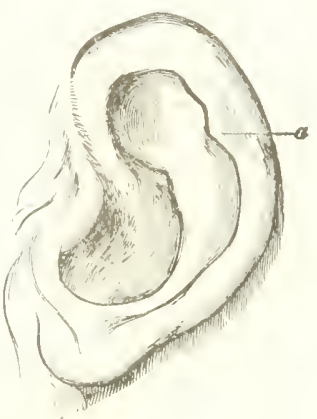

FIG. 29.-Human ear, modeled and drawn by Mr. Woolner. $a$, the projecting point. (From Romanes.) of the foetus of an orang (kindly sent me by Dr. Nitsche), in which it may be seen how different the pointed outline of the ear is at this period from its adult condition, when it bears a close general 
resemblance to that of man (including even the occasional appearance of the projecting point shown in the preceding woodcut). It is

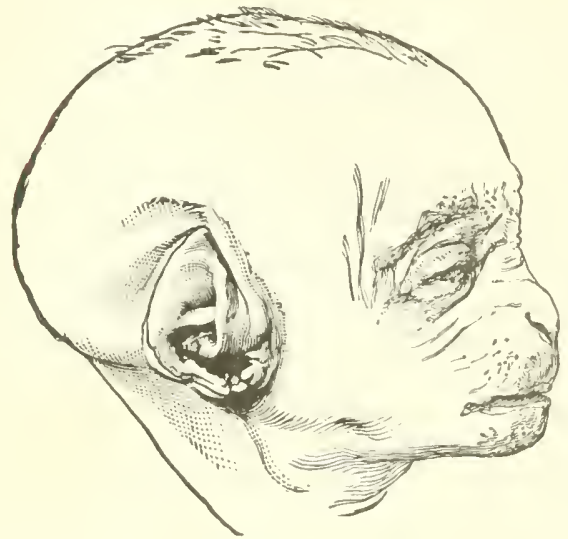

FIG. 30.-Foetus of an orang. Exact copy of a photograph, showing the form of ear at this early stage. (From Romanes.) evident that the folding over of the tip of such an ear, unless it is changed greatly during its further development, would give rise to a point projecting inwards."

The woodcut on page 57 (Fig. 3I) serves still further to show vestigial resemblances between the human ear and that of apes. The last two figures illustrate the general resemblance between the normal car of foetal man and the ear of an adult orangoutang. The other two figures on the lower line are intended to exhilbit occasional modifications of the adult human ear, which approximate simian characters somewhat more closely than does the normal type. It will be observed that in their comparatively small lobes these ears resemble those of all the apes; and that while the outer margin of one is not unlike that of the Barbary ape, the outer margin of the other follows those of the chimpanzee and orang. Of course it would be easy to select individual human ears which present cither of these characters in a more pronounced degree; but these ears have been chosen as models because they present both characters in conjunction. The upper row of figures likewise shows the close similarity of hair-tracts, and the direction of growth on the part of the hair itself, in cases where the human hair happens to be of an abnormally hirsute character. But this particular instance (which I do not think has been previously noticed) introduces us to the subject of hair, and hair-growth, in general.

8. Hair.-Adult man presents ruclimentary hairs over most parts of the body. Wallace has sought to draw a refined distinction between this vestigial coating and the useful coating of quadrumanous animals, in the absence of the former from the human back. But even

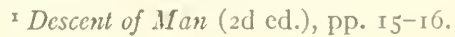




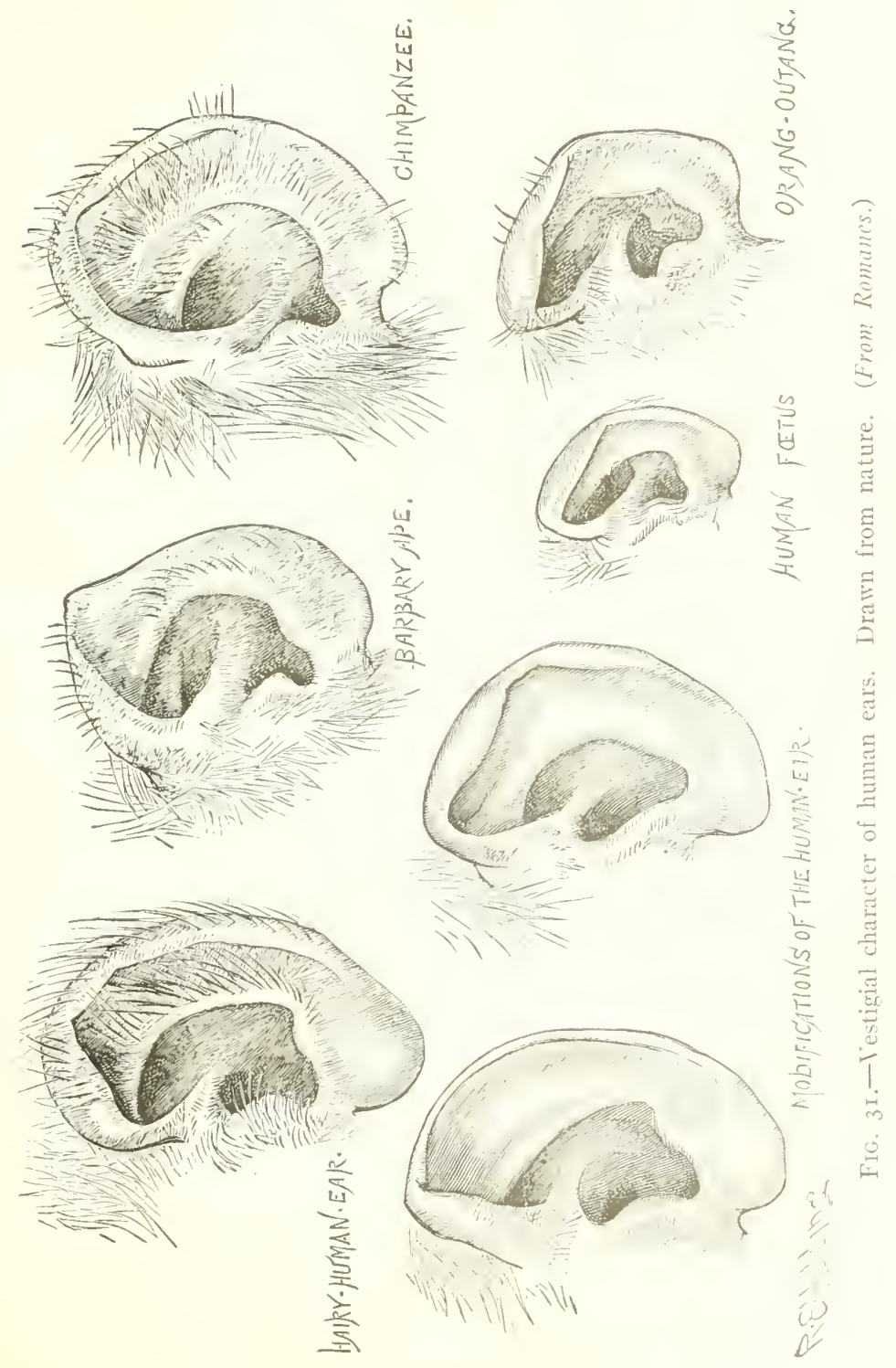




\section{I5S READINGS IN EVOLUTION, GENETICS, AND EUGENICS}

this refined distinction does not hold. On the one hand, the comparatively hairless chimpanzee which died last year in the Zoölogical Gardens ( $T$. calvus) was remarkably denuded over the back; and, on the other hand, men who present a considerable development of hair over the rest of their bodics present it also on their backs and shoulders. Again, in all men the rudimentary hair on the upper and !n:-:ar arm is directed towards the elbow-a peculiarity which occurs nowhere else in the animal kingdom, with the exception of the anthropoid apes and a few American monkeys, where it presumably has to do with arboreal habits. For, when sitting in trees, the orang, as obscrved by Mr. Wallace, places its hands above its head with its elbows pointing downwards; the disposition of hair on the arms and fore-arms then has the effect of thatch in turning the rain. Again, I find that in all species of apes, monkeys, and baboons which I have examined (and they have been numerous), the hair on the backs of the hands and feet is continued as far as the first row of phalanges; but becomes scanty, or disappears altogether, on the second row; while it is invariably absent on the terminal row. I also find that the same peculiarity occurs in man. We all have rudimentary hair on the first row of phalanges, both of hands and feet: when present at all, it is more scanty on the second row; and in no case have I been able to find any on the terminal row. In all cases these peculiarities are congenital, and the total absence or partial presence of hair on the second phalanges is constant in different species of Quadrumana. For instance, it is entirely absent in all the chimpanzees, which I have examined, while scantily present in all the orangs. As in man, it occurs in a patch midway between the joints.

Besides showing these two features with regard to disposition of hair on the human arm and hand, the woodcut on page 159 (Fig.32) illustrates a third. By looking closely at the arm of the very hairy man from whom the drawing was taken, it could be seen that there was a strong tendency towards a whorled arrangement of the hairs on the backs of the wrists. This is likewise, as a general rule, a marked feature in the arrangement of hair on the same places in the gorilla, orang, and chimpanzee. In the specimen of the latter, however, from which the drawing was taken this characteristic was not well marked. The downward direction of the hair on the backs of the hands is exactly the same in man as it is in all the anthropoid apes. Again, with regard to hair, Darwin notices that occasionally there appears in man a few hairs in the eyebrows much longer than the others; and that they seem to be 


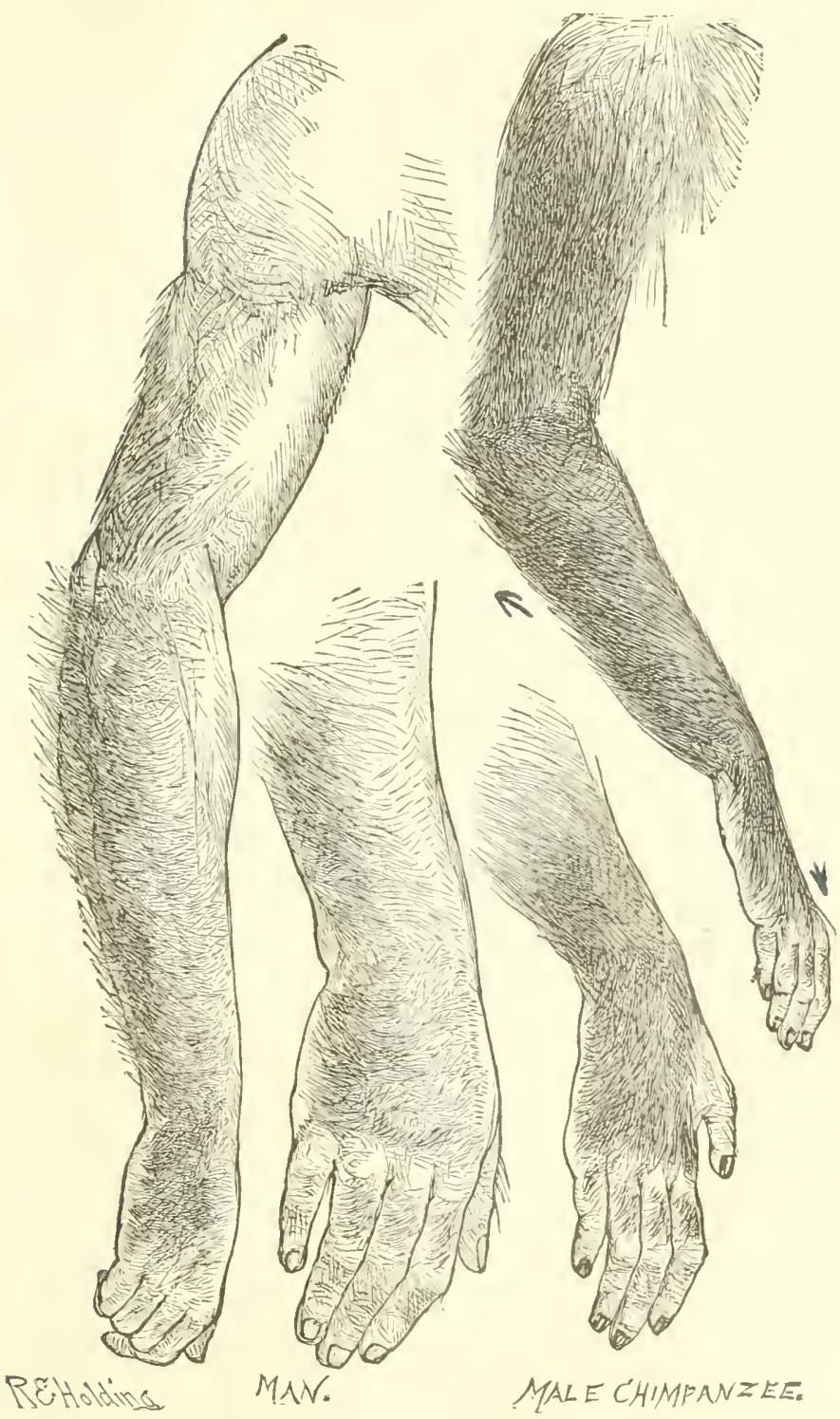

FIG. 32.-Hair tracts on the arms and hands of man, as compared with those of the chimpanzee. Drawn from life. (From Romanes.) 
representative of similarly long and scattered hairs which occur in the chimpanzee, macacus, and baboons.

Lastly, it may be here more conveniently observed than in the next chapter on Embryology, that at about the sixth month the human foetus is often thickly coated with somewhat long dark hair over the entire body, except the soles of the feet and palms of the hands, which are likewise bare in all quadrumanous animals. This covering, which is called the lanugo, and sometimes extends even to the whole forehead, ears, and face, is shed before birth. So that it appears to be useless for any purpose other than that of emphatically declaring man a child of the monkey.

9. Teeth.-Darwin writes:

"It appears as if the posterior molar or wisdom teeth were tending to become rudimentary in the more civilized races of man. These teeth are rather smaller than the other molars, as is likewise the case with the corresponding teeth in the chimpanzee and orang; and they have only two separate fangs. .... They are also much more liable to vary, both in structure and in the period of their development, than the other teeth. In the Melanian races, on the other hand, the wisdom-teeth are usually furnished with three separate fangs, and are usually sound (i.e., not specially liable to decay); they also differ from the other molars in size, less than in the Caucasian races."

Now, in addition to these there are other respects in which the dwindling condition of wisdom-teeth is manifested-particularly with regard to the pattern of their crowns. Indeed, in this respect it would seem that even in the anthropoid apes there is the beginning of a tendency to degeneration of the molar teeth from behind forwards. For if we compare the three molars in the lower jaw of the gorilla, orang, and chimpanzee, we find that the gorilla has five well-marked cusps on all three of them; but that in the orang the cusps are not so pronounced, while in the chimpanzee there are only four of them on the third molar. Now in man it is only the first of these three teeth which normally presents five cusps, both the others presenting only four. So that, comparing all these genera together, it appears that the number of cusps is being reduced from behind forwards; the chimpanzee having lost one of them from the third molar, while man has not only lost this, but also one from the second molar,--and it may be added, likewise partially (or even totally) from the first molar, as a frequent variation among civilized races. But, on the other hand, variations are often met with in the opposite direction, where the 
second or the third molar of man presents five cusps--in the one case following the chimpanzee, in the other the gorilla. These latter variations, therefore, may fairly be regarded as reversionary. For these facts I am indebted to the kindness of Mr. C. S. Tomes.

Io. Perforations of the humerus.-The peculiarities which we have to notice under this heading are two in number. First, the supra-condyloid foramen is a normal feature in some of the lower Quadrumana (Fig. 34), where it gives passage to the great nerve of
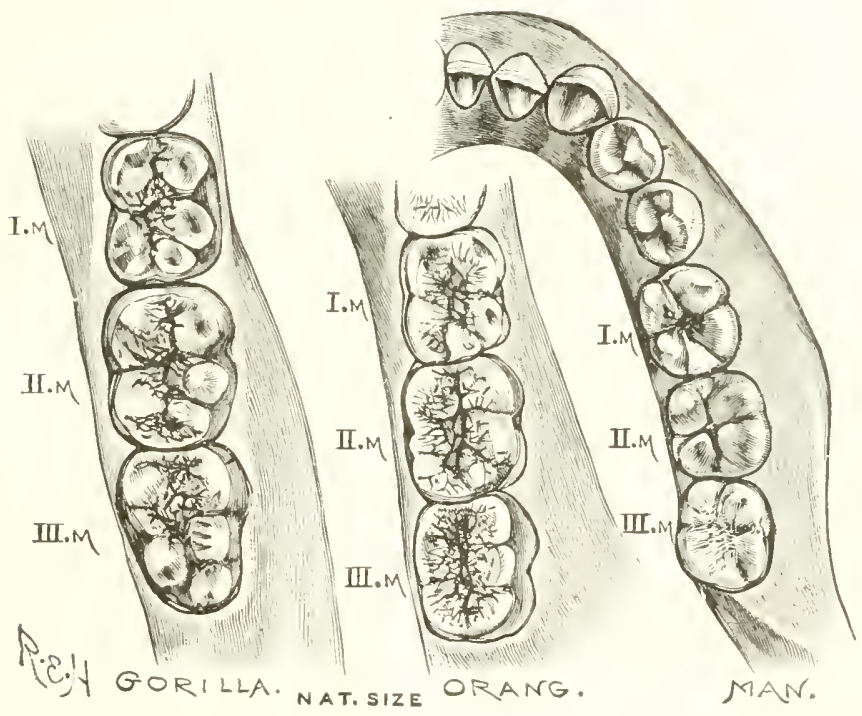

Fig. 33.-Molar teeth of lower jaw in gorilla, orang, and man. Drawn from nature, nat. size. (From Romanes.)

the forearm, and often also to the great artery. In man, however, it is not a normal feature. Yet it occurs in a small percentage of cases-viz., according to Sir W. Turner, in about one per cent, and therefore is regarded by Darwin as a vestigial character. Secondly, there is inter-condyloid foramen, which is also situated near the lower end of the humerus, but more in the middle of the bone. This occurs, but not constantly, in apes, and also in the human species. From the fact that it does so much more frequently in the bones of ancient - and also of some savage - races of mankind (viz. in 20 to 30 per cent of cases), Darwin is disposed to regard it also as a vestigial feature. 
On the other hand, Prof. Flower tells me that in his opinion it is but an expression of impoverished nutrition during the growth of the bone.

II. Flattening of Tibia.-In some very ancient human skeletons there has also been found a lateral flattening of the tibia, which rarely occurs in any existing human beings, but which appears to have been usual among the earliest races of mankind hitherto discovered. According to Broca, the measurements of these fossil human tibiae resemble those of apes. Moreover, the bone is bent and strongly

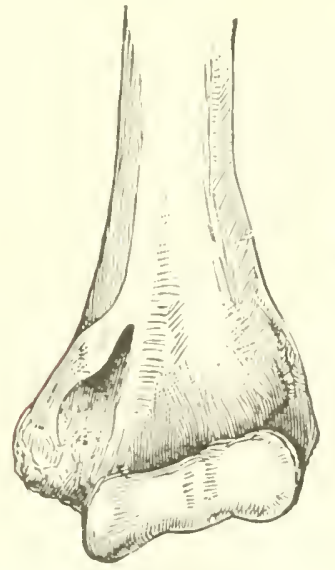

MAク.

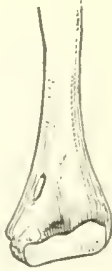

SAKI.

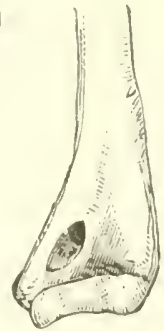

GAPVCHI

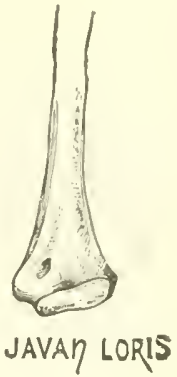

JAVAY LORIS

FIG. 34--Perforations of the humerus (supra-condyloid foramen) in three species of Quadrumana where it normally occurs, and in man, where it does not normally occur. Drawn from nature. (From Romancs.)

convex forwards, while its angles are so rounded as to present the nearly oval section seen in apes. It is in association with these ape-like human tibiac that perforated humeri of man are found in greatest abundance.

On the other hand, however, there is reason to doubt whether this form of tibia in man is really a survival from his quadrumanous ancestry. For, as Boyd-Dawkins and Hartmann have pointed out, the degree of flattening presented by some of these ancient human bones is greater than that which occurs in any existing species of anthropoid ape. Of course the possibility remains that the unknown species of ape from which man descended may have had its tibia more flattened than is now observable in any of the existing species. Never- 
theless, as some doubt attaches to this particular case, I do not press it - and, indeed, only mention it at all in order that the doubt may be expressed.

Similarly, I will conclude by remarking that several other instances of the survival of vestigial structures in man have been alleged, which are of a still more doubtful character. Of such, for example, are the supposed absence of the genial tubercle in the case of a very ancient jaw-bone of man, and the disposition of valves in human veins. From the former it was argued that the possessor of this very ancient jaw-bone was probably speechless, inasmuch as the tubercle in existing man gives attachment to muscles of the tongue. From the latter it has been argued that all the valves in the veins of the human body have reference, in their disposition, to the incidence of blood-pressure when the attitude of the body is horizontal, or quadrupedal. Now, the former case has already broken down, and I find that the latter does not hold. But we can well afford to lose such doubtful and spurious cases, in view of all the foregoing unquestionable and genuine cases of vestigial structures which are to be met with even within the limits of our own organization-and even when these limits are still further limited by selecting only those instances which refer to the very latest chapter of our long ancestral history. 


\section{CHAPTER XI}

\section{EVIDENCES FROM EMBRYOLOGY}

THE FACTS OF REPRODUCTION AND DEVELOPMENT

[It is now definitely known that all living creatures are mortal, at least as individuals, but they all have the capacity of continuing their life by the reproduction of offspring. This physical immortality is based upon an actual transmission from parent to offspring of some material substance which is so organized chemically as to be fully representative of the race or stock to which the parent belongs.

Reproduction may be asexual or sexual. In asexual development a new individual may be produced by a process of fission (dividing the parent into two or more parts, each of which has the capacity to develop into a whole new individual); by budding (the production of new individuals by means of outgrowths of the parent-body); or by giving off spores or eggs capable of development without fertilization (parthenogenesis). In sexual reproduction two kinds of parentinclividuals exist: one a female which is capable of giving off relatively large single cells, called eggs (ova); and the other a male, which is capable of producing minute, usually motile cells, called spermatozoa. A union of ovum and spermatozoön is usually necessary before the ovum can begin its development. It is the sexual method of reproduction that will chiefly concern us here, and, for present purposes, we may omit any further mention of the various asexual methods.

An ovum may be conceived of as an individual of some definite species or race reduced to the very lowest terms. It exhibits the characteristic cell structure, consisting of cytoplasm and nucleus, cell membrane, nuclear membrane, usually a centrosome (Fig. 43). Further details as to the minute structure of the nucleus are given in chapter xxvii, where the mechanism of Mendelian heredity is dealt with.-ED.]

"The reproductive cells from the two sexes," says Wright, " have very different appearances. In mammals, the ovum is a relatively large, spherical cell, just visible to the naked eye.

I From Sewall Wright, Principles of Livestock Breeding, United States Department of Agriculture, Bulletin No. 905 . 
"In birds, the yolk of an egg is really a single ovum, distended to an enormous size by food material. The sperm cell is very much smaller and can be seen well only with a high-power microscope. It is something like a tadpole in shape, having a small cell body, containing a little nucleus, and attached to this a long, whiplike process which beats rapidly while the cell is alive, enabling it to seek out and unite with the large passive egg in the act of fertilization. Enormous numbers of sperm cells are produced by the male, but only one takes part in fertilization. After the first has penetrated the membrane of an egg cell, a change takes place in the latter which prevents the entrance of others.

"The sperm activates certain formerly inert substances in the egg and the new combination cell (the zygote) starts almost at once to produce a new individual."

\section{OUTLINE OF ANIMAL DEVELOPMENT ${ }^{I}$}

\section{S. JORDAN AND V. L. KELLOGG}

The embryonic development is from the beginning up to a certain point practically alike, looked at in its larger aspect, for all the manycelled animals. That is, there are certain principal or constant characteristics of the l:eginning development which are present in the development of all many-celled animals. The first stage or phenomenon of development is the simple fission of the germ cell into halves (Fig. 35,b). These two daughter cells next divide so that there are four cells $(c)$; each of these divides, and this division is repeated until a greater or lesser number (varying with the various species or groups of animals) of cells is produced. These cells may not all be of the same size, but in many cases they are, no structural differentiation whatever being apparent among them.

The phenomenon of repeated division of the germ cell is called cleavage, and this cleavage is the first stage of development in the case of all many-celled animals. The germ or embryo in some animals consists now of a mass of few or many undifferentiated primitive cells lying together and usually forming a sphere (Fig. $35, e$ ), or perhaps separated and scattered through the food yolk of the egg. The next stage of development is this: the cleavage cells arrange themselves so as to form a usually hollow sphere or ball, the cells lying side by side to

${ }^{x}$ From D. S. Jordan and V. L. Kellogg, Evolution and Animal Lifc (copyright 1907). Used by special permission of the publishers, D. Appleton \& Company. 
form the outer circumferential wall of this hollow sphere $(f)$. This is called the blastula or blastoderm stage of development, and the embryo itself is called the blastula or blastoderm. This stage also is common to all the many-celled animals. The next stage in embryonic development is formed by the bending inward of a part of the blastoderm cell layer, as shown in $(\mathrm{g})$ (or the splitting off inwardly of cells from a special part of the blastula cell layer). This bending in may produce a small depression or groove; but whatever the shape or extent of the sunken-in part of the blastoderm, it results in distinguishing the blastoderm layer into two parts, a sunken-in or inner portion called

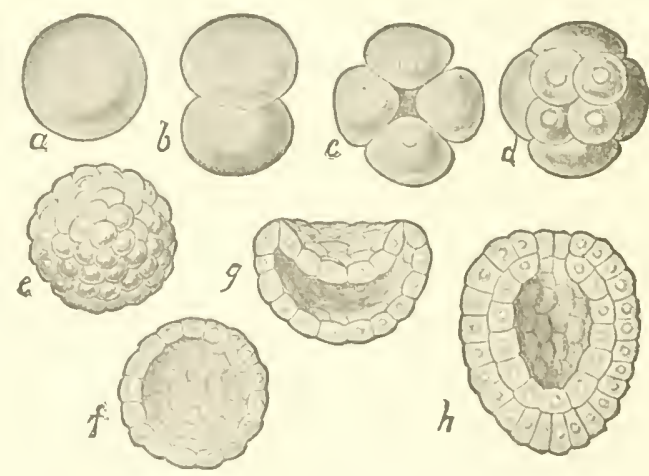

FIG. 35.-First stages in the embryonic development of the pond snail, Lymnacus. $a$, egg cell; $b$, first cleavage; $c$, second cleavage; $d$, third cleavage; $e$, after numerous cleavages; $f$, blastula -in section; $g$, gastrula just formingin section; $h$, gastrula completed-in section. (From Jordan and Kellogg, after Rabl.)

the endoblast and the other unmodified portion called the ectoblast. Endo- means within, and the cells of the endoblast of ten push so far into the original blastoderm cavity as to come into contact with the cells of the ectoblast and thus obliterate this cavity $(h)$. This third well-marked stage in the embryonic development is called the gastrula stage, and it also occurs in the development of all or nearly all manycelled animals.

In the case of a few of the simple many-celled animals the embryo hatches-that is, issues from the egg at the time of or very soon after reaching the gastrula stage. In the higher animals, however, development goes on within the egg or within the body of the mother until the embryo becomes a complex body, composed of many various 
tissues and organs. Almost all the development may take place within the egg, so that when the young animal hatches there is necessary little more than a rapid growth and increase of size to make it a fully developed mature animal. This is the case with the birds; a chicken just hatched has most of the tissues and organs of a full-grown fowl, and is simply a little hen. But in the case of other animals the young hatches from the egg before it has reached such an advanced stage of development; a young starfish or young crab or young honeybee just hatched looks very different from its parent. It has yet a great deal of development to undergo before it reaches the structural condition of a fully developed and fully grown starfish or crab or bee. Thus the development of some animals is almost wholly embryonic development-that is, development within the egg or in the body of the mother-while the development of other animals is largely postembryonic, or larval development, as it is often called. There is no important difference between embryonic and postembryonic development. The development is continuous from egg cell to mature animal, and whether inside or outside of an egg it goes on regularly and uninterruptedly.

The cells which compose the embryo in the cleavage stage and blastoderm stage, and even in the gastrula stage, are apparently all similar; there is little o: no differentiation shown among them. But from the gastrula stage on, development includes three important things; the gradual differentiation of cells into various kinds to form the various kinds of animal tissues; the arrangement and grouping of these cells into organs and body parts; and finally the developing of these organs and body parts into the special condition characteristic of the species of animal to which the developing individual belongs. From the primitive undifferentiated cells of the blastoderm, development leads to the special cell types of muscle tissue, of bone tissue, of nerve tissue; and from the generalized condition of the embryo in its early stages, development leads to the specialized condition of the body of the adult animal. Development is from the general to the special, as was said years ago by von Baer, the first great student of development.

A starfish, a beetle, a dow, and a horse are all alike in thei beginning - that is, the body of each is composed of a single cell, a single structural unit. And they are all alike, or very much alike through several stages of development; the body of each is first a single cell, then a number of similar undifferentiated cells, and then a 
blastoderm consisting of a single layer of similar undifferentiated cells. But soon in the course of development the embryos begin to differ, and as the young animals get further and further along in the course of their development, they become more and more different until each finally reaches its fully developed mature form, showing all the grcat structural differences between the starfish and the dove, the beetle and the horse. That is, all animals begin development apparently alike, - but gradually diverge from each other during the course of development.

There are some extremely interesting and significant things about this divergence to which attention should be given. While all animals are apparently alike structurally at the beginning of development, so far as we can see, they do not all differ noticeably at the time of the first divergence in development. The first divergence in development is to be noted between two kinds of animals which belong to different great groups or classes. But two animals of different kinds, both belonging to some one great group, do not show differences until later in their development. This can best be understood by an example. All the butterflies and beetles and grasshoppers and flies belong to the great group or class of animals called Insecta, or insects. There are many different kinds of insects, and these kinds can be arranged in subordinate groups (orders), such as the Diptera, or flies, the Lepidoptera, or butterflies and moths, and so on. But all have certain structural characteristics in common, so that they are comprised in one great class-the Insecta. Another great group of animals is known as the Vertebrata, or backboned animals. The class Vertebrata includes the fishes, the batrachians, the reptiles, the birds and the mammals, each composing a subordinate group, but all characterized by the possession of a backbone or, more accurately speaking, of a notochord, a backbonelike structure. Now, an insect and a vertebrate diverge very soon in their development from each other; but two insects, such as a beetle and a honeybee, or any two vertebrates, such as a frog and a pigeon, lo not diverge from each ther so soon. That is, all vertebrate animals diverge in one direction from the other great groups, but all the members of the great group keep together for some time longer. Then the subordinate groups of the Vertebrata, such as the fishes, the birds, and the others, diverge, and still later the different kinds of animals in each of these groups diverge from each other.

That the course of development of any animal from its beginning to fully developed adult form is - in all its essentials - fixed and certain 
is readily seen. All rabbits develop in the same way; every grasshopper goes through the same developmental changes from single egg cell to the full-grown, active hopper as every other grasshopper of the same kind-that is, development takes place according to certain natural laws; the laws of animal development. These laws may be roughly stated as follows: All many-celled animals begin life as a single cell, the fertilized egg cell; each animal goes through a certain orderly series of developmental changes which, accompanied by growth leads the animal to change from a single cell to the many-celled, complex form characteristic of the species to which the animal belongs; this development is from simple to complex structural condition; the development is the same for all individuals of one species. While all animals begin development similarly, the course of development in the different groups soon diverges, the divergence being of the nature of a branching, like that shown in the growth of a tree. In the free tips of the smallest branches we have represented the various species of animals in their fully developed condition, all standing more or less clearly apart from each other. But in tracing back the development of any kind of animal we soon come to a point where it very much resembles or becomes apparently identical with the development of some other kind of animal, and, in addition, the stages passed through in the developmental course may very much resemble the fully developed, mature stages of lower animals. To be sure, any animal at any stage in its existence differs absolutely from any other kind of animal, in that it can develop into only its own kind of animal. There is something inherent in each developing animal that gives it an identity of its own. Although in its young stages it may be hardly distinguishable from some other kind of animal in similar stages, it is sure to come out, when fully developed, an individual of the same kind as its parents were or are. A very young fish and a very young salamander are almost indistinguishably alike, but one is sure to develop into a fish and the other into a salamander. This certainty of an embryo to become an individual of a certain kind is called the law of heredity. Viewed in the light of development, there must be as great a difference between one egg and another as between one animal and another, for the greater difference is included in the less.

The significance of the developmental phenomena is a matter about which naturalists have yet very much to learn. It is believed, however, by practically all naturalists that many of the various stages in the development of an animal correspond to or repeat, in many 
fundamental features at least, the structural condition of the animal's ancestors. Naturalists believe that all backboned or vertebrate
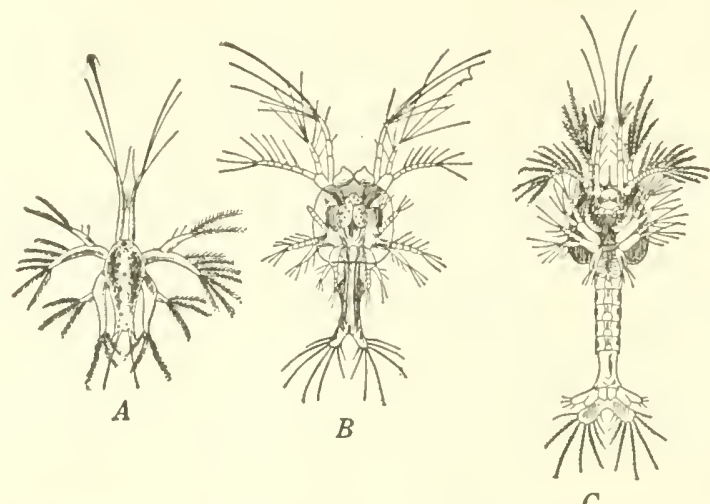

FIG. 36.- Stages in the development of the prawn, Peneus potimirium. A Nauplius larva; B, first zoëa stage; $C$, second zoëa stage. (From Jordan and Kellogg, after Fritz Mïller.)
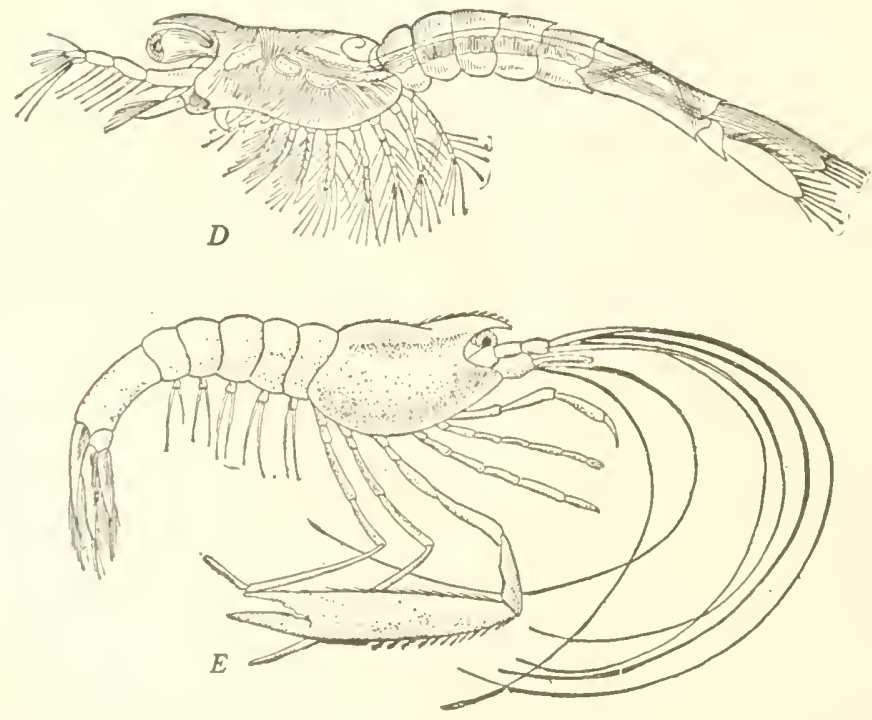

FIG. 37.-Later stages in the development of the prawn, Pencus potimirium. $D$, Mysis stage; $E$, adult stage. (From Jordan and Kellogg.) 
animals are related to each other through being descended from a common ancestor, the first or oldest backboned animal. In fact, it is because all these backboned animals - the fishes, the batrachians, the reptiles, the birds, and the mammals-have descended from a common ancestor that they all have a backbone. It is believed that the descendants of the first backboned animal have in the course of many generations branched off little by little from the original type until there came to exist very real and obvious differences among the backboned animals-differences which a mong the living backboned animals are familiar to all of us. The course of development of an individual animal is believed to be a very rapid and evidently much condensed and changed recapitulation of the history which the species or kind of animal to which the developing individual belongs has passed through in the course of its descent through a long series of gradually changing ancestors. If this is true, then we can readily understand why a fish and a salamander, a tortoise, a bird, and a rabbit, are all much alike, as they really are, in their earlier stages of development, and gradually come to differ more and more as they pass through later and later developmental stages. A crab has a tail in one of its developmental stages, so that at that time it looks like and really is like the mature stage of some tailed crustacean like a crayfish. A barnacle, which looks

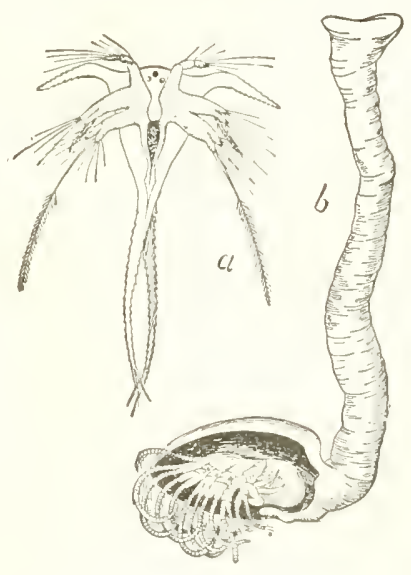

FIG. 38.-Metamorphosis of a barnacle, Lepas. a, larva; $b$, adult. (From Jordan and Kellogg.) a little like a crayfish or crab in its mature stage, is hardly to be distinguished in its immature life from a young crab or lobster. Sacculina, which is a still more degenerate crustacean, is only a sort of feeding sac with rootlet-like processes projecting into the body of the host crab on which it lives as a parasite, but the young free-swimming Sacculina is essentially like a barnacle, crayfish, or crab in its young stage.

However, it is obvious that this recapitulation or repetition of ancestral stages is never perfect, and it is often so obscured and modified by interpolated adaptive stages and characters that but little of an animal's ancestry can be learned from a scrutiny of its development. 


\section{I72 READINGS IN EVOLUTION, GENETICS, AND EUGENTCS}

The fascinating biogenetic law of Müller and Haeckel summed up in the phrase, "ontogeny is a recapitulation of phylogeny," must not be too heavily leaned on as a support for any speculations as to the phyletic affinities of any species or group of species of organisms. "Embryology is an ancient manuscript with many of the sheets lost, others displaced, and with spurious passages interpolated by a later hand." 


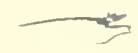

\title{
CHAPTER XII
}

\section{CRITIQUE OF THE RECAPITULATION THEORY ${ }^{I}$}

\author{
w. B. SCOTT
}

Embryology is the study of the development of the individual organism from its beginning in the egg to the attainment of the adult condition. This individual development is called ontogeny and the question of the relation of ontogeny to the ancestral history of the species, or phylogeny, constitutes one of the main problems of embryology. Around this problem many controversies have raged, controversies which have by no means arrived at a definite solution, even to-day. Thirty years ago the "recapitulation theory" was well-nigh universally accepted, according to which the individual development, or ontogeny, was regarded as an abbreviated repetition of the ancestral history of the species, or phylogeny. Haeckel called this theory the "fundamental biogenetic law" and upon it he established his whole "History of Creation." Nowadays, that "fundamental law" is very seriously questioned and by some high authorities is altogether denied. However, even those who take this extreme position concerning the recapitulation theory see in the facts of embryology one of the strongest supports of the doctrine of evolution.

It was very early recognized that the recapitulation theory could not be applied with literal exactness, but was subject to certain important exceptions and qualifications.

I. That the history must have been enormously abbreviated. After three weeks of incubation the tiny speck of protoplasm, which forms a circular mark on the yolk of a hen's egg, is developed into a fully formed chick, ready for hatching and able in large degree to take care of itself. On the other hand, the evolution of birds from their invertebrate ancestors, through the fishes, amphibians, and reptiles, the separation of the gallinaceous stock from other birds and the differentiation of this particular species were extremely slow processes, extending through unnumbered millions of years. Admitting recapitulation to the fullest extent, it is evidently a physical impossibility

From W. B. Scott, The Theory of Evolution (copyright I9I7). Used by special permission of the publishers, The Macmillan Company. 
that it should be a perfect repetition of phylogeny; very much of the long story must of necessity be omitted.

2. Through all the stages of development the embryo must be rendered al)le to live and grow and thrive through adaptation to its surroundings and changes in its enviromment. In some animals development takes place within the body of the mother; in others the embryo is protected by the hard egg-shell, as in birds, while the eggs of certain fishes and many invertebrates float freely in the sea and are almost without protection. Such differences in environment necessitate differences in the mode of development, while the presence or absence of a large amount of inert food-material, or yolk, exerts a great influence in determining the steps of ontogeny.

3. Many animals pass through a larval stage of development, in which the immature young leads an independent and self-sustaining existence, during which it is very different in appearance and structure from its adult parents. Familiar instances of this mode of development are to be found in the tadpole, which is the larva of the frog, and the caterpillar, the larva of a butterfly. Larvae are fully subject to the struggle for existence and must adapt themselves to their environment and to changes in that environment, exactly as do adults, if they are to survive. In this way many changes are introduced into the ontogeny which can have no phylogenetic significance. It is found in several known instances, that nearly allied species, living under different conditions, have quite different modes of ontogeny, though their ancestral history must have been substantially identical. In one and the same species of marine worms, for example, which inhabits both the warm Mediterranean and the cold waters of the North Sea, the larva of the northern form is quite distinct from that of the southern. In attempting to interpret the meaning of cmbryological facts, it is thus necessary to distinguish sharply between those features which are derived from a long inheritance, and are therefore called palingenctic, from those which have been secondarily introduced in response to the changing needs of embryonic or larval life. These secondary features are termed cenogenetic.

"If we are compelled to admit that cenogenetic characters are intermingled with palingenetic, then we cannot regard ontogeny as a pure source of evidence regarding phyletic relationships. Ontogeny accordingly becomes a field in which an active imagination has full scope for its dangerous play, but in which positive results are by no means everywhere to be obtained. To attain such results, the palin- 
genetic and cenogenetic phenomena must be sifted apart, an operation which required more than one critical grain of salt. On what grounds shall this critique be based? Assuredly not by way of a vicious circle on the ontogeny again; for if cenogenetic characters are present in one case, who will guarantee that a second case, used for a comparison with the first, does not likewise appear in cenogenetic disguise? If it once be admitted that not everything in development is palingenetic, that not every ontogenetic fact can be accepted at its face value, so to speak, it follows that nothing in ontogeny is immediately available for the critique of embryonic development. The necessary critique must be drawn from another source."

These remarks of Gegenbaur's were called forth by the state of wild speculation into which embryological work had fallen. As there were no generally accepted canons of interpretation for the facts of embryological development, different writers interpreted these facts in the most divergent and contradictory manner, resulting in a chaotic confusion, which led to a strong reaction against the whole method, though there can be little doubt that this reaction has gone too far.

"It must be evident to any candid observer, not only that the embryological method is open to criticism, but that the whole fabric of morphology, so far as it rests upon embryological evidence, stands in urgent need of reconstruction. For twenty years embryological research has been largely dominated by the recapitulation theory; and unquestionably this theory has illuminated many dark places and has solved many a perplexing problem that without its aid might have remained a standing riddle to the pure anatomist. But while fully recognizing the real and substantial fruits of that theory, we should not close our eyes to the undeniable fact that it, like many another fruitful theory, has been pushed beyond its legitimate limits. It is largely to an overweening confidence in the validity of the embryological evidence that we owe the vast number of the elaborate hypothetical phylogenies which confront the modern student in such bewildering confusion. The inquiries of such a student regarding the origin of any of the great principal types of animals involve him in a labyrinth of speculation and hypothesis in which he seeks in vain for conclusions of even an approximate certainty."

Many other equally vigorous and well-deserved criticisms of the embryological method might be cited, but it should be emphasized that these criticisms are all directed against the application of the method to the solution of definite and concrete problems of descent and 


\section{I76 READINGS IN EVOLUTION, GENETICS, AND EUGENICS}

relationship. None of them denies and many strongly affirm that embryology affords some of the strongest and most convincing evidence in favor of the evolutionary theory.

Let us examine some of this evidence. To begin with, it should be noted that, in following out the ontogeny or individual development, the observer witnesses the formation of something new, not merely the enlargement and unfolding of a pre-existing organism, though the theory of preformation, which was widely accepted in the eighteenth century, looked upon ontogeny preciscly in that way, as the growth of a germ which was the miniature of the parent. Such a theory was possible only before the development of microscopic technique had enabled the observer to detect the actual successive steps of change. The egg is a single cell, with the nucleus and all the parts of other undifferentiated cells, though it may be enormously enlarged by the presence of food-yolk. In the hen's egg this food-yolk is quite inert and the activity of development is confined to the minute disc of protoplasm on the outside of the yolk, while in the frog's egg the yolk is disseminated, though not uniformly, throughout the egg and in the mammalian egg, which is microscopic in size, there is no yolk. It is a very remarkable fact that all of the vertebrated animals, fishes, amphibians, reptiles, birds and mammals, however different their habits and modes of life, have a mode of ontogeny which is of even more characteristically and unmistakably the same plan than is the type of their adult structure, which was described in the last chapter. The egg, or the active portion of it, divides in a definite and regular manner into a very large number of cells, which arrange themselves in definite layers, an outer and an inner, and within these layers cell-aggregates form incipient organs, which, step by step, take on the adult condition. Not only is the plan and type of development essentially similar throughout the whole phylum of the vertebrates, but, in accordance with the recapitulation theory, many structural features which are permanent in lower forms appear in the embryos of higher and more advanced types. In the latter, however, these features are transitory and, in the course of development, they either disappear, or are so modified as to be very different, sometimes unrecognizable, in the adults.

At a certain stage of the ontogeny the embryo of a mammal has gill-pouches like a fish, the skeletal supports of the glll-pouches, the arteries and veins which supply them with blood, the structure of the heart, in short, the entire plan of the circulatory system is fish-like. 
At a later stage most of the gill-pouches have been obliterated, but one is retained and converted into the Eustachian canal, which connects the throat with the middle ear, inside of the ear-drum. Similarly, the

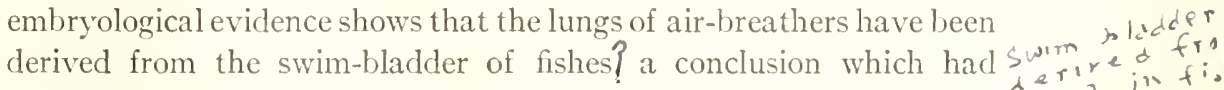
already been reached by comparative anatomy, for in a remarkable $j w n$

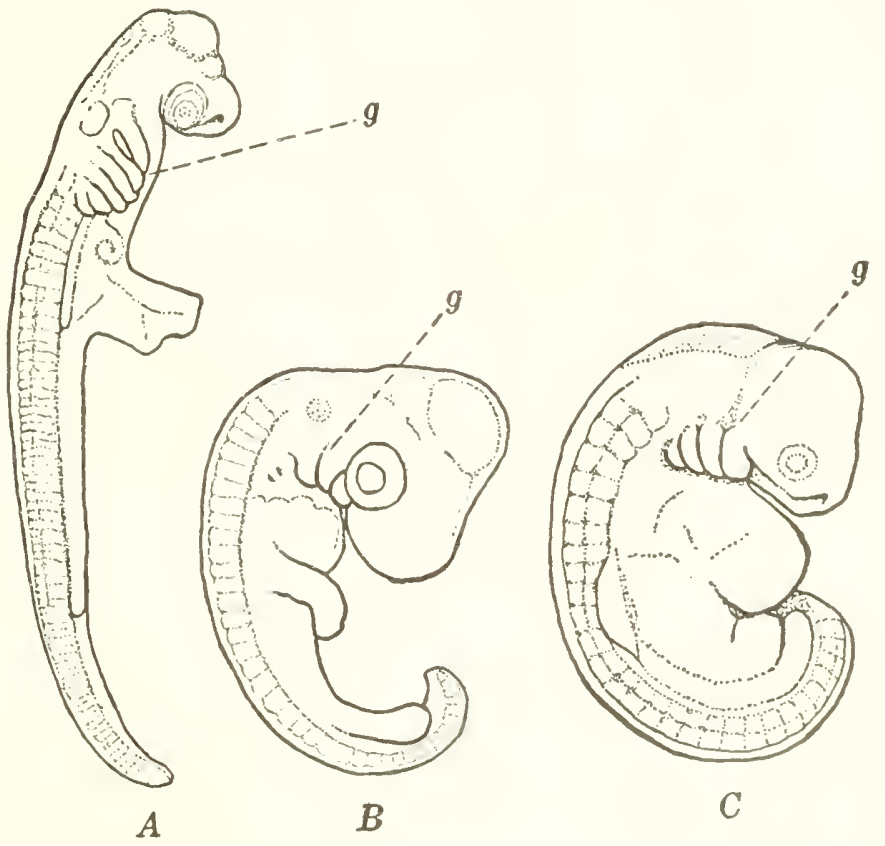

Fig. 39.-Embryos in corresponding stage of development of shark (A), fowl $(B)$, and $\operatorname{man}(C) ; g$, gill slits. (From Scott.)

group, known as the Dipnoi or lung-fishes, the air-bladder is utilized for purposes of respiration.

It has been objected that, while embryology may prove relationship within a single type, it fails to demonstrate any connection between different types, but this is not altogether true. The Tunicata, a curious group of marine animals once referred to the Mollusca, are shown by their ontogeny to be related to the vertebrates and the same is true of certain marine worms (Balanoglossus). Indeed, most modern zoölogists have adopted a scheme of classification, in which 
the type Chordata includes not only the true vertebrates, but also the Lancelet ( 1 mphioxus), the tunicates, and Balanoglossus; this scheme is founded upon the embryological evidence. Among the invertebrates even more remarkable examples have been observed. Such radically different types as the segmented worms and the shellfish (Mollusca) are brought into relationship by their ontogeny and their closely similar types of larvae, as are also, though less distinctly, the brachiopods or lamp-shells, and the Bryozoa. The Horseshoecrab, or King-crab, so abundant along our Atlantic coast, was long of uncertain affinities; originally referred to the Crustacea, largely because of its marine habits of life, embryology makes much more probable its relationship to the air-breathing scorpions and spiders, a result which has been examined previously from another point of view in connection with blood-tests.

Even before the publication of Darwin's Origin of Species one of the great stumbling blocks in the way of the theory of special creation was the existence in a great many animals of rudimentary organs, or such as are so far reduced and atrophied as to be of no service to their possessors. An analogy employed by my lamented friend, Mr. Richard Lydekker, may be advantageously repeated here. Let us suppose that a screw-steamer, with longitudinal shaft leading aft from the engine-room to the stern, where it carries the propeller, should, on close examination, reveal many signs that it has originally been a "side-wheeler," or paddle-boat. Recognizable remnants of paddleboxes, of bearings for a transverse shaft, and the like, are found; what would be the inevitable conclusion? No one would maintain that a naval architect, in possession of his senses, in constructing a screwsteamer would deliberately introduce features which are useful and appropriate only in a paddle-boat. The only reasonable explanation would be that the vessel had originally been built as a paddle-boat and had subsequently been converted into a screw-steamer and in the conversion it had not been found necessary completely to eradicate all traces of the original construction. Obviously, the same reasoning applies to rudimentary organs. The only satisfactory explanation of such useless remnants is that their possessors are descendants of ancestors in which those organs were fully functional. It seems quite absurd to assume that, in a separately and specially created animal, useless structures, reminiscent of other animals in which the same structures are useful and valuable, should be included, merely to indicate ideal relationships and community of plan. 
It was sought to break the force of this very serious objection to the theory of special creation by saying that apparently useless organs may nevertheless have functions which are still unknown to us and may be revealed by future discovery. In certain cases, like that of the thyroid gland in the neck, this contention has been justified, but there are many others to which it does not apply. For example, in the great and varied whale-tribe (order Cetacea) which includes the right, or whalebone, whales, the sperm-whales, the porpoises, dolphins, etc., the forelimbs have been converted into swimming paddles, but the hind limbs appear to have vanished completely, leaving no externally visible trace. Internally, however, recognizable remnants of the hind limb-bones may be found in various stages of reduction, which differ in the different members of the order. In the Greenland Right Whale the hip-bone, thigh-bone and shin-bone are indicated; in the Finwhale only the hip-bones and a minute rudiment of the thigh-bone are to be found; in the toothed whales only an almost unrecognizable remnant of the hip-bone is left and in one of the dolphins even that has disappeared. Similarly, the snakes have lost their limbs completely, so far as external appearance is concerned, and in most members of the group no trace of limbs is to be found on dissection, but in certain snakes the rudiments of limbs are to be detected. Leaving aside all preconceptions, which is the more probable explanation of such phenomena, the theory of special creation or the theory of evolution?

Even if it were admitted that all rudimentary organs and structures found in the adult have a certain unknown use and value, no one could maintain this with regard to the countless instances of structures which are developed in the embryo, but disappear entirely before birth. It is possible to mention but a very few of such instances out of the great number that have already been observed and recorded, but these few will suffice to illustrate the principle involved.

"Examples of this may be cited from the most widely different groups: in the embryo of insects, especially of beetles, pairs of legs are formed within the egg, not only on the head and thorax, but also on the abdomen, but while those on the head are transformed into mouth-parts, those on the thorax are farther developed in their jointing and musculature to be locomotive legs, those on the abdomen are again resorbed. In many fresh-water worms, the eggs of which are laid in a cocoon, from which they are hatched as a finished, minute, crawling worm, larval organs are nevertheless formed, which recall those of the Trochophore, the larva of the original worms, which swims 
freely in the sea. However, these larval organs.... are never properly functional, since no actually free-swimming larva is developed but the embryo merely floats in the albuminous fluid of the cocoon.

"A particularly beautiful example is offered by the whales in their embryological development, which has been thoroughly studied by Kukenthal. In the adult condition they show only the anterior extremities, but in the embryo the posterior pair, with their skeletal parts, are formed, but are afterwards completely atrophied. Although they are mammals, in the adult condition they have absolutely no covering of hair, since in their aquatic life another and more effective protection against loss of heat is given by means of a thick layer of blubber; only a few coarse bristles, partly with particular functions, have persisted on a few parts of the body. But in the embryo a dense covering of hair is formed, which is later transformed in a peculiar manner and atrophied. Further, a series of whales have no teeth in the adult condition, but only the well-known, eel-trap-like, horny plates, from which whale-bone is produced. Nevertheless, in the embryo there is a dentition of numerous teeth, which are, however, resorbed, without ever piercing the gum."I

Throughout the great group of the ruminants, which includes the oxen, buffaloes, bison, sheep, goats, antelopes, deer and giraffes, the collar-bone is invariably lacking, since it is superfluous on account of the exclusively locomotive manner in which the fore legs are employed. In the embryo sheep the collar-bone is established and even, to some extent ossified, but is subsequently resorbed and disappears entirely. No doubt, the collar-bone will be found in many other embryo ruminants, when the proper examination shall have been made, but its demonstrated presence in the foetal sheep is sufficiently striking. In the higher mammals the number of teeth was originally 44 , or I I on each side of both upper and lower jaws, but in most of the modern or existing groups of these higher mammals this number has been very considerably reduced through the suppression of certain teeth. We have every reason to believe that the ancestors of the forms with reduced dentition possessed teeth in full numbers and that there has actually been a loss of teeth in the course of descent. This conclusion is abundantly confirmed by the facts of embryology. Take, for example, the great group of the gnawing mammals or Rodentia, in which the front teeth or incisors, above and below, are reduced to one on each side, except in the rabbits. The incisors are chisel-shaped and

I Otto Maas, Die Abstammungslehre, pp. 273-74. 
are faced with hard enamel, so that the action of the upper teeth upon the lower keeps the cutting edges extremely sharp; these teeth do not form roots, but continue to grow throughout the lifetime of the animal. Between the chisel-like incisors and the grinding teeth, there is a long toothless gap, which, we assume, was, in the ancestors of the rodents, occupied by the second and third incisors, the canine and two or more grinders. This conclusion is justified by the facts of embryology; for instance, in the embryo of the squirrel several of the missing teeth are begun as distinct tooth-germs, but fail to develop, never cut the gum and are resorbed before birth.

All available evidence points to the conclusion that birds are descended from reptiles, a conclusion which is especially strengthened by the facts of palaeontology and will be examined more at length in the following lecture. Such a descent explains many otherwise puzzling features in the ontogeny of birds, in which reptilian characteristics appear in transitory fashion and are either modified so as to take on typically bird-like character, or are suppressed altogether. A remarkable example of this is the formation of rudimentary teeth in certain embryonic birds, followed by their resorption and disappearance before hatching,

It can hardly be contended that these rudimentary structures, which are confined to the embryonic stages of development and of which no trace remains in the adult, are so indispensable to the processes of ontogeny, that they were specially created to serve this temporary purpose. For such a contention there is not a particle of evidence and the theory of evolution, which regards these structures as useless remnants, due to inheritance from ancestors in which the structures are functional, offers much the most satisfactory solution of the problem that has yet been suggested.

Embryology further shows that evolution is not invariably an advance from lower and simpier to higher and more complex types, but may be by way of degeneration and degradation. The adoption of a parasitic mode of life is very apt to cause such degradation, and some very remarkable instances of the degeneration of parasites have been observed. An instructive example that may be cited is that of Sacculina, a nondescript creature that is parasitic on certain species of crabs. The parasite is attached to the body of its victim, underneath the tail, by means of root-like fibres which penetrate and ramify throughout the interior of the crab. The root-like fibres alssorb nutriment and convey it to the body of the parasite, which is reduced to a 
mere bag, without appendages, muscles, nervous system, sensory apparatus, digestive tract, or any determinable organs save those of reproduction. The creature has the power of assimilating the nutritive juices which are conveyed to it by the root-like filaments from the body of its host, and the power of reproduction, and it must have some respiratory and excretory capacity, though there are neither gills nor glands. From an examination of the adult parasite alone, it would be quite impossible to classify it and determine the type and class to which it should be referred, but embryology solves the problem. From the egg is hatched a free-swimming larva, which has jointed appendages, nervous, muscular and digestive systems and, in short, clearly belongs to that group of the Crustacea which includes the barnacles. This is degeneration carried nearly to the utmost possible extreme and yet the individual development shows the derivation of this otherwise problematical parasite and the steps through which it passed in its deterioration.

It was stated above that several distinguished naturalists altogether reject the recapitulation theory as a means of interpreting the facts of embryology. They do this on the ground that, inasmuch as changes and innovations in form or structure must arise in the germplasm, at the very beginning of ontogeny, there is no reason why such changes might not involve the whole course of embryological development. To my mind this a priori objection to the recapitulation theory is quite without force in view of the great body of observed facts, but there is no time to enter upon a discussion of such an abstract and difficult problem. For our present purpose, however, it is important to note that these objectors are staunch erolutionists and find in the community of mode in ontogeny between different classes of organisms one of the strongest arguments in support of the evolutionary doctrine. 


\section{PART III}

THE CAUSAL FACTORS OF ORGANIC EVOLUTION 


\title{
CHAPTER XIII
}

\section{INTRODUCTORY STATEMENT}

\author{
H. H. NEWMAN
}

Any investigation of the causes of evolution must be preceded by a survey of the facts to be explained. Some of the principal facts which must be taken into account have already been placed before the reader in the preceding section dealing with evidences of evolution. If there were no other good reason for dealing with those materials before beginning a discussion of causal theories of evolution, the pedagogical reason would be sufficient, because, until there is something to explain, the necessity for an explanation does not arise. We are of course aware that some writers prefer to deal with the facts of palaeontology, geographic distribution, classification, comparative anatomy, embryology, etc., after a discussion of the causes of evolution. Their avowed reason for this order of treatment is that the net results of a discussion of the causes underlying evolution may be used as a means of more fully analyzing the facts. This is indeed true, but it is also true that facts should come first and explanations afterward. As a final step, the facts profitably may be re-examined in the light of causal hypotheses.

One of the outstanding facts of animate nature is the phenomenon of adaptation. No naturalist has failed to note and marvel at the adaptiveness or fitness of organisms to their environment and that of parts of organisms for particular functions or activities. One of the most difficult problems in evolution is the problem of the origin and the perfection of adaptations, and most causal theories of evolution have been aimed largely at an explanation of adaptation. Consequently, before we enter upon a formal discussion of the causal theories we shall introduce an outline of some of the main facts about adaptations.

By way of introduction it should also be pointed out that the causes of evolution are not all of equal value. Some of the causes are to be conceived of as primary, others as secondary, or even tertiary. Variation, for example, is absolutely primary in importance. Without variation, change, which is the very essence of evolution, would of course be impossible. Not less important is heredity; for unless there be some factor which fixes variation so that it becomes a racial asset, 
there can be no real racial progress; and evolution is nothing more or less than racial, as opposed to individual, progress. So obvious did this seem that Charles Darwin accepted as axiomatic the general facts of variation and heredity and proceeded at once to a discussion of the directive factors of evolution. Since variation and heredity are now universally conceded to be primary factors, and selection, the Lamarckian factor, isolation, orthogenesis, etc., as secondary or guiding factors, it would seem more natural to proceed first to a discussion of variation and heredity. So much of our present knowledge of variation and heredity, however, is dependent upon the background furnished by Darwin that it seems to us a more effective pedagogical order to consider that vast and intricate conception of evolution which was first given life and unity by Charles Darwin, and has come now to be known as "Darwinism."

Just how broad the scope of Darwin's work and how important a rôle he played in the development of evolutionary biology is indicated in the following appreciation of Darwin which we have summarized largely from the admirable statement in Professor J. Arthur Thomson's book Darwinism and II uman Life.

WHAT WE OWE TO DARIVIN

I. The web of life - the idea of linkages, interdependencies, correlations in the living world. The idea is essentially ecological and has been expressed elsewhere as "organic equilibrium."

2. The struggle for cxistence - the inevitable consequence of Malthus' idea of overproduction. This struggle is both inter- and intraspecific, or may be a mere struggle against fate or against hard conditions of inorganic environment.

3. Tariability of living creatures - an idea derived from the study of changes under domestication and of diversity among wild individuals belonging to the same species.

4. Natural selection - the central idea which is to be studied presently.

5. Iindication of the evolution idea.-Darwin was the first effectively to marshal the evidences of evolution in sufficient force to compel the acceptance of the fact of evolution. Much that has already been presented under the hear of "Evidences of Evolution" belongs to Darwin. The placing of the fact of evolution on a sure foundation is believed by many to have been Darwin's principal contribution to science. 
6. The descent and ascent of 1 I an- "a recognition of man's solidarity with the rest of creation, of his affiliation to a Simian stock - that man and anthropoid apes are collateral branches from a common Primate stock which remains hidden in obscurity."

7. Liberation of intelligence. - "The Origin of Species has proved a veritable Magna Charta of intellectual liberties, for, as no other single document before or since, it has released the thoughts of man from the trammels of unreasoned conservatism and dogmatism."H. E. Crampton.

8. Ideal of scientific mood and method.-As Professor T. H. Morgan says, "It is the spirit of Darwinism, not its formulae, that we proclaim as our best heritage." Darwin was the first great evolutionist to use the inductive method, that of first securing an abundance of facts and then formulating theories to explain the facts.

The above-stated eight points give us an idea of the broader concept of Darwinism. Today the term "Darwinism" has come to acquire a much restricted and a technical meaning. To the modern evolutionist Darwinism has come to be practically synonymous with "natural selection," or at least with the general principle of "selection," some phases of which are termed "neo-Darwinism." Before we can adequately enter upon a study of Darwin's most characteristic causal theory of evolution - the natural-selection theory - it is almost imperative for us to know something of the background out of which this conception arose. Already we have presented in our survey of the evidences of evolution an array of facts most of which were known to Darwin and in accord with which he developed his causal theories. But we cannot afford to overlook the now well-known fact that what Darwinism chiefly aims to explain are the phenomena of adaptation and the web of life. These phenomena are to be conceived of as the / background of Darwinism and will be dealt with as such in the next chapters. 


\section{CHAPTER XIV}

\section{THE BACKGROUND OF DARWINISM}

\section{ADAPTATIONS}

\section{H. H. NEWMAN}

"The adaptation of every species of animal and plant to its environment," says Jordan and Kellogg,, "is a matter of everyday observation. So perfect is this adaptation in its details that its main facts tend to escape our notice. The animal is fitted to the air it breathes, the water it drinks, the food it finds, the climate it endures, the region which it inhabits. All its organs are fitted to its functions: all its functions to its environment. Organs and functions are alike spoken of in a half-figurative way as concessions to environment. And all structures and powers are in this sense concessions, in another sense, adaptations. As the loaf is fitted to the pan, or the river to its bed, so is each species fitted to its surroundings. If it were not so fitted, it would not live. But such fitness on the vital side leaves large room for variety in characters not essential to the life of the animal."

The authors quoted above appreciate what is perhaps the most significant fact about adaptations: that the adaptations are to a large extent molded by the environment and therefore fit the environment. So long as the environment remains uniform, a given species will remain unchanged, except for minor fluctuations and occasional mutations; but if the environment changes, sometimes even slightly, the development of the individual responds in such a way as to give a radically different end product. So we may conclude that a large part of the fitness of the organism to the environment is due to the fact that the development of each individual is molded by the environment so as to fit it. Thus some at least of the apparent mystery of adaptations is dispelled.

When we think of the fitness of the organism to the environment we take an entirely one-sided view of the matter, for if the organism fits the environment, no less certainly must the cnvironment fit the organism. This idea of the "fitness of the environment" has been

${ }^{2}$ From D. S. Jordan and V. L. Kellogg, Evolution and Animal Life. 
admirably discussed by Professor Lawrence J. Henderson in a stimulating volume. ${ }^{x}$

Henderson points out that the environment, no less than organisms, has had an evolution. The particular environmental complex as it exists today is absolutely unique. There is hardly an element of the effective environment that could be changed without causing the extinction of life or at least a transformation of it so profound that it might not be life at all as we know life. Water, for example, has a dozen unique properties that condition life. Carbon dioxide could not be replaced by any other substance. The properties of the ocean are so beautifully adjusted to life that we marvel at the exactness of its fitness. Finally, the chemical properties of carbon, hydrogen, and oxygen, the most abundant elements, are equally unique and unreplaceable. In brief, given the environment as it is, life could not be other than it is. The evolution of the environment and the evolution of organisms have gone hand in hand, or perhaps we might better say hand in glove, for this better expresses the idea of mutual fitness.

Within the realm of the general environment as conceived by Henderson there are almost innumerable special environments due to particular combinations of the various environmental units. Within the aquatic environment, for exarnple, there are variations such as differences in salinity, varying from extreme saltiness to almost total lack of salt; there are inshore conditions and open-sea conditions; there are surface conditions and those at relatively great depths; and there are great differences due to temperature. Similarly on land, there are surface conditions, subterranean conditions, caves, deserts, forests, plains, mountains, arctic, tropical conditions, and many others. No two areas on land are precisely similar in all respects. All of this makes for a corresponding multiplicity of animal and plant forms. In the case of plants the action of the environment is remarkably direct; for the plant cannot get away from a fixed environment. If the environment undergoes material change, the plant's only response is a structural one. For example, if plants that are accustomed to a relatively humid climate are grown in the desert they develop numerous xerophytic adaptations such as small leaves with greatly diminished transpiration surface, a thick epidermis, hairs, or spines, small stature, deep-root system, and other similar protections against the inimical desert conditions. Similarly, plants accustomed to grow in relatively

× L. J. Henderson, The Fitness of the Environment, I9r3. 
dry soil, if grown in soil that is covered over with water, will produce aquatic leaves and roots and undergo appropriate changes in epidermis and loss of supporting tissues, for plants that are buoyed up by water need little support.

Animals, on the other hand, are for the most part not so intimately related to a local environment as are plants. They are characteristically mobile creatures with varying capacities for wandering about and selecting the habitat that best suits them.

"By virtue of being unlike or possessing different properties," says Shelford, ${ }^{x}$ "the various animal species require different conditions for the best adjustment of their internal processes. For example, the carp lives in shallow and muddy ponds and rivers, while the brook trout lives only in clear swift streams. These two organisms are able to move about and find places to which they are suited. The differences between them are clearly indicated by the differences in the habitats which they prefer.

"By observation and by experimentation it has been shown that animals select their habitats. By this we do not mean that the animal reasons, but that selection results from regulating behavior. The animal usually tries a number of situations as the result of random movements, and stays in the set of conditions in which its physiological processes are least interfered with. This process is called selection by trial and error. If animals are placed in situations where a number of conditions are equally available, they will almost always be found living in or staying most of the time in one of the places. The only reason to be assigned for this unequal or local distribution of the animals is that they are not in physiological equilibrium in all the places. However, some animals move about so much that it is with some difficulty that we determine what their true habitats are."

This idea of habitat preference and habitat selection is extremely important for a correct understanding of adaptation, or the fitness of organisms to environments. Much of the observed fitness may be due to the fact that an organism has chosen out of a wide range of environments the one that best suits it. We cannot in such a case say that the environment has had a direct influence in shaping the organism any more than we could say that, when a man tries on various shoes and finds a pair to fit, he has been responsible for the fitness of the shoes.

Many special adaptations may be explained through habitat choice. Thus animals such as the duckbill platypus, the lung-fishes,

${ }^{2}$ V. E. Shelford, Animal Communities in Temperate America (1913). 
and others whose teeth are replaced by bony or chitinous plates that are used for crushing the hard shells of molluscs and crustaceans, may not confidently be said to have developed these crushing appliances and to have abandoned the use of teeth in adaptation to a habit of feeding upon hard-shelled prey; but rather it seems more likely that the loss of teeth and the development of crushers occurred through $a$. degenerative process incident to racial senescence and that the possession of the crushing equipment enabled them to avail themselves of a new type of food, formerly unavailable to them.

The organic environment. - In his admirable chapter entitlen "The Web of Life," which we shall quote entire, Professor Thomson has given us a vivid picture of vast systems of interdependencies that exist throughout the organic world. No species, no creature, lives to itself alone; it is intimately tied up with a host of other creatures with interwoven destinies. Thus one species of animal is adapted to live upon certain plants or other animals, which in turn may be dependent upon still other animals or plants. The elimination of one species may cause the elimination or the radical change of a dependent species. We cannot afford ever to forget this great truth of the oneness of nature. It is the keynote of life and of evolution.

Adaptation due partly to functional activity.-It is a commonplace which needs no specia demonstration to say that organs improve through use and deteriorate through disuse. Many organs, then, which in the adult condition appear to us to be so admirably adapted to perform certain duties, must be thought of as having been gradually molded by functioning during the entire period of individual development. If the motor nerve running to a limb bud of a growing embryo be severed at an early stage and no secondary nerve connection be established, the limb will continue to grow up to a certain point, but, in its paralyzed condition, will be incapable of exercising its functions and will cease to develop. A certain amount of development will therefore be seen to be independent of functioning, but full development of functional efficiency is obtained only through functioning.

"The relation between structure and function in an organism," says Professor Child, ${ }^{\text {" }}$ "is similar in character to the relation between the river as an energetic process and its banks and channel. From the moment that the river began to produce structural configurations in its environment, the products of its activity accumulated in certain

${ }^{\prime}$ C. M. Child, "Regulatory Processes in Organisms," Jour. Morph., Vol. XXII (I9I ). 
places and modified its flow. .... It moulds its banks and bottom, forming here a bar, there an island, here a bay, there a point of liand, but still flowing on, though its course, its speed, its depth, the character of the substances which its carries in suspension or in solution, all are altered, built up by its own past activity." According to this view, structure is simply the resultant of the interaction of function and environment or of functional activity. Though perhaps a little extreme for most of us, this view is, we believe, essentially correct. We are prone to overemphasize structure in our discussions of adaptation and evolution and to lay too little stress upon the energy side of development. Certainly no structure is ever formed without protoplasmic activity of a very definite sort, and in this sense adaptations are to be thought of as the results of functioning. Why, then, do we claim to be astonished at the effective way in which certain organs accomplish their functions, when functioning has taught them their task?

\section{LAWS OF ADAPTATION}

Adaptations have been variously classified by different writers. Perhaps the most significant classification is that of Osborn, which is based on their supposed evolutionary origin. According to this writer and others there are two categories of adaptations to environmental conditions: the first has to do with the tendency of unrelated species to assume similar structures under similar environmental conditions; the second has to do with the tendency of related species to assume different adaptive structures under different environmental conditions. In both categories the environment appears to be the determining factor.

(r) A good example of the first category, which illustrates what Osborn calls "the law of convergence or parallelism of form," is seen in the tendency of many aquatic types of vertebrates to assume the fishlike form. As is well shown in Fig. 40 , the shark (a fish), the ichthyosaur (an extinct aquatic reptile), and the porpoise (a marine mammal), all possess the same fusiform body best adapted for speed under water, the same types of locomotor structures, consisting of the great propeller fin (caudal fin) and the steering and balancing fins, the dorsal fins and paired fins. Apart from these superficial adaptations for swift locomotion in the water, the three types are profoundly different. The shark breathes with gills, the reptile and mammal with lungs, the fish and reptile are cold-blooded, the 

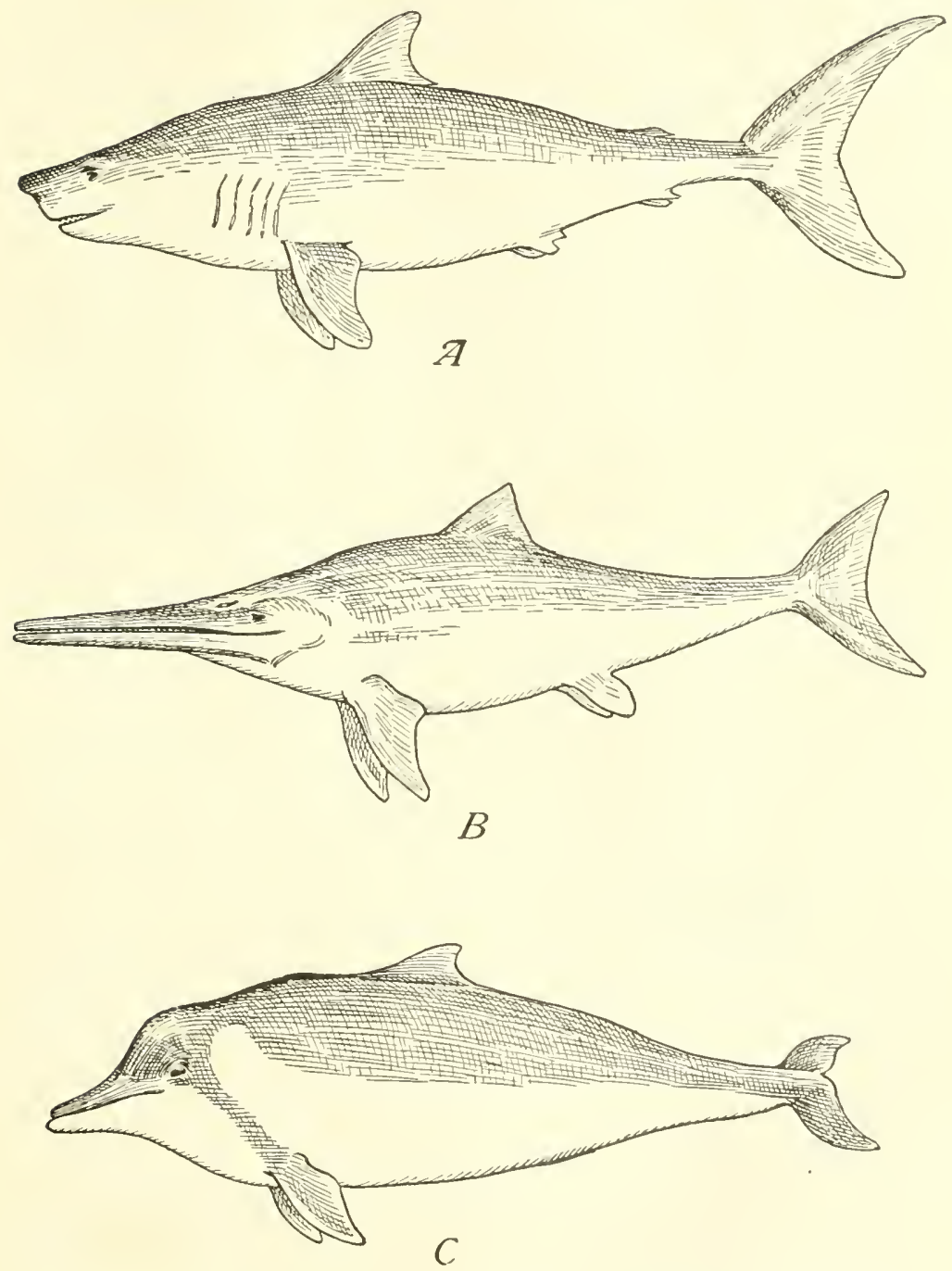

FIG. 40.-Three aquatic types of vertebrate, to illustrate convergent adaptation of three wholly unrelated forms of marine life. All three show the fusiform body, median and paired fins, though the skeletal structures are radically different. $A$, shark (Pisces); $B$, ichthyosaur (Reptilia); $C$, porpoise (Mammalia). (From Newman, after Osborn.) 
mammal warm-blooded. The internal anatomy of the three differs fundamentally in every detail.

A list of other types of convergence will more adequately illustrate the law.

Flying and parachuting animals occur among nearly all vertebrate and some invertebrate classes. Planes of some sort are found for supporting the body in the air. The plane is made in various ways in different groups, but functions much the same in all of them.

Running animals of various classes have long legs, and a tendency to stand on the toes. There is also in several unrelated groups the tendency to reduce the number of toes, the culmination of which is seen in the one-toed horses.

Climbing animals are all provided with clinging appendages of some sort, including such structures as hooked claws, prehensile fingers or tail, suction pads on the feet, and other similar adaptations.

Burrowing animals have, as a rule, extra-heavy shoulder girdle and strong fore limbs with heavy gouging claws. Many of them also are blind or nearly so, as befits life in dark underground passages.

Desert-dwelling animals as a rule are provided with heavy scales, spines, or armor, to prevent excessive loss of moisture and as a protection against spiny plants. They also usually have burrowing habits enabling them to escape the extremes of heat and cold.

Cave animals are usually blind or nearly so and are relatively pale in color, sometimes without any pigmentation.

Deep-sea animals of many sorts have phosphorescent organs by means of which they either attract their prey or find their way about the dark sea floor. Some of these organs, called "lanterns," can be used as searchlights. The eyes of deep-sea fish are either enormously" large or are "telescope eyes," adapted for sensing light of low intensities.

Ant-eating animals, belonging to several distinct groups, are heavily armored against the attacks of ants, have strong claws for digging up ant galleries, have long snouts or beaks with a long sticky tongue for capturing ants, and an arrangement of the glottis to prevent ants from crawling into the lungs.

2. There are almost innumerable examples of the law of divergence of form, which is called also the law of adaptive radiation. Almost every successful class or order of vertebrate animals, for example, has members that have adjusted themselves to all of the main modes of living. Thus among lizards, for example, there are primitive 
running forms that prefer the surface life and swift motion; subterranean burrowing types that sometimes are limbless like snakes, and are blind; many arboreal or climbing types; a few volant or flying types; a few ant-eating types; and several more or less completely aquatic types. Each of these types has the customary adaptations for its own mode of life.

We see, then, that whether divergent structures are molded into a semblance of similarity to fit a definite environment, or whether similar structures are modified in diverse ways to fit various divergent environments, the adaptation is related very definitely to the environment and to the functional life of the organism. No wonder, then, that so many biologists consider that the environment has been a molding force in the evolution of adaptations.

One of the most interesting discussions of adaptations is that of Weismann, who, it appears, is greatly impressed with the universality of adaptation. His thesis apparently is that if we had complete knowledge of the field of biology, we would discover that everything is adaptive, and that many structures or habits that now appear to us useless or non-adaptive, would be found to have a definite value to the organisms possessing them. Some authors take the opposite extreme and claim that adaptation has been merely read into a vast number of so-called adaptive structures and that when these structures shall have been adequately investigated they will be found to lack the value imputed to them by uncritical observers. Somewhere between these extreme views lies the truth.

Thus we see that a certain amount of adaptation is inevitable and needs only a formal physiological explanation. The fitness of the environment, habitat selection, and the relationship that exists between function and structure, are adequate explanations for the general fact of adaptation and thus take away much of the mystery that has shrouded the concept of fitness. There are, however, very many types of special adaptation which do not yield so readily to the general explanation given. Some of the most important of these will be described below.

\section{ADAPTATIONS CLASSIFIED}

Adaptations are variously classified by different authors, and that of Jordan and Kellogg is as good as any: "( $a$ ) food-securing; (b) selfdefense; $(c)$ defense of young; $(d)$ rivalry; $(e)$ adjustment to surroundings." 


\section{I96 READINGS IN EVOLUTION, GENETICS, AND EUGENICS}

Some very common adaptations may belong to several of these categories at once. Thus the sharp tecth and hooked claws of carnivorous mammals serve equally well for food-securing, for selfdefense, for defense of young, and for rivalry. Similarly, the horns of deer and other ungulates arc equally adapted for self-defense, defense of young, and rivalry.

There can be no especial advantage, in this connection, in presenting a detailed review of adaptations of the sorts given in the foregoing classification; therefore we shall confine our efforts to a description of a few typical adaptations about which the greatest controversy has raged.

\section{SOME SPECIAL ADAPTATIONS}

The electric organ of the torpedo, a widlely distributed elasmobranch fish, consists of a sort of honeycomb-like structure on each side of the head. This structure acts as a storage battery and is capable of storing up electricity of considerable voltage. The animal is capable of giving a very distinct shock to an attacker and can thus defend itself quite effectively. There is also an electric eel, native to the waters of Paraguay and Brazil, that is able to give severe shocks to bathers or to horses driven through the streams. A type of catfish native to the river Nile has a similar electric equipment. In all of these cases the storage battery is made up of modified voluntary muscles and is of considerable size.

The mammary glands of mammals are skin glands usually with well-defined ducts leading to the surface and terminating in teats. These glands are quite voluminous and serve admirably the purpose of feeding new-born young until the latter are able to use the more varied food normal to the adult. In the lowest mammals, the monotremes or egg-laying mammals, these glands are relatively poorly developed and diffuse; also they are known to be developed through a regional specialization of sweat glands. In the true mammals or Eutheria the glands are modified sebaceous or oil glands and may be seen to develop from the same embryonic rudiments as the latter.

The marsupial pouch of the kangaroo and its allies is a pocketlike fold of the integument, folded forward or backward over the region of the abdomen in which are located the mammary glands. This pouch is used as a shelter for the tiny immature larval foetuses. Hartmann has recently described a very striking piece of behavior in connection with the birth of young opossums. The young are born 
in an exceedingly immature state and looking like tiny pink grubs. They crawl under their own power, by means of a swimming-like motion, through the hairs of the mother's abdomen, till they reach the pouch. This they enter unaided and each tiny larva finds for itself a slender tubular teat, which it swallows and holds in place by a specially adapted hold-fast mouth. The young remains attached fixedly to this teat for some weeks, feeding almost constantly on milk. After a long interval the teat is released, the mouth metamorphoses into the adult form and the young feeds only at intervals, as do the young of other mammals. This complex of adaptive structures and instincts is among the most remarkable in the annals of biology.

Nest-making instincts in birds represent, on the behavior side, adaptations of extraordinary perfection. Some nests are built with the greatest care and precision, others represent a relatively crude and slovenly performance. Some nests are made of twigs, fibres, and mud, others of mud alone, still others are hollowed out in clay or sand banks, and some are made in holes in the ground. In any case, the type of nest is highly specific and due to a hereditary instinct; for birds receive no instruction in nest-making.

Before bringing to a close this brief list of particularly noteworthy adaptations let us recall to mind the series of special adaptations listed as examples of the laws of adaptation, such as aquatic, arboreal, cursorial, flying, burrowing, ant-eating, and, especially, adaptations of deep-sea animals.

\section{PARASITISM AND DEGENERATION}

A vast number of animals and plants have given up the active search for food and have taken up the relatively easy habits of parasitism. In adaptation to this life certain structures have developed and many of the characters found in independent, free-roving creatures have disappeared or become reduced to mere vestiges. Thus the more completely dependent or parasitic an animal becomes, the more completely does it lose its organs of locomotion and its sense organs such as eyes, auditory organs, tentacles, etc. Some animals are free-living when young or in the larval condition and only settle down to a parasitic life when near the end of the life-cycle; other animals are parasitic only when young or larval and become independent in the adult condition; still others are parasitic throughout the entire life-cycle and pass from host to host without any interval of independent life. Some of these complete parasites pass one phase of the life-cycle on one species of host and the remainder on another 


\section{I98 READINGS IN EVOLUTION, GENETICS, AND EUGENICS}

species of host. Thus the liver fluke in the adult condition lives in the gall bladder of the sheep, while the early larvae live within the body cavities of a species of land snail. The transfer from host to host in this case must be a procedure involving many chances of failure to a very few chances of success, and, in adaptation to these vicissitudes, the number of eggs and larvae produced by a single adult individual runs up into the millions.

The classic case of extreme parasitic aregeneration is that of Sacculina. The young larva of Sacculina is a typical entomostracan crustacean larva which swims about and leads a free life for a time, but soon attaches itself by means of its antennae to a hair pit of a crab, a small hole in the latter's armor. The internal tissues of the larva then undergo degenerative processes and are reduced to an almost fluid mass of embryonic cells, which flow through the hair pore of the crab, and into the latter's lymph spaces. The small mass of cells then rounds up and is carried about with the circulation of the crab's blood until it comes to a favorable place of lodgment, usually the wall of the intestine just back of the stomach. Here it flattens out and sends rootlike branches almost all over the crab's body, like a malignant tumor in its invasion of foreign tissues. The unbranched part of the parasite is little more than a sac of reproductive organs, and these produce eggs and sperms, which unite to produce larvae. By this time the host is killed and, with the decay of its body, the larvae escape into the sea water ready for a brief period of free life before attacking another host.

Almost every group of animals and most of the groups of plants have their parasitic representatives and every degree of parasitism and the accompanying degenerative changes are to be found. Of course, it is an open question whether parasitism causes degeneration or whether degenerating creatures take refuge in parasitism; but in either case the adaptive features of the situation are obvious.

Commensalism.- If parasitism be defined as an association between two organisms in which one (the parasite) lives at the expense of and to the detriment of the other (the host), commensalism may be defined as an association in which the two organisms exist in close association without any positive detriment to either. In some cases the claim is made that the association is mutually beneficial, but as a rule the relation is relatively one-sided.

An interesting example of commensalism is that of the sea cucumber and the little fish Fierasfer. This strange little animal inhabits 
the rectum of the sea cucumber and may be seen to lie with only its head out. From this shelter it darts forth to capture its prey; which done, it returns to its shelter.

Curiously enough the vent of the little fish is situated just back of its mouth so that its wastes may be voided when in its usual position. There can be no advantage to the sea cucumber in such an arrangement, though no particular harm is done. Another case of this sort is that of several species of Remora which attach themselves by a large diskoid adaptation on top of the head to various fish such as sharks, barracudas, etc.

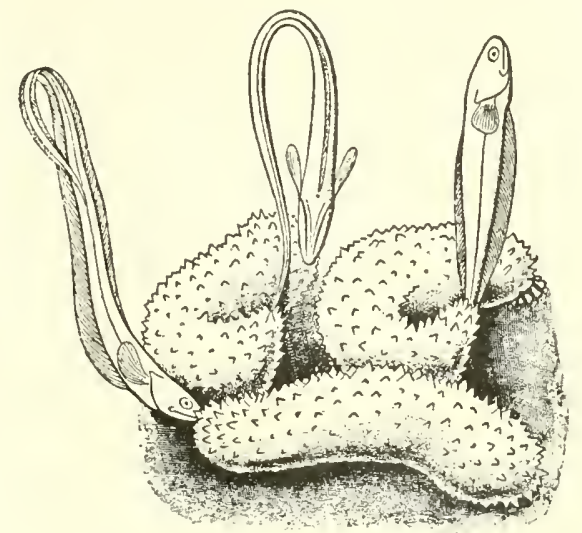

Fig. 4I.-Fierasfer acus, penetrating the anal openings of holothurians, $\frac{2}{5}$ natural size. (From Boulenger, after Emery.)

The sucking disk is a modified dorsal fin. The remora merely gains free transportation to more favorable feeding-grounds. When the desired food is sighted the passenger leaves its conveyance temporarily, but returns by a sudden swift dash and resumes its hold. The shark gets nothing except perhaps the sense of companionship, and is also undoubtedly somewhat hindered in its locomotion.

Some of the most remarkable cases of commensalism are found in connection with elaborate colonies of ants. In some cases two species of ants live together in the relationship of masters and slaves. The master species is unable to perform any of the ordinary duties of the colony, such as securing food, taking care of young, etc. In extreme cases the masters are only soldiers, specialized for fighting and marauding, and cannot even feed themselves unaided. The slave species would be able to carry on to some extent if not captured, but thrives exceptionally well under the protection of the soldier species. There are among ants many varieties of commensal relationship less extreme than this, but this will serve as a typical case.

Communal life.-Among the higher insects and higher vertebrates, especially among the ants and bees, we find a very elaborate social life. In ants, for example, the typical colony consists of a queen (the only fertile female in the colony), several males (mates of the queen), 
ordinary workers (sterile females of the first type), soldiers (sterile females of the second type), and sometimes officers (especially large and powerful sterile females that seem to direct the line of march in legionary ants). All of these casts are produced from the eggs of one female and are the result of various special diets permitted the larvae by the workers. Among bees, similarly, there is one queen, a number of drones (males), and the sterile female workers, who perform the functions of nursing the larvae, cleaning up the hive, collecting pollen and nectar, and making honey and wax. Detailed accounts of the lives of bees have been given by various authors, notably by Maeterlinck in his Life of the Bee.

\section{COLOR IN ANIMALS}

"The phenomena of color in both animals and plants," says Metcalf, "are among the most remarkable and interesting in the whole realm of nature. It is not so much the way in which the color is produced, whether by pigments or by refraction, that interests us in this connection, as it is the uses to which colors are put. Let us first refer to the colors of animals.

"According to the uses to which colors in animals are put, we may classify them, for purposes of description, as follows:

"Indifferent coloration, not useful, so far as we can judge;

Colors of direct physiological value;

Protective coloration and resemblances;

Aggressive coloration and resemblances;

Alluring coloration and resemblances;

Warning coloration;

Immunity coloration;

Mimetic coloration and resemblances;

A. Protective

B. Aggressive

Signals and recognition marks;

Confusing coloration;

Sexual coloration."

A few examples of these categories of animal coloration will serve to illustrate the ways in which they are believed to be adaptive and thus better to fit the organism for its struggle for existence.

Protective resemblance.-Many animals that live at or near the surface of the sea are practically transparent. Fishes are commonly

'M. M. Metcalf, Organic Evolution (1911). 
dark-colored above and light-colored below, so that to the enemy above they blend with the dark bulk of the water and to the enemy below they are hidden by the fact that the shadow cast by their own bulk is sufficiently neutralized by the ventral light coloring to render them inconspicuous.

A very large number of arboreal animals are green; such as grasshoppers, leaf hoppers, spiders, green lizards, parrots, etc. Prairie and desert animals are usually dull-colored like their surroundings. Many butterflies are brightly colored like the flowers upon which they feed. Many arctic animals are white like their snowy background.

Some animals, like the chameleon and the flounder, change their colors so as to keep in harmony with changing backgrounds.

There are many cases of protective resemblance, involving both form and color, between an organism and some particular feature of its environment. The walking-stick insect is long and slender and colored like a twig. Many caterpillars when disturbed stand out stiff and straight like leafless twigs. A species of sea-horse (a teleost fish) has its fins fringed out into structures that closely resemble the fronds of seaweed in which the animal lives. Many insects, belonging to several orders, have very striking resemblances to leaves. The case of Kallima (Fig. 42), the dead-leaf-butterfly is a classic example of this type of protective resemblance. The resemblance is so nearly perfect that, when one has mounted specimens of butterfly and leaf before him, he has to examine them closely to detect the fraud. The details of the leaf color, veins, petiole, marginal notches, even wormholes, so common in dead leaves, are reproduced in the butterfly's wings. Many treefrogs have a leaf-shaped pattern bordered with black to resemble the shadow cast by a leaf. These are only a few scattering examples of an exceedingly prevalent type of adaptation.

Aggressive coloration and resemblance.-There is a close similarity between this phenomenon and the one just dealt with, but instead of being used defensively, it is used offensively, in that it enables the predaceous animal to remain hidden from its prey. Thus the polar bear and the arctic fox are white and therefore inconspicuous to seals and arctic birds, their prey. Perhaps the most striking instance of this type of coloration is that of the tiger, whose tawny coat and dark stripes resemble the reeds and their vertical shadows in the jungle.

Alluring coloration and resemblace.-- "In India," says Metcalf, "there is a Mantis (insect) which in shape and color resembles an 
orchid blossom. It deceives butterflies and other insects, which it captures as they approach the seeming flower. In Java there is a spider which resembles a bit of bird excrement upon which butterflies are so apt to light. This resemblance enables it to capture the butterflies upon which it feeds."

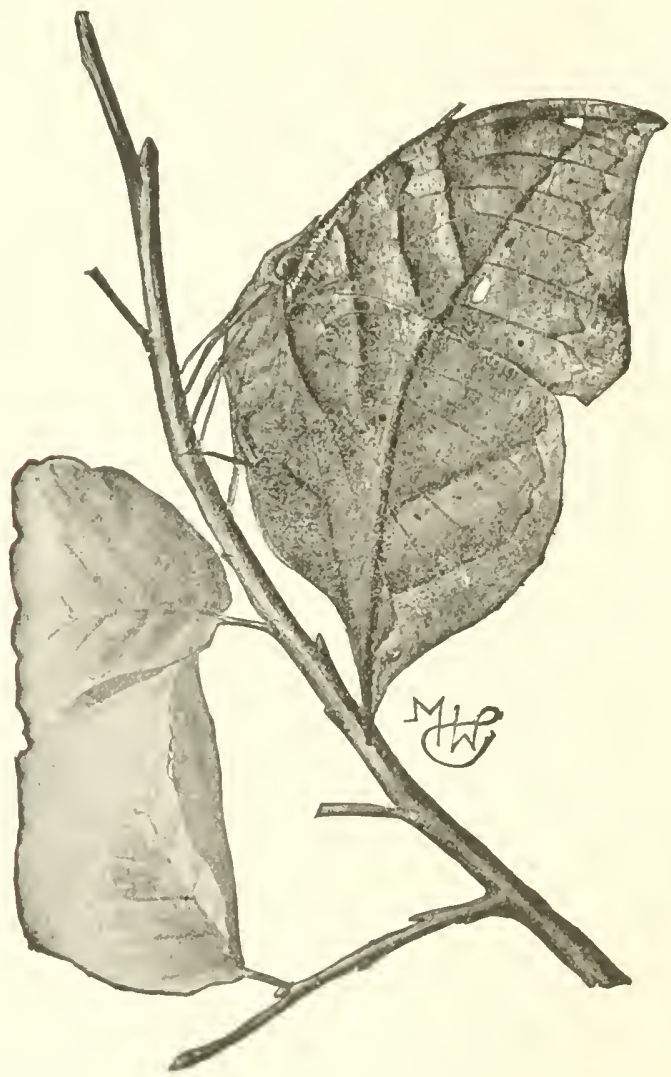

Fig. 42.-Kallima, the "dead-leaf butterly." (From Jordan and Kellogg.)

Warning coloration.-Many animals that are for various reasons harmful or dangerous to other animals have strikingly distinct color patterns which have been interpreted by some authors as warning marks to keep off possible attackers. Bees, wasps, hornets, some poisonous snakes, many spiders, all of which have stings or fangs, are marked with bands of contrasting colors. Other animals that are 
nauseous if eaten, still others, like the skunk and his tribe, that produce offensive odors, have well-defined markings that are classed as examples of warning coloration.

Immunity coloration.-Professor Reighard has taken exception to the interpretation of conspicuous coloration as warning adaptations. His theory of "immunity coloration" furnishes an alternative interpretation which appears less open to criticism. According to this idea well-protected animals are relatively safe from attack and therefore may become conspicuous without endangering themselves. They are immune and therefore their conspicuous markings may be merely the result of color run riot without any check on the part of natural selection.

Mimicry.-This is a special type of protective coloration in which an otherwise defenseless species has a striking resemblance to some well-protected species with warning coloration. Thus wasps and bees are "mimicked" by flies, beetles, and moths. They enhance the resemblance by similarities of behavior and habitat. Ants are protected by the fact that they contain formic acid, which is distasteful to most animals (though some animals feed very largely on them). Consequently there are many ant mimics belonging to several orders of insects and to spiders. In some cases these ant mimics are inhabitants of ant colonies and succeed in passing themselves off as ants even among the ants themselves. The classic cases of mimicry, however, are those in which certain species of edible butterflies are said to mimic other, unrelated, nauseous species of butterflies.

It is very difficult to distinguish the model from the mimic except by careful anatomical examination which, of course, could not be applied in nature. It should be said about mimicry, however, that it would work only in case the mimic occurs in much smaller numbers than the model, and that the two species occupy the same regions at the same ime. Some critics have claimed that these conditions do not prevail in all cases. If their contention is valid, the usual explanations of mimicry need revision. Cases of aggressive mimicry are noted among certain predaceous animals, such as spiders which mimic flies and ants, and are therefore able to approach their prey more effectively.

Signals or recognition marks. - The common cotton-tail rabbit raises its white tail when it runs. This is interpreted as a signal of danger to other rabbits. Some antelopes have a conspicuous white rump which is supposed to be a danger signal. Many distinct specific 
markings such as the red heads of woodpeckers, distinct white or black bars on the wings of other birds, may serve for recognition purposes within the species.

Confusing coloration.-Many butterflies and moths, and not a few birds have rather conspicuous markings when in flight, which may serve as specific recognition marks; but when they alight after a zigzag course through the air, they cover up the conspicuous markings and blend with the background in various ways. They are supposed to alight when in danger of capture and they apparently disappear, much to the confusion of the pursuer. Thus Kallima, the dead-leaf butterfly, is quite conspicuous from above while in flight, but when it alights, it cannot readily be distinguished from a dead leaf.

Sexual coloration. - A great many groups of animals exhibit a pronounced sexual dimorphism in color and pattern. The most conspicuous instance of this is that of birds among which the female is usually protectively colored so as to be inconspicuous when on the nest or when sheltering the young, while the male of the same species is frequently conspicuously colored. Similar situations are found among butterflies and moths in which sometimes one sex and sometimes the other is the more elaborately colored. Sexual coloration is also common among teleost fishes, lizards, spiders, and many other groups. Charles Darwin devised a special "sexual selection" theory" to account for just this type of adaptation.

One more kind of coloration that is not specifically dealt with by Metcalf is what has now come to be known as "camouflage." Many animals when viewed out of their environment appear to be very conspicuous owing to the juxtaposition of patches of irregular colors. In their natural surroundings, however, they become practically invisible. Thus the nighthawk with its strongly contrasted patterns almost fades from view against the bark of a tree.

For cxcellent illustrations of animal colorations the reader is referred to Professor Metcalf's book Organic Evolution, where he has gathered together in color plates many of the finest examples of the phenomena under discussion.

General considerations.-Adaptations are characteristic of a!l living organisms and must be accounted for by any evolutionary theory that is to be acceptable. Any theory that claims to account for new species but does not account for adaptations is at best only a partial explanation. All of the phenomena which have been briefly mentioned in this chapter, together with the more intricate phases of 
general adaptiveness involved in the idea of "the web of life," are part of the background of Darwinism and were in the mind of Darwin when he thought out the great generalization called "natural selection." The "web of life" idea has been admirably presented by Professor Thomson, Scotland's most skilful and prolific biological writer. The present writer feels that no student of evolution should miss the opportunity of getting into the spirit of Darwinism with this distinguished author, and to make this desideratum easily attainable, the chapter is quoted unchanged as part of the general text and immediately follows this discussion. 


\title{
CHAPTER XV
}

\section{THE BACKGROUND OF DARWINISM-Continued}

\author{
THE WEB OF LIFE $^{x}$ \\ J. ARTHUR THOMSON
}

Naturalists, in the true sense, who study the life of living creature: in nature, have always been distinguished by a keen perception of the interrelations of things. Whether we take Gilbert White as representing the old school, or W. H. Hudson as representing the new, we get from their observations the same impression of nature as a vibrating system, most surely and subtly interconnected. But it seems just to say that no naturalist, before or since, has come near Darwin in his realisation of the web of life, in his clear vision and picture of the vast system of linkages that penetrates throughout the animated world.

Correlation of organisms as well as correlation of orgarss. - In thinking of a living body we are accustomed to the idea of the correlation of organs. It is of the very nature of an organism that there should be mutual dependence among its parts. The organs are all partners in the business of life, and if one member changes others also are affected. This is especially true of certain organs that have developed and evolved together, and are knit by close physiological bonds. We know in health how nerve and muscle, brain, and sense organs, heart and lungs, are closely bound together in the bundle of life. We know in disease that a change in one organ often affects another, and the fact remains though the nexus is sometimes mysterious. The state of our liver may give colour to our whole intellectual firmament, and a slight ocular derangement may warp a wise man's philosophy. The far-reaching importance of a little organ like the thyroid gland beside the larynx is well known; our intellectual as well as our bodily health depends on its soundness. Now, just as there is a correlation of organs within the body, so there is a correlation of organisms in that system of things which we call Nature. In both cases we are here using the word "correlation" in its deeper sense--

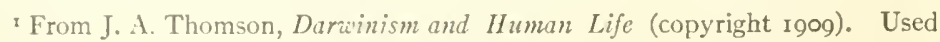
by special permission of the publishers, Henry Holt \& Company. 
that the various parts are more than mutually dependent, that they are in some measure co-ordinated, making larger systems workable.

What the metaphor of "the web of life" suggests.-We may use the metaphor "web of life" in two ways. On the one hand, Nature has a woven pattern which science seeks to read, each science following the threads of a particular colour. There is a warp and woof in this web, which to the zoölogist usually appear as "hunger" and "love." There is a changing pattern in the web, becoming more complex as the ages pass; and this is evolution. But the essential idea of a web is that of interlinking and ramifying. We can never tell where a thread will lead to. If one be pulled out, many are loosened. This is true of Nature through and through.

The phrase "web of life" suggests another picture - the web of a spider-often an intricate system, with part delicately bound to part so that the whole system is made one. "The quivering fly entangled in a corner betrays itself throughout the web; often it is felt rather than seen by the lurking spinner. So in the substantial fabric of the world part is bound to part. In wind and weather, or in the business of our life, we are daily made aware of results whose first conditions are very remote; and chains of influence, not difficult to demonstrate, link man to beast, and flower to insect. The more we know of our surroundings the more we realise that nature is a vast system of linkages, that isolation is impossible."

Dependence of living creatures on their surroundings.-We do not know what life in principle is, but we may describe living as action and reaction between organisms and their environment. This is the fundamental relation - the dependence of living creatures on appropriate surroundings, and the primary illustrations of linkages must be found here. The living creatures are real, just in the same sense as the surroundings are real; but it is plain that we cannot abstract the living creatures from their surroundings. When we try to do this they dieeven in our thought of them, and our biology is only necrology. Huxley compared a living creature to a whirlpool in a river; it is always changing, yet always apparently the same; matter and energy stream in and stream out; the whirlpool has an individuality and a certain unity, yet it is wholly dependent upon the surrounding currents. One may push the whirlpool metaphor too far, so as to give a false simplicity to the facts, for when vital whirlpools began to be there also emerged what cannot be discerned in crystal or dewdrop-the will to live, a capacity of persistent experience, and the power of giving rise to 
other lives. To ignore this is to attempt a falsely simple natural history. But what Huxley's metaphor of the whirlpool does vividly express is the dependence of living creatures on their surroundings. We camnot understand either the whirlpool or the trout apart from the stream.

When we think out this fundamental dependence upon surroundings, we see, for instance, that all our supplies of energy, all our powers of every kind - with our own hands, or by the use of animals, or by means of machinery-are traccable to the sun. Or again, it is easy to show that our society depends fundamentally not on gold, but on iron. We depend for food on plants and animals, and through these animals on plants ultimately; the plants feed upon air, water, and salts, which, with the aid of the energy of the sunlight, they build up into complex organic compounds; they cannot do this unless the sun shines through a screen of green pigment called chlorophyll; there cannot be chlorophyll without iron; therefore our whole social framework is founded on iron.

Nutritive chains. - Plants feed on their inanimate environment in a direct way that is impossible to animals, so we pass insensibly from dependence on surroundings to those mutritive chains which bind living creatures together in long series often quaintly suggestive of "The House That Jack Built" and similar old rhymes. We have ceased to wonder at the circulation of the blood in our body; have we begun to wonder enough at the ceaseless circulation of matter in the system of nature? As Heraclitus said, $\pi \dot{a} \nu \tau \alpha \dot{\rho} \epsilon \dot{\ell}$, all things are in flux. "The rain falls; the springs are fed; the streams are filled and flow to the sea; the mist rises from the deep and the clouds are formed, which break again on the mountain-side. 'The plant captures air, water, and salts, and, with the sun's aid, builds them up by vital alchemy into the bread of life, incorporating this into itself. The animal eats the plant and a new incamation begins. All flesh is grass. The animal becomes part of another animal, and the reincarnation continues." The silver cord of the bundle of life is loosed, and earth returns to earth. The microbes of decay break down the dead, and there is a return to air and water and salts. We may be sure that nothing real is ever lost; we are sure that all things flow. Penelope-like, Nature is continually unravelling her web and making a fresh start.

Nexus between mud and clear thinking.-To keep a famous inland fish-pond from giving out, some boxes of mud and manure were placed at the sides. Bacteria-the minions of all putrefaction- 
worked in the mud and manure, making food for minute Infusorians which multiply so rapidly that there may be a million from one in a week's time. A cataract of Infusorians overflowed from box to pond, and the water-fleas and other small fry gathered at the foot of the fall and multiplied exceedingly. Thus the fishes were fed, and, as fishflesh is said to be good for the brain, we can trace a nexus from mud to clear thinking. What was in the mud became part of the Infusorian, which became part of the Crustacean, which became part of the fish, which became part of the man. And it is thus that the world goes round.

Correlation between catches of mackerel and amount of spring sunlight.-A curious and most interesting correlation has been discovered by Dr. E. J. Allen between catches of mackerel and the amount of sunlight. The more sunshine in May, the more mackerel at Billingsgate. How does this work out? Mr. G. E. Bullen shows that "for the years I903-I907 there appears to be a correlation between the number of mackerel taken during May, and the amount of Copepod plankton, upon which the mackerel feed, taken in the neighborhood of the fishing grounds during the same month." Mr. W. J. Dakin shows that the food of Copepods consists largely of the vegetable organisms of the plankton, such as diatoms, and of Infusoria-like organism: called Peridinidae. But the production of this microscopic plankton, the "stock" of the "seasoup," depends partly on the composition of the sea-water, partly on the temperature, and partly on the amount of light available. There seems to be no correlation between the surface temperature and the abundance of mackerel, but Dr. Allen has shown a correspondence between sunshine and the catches. Thus we see that, if all flesh is grass, then in the same sense all fish is diatom.

Nutritive chains in the deep sea.-If we pass from the sunlit open sea to the floor of the deep sea-that strange, dark, cold, silent, plantless world-we find carnivorous animal preying upon carnivorous animal through long series-fish feeds on fish, fish on Crustacean, Crustacean on worm, worm on still smaller fry, and all ultimately depend on the basal food-supply-the ceaseless shower of moribund atomies sinking from the surface waters many miles, it may be, overhead, like the snowflakes on a quiet winter day.

Dependence of one organism on another for the continuance of the species.-Passing from "nutritive chains," we may select a few illustrations of the dependence of one creature upon another for the 
continuance of its kind. The crowning instances are to be found in interrelations between plants and animals which secure cross-fertilisation and the distribution of seeds. To both of these Darwin devoted much attention, and they were always favourite subjects with him.

Everyone knows that flowering plants and flower-visiting insects have grown up throughout long ages together, in alternate influence and mutual perfecting. They are now fitted to one another as hand to glove. The insects visit the flowers for food; in so doing they carry the fertilising golden dust from blossom to blossom, so that the possible seeds become real seeds.

In I793 a Berlin naturalist, Christian Konrad Sprengel, like Darwin in his perception of the web of life, published a pioneer book entitled The Secret of Nature Discovered in the Structure and Fertitization of Flowers, in which he showed that most flowers have nectar which insects enjoy; that by the insects' visits pollination is secured; that there is no detail of the flower without its meaningthe colour is a flag to attract the insect's eye, conspicuous spots are honey-guides to the explorers, there are arrangements for keeping the pollen dry and for dusting it on the insects, and so on. If Sprengel had only discovered the utility of the cross-fertilisation, which Darwin proved experimentally, his work could hardly have been overlooked for nearly seventy years. In I84 I it came into Darwin's hands, and impressed him as being "full of truth," although "with some little nonsense." In Darwin's work Sprengel had his long-delayed reward.

Darwin's instance of the connection between cats and clover.One of Darwin's instances of the web of life - given in connection with the pollination of flowers-has become familiar all over the world. It should never become trite to us and it should never be regarded as more than a particularly clear illustration of a general fact. "Plants and animals, remote in the scale of nature, are bound together by a web of complex relations. . . . I have found, from experiments, that humble-bees are almost indispensable to the fertilisation of the heart'sease ( $V^{r}$ iola tricolor), for other bees do not visit this flower. I have also found that the visits of bees are necessary for the fertilisation of some kinds of clover-thus, too heads of red clover (Trifolinm pratense) produced 27,000 seeds, but the same number of protected hearls produced not a single seerl. Humble-bees alone visit red clover, as other bees cannot reach the nectar. . . . Hence we may infer as highly probable that, if the whole genus of humble-bees became extinct or very rare in England, the heart's-ease and red clover would become 
very rare, or wholly disappear." We know that the red clover imported to New Zealand did not bear fertile seeds until humble-bees were also imported. "The number of humble-bees in any district depends in a great measure on the number of field-mice, which destroy their combs and nests; and Colonel Newman, who has long attended to the habits of humble-bees, believes that more than two-thirds of them are thus destroyed all over England." Now the number of mice is largely dependent, as everyone knows, on the number of cats; and Colonel Newman says: "Near villages and small towns I have found the nests of humble-bees more numerous than elsewhere, which I attribute to the number of cats that destroy the mice." Thus we may say, with Darwin, that next year's crop of purple clover is influenced by the number of humble-bees in the district, which varies with the number of field-mice; that is to say, with the abundance of cats!

Scattering of seeds. - It is a fascinating chapter of natural history which tells us how cross-pollination is effected-here by a bee and there by a butterfly, occasionally by a long-billed humming-bird beautifully poised before the flower with almost invisibly rapid vibrations of its wings, and occasionally by a slowly moving snail of epicure appetite. But not less important is the part played by animals in the scattering of seeds, and here again Darwin gives us the classic case of fourscore seeds germinatung out of a ball of mud from a bird's foot. From one instance you may learn all, and see that much of Darwin's work has been an eloquent commentary on that memorable saying about the sparrow that falls to the ground. Such a simple event literaily sends a throb through surrounding nature; we can follow its effects a few steps, just as we follow for a few yards the ripples made when we throw a stone into a still lake; in either case can we doubt that the spreading influences are real, though they pass beyond our ken?

Interrelations between fresh-water mussels and fishes.-As a striking illustration of the inter-linking of different forms of life, we may take the case of the fresh-wrater mussels and their larvae. The fertilised eggs develop in the outer gill-plate of the mother-mussel, and minute bivalve larvae, called Glochidia, are formed. The mussel keeps these within the cradle until a fresh-water fish-such as the minnowcomes into the vicinity, and then she sets them free. In a way that we do not understand, the simple constitution of the larvae is tuned to respond to the presence of nimnows and the like, and with snapping valves they manage to fix themselves to their host. After a short 
period of temporary parasitism, at the end of which there is a metamorphosis, they drop off from the fish into the mud, often far from their birth-place. This is curious enough, but the idea of linkages becomes incandescent in the mind when we note that, just as the freshwater mussel has young temporarily parasitic on fishes, so a freshwater fish, the bitterling (Rhodeus amarus), has its young temporarily parasitic in the gills of the mussel.

Life-histories of parasites. - When we pass to parasites in a stricter sense we find the most extraordinary interconnections, the most widely separated animals often sharing a parasite between them. Liver-rot, which has repeatedly killed a million sheep in a year in Britain alone, is due to a parasite which passes from sheep to water, from water to water-snail, from water-snail to grass, from grass to sheep. The tapeworm of the cat has its bladder-worm stage in the mouse, the sturdie-worm of the sheep's brain has its tape-worm stage in the dog, and similar relations hold for hundreds of species. The troublesome threadworm of human blood (Filaria sanguinis hominis) is transferred from man to man by the mosquito, and the guinea-worm which was probably the fiery serpent that vexed the Israelites in the desert, which passes into man in drinking-water, spends its youth in a minute water-flea, called by the giant's name of Cyclops. The importance of tse-tse flies in transmitting the minute animals which cause sleeping-sickness and allied diseases is known to all. We have spoken of the connection between cats and clover, and there is a not less striking connection between cats and plague. For it seems to have been shown in India that the more cats the fewer rats, and the fewer rats the fewer rat-fleas, which are the agents in passing the plaguegerms to man.

Far-reaching influence of certain animals; earthworms.-IVe realise the idea of the web of life in another way when we consider the far-reaching influence of particular kinds of activity, the best instance being the work of earthworms. In I 777 Gilbert White got at the very root of the matter. "The most insignificant insects and reptiles are of much more consequence and have more influence in the economy of nature than the incurious are aware of. . . . Earthworms, though in appearance a small and despicable link in the chain of nature, yet, if lost, would make a lamentable chasm. . . . Worms seen to be the great promoters of vegetation, which would proceed but lamely without them, by boring, perforating, and loosening the soil, and rendering it pervious to rains and the fibres of plants; by drawing straws and 
stalks of leaves and twigs into it; and, most of all, by throwing up such infinite numbers of lumps of earth called worm-casts, which, being their excrement, is a fine manure for grain and grass. Worms probably provide new soil for hills and slopes where the rain washes the earth away; and they affect slopes probably to avoid being flooded. ... The earth without worms would soon become cold, hardbound, and void of fermentation, and consequently sterile..... These hints we think proper to throw out, in order to set the inquisitive and discerning at work. A good monograph of worms would afford much entertainment and information at the same time, and would open a large and new field in natural history."

The monograph that Gilbert White wished for in 1777 was published by Darwin in ISSr, the year before he died- "the completion," he said, "of a short paper read before the Geological Society more than forty years ago." With his characteristic thoroughness and patience he worked out the part that earthworms have played in the history of the earth, and proved that they deserve to be called the most useful animals. By their burrowing they loosen the earth, making way for the plant rootlets and the raindrops; by bruising the soil in their gizzards, they reduce the particles to more useful, powdery form; by burying the surface with castings brought up from beneath, they have been for untold ages ploughers before the plough, and by burying leaves they have made a great part of the vegetable mould over the whole earth. In illustration of the last point, we may notice that we recently found thirteen midrils of the leaves of the rowan, or mountain ash, radiating round one hole like the spokes of a wheel; the withering leaflets had been carried down, and two were sticking up at the mouth of the burrow; that meant gi leaflets to one hole. Darwin showerl that there often are 50,000 (and there may be 500,000) earthworms in an acre; that they often pass ten tons of soil per acre per annum through their bodies; and that they often cover the surface at the rate of three inches in fifteen years. Though our British worms only pass out about $20 \mathrm{oz}$. of earth in a year, the weights thrown up in a year on two separate square yards which Darwin watched were respectively $6.75 \mathrm{lb}$. and $8.387 \mathrm{lb}$., which correspond to $4^{\frac{1}{2}}$ and I 8 tons per acie per annum.

We follow the work furiher and it becomes evident that the constant exposure of the soil bacteria on the surface is bound to be important, on the one hand, in allowing them to be scattered by wind and rain, on the other in exposing them to the beneficent action of the 
sunlight-which is the most universal, effective, and economical of all germicides.

In Yorubaland, on the West Coast of Africa, Mr. Alvan Millson calculated that about 62,233 tons of subsoil are brought every year to the surface of each square mile, and that every particle of earth, to the depth of two feet, is brought to the surface once in twenty-seven years. It need hardly be added that the district is fertile and healthy.

Earthworms play their part in the disintegration of rocks, letting the solvent humus-acids of the soil down to the buried surface. Their castings on the hill-slopes are carried down by wind and rain and go to swell the alluvium of the distant valleys or the wasted treasures of the sea. The well-known parallel leclges along the slopes of grass-clad hills are partly due to earthworm castings caught on sheep-tracks, and thus we begin to connect the earthworms not only with our wheatsupply but with our scenery. Well may we say, with Darwin: "It may be doubted whether there are many other animals which have played so important a part in the history of the world as have these lowly organised creatures." Those who wish to understand Darwinism should always begin with Darwin's last book-The Formation of Vegetable Mould through the Action of IVorms (r88r). It illustrates the web of life, the idea of which is essential to an understanding of the struggle for existence and natural selection. But it also illustrates what Darwin had learned from Lyell-that great results may be brought about by accumulation of infinitesimal items. As Professor A. Milnes Marshall said: "The lesson to be derived from Darwin's life and work cannot be better expressed than as the cumulative importance of infinitely little things."

Termites, or white ants.-Henry Drummond, in his Tropical Africa, tried to make out a case for the agricultural importance of termites, or white ants. It is well known that these old-fashioned insects have a pruning action in the forest, destroying dead wood with great rapidity. Houses and furniture, fences and boxes, as well as forest-trees, fall under their jaws. In some places, "if a man lay down to sleep with a wooden leg, it would be a heap of sawdust in the morning." But what of the termites' agricultural importance? The point is that they keep the soil circulating by constructing earthen tunnels up the sides of trees and posts and by making huge obelisk-like ant-hills, or termitaries. "The earth-tubes crumble to dust, which is scattered by the wind; the rains lash the forests and soils with fury, and wash off the loosened grains to swell the alluvium of a distant 
valley." It must be noted, however, that Drummond did not prove his case with sufficient precision, and there is, as Escherich points out in his beautiful study of termites, this difficulty, that, while the castings of earthworms are soft and loose, the earth-tubes and constructions of termites are stony.

Escherich does, however, admit that the termites have some agricultural importance, and he points out that there are other services to be put to the credit side of their account. They prune off wood that has begun to go; they destroy rotting things, including the bodies of small animals; they make for cleanliness and health. In some low-lying tracts, as Silvestri has shown, there are dry stretches, "termite islands," which have been gradually built up from the broken-down remains of termitaries. Nor should it be forgotten that the white ants are often used as food. On the other hand, Escherich does not hesitate to rank them as among the great hindrances to the spread of civilisation. They insidiously devour everything wooden, from the telegraph-post to the wooden butt of the gun hanging against the wall, from books in the library to corks in the cellar. There does not seem sufficiently precise information in regard to the living plants that they attack, and no safe general statement can be made except that their appetite is large and catholic.

With a centre in earti.worms, what a variety of interests must be included within the radius of their life and work!-centipedes, birds, moles, seedlings, man. The same is true of termites, and two further illustrations may be given. Observers have reported about thirty different species of termites with the habit of feeding on fungi grown within the termitary on specially constructed mazy beds. The habit is interesting in many ways; for instance, because the fungi afford a supply of nitrogenous material which is scarce in the ordinary diet of wood, and also because a similar habit occurs in the quite unrelated true ants. Finally, the web is illustrated by the numerous boarders, mostly beetles, that are found in the termitaries-not hostile intruders or parasites, but guests which are fed and cared for apparently for the sake of a palatable exudation with a pleasant, narcotising effect on the termites. With a centre in termites, what a variety of interests must we not include within the radius of their life and work!- - fungi and trees, beetles and birds, lizards and anteaters, and man more than any.

The hand of life upon the earth.-The hand of life has been working upon the earth for untold ages. Take plants, for instance. The seaweeds lessen the force of the waves, the lichens eat into the 
rocks, the mosses form huge sponges on the moors which keep the streams flowing in days of drought. Nany little plants are forever smoothing away the wrinkles on the earth's--their mother's-face, and they adorn her with jewels. Others that have formed coal have enriched her with ages of entrapped sunlight. The grass - which began to appear in Tertiary ages-protects the earth like a garment; the forests affect rainfall and temper climate, besides sheltering multitudes of living things, to many of whom every blow of the axe is a deathknell. No plant, from bacterium to oak-tree, lives or dies to itself, or is without its influence upon the earth. So among animals there are destructive borers and burrowers and conservative agents, such as the coral-polyps and the chalk-forming Foraminifera.

Practical importance of a realisation of the web of life-What has Darwinism to do with human life? The answer at this stage in our inquiry is clear: we must respect the web of life if we wish to master Nature. She must be humoured, not bullied. Emerson inclucled in his vision of a perfected earth the absence of spiders, but the absence of spiders-which snare so many injurious insects-would mean the alssence of much else, man probably included. In a northern county in Scotland the proprietors were justly annoyed at the injuries inflicted on young trees by squirrels, and they formed a squirrel club), setting a price on the beautiful rodent's head. Perhaps a wiser course would have been to begin by inquiring what disturbance of the balance of nature had allowed the squirrels to multiply so disastrously. But, after a period of squirrel-slaughter and some jubilation thereat, a cloud legan to rise in the sky. The wood-pigeons were multiplying worse than ever, and the farmers, at least, said with no uncertain voice that they preferred the squirrels. An imperfect recognition of the web of life had left out of account the notable fact that squirrels destroy large numbers of young wood-pigeons.

One of the hopeful symptoms of the last few years is the reawakening of an interest in woods and forests. Everyone knows how terribly these have been wasted, and how the disastrous results have affected rainfall and irrigation, climate and crops, and even the character of the people. Here what was once a pleasant stream is now like a gravelly road, and there the fertile plains are flooded; here the wind is sweeping away the soil, and there both beauty and health have departed. The birds which the woods once sheltered are driven elsewhere, and the insect-pests are rife among the crops. For "the cheapest and most efiective insecticides are birds." 
The recognition of consequences-often far-reaching-grows with us as we work with the idea of the web of life, as we see in proper perspective the criminality of those who are ruthless. President Roosevelt has declared his abomination of "the land-skinner"- "the individual whose idea of developing the country is to cut every stick of timber off it, and then leave a barren desert for the home-maker who comes in after him. That man is a curse, and not a blessing to the country. The prop of the country must be the man who intends so to run bis business that it will be profitable to his children after him." Every right-thinking man, and especially those who have grasped the idea of the web of life, will say with Roosevelt, "I am against the landskinner every time."

It may be said that man must exterminate a good deal if he is to go on peaceably with his business, and it will be admitted that there has never been a strong enthusiasm, humanitarian or otherwise, against the elimination of rattlesnakes, and such like. The naturalist's answer is that every crusade should be carefully considered on its own merits, and that every careless and hasty destruction of life is to be condemned. Even in regard to snakes killing may be carried too far. Some creatures are, as it were, on the fringes of the web, while others occupy a position where many threads meet. It is scientifically and aesthetically deplorable that birds like the great auk and mammals like the quagga should have been exterminated, but it is practically much more deplorable that we have lost so many hawks and weasels and other members of that pertinacious army whose guerilla warfare keeps hundreds of more humdrum creatures up to the scratch, and keeps "vermin" from becoming a plague. Moreover, it is extremely difficult to tell what may be the consequences of exterminating any creature-remote as it may seem from the beaten track of human affairs. One of the obvious lessons of Darwinism is that we should be slow to call any change unimportant. Everything counts, or may count. A so-called unimportant animal is destroyed and no immediate ill effects are seen. But who can tell?

Very pertinent, for instance, is the question: What about the parasites that used to complete their life-history in romantic routine in this extinguished animal? Have we extinguished the parasite also? Or is it waiting, with a whip of scorpions, to chastise mankind for their ignorance of Darwinism?

The practical importance of recognising the web of life has been proved by the heary penalties which man has often had to pay for 
disturbing the balance of nature, carcless of results and ruthless of beauty, for not admitting that if we would master Nature we must first understand her. How much has Australia had to pay for the introduction of rabbits in 1860 , or America for sparrows? Sometimes the introduction has been unconscious, and man has only to blame himself for letting the intruder take hold, as in the case of the Phylloxera in France, or of the Colorado Beetle in Ireland. "Ignorance of nature," Mr. A. H. S. Lucas say's, "is costly. By disturbing the balance of nature, man has introduced foes into his own household." Speaking of Australia, he says: "How much is needed for the eradication of Bathurst Burr, Prickly Pear, Water-hyacinth, Bramble and Sweetbriar, Codlin Moth, Waxy Scale, Pear Slug, and Red Spider. owing to carelessness or lack of knowledge in early days ?"

An obvious moral is that we should be careful in our introductions of new organisms - man included-into new surroundings. The primary consequences may be predictable, but the secondary and the tertiary conscquences-who is sufficient for these things? We have records of the unconscious introduction of rats into Jamaica, where they became a pest. To destroy them mongooses were imported, and the rats were soon checked. But the mongooses, having finished the rats, began to eat up the poultry and young birds of various kinds. As this went on the injurious insects and ticks, that the birds used to eat, began to gain the ascendant. A recent report-which requires confirmation-says that the increase of ticks is making life a burden to the mongooses. Thus a balance will be again arrived at. There is no doubt of that, but how much is often unnecessarily lost by the way! 


\section{CHAPTER XVI}

\section{NATURAL SELECTION}

CHARLES DARIVIN

INTRODUCTORY Note.-This entire chapter is made up of carefully chosen passages from Darwin's Origin of Species. So much has falsely been called "Darwinism" that it is well for the reader to have a statement of Darwin's views in his own words. Every student of evolution should read the whole of the Origin of Species. It is all so good that one finds it difficult to leare out anything. The following excerpts will, we believe, give the gist of natural selection.

We present first certain of the ideas that underlie or are postulates of the theory; then the theory itself is presented; the theory of sexual selection interpolated; and then follow examples of the way in which adaptations are accounted for by natural selection. Darwin's own statement of the most serious difficulties and objections to the theory, and his answers to these, bring this chapter to a close.

\section{FOUNDATION STONES OF NATLRAL SELECTION}

DARWIN'S OWN ESTIMATE AS TO THE RÔLE OF NATURAL SELECTION IN EVOLUTION

No one ought to feel surprised at much remaining as yet unexplained in regard to the origin of species and varieties, if he make due allowance for our profound ignorance in regard to the mutual relations of the many beings which live around us. Who can explain why one species ranges widely and is very numerous, and why another allied species has a narrow range and is rare? Yet these relations are of the highest importance, ior they determine the present welfare and, as I believe, the future success and modification of every inhabitant of this world. Still less do we know of the mutual relations of the innumerable inhabitants of the world during the many past geological epochs in its history. Although much remains obscure, and will long remain obscure, I can entertain no doubt, after the most deliberate study and dispassionate judgment of which I am capable, that the view which most naturalists until recently entertained, and which I formerly entertained-namely, that each species has been independently created-is erroneous. I am fully convinced that species are not immutable; but that those belonging to what are called the same genera are lineal descendants of some other and generally extinct species, in the same manner as the acknowledged varieties of any one species are the descendants of that species. Furthermore, I am convinced that Natural Selection has been the most important, but not the exclusive, means of modification. 


\section{EFFECTS OF IIABIT AND OF THE USE OR DISUSE OF,PARTS; CORRELATED VARIATION; INHERITANCE}

Changed habits produce an inherited effect, as in the period of the flowering of plants when transported from one climate to another. With animals the increased use or disuse of parts has had a more marked influence; thus I find in the domestic duck that the bones of the wing weigh less and the bones of the leg more, in proportion to the whole skeleton, than do the same bones in the wild-duck; and this change may be safely attributed to the domestic duck flying much less, and walking more, than its wild parents. The great and inherited development of the uddlers in cows and goats in countries where they arc habitually milked, in comparison with these organs in other countries, is probably another instance of the effects of use. Not one of our domestic animals can be named which has not in some country drooping ears; and the view, which has been suggested that the drooping is due to disuse of the muscles of the ear, from the animals being seldom much alarmed, seems probable.

Many laws regulate variation, some few of which can be dimly seen, and will hereafter be briefly discussed. I will here only allude to what may be called correlated variation. Important changes in the embryo or larva will probably cntail changes in the mature animal. In monstrosities, the correlations between quite distinct parts are very curious; and many instances are given in Isidore Geoffroy St. Hilaire's great work on this subject. Breeders believe that long limbs are almost always accompanied by an elongated head. Some instances of correlation are quite whimsical: thus cats which are entircly white and have blue eyes are generally deaf; but it has been lately stated by Mr. Tait that this is confined to the males. Color and constitutional peculiarities go together, of which many remarkable cases could be given amongst animals and plants. From facts collected by Heusinger, it appears that white sheep and pigs are injured by certain plants, whilst dark-colored individuals escape: Professor Wyman has recently communicated to me a good illustration of this fact; on asking some farmers in Virginia how it was that all their pigs were black, they informed him that the pigs ate the paint-root (Lachnanthes), which colored their bones pink, and which caused the hoofs of all but the black varieties to drop off; and one of the "crackers" (i.e., Virginia squatters) added, "we select the black members of a litter for raising, as they alone have a good chance of living." Hairless dogs have imperfect teeth; long-haired and coarse-haired animals are apt to 
have, as is asserted, long or many horns; pigeons with feathered feet have skin between their outer toes; pigeons with short beaks have small feet, and those with long beaks large feet. Hence if man goes on selecting, and thus augmenting, any peculiarity, he will almost certainly modify unintentionally other parts of the structure, owing to the mysterious laws of correlation.

DARWIN'S IDEA OF THE CAUSES RESPONSIBLE FOR THE ORIGIN OF DOMESTIC RACES

To sum up on the origin of our domestic races of animals and plants. Changed conditions of life are of the highest importance in causing variability, both by acting directly on the organization, and indirectly by affecting the reproductive system. It is not probable that variability is an inherent and necessary contingent, under all circumstances. The greater or less force of inheritance and reversion determine whether variations shall endure. Variability is governed by many unknown laws, of which correlated growth is probably the most important. Something, but how much we do not know, may be attributed to the definite action of the conditions of life. Some, perhaps a great, effect may be attributed to the increased use or disuse of parts. The final result is thus rendered infinitely complex. In some cases the intercrossing of aboriginally distinct species appears to have played an important part in the origin of our breeds. When several breeds have once been formed in any country, their occasional intercrossing, with the aid of selection, has, no doubt, largely aided in the formation of new sub-breeds; but the importance of crossing has been much exaggerated, both in regard to animals and to those plants which are propagated by seed. With plants which are temporarily propagated by cuttings, buds, etc., the importance of crossing is immense; for the cultivator may here disregard the extreme variability both of hybrids and of mongrels, and the sterility of hybrids; but plants not propagated by seed are of little importance to us, for their endurance is only temporary. Over all these causes of Change, the accumulative action of Selection, whether applied methodically and quickly, or unconsciously and slowly but more efficiently, seems to have been the predominant Power.

DARWIN'S IDEA OF THE ORIGIN OF VARIETIES, SPECIES, AND GENERA IN NATURE

Finally, varieties cannot be distinguished from species-except, first, by the discovery of intermediate linking forms; and, secondly, by a certain indefinite amount of difference between them; for two 


\section{READINGS IN EVOLUTION, GENETICS, AND EUGENICS}

forms, if differing very little, are generally ranked as varieties, notwithstanding that they cannot be closely connected; but the amount of difference considered necessary to give to any two forms the rank of species cannot be defined. In genera having more than the average number of species in any country, the species of these genera have more than the average number of varieties. In large genera the species are apt to be closely, but unequally, allied together, forming little clusters round other species. Species very closely allied to other species apparently have restricted ranges. In all these respects the species of large genera present a strong analogy with varieties. And we can clearly understand these analogies, if species once existed as varieties, and thus originated; whereas, these analogies are utterly inexplicable if species are independent creations.

We have, also, seen that it is the most flourishing or dominant species of the larger genera within each class which on an average yield the greatest number of varieties; and varieties, as we shall hereafter see, tend to become converted into new and distinct species. 'Thus the larger genera tend to become larger; and throughout nature the forms of life which are now dominant tend to become still more dominant by leaving many modified and dominant descendants. But by steps hereafter to be explained, the larger genera also tend to break up into smaller genera. And thus, the forms of life throughout the universe become divided into groups subordinate to groups.

THE TERM "STRUGGLE FOR EXISTENCE" USED IN A LARGE SENSE

I should premise that I use this term in a large and metaphorical sense including dependence of one being on another, and including (which is more important) not only the life of the individual, but success in leaving progeny. Two canine animals, in a time of dearth, may be truly said to struggle with each other which shall get food and live. But a plant on the edge of a desert is said to struggle for life against the drought, though more properly it should be said to be dependent on the moisture. A plant which annually produces a thousand seeds, of which only one of an average comes to maturity, may be more truly said to struggle with the plants of the same and other kinds which already clothe the ground. The mistletoe is dependent on the apple and a few other trees, but can only in a far-fetched sense be said to struggle with these trees, for, if too many of these parasites grow on the same tree, it languishes and dies. But several secdling mistletoes, growing close together on the same branch, 
may more truly be said to struggle with each other. As the mistletoe is disseminated by birds, its existence depends on them; and it may metaphorically be said to struggle with other fruit.bearing plants, in tempting the birds to devour and thus disseminate its seeds. In these several senses, which pass into each other, I use for convenience' sake the general term of Struggle for Existence.

GEOMETRICAL RATIO OF IXCREASE

A struggle for existence inevitably follows from the high rate at which all organic beings tend to increase. Every being, which during its natural lifetime produces several eggs or seeds, must suffer destruction during some period of its life, and during some season or occasional year, otherwise, on the principle of geometrical increase, its numbers would quickly become so inordinately great that no country could support the product. Hence, as more individuals are produced than can possibly survive, there must in every case be a struggle for existence, either one individual with another of the same species, or with the individuals of distinct species, or with the physical conditions of life. It is the doctrine of Malthus applied with manifold force to the whole animal and vegetable kingdoms; for in this case there can be no artificial increase of food, and no prudential restraint from marriage. Although some species may be now increasing, more or less rapidly, in numbers, all cannot do so, for the world would not hold them.

NATURAL SELECTION; OR THE SURVIVAL OF THE FITTEST

How will the struggle for existence, briefly discussed in the last chapter, act in regard to variation? Can the principle of selection, which we have seen is so potent in the hands of man, apply under nature? I think we shall see that it can act most efficiently. Let the endless number of slight variations and individual differences occurring in our domestic productions, and, in a lesser degree, in those under nature, be borne in mind; as well as the strength of the hereditary tendency. Under domestication, it may be truly said that the whole organization becomes in some degree plastic. But the variability, which we almost universally meet with in our domestic productions, is not directly produced, as Hooker and Asa Gray have well remarked, by man; he can neither originate varieties, nor prevent their occurrence; he can only preserve and accumulate such as do occur. Unintentionally he exposes organic beings to new and changing conditions 
of life, and variability ensues; but similar changes of conditions might and do occur under nature. Let it also be borne in mind how infinitely complex and close-fitting are the mutual relations of all organic beings to each other and to their physical conditions of life; and consequently what infinitely varied diversities of structure might be of use to each being under changing conditions of life. Can it, then, be thought improbable, seeing that variations useful to man have undoubtedly occurred, that other variations useful in some way to each being in the great and complex battle of life, should occur in the course of many successive generations? If such do occur, can we doubt (remembering that many more individuals are born than can possibly survive) that individuals having any advantage, however slight, over others, would have the best chance of surviving and of procreating their kind? On the other hand, we may feel sure that any variation in the least degree injurious would be rigidly destroyed. This preservation of favorable individual differences and variations, and the destruction of those which are injurious, I have called Natural Selection, or the Survival of the Fittest. Variations neither useful nor injurious would not be affected by natural selection, and would be left either a fluctuating element, as perhaps we see in certain polymorphic species, or would ultimately become fixed, owing to the nature of the organism and the nature of the conditions.

Several writers have misapprehended or objected to the term Natural Selection. Some have even imagined that natural selection induces variability, whereas it implies only the preservation of such variations as arise and are beneficial to the being under its conditions of life. No one objects to agriculturists speaking of the potent effects of man's selection; and in this case the individual differences given by nature, which man for some object selects, must of necessity first occur. Others have objected that the term selection implies conscious choice in the animals which become modified; and it has even leen urged that, as plants have no volition, natural selection is not applicable to them! In the literal sense of the word, no doubt, natural selection is a false term; but who ever objected to chemists speaking of the elective affinities of the various elements?-and yet an acid cannot strictly be said to elect the base with which it in preference combines. It has been said that I speak of natural selection as an active power or Deity; but who objects to an author speaking of the attraction of gravity as ruling the movements of the planets? Everyone knows what is meant and is implied by such metaphorical expres- 
sions; and they are almost necessary for brevity. So again it is difficult to avoid personifying the word Nature; but I mean by Nature only the aggregate action and product of many natural laws, and by laws the sequence of events as ascertained by us. With a little familiarity such superficial objections will be forgotten.

We shall best understand the probable course of natural selection by taking the case of a country undergoing some slight physical change, for instance, of climate. The proportional numbers of its inhabitants will almost immediately undergo a change, and some species will probably become extinct. We may conclude, from what we have seen of the intimate and complex manner in which the inhabitants of each country are bound together, that any change in the numerical proportions of the inhabitants, independently of the change of climate itself, would seriously affect the others. If the country were open on its borders, new forms would certainly immigrate, and this would likewise seriously disturb the relations of some of the former inhabitants. Let it be remembered how powerful the influence of a single introduced tree or mammal has been shown to be. But in the case of an island, or of a country partly surrounded by barriers, into which new and better adapted forms could not freely enter, we should then have places in the economy of nature which would assuredly be better filled up, if some of the original inhabitants were in some manner modified; for, had the area been open to immigration, these same places would have been seized on by intruders. In such cases, slight modifications, which in any way favored the individuals of any species by better adapting them to their altered conditions, would tend to be preserved; and natural selection would have free scope for the work of improvement.

We have good reason to believe, as shown in the first chapter, that changes in the conditions of life give a tendency to increased variability and in the foregoing cases the conditions have changed, and this would manifestly be favorable to natural selection, by affording a better chance of the occurrence of profitable variations. Unless such occur, natural selection can do nothing. Under the term of "variations," it must never be forgotten that mere individual differences are included. As man can produce a great result with his domestic animals and plants by adding up in any given direction individual differences, so could natural selection, but far more easily from having incomparably longer time for action. Nor do I believe that any great physical change, as of climate, or any unusual degree of isolation to check immigration, 
is necessary in order that new and unoccupied places should be left, for natural selection to fill up by improving some of the varying inhabitants. For as all the inhabitants of each country are struggling together with nicely balanced forces, extremely slight modifications in the structure or habits of one species would often give it an advantage over others; and still further modifications of the same kind would often still further increase the advantage, as long as the species continued under the same conditions of life and profited by similar means of subsistence and defense. No country can be named in which all the native inhabitants are now so perfectly adlapted to each other and to the physical conditions under which they live, that none of them could be still better adapted or improved; for in all countries, the natives have been so far conquered by naturalized productions, that they have allowed some foreigners to take firm possession of the land. And as foreigners have thus in every country beaten some of the natives, we may safely conclude that the natives might have been modified with advantage, so as to have better resisted the intruders.

As man can produce, and certainly has produced, a great result by his methodical and unconscious means of selection, what may not natural selection effect? Man can act only on external and visible characters: Nature, if I may be allowed to personify the natural preservation or survival of the fittest, cares nothing for appearances, except in so far as they are useful to any being. She can act on every internal organ, on every shade of constitutional difference, on the whole machinery of life. Man selects only for his own good: Nature only for that of the being which she tends. Every selected character is fully exercised by her, as is implied by the fact of their selection. Man keeps the natives of many climates in the same country; he seldom exercises each selected character in some peculiar and fitting manner; he feeds a long-and a short-beaked pigeon on the same food; he does not exercise a long-backed or long-legged quadruped in any peculiar manner; he exposes sheep with long and short wool to the same climate. He does not allow the most vigorous males to struggle for the females. He does not rigidly destroy all inferior animals, but protects during each varying season, as far as lies in his power, all his productions. He often begins his selection by some half-monstrous form; or at least by some modification prominent enough to catch the eye or to be plainly useful to liim. Under nature, the slightest differences of structure or constitution may well turn the nicely balanced scale in the struggle for lie, and so be preserved. How fleeting are the 
wishes and efforts of man! how short his time! and consequently how poor will be his results, compared with those accumulated by Nature during whole geological periods! Can we wonder, then, that Nature's productions should be far "truer" in character than man'sproductions; that they should be infinitely better adapted to the most complex conditions of life, and should plainly bear the stamp of far higher workmanship?

It may metaphorically be said that natural selection is daily and hourly scrutinizing, throughout the world, the slightest variations; rejecting those that are bad, preserving and adding up all that are good; silently and insensibly working whenever and wherever opportunity offers, at the improvement of each organic being in relation to its organic and inorganic conditions of life. We see nothing of these slow changes in progress, until the hand of time has marked the lapse of ages, and then so imperfect is our view into long-past geological ages, that we see only that the forms of life are now different from what they formerly were.

In order that any great amount of modification should be effected in a species, a variety when once formed must again, perhaps after a long interval of time, vary or present individual differences of the same favorable nature as before; and these must be again preserved, and so onwards step by step. Seeing that individual differences of the same kind perpetually recur, this can hardly be considered as an unwarrantable assumption. But whether it is true, we can judge only by seeing how far the hypothesis accords with and explains the general phenomena of nature. On the other hand, the ordinary belief that the amount of possible variation is a strictly limited quantity is likewise a simple assumption:

Although natural selection can act only through and for the good of each being, yet characters and structures, which we are apt to consider as of very trifling importance, may thus be acted on. When we see leaf-eating insects green, and bark-feeders mottled-gray; the alpine ptarmigan white in winter, the red-grouse the color of heather, we must believe that these tints are of service to these birds and insects in preserving them from danger. Grouse, if not destroyed at some period of their lives, would increase in countless numbers; they are known to suffer largely from birds of prey; and hawks are guided by eyesight to their prey-so much so, that on parts of the Continent persons are warned not to keep white pigeons, as being the most liable to destruction. Hence natural selection might be effective in giving 


\section{READINGS IN EVOLUTION, GENETICS, AND EUGENICS}

the proper color to each kind of grouse, and in keeping that color, when once acquired, true and constant. Nor ought we to think tha" the occasional destruction of an animal of any particular color woulu produce little effect: we should remember how essential it is in a flock of white sheep to destroy a lamb with the faintest trace of black. We have seen how the color of the hogs, which feed on the "paint-root" in Virginia, determines whether they shall live or die. In plants, the down on the fruit and the color of the flesh are considered by botanists as characters of the most trifling importance: yet we hear from an excellent horticulturist, Downing, that in the United States smoothskinned fruits suffer far more from a beetle, a Curculio, than those with down; that purple plums suffer far more from a certain disease than yellow plums; whereas another disease attacks yellow-fleshed peaches far more than those with other colored flesh. If, with all the aids of art, these slight differences make a great difference in cultivating the several varieties, assuredly, in a state of nature, where the trees would have to struggle with other trees and with a host of enemies, such differences would effectually settle which variety, whether a smooth or downy, a yellow- or purple-fleshed fruit, should succeed.

In looking at many small points of difference between species, which, as far as our ignorance permits us to judge, seem quite unimportant, we must not forget that climate, food, etc., have no doubt produced some direct effect. It is also necessary to bear in mind that, owing to the law of correlation, when one part varies, and the variations are accumulated through natural selection, other modifications, often of the most unexpected nature, will ensue.

As we see that those variations which, under domestication, appear at any particular period of life, tend to reappear in the offspring at the same period; for instance, in the shape, size, and flavor of the seeds of the many varieties of our culinary and agricultural plants; in the caterpillar and cocoon stages of the varieties of the silk-worm; in the eggs of poultry, and in the color of the down of their chickens; in the horns of our sheep and cattle when nearly adult; so in a state of nature natural selection will be enabled to act on and modify organic beings at any age, by the accumulation of variations profitable at that age, and by their inheritance at a corresponding age. If it profit a plant to have its seeds more and more widcly disseminated by the wind, I can see no greater difficulty in this being effected through natural selection, than in the cotton-planter increasing and improving by selection the down in the pods on his cotton-trees. Natural 
selection may modify and adapt the larva of an insect to a score of contingencies, wholly different from those which concern the mature insect; and these modifications may affect, through correlation, the structure of the adult. So, conversely, modifications in the adult may affect the structure of the larva; but in all cases natural selection will ensure that they shall not be injurious: for if they were so, the species would become extinct.

Natural selection will modify the structure of the young in relation to the parent, and of the parent in relation to the young. In social animals it will adapt the structure of each individual for the benefit of the whole community, if the community profits by the selected change. What natural selection cannot do, is to modify the structure of one species, without giving it any advantage, for the good of another species; and though statements to this effect may be found in works of natural history, I cannot find one case which will bear investigation. A structure used only once in an animal's life, if of high importance to it, might be modified to any extent by natural selection; for instance the great jaws possessed by certain insects, used exclusively for opening the cocoon-or the hard tip to the beak of unhatched birds, used for breaking the egg. It has been asserted, that of the best shortbeaked tumbler-pigeons a greater number perish in the egg than are able to get out of it; so that fanciers assist in the act of hatching. Now if nature had to make the beak of a full-grown pigeon very short for the bird's own advantage, the process of modification would be very slow, and there would be simultaneously the most rigorous selection of all the young birds within the egg, which had the most powerful and hardest beaks, for all with weak beaks would inevitably perish; or, more delicate and more easily broken shells might be selected, the thickness of the shell being known to vary like every other structure.

It may be well here to remark that with all beings there must be much fortuitous destruction, which can have little or no influence on the course of natural selection. For instance a vast number of eggs or seeds are annually devoured, and these could be modified through natural selection only if they varied in some, manner which protected them from their enemies. Yet many of these eggs or seeds would perhaps, if not destroyed, have yielded individuals better adapted to their conditions of life than any of those which happened to survive. So again a vast number of mature animals and plants, whether or not they be the best adapted to their conditions, must be annually 
destroyed by accidental causes, which would not be in the least degree mitigated by certain changes of structure or constitution which would in other ways be beneficial to the species. But let the destruction of the adults be ever so heavy, if the number which can exist in any district be not wholly kept down by such causes, or again let the destruction of eggs or seeds be so great that only a hundredth or a thousandth part are developed, yet of those which do survive, the hest adapted individuals, supposing that there is any variability in a favorable direction, will tend to propagate their kind in larger numbers than the less well adapted. If the numbers be wholly kept down by the causes just indicated, as will often have been the case, natural selection will be powerless in certain beneficial directions; but this is no valid objection to its efficiency at other times and in other ways; for we are far from having any reason to suppose that many species ever undergo modification and improvement at the same time in the same area.

\section{SEXUAL SELECTION}

Inasmuch as peculiarities often appear under domestication in one sex and become hereditarily attached to that sex, so no doubt it will be under nature. Thus it is rendered possible for the two sexes to be modified through natural selection in relation to different habits of life, as is sometimes the case; or for one sex to be modified in relation to the other sex, as commonly occurs. This leads me to say a few words on what I have called Sexual Selection. This form of selection depends, not on a struggle for existence in relation to other organic beings or to external conditions, but on a struggle between the individuals of one sex, generally the males, for the possession of the other sex. The result is not death to the unsuccessful competitor, but few or no offspring. Sexual selection is, therefore, less rigorous than natural selection. Generally, the most vigorous males, those which are best fitted for their places in nature, will leave most progeny. But in many cases, victory depends not so much on general vigor, as on having special weapons, confined to the male sex. A hornless stag or spurless cock would have a poor chance of leaving numerous offspring. Sexual selection, by always allowing the victor to breed, might surely give indomitable courage, length to the spur, and strength to the wing to strike in the spurred leg, in nearly the same manner as does the brutal cock-fighter by the careful selection of his best cocks. How low in the scale of nature the law of battle descends, I know not; male alligators have been described as fighting, bellowing, and whirl- 
ing around, like Indians in a war-dance, for the possession of the females; male salmons have been observed fighting all day long; male stag-beetles sometimes bear wounds from the huge mandibles of other males; the males of certain hymenopterous insects have been frequently seen by that inimitable observer M. Fabre, fighting for a particular female who sits by, an apparently unconcerned beholder of the struggle, and then retires with the conqueror. The war is, perhaps, severest between the males of polygamous animals, and these seem oftenest provided with special weapons. The males of carnivorous animals are already well armed; though to them and to others, special means of defense may be given through means of sexual selection, as the mane of the lion, and the hooked jaw to the male salmon; for the shield may be as important for victory as the sword or spear.

Amongst birds, the contest is often of a more peaceful character. All those who have attended to the subject believe that there is the severest rivalry between the males of many species to attract, by singing, the females. The rock-thrush of Guiana, birds of paradise, and some others, congregate; and successive males display with the most elaborate care, and show off in the best manner, their gorgeous plumage; they likewise perform strange antics before the females, which, standing by as spectators, at last choose the most attractive partner. Those who have closely attended to birds in confinement well know that they often take individual preferences and dislikes: thus Sir R. Heron has described how a pied peacock was eminently attractive to all his hen birds. I cannot here enter on the necessiry details; but if man can in a short time give beauty and an elegant carriage to his bantams, according to his standard of beauty, I can see no good reason to doubt that female birds, by selecting, during thousands of generations, the most melodious or beautiful males, according to their standard of beauty, might produce a marked effect. Some well-known laws, with respect to the plumage of male and female birds, in comparison with the plumage of the young, can partly be explained through the action of sexual selection on variations occurring at different ages, and transmitted to the males alone or to both sexes at corresponding ages; but I have not space here to enter on this subject.

Thus it is, as I believe, that when the males and females of any animal have the same general habits of life, but differ in structure, color, or ornament, such differences have been mainly caused by sexual 


\section{READINGS IN EVOLUTION, GENETICS, AND EUGENICS}

selection: that is, by individual males having had, in successive generations, some slight advantage over other males, in their weapons, means of defence, or charms, which they have transmitted to their male offspring alone. Yet, I would not wish to attribute all sexual differences to this agency: for we see in our domestic animals peculiarities arising and becoming attached to the male sex, which apparently have not been augmented through selection by man. 'The tuft of hair on the breast of the wild turkey-cock cannot be of any use, and it is doubtful whether it can be ornamental in the eyes of the female bird; indeed, had the tuft appeared under domestication, it would have been called a monstrosity.

ILLUSTRATIONS OF THE ACTION OF NATURAL SELECTION, OR THE SURVIVAL OF THE FITTEST

In order to make it clear how, as I believe, natural selection acts, I must beg permission to give one or two imaginary illustrations. Let us take the case of a wolf, which preys on various animals, securing some by craft, some by strength, and some by fleetness; and let us suppose that the fleetest prey, a deer for instance, had from any change in the country increased in numbers, or that other prey had decreased in numbers, during that season of the year when the wolf was hardest pressed for food. Under such circumstances the swiftest and slimmest wolves would have the best chance of surviving and so be preserved or selected, provided always that they retained strength to master their prey at this or some other period of the year, when they were compelled to prey on other animals. I can see no more reason to doubt that this would be the result, than that man should be able to improve the fleetness of his greyhounds by careful and methodical selection, or by that kind of unconscious selection which follows from each man trying to keep the best dogs without any thought of modifying the breed. I may add, that, according to Mr. Pierce, there are two varieties of the wolf inhabiting the Catskill Mountains, in the United States, one with a light greyhound-like form, which pursues deer, and the other more bulky, with shorter legs, which more frequently attacks the shepherd's flocks.

It should be observed that, in the above illustration, I speak of the slimmest individual wolves, and not of any single strongly marked variation having been preserved. In former editions of this work I sometimes spoke as if this latter alternative had frequently occurred. I saw the great importance of individual differences, and this led me fully to discuss the results of unconscious selection by man, which 
depends on the preservation of all the more or less valuable individuals, and on the destruction of the worst. I saw, also, that the preservation in a state of nature of any occasional deviation of structure, such as a monstrosity, would be a rare event; and that, if at first preserved, it would generally be lost by subsequent intercrossing with ordinary individuals. Nevertheless, until reading an able and valuable article in the North British Review (I867), I did not appreciate how rarely single variations, whether slight or strongly marked, could be perpetuated. The author takes the case of a pair of animals, producing during their lifetime two hundred offspring, of which, from various causes of destruction, only two on an average survive to pro-create their kind. This is rather an extreme estimate for most of the higher animals, but by no means so for many of the lower organisms. He then shows that if a single individual were born, which varied in some manner, giving it twice as good a chance of life as that of the other individuals, yet the chances would be strongly against its survival. Supposing it to survive and to breed, and that half its young inherited the favorable variation; still, as the Reviewer goes on to show, the young would have only a slightly better chance of surviving and breeding; and this chance would go on decreasing in the succeeding generations. The justice of these remarks cannot, I think, be disputed. If, for instance, a bird of some kind could procure its food more easily by having its beak curved, and if one were born with its beak strongly curved, and which consequently flourished, nevertheless there would be a very poor chance of this one individual perpetuating its kind to the exclusion of the common form; but there can hardly be a doubt, judging by what we see taking place under domestication, that this result would follow from the preservation during many generations of a large number of individuals with more or less strongly curved beaks, and from the destruction of a still larger number with the straightest beaks.

SUMMARY OF CHAPTER ON NATURAL SELECTION

If under changing conditions of life organic beings present individual differences in almost every part of their structure, and this cannot be disputed; if there be, owing to their geometrical rate of increase, a severe struggle for life at some age, season, or year, and this certainly cannot be disputed; then, considering the infinite complexity of the relations of all organic beings to each other and to their conditions of life, causing an infinite diversity in structure, constitution, and habits, to be advantageous to them, it would be a most 


\section{READLNGS IN EVOLUTION, GENETICS, AND EUGENICS}

extraordinary fact if no variations had ever occurred useful to eacl being's own welfare, in the same manner as so many variations have occurred useful to man. But if variations useful to any organic being ever do occur, assuredly individuals thus characterized will have the best chance of being preserved in the struggle for life; and from the strong principle of inheritance, these will tend to produce offspring similarly characterized. This principle of preservation, or the survival of the fittest, I have called Natural Selection. It leads to the improvement of each creature in relation to its organic and inorganic conditions of life; and consequently, in most cases, to what must be regarded as an advance in organization. Nevertheless, low and simple forms will long endure if well fitted for their simple conditions of life.

Natural selection, on the principle of qualities being inherited at corresponding ages, can modify the egg, seed, or young, as easily as the adult. Amongst many animals, sexual selection will have given its aid to ordinary selection, by assuring to the most vigorous and best adapted males the greatest number of offspring. Sexual selection will also give characters useful to the males alone, in their struggles or rivalry with other males; and these characters will be transmitted to one sex or to both sexes, according to the form of inheritance which prevails.

Whether natural selection has really thus acted in adapting the various forms of life to their several conditions and stations, must be judged by the general tenor and balance of evidence given in the following chapters. But we have already seen how it entails extinction; and how largely extinction has acted in the world's history, geology plainly declares. Natural selection, also, leads to divergence of character; for the more organic beings diverge in structure, habits, and constitution, by so much the more can a large number be supported on the area, of which we see proof by looking to the inhabitants of any small spot, and to the productions naturalized in foreign lands. Therefore, cluring the modification of the descendants of any one species, and during the incessant struggle of all species to increase in number, the more diversified the descendants become, the better will be their chance of success in the battle for life. Thus the small differences distinguishing varieties of the same species, steadily tend to increase, till they equal the greater differences between species of the same genus, or even of distinct genera.

We have seen that it is the common, the widely-diffused and widely ranging species, belonging to the larger genera within each 
class, which vary most; and these tend to transmit to their modified offspring that superiority which now makes them dominant in their own countries. Natural selection, as has just been remarked, leads to divergence of character and to much extinction of the less improved and intermediate forms of life. On these principles, the nature of the affinities, and the generally well-defined distinctions between the innumerable organic beings in each class throughout the world, may be explained. It is a truly wonderful fact-the wonder of which we are apt to overlook from familiarity-that all animals and all plants throughout all time and space should be related to each other in groups subordinate to groups, in the manner which we everywhere beholdnamely, varieties of the same species most closely related, species of the same genus less closely and unequally related, forming sections and sub-genera, species of distinct genera much less closely related, and genera related in different degrees, forming sub-families, families, orders, sub-classes and classes. The several subordinate groups in any class cannot be ranked in a single file, but seem clustered round points, and these round other points, and so on in almost endless cycles. If species had been independently created, no explanation would have been possible of this kind of classification; but it is explained through inheritance and the complex action of natural selection, entailing extinction and divergence of character, as we have seen illustrated in the diagram.

The affinities of all the beings of the same class have sometimes been represented by a great tree. I believe this simile largely speaks the truth. The green and budding twigs may represent existing. species; and those produced during former years may represent the long succession of extinct species. At each period of growth all the growing twigs have tried to branch out on all sides, and to overtop and kill the surrounding twigs and branches, in the same manner as species and groups of species have at all times orermastered other species in the great battle for life. The limbs divided into great branches, and these into lesser and lesser branches, were themselves once, when the tree was young, budding twigs; and this connection of the former and present buds by ramifying branches may well represent the classification of all extinct and living species in groups subordinate to groups. Of the many twigs which flourished when the iree was a mere bush, only two or three, now grown into great branches, yet survive and bear the other branches; so with the species which lived during long-past geological periods, very few have left living and modified descendants. 


\section{READINGS IN EVOLUTION, GENETICS, AND EUGENICS}

From the first growth of the tree, many a limb and branch has decayed and dropped off; and these fallen branches of various sizes may represent those whole orders, families, and genera which have now no living representatives, and which are known to us only in a fossil state. As we here and there see a thin straggling branch springing from a fork low down in a tree, and which by some chance has been favored and is still alive on its summit, so we occasionally see an animal like the Ornithorhynchus or Lepidosiren, which in some small degree connects by its affinities two large branches of life, and which has apparently been saved from fatal competition by having inhabited a protected station. As buds give rise by growth to fresh buds, and these, if vigorous, branch out and overtop on all sides many a feebler branch, so by generation I believe it has been with the great Tree of Life, which fills with its dead and broken branches the crust of the earth, and covers the surface with its ever-branching and beautiful ramifications.

\section{DIFFICULTIES AND OBJECTIONS TO NATURAL SELECTION AS SEEN BY DARWIN}

Long before the reader has arrived at this part of my work, a crowd of difficulties will have occurred to him. Some of them are so serious that to this day I can hardly reflect on them without being in some degree staggered; but, to the best of my judgment, the greater number are only apparent, and those that are real are not, I think, fatal to the theory.

These difficulties and objections may be classed under the following heads: First, why, if species have descended from other species by fine gradations, do we not everywhere see innumerable, transitional forms? Why is not all nature in confusion, instead of the species being, as we see them, well defined?

Secondly, is it possible that an animal having, for instance, the structure and habits of a bat, could have been formed by the modification of some other animal with widely different habits and structure? Can we believe that natural selection could produce, on the one hand, an organ of trifling importance, such as the tail of a giraffe, which serves as a fly-flapper, and, on the other hand, an organ so wonderful as the eye?

Thirdly, can instincts be acquired and modified through natural selection? What shall we say to the instinct which leads the bee to make cells, and which has practically anticipated the discoveries of profound mathematicians? 
Fourthly, how can we account for species, when crossed, being sterile and producing sterile offspring, whereas, when varieties are crossed, their fertility is unimpaired?

\section{ANSWER TO THE FIRST DIFFICULTY}

On the Absence or Rarity of Transitional Varieties.-As natural selection acts solely by the preservation of profitable modifications, each new form will tend in a fully stocked country to take the place of, and finally to exterminate, its own less improved parent-form and other less-favored forms with which it comes into competition. Thus extinction and natural selection go hand in hand. Hence, if we look at each species as descended from some unknown form, both the parent and all the transitional varieties will generally have been exterminated by the very process of the formation and perfection of the new form.

But, as by this theory innumerable transitional forms must have existed, why do we not find them embedded in countless numbers in the crust of the earth? It will be more convenient to discuss this question in the chapter on the Imperfection of the Geological Record; and I will here only state that I believe the answer mainly lies in the record being incomparably less perfect than is generally supposed. The crust of the earth is a vast museum; but the natural collections have been imperfectly made, and only at long intervals of time.

\section{ANSWER TO-THE SECOND DIFFICULTY: ORGANS OF EXTREME PERFECTION AND COMPLICATION}

To suppose that the eye with all its inimitable contrivances for adjusting the focus to different distances, for admitting different amounts of light, and for the correction of spherical and chromatic aberration, could have been formed by natural selection, seems, I freely confess, absurd in the highest degree. When it was first sand that the sun stood still and the world turned round, the common sense of mankind declared the doctrine false; but the old saying of Vox populi, vox Dei, as every philosopher knows, cannot be trusted in science. Reason tells me, that if numerous gradations from a simple and imperfect eye to one complex and perfect can be shown to exist, each grade being useful to its possessor, as is certainly the case; if further, the eye varies and the variations be inherited, as is likewise certainly the case; and if such variations should be useful to any animal under changing conditions of life, then the difficulty of believing 


\section{READINGS IN EVOLUTION, GENETICS, AND EUGENICS}

that a perfect and complex eye could be formed by natural selection, though insuperable by our imagination, should not be considered as subversive of the theory. How a nerve comes to be sensitive to light, hardly concerns us more than how life itself originated; but I may remark that, as some of the lowest organisms, in which nerves cannot be detected, are capable of perceiving light, it does not seem impossible that certain sensitive elements in their sarcode should become aggregated and developed into nerves, endowed with this special sensibility.

In searching for the gradations through which an organ in any species has been perfected, we ought to look exclusively to its lineal progenitors; but this is scarcely ever possible, and we are forced to look to other species and genera of the same group, that is to the collateral descendants from the same parent-form, in order to see what gradations are possible, and for the chance of some gradations having been transmitted in an unaltered or little altered condition. But the state of the same organ in distinct classes may incidentally throw light on the steps by which it has been perfected.

The simplest organ which can be called an eye consists of an optic nerve, surrounded by pigment-cells and covered by translucent skin, but without any lens or other refractive body. We may, however, according to M. Jourdain, descend even a step lower and find aggregates, of pigment-cells, apparently serving as organs of vision, without any nerves, and resting merely on sarcodic tissue. Eyes of the above simple nature are not capable of distinct vision, and serve only to distinguish light from darkness. In certain star-fishes, small depressions in the layer of pigment which surrounds the nerve are filled, as described by the author just quoted, with transparent gelatinous matter, projecting with a convex surface, like the cornea in the higher animals. He suggests that this serves not to form an image, but only to concentrate the luminous rays and render their perception more easy. In this concentration of the rays we gain the first and by far the most important step towards the formation of a true, picture-forming eye; for we have only to place the naked extremity of the optic nerve, which in some of the lower animals lies deeply buried in the body, and in some near the surface, at the right distance from the concentrating apparatus, and an image will be formed on it.

In the great class of the Articulata, we may start from an optic nerve simply coated with pigment, the latter sometimes forming a sort 
of pupil, but destitute of a lens or other optical contrivance. With insects it is now known that the numerous facets on the cornea of their great compound eyes form true lenses, and that the cones include curiously modified nervous filaments. But these organs in the Articulata are so much diversified that Müller formerly made three main classes with seven subdivisions, besides a fourth main class of aggregated simple eyes.

When we reflect on these facts, here given much too briefly, with respect to the wide, diversified, and graduated range of structure in the eyes of the lower animals; and when we bear in mind how smatl the number of all living forms must be in comparison with those which have become extinct, the difficulty ceases to be very great in believing that natural selection may have converted the simple apparatus of an optic nerve, coated with pigment and invested by transparent membrane, into an optical instrument as perfect as is possessed by any member of the Articulate Class.

He who will go thus far, ought not to hesitate to go one step further, if he finds on finishing this volume that large bodies of facts, otherwise inexplicable, can be explained by the theory of modification through natural selection; he ought to admit that a structure even as perfect as an eagle's eye might thus be formed, although in this case he does not know the transitional states. It has been objected that in order to modify the eye and still preserve it as a perfect instrument, many changes would have to be effected simultaneously, which, it is assumed, could not be done through natural selection; but as I have attempted to show in my work on the variation of domestic animals, it is not necessary to suppose that the modifications were all simultaneous, if they were extremely slight and gradual. Different kinds of modification would, also, serve for the same general purpose: as Mr. Wallace has remarked, "if a lens has too short or too long a focus, it may be amended either by an alteration of curvature, or an alteration of density; if the curvature be irregular, and the rays do not converge to a point, then any increased regularity of curvature will be an improvement. So the contraction of the iris and the muscular movements of the eye are neither of them essential to vision, but only improvements which might have been added and perfected at any stage of the construction of the instrument." Within the highest division of the animal kingdon, namely, the Vertebrata, we can start from an eye so simple, that it consists, as in the lancelet, of a little 


\section{READINGS IN EVOLUTION, GENETICS, AND EUGENICS}

sack of transparent skin, furnished with a nerve and lined with pigment, but destitute of any other apparatus. In fishes and reptiles, as Owen has remarked, "the range of gradations of dioptric structures is very great." It is a significant fact that even in man, according to the high authority of Virchow, the beautiful crystalline lens is formed in the embryo by an accumulation of epidernic cells, lying in a sacklike fold of the skin; and the vitreous body is formed from embryonic sub-cutaneous tissue. To arrive, however, at a just conclusion regarding the formation of the eye, with all its marvellous yet not absolutely perfect characters, it is indispensable that the reason should conquer the imagination; but I have felt the difficulty far too keenly to be surprised at others hesitating to extend the principle of natural selection to so startling a length.

It is scarcely possible to avoid comparing the eye with a telescope. We know that this instrument has been perfected by the longcontinued efforts of the highest human intellects; and we naturally infer that the eye has been formed by a somewhat analogous process. But may not this inference be presumptuous? Have we any right to assume that the Creator works by intellectual powers like those of man? If we must compare the eye to an optical instrument, we ought in imagination to take a thick layer of transparent tissue, with spaces filled with fluid, and with a nerve sensitive to light beneath, and then suppose every part of this layer to be continually changing slowly in density, so as to separate into layers of different densities and thicknesses, placed at different distances from each other, and with the surfaces of each layer slowly changing in form. Further we must suppose that there is a power, represented by natural selection or the survival of the fittest, always intently watching each slight alteration in the transparent layers; and carefully preserving each which, under varied circumstances, in any way or in any degree, tends to produce a distincter image. We must suppose each new state of the instrument to be multiplied by the million; each to be preserved until a better one is produced, and then the old ones to be all destroyed. In living bodies, variation will cause the slight alterations, generation will multiply them almost infinitely, and natural selection will pick out with unerring skill each improvement. Let this process go on for millions of years; and during each year on millions of individuals of many kinds; and may we not believe that a living optical instrument might thus be formed as superior to one of glass, as the works of the Creator are to those of man? 
DARWIN'S SUMMARY OF HIS ANSWER TO THE THIRD DIFFICULTY, THAT OF ACCOUNTING FOR THE ACQUISITION AND MODIFICATION OF INSTINCTS THROUGH NATURAL SELECTION

I have endeavored in this chapter briefly to show that the mental qualities of our domestic animals vary, and that the variations are inherited. Still more briefly I have attempted to show that instincts vary slightly in a state of nature. No one will dispute that instincts are of the highest importance to each animal. Therefore there is no real difficulty, under changing conditions of life, in natural selection accumulating to any extent slight modifications of instinct which are in any way useful. In many cases habit or use and disuse have probably come into play. I do not pretend that the facts given in this chapter strengthen in any great degree my theory; but none of the cases of difficulty, to the best of my judgment, amnihilate it. On the other hand, the fact that instincts are not always absolutely perfect and are liable to mistakes: that no instinct can be shown to have been produced for the good of other animals, though animals take advantage of the instincts of others; that the canon in natural history, of "Natura non facit saltum," is applicable to instincts as well as to corporeal structure, and is plainly explicable on the foregoing views, but is otherwise inexplicable, all tend to corroborate the theory of natural selection.

This theory is also strengthened by some few other facts in regard to instincts; as by that common case of closely allied, but distinct, species, when inhabiting distant parts of the world and living under considerably different conditions of life, yet often retaining nearly the same instincts. For instance, we can understand, on the principle of inheritance, how it is that the thrush of tropical South America lines its nest with mud, in the same peculiar manner as does our British thrush; how it is that the Hornbills of Africa and India have the same extraordinary instinct of plastering up and imprisoning the females in a hole in a tree, with only a small hole left in the plaster through which the males feed them and their young when hatched; how it is that the male wrens (Troglodytes) of North America build "cocknests," to roost in, like the males of our Kitty-wrens, a habit wholly unlike that of any other known bird. Finally, it may not be a logical deduction, but to my imagination it is far more satisfactory to look at such instincts as the young cuckoo ejecting its foster-brothers, ants making slaves, the larvae of ichneumonidae feeding within the live bodies of caterpillars, not as specially endowed or created 


\section{READINGS IN EVOLUTION, GENETICS, AND EUGENICS}

instincts, but as small consequences of one general law leading to the advancement of all organic beings, namely, multiply, vary, let the strongest live and the weakest clie.

D.ARIIN'S SUMMARY OF HIS ANSWER TO THE DIFFICULTY AS TO TIIE INABILITY OF NATURAL SELECTION TO ACCOUNT FOR TIE FACT TIIAT SPECIES WHEN CROSSEi) ARE STERILE OR PRODUCE STERILE OFFSPRING, WHEREAS WIIEN VARIETIES ARE CROSSED THEIR FERTILITY IS UNIMIP.IIRED

First crosses between forms, sufficiently distinct to be ranked as species, and their hybrids, are very generally, but not universally sterile. The sterility is of all degrees, and is often so slight that the most careful experimentalists have arrived at diametrically opposite conclusions in ranking forms by this test. The sterility is innately variable in individuals of the same species, and is eminently susceptible to the action of farorable and unfavorable conditions. The degree of sterility does not strictly follow systematic affinity, but is governed by several curious and complex laws. It is generally different; and sometimes widely different in reciprocal crosses between the same two species. It is not always equal in degree in a first cross and in the hybrids produced from this cross.

In the same manner as in grafting trees, the capacity in one species or variety to take on another, is incidental on differences, generally of an unknown nature, in their vegetative systems, so in crossing, the greater or less facility of one species to unite with another is incidental on unknown differences in their reproductive systems. There is no more reason to think that species have been specially endowed with various degrees of sterility to prevent their crossing and blending in nature, than to think that trees have been specially endowed with various and somewhat analogous degrees of difficulty in being grafted together in order to prevent their inarching in our forests.

The sterility of first crosses and of their hybrid progeny has not been acquired through natural selection. In the case of first crosses it seems to depend on several circumstances; in some instances in chief part on the early death of the embryo. In the case of hybrids, it apparently depends on their whole organization baving been disturbed by being compounded from two distinct forms; the sterility being closely allied to that which so frequently affects pure species, when exposed to new and unnatural conditions of life. He who will explain these latter cases will be able to explain the sterility of hybrids. This view is strongly supported by a parallelism of another kind: namely, that, firstly, slight changes in the conditions of life add to the 
vigor and fertility of all organic beings; and secondly, that the crossing of forms, which have been exposed to slightly different conditions of life or which have varied, favors the size, vigor, and fertility of their offspring. The facts given on the sterility of the illegitimate unions of dimorphic and trimorphic plants and of their illegitimate progeny, perhaps render it probable that some unknown bond in all cases connects the degree of fertility of first unions with that of their offspring. The consideration of these facts on dimorphism, as well as of the results of reciprocal crosses, clearly leads to the conclusion that the primary cause of the sterility of crossed species is confined to differences in their sexual elements. But why, in the case of distinct species, the sexual elements should so generally have become more or less modified, leading to their mutual infertility, we do not know; but it seems to stand in some close relation to species having been exposed for long periods of time to nearly uniform conditions of life.

It is not surprising that the difficulty in crossing any two species, and the sterility of their hybrid offspring, should in most cases correspond, even if due to distinct causes: for both depend on the amount of difference between the species which are crossed. Nor is it surprising that the facility of effecting a first cross, and the fertility of the hybrids thus produced, and the capacity of being grafted togetherthough this latter capacity evidently depends on widely different circumstances-should all run, to a certain extent, parallel with the systematic affinity of the forms subjected to experiment; for systematic affinity includes resemblances of all kinds.

First crosses between forms known to be varieties, or sufficiently alike to be considered as varieties, and their mongrel offspring, are very generally, but not, as is so often stated, invariably fertile. Nor is this almost universal and perfect fertility surprising, when it is remembered how liable we are to argue in a circle with respect to varieties in a state of nature; and when we remember that the greater number of varieties have been produced under domestication by the selection of mere external differences, and that they have not been long exposed to uniform conditions of life. It should also be especially kept in mind that long-continued domestication tends to eliminate sterility, and is therefore little likely to induce this same quality. Independently of the question of fertility, in all other respects there is the closest general resemblance between hybrids and mongrels, in their variability, in their power of alssorbing each other by repeated crosses, and in their inheritance of characters from both parent-forms. 


\section{READINGS IN EVOLUTION, GENETICS, AND EUGENICS}

Finally, then, although we are as ignorant of the precise cause of the sterility of first crosses and of hylbrids as we are why animals and plants removed from their natural conditions become sterile, yet the facts given in this chapter do not seem to me opposed to the belief that species aboriginally existed as varieties. 


\section{CHAPTER XVII}

\section{CRITIQUE OF DARIINISM}

[The last chapter dealt with the central ideas of Darwin as told by himself. Some of the chief objections to the theory were also presented as Darwin saw them, and his own answers to these objections were given. These four objections are not by any means all that Darwin foresaw, for he presented in another chapter a discussion of "Miscellaneous Objections to the Theory of Natural Selection." Before entering upon a general criticism of Darwinism, it would be advantageous to have before us a brief and pointed summary of Darwin's theory-natural selection-now known technically as Darwinism. The writer knows of no better short statement of the true content of Darwinism than the following summary by Professor Vernon L. Kellogg.-ED.]

\section{SUMMARY OF DARIVIN'S NATURAL-SELECTION THEORY ${ }^{I}$}

VERNON L. KELLOGG

Darwinism may be difined as a certain rational, causo-mechanical (hence, non-teleologic) explanation of the origin of new species. The Darwinian explanation rests on certain observed facts, and certain inductions from these facts. The observed facts are: (I) the increase by multiplication in geometrical ratio of the individuals in every species, whatever the kind of reproduction which may be peculiar to each species, whether this be simple division, sporulation, budding, parthenogenesis, conjugation and subsequent division, or amphimixis (sexual reproduction); (2) the always apparent slight (to greater) variation in form and function existing among all individuals even though of the same generation or brood; and (3) the transmission, with these inevitable slight variations, by the parent to its offspring of a form and physiology essentially like the parental. The inferred (also partly observed) facts are: (I) a lack of room and food for all these new individuals produced by geometrical multiplication and consequently a competition (active or passive) among those individuals having any ecologic relations to one another, as, for example, among

${ }^{I}$ From V. L. Kellogg, Darwinism To-Day (copyright 1907). Used by permission of the publishers, Henry Ilolt \& Company. 


\section{READINGS IN EVOLUTION, GENETICS, AND EUGENICS}

those occupying the same locality, or needing the same food, or needing each other as food; (2) the probable success in this competition of those individuals whose slight differences (variations) are of such a nature as to give them an advantage over their confrères, which results in saving their life, at least until they have produced offspring; and (3) the fact that these "saved" individuals will, by virtue of the already referred to action of heredity, hand down to the offspring their advantageous condition of structure and physiology (at least, as the "mode" or most abundantly represented condition, among the offspring).

The competition among individuals and kinds (species) of organisms may fairly be called a struggle. This is obvious when it is active, as in actual personal battling for a piece of food or in attempts to capture prey or to escape capture, and less obvious when it is passive, as in the endurance of stress of weather, hunger, thirst, and untoward conditions of any kind. The struggle is, or may be, for each individual threefold in nature: (I) an active struggle or competition with other individuals of its own kind for space in the habitat, sufficient share of the foorl, and opportunity to produce offspring in the way peculiar and common to its species; (2) an active or passive struggle or competition with the individuals of other species, which may need the same space and food as itself, or may need it or its eggs or young for food; and (3) an active (or more usually passive) struggle with the physicochemical external conditions of the world it lives in, as varying temperature and humidity, storms and floods, and natural catastrophes of all sorts. For any individual or group of individuals any of these forms of struggle may be temporarily ameliorated, as is ( $\mathrm{r}$ ) the intra-specific struggle among the thousands of honey-bee individuals living together altruistically, in one hive, or (2) the inter-specific struggle, when two species live together symbiotically as the hermit crab Eupagurus and the sea-anemone P'odocoryne, or (3) the struggle against untoward natural conditions as in special times or places of highly farourable climate, etc. Or for any individual or group of individuals all forms of the struggle may be coincidently active and severe. The resultant of these existing conditions is, according to 1)arwin and his followers, an inevitable natural selection of indivicluals and of species. Thousands must die where one or ten may live to maturity (i.e., to the time of producing young). Which ten of the thousand shall live depends on the slight but sufficient advantage possessed by ten individuals in the complex struggle for 
existence due to the fortuitous possession of fortunate congenital differences (variations). 'Tle nine hundred and ninety with unfortunate congenital variations are extinguished in the struggle and with them the opportunity for the perpetuation (by transmission to the offspring) of their particular variations. There are thus leit ten to reproduce their advantageous variations. The offspring of the ten of course will vary in their turn, but will vary around the new and already proved advantageous parental condition: among the thousand, say, offspring of the original saved ten the same limitations of space and food will again work to the killing off before maturity of nine hundred and ninety, leaving the ten best equipped to reproduce. This repeated and intensive selection learls to a slow but stearly and certain modification through the successive generations of the form and functions of the species; a modification always toward adaptation, toward fitness, toward a moulding of the body and its beliaviour to safe conformity with external conditions. The exquisite adaptation of the parts and functions of the animal aml plant as we see it every day to our infinite adniration and wonder has all come to exist through the purely meclianical, inevitable weeling out and selecting by Nature (by the environmental determining of what may and what may not live) (hrough uncounted generations in unreckonable time. This is Darwin's caus,-mechanical theory to explain the transformation of species and the infinite variety of alaptive modification. A rigorous automatic Natural Selection is the essential idea in I)irwinism, at least in Darwinism as it is held by the present-day followers of Darwin.

OBJECTIONS TO DARWIXISII

[r. Darwin in a letter to his friend Hooker (January II, IS 44 ) expresses his contempt of Lamarch's icleas in the following words: "Heaven defend me from Lamarck's nonsense of a 'tendency to progression,' 'allaptations from the slow willing of animals,' etc. . . . . Lamarck's work appeared to me to be extremely poor; I got not a fact or idea from it."

In spite of these views I)arwin's Origin of Species is intertarded with Lamarckian explanations. Whenever the author feels the shortcomings of the selection factor he lapses into an explimation involving the idea that the effects of use and clisuse of organs are inheriterl. Followers of Darwin, especially Weismann, felt this to be the chief defect in the fabric of Darwinism and bent their efforts chietly toward purging Darwinism of all taint of Lamarckism. 


\section{READINGS IN EVOLUTION, GENETICS, AND EUGENICS}

2. Darwin insisted upon the idea that minute fluctuating variations, which we now know are to a large extent non-heritable, were the principal, if not the sole, materials for natural selection to work upon. He knew of a considerable number of "sports" or "saltatory" variations" (now called mutations), lut considered these too infrequent to furnish the necessary basis for selection. We now know that mutations may be as small as fluctuating variations or as large as "sports" and that they are of much more frequent occurrence than Darwin supposed.

3. Darwin considered all variations as heritable. He did not distinguish between somatic variations and germinal variations. In fact, as we learn from a study of his pangenesis theory, he considered all variations as in the first instance somatic, and subsequently transferred by means of gemmules to the germ cells. Every somatic variation, whether induced by use, disuse, in response to environmental stimulus, or through mere spontaneous variability, was supposed to be able to give off gemmules into the blood stream that would carry to the germ cells the physical basis of the varying character. 'The pangenesis mechanism is now known to have no basis in fact.

4. The natural-selection theory is based upon a mistaken conception of the methods of artificial selection. Darwin believed, without having any proof for this belief, that the way in which domestic varieties had been so profoundly modified at the hands of man was by the conscious or unconscious selection of slight fluctuating variations in favorable or desired directions, and that this resulted in the cumulative improvement or enhancement of the desired characters over a long series of generations. Darwin supposes that the radically changed conditions of domestication hasten and stimulate variability, thus offering a better opportunity for selection. 'Transferring this idea to nature, he thinks that changed natural conditions stimulate variability, just as does domestication, and that this is seized upon by natural selection to make for adaptation to the new environment and the resultant origin of new species.

Our morlern experimental studies have shown that somatic modifications due to environmental changes are not hereditary, and that all of the recent domestic varieties whose origin has been observer have been the result of suddenly appearing germinal variations or mutations, that arrive fully formed and cannot be improved by selection, except that they usually need to be selected out or isolated in 
order to prevent swamping out through intercrossing with the parent-type.

5. Objection has frequently been made to Darwin's idea of the purely fortuitous or chance character of variations. According to this view variations occur in all structures and in all directions at haphazard, so that there would be the widest possible opportunity for a given adaptive variation to occur just when the circumstances would demand. It now appears that variations do not occur in all directions in random fashion, but that they tend to follow certain definite paths of change; in other words, variations are, to a considerable extent at least, orthogenetic. If variations really tend to follow certain definite lines, owing to purely internal causes, natural selection would be unnecessary, at least until orthogenesis went too far for the good of the species, or far enough to be of real importance in the struggle for existence.

6. The difficulty of explaining how natural selection could make use of the initial stages of adaptive structures is obvious. It is inconceivable that the first, almost imperceptible variation in a favorable direction could be of selective value, so as to effect the survival of the individual or the relative number of its offspring. What would be the advantage of the first few hairs of a mammal or the first steps toward feathers in a bind when these creatures were beginning to diverge from their reptilian ancestors? This objection is, of course, based on the fluctuating-variation idea. If the mutation idea were substituted, the difficulty would, to a great extent, clear up; for a niutation might be of sufficient importance in one generation to have selective value from the very first.

7. Natural selection is said to be incapable of explaining the origin of coadaptive and highly complex adaptations whose effectiveness depends upon the perfection of their adjustments to one another. For example, we may refer to some of the perfected adaptations described in chapter xiv. In the case of the electric organs of certain fish, the Darwinian assumption would be that the first step in the direction of an electric organ would be a very small one, and that it was built up little by little by means of natural selection. But, say the critics, the electric organ would be of no value until it became powerful enough to impart an effective shock to the intruder, and this would not be possible if the character began in a small way. The whole phenomenon of protective resemblance is open to the same type of criticism. As a specific example of this we may cite the case of the dried-leaf 
butterfly, Kallima, previously described (pp. 201, 202). In its present condition this animal has a strikingly detailed resemblance to a dried leaf, which is therefore doubtless of some value. But of what value would be the first tiny change in the direction of resemblance? Until its resemblance became close enough actually to deceive the enemies of butterflies, the critics claim, there would be no chance for selection to act.

S. It is frequently objected that a vast number of characters of organs are useless or non-adaptive and, as such, could not have arisen through the instrumentality of natural selection. If these useless characters, which are sometimes quite large and prominent, are independent of natural selection, why do we need natural selection to explain adaptive characters? It is also claimed that a vast number of specific peculiarities are useless and therefore could not have helped in the differentiation of species. It should be said in defense that Darwin realized this difficulty quite as clearly as do his critics and was greatly puzzled by it. His idea of correlated variability, however, helps to answer it, for it may well be that many of these apparently useless characters are correlated, or linked in inheritance, with characters of supreme selective value such as general hardiness or great fecundity. Darwin also points out that we are not in a position at present to pronounce judgment on the value of many structures or functions that have been adjudged non-adaptive.

9. Certain characters in organisms, past and present, have been interpreted as overspecializations, organs that have evolved beyond the range of usefulness or that are more elaborate than is demanded for survival under the conditions of life. The case of the extinct Irish etk is often citer as an example of overspecialization. This group of animals went to extremes in the development of size and elaboration of horns far beyond the range of usefulness, so that it is said to have brought about the extinction of the race. Natural selection, which is supposed to have brought the horns up to the point of adaptive perfertion, should have kept them within the bounds of usefulness.

Again, the enormously overgrown and overspecialized dinosaurs of long ago are thought of as having followed their lines of evolution far beyond the point of greatest effectiveness and adaptability.

Io. The rudimentation of structures, which is such a common phenomenon in nature, is said to meet with no adequate explanation on a selection basis. The case of the whale's vestigial hind limbs is a case in point. Darwin's explanation would be that under aquatic conditions the first whale ancestors would be handicapped by hind 
legs and that any decrease in their size, which would be enhanced by disuse, would be of advantage. This might seem reasonable during the main period of limb reduction, but, after the limb is reduced to a subcutaneous rudiment, there could be little advantage in carrying the rudimentation still farther. Some whales have the hind limbs much more profoundly reduced than others, although they are all thoroughly out of the way and involve no hindrance in swimming. Any number of similar cases of the same kind might be cited. Darwin had no explanation to offer except a resort to Lamarckism; but Weismann, the ablest neo-Darwinian, offered the theory of panmixia to cover this objection, a theory which is mentioned in chapter $i$ and will be discussed later.

II. It is objected that, unless favorable variations occur in a large number of individuals at the same time, the character would be swamped out by intercrossing with individuals not possessing the favorable variation. The probability that such a swamping-out would occur was shown mathematically by various critics. By way of answer to this objection there arose a number of "isolation theories," according to which favorably varying individuals would be protected from back-crossing with the non-varying individuals. We might also point out that the Mendelian laws of dominance and segregation would serve to prevent loss of any new favorable character.

I2. It is objected that natural selection might explain the "survival, but not the arrival, of the fittest." But Darwin met this perfectly when he said: "Some have even imagined that natural selection induces variability, whereas it implies only the preservation of such variations as arise and are beneficial to the being under its conditions of life."

I3. Criticism has been directed against natural selection because of the fact that some of the supporters of Darwinism, notably Weismann, have made the claim that natural selection is the sole cause of evolution. This idea of the Allmacht or all-sufficiency of natural selection was not Darwin's, as is clear from the following statement: "I am convinced that natural selection has been the most important, but not the exclusive means of modification."

I4. It is objected that many, if not most, of the fluctuating variations with which Darwinism deals are purely quantitative or plusand-minus variations; whereas the differences between species are qualitative. This is a serious objection and difficult to meet, yet a fair defense has been formulated by leading neo-Darwinians. 
I5. There is a growing skepticism on the part of biologists as to the extreme fierceness of the struggle for existence and of the consequent rigor of selection. It may be auswered that no very obvious fierceness is implied in the theory. So long as overproduction and a shortage of space and food exists the struggle for existence is inevitable.

I6. Special objections are offered to the subsidiary theory of scxual selection. It is said that the type of sexual selection involving active rivalry and battling for mates needs no special theory, inasmuch as this is a mere phase of the struggle for the maintenance of the full life, including the chance to leave offspring. It is against the other side of sexual selection, which involves passivity on the part of the male and active choice on the part of the female of the more beautiful or otherwise attractive male, that objection is raised. It is claimed that such choice implies too high aesthetic powers in animals of relatively poor vision and mentality. Experiments have been performed with moths, in which the male and female coloration is strikingly different, in order to determine whether females actually do exercise any choice of mates that is based on considerations of appearance. 'The result proved conclusively that color patterns have no value in mating, but that the female is passive and mates with the first male to present himself, while the male finds the female through his exquisitely effective sense of smell.

We know now, however, that secondary sexual characters are intimately bound up in a physiological way with the functioning of the sex glands and are therefore doubtless to be interpreted as mere non-adaptive correlative variations that need no special evolutionary explanation.

\section{DEFENSE OF DARIVINISM}

In presenting these sixteen objections, we have in most cases indicated the lines upon which the objections have been met, if they have been met. Not all of these objections are considered serious at the present time, for some are based upon lack of a full knowledge of what Darwin actually wrote; others are largely academic in character and fail to stand up under actual test; still others have been more or less adequately met by subsidiary or supporting theories which have been advanced by various neo-Darwinians.

Most of the special objections raised in this chapter have received the attention of various able Darwinians, and the student of evolution would doubtless be interested in the expert and fair-minded defense 
of Jarwinism at the hands of Professor V. L. Kellogg as it appears in his book Darinism To-Day.

A much briefer and considerably more general defense is that of J. L. Tayler, which is as follows.-ED.]:

\section{GENERAL DEFENSE OF DARWINISM ${ }^{\perp}$}

\section{J. L. T.AYLER}

To realise how far the theory of selection is capalsle of explaining the facts of organic evolution, it is necessary to bear in mind the postulates in which the theory is founded.

I. It is obvious that natural selection can only act by preserving or eliminating the complete organism. Selection must therefore be organismal. This I)arwin and other selectionists have clearly recognised.

2. As the whole organism must survive, if the farourable variation or variations are to le preserved, it follows that certain minor unfavourable variations may also be preserved if they happen to exist in an individual which survives on account of its major favourable variations. And since no individual is completely adapted to its environment, it follows that there must be ahways a variable amount of residual unfavourable variability in every organism.

3. This residual untavourable varialility may be of considerable utility under changed conditions:

4. Complementary specialisation of parts, as Spencer has shown. is favourable to successful competition, and as it is the whole organism that is selected or eliminated, it follows that any weakness of one specialised part, since it would disturl, the balance of all, would be detrimental. The more complex the organism, the more spccialised the structures, the more dependent one part will be on the others for its existence, hence a complementary specialising tendency will be favoured by selection, and therefore all struggles of one part of an organism with another will be reduced to a minimum.

It is clear that there must $h e$ some underlying criterion which determines whether any given organism shall be selected or not, and that criterion must be the net result of its adaptability to its cnvironment. One oreanism may conceivably survive, by its possession of a large number of small favourable variations, while another may survive in virtue of a single valuable one, but in each case it would be

x From J. L. Tayler, "The Scope of Natural Selection," Nainral Science, I Sog. 


\section{READINGS IN EVOLUTION, GENETICS, AND EUGENICS}

the whole value of that organism which determined its survival. This fact is continually disregarded by opponents of the neo-Darwinian position, yet this selection of the organism as a whole is the fundamental postulate from which the theory of selection starts. Thus it is not uncommom to read criticisms bearing on the early development of some organ, in which the inadequacy of selection is supposed to be proved by the writer demonstrating, or believing he has demonstrated, the fact that the particular variation in question must have been too small to be by itself of selection value. In many cases the particular variation would, no doubt, if taken alone be, as the objector asserts, too unimportant to be selected, but as it is the whole organism that is selected, it is not logical to make an artificial separation and study the development of one organ or structure irrespective of the other organs with which it is in nature associated. Every organ in its evolution must be considered in relation to the whole of the particular organism in which that particular stage of development of that organ is found.

Starting, therefore, with this fact that the net value of adaptability of the whole organism to its environment must be the basis which determines selection or elimination, it will follow that certain lines of development will result from the application of this criterion. In a series of organisms placed under new conditions, elimination will proceed along lines essential to bring about a proper adjustment to the new conditions. If the offspring of these adjusted organisms merely repeated in their generation the characters of the exterminated as well as of the surviving organisms, that temporary adjustment would be permanent as long as the conditions were unchanged. But since the offspring are produced only by the surviving organisms, selection is continually raised to higher and higher planes of adaptation, and, therefore, as long as conditions remain constant, the tendency of selection must be, as Darwin clearly saw, cumulative. He did not, however, apparently see that from this cumulative tendency definite variability must arise out of indefinite.

Selection in direct relation to climatic conditions is, therefore, of rery minor importance, while selection among the members of a species and all forms of inter-organismal selection is of infinitely more importance, since it is this interaction, producer by the offspring in different degrees inheriting the advantages of both parents (both of whom have survived on account of certain advantages), that leads to the cumulative development and never-ending struggle for survival. 
Darwin came very near to this conception of definite variability when he pointed out that "if a country were changing, the altered conditions would tend to cause variation, not but what I believe most beings vary at all times enough for selection to act on." Extermination would expose the remainder to the "mutual action of a different set of inhabitants, which I believe to be more important to the life of each being than mere climate," and as "the same spot will support more life if occupied by very diverse forms," it is evident that selection will favour very great diversity of structure.

Bearing in mind this cumulative action of selection it will follow that under constant or relatively constant conditions the struggle for successful living will become more and more selective in character, even if the actual number of inhabitants remain more or less the same as when the struggle first commenced. The selection of variations will thus tend to pass through certain more or less ill-defined, but nevertheless, real stages. In proportion as the struggle becomes intense, either from the number or from the increasing adaptability of the organisms, or both, certain major essential adaptations, which were necessary for the climatic and other more or less comparatively simple conditions, will be supplemented by minor auxiliary variations which in the earlier stages would not have appeared. And still later, as more and more rigor us conditions of life were imposed, the advantage would tend to rest with those organisms which possessed highly co-ordinated adaptations, since this would entail more rapid responsiveness to environment.

As evolution advances from the unspecialised to the specialised, and higher and higher forms of life come into being, with increasing complexity and specialisation of parts entailing an increasingly delicate adjustment of those parts to each other's needs, the relation of each part to the whole organism becomes of more and more importance, and it follows that selection must become more and more generalised in its action. No single variation could be of service to any of the higher forms of life unless it was in more or less complete harmony with the whole tendency of the individual. The adjustment of parts and their mutual interdependence make it essential for adaptation that the relation of parts be preserved; consequently, correlated minute favourable variations will tend to be more and more selected as evolution passes from the unspecialised to the specialised forms of life. This response of the whole organism should be still more delicate in those forms of life that are continually subjecting themselves to 


\section{6 \\ READINGS IN EVOLUTION, GENETICS, AND EUGENICS}

changed conditions; hence this delicacy of adjustment is far more necessary in the higher forms of animal life than in more stationary plant organisms, and in the developing nervous systems of animals we have just the central adjusting system that is required for these conditions. Writh evolution of type there will thus be an increasingly definite tendency given to organic, especially the animal, forms of life, if the acting principle of evolution has been selectional. Selection is, therefore, able to account for the steadily progressive tendency of life as a whole without calling to its aid any unknown and doubtful perfecting principle.

To summarise: Natural selection, acting on the whole organism, tends to produce more and more definite tendencies in all surviving forms of life, which tendencies are progressive and continuous in character. Variable conditions, by partially altering the line of selection, induce a temporary indefiniteness. And lastly, the process of selection being itself able to be the indirect, though not the direct, cause of those favourable variations, which it subsequently selects from, is able to dispense with any subsidiary factors, provided it has a certain number of elementary properties of life which afford sufficient material to work with.

\section{EXPERIMENTAL SUPPORT OF TIE EFFECTIVENESS \\ OF NATURAL SELECTION}

[Weldon's experiments with the shore-crabs of Plymouth Sound.These experiments seem to show that under changed environmental conditions natural selection acts upon minute fluctuating variations of linear or quantitative type so as to produce an alteration in the species; exactly as Darwinism would hold. A large breakwater was so placed near the mouth of Plymouth Sound that the rate of flow of the river water was greatly slowed down in certain regions. This allowed an increased settling of the fine china-clay sediment that is carried by the river, and the changed condition caused the death of numerous crabs of the species Carcinus maenas. The question arose as to whether the survivors and those that had perished showed any consistent differences on the basis of which selection could be operating. Careful measurements of hundreds of individuals showed that the mean breadth of frontum is slightly less in the survivors than in the perished. Measurements were repeated in two subsequent years and it was found that there was a progressive narrowing of the frontum. As an experimental check upon these conclusions Weldon 
placed a number of crabs in a large aquarium, in which china-clay was kept partly in suspension, and found that about half of them died. Again the survivors were compared statistically with the perished and the same relation was found to hold: that the survivors had a mean frontal breadth distinctly narrower than that of the perished. Weldon concludes that his experiments "have demonstrated two facts about these crabs: the first that their nean frontal breadth is diminishing vear by year at a measurable rate, which is more rapid in males than in females: the second is that this diminution in frontal breadth occurs in the presence of a material, namely, fine mud, which is increasing in amount, and which can be shown experimentally to destroy broad-fronted crabs at a greater rate than crabs with narrower frontal margins.... and I see no escape from the conclusion that we have here a case of Natural Selection acting with great rapidity, because of the rapidity with which the conditions of life are changing."

Cesnola's experiments with Mantis.-To test the selective value of color markings Cesnola fixed specimens of the brown and green Iantis religiosa on plants, some of which were against harmonious. others against disharmonious backgrounds. The result was that most of those which were inconspicuous because of a harmonious background escaped. while most of the others were eaten up by birds.

Poulton's and Sanders' experiments with butterfiy pupae.Numerous pupae of various colors were placed under conditions favoring protective coloration and others under opposite conditions. The conclusion was that protective coloration is a real survival factor, and one that operates so as to give the protectively colored individual a decided adrantage in the struggle for existence.

Davenport's experiments with chickens. - A number of chickens, some black, some white, and some barred or checkered in color, were allowed to wạnder free in the fields. Hawks killed most of the whites and many of the blacks, but spared, to a large extent, the less conspicuous checkered and barred types which are harder to detect against a mixed background.

All of these experiments merely tend to show that discriminate survival actually occurs, but only the experiment of Weldon has a bearing on the possibility that mere quantitative changes of small dimensions might under certain conditions be of selective value. We badly need more experimental evidence of this sort and until this is forthcoming we shall have to admit that there is very little 


\section{$25^{8}$ READINGS IN EVOLUTION, GENETICS, AND EUGENICS}

experimental evidence in favor of the type of natural selection that Darwin stood for.

\section{TIE PRESENT STATUS OF NATURAL SELECTION}

It has come to be rather generally believed that the natural selection that Darwin himself believed in stands almost unscathed as one very important causal factor. In fact it is the only explanation ever offered for adaptation that even approaches adequacy. As an explanation of the origin of new types or new species it falls far short of adequacy, and I think Darwin evidently realized this, although he was unfortunate enough to entitle his book Origin of Species. As an explanation of the origin and perfection of adaptation natural selection has only one rival, the far less satisfactory Lamarckian theory of the inheritance of acquired characters. There is a strong tendency among geneticists to conclude that the modern germ-plasm hypothesis, with the aid of mutations and the mechanism of Mendelian inheritance, furnishes all the necessary explanation of the causes of evolution. There is, however, marked dissent to this extreme position. In his critique of De Vries's rather extreme position that the mutation theory needs no aid from natural selection, Weismann shows in most able fashion the inadequacy of mutations to account for adaptation, and, in contrast, how well natural selection accounts for them.

In a very recent paper Professor C. C. Nutting attempts to show that natural selection is still an important factor in evolution and quite in harmony with both the mutation theory and Mendelism. We perhaps can close the present chapter no more fittingly than by quoting Professor Nutting's paper.-Ev.]

\section{THE RELATION OF MIENDELISM AND THE MUTATION THEORY TO NATURAL SELECTION ${ }^{\mathrm{r}}$}

\section{C. Nutting}

Two marked tendencies are evident in the history of any important theory after its publication.

First. The followers of the discoverer carry the theory too far and attempt too universal an application. This is manifestly true of Wallace and Weismann who out-Darwined Darwin in their claims for natural selection; of the followers of Mendel, such as Morgan and

I From an address given before the Genctics branch of the Amcrican Association for the Advancement of Scicnce, December, 1920; Science, N.S., Vol. LIII. 
Pearl; and of many mutationists who make much greater claims for that theory than does De Vries himself.

Second. Each generation of biologists is so occupied with its own work and contemporary theories that it makes no real effort to understand preceding theories.

This second tendency seems to me most marked in the attitude of present workers along genetic lines towards natural selection. They reveal an apparent lack of understanding of what Darwin really meant and of what he claimed; and when criticising that theory they are often engaged in the classic, but unprofitable, exercise of "fighting windmills."

In view of these facts I hope you will pardon me if I present in as few words as possible just what I believe to be the main factors which Darwin presented as resulting, in their actions and reactions, in natural selection. These factors are three in number:

First. Heredity, by which the progeny tend to resemble their parents more than they do other individuals of the same species.

Second. Individual variation, by which the progeny tend to depart from the parental type and sometimes from the specific type.

Third. Geometrical ratio of increase, by which each species tends to produce more individuals than can survive.

Each of these factors is practically axiomatic, so little is it open to argument.

No one doubts the fact of heredity, whether pangenesis, Weismannism or Mendelism be the correct expression of the mechanism involved. These do not affect the fact of heredity nor invalidate it as a factor in natural selection.

No one doubts the fact of variation; whether it is the "individual variation" of Darwin, the "fluctuating variety" or the "mutation" of De Vries. All that is necessary for Darwin's purpose is that there be heritable variations. That there are such things all parties agree and it matters little what you call them. They are adequate to act as a factor in the Darwinian scheme.

No one doubts the fact of geometrical ratio of increase. It is a proposition easily capable of mathematical demonstration, and that is sufficient for Darwin's purpose.

These three factors, then, are not debatable as facts, whatever their mechanism or causes.

A moment's reflection will show that geometrical ratio of increase is a quantitative factor, giving an abundance of individuals from 
which to select; that individual variation is a qualitative factor, giving the differences which make a selection possible; and that heredity is a conservative factor, holding fast those characters which better fit the organism to its environment.

Now it seems to me that there is no possible outcome of the necessary action and interaction of these three factors that would not be a selection of some sort. Darwin thought it comparable in a large way to the selection by which the stock-breeder improves his herd, and therefore called it "natural selection," carefully guarding the phrase from misinterpretation from the teleological angle as well as from a too close parallelism between artificial and natural selection. And I believe no one has suggested a more acceptable term for the process of selection resulting from the interplay of natural laws.

Three outstanding theories have been advanced since the publication of the Origin, each involving an advance in our knowledge of the mechanism of heredity on the one hand and the origin of variations on the other.

Weismann's theory of the continuity and stability of the germ plasm was of immense importance in its discussion of the mechanism of heredity, and his amphimixis gave a plausible explanation of the origin of variations. His results were almost universally regarded as confirming and greatly extending the scope of natural selection.

Mendel's theory regarding the purity of the gametes, their segregation in the sex cells, and the whole complex Mendelian mechanism so admirably described by Morgan; all of these, fascinating and important as they are, deal with the mechanism rather than the fact of heredity. In my opinion their acceptance or rejection does not affect the status of natural selection as a theory of organic evolution.

But it is the theory of mutation that has furnished most of the ammunition for the opponents of natural selection; and this in spite of the fact that De Vries, the originator of the mutation theory, expresses himself with great clarity as follows:

"My work claims to be in full accord with the principles laid down by Darwin and to give a thorough and sharp analysis to some of the ideas of variability, inheritance, selection, and mutation which were necessarily vague in his time."

In 1904, when these words were published, there did seem to be a sharp distinction between the ideas of Darwin and those of De Vries. The former believed that natural selection acted upon many small variations and accumulated them until the differences were sufficient 
to constitute new species; while De Vries claimed that new species were formed by the sudden appearance by mutations of forms specifically distinct from the parents. That mutants were new species!

It seems evident that Darwin did not regard "saltatory evolution" as the common method, while De Vries did.

Darwin believed that individual, usually small, variations furnished the material on which selection acts; while De Vries thought that mutants, usually large variations, furnished the material. (Both, however, believed thoroughly that natural selection was a vera causa of evolution.

But things have changed greatly since I904. The work of Morgan, Castle, Jennings and a host of others has shown that many mutations are so small, from a phenotypic standpoint, that they are quantitatively no greater than the individual variations of Darwin; and that they are heritable in the Mendelian way?

Castle produced a perfectly graded series of hooded rats which exhibits almost ideally the steps by which a new form might be oroduced by natural selection. He says:

'If artificial selection can, in the brief span of a man's lifetime, mould a character steadily in a particular direction, why may not natural selection in unlimited time also cause progressive evolution in directions useful to the organism?",

Jennings says:

"Sufficiently thorough study shows that minute heritable variations-so minute as to represent practically continuous gradationsoccur in many organisms: some reproducing from a single parent, others by biparental reproduction. . . . . It is not established that heritable changes must be sudden large steps; while these may occur, minute heritable changes are more frequent. (Evolution according to the typical Darwinian scheme, through the occurrence of many small variations and their guidance by natural selection, is perfectly consistent with what experimental and paleontological studies show us; to me it appears more consistent with the data than does any other theory.")

Many believers in mutation have been needlessly befuddled by the diverse meanings of "variations" as used by Darwin and De Vries. Darwin included in his "individual variations" both the "fluctuating varieties" and the "mutations" of De Vries. Phenotypically they cannot even now be distinguished. De Vries himself candidly admits that this was Darwin's attitude, thus proving himself 
more clear-sighted than many of his followers. All that Darwin needed for his purpose was proof of variations that are heritable, and these are found in mutations, be they large or small.

Just as Mendelism has to do with the mechanism and not the fact of heredity, so the mutation theory deals with the nature and not the fact of variations.) Neither, in my opinion, has any implication that is antagonistic to the theory of natural selection.

The statement has been made that natural selection "originates nothing" because it does not explain the origin of variations. I must confess scant patience with this point of view. As well say that the sculptor does not make the statue because he does not manufacture the marble or his chisel; or that the worker in mosaic originates nothing because he does not make the bits of stone which he assembles in his design!

The material corresponding to the bits of stone in the mosaic is furnished by heredity and variation, and its quantity by geometrical ratio of increase.) (Natural selection acts in selecting and putting together this material in the formation of new species. Thus, in a true sense, it seems evident that something new has appearedsomething that is, but was not)

Another favorite figure, introduced I believe by De Vries, is "Natural selection acts only as a sieve" determining which forms shall be retained and which shall be discarded. This also seems to me to fall short of a complete statement of the truth. If the material subjected to the sifting process be regarded as changing with each generation by the addition of variations, or mutations if you prefer, some of which are favorable to a nicer adjustment of the species to its environment, the figure would be more nearly correct. 'To make it complete, however, the mesh of the sieve must cliange from generation to generation so that a quantitative variation which would be preserved in one generation would be discarded in a later one. But in this case natural selection would do more than a sieve could do. It woulc combine a number of favorable variations in the production of something new, a new species!

In conclusion it seems to me that we are justified in maintaining that Mendelism and the mutation theory, while forming the basis of the most brilliant and important advances in biological knowledge of the last half-century, have neither weakenel nor supplanted the Darwinian conception of the "Origin of species by means of Natural Selection. 


\title{
CHAPTER XVIII
}

\section{OTHER THEORIES OF SPECIES-FORMING}

\author{
H. H. N.
}

\section{THEORIES AUXILIARY TO NATURAL SELECTION}

The post-Darwinian causo-mechanical theories fall quite naturally into two categories: those that were devised by Darwinians to bolster up natural selection and to free it of some of its most obvious objections, while retaining the essential features of the principle; and those that were meant to be substitutes for and therefore quite opposed to natural selection. The former theories have been classed as auxiliary, and the latter as alternative theories to natural selection.

The several theories of Weismann will be dealt with first as the most important of the purely auxiliary theories. "Panmixia" is designed to explain, without recourse to Lamarckism and in harmony with natural selection, the degeneration or atrophy of organs which seemed to be inadequately explained by Darwin. "Germinal Selection" is supposed to explain the initial stages of adaptations and allied phenomena, and thus to aid natural selection at one of its weakest points.

WEISMANN'S THEORY OF PANMIXIA

The following statement of "panmixia," as given by S. Herbert, is concise and to the point:

"Cessation of selection as a cause of atrophy was first proposed by Romanes. Later on, Weismann, whilst examining the validity of the principle of use-inheritance, adopted the same idea, called by him 'panmixia,' in order to account for the dwindling and disappearance of useless organs without having recourse to the Lamarckian factors. If natural selection leads to the mating of select types, so that those below a certain standard are prevented from propagating, it follows that, with the cessation of selection, a general crossing of all types, inclucling the inferior ones, must take place, and thus lower the average quality of the whole stock. Weismann explained in this manner, for instance, the prevalence of short-sightedness among civilized people. The individuals with defective eyesight not being weeded out in modern society, the sharpness of the eyesight of the population sinks gradually. The same would apply to the deterioration of the teeth 


\section{READINGS IN EVOLUTION, GENETICS, AND EUGENICS}

of man, of the breast-gland of modern women, etc. The fact that degeneration generally progresses so slowly, often taking thousands and thousands of years, seemed to him a sufficient proof of the inadequacy of the Lamarckian explanation. For if the effect of disuse were transmitted in accumulating ratio in the successive generations, a useless organ ought to disappear much more quickly.

"Weismann originally attributed a great effect to panmixia, and considered that nearly 90 per cent. of the reduction of rudimentary organs was due to it; the remainder, up to the complete loss of the organs, being accounted for by reversed selection. Romanes was much more modest in his estimate, and only allowed about 10 to 20 per cent. to this cause; while Lloyd Morgan gave only 5 per cent. reduction of the original size. The final reduction of the organ to zero is still not accounted for by any of these theories. Calling to aid a failure of the force of heredity, as Romanes did, can hardly be considered a solution of the problem. First of all, the force of heredity does not explain anything in the case. It only restates the problem. We want to know what the force of heredity is. Secondly, if the force of heredity does fail, we should have to explain why it wanes in some cases and not in others. For the reduction and elimination of rudimentary organs occurs apparently in the most irregular, haphazard manner.

"But can panmixia really reduce an organ? Plate, in agreement with Spencer, Eimer, and others, denies any such possibility. An organ in a given condition of its existence varies around a mean or average, the plus and minus variations generally being equally frequent. It follows, therefore, that if all the existing variations are crossed in propagation, the organ remains stationary. Selection only improves the organ by cutting off the minus variations; the absence of selection would simply leave the organ where it was before the selection. At most it could only sink a very little below the average. That this is so is seen in organs which are not under the sway of selection at all. There are numberless such indifferent species characters, which ought gradually to dwindle and disappear, yet they remain fairly constant, though continually exposed to the swamping effect of panmixia. Panmixia may explain the functional degeneration of an organ, but cannot explain its actual rudimentation.

"Weismann himself in later times abandoned panmixia as a sufficient means of explanation, and resorted to a new theory-that of germinal selection."

${ }^{2}$ From S. Herbert, First Principles of Evolution (เ9г3). 
WEISMANN'S THEORY OF GERMINAL SELECTION

This theory was intended to rehabilitate the selection principle which had lost a great deal of prestige because of the serious character of the objections that had heen raised against it, most of which have been stated in the last chapter. The theory is believed by its author to overcome all objections and doulsts and to clear away all difificulties. "Its strength," says Plate, "shall avail in four directions. First, it shall explain how not only degeneration (physiological) but rudimentation (morphological) occurs in panmixia; second, why exactly those variations needed for the development of a certain adaptation appear at the right time; third, how correlation of adaptation comes to exist; and fourth, how variations are ainle to develop orthogenetically along a definite line without depending on the necessity of a personal selection raising them step by step."

The essential feature of germinal selection, as the name implies, is a transfer of the struggle for existence to the germ cell. The germ cell is assumed to be a greatly reduced and simplified sample of the characters of the whole organism. Each independently variable part of the organism is supposed to be represented in the germ cell by a minute physiological unit, unique in composition and capable of reproducing the part in question in a new organișm. These hereditary units are called "determinants." Thus there is a different kind of determinant for each muscle of the body, for each lone, or for each independently functioning blood ressel; but, since all red blood corpuscles are alike, there would be only one determinant for all of them. These determinants have to grow, and in cell division, to divide so as to furnish to daughter germ cells all of the necessary determinants for a whole individual. In their process of growth and multiplication, which goes on very rapidly at certain periods in the germ-cell cycle, these determinants are in competition among themselves for the available food supply. Some may be more farorably placed than others or may be more active chemically than others. There will thus arise a struggle within the germ for a chance to grow and reproduce their kind, which, for these determinants, might be as bitter as would be the struggle in nature among the whole organisms that are in competition for a place in the world. A determinant favored, perhaps: accidentally or possibly lecause of inherent activity, by a grood food supply would wax stronger and grow faster and would, logically, produce a larger and more effective part when that particular germ cell developed into an adult. Other germ cells that would be the offspring 


\section{READINGS IN EVOLUTION, GENETICS, AND EUGENICS}

of this germ cell would continue the struggle among determinants, and it would be expected that the strong determinant would continue to gain further advantage until the structure it represents reached its maximum efficiency. Similarly, a determinant that was for some reason deprived of its fair share of nutriment at any time would be weakened and would produce in cell division weakened daughter determinants. These in turn, unless especially favored, would wage a losing fight and continue to grow smaller and weaker. Each individual that might develop from such germ cells would have the characters whose determinant had been weakened in a reduced and progressively degenerating condition. Finally, certain determinants might starve entirely, and the part for which they stood would disappear entirely from the ontogeny of the individual arising from these germ cells.

In this way Weismann tried to explain the gradual dwindling and the final elimination of useless organs. So also he would explain definitely directed or orthogenetic variations, because germinal selection, once started in a given direction, continues automatically till the goal of adaptiveness is reached.

The most potent objections to the theory of germinal selection are as follows:

I. There should be, according to this theory, certain pronounced tendencies in variability in definite directions, whereas fluctuating variations nearly always distribute themselves evenly about the mean or mode, and the same specific mean or mode is stationary in successive generations.

2. The theory implies too rapid and too general modification of parts and therefore does not accord with the fact that species are decidedly constant, except for occasional mutations, over long periods of time. To meet this objection Weismann proposes a new selfcorrecting mechanism that checks too rapid a development of characters.

3. The over- or undernourishment of determinants might conceivably induce size changes in characters already present, but could hardly be responsible for the origin of qualitatively different characters.

4. Actual experiments in over- and underfeeding of animals have been carried on by certain experimenters in order to test out the theory of germinal selection. In the experiments of Kellogg, for example, involving feeding silkworm larvae only one-eighth of the norma! amount of food, the only result was that the mature individuals were 
dwarfed in size. The relative sizes of the parts were unaltered, showing that there had been no real struggle among the determinants; for, on the theory of germinal selection, only the stronger determinants would have survived and the weaker ones would have been starved out. Partial individuals, moreover, lacking certain organs and overdeveloped in others, would have been produced instead of individuals merely smaller in all parts.

These are the specific objections to the theory, but more important than all of these is the general objection that follows:

"Thus Weismann," says Morgan, " "has piled up one hypothesis on another as though he could save the integrity of the theory of natural selection by adding new speculative matter to it. The most unfortunate feature is that the new speculation is skilfully removed from the field of verification, and invisible germs whose sole functions are those which Weismann's imagination bestows on them, are brought forward as though they could supply the deficiencies of Darwin's theory. This is, indeed, the old method of the philosophizers of nature. An imaginary system has been invented which attempts to explain all difficulties, and if it fails, then new inventions are to be thought of. Thus we see where the theory of selection of fluctuating germs has led one of the most widely known disciples of the Darwinian theory.

"The worst feature of the situation is not so much that Weismann has advanced new hypotheses unsupported by experimental evidence, but that the speculation is of such a kind that it is, from its very nature, unverifiable, and therefore useless. Weismann is mistaken when he assumes that many zoölogists object to his methods because they are largely speculative. The real reason is that the speculation is so often of a kind that cannot be tested by observation and experiment."

It seems almost impossible that the same Professor Morgan, who wrote the foregoing paragraphs in 1903, should now be the leading exponent of a theory of the mechanics of hereditary transmission which depends upon hereditary units almost identical with Weismann's "determinants," for the "genes" or "factors" of Morgan are minute corporeal bodies in the germ cells which determine the characters of the adult individual.

The difference is, however, that the "genes" of Morgan are experimentally demonstrable and have behind them a vast amount of real evidence for their existence.

'From T. H. Morgan, Evolution and Adaptation. 
In this chapter the writer has purposely avoided entering into the more elaborate intricacies of the Weismannian theories of development and heredity. The theories have been so generally discredited and play so small a part in modern biological thought that it seems useless to burden the reader's mind with needless complexities.

Certain other phases of Weismann's work, especially his ideas of the germ plasm, its separateness and its continuity, are more appropriately studied in connection with genetics than at the present time.

ROUX'S THEORY OF INTRASELECTION OR THE BATTLE OF THE PARTS

In point of time this theory antedates Weismann's theories, since it was proposed in $188 \mathrm{r}$. In some respects it is a more acceptable theory than germinal selection, but in others quite unacceptable. The theory is designed primarily to explain the origin of the "fine and delicate inner adaptations" of organisms, which do not come in contact with the external environment and therefore could not be directly affected by it. The idea is that there is a sort of struggle among the tissues for a chance to develop in the direction of functional perfection. Certain contacts, stresses, and pressures of part on part aid or hinder the development of parts. Thus, where muscular pressure on bone is greatest or weight borne by bone is greatest there will the most bony tissue be laid down in the form of lamellae. The result is that any given bone improves its structure by resistance to strain and pressure, which is a case of improvement with use. We may then inquire how such a change in the individual could affect the evolution of the race. The only reply involves the adoption of a distinctly Lamarckian concept, and this at present is quite unacceptable.

COINCIDENT SELECTION OR ORGANIC SELECTION

This theory has been masked under various guises. In addition to the two titles given above, it has appeared under the names "ontogenetic selection" and "orthoplasy." The main idea, according to Herbert, is that "the individually acquired characters, though not transmitted to the offspring, serve to tide the successive generations over the critical period until germinal (inborn) variations of the same kind appear which are inheritable. Ontogenetic (individually acquired) adaptations and natural selection work together towards the same end.

"This hypothesis would help to account for two related difficult points in the theory of natural selection. Firstly, it would explain the possibility of the slow accumulation of germinal variations in their 
first stages before they attain selective value; secondly, it would make correlated adaptations feasible by supplying ontogenetic (individually acquired) modifications, until the material for the appropriate germinal adaptations arose.

"It has been objected to this theory that, since the individually acquired modifications possess the main selective value in these instances, there is no reason why the corresponding germinal variations should be fostered at all. The individuals with the right, but slight, congenital variations would have no advantage over their fellows who show no such coincident variations. Nor is there any ground to assume that individuals with the greatest amount of plastic modification in a given direction will tend to exhibit similar innate variations to a greater degree than those individuals not possessing this plasticity."

ISOLATION THEORIES

One of the objections to natural selection was that a favorable variation appearing in one or a few individuals would be lost because the individuals possessing it would interbreed with those not possessing it, which presumably would be much more numerous. If there were any kind of agency whose effect would be a partial or complete inhibition of intercrossing, the f. vorable character would have a chance to survive.

Several related theories have arisen that deal with possible isolative or segregative agencies that might serve to prevent promiscuous intercrossing, and these have received the names geographic isolation, climatic isolation, reproductive isolation, and physiologic isolation.

Geographic isolation.-Moritz Wagner was the founder of this theory. He was a very extensive traveler and had a vast knowledge of the details of the geographic distribution of animals. He believed that isolation was absolutely essential in the differentiation of species. He at first thought of his theory as auxiliary to natural selection, but later, strongly impressed by the facts he had collected, he concluded that isolation was an independent and alternative explanation of species-forming. The underlying idea is one that has already received attention in chapter vii, under "Evidences from Geographic Distribution." Any successful species tends to spread in all directions until checked by barriers. Some few members of a species under favorable conditions may surmount the barrier and become isolated. The result

IFrom S. Herbert, First Principles of Evolution (1913). 


\section{READINGS IN EVOLUTION, GENETICS, AND EUGENICS}

will be that, if they differ in any definite way from the main body of the species, a new elementary species will at once gain a foothold and will evolve independently of the parent-species. If a certain area of land is cut off from a continent so as to form a continental island, the members of each species that have become isolated will evolve independently of the main body of the species and will have their own peculiar lines of variation preserved from back-crossing with the parent-species.

Professor David Starr Jordan, ${ }^{1}$ the leading proponent of the theory of geographic isolation in America says:

"It is now nearly forty years since Moritz Wagner (I868) first made it clear that geographic isolation (räumlicke Sonderung) was a factor or condition in the formation of every species, race, or tribe of animal or plant we know on the face of the earth. This conclusion is accepted as almost self-evident by every competent student of species or of the geographical distribution of species. But to those who approach the subject of evolution from some other side the principles set forth by Wagner seem less clear. They have never been confuted, scarcely ever attacked, so far as the present writer remembers, but in the literature of evolution of the present day they have been almost universally ignored. Nowadays much of our discussion turns on the question of whether or not minute favorable variations would enable their possessors little by little to gain on the parent stock, so that a new race would be established side by side with the old, or on whether a wide fluctuation or mutation would give rise to a new species which would hold its own in competition with the parent. In theory, either of these conditions might exist. In fact, both of them are virtually unknown. In nature a closely related distinct species is not often quite side by side with the old. It is simply next to it, geographically or geologically speaking, and the degree of distinction almost always bears a relation to the importance or the permanence of the barrier separating the supposed new stock from the parent stock.

"A flood of light may be thrown on the theoretical problem of the origin of species by the study of the probable, actual origin of species with which we are familiar or of which the actual history or the actual ramifications may in some degree be traced.

"In regions broken by few barriers, migration and interbreeding being allowed, we find widely distributed species, homogeneous in their character, the members showing individual fluctuation and climatic

science, N.S., Vol. XXII (1905). 
effects, but remaining uniform in most regards, all representatives slowly changing together in the process of adlaptation by natural selection. In regions broken by barriers which isolate groups of individuals we find a great number of related species, though in most cases the same region contains a smaller number of genera or families. In other words, the new species will be formed conditioned on isolation, though these same barriers may shut out altogether forms of life which would invade the open district.

"Given any species in any region, the nearest related species is not likely to be found in the same region nor in a remote region, but in a neighboring district separated from the first by a barrier of some sort.

"Doubtless wide fluctuations or mutations in every species are more common than we suppose. With free access to the mass of the species, these are lost through interbreeding. Isolate them as in a garden or an enclosure or on an island, and these may be continued and intensified to form new species or races. Any horticulturist will illustrate this.

"In all these and in similar cases we may confidently affirm: The adaptive characters a species may present are due to natural selection or are developed in connection with the demands of competition. The characters, non-adaptive, which chiefly distinguish species do not result from natural sele tion, but from some form of geographical isolation and the segregation of individuals resulting from it."

J. T. Gulick, another exponent of the efficacy of geographic isolation in species-forming, has offered in evidence of his views facts about the distribution of Hawaiian land snails. In the island of Oahu, for example, the volcanic ridges have been eroded out into a series of isolated valleys in the bottoms of which grows abundant vegetation, while on the highlands there is little but barren rock. The climatic conditions of all the numerous valleys are the same, but, remarkably enough, each variety of snail is confined not only to one island, but to a definite valley on an island. The degree of difference, moreover, between varieties is in proportion to the distance that separates them. Gulick claimed that he was able to estimate the degree of divergence between the snails of any two valleys by measuring the number of miles that lay between them. Gulick's findings have been extensively corroborated by recent explorations on the snails of other oceanic islands by Crampton.

An interesting type of isolation that hardly can be termed geographic, yet is essentially equivalent to the latter in its effects, is found 
in connection with the extensive group of lice (Mallophaga) that live their whole lives buried among the feathers of birds or the hair of mammals. These animals cannot fly and are quite effectively isolated for life upon a particular bird. They do, however, during the intimate period of nesting, pass from parent to offspring, so that they may be said to be isolated upon definite genetic lines. In the case, especially, of birds like the eagle, a bird of long life and monogamous habits, the parasite becomes as isolated as might be a race on a small island. The result is that sometimes the lice of a single bird and its offspring are of quite a distinct variety, which has become fixed by inbreeding until a high degree of uniformity has been attained. Such an isolated variety may be almost as distinct as a true species. Obviously in this case, as in others, isolation must have had a real effect upon speciesforming quite apart from natural selection, except in so far as the unfit variants have not survived.

The writer's impression is that isolation as a factor in evolution has been undervalued by the majority of writers on the subject. It is a highly important and essential factor in the establishment of species. If natural selection may be said to be the prime factor in producing adaptations, isolation may be said to be the prime factor in species differentiation, guided only within moderate limits by natural selection.

Biologic isolation. - The effects of this type of isolation are not nearly so well established as are those of geographic isolation. According to this theory, differences in the rate of development or earliness or lateness of the breeding season would serve to prevent certain varieties from intercrossing. Only those individuals which were sexually active simultaneously would mate, and individuals with different breeding times and seasons would be isolated from one another and would likely maintain the variations that arose in the isolated stocks. The main weakness of this phase of isolation is, however, that we have so little actual evidence that it is operative in nature.

Reproductive isolation. - A much more real type of isolation than the last named is involved in reproduction. Several conditions may arise of entirely distinct sorts that will tend to inhibit mating at random. The first agency has been called "assortative mating" and implies a sort of race feeling involving either a special attraction of like for like, based on similarity of odors, colors, etc., or an antipathy toward opposites or unlikes. The inhibition to general mating may involve a mere mechanical lack of fit in certain organs necessary for 
successful mating. Such conditions are readily observable between closely allied species. Again, the prevention of intercrossing may result from the appearance of a lowered interfertility between the variant individuals and those of the parent-stock. If individuals varying in the same direction were even slightly more fertile inter se than those varying in different directions there would be a progressive tendency in a series of generations for the varying individuals to diverge more and more markedly, and ultimately to become practically sterile except with members of their own group.

That environmental changes do frequently affect the fertility of animals is seen when wild animals are kept in confinement. Relatively few wild animals breed in captivity. Such a lowering of fertility as the result of environmental changes might restrict crossing between unlike forms, while permitting it among the like ones.

Summary on isolation theories.-There is a great divergence of opinion as to the importance of isolation as a causal factor in speciesforming. Some writers, such as D. S. Jordan and V. L. Kellogg, consider isolation an indispensable, and therefore primary, factor; others, especially geneticists, almost ignore it as an effective factor. Still others, like the present writer, take a middle ground and conclude that isolation, especially geographic isolation, has helped greatly in the segregation and establ:shment of well-defined groups such as species or varieties, the latter developing into the former after prolonged isolation and the addition of new variations. Isolation theories, however, have no light to shed upon the difficult problem of adaptation, and it is here that isolation is auxiliary to natural selection.

THEORIES ALTERNATIVE TO NATURAL SELECTION

The three theories that have been offered by their authors as substitutes for natural selection are:

I. Theory of the inheritance of acquired characters commonly called Lamarckism: This theory has been outlined in the chapter on the history of evolution (pp. Ig ff.). It will again be dealt with in considerable detail in chapter xxii. For the present, then, we may pass by this theory without further comment.

2. The orthogenesis theories: These theories have already been presented in sufficient detail for our purposes in chapter ii (pp. $33 \mathrm{ff}$.).

3. The mutation theory of Hugo De Vries: This theory has been dealt with in chapter ii, and will be discussed in further detail in chapter xxiv. 


\section{READINGS IN EVOLUTION, GENETICS, AND EUGENICS}

4. The tetrakinctic theory of H.F. Osborn: This is a recent restatement in energistic terms, of the causo-mechanical basis of evolution. It is placed in the next chapter, but cannot fully be understood until the subject of genetics has been presented.

It is almost impossible satisfactorily to pursue a further study of the causal factors of evolution without encroaching upon the field that is now called genetics, and so we shall pass without further explanations to a consideration of this field of experimental and analytical evolution. 


\section{CHAPTER XIX}

\section{A NEW COMPOSITE CAUSO-MECHANICAL THEORY OF EVOLUTION (THE TETRAKINETIC THEORY) ${ }^{\mathrm{T}}$

\author{
HENRY FAIRFIELD OSBORN
}

\section{THE ENERGY CONCEPT OF LIFE}

While we owe to matter and form the revelation of the existence. of the great law of evolution, we must reverse our thought in search for causes and take steps toward an energy conception of the origin of life and an energy conception of the nature of heredity.

So far as the creative power of energy is concerned, we are on sure ground: in physics energy controls matter and form; in physiology function controls the organ; in animal mechanics motion controls and, in a sense, creates the form of muscles and bones. In every instance some kind of energy or work precedes some kind of form, rendering it probable that energy also precedes and controls the evolution of life.

The total disparity between invisible energy and visible form is the second point which strikes us as in favor of such a conception, because the most phenomenal thing about the heredity-germ is its microscopic size as contrasted with the titanic beings which may rise out of it. The electric energy transmitted through a small copper wire is yet capable of moving a long and heavy train of cars. The discovery by Becquerel and Curie of radiant energy and of the properties of radium the energy per unit of mass is enormously greater than the energy quanta which we were accustomed to associate with units of mass; whereas, in most man-made machines with metallic wheels and levers, and in certain parts of the animal machine constructed of muscle and bone, the work done is proportionate to the size and form. The slow dissipation or degradation of energy in radium has been shown by Curie to be concomitant with the giving off of an enormous amount of heat, while Rutherford and Strutt declare that in a very minute amount of active radium the energy of degradation would entirely dominate and mask all other cosmic modes of transformation

I From H. F. Osborn, The Origin and Evolution of Life (copyright I916). Used by special permission of the publishers, Charles Scribner's Sons. 


\section{READINGS IN EVOLUTION, GENETICS, AND EUGENICS}

of energy; for example, it far outweighs that arising from the gravitational energy which is an ample supply for our cosmic system, the explanation being that the minutest energy elements of which radium is composed are moving at incredible velocities, approaching often the velocity of light, i.e., I $\$ 0,000$ miles per second. The energy of radium differs from the supposed energy of life in being constantly dissipated and degraded; its apparently unlimited power is being lost and scattered.

We may imagine that the energy which lies in the life-germ of heredity is very great per unit of mass of the matter which contains ' it, but that the life-germ energy, unlike that of radium, is in process of accumulation, construction, conservation, rather than of dissipation and destruction.

Following the time ( 1620 ) when Francis Bacon divined that heat consists of a kind of motion or brisk agitation of the particles of matter, it has step by step been demonstrated that the energy of heat, of light, of electricity, the electric energy of chemical configurations, the energy of gravitation, are all utilized in living as well as in lifeless substances. Moreover, no form of energy has thus far been discovered in living substances which is peculiar to them and not derived from the inorganic world. In a broad sense all these manifestations of energy are subject to Newton's dynamical laws which were formulated in commection with the motions of the heavenly bodies, but are found to apply equally to all motions great or little.

These three fundamental laws are as follows:

I

Corpus oinne perseverare in statu suo quiescendi vel movendi uniformiter in directum, nisi quatenus illud a viribus impressis cogitur statum suum mutare.

\section{II}

Mutitionem motus proportionalem esse vi motrici impressae, et fieri secundum lineam rectam qua vis illa imprimitur.

\section{III}

Actioni contrariam semper et aequalem esse reactionem: sive corporum dluorum actiones in se mutuo semper esse aequales et in partes contrarias dirigi.

\section{I}

Every body perseveres in its state of rest, or of uniform motion in a right line, unless it is compelled to change that state by forces impressed thereon.

\section{II}

The alteration of motion is ever proportional to the motive force impresserl; and is made in the direction of the right line in which that force is impressed.

\section{III}

To every action there is always opposed an cqual reaction: or the mutual actions of two bodies upon each other are always equal, and directed to contrary parts. 
Newton's third law of the equality of action and reaction is the foundation of the modern doctrine of energy, not only in the Newtonian sense but in the most general sense. Newton divined the principle of the conservation of energy in mechanics; Rumford ( 1798 ) maintained the universality of the laws of energy; Joule (I843) established the particular principle of the conservation of energy, namely the exact equivalence between the amount of heat produced and the amount of mechanical energy destroyed; and Helmholtz, in his great memoir Über die Erhaltung der Kraft, extended this system of conservation of energy throughout the whole range of natural phenomena. A familiar instance of the so-called transformation of energy is where the sudden arrest of a cool but rapidly moving body produces heat. This was developed as the first law of thermod ynamies.

At the same time there arose the distinction between potential energy, which is stored away in some latent form or manner so that it can be drawn upon for work-such energy being exemplified mechanically by the bent spring, chemically by gunpowder, and electrically by a Leyden jar-and kinetic energy, the active energy of motion and of heat.

While all active mechanical energy or work may be converted into an equivalent amount of heat, the opposite process of turning heat into work involves more or less loss, dissipation, or degradation of energy. This is known as the second law of thermodynamics and is the outgrowth of a principle discovered by Sadi Carnot. ( $\mathrm{IS}_{24}$ ) and developed by Kelvin ( 1852,1853 ). The far-reaching conception of cyclic processes in energy enunciated in Kelvin's principle of the dissipation of available energy puts a diminishing limit upon the amount of heat energy available for mechanical purposes. The available kinetic energy of motion and of heat which we can turn into work or mechanical effect is possessed by any system of two or more bodies in virtue of the relative rates of motion of their parts, velocity being essentially relative.

These two great dynamical principles that the energy of motion can be converted into an equivalent amount of heat, and that a certain amount of heat can be converted into a more limited amount of power were discovered through observations on the motions of larger masses of matter, but they are believer to apply equally to such motions as are involved in the smallest electrically charged atoms (ions) of the chemical elements and the particles flying off in radiant energy as phosphorescence. Such movements of infinitesimal particles underlie 


\section{READINGS IN EVOLUTION, GENETICS, AND EUGENICS}

all the physicochemical laws of action and reaction which have been observed to occur within living things. In all physicochemical processes within and without the organism by which energy is captured, stored, transformed, or released the actions and reactions are equal, as expressed in Newton's third law.

Actions and reactions refer chiefly to what is going on between the parts of the organism in chemical or physical contact, and are subject to the two dynamical principles referred to above. Interactions, on the other hand, refer to what is going on between material parts which are connected with each other by other parts, and cannot be analyzed at all by the two great dynamical principles alone without a knowledge of the structure which connects the interacting parts. For example, in interaction between distant bodies the cause may be very feeble, yet the potential or stored energy which may be likerated at a distant point may be tremendous. Action and reaction are chiefly simultaneous, whereas interaction connects actions and reartions which are not simultaneous; to use a simple illustration: when one pulls at the reins the horse feels it a little later than the moment at which the reins are pulled-there is interaction between the hand and the horse's mouth, the reins being the interacting part. An interacting nerve-impulse starting from a microscopic cell in the brain may give rise to a powerful muscular action and reaction at some distant point. An interacting enzyme, hormone, or other chemical messenger circulating in the blood may profoundly modtfy the growth of a great organism.

Out of these physicochemical principles has arisen the conception of a living organism as composed of an incessant series of actions and reactions operating under the dynamical laws which govern the transfer and transformation of energy.

The central theory which is developed in our speculation on the Origin of Life is that every plyysicochemical action and reaction concerned in the transformation, conservation, and dissipation of energy, produces also, either as a direct; icsult or as a by-product a physicochemical agent of interaction which pormeates and affects the organism as a whole or affects only some special part. Through such interaction the organism is made a unit and acts as one, because the activities of all its parts are correlated. This idea may be expressed in the following simplified scheme of the functions or physiology of the organism: 


\section{ACTION \\ AND}

Reaction

Functions of the

Capture, Storage, and Release of

Energy

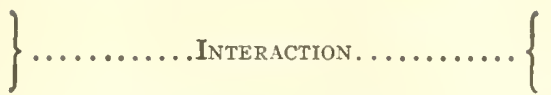

Functions of the

Coördination, Balance, Coöperation, Compensation, Acceleration, Retardation, of Actions and Reactions
ACTION

AND

Reaction

Functions of the

Capture, Storage, and Release of

Energy

Since it is known that many actions and reactions of the organism-such as those of general and localized growth, of nutrition, of respiration-are coördinated with other actions and reactions through interaction, it is but a step to extend the principle and suppose that all actions and reactions are similarly coördinated; and that while there was an evolution of action and reaction there was also a corresponding evolution of interaction, for without this the organism would not evolve harmoniously.

Evidence for such universality of the interaction principle has been accumulating rapidly of late, especially in experimental medicine and in experimental biology. It is a further step in our theory to suppose that the directing power of heredity which regulates the initial and all the subsequent steps of development in action and reaction, gives the orders, hastens development at one point, retards it at another, is an elaboration of the principle of interaction. In lowly organisms like the monids these interactions are very simple; in higher organisms like man these interactions are elaborated through physicochemical and other agents, some of which have already been discovered although doubtless many more await discovery. Thus we conceive of the origin and development of the organism as a concomitant evolution of the action, reaction, and interaction of energy. Actions and reactions are borrowed from the inorganic world, and elaborated through the production of the new organic chemical compounds; it is the peculiar evolution and elaboration of the physical principle of interaction which distinguishes the living organism.

Thus the evolution of life may be rewritten in terms of invisible energy, as it has long since been written in terms of visible form. All visible tissues, organs, and structures are seen to be the more or less simple or elaborate agents of the different modes of energy. One after another special groups of tissues and organs are created and coördinated-organs for the capture of energy from the inorganic environment and from the life environment, organs for the storage of energy, organs for the transformation of energy from the potential state into 
the states of motion and heat. Other agents of control are evolved to bring about a harmonious balance between the various organs and tissues in which energy is released, hastened or accelerated, slowed down or retarded, or actually arrested or inhilited.

In the simplest organisms energy may be captured while the organism as a whole is in a state of rest; but at an early stage of life special organs of locomotion are evolved by which energy is sought out, and organs of prehension by which it may be seized. Along with these motor organs are developed organs of offense and defense of many kinds, by means of which stored energy is protected from capture or invasion by other organisms. Finally, there is the most mysterious and comprehensive process of all, by which all these manifold modes of energy are reproduced in another organism.

\section{THE FOUR COMPLEXES OF ENERGY}

The theoretic evolution of the four complexes is somewhat as follows:

I. In the order of time the Inorganic Environment comes first; energy and matter are first seen in the sun, in the earth, in the air, and in the water-each a very wonderful complex of energies in itself. They form, nevertheless, an entirely orderly system, held together by gravitation, moving under Newton's laws of motion, subject to the more newly discovered laws of thermodynamics. In this complex we observe actions and reactions, the sum of the taking in and giving out of energy, the conservation of energy. We also observe interactions wherein the energy released at certain points may be greater than the energy received, which is merely a stimulus for the beginning of the local energy transformations. This energy is distributed among the eighty or more chemical elements of the sun and other stars. These elements are combined in plants into complex substances, generally with a storage of energy. Such substances are disintegrated into simple substances in animals, generally with a release of energy. All these processes are termed by us physicochemical.

2. With life something new appears in the universe, namely, a union of the internal and external adjustment of energy which we appropriately call an Organism. In the course of the evolution of life every law and property in the physicochemical world is turned to advantage; every chemical element is assembled in which inorganic properties may serve organic functions. There is an immediate or gradual separation of the organism into two complexes of energy, 
namely, first, the energy complex of the organism, which is perishable with the term of life of the individual, and second, the germ or heredity substance, which is perpetual.

3. The idea that the germ is an energy complex is an as yet unproved hypothesis; it has not been demonstrated. The Heredity-Germ in some respects bears a likeness to latent or potential interacting energy, while in other respects it is entirely unique. The supposed germ energy is not only cumulative but is in a sense imperishable, selfperpetuating, and continuous during the whole period of the evolution of life upon the earth, a conception which we owe chiefly to the law of the continuity of the germ-plasm formulated by Weismann. Some of the observed phenomena of the germ in Heredity are chiefly analogous to those of interaction in the Organism, namely, directive of a series of actions and reactions, but in general we know no complete physical or inorganic analogy to the phenomena of heredity; they are unique in nature.

4. With the multiplication and diversification of individual organisms there enters a new factor in the environment, namely, the energy complex of the Life Environment.

Thus there are combined certainly three and, possibly, four complexes of energy, of which each has its own actions, reactions, and interactions. The evolution of life proceeds by sustaining these actions, reactions, and interactions and constantly building up new ones: at the same time the potentiality of reproducing these actions, reactions, and interactions in the course of the development of each new organism is gradually being accumulated and perpetuated in the germ.

From the very beginning every individual organism is competing with other organisms of its own kind and of other kinds, and the law of the survival of the fittest is operating between the forms and functions of organisms as a whole and between their separate actions, reactions, and interactions. This, as Weismann pointed out, while apparently a selection of the individual organism itself, is actually a selection of the heredity-germ complex, of its potentialities, powers, and predispositions. Thus Selection is not a form of energy, nor a part of the energy complex; it is an arbiter between different complexes and forms of energy; it antedates the origin of life just as adaptation or fitness antedates the origin of life, as remarked by Henderson.

Thus we arrive at a conception of the relations of organisms to each other and to their environment as of an enormous and always 
increasing complexity; sustained through the interchange of energy. Darwin's principle of the survival or elimination of various forms of living energy is, in fact, adumbrated in the survival or elimination of various forms of lifeless energy as witnessed among the stars and planets. In other words, Darwin's principle operates as one of the causes of evolution in making the lifeless and living worlds what they now appear to be, but not as one of the energies of evolution. Selection merely determines which one of a combination of energies shall survive and which shall perish.

The complex of four interrelated sets of physicochemical energies which I have previously set forth as the most fundamental biologic scheme or principle of development may now be restated as follows:

In each organism the phenomena of life represent the action, reaction, and interaction of four complexes of physicochemical energy, namely, those of (I) the Inorganic Environment, (2) the developing Organism (protoplasm and body-chromatin), (3) the germ or Heredity-Chromatin, (4) the Life Environment. Upon the resultant actions, reactions, and interactions of potential and kinetic energy in each organism Selection is constantly operating wherever there is competition with the corresponding actions, reactions, and interactions of other organisms.

This principle I shall put forth in different aspects as the central thought of these lectures, stating at the outset and often recurring to the admission that it involves several unknown principles and especially the largely hypothetical question whether there is a relation between the action, reaction, and interaction of the internal energies of the germ or heredity-chromatin with the cxternal energies of the inorganic environment, of the developing organism, and of its life environment. In other words, while this is a principle which largely governs the Organism, it remains to be discovered whether it also governs the causes of the Evolution of the Germ.

As observed in the preface we are studying not one but four simultancous evolutions. Each of these evolutions appears to be almost infinite in itself as soon as we can examine it in detail, but of the four that of the germ or heredity-chromatin so far surpasses all the others in complexity that it appears to us infinite.

The physicochemical relations between these four evolutions, including the activities of the single and of the multiplying organisms of the Life Environment, may be expressed in diagrammatic form as follows: 
Organism A

Under

Neaton's Law's of Motion and

Modern Thermodynamics

Actions, Reactions, and Intcractions

of the

I. Inorganic Environment: physicochemical energies of space, of the sun, earth, air, and water.

2. Organism: physicochemical energies of the developing individual in the tissues, cells, protoplasm, and cellchromatin.

3. Heredity-Gcrm:

physicochemical energies of the hereditychromatin included in the reproductive cells and tissues.

4. Life Enaironment:

physicochemical energies of other organisms.
OrganismS B-Z

Under

Newton's Laws of Motion and

Modern Thermodynamics

Actions, Reactions, and

Intcractions of the

I. Inorganic Environment: physicochemical energies of space, of the sun, earth, air, and water.

2. Organism:

physicochemical energies of the developing individual in the tissues, cells, protoplasm, and cellchromatin.

Survival of the fittest: competition, selection, and elimination of the energies and forms.

If a single name is demanded for this conception of evolution it might be termed the tetrakinetic theory in reference to the four sets of internal and external energies which play upon and within every individual and every race. In respect to form it is a tetraplastic theory in the sense that every living plant and animal form is plastically moulded by four sets of energies. The derivation of this conception of life and of the possible causes of evolution from the laws which have been developed out of the Newtonian system, and from those of the other great Cambridge philosopher, Charles Darwin, are clearly shown in the above diagram. 
PART IV

GENETICS 


\title{
CHAPTER XX
}

\section{THE SCOPE AND METHODS OF GENE'TICS}

\author{
H. H. N.
}

\section{DEFINITIONS}

"Genetics is the science which seeks to account for the resemblances and the differences which are exhibited among organisms related by descent."-Babcock and Clausen.

"Genetics may be defined as the science which deals with the coming into being of organisms. It does not refer, however, to the first creation of organic beings, but rather to the present every-day creation of new individuals or new races. It refers particularly to the part that parent organisms have in bringing new organisms into being and to the influence which parents exert on the characteristics of their offspring. In this sense it is nearly equivalent to the term heredity."-W. E. Castle.

"Heredity may be defined as organic resemblance based on descent."-IV. E. Castle.

"Heredity is commoniy defined as the tendency of offspring to develop characters like those of the parents."-Babcock and Clausen.

\section{THE SCOPE AND METHODS OF GENETICS}

Genetics is the study of evolution from a new point of view. The great evolutionists of the past were devotees of the inductive method in science which consists of collecting data and devising theories to explain the data. None of the older evolutionists attempted to put their theories to experimental tests. Thus their theories, though in some respects well founded, never reached that stage of scientific proof which involves the use of the experimental method. The new method in evolution is that of experiment under controlled conditions. If new characters arise before the eyes of the investigator in a known stock of animals or plants and the factors responsible for the change are known and are capable of control, it may be said that man has actually taken a hand in evolution. If new characters arise in a known stock, but from an unknown cause, the course of the new character in inheritance may be controlled and some knowledge of the 
mechanism of heredity may be obtained by an analysis of its modes of heredity. It is this new experimental and analytic method of studying evolution that we have come to designate as genetics.

Three principal methods of attack upon the problems of genetics have been successful in advancing our knowledge.

a) Experimental breeding. - This method was first systematized by Mendel and consists of breeding together two individuals possessing certain more or less contrasting characters and determining the ratios in which the parental characters reappear in the offspring. This method has been extremely fruitful and in connection with the second method, that of cytology, has made clear much that was obscure to Darwin and his followers.

b) Cytology.-This second method involves the microscopic study of the germ cells during the most critical periods of their cycle. It seems very probable that we can now view under the microscope the actual heredity machine and see how it works.

c) The statistical method.- - It is usually conceded that Sir Francis Galton was the first to use the method of statistics in the study of heredity. By means of correlation tables he was able to compare large groups of parents with large groups of offspring with respect to any unit character, and to state the degree of heredity in definite mathematical terms. The modern science of biometry is used extensively at the present time for determining the degree of variability of characters which vary only slightly or irregularly and the exact degree of correlation that exists between different hereditary characters.

All three of these methods of attacking the problems of genetics have been fruitful in results and all are essential to an adequate understanding of the workings of evolution.

The subject-matter of genetics consists of: (a) a knowledge of the principles of ontogeny, the development of the individual from the germ-cell stage to the adult stage; $(b)$ a knowledge of the behavior of the germ cells from one generation to the next, involving the so-called "origin" of germ cells, maturation and fertilization of germ cells, and the exact behavior of the chromosomes during the entire germ-cell cycle; (c) a knowledge of variation, including a determination of what distinct kinds of variation occur, where in ontogeny variations are initiated, the causes of variation, etc.; $(d)$ what kinds of variations are inherited and according to what laws-the whole subject of Mendelian heredity; $(\rho)$ the determination of sex and the relation of sex 
to heredity; $(f)$ theories as to the mechanism that brings about the observed regularity in heredity, including theories of linkage, crossovers, and other phases of neo-Mendelian heredity.

THE IMPORTANCE OF THE CELL THEORY IN GENETICS

All organisms are composed of minute units called cells. A cell is the smallest particle of living matter capable of growing and multiplying. The only continuity between two successive generations is a cellular continuity, involving a continuous series of cell divisions. All cells are the offspring by division of previous cells. We distinguish two main categories of cells: body or somatic cells and germ cells.

In germinal reproduction, the only kind of reproduction possible in the more highly differentiated animals, the material continuity between parent and offspring is through the germ cell. A parental germ cell produces an offspring. The germ cell therefore is called the hereditary bridge.

The only way, then, in which a parent can transmit his or her characteristics to an offspring is through the germ cell. Every hereditary character, whether old or new, must have its differential cause in the germ cell. The germ cells are therefore called the bearers of the heritage, and in the next chapter Professor M. F. Guyer gives an account of the cellular basis of variation and heredity. 


\section{CH.IPTER XXI}

\section{THE BEARERS OF THE HERITAGE}

\section{AN ACCOUNT OF THE CELLULAR BASIS OF HEREDITY'I \\ MICHAEL F. GUYER}

Structure of the cell.--Before we can understand certain necessary details of the physical mechanism of inheritance we must inquire a little further into the finer structure of the cell and into the nature of cell-division. A typical cell, as it would appear after treatment with various stains which bring out the different parts more distinctly, is shown in Fig. 4.3. Typical, not that any particular kind of living cell resembles it very closely in appearance, but because it shows in a diagrammatic way the essential parts of a cell. In the diagram, there are two well-marked regions: a central muclcus and a peripheral cell-body or cytoplasm. Other structures are pictured, but only a few of them need command our attention at present. At one side of the nucleus one observes a small dot or granule surrounded by a denser area of cytoplasm. This body is called the centrosome. The nucleus in this instance is bounded by a well-marked nuclear membrane and within it are several substances. What appear to be threads of a faintly staining material, the linin, traverse it in every direction and form an apparent network. The parts on which we wish particularly to rivet our attention are the densely stained substances scattered along or imbedded in the strands of this network in irregular granules and patches. This substance is called chromatin. It takes its name from the fact that it shows great afinity for certain stains and becomes intensely colored by them. This deeply colored portion of the cell, the chromatin, is by most biologists regarded as of great importance from the standpoint of heredity. One or more larger masses of chromatin or chromatin-like material, known as chromatin nuclcoli, are often present, and not infrequently a small spheroidal body, differing in its staining reactions from the cliromatin-nucleolus and sometimes called the true mucleolus, exists.

Cell-division.- In the simplest type of cell-division the nucleus first constricts in the midlle, and finally the two halves separate.

${ }^{2}$ From M. F. Guyer, Being Well Born (copyright igr6). Used by special permission of the publishers, The Bobbs-Merrill Company. 
This separation is followed by a sinilar constriction and final division of the entire cell-bodly, which results in the production of two new cells. This form of cell-clivision is known as simple or direct division. Such a simple division, while found in higher animals, is less frequent and apparently much less significant than another type of division which involves profound changes and rearrangements of the nuclear contents. The latter is termed mitolic or indirect cell-division. Fig. 44 illustrates some of the stages which are passed through in indirect cell-division. The centrosome which lies passively at the side of the nucleus in the typical cell (Fig. 44, a) awakens to activity, divides and the two components come to lie at the ends of a fibrous spindle. In

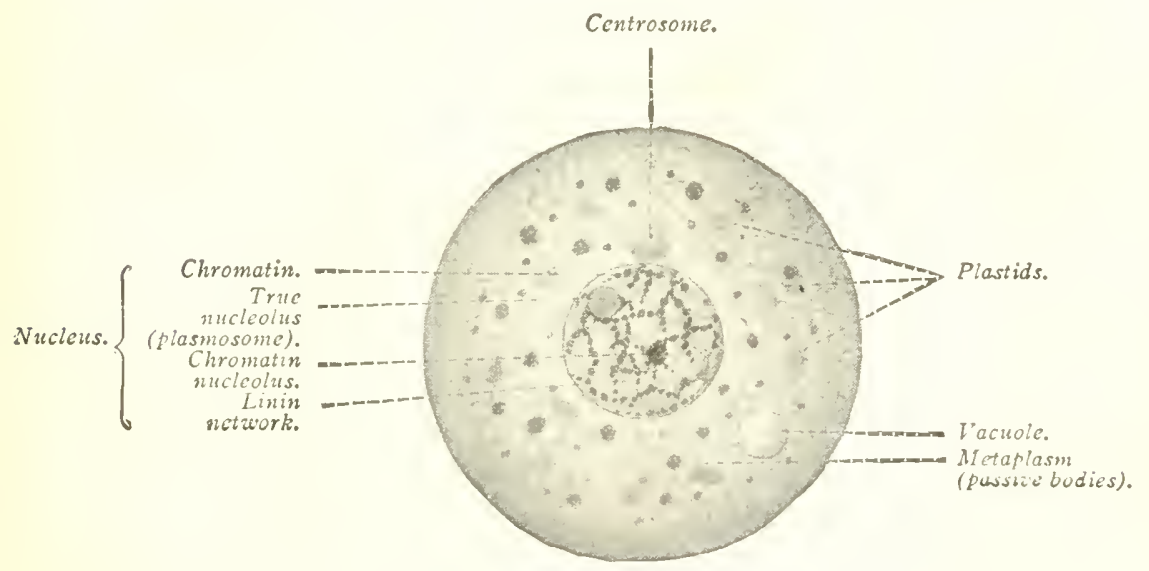

Fic. 43.-Diagram of a cell, showing various parts. (From Guycr.)

the meantime, the interior of the nucleus is undergoing a transformation. The granules and patches of chromatin begin to flow together along the nuclear network and become more and more crowled until they take on the appearance of one or more long deeplystained threads wound back and forth in a loose skein in the nucleus (Fig. 44, b). If we examine this thread closely, in some forms it may be seen to consist of a series of deeply-stainerl chromatin granules packed closely together, intermingled with the substance of the original nuclear network.

As the preparations for division go on the coil in the nucleus breaks up into a number of segments which are designated as chromosomes (Fig. 44, ). The nuclear membrane disappears. The chromosomes 
and the spindle-fibers ultimately come to lie at the equator of the spindle as shown in Fig. 44, $d$. Each chromosome splits lengthwise to form two daughter chromosomes which then diverge to pass to the
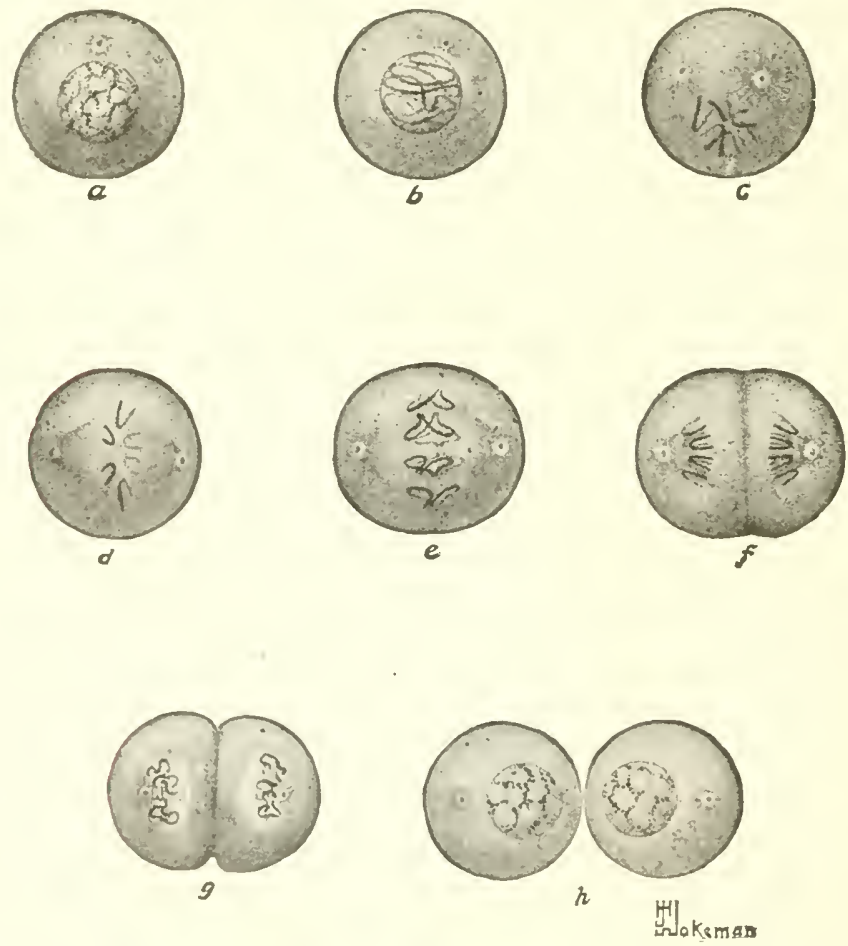

FIG. 44.-Diagram showing representative stages in mitotic or indirect celldivision. $a$, resting cell with reticular nucleus and single centrosome; $b$, the two new centrosomes formed by division of the old one are separating and the nucleus is in the spireme stage; $c$, the nuclear wall has disappeared, the spireme has broken up into six separate chromosomes, and the spindle is forming between the two centrosomes; $d$, equatorial plate stage in which the chromosomes occupy the equator of the spindle; $e, f$, each chromosome splits lengthwise and the daughter chromosomes thus formed approach their respective poles; $g$, reconstruction of the new nuclei and division of the cell body; $h$, cell division completed. (From Guyer.)

poles of the spindle (Fig. 44, $e$ and $f$ ). Thus each end of the spindle comes ultimately to be occupied by a set of chromosomes. Moreover, each set is a duplicate of the other, because the substance of any individual chromosome in one group has its counterpart in the other. 
In fact this whole complicated system of indirect division is regarded by most biologists as a mechanism for bringing about the precise halving of the chromosomes.

The chromosomes of each group at the poles finally fuse and two new nuclei, each similar to the original one, are constructed (Fig. 44, $g$ and $h$ ). In the meantime a division of the cell-body is in progress which, when completed, results in the formation of two complete new cells.

As all living matter, if given suitable food, can convert it into living matter of its own kind, there is no difficulty in conceiving how the new cell or the chromatin material finally attains to the same bulk that was characteristic of the parent cell. In the case of the chromatin, indeed, it seems that there is at times a precocious doubling of the ordinary amount of material before the actual division occurs.

Chromosomes constant in number and appearance. - With some minor exceptions, to be noted later, which increase rather than detract from the significance of the facts, the chromosomes are always the same in number and appearance in all individuals of a given species of plants or animals. That is, every species has a fixed number which regularly recurs in all of its cell-divisions. Thus the ordinary cells of the rat, when preparirg to divide, each display sixteen chromosomes, the frog or the mouse, twenty-four, the lily twenty-four and the maw-worm of the horse only four. The chromosomes of different kinds of animals or plants may differ very much in appearance. In some they are spherical, in others rod-like, filamentous or perhaps of other forms. In some organisms the chromosomes of the same nucleus may differ from one another in size, shape, and proportions, but if such differences appear at one division they appear at others, thus showing that in such cases the differences are constant from one generation to the next.

Significance of the chromosomes.-The question naturally arises as to what is the significance of the chromosomes. Why is the accurate adjustment which we have noted for their division necessary? The very existence of an elaborate mechanism so admirably adapted to their precise halving, predisposes one toward the belief that the chromosomes have an important function which necessitates the retention of their individudity and their equal division. Many biologists accept this along with other evidences as indicating that in chromatin we have a substance which is not the same throughout, that 


\section{READINGS IN EVOLUTION, GENETICS, AND EUGENICS}

different regions of the same chromosome have different physiological values.

When the cell prepares for divisions, the granules, as we have seen, arrange themselves serially into a definite number of strands which we have termed chromosomes. Judging from all available evidence, the granules are self-propagating units; this is, they can grow and reproduce themselves. So that what really happens in mitosis in the splitting of the chromosomes is a precise halving of the series of individual granules of which each chromosome is constituted, or in other words each granule has reproduced itself. Thus each of the two daughter cells presumably gets a sample of every kind of chromosomal particle, hence, the two cells are qualitatively alike. To use a homely illustration we may picture the individual chromosomes to ourselves as so many separate trains of freight cars, each car of which is loaded with different merchandise. Now, if every one of the trains could split along its entire length and the resulting halves each grow into a train similar to the original, so that instead of one there would exist two identical trains, we should have a phenomenon analogous to that of a dividing chromosome.

Cleavage of the egg.- It is through a series of such divisions as these that the zygote or fertilized egg-cell builds up the tissues and organs of the new organism. The process is technically spoken of as cleavage. Cleavage generally begins very shortly after fertilization. The fertile egg-cell divides into two, the resulting cells divide again and thus the process continucs, with an ever-increasing number of cells.

Chief processes operative in building the body. - Although of much interest, space will noi permit of a discussion in detail of the building up of the special organs and tissues of the body. It must suffice merely to mention the four chief processes which are operative. These are, (I) infoldings and outfoldings of the various cell complexes; (2) multiplication of the component cells; (3) speciai changes (histological differentiation) in groups of cells; and (4) occasionally resorption of certain areas of parts.

The origin of the new germ-cells.-On account of the unusual importance from the standpoint of inheritance, which attaches to the germ-cells, a final word must be said about their origin in the embryo. While the evidence is conflicting in some cases, in others it has been well established that the germ-cells are set apart very early from the cells which are to differentiate into the o-dinary body tissues. Fig. 45, 1, shows a section through the eight-celled stage of Miastor, a fly, 
in which a single large, primordial germ-cell $(p . g . c$.$) has already been$ set apart at one end of the developing embryo. The nuclei of the rest of the embryo still lie in a continuous protoplasmic mass which has not yet divided up into separate cells. The densely stained nuclei at the opposite end of the section are the remnants of nurse-cells which originally nourished the egg. Fig. $45, B$, is a longitudinal section
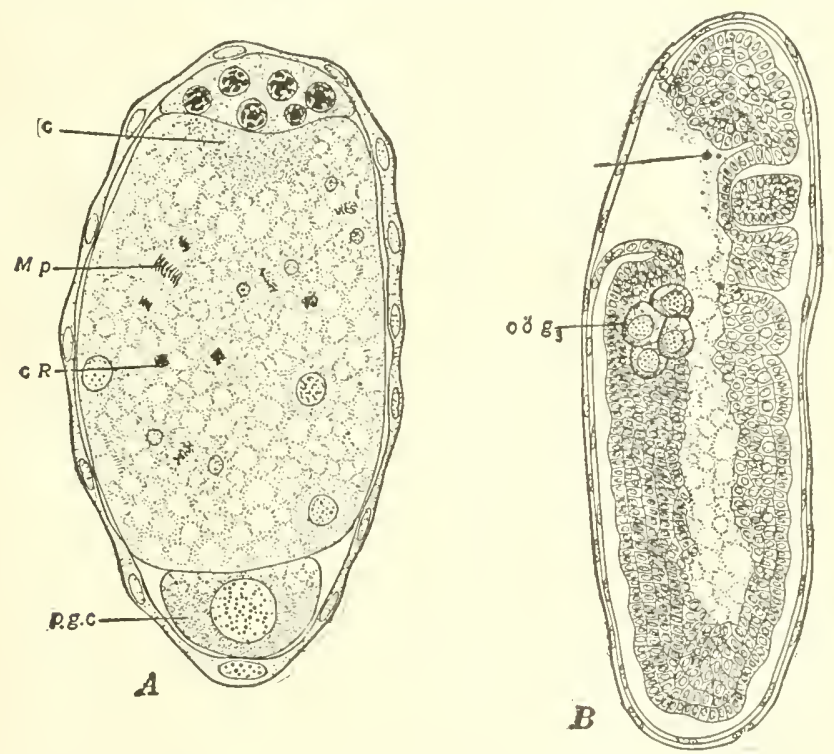

FIG. 45.-A, germ-cell (p.g.c.) set apart in the eight-celled stage of cleavage in Miastor americana. (Afler Hegner.) The walls of the remaining seven somatic cells have not yet formed, though the resting or the dividing $(I p)$ nuclei may be seen; $c R$, chromatin fragments cast off from the somatic cells; $B$, section lengthwise of a later embryo of Miastor; the primordial egg-cells $\left(0 \ddot{\circ} g_{3}\right)$ are conspicuous. (From Guyer, after Hegner.)

through a later stage in the development of Miastor; the primitive germ-cells (oög) are plainly visible. Still other striking examples might be cited. Even in vertebrates the germ-cells may often be detected at a very early period.

Significance of the early setting apart of the germ-cells.-It is of great importance for the reader to grasp the significance of this early setting apart of the germ-cells because so much in our future discussion. hinges on this fact. The truth of the statement made in a previous chapter that the body of an individual and the reproductive substance 


\section{READINGS IN EVOLUTION, GENETICS, AND EUGENICS}

in that body are not identical now becomes obvious. For in such cases as those just cited one sees the germinal substance which is to carry on the race set aside at an early period in a given individual; it takes no part in the formation of that individual's body, but remains a slumbering mass of potentialities which must bide its time to awaken into expression in a subsequent generation. Thus an egg does not develop into a body which in turn makes new germ-cells, but body and germ-cells are established at the same time, the body harboring and nourishing the germ-cells, but not generating them. The same must be true also in many cases where the earliest history of the germ-cells cannot be visibly followed, because in any event, in all higher animals, they appear long before the embryo is mature and must therefore be descendants of the original egg-cell and not of the functioning tissues of the mature individual. This need not necessarily mean that the germ-cells have remained wholly unmodified or that they continue uninfluenced by the conditions which prevail in the body, especially in the nutritive blood and lymph stream, although as a matter of fact most biologists are extremely skeptical as to the probability that influences from the body beyond such general indefinite effects as might result from under-nutrition or from poisons carried in the blood, modify the intrinsic nature of the germinal substances to any measurable extent.

Germinal continuity.-The germ-cells are collectively termed the germinal protoplasm and it is obvious that as long as any race continues to exist, although successive individuals die, some germinal protoplasm is handed on from generation to generation without interruption. This is known as the theory of germinal continuity. When the organism is ready to reproduce its kind the germ-cells awaken to activity, usually unclergoing a period of multiplication to form more germ-cells before finally passing through a process of what is known as maturation, which makes them ready for fertilization. The maturation process proper, which consists typically of two rapidly succeeding divisions, is preceded by a marked growth in size of the individual cells.

Individuality of chromosomes.-Before we can understand fully the significance of the changes which go on during maturation we shall have to know more about the conditions which prevail among the chromosomes of cells. As already noted each kind of animal or plant has its own characteristic number and types of chromosomes when these appear for division by mitosis. In many organisms the chromosomes are so nearly of one size as to make it difficult or impossible to 
be sure of the identity of each individual chromosome, but on the other hand, there are some organisms known in which the chromosomes of a single nucleus are not of the same size and form (Fig. 46). These latter cases enable us to determine some very significant facts. Where such differences of shape and proportion occur they are constant in each succeeding division so that similar chromosomes may be identified each time. Moreover, in all ordinary mitotic divisions where the conditions are accurately known, these chromosomes of different types are found to be present as pairs of similar elements; that is, there are two of each form or size.

Pairs of similar chromosomes in the nucleus because one chromosome comes from each parent.--When we recall that the original fertilized egg from which the individual develops is really formed by the union of two gametes, ovum and spermatozoön, and that each

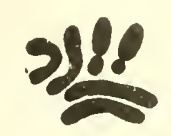

A

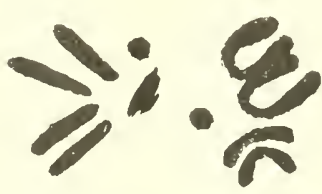

$B$

Fig. 46. $-A$, chromosomes of the mosquito (Culex). (After Stevens.) B, chromosomes of the fruit fly (Drosophila). (Aficr $M /$ ctz.) Both of these forms have an unusually small number of chromosomes. (From Guyer.)

gamete, being a true cell, must carry its own set of chromosomes, the significance of the pairs of similar chromosomes becomes evident; one of each kind has probably been contributed by each gamete. This means that the zygote or fertile ovum contains double the number of chromosomes possessed by either gamete, and that, moreover, each tissue-cell of the new individual will contain this dual number. For, as we have seen, the number of chromosomes is, with possibly a few exceptions, constant in the tissue-cells and early germ-cells in successive generations of individuals. For this to be true it is obvious that in some way the nuclei of the conjugating gametes have come to contain only half the usual number. Technically the tissue-cells are said to contain the diploid number of chromosomes, the gametes the reduced or haploid number.

In maturation the number of chromosomes is reduced by onehalf.-This halving, or as it is known, reduction in the number of chromosomes is the essential feature of the process of maturation. It 
is accomplished by a modification in the mitotic division in which instead of each chromosome splitting lengthwise, as in ordinary mitosis, the chromosomes unite in pairs (Fig. $47, b$ ), a process known technically as synapsis, and then apparently one member of each pair passes entire into one new daughter cell, the other member going to the other daughter cell (Fig. 47, c). In the pairing preliminary to this reduction division, leaving out of account certain special cases to be considered
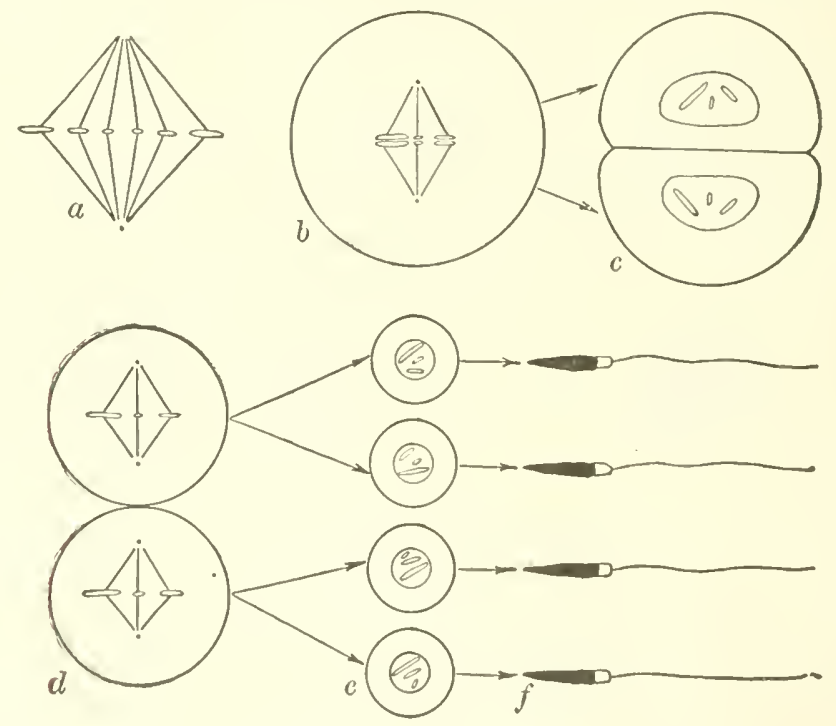

FIg. 47.-Diagram to illustrate spermatogenesis. $a$, showing the diploid number of chromosomes (six is arbitrarily chosen) as they occur in divisions of ordinary cells and spermatogonia; $b$, the pairing (synapsis) of corresponding mates in the primary spermatocyte preparatory to reduction; $c$, each secondary spermatocyte receives three, the haploid number of chromosomes; $d$, division of the secondary spermatocytes to form $e$, spermatids, which transform into $f$, spermatozoa. (From Guyer.)

later, according to the best evidence at our command the union always takes place between two chromosomes which match each other in size and appearance. Since one of these is believed to be of maternal and the other of paternal origin, the ensuing division separates corresponding mates and insures that each gamete gets one of each kind of chromosome although it appears to be a matter of mere chance whether or not a given cell gets the paternal or the maternal representative of that kind. 
Maturation of the sperm-cell.-In the maturation of the male gamete the germ-cell, now known as a spermatogonium, increases greatly in size to become a primary spermatocyte. In each primary spermatocyte the pairing of the chromosomes already alluded to occurs as indicated in Fig. 47, where six is taken arbitrarily to indicate the ordinary or diploid number of chromosomes, and three the reduced or haploid number. The division of the primary spermatocyte gives rise to two secondary spermatocytes (c), the paired chromosomes separating in such a way that a member of each pair goes to each
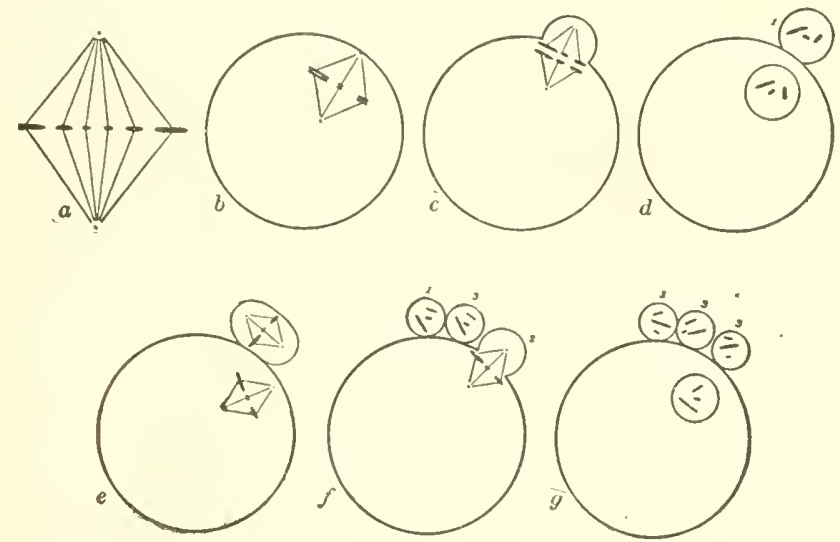

FIG. 48.-Diagram to illustrate oögenesis. $a$, showing the diploid number of chromosomes (six is arbitrarily chosen) as they occur in ordinary cells and in oögonia; $b$, the pairing of corresponding mates preparatory to reduction; $c, d$, the reduction division, giving oft the first polar body; $e$, egg preparing to give off the second polar body, first polar body ready for division; $f$, second polar body ready for division; $g$, second polar body given off, division of first polar body completed. The egg nucleus, now known as the female pronucleus, and each polar body contain the reduced or haploid number of chromosomes. (From Guycr.)

secondary spermatocyte. Each secondary spermatocyte (d) soon divides again into two spermatids (e), but in this second division the chromosomes each split lengthwise as in an ordinary division so that there is no further reduction. In some forms the reduction division occurs in the secondary spermatocytes instead of the primary. Each spermatid transforms into a mature spermatozoön $(f)$. The spermatozoa of most animals are of linear form, each with a head, a middle-piece and a long vibratile tail which is used for locomotion. The head consists for the most part of the transformed nucleus and is consequently the part which bears the chromosomes. 
Maturation of the egg-cell.-As regards the behavior of the chromosomes the maturation of the ovum parallels that of the spermcell. There are not so many primordial germ-cells formerl and only one out of four of the ultimate cells becomes a functional egg. As in maturation of the sperm-cell there is a growth period in which oögonia enlarge to become primary oücytes (Fig. 48, b). In each primary

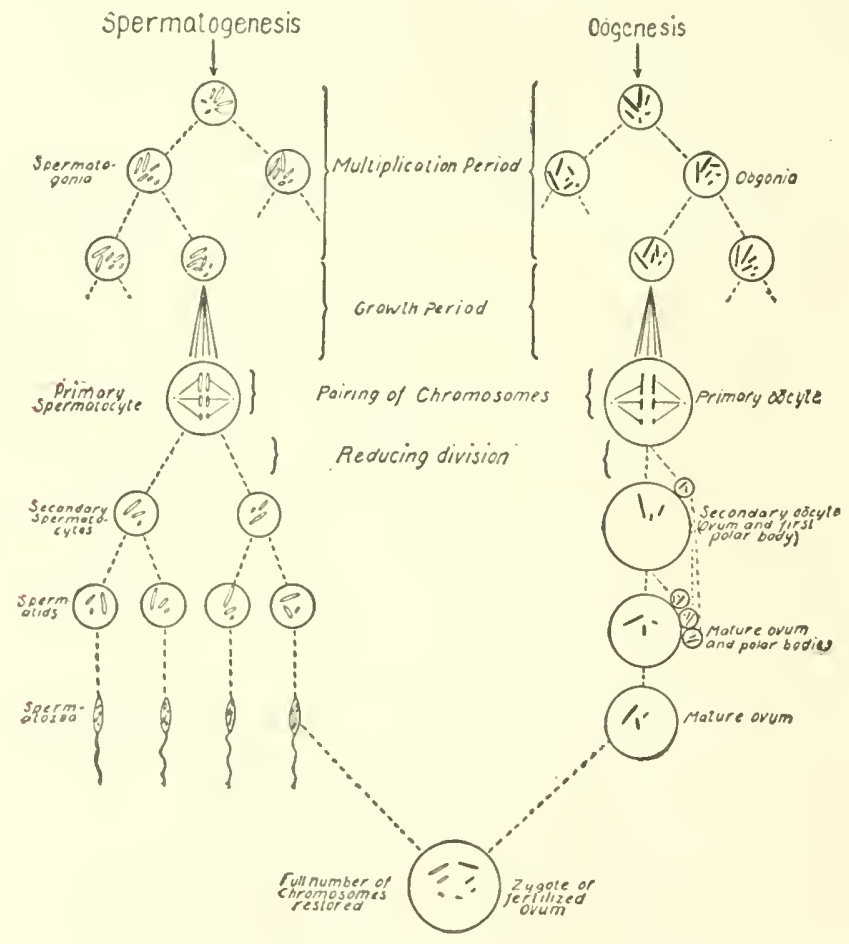

Fig. 49.-Diagram showing the parallel between maturation of the spermcell and maturation of the ovum. (From Guyer.)

oöcyte as in the primary spermatocyte the chromosomes pair and two rapidly succeeding divisions follow in one of which the typical numerical reduction in the chromosomes occurs. A peculiarity in the maturation of the ovum is that there is a very unequal division in the cytoplasm in cell-division so that three of the resulting cells usually termed polar bodies are very small and appear like minute buds on the side of the fourth or egg-cell proper. 
The scheme of this formation of the polar bodies is indicated in Fig. 48. In Fig. $48, b$ the chromosomes are seen paired and ready for the first division; that is, for the formation of the first polar body. Figs. $48, c, d$ show the giving off of this borly. Note that while only a small proportion of the cytoplasm passes into this tiny cell, its chromatin content is as great as that of the ovum. A second polar body (Fig. $48, e$ ) is formed by the egg, but in this case each chromosome splits lengthwise, as in ordinary mitosis, and there is no further numerical reduction. In the meantime, typically, a third polar body is formed by division of the first. (Stages $e, f, g$.)

Parallel between the maturation of sperm- and egg-cell.-This rather complex procedure of the germ-cells will be rendered more intelligible through a careful study of Figs. 47, 48, and 49, which indicates the parallel conditions in spermatogenesis and oögenesis.

The view now generally held regarding the polar bodies is that they are really abortive eggs. They later disappear, taking no part in embryo-formation. It can readily be seen how such an unequal division is advantageous to the large cell, for it receives all of the rich store of food material that would be distributed among the four cells if all were of equal size. This increased amount of food is a favorable provision for the forthcoming offspring whose nourishment is thus more thoroughly insured.

On the other hand, all of the sperm-cells develop into complete active forms, which, as aforesaid, usually become very much elongated and develop a motile organ of some kind. In such cells an accumulation of food to any large extent would hinder rather than help them, because it would seriously interfere with their activity.

Fertilization. - In fertilization (Fig. 50) the spermatozoön penetrates the wall of the ovum and after undergoing considerable alteration its nucleus fuses with the nucleus of the egg. In some forms only the head (nucleus) and middle-piece enter, the tail being cut off by a so-called fertilization membrane which forms at the surface of the egg and effectually blocks the entrance of other spermatozoa. Thus normally only one spermatozoön unites with an egg. In some forms while several may enter the egg only one becomes functional. As soon as the nucleus of the spermatozoön, now known as the male pronucleus, reaches the interior of the egg, it enlarges and becomes similar in appearance to the female pronucleus. It swings around in such a way (Fig. 5o, $b$ ) that the middle piece, now transformed into a centrosome, lies between it and the female pronucleus. The two pronuclei 
$(c, d, e)$, each containing the reduced number of chromosomes, approach, the centrosome divides, the nuclear walls disappear, the typical division spindle forms, and the chromosomes of paternal and maternal origin respectively come to lie side by side at the equator of the spindle ready for the first division or cleavage $(f, g)$. It will be noted that the
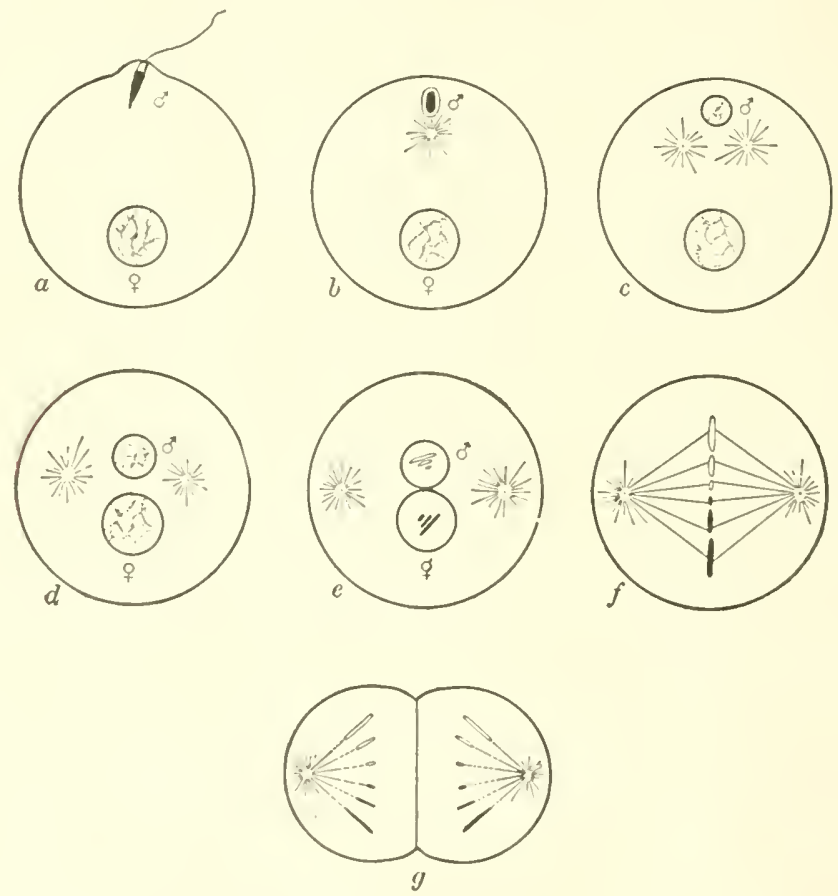

FIG. 50,-Diagram to illustrate fertilization; ; male pronucleus; + , female pronucleus; observe that the chromosomes of maternal and paternal origin respectively do not fuse. (From Guyer.)

individual chromosomes do not intermingle their substance at this time, but each apparently retains its own individuality. There is considerable evidence which indicates that throughout life the chromosomes contributed by the male parent remain distinct from those of the female parent. Inasmuch as each germ-cell, after maturation, contains only half the characteristic number of chromosomes, the original number is restored in fertilization.

Significance of the behavior of chromosomes. - The question confronts us as to what is the significance of this elaborate system 
which keeps the chromosomes of constant size, shape and number; which partitions them so accurately in ordinary cell-division; and which provides for a reduction of their numbers by half in the germ-cell while yet securing that each mature gamete gets one of each kind of chromosome. Most biologists look on these facts as indicating that the chromosomes are specifically concerned in inheritance.

In the first place it is recognized that as regards the definable characters which separate individuals of the same species, offspring may inherit equally from either parent. And it is a very significant fact that while the ovum and spermatozoön are very unequal in size themselves, the chromosomes of the two germ-cells are of the same size and number. This parity in chromosomal contribution points clearly to the means by which an equal number of character determiners might be conveyed from each parent. Moreover it is mainly the nucleus of the sperm-cell in some organisms which enters the egg, hence the determiners from the male lin must exist wholly or largely somewhere in the nucleus. And the bulk of the nucleus in the spermatozoön consists of the chromosomes or their products.

A single set of chromosomes derived from one parent only is sufficient for the production of a complete organism.- That a single or haploid set of chromosomes as seen in the gametes is sufficient contribution of chromatin for the production of a complete organism is proved by the fact that the unfertilized eggs of various animals (many echinoderms, worms, mollusks, and even the frog) may be artificially stimulated to development without uniting at all with a spermatozoön. The resulting individual is normal in every respect except that instead of the usual diploid number it has only the single or haploid number of chromosomes. Its inheritance of course is wholly of maternal origin. The converse experiment in echinoderms in which a nucleus of male origin (that is, a spermatozoön) has been introduced into an egg from which the original nucleus has been removed shows that the single set of chromosomes carried by the male gamete is also sufficient to coöperate with the egg-cytoplasm in developing a complete individual.

The duality of the body and the singleness of the germ.- Since every maternal chromosome in the ordinary cell has an equivalent mate derived from the male parent, it follows therefore, supposing the chromosomes do have the significance in inheritance attributed to them, that as regards the measurable inheritable differences between two individuals, the ordinary organism produced through the union 
of the two germ-cells is, potentially at least, dual in nature. On the other hand through the process of reduction the gametes are provided with only a single set of such representatives. This duality of the body and singleness of the mature germ is one of the most striking facts that come to light in embryology. How well the facts fit in with the behavior of certain hereditary characters will be seen later in our discussions of Mendelism.

The cytoplasm not negligible in inheritance.-Just what part is played by the cytoplasm in inheritance is not clear, but it is probably by no means a negligible one. The cytoplasm of a given organism is just as distinctive of the species or of the individual of which it forms a part as are the chromosomes. It is well established that neither nucleus nor cytoplasm can fully function or even exist long without the other, and neither can alone produce the other. They undoubtedly must coöperate in building up the new individual, and the cytoplasm of the new indiviclual is predominantly of maternal origin. It is obvious that all of the more fundamental characters which make up an organism, such, for instance, as make it an animal of a certain order or family, as a human being or a log or a horse, are common to both parents, and there is no way of measuring how much of this fundamental constitution comes from either parent, since only closely related forms will interbreed. In some forms, moreover, the broader fundamental features of embryogeny are already established before the entrance of the spermatozoonn. It is probable therefore that instearl of asserting that the entire quota of characters which go to make up a complete individual are inherited from each parent equally, we are justified only in maintaining that this equality is restricted to those measurable differences which veneer or top off, as it were, the individual. We may infer that in the development of the new loeing the chromosomes of the egg together with those derived from the male work jointly on or with the other germinal contents which are mostly cytoplasmic materials of maternal origin.

The chromosomes possibly responsible for the distinctiveness of given characters. - It seems probable that in the establishment of certain basic features of the organism the coöperation of the cytoplasm with chromatin of either maternal or paternal origin might accomplish the same end, but that certain distinctive touches are added or come cumulatively into expression through influcnces carried, predominantly at least, in the chromatin from one as against the other parent. These last distinctive characters of the plant or animal constitute the 
individual differences of such organisms. In this connection it is a significant fact that in young bybrids between two distinct species the early stages of development, especially as regards symmetry and regional specifications, are exclusively or predominantly maternal in character, but the male influence becomes more and more apparent as development progresses until the final degree of intermediacy is attained.

From the evidence at hand this much seems sure, that the paternal and maternal chromosomes respectively carry substances, be they ferments, nutritive materials or what not, that are instrumental in giving the final parity of personal characters which we observe to be equally heritable from either line of ancestry. It is clear that most of the characters of an adult organism cannot be merely the outcome of any unitary substance of the germ. Each is the product of many coöperating factors and for the final outcome any one coöperant is probably just as important in its way as any other. The individual characters which we juggle to and fro in our breeding experiments seem apexed, as it were, on more fundamental features of organic chemical constitution, polarity, regional differentiation, and physiological balance, but since such individual characters parallel so closely the visible segregations and associations which go on among the chromosomes of the germ-cells i. would seem that they, at least, are represented in the chromosome; by distinctive coöperants which give the final touch of specificity to those hereditary characters which can be shifted about as units of inheritance.

Sex and heredity.-Whatever the origin of fertilization may have been in the world of life, or whatever its earliest significance, the important fact remains that to-day it is unquestionably of very great significance in relation to the phenomena of heredity. For in all higher animals, at least, offspring may possess some of the characteristics originally present in either of two lines of ancestry, and this commingling of such possessions is possible only through sexual reproduction. As has already been seen, in the pairing of chromosomes previous to reduction, the corresponding members of a pair always come together so that in the final segregation each gamete is sure to have one of each kind although whether a given chromosome of the haploid set is of maternal or paternal origin seems to be merely a matter of chance. Thus, for instance, if we arbitrarily represent the chromosomes of a given individual by $1 B C, a b c$, and regard $A, B$ and $C$ as of paternal and $a, b$, and $c$ as of maternal origin, then in synapsis 
only $A$ and $a$ can pair together, $B$ and $b$, and $C$ and $c$, but each pair operates independently of the other so that in the ensuing reduction division either member of a pair may get into a cell with either member of the other pairs. That is, the line up for division at a given reduction might be any one of the following, $A B C A B C A b c A b C$ $a b c \quad a b C \quad a B C \quad a B c^{\circ}$. This would yield the following eight kinds of gametes, $A B C, a b c, A B c, a b C, A b c, a B C, A b C, a B c$, each bearing one of each kind of chromosome required to cover the entire field of characters necessary to a complete organism. And since each sex would be equally likely to have these eight types of gametes and any one of the eight in one indiridual might meet any one of the eight of the other, the possible number of combinations in the production of a new individual from such germ-cells would be $8 \times 8$, or 64 . With the larger numbers of chromosomes which exist in most animals it is readily seen that the number of possible combinations becomes very great. Thus any individual of a species with twenty chromosomes - and many animals, including man, have more-would have ten pairs at the reduction period and could therefore form $(2)^{\mathrm{ro}}$, or I, 024 different gametes in each sex. And since any one of these in one sex would have an equal chance of meeting with any one in the opposite sex, the total number of possible different zygotes that might be produced would be $(\mathrm{I}, 024)^{2}$, or $\mathrm{I}, 048,576$. Sex, therefore, through recombinations of ancestral materials, undoubtedly means, among other things, the production of great diversity in offspring. 


\title{
CHAPTER XXII
}

\author{
VARIATION \\ ERNEST BROWN BABCOCK AND ROY ELWOOD CLAUSEN
}

Organic differences, their nature and causes, have furnished abundant material for speculative enquiry since time immemorial. The great significance of the fact of organic individuality was not fully grasped until Lamarck founded his theory of evolution which postulated the progressive, imperceptible change of one species into another. It remained for Darwin to scrutinize all phases of organic life, past and present, wild and domesticated, in his search for a guiding principle which should explain the course of evolution. Darwin's hypothesis of natural selection assumes variability without enquiring into its causes, but this does not mean that Darwin was not concerned with the problem of causes. In both his Origin of Species and I'ariation in Animals and Plants under Domestication the causes of variability are often referred to and he suggested among others, the kind and amount of food, climatic changes and hybridization. Our respect for the great naturalist's keen perception deepens when we realize that very little has been added as yet to our knowledge of the causes of variation.

The universality of variation.-Individuality is common to all organisms. No two trees, no two leaves, no two cells in a leaf are identical in every respect. Individuals sometimes appear exactly alike but even identical twins will be found to differ in some features. The shepherd knows his sheep individually and the orchardist his trees. Were there no differences in individuals there would be no changes in species and there could be no improvement of cultivated plants. "Variation is at once the hope and despair of the breeder," the hope because without it no improvement would be possible, the despair because very often, when improvement has been made, variation results in a tendency to fall below the standard previously reached. In the sugar beet, for example, a high percentage of sugar has been maintained by continually testing and selecting the "mother" beets for the next crop of seed. Howerer, this necessity for continual

${ }^{I}$ From E. R. Babcock and R. E. Clausen, Genctics in Relation to Agriculture (copyright I9r8). Used by special permission of the publishers, The McGrawHill Book Company. 
selection does not exist in respect to all important field crops although they are subject to the general law of variation. That this must be so is clear when we realize that many natural species as well as cultivated varieties of plants are really mixtures of sub-species, varieties, or races and that upon being isolated these distinct forms reproduce their own particular type. This is most easily demonstrated in plants normally self-fertilized, yet in all naturally cross-fertilized plants and in higher animals this same endless diversity among individuals is even more marked.

The variation concept.-As we have implied in the above remarks the term variation may be used in very different senses in referring to different phenomena. Thus variation within a species or variety means that the group in question is heterogeneous. Among individuals rariation may consist of differences between members of the same generation or between parents and offspring. Even when thus restricted, however, the term is apt to prove ambiguous. Hence it is necessary to give some thought to the sources, nature and causes of these individual differences in order that we may use clear-cut expressions which shall always convey to one another a concept of the same particular sort of organic difference.

Classification of variations.-I. IIeritability. Character differences either represent something specific in the germ or they are merely the effect of external stimuli upon the individual soma. In the first case they are inherited, although they will not reappear necessarily in all later generations or in all the progeny. In the second case they will not be inherited. This is a fundamental distinction and may well serve as our primary basis of classification. According to herilability variations are either germinal or somatic. Under germinal variations we recognize two sul)-classes, combinations and mutations. Purely somatic variations will be referred to hereafter as modifications.

Hodifications are non-heritable differences between the individuals of a race caused by the unequal influence of different environmental factors. Such variations frequently approximate continuity and, when studied statistically, display the normal variability curve, which will be explained in a subsequent chapter. [See chap. xxv.]

Combinations are heritable differences between the individuals of a race or between the offspring of a pair of parents caused by segregation and recombination of hereditary units. They also frequently display the normal variability curve. 
1/ ututions are heritable differences between parents and offspring which do not depend upon segregation and recombination.

These three categrorie's, as Baur has shown, are not to le recognized and separated merely according to appearances. The cause of any inclividual differences can usually be established only by careful breeding experiments: but by this means the separation of the three categories is always possible as the boundaries between them are quite sharp. Modifications are somatic effects of environmental differences and should not be confused with germinal changes which are sometimes induced by natural or artificial means and which result in the production of mutations. Within this first category must be inclurded all place-effects in plants and somatic envirommental effects in animals. Modifications comprise a large portion of what are commonly spoken of as fluctuations due to environment, but all cases of fluctuatting variation are not modifications inasmuch as variations due to combinations frequently display the normat variability curve also. Modifications are not heritatsle. The second category, variation by combination of hereditary units is often confused with modification, as already stated, lecause of the fact that variations caused by segregation and recombination when studier statistically often display the normal varialsility curve. This is especially apt to be the case in quantitative cheracters (those of size or weight) and segregation and recombination may be the cause of grarlation in cotor intensity. In autogamous (self-fertilized) organisms hyl, ridization between races is sufficiently rare to be negligithe in this connection, i. e., in such species the fluctuating variations are calused by the environment. But in allogamous organisms (those in which two individuals are necessary to accomplish sexual reproduction) fluctuating variations may be caused either hy the environment, hy segregation and recombination of factors, or by both causes acting together. We shall take up the third categry, mutations, in a tater chapter. For the present it is sufficient to remember tlrat mutations are no douht the least frequent of the three classes, that easily distinguishable mutations are compratively rare, but that there may also occur true mutations of such morlerate extent, as compared with the poupulation, that their existence would only be detected by hreeding tests, since their progeny would exhilhit a different range of fluctuation from that of the population.

2. Nature. We may next enquire into the nature of variation as it affects the organism. Lpon this basis we may distinguish between 
four classes: morphological, physiological, psychological and ecological.

Morphological variations are differences in size and form. In general morphological variations have more significance for the biologist than for the agriculturist. However, in many products of the farm, size and conformation are of decided importance. Two sub-classes under morphological variations are meristic and homeotic variations. Meristic variations are differences in number of repeated parts such as the petals in a flower, the leaflets in a compound leaf or number of phalanges. Homeotic variations are differences caused by the replacement of one part by another, as the production of an antenna in place of an eye in an insect.

Physiological variations are differences in quality and performance. Examples of qualitative variations are difference in degree of hardness of bone, flavor of meat, richness of milk, difference in normal color, resistance to drouth, frost or alkali. Variations in performance constitute the most important group for the producer. Differences in performance are sometimes, though not necessarily, associated with certain details of structure.

Psychological variations are differences in mental traits. That mental and nervous conditions have very definite effects upon physical conditions is well known, but the problem of distinguishing between purposeful action and automatic response, between manifestations of reason and manifestations of instinct, is set for the students of animal behavior. While variations in mental characteristics have an important place in eugenics and merit the attention of livestock breeders, yet the inheritance of psychological characters must be more extensively investigated before the subject can be considered with profit in a fundamental study of genetics.

Ecological variations are those differences between individuals that result from their fixed relation to the environment. These differences are especially noticeable in plants and are known as place-effects or place variations. This category includes some of the phenomena of variation in crop yield and hence is of immediate significance to agriculture.

3. According to differences between them there are two general classes of variations: first, the slight differences in every character which are always to be observed even among individuals of identical heredity; second, unusual, striking differences commonly known as sports. The first class are called normal, indefinite fuctuating or 
continuous variations and the second, abnormal, definite and discontinuous variations. It should be noted, however, that all discontinuous variations are not necessarily definite or even distinguishable. Continuous variations when examined statistically are found to conform to the law of statistical regularity. That is, if measured and plotted the graph will approximate the normal curve of variability. Continuous variations are either heritable (combinations) or nonheritable (modifications) and, as was stated above, the only certain method of determining the class in which a given case may fall is the breeding test. Discontinuous variations are essentially discrete differences whether they be large or small. They are also either heritable or non-heritable, and there is no correlation between size and heritability. Thus the extremely large and small mustard plants, considered by themselves, are discontinuous variations, but they are almost certainly due entirely to environmental differences and seed from the small plant if grown under optimum conditions would produce plants of normal size. On the other hand, it is known that many minute differences in organisms are heritałle.

4. According to direction variations are classed as orthogenetic and fortuitous. Orthogenetic variations are those differences found in individuals related by descent which form progressrve series tending in a definite direction. Many remarkable illustrations are found among paleontological records of the evolution of animals. Occasional examples are found among short-lived or vegetatively propagated species. The remarkable series of variations of the Boston fern is a good example. Fortuitous variations are chance differences occurring in all directions.

5. According to cause variations are either ectogcnetic, differences arising from conditions acting lipon the organism from without; or autogenetic, differences resulting from strictly internal relations between germ and soma.

Variation and development.-Somatogenesis, in sexually produced multicellular organisms, includes the entire history of cellular multiplication and specialization from the first cleavage of the fertilized (or parthenogenetic) egg :o the completion of all adult features. From the standpoint of individual development it includes gametogenesis, for the production of sexual glands and of secondary sexual characters are merely phases of differentiation. Cell growth and cell function depend directly upon the activity of the living substance within the cell. The nature and degree of his activity depends upon 
two sets of determining causes acting simultaneously. First, there are the specific hereditary determiners or genetic factors, which react with the other elements of the protoplasm and, under favorable circumstances, condition normal development. Second, there are all the conditions external to the cell which stimulate or inhibit protoplasmic activity. These "developmental stimuli" are chemical and physical changes wrought by energy from without the organism or caused by its own physiological activities. Chemical stimuli are excrted mainly through the medium of the circulating liquid which surrounds each living cell. Normally this fluid contains the elements essential for maintenance of life as well as various waste products. It may also bear toxic sulstances that suppress or inhibit the cell functions and in higher animals it contains the secretions of the ductless, sexual and other glands that profoundly affect development. Physical stimuli are exerted chiefly from without and upon the organism as a whole. They include changes in temperature, light and density of medium, the effects of electric and radiant energy, force of gravity, etc. Obviously, so many interrelated causes acting simultaneously, each being independently capable of inducing a change in the end product, may cause an infinite number of differences in substance and in degree of development.

Variation and environment.---External stimuli affect the development of characters in three ways: (I) they modify the development of inherited characters; (2) they actually condition the production of characters whose hereditary determiners are present in the germplasm; (3) they may cause germinal variations which result in the appearance of new heritable characters. 'The following are illustrations of these effects with reference to particular environmental factors.

I. Environment modifies development of inherited characters.(a) Light and Function. Klebs reports the result of growing the Showy Sedum (Scdum spectabile) in white, red, and blue light. The diverse effects of the three kinds of light are clearly shown in Fig. 5 r. Although the visible differences between the three plants were very pronouncerl the experiment was carried much farther. During ico5-6 observations were made on the numbers of stamens in the flowers of plants similarly propagated under white, red, and blue light and under variations, conditions of temperature, moisture, and food. About 20,000 flowers were examined and six distinct types were found, according to the variation in number of stamens. These had the 
following average numbers of stamens: (I) 9.68 , (2) $8.45,(3) 6.54$, (4) $5.05,(5) 9.47,(6) 7.33$. Finally, Klebs subjecterl similar plants from white, red, and blue light to chemical analysis in order to secure further evidence of the physiological effects of light of different wave

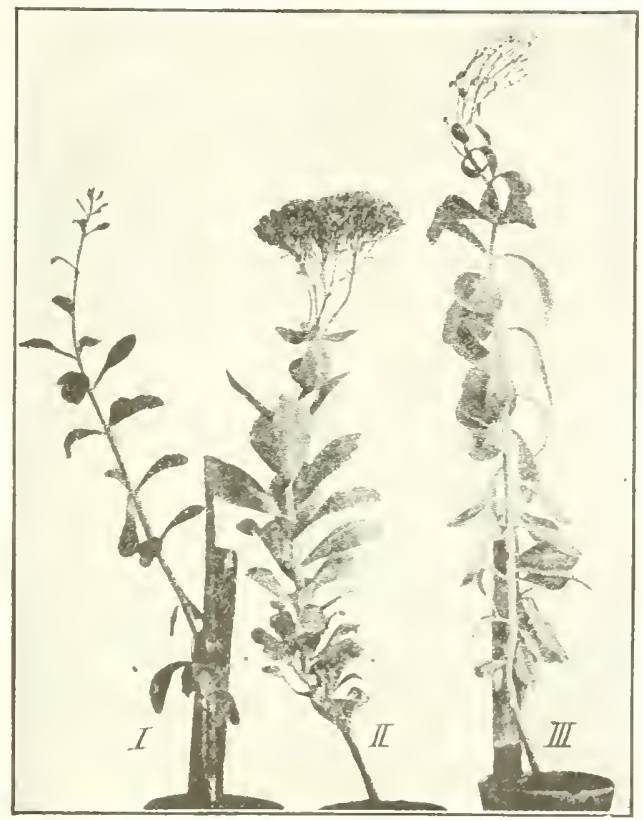

Fig. 5I.-Scdum spectabile. The three shoots (taken from a single plant) were planted in small pots on March I 2, 1904, and placed in different greenhouses, $I$, in blue light; $I I$, in mixed white light; $I I I$, in red light. Photographed on September 30, I914. (From Babcock and (lausen, after Klibs.)

lengths. Table I shows the composition of the leares in three plants like those shown in Fig. 51. They were in their respective greenhouse: from June 6 to September 7. The percentages shown are per roo g. of dry substance.

In comparing these percentages it should be remembered that the plant in white light produced $132+$ flower buds and the plant in red light 405 , while the plant in blue light profluced none. This explains the higher percentage of ash, nitrogen and protein in the last. On the other hand, the amounts of starch and sugar found in the plant from white light are decidedly larger than the one from blue light. 
In short, according to Klebs, in comparison with normal white light, the production of organic substances, such as starch and sugar, is

T. ABLE I

Chemical Composition of Three Plants of Scdum Speclabile Grown in Wilte, Red, ANd Blue Light

\begin{tabular}{|c|c|c|c|}
\hline Substance & White & Red & Blue \\
\hline 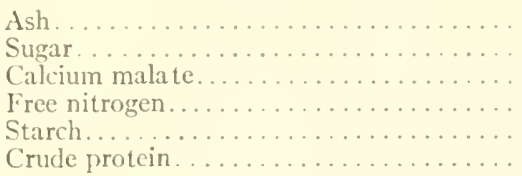 & $\begin{array}{l}\text { I } 3.20 \\
\text { I } 1.04 \\
22.20 \\
\text { 0. } 16 \\
5.82 \\
5.33\end{array}$ & $\begin{array}{l}13.20 \\
\text { I5. } 40 \\
\text { I } 8.02 \\
0.33 \\
3.66 \\
6.15\end{array}$ & $\begin{array}{r}18.60 \\
2.40 \\
18.10 \\
\text { 0. } 59 \\
\text { 1. } 20 \\
7.64\end{array}$ \\
\hline
\end{tabular}

diminished under the influence of blue light as microchemical and macrochemical tests distinctly show. In consequence of this diminished assimilation of carbon dioxide the rosettes become purely

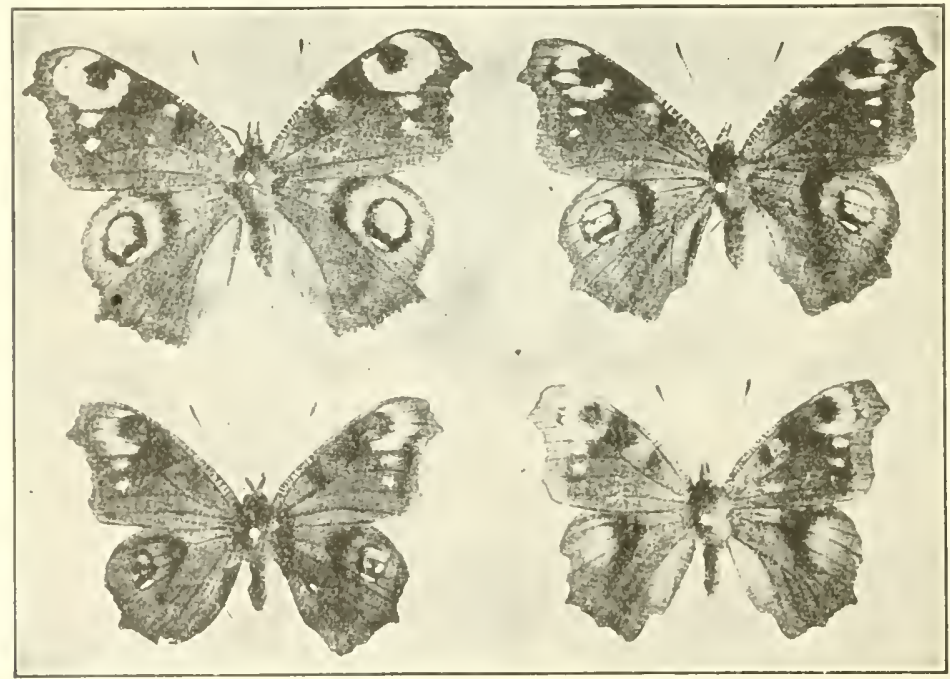

Fig. 52.--Above the diurnal peacock butterfly (Vanessa io), and below, forms produced hy subjecting the pupae to unusual temperatures. (From Babcock and Clausen, afler Goldschmidt.)

vegetative. In red light the carbon assimilation is greater than in blue light but less than in white. These experiments prove that the transformation of a plant "ripe to flower" into a vegetative one 
is possible on the one hand by an increase of temperature and of inorganic salts, and on the other hand by a decrease of carbon assimilation.

b) Temperature and pigmentation. Many experiments in the rearing of moths and butterflies under controlled temperatures prove that degree of pigmentation is profoundly influenced by the temperature at which the pupae are kept. Some species exhibit seasonal dimorphism in the wild state. By taking pupae of the common European form of the swallowtail butterfly, Papilio machaon, and subjecting them to a temperature of $37^{\circ}$ to $38^{\circ} \mathrm{C}$., Standfuss obtained the characteristic summer form which occurs in Palestine. Again it has been shown by temperature experiments that many variations

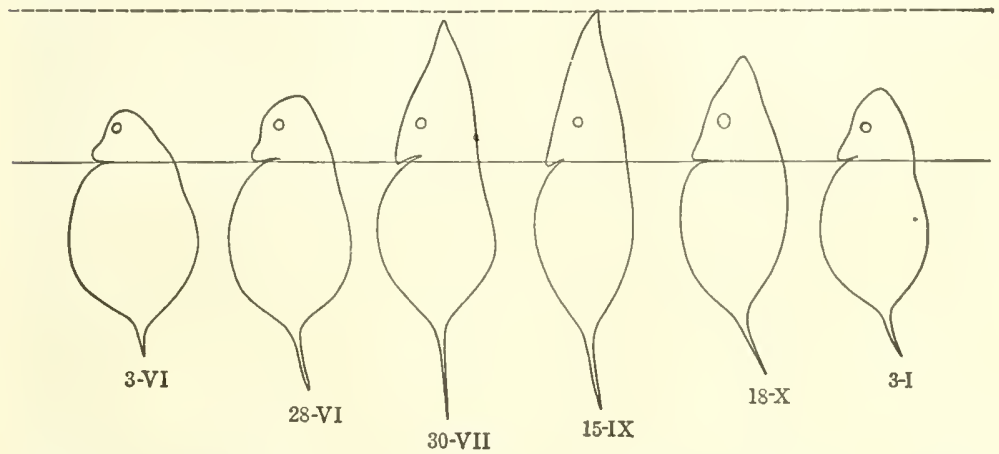

FIG. 53.-Morphological cycle of head height in Hyalodaphnia. Roman numerals designate months. (From Babcock and Clausen, after Woltereck.)

found among insects in nature are merely aberrations due to temperature effects. Goldschmidt by artificially controlled temperatures has produced a series of forms of the diurnal peacock butterfly, Vanessa io, which show the fading out of the "peacock eye" mark (see Fig. 52).

c) Food and structure. Woltereck was able to prove that the form (hence the structure) of the fresh water crustacean, Hyalodaphnia, varies directly with the food supply. These minute animals produce many generations during a season and the successive generations from the same water exhibit a morphological cycle, the earlier and later generations having shorter heads and the generations produced from midsummer to autumn having longer ones. Fig. 53 is a reproduction of Woltereck's diagram of the morphological cycle in Hyalodaphnia showing variation in head and shell length as found on successive 


\section{I6 READINGS IN EVOLUTION, GENETICS, AND EUGENICS}

dates from June 3 to January 3. By raising these animals under constant temperature conditions and varying the strength of the nutrient solution, Woltereck proved that the relative size of body parts varied with the food. In Fig. 54 the percentages of head height to shell in length are plotted as abscissas and the numbers of individuals as ordinates. Animals from three strengths of nutrient media were measured, the curves of those from the weaker, the medium and the richer media being shown at $m_{1}, m_{2}$ and $m_{3}$ respectively.

d) Moisture and plumage color. Beebe experimented with the pigeon, Scardafella inca. This species, as found in North and Central America, is very constant in color of plumage, but in the moist tropics

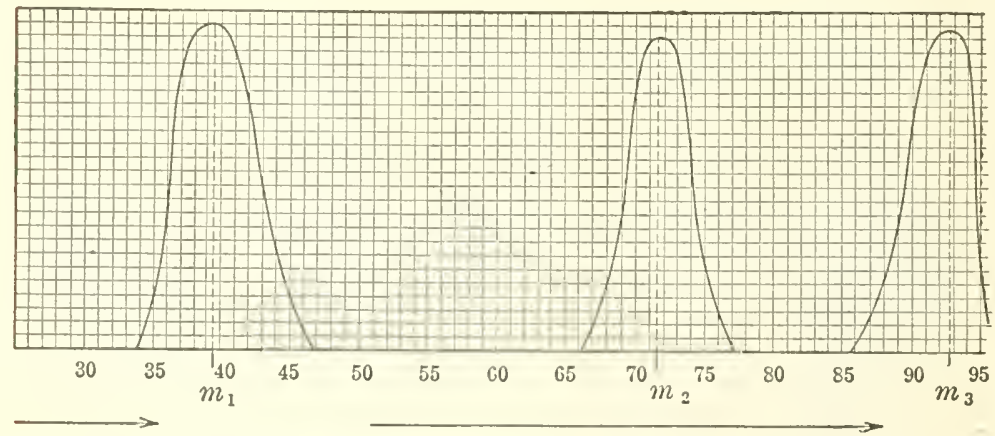

FIG. 54.-Schematic curves of head height in IIyalodaphnia as grown in media of three different food values. (From Babcock and Clausen, after Iroltereck.)

the following darker colored forms occur: in Honduras, dialeucos; in Venezuela, ridgwayi; in Brazil, braziliensis; and these differ in the amount of pigment in the feathers. By subjecting the birds of the northern type to an especially moist atmosphere, Beebe caused them to be so influenced that with each new moulting, whether natural or artificially induced, they always developed darker feathers. Thus a wild bird having pigment in 25.9 per cent of its area, would have after the second moulting under experimental conditions, 38 per cent and after the third, 41.6 per cent. Thus during the experiment the typical form assumed the appearance of the three other forms and finally developed plumage markings which have never been seen in nature. Fig. 55 shows the type form, inca, the three geographical variants, and the darkest artificially produced form. 
2. Environment conditions development of inherited characters.(a) Light and metabolism. In a general sense light conditions lifu in all normally green plants. It certainly conditions nomal development in such plants. Potatoes sprouted in a dirk room rlevelop no chlorophyll in the stems and the rudimentary leaves are abortive. In many luubous plants, however, the influence of moisture and heat are sufficient to induce leaf growth and eren development of the inflorescense, but it is all done at the expense of the food storerl up in the bulbs.

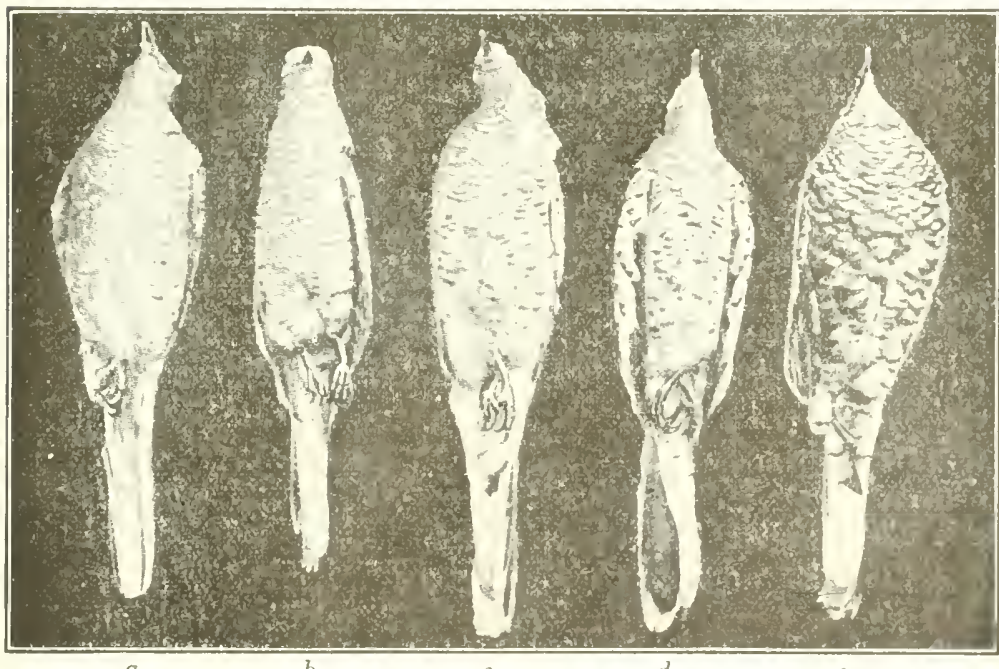

a

$c$

$\varepsilon$

FIG. 55.-a, Typical wild pigeon, Scardafolla inca; b, the form dialeman; $c$, braziliensis; $d$, ridgrayi; $c$, inca after three moultings in a moist atmosphere. (Afler Becbe, from Babcock and Clausen.l

b) Temperature and flower color. Batur reports an experiment with a red variety of the Chinese primrose, Primula sinensis rubra. If plants of this variety are raised by the usual method unt il about one week before time to bloom and then some of the plants are jut in at warm room under partial shade (temperature from $30^{\circ}$ to $35^{\circ} \mathrm{C}$.) and the remainder in a cool house (tcmperature from $15^{\circ}$ to $20^{\circ} \mathrm{C}$.), when they bloom those in the warm temperature have pure white flowers while those in the cool temperature have the normal red crolor of the variety. Moreover, if plants are brought from the warm into the 
cool temperature the flowers which develop later on will be normal red in color. Thus it cannot be said that this primula inherits either red or white flowers. What it really inherits is ability to react in certain ways under the influence of temperature.

c) Food and fertility. It is well known that the kind of food supplied to the larvae of bees determines whether the females shall be fertile (queens) or infertile (workers). The striking differences in structure and instincts of the two classes of females are all conditioned by the food provided for the larvae. Each larva inherited the capacity to react in either way according to the stimulus received.

d) Moisture and structure. Morgan reports a variety of the pomace fly, Drosophila ampelophila, with abnormal abdomen; "the normal black bands of the abdomen are broken and irregular or even entirely absent. In flies reared on moist food the abnormality is extreme; but even in the same culture the flies that continue to hatch become less and less abnormal as the culture becomes more dry and the food scarce, until finally the flies that emerge later cannot be told from normal flies. If the culture is kept well fed (and moist) the change does not occur, but if the flies are reared on dry food they are normal from the beginning.'

3. Environment may cause new heritable characters.-As yet there is a dearth of evidence which can be accepted as scientific proof that external stimuli actually cause germinal variations. At the same time there is an abundance of data which falls into the class of circumstantial evidence in favor of such a doctrine. Moreover, there are a few cases in which new heritable characters have been artificially produced by carefully controlled external stimuli. Hence some germinal variations are apparently caused by known environmental conditions and we are justified in recognizing this third category of developmental differences due to environmental effects.

Considerable evidence of permanent changes in both morphological and physiological characters has been secured from experiments with the culture of bacteria and yeast, in unusual culture media, in the presence of toxic solutions, or under extreme temperature conditions. The significant results of four investigators who worked independently, Hansen, Barber, Wolf, and Jordan, have been reviewed and discussed in regard to their bearing on genetic theory by Cole and Wright. 'The four investigators mentioned above used refined methods and three of them began by isolating a single organism from whose progeny they obtained distinct strains or biotypes which 
remained constant for hundreds of test-tube "generations." It must be admitted that in most of these cases no specific influences can be named as the direct cause of the inherited variation. But there is no longer any doubt that permanent, discontinuous variations do occur spontaneously in these lowest organisms, and it is highly probable that certain incidental, external forces play an important part in inducing such variations.

Direct experimental attack upon the germ cells themselves has been made with plants by a number of investigators, notably by MacDougal, who injected very dilute solutions of potassium iodide, zinc sulphate, sugar, etc., directly into the ovaries of various plants immediately before fertilization. Consequently somatic changes have been produced which were inherited throughout several generations.
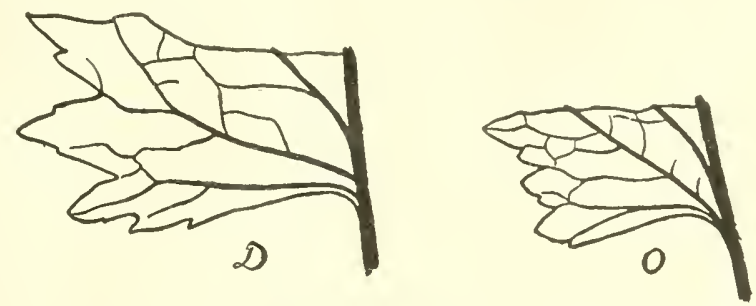

Fig. 56.-O, portion of leaf of Scrophularia showing branching lateral vein; $D$, branching vein replaced by two laterals in leaf of seedling grown from seed produced by an injected ovary. Also note the difference in size and margin of leaves. (From Babcock and Clausen, after MacDougal.)

By means of check experiments and observations it was found that these germinal variations were not caused by the wounding of the ovary and it is thought that they must have been induced in some way by the presence of the foreign chemical solution in the ovary. Fig. $5^{6}$ shows a morphological change which appeared in a seedling of an unnamed species of Scrophularia as a result of ovarial injection. Having tested the species sufficiently to determine that it was a simple one, MacDougal treated several ovaries with potassium iodide, one part in 40,000 and secured seed. No other species of Scrophularia grew near the cultures. From this seed only three plants were raised. "One formed a shoot fairly equivalent to the normal, finally producing flowers in which the anthocyans were of a noticeably deep hue. The two remaining plantlets were characterized by a succulent aspect of the leaves and by a lighter and yellow color of the leaves and stems. 
The flowers on one of the derivatives, as they may be called, were so completely lacking in color as to be a cream-white, this derivative being designated as albida, while the other showed some marginal color and a rusty tinge and was designated as rufida. . . . . Seeds of the original two derivatives were sowed in the greenhouse. But one plant of albida, the most extreme departure, survived, while four of rufl.da were secured." MacDougal compared these second generation seedlings with seedlings from the original stock of the species, noting differences in size and margin of leaves, length of petioles and number of marginal glands. He found that the differences shown by the first generation appeared again in the second generation. Striking as these results appear it must be admitted that it would be difficult, on account of the small numbers of individuals differing from the parent type, to prove satisfactorily to the biometrician that they were not mutations which would have occurred regardless of the ovarial treatment.

What appear to be germinal variations in the tomato have been induced by intensive feeding. T. H. White tested the effect of dried blood, dissolved phosphate rock, sulphate of potash and iron filings all in excessive amounts, and (with the exception of the iron) in various combinations, on the Red Cherry tomato. The lack of data on control cultures of seedlings from the same parent as the experimental cultures makes it impossible to compare the actual amount of permanent variation produced. T. H. White states that measurements "show that the plants of the sixth generation grown under the influence of the drierl blood are one-third larger in height, length of leaf and size of fruit, than those of the second." The author concludes that "there can be no lloubt.... that, in the case of Red Cherry treated with dried blood, there is permanent variation to the third generation." If these results are corroborated by more carefully planned and rigidly controlled experiments they will add the weight of scientific proof of a principle in plant breeding long since recognized on empirical grounds, to wit, that the introduction of wild plants into intensive cultivation induces variation. Furthermore, it suggests a possible means for rapid permanent improvement of wild forms with which hybridization may be impracticable.

In experiments on lower animals, e.g., the protozoa, the same difficulty is met with as has been encountered in bacteria and yeasts. in that it is manifestly impossible to distinguish between somatic and germinal variations. Moreover, in most of these experiments, as with most of those on higher animals, the necessary conditions for rigid 
scientific analysis have been lacking. Either the same strain as was subjected to artificial conditions was not grown for comparison under natural conditions or else the conditions themselves were not sufficiently well controlled to permit of certain analysis. It is interesting to note that the pomace fly, Drosophila ampelophila, which has produced more mutations so far as we know than any other organism, was subjected to the effects of ether on a grand scale and under controlled conditions by Morgan, but that not a single mutation was observed to result from this treatment. However, mutations have subsequently appeared again and again in cultures of "wild" flies not only of this species but also of other species of Drosophila. Thus it appears that germinal variations frequently occur independently of external stimuli. It also seems that a tendency to produce mutations may be inherited.

With animals the best known experiments on the artinicial production of germinal variations are those of Tower who worked with the Colorado potato beetle, Leptinotarsa decemlineata, and related species. Like other arthropods these beetles are more directly under the influence of temperature changes at least than are warm-blooded animals. Tower first determined the period in ontogeny when external stimuli will affect the germ cells. He found that in Leptinotarsa the germ cells do not become susceptible to external stimuli until after the time in ontugeny when the color pattern of the individuals subjected to the stimuli can be influenced. He found that eggs were most susceptible just before and during maturation and this observation is in agreement with those of Fischer, Standfuss, Weismann and others who have conducted similar investigations. Tower concluded that certain individuals from the germ cells of a stimulited parent "show intense heritable variations, whereas those not acted upon do not show these changes." Most of the inherited variations involve changes in the pigmentation of the body parts. In certain cases there was an actual change in the color pattern. It is to these results that Tower attaches the greatest significance inasmuch as most similar experiments have not succeeded in causing pattern changes. In spite of the elahorateness of 'Tower's methods considerable skepticism exists regarding the validity of his conclusions, and this has not been lessened by the non-appearance of confirmatory data. In a recent paper he reports the production of very striking germinal modifications in $L$. decemlineatu as a result of sulj jecting it morphologically homogeneous race to an extreme change in environ- 


\section{READINGS IN EVOLUTION, GENETICS, AND EUGENICS}

ment. However, it is still a question whether the material used may not be heterogeneous as regards the germinal factors that condition certain physiological characters.

Stockard's investigations on the effect of alcohol on the progeny of guinea pigs have shown that the germ cells as well as the somatic tissues of the alcoholized animals are injured.

On the whole it must be admitted that the experimental induction of heritable variations is still largely an unworked field. The complex conditions to be considered and consequent obstacles to be overcome are appreciated by no one more fully than by those who have attempted such investigations. For, as Tower has said: "It is evident that the problem of germinal change is one of difficulty, and involves more of indirect than of direct methors of investigation. There is little reason to expect that present biochemical methods can give a solution, but they may give valuable suggestions for further indirect investigation. It seems not improbable, however, that this problem, like so many others in biology, must await the solution of the larger question of what life is before it will be possible to express in exact terms the nature of germinal changes. Our present status, with several methods of production and much knowledge of the behavior of induced germinal changes available, is a basis from which great advances in knowledge and in operation may reasonably be expected." 


\section{CHAPTER XXIII}

\section{ARE ACQUIRED CHARACTERS (MODIFICATIONS) HEREDITARY?}

InTRODUCTORY Note.-In the previous chapter, under the heading "Classification of Variations," the authors pointed out that germinal variations are hereditary, and somatic variations (modifications) are not hereditary. That germinal variations are hereditary and may be produced in a number of different ways was made clear in the last chapter, but the statement that somatic modifications are never in the least hereditary is equivalent to a total denial of the doctrine of the "Inheritance of Acquired Characters," the so-called Lamarckian theory, which was briefly presented in chapter ii.

This is not a closed question and the final answer has been given neither in the negative nor in the affirmative. The problem is of utmost import for evolutionists and for all who are interested in race improvement. So important is it to view this question fairly that we shall quote extensively from several of the leading students of the problem.

\section{MISUNDERSTANDINGS AS TO THE QUESTION AT ISSUE}

\section{J. ARTHUR THOMSON}

The precise question is this: Can a structural change in the body induccd by some change in ise or disuse, or by a change in surrounding influence, affect the germ-cells in such a specific or representative way that the offspring will through its inheritance exhibit, even in a slight degree, the modification which the parent acquired?

Before we pass to discuss the evidence pro and con it will be useful to notice some frequently recurring misunderstandings, the persistence of which would make further argument futile.

Misunderstanding I.- How can there be progressive evolution if acquired characters are not transmitted?-Those who have not thought clearly on the subject often shake their heads sagely and remark that they "do not see how evolution could have been possible at all unless what is acquired by one generation is handed on to the next." To this we have simply to answer (I) that our first business is to find out the facts of the case, careless whether it makes our interpretation of the history of life more or less difficult, and (2) that in the supply of germinal variations, whose transmissibility is unquestioned, there is ample raw material for evolution. We know a little about the abundant

¿ From J. A. Thomson, Heredity (copyright 1907). Used by special permission of the publisher, John Murray, London. 
crop of variations at present supplied; there is no reason to believe that it was less abundant in the past.

Misunde-standing II.-Interpretations are not facts.-There are many adaptive characters in plants and animals which may be superficially interpreted as due to the direct result of use and disuse or of environmental influence. The Lamarckians have so interpreted them, and the Lamarckian way of looking at adaptations has become habitual to many uncritical minds. They see on modern flowers the footprints of insects which have visited them for untold ages; they speak of the dwindling of the whale's hind-limbs through disuse, of the hardening of the ancestral horses' hoofs as they left the marshes and ran on harder ground; they picture the giraffe by persistent effort lengthening out its neck a few millimetres every century, as the acacia raised its leaves higher and higher off the ground; and they say that animate nature is so full of evidences of the inheritance of acquired characters that no further argument is needed.

But all this is a begging of the question. It is easy to find structural features which may be interpreted as entailed acquired characters, if acquired characters can be entailed. Obviously, however, we must deal with what we can prove to be modifications, or with what we can plausibly regard as modifications because we find their analogues in actual process of being effected to-day.

It is easy to say that the blackness of the negro's skin was produced by the tropical sun, and that it is now part of his natural inheritance. It is easy to say this, but absolutely futile. Let us first catch our modifications.

The Golden Rod (Solidago virgaurea) growing on the Alps is precocious in its flowering when compared with representatives of the same species growing in the lowlands. Hoffmann found that Alpine forms transplanted to Giessen remained precocious, therefore the acquired precocity had become heritable. But there is no evidence that the precocity was acquired; it may have been the outcome of the selection of germinal variations.

The African Wart-hog (Phacochoerus) has the peculiar habit of kneeling down on its fore-limbs as it routs with its huge tusks in the ground and pushes itself forward with its hind-limbs. It has strong horny callosities protecting the surfaces on which it kneels, and these are seen even in the embryos. This seems to some naturalists to be a satisfactory proof of the inheritance of an acquired character. It is to others simply an instance of an adaptive peculiarity of germinal origin wrought out by natural selection. 
Misunderstanding III.-Begging the question by starting with what is not proied to be a modification.-There is no relevancy in citing cases where an abnormal bodily peculiarity re-appears generation after generation, unless it be shown that the peculiarity is a modification, and not an inborn variation whose transmissibility is arlmitted by all. Short-sightedness may recur in a family-series generation after generation, but there is no evidence to prove that the original short-sightedness was a modification. In all probability, shortsightedness is in its origin a germinal variation, like so many other bodily idiosyncrasies.

In regard to some diseases, such as rheumatism, it is often said dogmatically by those who know little about the matter that the original affection in the ancestor was brought about by some definite external influence--such as a cold drive or a damp bed; but it seems practically certain that in all such cases we have to do with an inborn predisposition, to the expression of which the cold drive or the damp bed were merely the liberating stimulus, comparable to the pulling of the trigger in a loaded gun. The liberating stimulus is, of course, of great importance, both in the case of the gun's discharge and the organism's disease, but it only goes a little way towards a satisfactory interpretation in either case. Not that we can explain the origin of rheumatism or shortsightedress or any such thing - there is no explanation in calling them germinal variations that cropped up; but we are almost certain that they never are modifications or acquired characters.

Herbert Spencer twits those who are sceptical as to the transmission of acquired modifications with assigning the most flimsy reasons for rejecting a conclusion they are averse to; but when Spencer cites the prevalence of short-sightedness among the "notoriously studious" Germans, the inheritance of a musical talent, and the inheritance of a liability to consumption, as evidence of the inheritance of modifications, we are reminded of the pot calling the kettle black.

Over and over again in the prolific literature of this discussion the syllogism is advanced, either in regard to gout or something analogous-

Gout is a modification of the body; an acquired character;

Gout is transmissible;

Modifications are sometimes transmissible.

It may be formally a good argument, but there is every reason to deny the major premise. There is no proof that the gouty habit had an exogenous origin - that it was, to begin with, for instance, the direct result of high living; though it is generally admitted that 
excesses in eating or drinking may give a stimulus to its expression. "The conclusion that I have arrived at," says Prof. D. J. Hamilton, "is that the gouty habit of body has arisen as a variation, and as such is hereditarily transmissible, and that excess of diet and alcohol merely renders the habit of body apparent." It may also be pointed out that gout and rheumatism and the like are rather processes of metabolism than structural modifications, though the latter may ensue.

After pointing out the irrelevancy of citing cases of the hereditary recurrence of polydactylism, haemophilia, colour-blindness in man, or the absence of horns in cattle or of tails in cats, as instances of the transmission of acquired characters, Prof. Ernst Ziegler says: "Only that can be regarded as 'acquired' which is produced in the course of the individual life, during and after the period of development, exclusively under the influence of external conditions; the term is in no wise applicable to peculiarities which, as one says, arise of themselves from a predisposition already present in the germ."

Misunderstanding IV.-Wistaking the reappearance of a modification for transmission of a modification.- - It is of little service to cite cases where a particular modification reappears generation after generation uriless it be shown that the change recurs as part of the inheritance, and not simply because the external conditions which evoked it in the first generation still persisted to evoke it in those that followed. Reappearance is not synonymous with inheritance.

Misunderstanding V.-Mistaking re-infection for transmission.-A particular form of the fourth misunderstanding has to do with facts so special that it may be conveniently treated of separately. It has to do with microbic discases. It is admitted that a parent infected with tubercle-bacillus or with the microbe of syphilis may have offspring also infected. But such cases are irrelerant in the discussion. Infection, whether before or after birth, has nothing to do with inheritance. As Dr. Ogilvie says, "Wherever the transmission of infectious disease from parent to offspring has been adduced to support the doctrine of the inheritance of acquired cliaracters, it has been done in utter misconception of its meaning and scope."

Medical men have sometimes condescended to make a subtle distinction between "hereditary" and "congenital" syphilis-the latter manifested at birth, the former some time afterwards! It seems strange that they have failed to recognise that there is no reason to use the word "hereditary" at all in this connection. What occurs is an infection, and it is theoretically immaterial at what stage the infection occurs. A microbe cannot be part of an inheritance. 
Misunderstanding VI.-Transmission in unicellulars is not to the point.-It is not to the point to cite cases where unicellular organisms, such as bacteria or monads, have been profoundly and heritably modified by artificial culture, so that, for instance, the descendants of a virulent microbe have been made to lose their evil potency. It is irrelevant because in regard to unicellular organisms we cannot draw the distinction between body and germinal matter, apart from which the concept of modifications is of no value. In artificial culture the whole character of the unicellular organism-its particular metabolism -is altered; it multiplies by dividing into two or more parts, which naturally retain the altered constitution. But this is worlds away from the supposed case of an alteration in the structure of the little toe so affecting the germ-cells that the offspring inherit a corresponding deformation.

Professor L. Errera (I899) reported an experiment with a simple but multicellular mould (Aspergillus niger), which adapted itself to a medium more concentrated than the normal. The second generation of the mould was more adapted than the first, and the adaptation to the concentrated medium was not wholly lost after rearing in the normal medium again. This looks like evidence of the inheritance of the acquired adaptive quality which was brought about as a direct modification. But the case does $r_{i}$ t really help us, since the distinction between soma and germ-plasm is not more than incipient in the mould in question. And even if the distinction were more marked, it would only show that the germ-plasm is capable of being affected along with the body, by a deeply saturating influence, which nobody has ever denied.

Misunderstanding VII.-Changes in the germ-cells along with changes in the body are not relevant.-Another misunderstanding is due to a failure to appreciate the distinction between a change of the reproductive cells along with the body, and a change in the reproductive cells conditioned by and representative of a particular change in bodily structure. The supporters of the hypothesis that modifications may be transmitted point to the tragic cases where some poisoning of the parent's system, by alcohol, opium, or some toxin, is followed by some deterioration in the offspring. There is no doubt as to the fact; the question is as to the correct interpretation.

I. In some cases it may be that the whole system of the parent is poisoned-reproductive cells as well as body; the effect may be as direct on the germ-cells as on the nerve-cells. These, therefore, are not cases on which to test the transmissibility of an acquired character-i.e., 


\section{$3^{2 S}$ READINGS IN EVOLUTION, GENETICS, AND EUGENICS}

of a particular somatic modification. If a local poisoning had a structural effect on some particular organ, and if that structural effect was reproduced in any degree in the offspring, the case would be relevant; but when the whole organism is soaked in a poison the case is irrelevant. If it could be said that the sunshine, which brings about sun-burning in the skin, soaks through the organism even to its reproductive cells and specifically affects them, in a manner analogous to the saturating poison, we should have a physiological basis for expecting the inheritance of sun-burning. But we cannot make this assumption. We have no warrant for believing that the modification of a part re-echoes in a definite specific way through the organism until even the penetralia of the germ-cells reverberate.

2. A parent organism is poisoned, and there are structural results of that poisoning. The offspring are born poisoned, and show similar structural peculiarities. This may be due to the fact that the germcells were poisoned along with the parental body; but it may also be due, in the case of a mother, to a poisoning of the embryo before birth, in a manner comparable to a pre-natal infection.

3. In some cases-e.g., of alcoholism in successive generationsthere may be poisoning of the germ-cells along with the body, there may be poisoning of the embryo before birth, and of the infant after; but it may also be that what is really inherited is a specific degeneracy of nature, an innate deficiency of control, perhaps, which led the parent to alcoholism, and which may find the same or some other expression in the child.

Cases are known in which the children of a dipsomaniac father and a quite normal mother have exhibited a tendency to alcoholism, insanity, and the like. In this case the possibility of poisoning the unborn child is eliminated, but there remain three possibilities of interpretation-that there was specific poisoning of the paternal germcells; that what was inherited was the constitutional weakness which expressed itself as alcoholism in the father; and that there were detrimental influences in the early nutrition, environment, education"nurture," in short - of the offspring.

But while we have admitted a good deal, we have not admitted the transmissibility of a particular structural modification brought about in the parental body as a result of the toxin.

Misunderstanding VIII.-Failure to distinguish between the possible inheritance of a particular modification and the possible inheritance of indirect results of that modification, or of changes correlated with 
it.-At first sight this seems hair-splitting, but it is a crucial point. Through his vigorous exercise the blacksmith develops a muscular arm worthy of admiration; the shoemaker acquires skeletal and muscular peculiarities less admirable. There are many permanent and profound modifications associated with particular occupations. Are we to believe, it is asked, that the occupation of the parents has no influence on the offspring? Are we to believe, it is asked, that the children of soldier, sailor, tinker, tailor, are in no way affected by the parental functions?

It would be interesting to have precise data in regard to this, but it is generally admitted that when parents have healthful occupations their offspring are likely to be more rigorous. The matter is complicated by the difficulty of estimating how much is due to good nurture before and after birth. It is not unlikely, too, that some profound parental modifications may influence the general constitution, may even affect the germ-cells, and may thus have results in the offspring. But unless the offspring show peculiarities in the same divection as the original modifications, we have no data bearing precisely on the question at issue.

A belief in the inheritance of modifications was perhaps expressed in the old proverb, "The fathers have eaten sour grapes, and the children's teeth are set on edge" - a proverb which Ezekiel with such solemnity said was not any more to be used in Israel. Now if "setting on edge "was a structural modification, and if the children's teeth were "set on edge" as their fathers' had been before them, there would be a presumption in favour of the transmission of this acquired character, though it would be still necessary to inquire carefully whether the children had not been in the vineyard too. But if, as Romanes said, the children were born with wry necks, we should have to deal with the inheritance of an indirect result of the parent's vagaries of appetite, and not with any direct representation in inheritance of the particular modification produced in the paternal dentition.

Misunderstanding IX.- Appealing to data from not more than two generations.- It has often been pointed out that animals transported to a new country or environment may exhibit some modification apparently the result of the novel influence, and that their offspring in the same environment may exhibit the same modification in a greater degree. Thus sheep may show a change in the character and length of their fleece, and their progeny may show the same change more markedly. 
But it is perfectly clear that if the evidence does not go beyond this, nothing is proved that affects the question at issue. It was to be expected that the offspring should show the modification in a more marked degree than their parents did, since the offspring were subjected to the modifying influences from birth, whereas their parents were influenced on!y from the date of their importation.

What would be welcome is evidence that the third generation is more markedly modified than the second; then there would be data worth considering. Only then would it be necessary to consider Weismann's somewhat subtle discussion as to the influence of climate.

TIIE INHERITANCE OR NON-INHERITANCE OF ACQUIRED CIIARACTERS ${ }^{I}$ EDWIN GRANT CONKLIN

Few questions in biology have been discussed so fully and so fruitlessly as this. It is a problem of the greatest interest not only to students of biology but also to sociologists, educators and philanthropists and yet it is still to a certain extent an unsolved problem.

Opinions of Lamarck and Darwin.-It is well known that Lamarck taught that characters due to desire or need, use or disuse, and to changed environment or conditions of life were inherited and thus brought about progressive evolution. Long ago desire or need was repudiated as a factor of evolution. Lowell satirized it in his Biglow Papers in these words:

"Some filosifers think that a fakkilty's granted The minnit it's felt to be thoroughly wanted.

That the fears of a monkey whose holt chanced to fail Drawed the vertibry out to a prehensile tail.'

Darwin wrote to Hooker, "Heaven forfend me from Lamarck's nonsense of adaptation from the slow willing of animals"; but although he repudiated this feature of Lamarckism he held that characters due to use or disuse and to changed conditions of life might be inherited and he proposed his hypothesis of pangenesis in order to explain the process of the transmission of such characters to the germ cells.

Weismann's theories. -Weismann introrluced a new era in biology by denying the inheritance of all kinds of acquired characters, and by challenging the world to produce evidence that would stand a

× From E. G. Conklin, Heredity and Environment (copyright I919). Used by special permission of the publishers, The Princeton University Press. 
rigorous analysis. But Weismann's greatest service lay in his constructive theories rather than in destructive criticism; he forever disposed of theories of pangenesis and the like by showing that the germ cells are not built up by contributions from the body and that characters are not transmitted from generation to generation; but on the other hand that there is transmitted a germ plasm which is relatively independent of the body and which is relatively very stable in organization. This epoch-making theory of Weismann's has naturally undergone some changes, as the result of new discoveries. It is no longer believed that the germ plasm is really independent of the body, nor that it is absolutely stable, as Weismann at one time held. There is no doubt that the germ cells and the germ plasm are physiologically related to other cells and to other plasms, and similarly there is no doubt that the germ plasm although very stable can and does change its constitution under some rare conditions. But in the main the germ plasm theory is accepted by the great majority of biologists to-day, and recent work in genetics and cytology has brought many confirmations of this theory.

Distinctions between hereditary and acquired characters.-As long as it was believed that the developed characters of an organism could be transmitted as such to its descendants it was customary to speak of developed characters as hereditary or acquired and to talk of the inheritance or non-inheritance of acquired characters. This distinction is not a logical one for all developed characters are invariably the result of the responses of the germinal organization to environmental stimuli; and of course no developed character can be purely hereditary or purely environmental. But when a given character arises in many individuals of the same genotype under different environmental conditions it is probable that heredity, which is the constant factor in this case, is also the determining factor for that character. On the other hand if a character develops in response to peculiar stimuli and does not appear in other individuals of the same genotype in which such stimuli are lacking it is said to be an environmental or acquired character. In fine, inherited characters are those whose distinctive or differential causes are in the germ cells, while acquired characters are those whose differential causes are environmental.

Statement of problem.-Briefly stated the question of the inheritance of acquired characters is this: Can the differential cause of a character be shifted from the environment to the germ plasm? Can 


\subsection{READINGS IN EVOLUTION, GENETICS, AND EUGENICS}

peculiarities of the environment which influence the development of somatic characters so affect the germ cells that they will produce these somatic characters in the absence of the peculiar environment? Can the characteristics of a developed organism enter into its germ cells and be born again in the next generation? Considering the fact that germ cells are cells and contain no adult characteristics, it seems very improbable that any peculiarity of environment whether of nutrition, use, disuse or injury, which brings about certain peculiarities of developed characters in the adult, could so change the structure of the germ cells as to cause them to produce this same character in subsequent generations in the absence of its extrinsic cause. How, for example, could defective nutrition, which leads to the production of rickets, affect the germ cells, which contain no bones, so as to produce rickets in subsequent generations, although well nourished? Or how can over-exertion, leading to hypertrophy of the heart, so affect the germ cells that they, in turn, would produce hypertrophied hearts in the absence of over-exertion, seeing that germ celts have no hearts? Or how could the loss or injury of eyes or teeth or legs lead to the absence or weakened development of these organs in future generations, seeing that inheritance must be through germ cells which possess none of these structures?

Lack of evidence for inheritance of acquired characters.-But, apart from these general objections to the doctrine of the inheritance of acquired characters, there are many special difficulties. There is no conclusive and satisfactory evidence in favor of such inheritance. Almost all the evidence adduced serves to show only that characters are acquired, not that they are inherited.

It is a matter of common observation that mutilations are not inherited; wooden legs do not run in families, although wooden heads do. The evidence for the inheritance of peculiarities due to use or disuse is wholly inconclusive; for example, did the giraffe get his long neck because he browsed on trees, or does he browse on trees because he has by inheritance a long neck? Did attempts to fly lead to the development of wings in birds, or do birds fly because heredity has given them wings? Did life in caves make cave animals blind, or did blind animals resort to caves because the struggle for existence there was less severe for them? The evidence is in favor of the second of each of these alternatives rather than of the first.

There still remains the question of the inheritance of certain characters due to environment, though here also the most clear-cut 
evilence is against this proposition. That unusual conditions of food, temperature, moisture, etc., may affect the germ cells so as to produce general and indefinite variations in offspring is probable, but this is a very different thing from the inheritance of acquired characters. The germ cells being a part of the parental organism may be modified by such changes in the environment as affect the body as a whole, they may be well nourished or starved, they may be modified by changed conditions of gravity, salinity, pressure, temperature, etc., and these modifications of the germ cells probably lead to certain general modifications of the adult, which may be larger or smaller, stronger or weaker, according as the germ is well or poorly nourished, but it is incredible that the environment which produces rickets, or hypertrophied heart, or loss of sight in one generation should modify the germ cells in such a peculiar and definite way that they should give rise in the next generation to these particular peculiarities, in the absence of the extrinsic cause which first produced them. The inheritance of acquired characters is incredible, because the egg is a cell and not an adult organism; and in this case there is no sufficient evidence that the thing which is incredible really does happen.

No inherited influence of stock on graft.--If specific changes of environment produced specific changes in heredity we should expect to find that where different pla.lts or animals are grafted together each would modify more or less the hereditary constitution of the other. But this does not occur. Everybody knows that when a branch of a particular kind of fruit tree is grafted upon a tree of a different variety the quality of the fruit borne by that branch is not altered by its close union with the new stock. The same is true of all forms of animal grafts. Harrison cut in two young tadpoles of two species of frog, Rana sylratica and Rana palustris, and spliced the anterior half of one to the posterior half of the other. These frogs and their tadpoles differ in color as well as in other respects, $R$. syliatica being more deeply pigmented than $R$. palustris. In the grafted tadpoles each half preserved its own peculiarities even up to the adult condition.

A still more striking case of the persistence of heredity in spite of environmental changes is found in experiments in which the ovaries are removed from one variety of animal and transplanted to another variety. Guthrie made such transplation in the case of fowls and concluded that there was some influence of the foster mother upon the transplanted ovary, but Davenport, who repeated his experiments, was unable to confirm his results. Finally Castle and Phillips furnished 
the most conclusive demonstration that the hereditary characteristics of the transplanted ova are in no wise changed by the fostcr mother. They removed the ovary from a pure black guinea-pig and put it in the place of the ovary of a pure white animal. After recovering from the operation this white female with the "black" ovary was bred to a pure white male. Three litters of offspring from these parents were all pure black. Although both parents were pure white all the offspring of the $\mathrm{F}_{\text {I }}$ generation were black because they came from "black" eggs and black is dominant over white. The fact that these "black" eggs developed in the body of a white female did not in the least change their hereditary constitution.

Dominants and recessives remain pure.-A still more intimate union takes place when the dominant and recessive characters come together in any zygote. These characters, or rather the factors which determine them, may be intimately associated in every cell of the organism throughout an entire generation and yet we may get a clean separation of these characters in the next generation; in many cases neither the dominant nor the recessive character has been at all modified by its most intimate association with the other.

Climatic effects not inherited.-A striking instance of the purely temporary effect of the environment and of the long persistence of hereditary constitution amidst new environmental conditions, which have greatly changed the appearance of the developed organisms, is found in the case of alpine plants. Nägeli says that such plants, which have preserved the characters of high mountain plants since the ice age, lose these characters perfectly during their first summer in the lowlands.

Summary.--If acquired characters were really inherited we should expect to find many positive evidences of this instead of a few sporadic and doubtful cases. In particular why do we not find in plant or animal grafting that the influence of the stock changes the hereditary potencies of the graft? Why do we not find that transplanted ovaries show the influence of the foster mother as Guthrie supposed-a thing which has been disproved by Castle? Why do dominant and recessive characters remain pure, even after their intimate union in a hybrid, so that pure dominants and pure recessives may be obtained in subsequent generations from this mixture? Why does every child have to learn anew what his parents learned so laboriously before him? Even the strongest defenders of the inheritance of acquired characters are constrained to admit that it occurs only sporadically and exceptionally. 
Neo-Lamarckism.-Many modifications of the Lamarckian hypothesis of the inheritance of acquired characters have been proposed in recent years. Foremost among those are the "mneme" theory of Semon and the "centro-epigenesis" theory of Rignano. To Semon as to many other biologists the apparent resemblance between memory and heredity has seemed significant, and this furnishes the basis of his theory. Semon holds that every condition of life, every functional activity of an organism leaves a permanent record of itself in what he calls an "engramme." If these conditions or activities are long continued their engrammes are heaped up and affect heredity. Semon does not ask if "acquired characters" are inherited, but rather "Are the hereditary potencies of the germ cells altered by stimuli acting on the parental body?" This is a very different thing from the inheritance of a particular acquired character, and there is some evidence that such stimuli may in rare instances produce changes in the hereditary constitution of the germ plasm though these evidences are by no means conclusive.

Temporary effects of environment; "induction."-On the other hand certain changes may be produced in germ cells or embryos which last for only a generation or two and then disappear. It is well known that plants grown in poor soil are smaller and produce smaller seeds than those grown in good so 2 , and De Vries, Bauer and Harris find that such seeds produce smalier plants having smaller seeds than do seed of normal size. This is an after effect of poor nutrition which changes the amount of food material in the seeds and through this the size of the plant which develops from the seed, but it does not change the hereditary constitution. Woltereck found that in Daphria there is an after effect of cold lasting for one or two generations, and this he calls "induction," when the effect lasts for one generation, or "preinduction" when it lasts for two or three generations. Whitney found that rotifers poisoned with alcohol were weaker in resistance to copper salts and were less fertile than others, and when brought back to normal conditions the first generation was weak but the second was normal. On the other hand Stockard finds that the injurious effects of alcohol on guinea pigs persist through two or more generations. In man alcohol may have an "induction" effect on offspring, but fortunately it does not seem to alter hereditary constitution. Probably of a similar character are Sumner's results; he found that mice raised in the cold have shorter tails than those raised in higher temperatures and this modified character appears in the next generation. If this is an after effect or "induction" it should disappear in the following generations. 
Kammerer found that salamanders with black and yellow spots when reared on yellow soil gradually lose their black color, becoming more yellow, and their young continue to grow more yellow until finally almost all black may disappear. The offspring of such salamanders are said to be more yellow than normal; but this work has been called in question and needs confirmation. Even if confirmed the result may be an after effect or "induction" which would soon disappear under usual conditions, and there is no evidence that it is really inherited.

Such cases are not instances of true inheritance; they do not signify a change in the hereditary constitution but an influence on the germ cells of a nutritive or chemical sort comparable with what takes place when fat stains are fed to animals; the eggs of such animals are stained, and the young which develop from such eggs are also stained, though the germinal constitution remains unchanged. The very fact that the changed condition is reversible and that it disappears within a short time is evidence that it is not really inherited.

In conclusion: (I) Developed characters, whether "acquired". or not, are never transmitted by heredity, and the hereditary constitution of the germ is not changed by changes in such characters. (2) Possibly environmental stimuli acting upon germ cells at an early stage in their development may rarely cause changes in hereditary constitution, but changes produced in somatic celis do not cause corresponding changes in the hereditary constitution of the germ cells. (3) Germ cells like somatic cells may undergo modifications which are not hereditary; if starved they may produce stunted individuals and this effect may last for two or three generations; they may be stained with fat stains and the generation to which they give rise be similarly stained; they may be poisoned with alcohol or modified by temperature and such influence be carried over to the next generation without becoming hereditary. All such cases are known as "incluction" and many instances of the supposed inheritance of acquired characters come under this category. (4) Environment may profoundly modify' individual development but it does not generally modify heredity.

\section{THE OTHER SIDE TO THE QUESTION}

[It will have been noted that the chief objection to the idea of the possibility of acquired characters being inherited comes to us as a heritage of the rather extreme Weismannian concept of the "germ 
plasm." According to this view as brought out by Professor Guyer (p. 296), there is an unbroken continuity from generation to generation of the germ plasm. Germ cells are thought of as remaining entirely undifferentiated for any somatic function and as therefore capable of starting at the beginning to develop a new individual. The germ cell is supposed to be "set apart at an early period in a given individual; it takes no part in the formation of the individual's body, but remains a slumbering mass of potentialities which must bide its time to awaken into expression in a subsequent generation."

Physiologists object to this idea that the germ cells are so distinctly different from body cells and that they are so insulated, as it were, from the soma as to be immune to any changes that may affect the latter. Two kinds of data are offered in opposition to this concept. A few observers, notably Professor C. M. Child, have described cases in which somatic cells, that already had become differentiated as primitive muscle cells, lost their differentiation and returned to a germinal condition. If this kind of thing were general, and it is probably not, germ cells might conceivably be produced from functioning soma cells and might therefore iurnish a mechanism for the transmission of the effects of use and disuse. It should be emphasized, however, that, among animals at least, there is extremely little evidence in support of the idea that differentiated body cells give rise to germ cells.

Among plants, however, a different situation prevails. In the Begonia, for example, any part of a plant if cut off is capable of producing a whole new plant. Even a purely regetative organ like a leaf, if cut off and partially buried in soil, will bud off a new plant which will produce flowers with perfectly typical germ cells. We have to admit, in this case, either that leai tissues contain undifferentiated germ cells or that somatic issues give rise to germ cells. The first alternative is in harmony with the germ-plasm hypothesis, the second is the preferred view of the opponents of this hypothesis.

Among animals, as for example annelid worms, it is quite common to find the germ cells aggregated in a few segments of the body. If a part of the body in which there are no recognizable germ cells be cut off, it will, under proper conditions, regenerate the lost parts and become a complete worm with functional germ cells. The same alternative explanations that were offered for the Begonia case apply equally well here. Numerous other cases of the same sort are well known to all zoölogists. To the advocate of the "germ-plasm" theory 


\section{READINGS IN EVOLUTION, GENETICS, AND EUGENICS}

they offer no difficulties because he can always fall back upon the statement that, among the lower forms at least, there is reserve germ plasm equally distributed over the whole body ready to differentiate into definite germ cells when needed. This type of appeal is abhorrent to the physiologist, and with some justification, for it really begs the question by assuming that any cell that is capable of forming germ cells belongs to the more or less sacred lineage of germ plasm.

If we confine the application of the germ-plasm idea to the higher animals, such as vertebrates and insects, we would obviate these chief objections, and the present writer would take the view that it is only among the upper ranges of highly specialized animals that the continuity of the germ-plasm concept holds solidly.

Another chief objection to the germ-plasm concept has to do with the supposerl insulation or apartness of the germ plasm. Physiologists have found that there is an extremely intimate correlation in function between practically all parts of a living organism. Many of the structures, such as the rudimentary pituitary body, the thyroids, the adrenal body, and various other bodies whose function was long unknown, have now been shown to exercise a profound effect on the development of the whole body. Since practically all tissues are known to affect at least some other tissues, is it likely, the physiologist asks, that none of the other tissues affect the germinal tissues? The organism is to be viewed, it is said, not as a collection of independently functioning parts, but as a single coherent unit. On this view no tissue can be thought of as beyond the influence of organic changes.

The classic argument of the Weismannians was that we can conccive of no mechanism by means of which somatic changes can be carried back into the germ cells, and therefore there is no such mechanism. Now the fallacy of this argument is obvious; even if we could conceive of no suitable mechanism for this purpose, this does not preclude the existence of such a mechanism. Moreover, according to Professor Guyer, just such a mechanism actually exists, as will be brought out in the following quotation from one of his recent publications.-ED.]

\section{A POSSIBLE MECIIANISU FOR THE TRANSMIISSION OF ACQUIRED CIIARACTERS}

MICIIAEL F. GUYER

Some selectionists glibly assert that new characters arise as the result of spontaneous changes in the germ. What is meant by this?

"From M. F. Guyer, "Immune Sera and Certain Biological Problems," Americun Maturalish, Vol. LV (192I). 
Just what is a spontaneous change? No one has ever succeeded in telling us. And we may suspect, though perhaps it is heresy to do so, that it is a well-sounding phrase that is the equivalent of the three words, "I don't know." Unwilling to admit of the modifying influence of external agencies on the germ, such theorists resort to the fiction of a spontaneous change. Coleridge somewhere has said, "What's gray with age becomes religion." We have toyed so long with this idea of germinal continuity and the invulnerability of the germ, that it has become for some of us wellnigh sacrosanct. Living matter is living matter wherever it may be found, but when it happens to be in the germ-cells, verily, "this corruptible has put on incorruption and this mortal immortality"!

Now, no one to-day, qualified by his knowledge of embryology and genetics to the right of an opinion, would, I think, deny that the new organism is in the main the expression of what was in the germline, rather than of what it got directly from the body of its parents, but does this fact necessarily carry with it the implication that the germ is insusceptible to modification from without? Is not the serum of organisms with blood or lymph an excellent medium through which external influences may operate upon it? Is it not more reasonable to postulate the origination of germinal changes through some such mechanism as this than $t_{1}$ attribute it to mysterious "spontaneous changes"?

With such thoughts in mind I and my research associate, Dr. E. A. Smith, set about making various tests. Without attempting to tell you of our as yet unsuccessful attempts to secure cytolysins which will operate in the developmental stages of such periodically renewed structures as feathers, or to weary you with the history of our various other failures-of which there are an abundance- $\mathrm{I}$ wish to speak briefly about certain antenatal effects we secured in rabbits by means of fowl-serum sensitized against rabbit crystalline lens, and of the fact that such induced defects may become heritable.

The crystalline lens of the rabbit was selected as antigen, and fowls as the source of the antibodies. The lenses of newly killed rabbits were pulped thoroughly in a mortar and diluted with normal saline solution. About four cubic centimeters of this emulsion was then injected intraperitoneally or intravenously into each of several forls. Four or five weekly treatments with such lens-emulsions were given. Then a week or ten days after the last injection the blood-serum of one or more of the fowls was used for injection into pregnant rabbits. The rabbits had been so bred as to have the young advanced to about 
the tenth day of pregnancy, since from the tenth to the thirteenth day seems to be a particularly important period in the development of the lens. It is then growing rapidly and becomes surrounded by a rich vascular network that later disappears. From four to seven cubic centimeters of the sensitized fowl-serum were injected intravenously into the pregnant rabbits at intervals of two or three days for from ten days to two weeks. Several rabbits died from the treatment and many young were killed in utero. Of sixty-one surviving young from mothers thus treated, four had one or both eyes conspicuously defective and five others had eyes which were clearly abnormal. It is possible that still others were more or less affected, since we judged only by obrious, visible effects. We found later in some of the descendants of these individuals that rabbits which passed for normal during their earlier months subsequently manifested traces of defects in their lenses or in other parts of the eye.

The commonest abnormality seen in both the original subjects and in their descendants was partial or complete opacity of the lens, usually accompanied by reduction in size. Other defects were cleft iris, persistent hyaloid artery, bluish or silvery color instead of the characteristic red of the albino eye, microphthalmia and even almost complete disappearance of the eyeball. Taking into account the method of embryological development, however-the relation of lens, optic cup, and choroid fissure - the defects are probably all attributable. to the early injury of the lens. In some cases, both among originals and descendants, an eye microphthalmic at birth may undergo further degeneration such as collapse of the ball and what appears to be a resorption as if some solvent were operating upon it. The eyes of the mothers apparently remained unaffected. This is probably due to the fact that the lens tissue of the adlult rabbit is largely avascular and therefore did not come into contact with the injected antiboclies.

That the changes in the eyes of the fetuses resulted from the action of lens antibodies is indicated by the fact that in not one of the fortyeight controls obtained from mothers which had been treated with unsensitized fowl-serum or with fowl-serum sensitized to rabbit tissue other than lens, was there evidence of eye-defects, and I may add, that among the hundred or more young obtained later from mothers which were being experimented upon with various types of sera or protein extracts, for other purposes, not a single case of eye-defect has appeared. 
As already stated, once the anomaly is secured it may be transmitted to subsequent generations through breeding. So far we have succeeded in passing it to the eighth generation without any other than the original treatment. The imperfection, indeed, tends to become worse in succeeding generations and also to occur in a proportionately greater number of young. Though not analyzed completely as to its exact mode of inheritance, it has in general, the characteristics of a Mendelian recessive. Like such anomalies as Jurachydactyly or polydactyly in man, the transmission is not infrequently of an irregular, unilateral type, sometimes only the right, at others only the left eye showing the defect. In the later generations, probably in some measure as the result of selective breeding, there is an increasing number of young which have both eyes affected.

To determine whether the reappearance of the defect was due merely to the passing on of antibodies or kindred substances from the blood stream of the mother, or to true inheritance, we mated defectiveeyed males to normal females from strains of rabbits unrelated to our defective-eyed stock. The first generations produced in this way were invariably normal-eyed, but when females of this generation were mated to defective-eyed males again, we secured defective-eyed young after the manner of an extracted Mendelian recessive. It is obvious that in such casc.s the abnormality could only have been conveyed through the germ-cells of the male, and that it is, therefore, an example of true inheritance. Subsequent matings have shown that these young transmit the eye-anomalies as effectively as do individuals of the original lines. A new strain of defective-eyed young, established about the time our original paper went to press, is also flourishing and, as regards transmission of the defect, seems to differ in no way from the earlier stock.

But now, let us inquire as to where all this leads. Without entering into a discussion of just what, serologically, is taking place in the body or in the germ of fetuses borne by the lens-treated mothers, the point I wish to emphasize is that a certain specific effect has been produced; and, what is of greater moment, once the condition is established it may be not merely transmitted, but inherited. Whether the lens of the uterine young is first changed and then in turn induces a change in the lens-producing antecedents in the germ-cells of these young, or whether the specific antibody simultaneously affects the eyes and the germ-cells of the young is not clear. In any event it is evident that there is some constitutional identity between the 


\section{READINGS IN EVOLUTION, GENETICS, AND EUGENICS}

substance of the mature organ in question and the material antecedents of such an organ as it exists in the germ.

Biologically considered, the most significant fact is that specific antibodies can induce specific modifications in the germ-cell. Whether these antibodies are transmitted from the mother's blood or engendered in that of the young would seem to be of secondary importance. It stands to reason that antibodies originated in an animal's own blood will modify germinal factors if corresponding antibodies introduced from without can accomplish this.

The whole question as to how important such a fact may be in contributing to an understanding of the causes of the germinal changes in organisms in general, which lead to variation and evolution, hinges on the question of whether changes in an animal's tissue will induce the formation of antibodies or kindred active substances in its own body. We have steadily accumulating evidence that such reactions do occur.

In our own laboratory, for example, after many attempts we have succeeded in securing a defective-eyed young rabbit from a mother of normal stock by injecting her repeatedly with pulped rabbit lens before and during pregnancy. Since the young rabbit in question has both eyes badly affected there can be no question that a rabbit can build antibodies against rabbit-tissue which are as effective as those engendered in a foreign species such as the fowl. We have likewise found it relatively easy to secure spermatoxins by directly injecting rabbits, both male and female, with rabbit spermatozoa. Moreover, a given male will develop antibodies against his own spermatozoa if he is injected intravenously with the latter.

We are also securing evidence that serologic reactions induced in the fetus through operations on the mother are not mere passive transmissions, but may become actively participated in by the tissues of the fetus. For example, female rabbits sensitized with typhoid vaccine followed by living typhoid germs may transmit to their young and even to their grand descendants the ability to agglutinate typhoid bacilli in serum diluted from 60 to 160 times. From the standpoint of heredity we have no reason so far for maintaining that this is anything but placental transmission, though we are going to practice immunization generation after generation for a number of generations to determine if a truly hereditary immunity will be established. However, facts have come to light which show that there is more concerned in the operation than a mere transfer of antibodies from mother to 
fetus. For instance, the blood of young shortly after birth may show a higher titer than that of the mother. Again, after two or three months of development the young of certain of the sensitized mothers have shown a rather sudden rise in titer, much above that of the mothers. In such cases it would seem that some mechanism in the young rabbit itself is constructing antibodies which supplement those passively derived from the mother. Possibly in the process of development some organ important in such reactions just came into functioning. If this is true further experiments may throw some light on the perplexing question of the source or sources of the antibodies in an animal. After a few weeks, in such cases, the titer drops back again. In still another set of experiments we found that young from a sensitized mother, when nursed by a normal untreated mother, retained a fairly high titer for several months and even showed the rise of titer mentioned. On the other hand, young of an untreated mother when nursed by a sensitized mother acquired a fairly high titer from the milk of the foster mother but lost it rapidly after weaning time. Thus there are evidently constitutional factors operative in the young which have acquired their immunity through the placenta which are absent in the young whose antibodies were conveyed through food.

That changes in the blood serum may be caused by changed conditions in the tissues is further attested by many facts. For example, in pregnancy, the newly forming placenta may set free cells or cellproducts which, sometimes at least, cause changes in the blood-serum of the mother, though the exact nature of these changes is in dispute. Romer, using the complement-fixation technique, found that the serum of adult human beings may possess antibodies for their own lens proteins. Bradley and Sansum, employing anaphylactic reactions, found that guinea-pigs injected with guinea-pig tissue-proteins (liver, heart, muscle, testicle, kidney) develop immunity reactions. Again during the late war, the type of toxic action to which anaphylactic shock conforms was found to exist after extensive injury of the soft tissues. It resulted apparently from the absorption of poisonous substances of tissue origin into the circulation. In fact, various cells and tissues when injured liberate such poisons, and even blood in clotting is known to acquire a transient toxicity of this type.

With facts such as these before us, is it not a rational hypothesis to assume that changes in various parts of a body may on occasion influence the representatives of such parts in the germ-cells borne by that body? This appears all the more probable when we recall the 


\section{4}

facts learned from a study of precipitins and of anaphylaxis that each species of animal has a thread of fundamental similarity underlying the proteins of all its tissues. There is no reason to suppose that germinal tissue forms an exception. The further fact that homologous tissues, though existing in different species of animals, possess similar chemical characteristics, shows that to get an effect there need not be absolute chemical identity between the substance of such a tissue as the lens and the germinal constituents of which it is the expression. And if this is true for lens, why not for other tissues?

The blood-serum of any organism with blood thus affords a means of conveying the effects of changes in a parental organ to the germcell which contains the antecedent of such an organ. As long as there is little change in the somatic element its germinal correlative would presumably remain constant, but any alternations of the soma which give rise to the formation of anti-bodies or other active agents, particularly if long continued, might induce changes in the germ. Such a hypothesis would seem to be plausible at least in accounting for degenerative changes such as the deterioration of eyes in such forms as the mole, or in fact, in the formation of vestigial organs in general.

On the other hand, there is no reason to infer that changes inducerl in the blood-serum may not also be instrumental in leading to progressive as well as regressive evolution. If we may have germinally destructive constituents engendered in the blood there is no valid reason for supposing that we may not also have constructive ones. When we learn more about what initiates and promotes growth in a part through exercise, or what causes hypertrophy of an organ, we may likewise find how corresponding germinal antecedents of that part may be enhancer. Until such time we shall probably remain in the dark regarding the mechanism of progressive germinal changes. As already indicated, in the hormones and chalones we have a wonderful series of secretions normally circulating in the blood and maintaining general physiological equilibrium. That reciprocal stimulations of various organs occur by this means is a well-established fact. Hypertrophy or atrophy of an endocrine gland may produce pronounced effects in the furthermost reaches of the body. Again we may inquire, is it reasonable to suppose that the germinal tissues will be inviolate to all this ebb and flow of chemical influence? Should we not expect specific reactions or selections here no less surely than in other tissues? Destruction of the pars buccalis of the hypophysis in the frog-tadpole will cause profound alteration in other endocrine organs such as the 
adrenals and thyroids, will retard the growth rate, render the entire organism albinous, and produce in the individual pigment cells a condition of sustained contraction. Shall we conclude that such a farreaching influence as this, particularly in a developing organism, will pass the germ-cells by unscathed?

Similarly, growth in man is known to be controlled by a pituitary secretion that is carried by the blood to the various organs. The normal development of secondary sexual characters is determined by products from the testes or ovaries, and the activities of the generative organs themselves are intimately associated with the functioning of the adrenal and other glands. The periods of ovulation are inhibited by secretions from the corpus luteum; lactation is incited by products of the corpus luteum, the involuting uterus and the placenta; the carbohydrate metabolism in the liver and even in the most distant muscles is profoundly influenced by substances formed in the pancreas; the pancreas, liver, and intestinal glands are set to secreting through the stimulus of a product formed in the duodenal and jejunal mucosae. And still others of such remarkable interrelations can be cited.

Truly one may pronounce that social complex of reciprocating individuals termed cells which make up an organism, "members one of another." And with all of these co-operative activities of the various parts of the body it is inconceivable to me, at least, that the germ-cells, bathed in the same fluid, nourished with the same food, stand wholly apart.

May we not surmise then that as regards inheritance and evolution, Lamarck was not wholly in error when he stressed the importance of use and disuse of a part, or of modifications due to environmental change, in altering the course of the hereditary stream, particularly if we conceive of these influences as being prolonged, possibly over many generations? Have we not in the serological mechanism of the body of animals an adequate means for the incitement of the germinal changes which underly certain aspects of evolution? 


\section{CHAPTER XXIV}

\section{THE MUTATION THEORY}

[It will be recalled that Darwin, although depending upon the ever-present fluctuating variations as the material for natural selection to work upon, recognized the occasional occurrence of "sports" or "saltatory variations." These, however, seemed to him to be so rare in nature as to offer no adequate basis for selection. During the latter part of the nineteenth century several investigators, feeling the inadequacy of fluctuating variations to produce qualitatively new characters, decided to make a more careful examination of animals and plants in nature in order to discover whether saltatory variations might not be of more frequent occurrence than Darwin had supposed.

In England William Bateson collected a large number of instances of a type of variation which he called discontinuous in contradistinction to the continuous type which we have been calling fluctuations. Such variations, instead of being in a closely graded series with the typical variations of a species, were frequently quite sharply different from the majority. Although no experiments were conducted in order to test the hereditability of these "discontinuous variations," it is probable that some of them were "mutations" in the sense of De V'ries.

At about the same time Hugo De Vries in Holland, probably as the result of his rediscovery of Mendel's work and his confirmation of the latter's laws of heredity, became convinced that new species arise not by the accumulation, through natural selection, of minute fluctuating variations, but by the sudden appearance in one generation of fully formed new elementary species. He began a systematic research for species of plants in nature that were giving rise to new species. Many species were examined in their natural surroundings and were then brought into the experimental garden for more careful observation, but for a long time the search for a species throwing off new elementary species was unsuccessful. Finally, however, in a field near Hilversum, in the vicinity of Amsterdam, he found what seemed to him to be just the kind of plant he had been looking for in the evening, primrose (Oenothera lamarckiana). 
"Lamarck's evening-primrose" (Fig. 57), says De Vries, "is a stately plant, with a stout stem, attaining often a height of I.6 meters and more. When not crowded the main stem is surrounded by a large

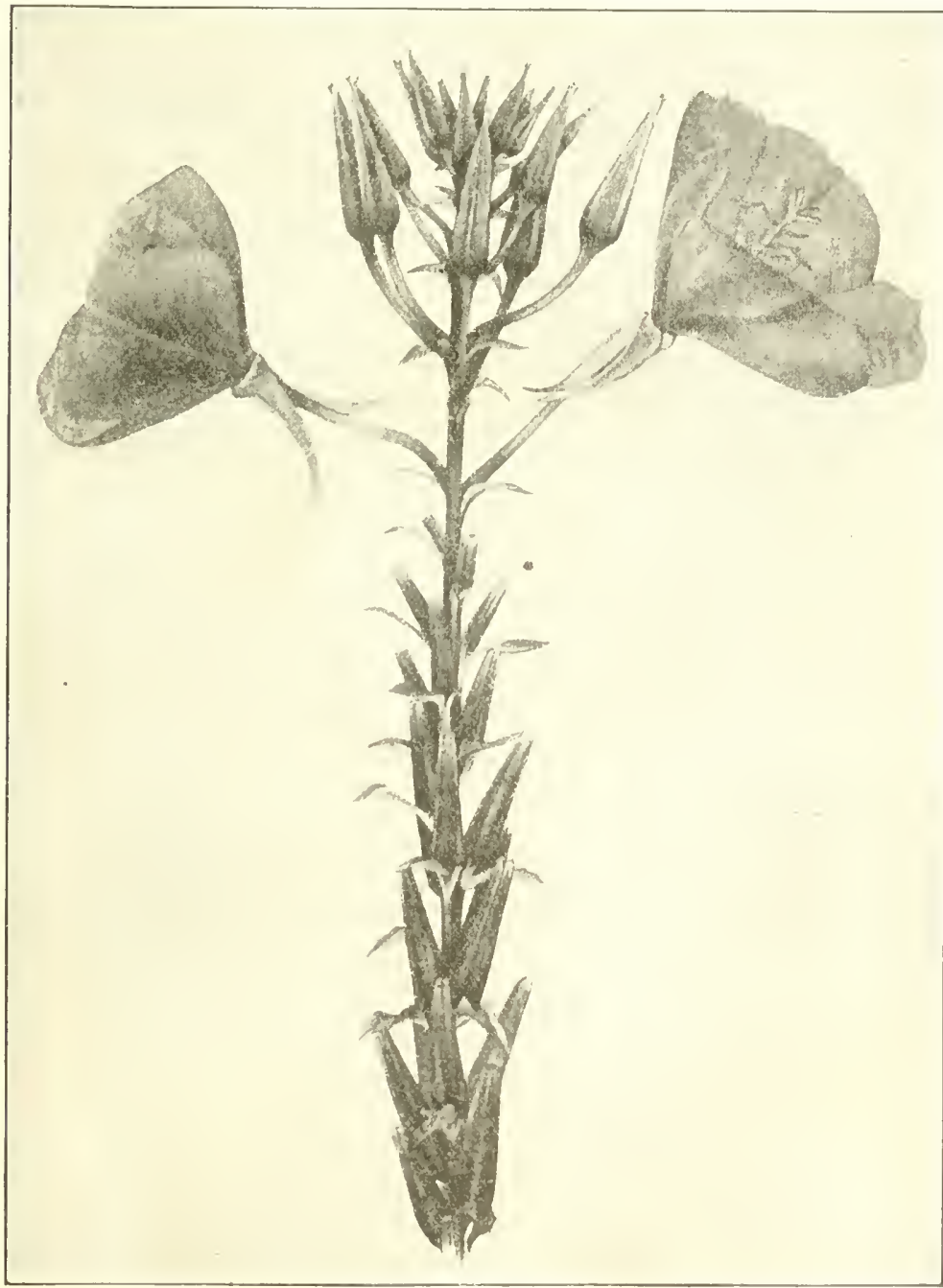

Fig 57.-Ocnothera lamarckiana, the original type used by Itelries in his experiments. This is the stock from Hilversum, from which arose in successive generations a series of mutants. (From De I'ries.) 


\section{$34^{S}$ READINGS IN EVOLUTION, GENETICS, AND EUGENICS}

circle of smaller branches, growing upwards from its base so as to form a dense brush. .... The flowers are large and bright yellow attracting immediate attention even from a distance. They open toward evening, as the name indicates, and are pollinated by bumble-bees and moths."

On account of the classic character of De Vries's mutants of Ocnothera lamarckiana we shall follow his own detailed description of the more significant of these.-ED.]

\section{NEW SPECIES (MUTANTS) OF OENOTHERA ${ }^{\text {I }}$}

HUGO DE VRIES

This striking species (Oenothera lamarckiana) was found in a locality near Hilversum, in the vicinity of Amsterdam, where it grew in some thousands of individuals. Ordinarily biennial, it produces roset:es in the first, and stems in the second year. Both the stems and the rosettes were at once seen to be highly variable, and soon distinct varieties could be distinguished among them.

The first discovery of this lacality was made in I886. Afterwards I visited it many times, often weekly or even daily during the first few years, and always at least once a year up to the present time. This stately plant showed the long-sought peculiarity of producing a number of new species every year. Some of them were observed directly on the field, either as stems or as rosettes. The latter could be transplanted into my garden for further observation, and the stems yielded seeds to be sown under like control. Others were too weak to live a sufficiently long time in the field. 'They were discovered by sowing seed from indifferent plants of the wild locality in the garden. A third and last method of getting still more new species from the original strain was the repetition of the sowing process, by saving and sowing the seed which ripened on the introduced plants. These various methods have led to the discovery of over a dozen new types never previously observed or described.

Leaving the physiological side of the relations of these new forms for the next lecture, it would be profitable to give a short description of the several novelties. To this end they may be combined under five different heads, according to their systematic value. The first head includes those which are evidently to be considered as varieties,

${ }^{I}$ From H. De Vries, Species and Varieties (copyright 1904). Used by special permission of the publishers, The Open Court Publishing Company. 
in the narrower sense of the word, as previously given. The second and third heads indicate the real progressive elementary species, first those which are as strong as the parent-species, and secondly a group of weaker types, apparently not destined to be successful. Under the fourth head I shall include some inconstant forms, and under the last head those that are organically incomplete.

Of varieties with a negative attribute, or real retrograde varieties, I have found three, all of them in a flowering condition in the field. I have given them the names of laerifolia, brevistylis and namella.

The laevifolia, or smooth-leaved variety, was one of the very first deviating types found in the original field. This was in the summer of $\mathrm{s} 887$, seventeen years ago. It formed a little group of plants grow.ing at some distance from the main body, in the same field. I found some rosettes and some flowering stems and sowed some seed in the fall. The variety has been quite constant in the field, neither increasing in number of individual plants nor changing its place, though now closely surrounded by other lamarckianas. In my garden it has proved to be constant from seed, never reverting to the original lamarckiana, provided intercrossing was excluded.

It is chiefly distinguished from Lamarck's evening-primrose by its smooth leaves, as the name indicates. The leaves of the original form show numerous sinuosities in their blades, not at the edge, but anywhere between the veins. The blade shows numbers of convexities on either surface, the whole surface being undulated in this manner; it lacks also the brightness of the ordinary evening-primrose or Oenothera biennis.

These undulations are lacking or at least very rare on the leaves of the new laevifolia. Ordinarily they are wholly wanting, but at times single leaves with slight manifestations of this character may make their appearance. They warn us that the capacity for such sinuosities is not wholly lost, but only lies dormant in the new variety. It is reduced to a latent state, exactly as are the apparently lost characters of so many ordinary horticultural varieties.

Lacking the undulations, the laevifolia-leaves are smooth and bright. They are a little narrower and more slender than those of the lamarckiana. The convexities and concavities of leaves are a useful character in dry seasons, but during wet summers, such as those of the last few years, they must be considered as very harmful, as they retain some of the water which falls on the plants, prolonging the action of the water on the leaves. This is considered by some writers 
to be of some utility after slight showers, but was observed to be a source of weakness during wet weather in my garden, preventing the leaves from drying. Whether the laevifolia would do better under such circumstances, I have, however, omitted to test.

The flowers of the laevifolia are also in a slight degree different from those of lamarckiana. The yellow color is paler and the petals are smoother. Later, in the fall, on the weaker side branches these differences increase. The lacvifolia petals become smaller and are devoid of the emargination at the apex, becoming ovate instead of obcordate. This shape is often the most easily recognized and most striking mark of the variety. In respect to the reproductive organs, the fertility and abundance of good seed, the laevifolia is by no means inferior or superior to the original species.

$O$. brevistylis, or the short-styled evening-primrose, is the most curious of all my new forms. It has very short styles, which bring the stigmas only up to the throat of the caly $\mathrm{x}$-tube, instead of upwards of the anthers. The stigmas themselves are of another shape, more flattened and not cylindrical. The pollen falls from the anthers abundantly on them, and germinates in the ordinary manner.

The ovary which in lamarckiana and in all other new forms is wholly underneath the calyx-tube, is here only partially so. This tube is inserted at some distances under its summit. The insertion divides the ovary into two parts: an upper and a lower one. The upper part is much reduced in breadth and somewhat attenuated, simulating a prolongation of the base of the style. The lower part is also reduced, but in another manner. At the time of flowering it is like the ovary of lamarckiana, neither smaller nor larger. But it is only reached by very few pollen-tubes, and is therefore always very incompletely fertilized. It does not fall off after the fading away of the flower, as unfertilized ovaries usually do; neither does it grow out, nor assume the upright position of normal capsules. It is checked in its development, and at the time of ripening it is nearly of the same length as in the beginning. Nany of them contain no good seeds at all; from others I have succeeded in saving only a hundred seeds from thousands of capsules.

These seeds, if purely pollinated, and with the exclusion of the visits of insects, reproduce the variety entirely and without any reversion to the lamarckiana type.

Correlated with the detailed structures is the form of the flowerbuds. They lack the high stigma placed above the anthers, which in 
the lamarckiana, by the vigorous growth of the style, extends the calyx and renders the flower-bud thinner and more slender. Those of the brevistylis are therefore broader and more swollen. It is quite easy to distinguish the individuals by this striking character alone, although it differs from the parent in other particulars.

The leaves of the $O$. brevistylis are more romded at the tip, but the difference is only pronounced at times, slightly in the adult rosettes, but more clearly on the growing summits of the stems and branches. By this character the plants may be discerned among the others some weeks before the flowers begin to show themselves.

But the character by which the plants may be most easily recognized from a distance in the field is the failure of the fruits. They were found nearly every year in varying, but always small numbers.

Leaving the short-styled primrose, we come now to the last of our group of retrograde varieties. This is the $O$. namnella, or the dwarf, and is a most attractive little plant. It is very short of stature, reaching often a height of only $20-30 \mathrm{~cm}$., or less than one-fourth of that of the parent. It commences flowering at a height of $10-15 \mathrm{~cm}$, while the parent-form often measures nearly a meter at this stage of its development. Being so very dwarfed the large flowers are all the more striking. They are hardly inferior to those of the lamarckiana, and agree with them in s'ructure. When they fade away the spike is rapidly lengthened, and sten becomes much longer than the lower or vegetative part of the stem.

The dwarfs are one of the most common mutations in my garden, and were observed in the native locality and also grown from seeds saved there. Once produced they are absolutely constant. I have tried many thousands of seeds from various dwarf mutants, and never observed any trace of reversion to the lamarkinna type. I have also cultivated them in successive generations with the same result. In a former lecture we have seen that contrary to the general run of horticultural belief, varieties are as constant as the best species, if kept free from hybrid admixtures. This is a general rule, and the exceptions, or cases of atavism, are extremely rare. In this respect it is of great interest to observe that this constancy is not an acquired quality; but is to be considered as innate, because it is already fully developed at the very moment when the original mutation takes place.

From its first leares to the rosette period, and through this to the lengthening of the stem, the dwarfs are easily distinguished from any other of their congeners. The most remarkable feature is the shape 


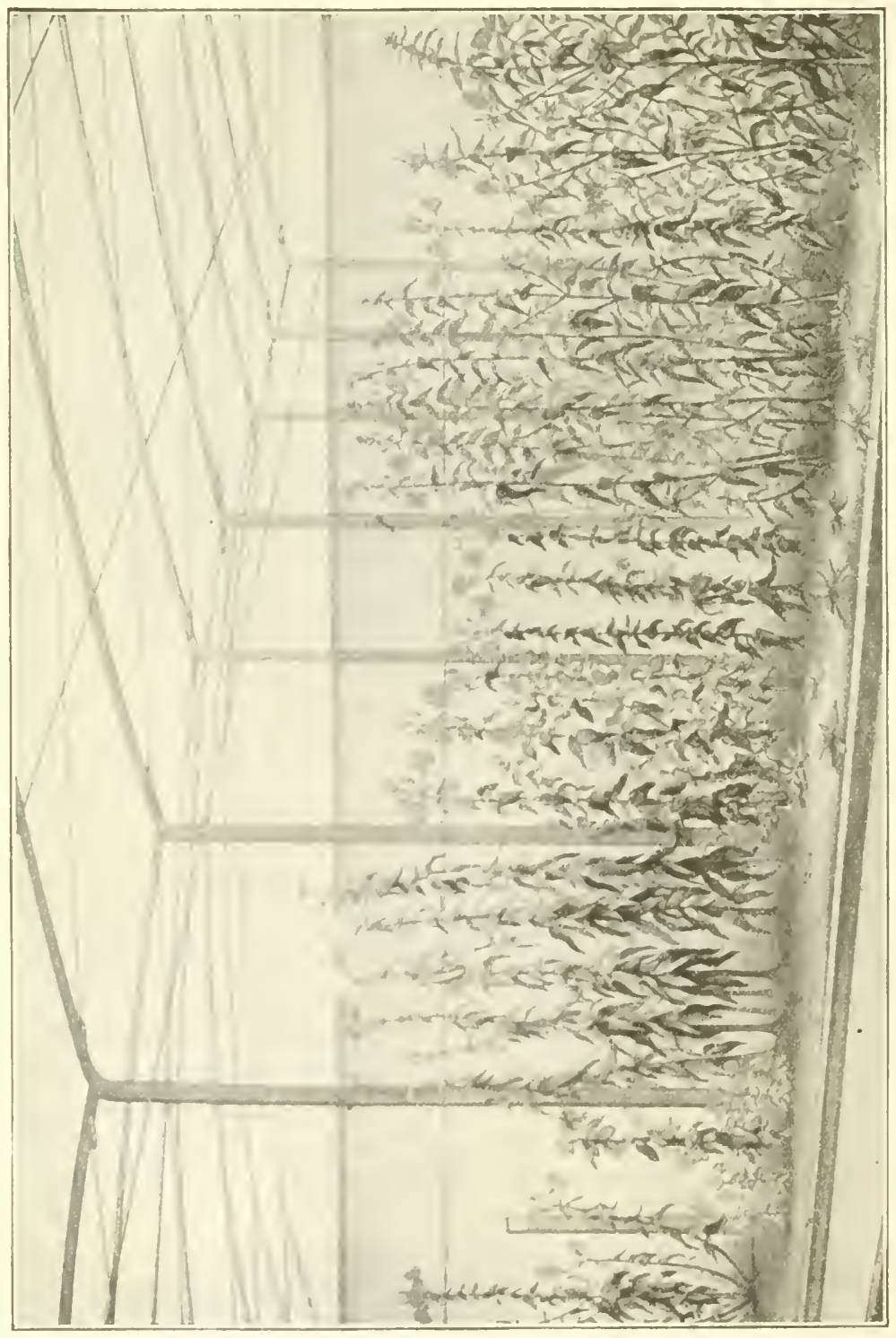


of the leaves. They are broader and shorter, and especially at the base they are broadened in such a way as to become apparently sessile. The stalk is very brittle, and any rough treatment may cause the leaves to break off. The young seedlings are recognizable by the shape of the first two or three leaves, and when more of them are produced, the rosettes become dense and strikingly different from others. Later leaves are more nearly like the parent-type, but the petioles remain short. The bases of the blades are frequently almost cordate, the laminae themselves varying from oblong-ovate to ovate in outline.

The stems are often quite unbranched, or branched only at the base of the spike. Strong secondary stems are a striking attribute of the lamarckiana parent, but they are lacking, or almost so in the dwarfs. The stem is straight and short, and this, combined with the large crown of bright flowers, makes the dwarfs eminently suitable for bed or border plants. Unfortunately they are very sensitive, especially to wet weather.

Oenothera gigas and O. rubrinervis, or the giant, and the red-veined evening primroses, are the names given to two robust and stout species, which seem to be equal in vigor to the parent-plant, while diverging from it in striking characters. Both are true elementary species, differentiated from :amarckiana in nearly all their organs and qualities, but not showing any preponderating character of a retrograde nature. Their differences may be compared with those of the elementary species of other genera, as for instance, of Draba, or of violets, as will be seen by their description.

The giant evening-primrose, though not taller in stature than O. lamarckiana, deserves its name because it is so much stouter in all respects. The stems are robust, often with twice the diameter of lamarckiana throughout. The internodes are shorter, and the leaves more numerous, covering the stems with a denser foliage. This shortness of internodes extends itself to the spike, and for this reason the flowers and fruits grow closer together than on the parent-plant. Hence the crown of bright flowers, opening each evening, is more dense and more strikingly brilliant, so much the more so as the individual flowers are markedly larger than those of the parents. In connection with these characters, the flower-buds are seen to be much stouter than those of lamarckiana. The fruits attain only half the normal size, but are broader and contain fewer, but larger seeds. 
The rubrinervis is in many respects a counterpart to the gigas, but its stature is more slender. The spikes and flowers are those of the lamarckiana, but the bracts are narrower. Red veins and red streaks on the fruits afford a striking differentiating mark, though they are not absolutely lacking in the parent-species. A red hue may be seen on the calyx, and even the yellow color of the petals is somewhat deepened in the same way. Young plants are often marked by the pale red tinge of the mid-veins, but in adult rosettes, or from lack of sunshine, this hue is often very faint.

The leaves are narrow, and a curious feature of this species is the great brittleness of the leaves and stems, especially on annual individuals, for example, on those that make their stem and flowers in the first year. High turgidity and weak development of the mechanical and supporting tissues are the anatomical cause of this deficiency, the bast-fibres showing thinner walls than those of the parent-type under the microscope. Young stems of rubrinervis may be broken off by a sharp stroke, and show a smooth rupture across all the tissues, while those of lamarckiana are very tough and strong.

Both the giant and the red-veined species are easily recognized in the rosette-stage. The very young seedlings of the latter are not clearly differentiated from the lamarckiana, and often a dozen leaves are requirerl before the difference may be seen. Under ordinary circumstances the young plants must reach an age of about two months before it is possible to discern their characters, or at least before these characters have become reliable enough to enable us to judge of each individual without doubt. But the divergencies rapidly become greater. The leaves of $O$. gigas are broader, of a deeper green, the blade more sharply set off against the stalk, the whole rosettes becoming stout and crowded with leaves. Those of $O$. rubrinervis on the contrary are thin, of a paler green and with a silvery white surface; the blades are elliptic, often being only $2 \mathrm{~cm}$. or less in width. They are acute at the apex and gradually narrowed into the petiole.

It is quite evident that such pale narrow leaves must produce smaller quantities of organic food than the darker green and broad organs of the gigas. Perhaps this fact is accountable partly, at least, for the more robust growth of the giant in the second year. Perhaps also some relation exists between this difference in chemical activity and the tendency to become annual or biennial. The gigas, as a rule, produces far more, and the mbrinervis far less biennial plants, than the lamarckiana. Annual culture for the one is as unreliable as 
biennial culture for the other. Rubrinervis may be annual in apparently all specimens, in sunny seasons, which would allow a large part of the gigas to remain in the state of rosettes during the entire first summer. It would be very interesting to obtain a fuller insight into the relation of the length of life to other qualities, but as yet the facts can only be detailed as they stand.

Both of these stout species have been found quite constant from the very first moment of their appearance. I have cultivated them from seed in large numbers, and they have never reverted to the lamarckiana. From this they have inherited the mutability or the capacity of producing in their turn new mutants. But they seem to have done so incompletely, changing in the direction of more absolute constancy. This was especially observed in the case of mbrinervis, which is not of such rare occurrence as $O$. gigas, and which it has been possible to study in large numbers of individuals. So for instance, "the red-veins" have never produced any dwarfs, notwithstanding they are produced very often by the parent-type. And in crossing experiments the red-veins gave proof of the absence of a mutative capacity for their production.

[Besides the mutants just described there occurred two weak forms that could survive only if reared under protection and would have failed to survive in nature. Here we have a place for the action of natural selection, but operating with mutations instead of with fluctuating variations. These two mutants are "the whitish and the oblong-leaved evening-primroses or the Oenothera albida and oblonga."

All of the mutants so far mentioned are constant forms that breed true to type. Certain other types were either incapable of being bred or else were decidedly inconstant. Ocnothera lata had only pistillate flowers and therefore could not be fertilized by pollen of the same mutant. Ocnothera scintillous and $O$. clliptica are fertile to their own pollen, but produce progeny only partly like the parent, the rest reverting to the original type Oenothera lamarkiana.-ED.]

\section{SUMMARY OF DE VRIES'S MUTATION THEORY \\ THOMIS HUNT MOROIN}

We may now proceed to examine the eridence from which De Vries has been led to the general conclusions given in the preceding pages. De Vries found at Hilversum, near Amsterdam, a locality

${ }^{\mathrm{I}}$ T. H. Morgan, Evolution and Adaptation (I903). Used by special permission of the publishers, The Macmillan Company. 
where a number of plants of the evening primrose, Oenothera lamarckiana, grow in large numbers. This plant is an American form that has been imported into Europe. It often escapes from cultivation, as is the case at Hilversum, where for ten years it had been growing wild. Its rapid increase in numbers in the course of a few years may be one of the causes that has led to the appearance of a mutation period. The escaped plants showed fluctuating variations in nearly all of their organs. They also had produced a number of abnormal forms. Some of the plants came to maturity in one year, others in two, or in rare cases, in three, years.

A year after the first finding of these plants De Vries observed two well-characterized forms, which he at once recognized as new elementary species. One of these was $O$. brevistylis, which occurred only as female plants. The other new species was a smooth-leafed form with a more beautiful foliage than O. lamarckiana. This is O. laevifolia. It was found that both of these new forms bred true from selffertilized sceds. At first only a few specimens were found, each form in a particular part of the field, which looks as though each might have come from the seeds of a single plant.

These two new forms, as well as the common O. lamarckiana, were collected, and from these plants there have arisen the threc groups of families of elementary species that De Vries has studied. In his garden other new forms also arose from those that had been brought under cultivation. The largest group and the most important one is that from the original $O$. lamarckiana form. The accompanying table shows the mutations that arose between I 887 and I 899 from these plants. The seerls were selected in each case from self-fertilized plants of the lamarckiana form, so that the new plants appearing in each horizontal line are the descendants in each generation of lumarckiana parents. It will be observed that the species, O. oblonga, appeared again and again in considerable numbers, and the same is true for several of the other forms also. Only the two species, O. gigas and $O$. scintillans, appeared very rarely (Fig. 59).

Thus 1)e Vries harl, in his seven generations, about fifty thousand plants, and about eight hundred of these were mutations. When the flowers of the new forms were artificially fertilized with pollen from the flowers of the same plant, or of the same kind of plant, they gave rise to forms like themselves, thus showing that they are true elementary species. It is also a point of some interest to observe that all these forms differed from each other in a large number of particulars. 
Only one form, O. scintillans, that appeared eight times, is not constant as are the other species. When self-fertilized its seeds produce always three other forms, O. scintillans, O. oblonga, and $O$. lamarckiana. It differs in this respect from all the other elementary species, which mutate not more than once in ten thousand individuals.

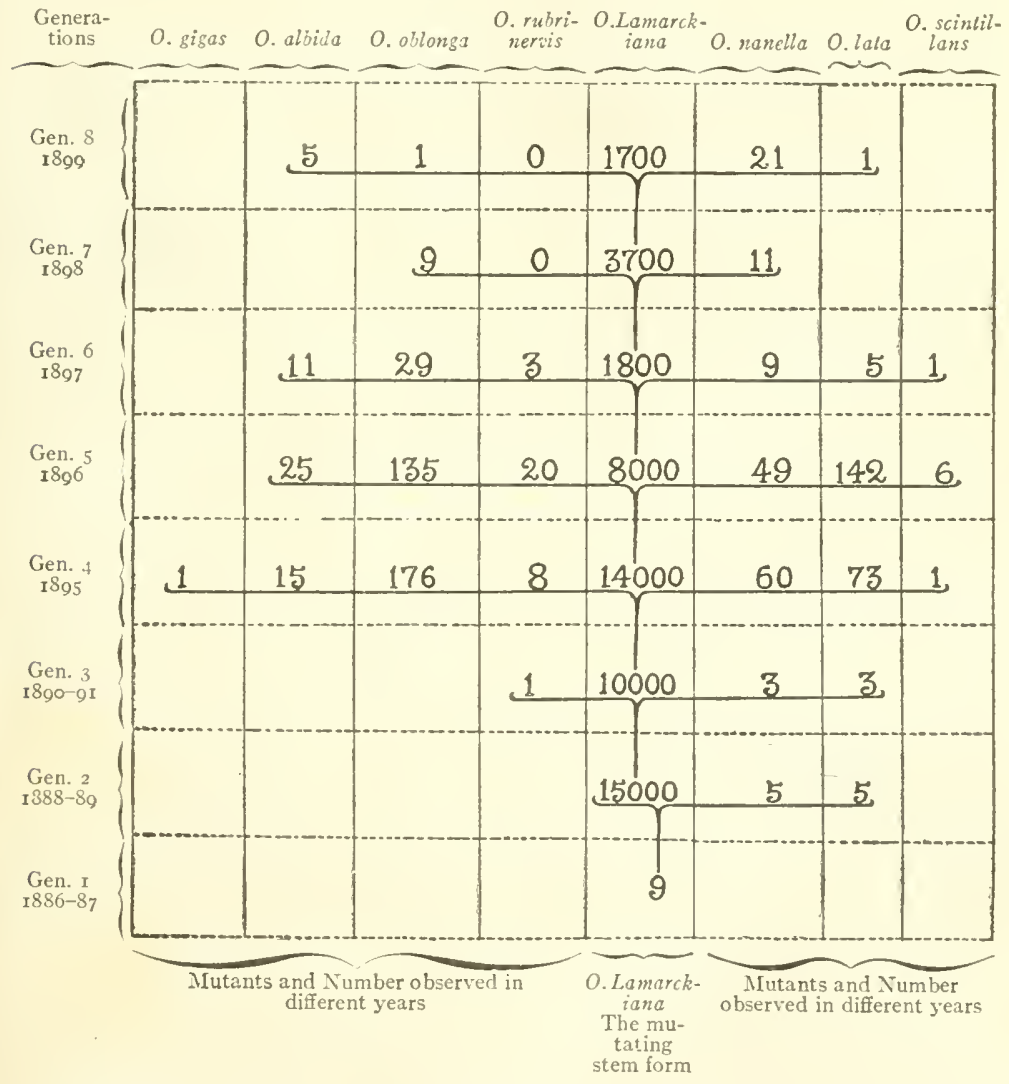

Fig. 59.-Diagram showing in condensed form the genealogy of the Oenothera Lamarckiana family and its various mutants during successive years. The numbers under each type represent the number of new types observed each year. (From Tower.)

From the seeds of one of the new forms, C. laevifolia, collected in the field, plants were reared, some of which were O. lamarckiana and others O.laevifolia. They were allowed to grow together, and their descendants gave rise to the same forms found in the lamarckiana 
family, described above, namely, O. lata, elliptica, nannella, rubrineris, and also two new species, O. spatulata and leptocarpa.

In the lata family, only female flowers are produced, and, therefore, in order to obtain seeds they were fertilized with pollen from other species. Here also appeared some of the new species already mentioned, namely, albida, nannella, lata, oblonga, rubrinerris, and also two new species, clliptica and subovata.

De Vries also watched the field from which the original forms were obtained, and found there many of the new species that appeared under cultivation. These were found, however, only as weak young plants that rarely flowered. Five of the new forms were seen either in the Hilversum field, or else raised from seeds that had been collected there. These facts show that the new species are not due to cultivation, and that they arise year after year from the seeds of the parent form, O. lamarckiana.

Conclusions.-From the evidence given in the preceding pages it appears that the line between fluctuating variations and mutations may be sharply drawn. If we assume that mutations have furnished the material for the process of evolution, the whole problem appears in a different light from that in which it was placed by Darwin when he assumed that the fluctuating variations are the kind which give the material for evolution.

From the point of view of the mutation theory, species are no longer looked upon as having been slowly built up through the selection of individual variations, but the elementary species, at least, appear at a single advance, and fully formed. This need not necessarily mean that great changes have suddenly taken place, and in this respect the mutation theory is in accord with Darwin's view that extreme forms that rarely appear, "sports," have not furnished the material for the process of evolution.

As De Vries has pointed out, each mutation may be different from the parent form in only a slight degree for each point, although all the points may be different. The most unique feature of these mutations is the constancy with which the new form is inherited. It is this fact, not previously fully appreciated, that De Vries's work has brought prominently into the foreground. There is another point of great interest in this connection. Many of the groups that Darwin recognized as varieties correspond to the elementary species of De Vries. These varieties, Darwin thought, are the first stages in the formations of species, and, in fact, cannot be separated from species in most cases. The main difference between the selection theory and 
the mutation theory is that the one supposes these varieties to arise through selection of individual variations, the other supposes that they have arisen spontaneously and at once from the original form. The development of these varieties into new species is again supposed, on the Darwinian theory, to be the result of further selection, on the mutation theory, the result of the appearance of new mutations.

In consequence of this difference in the two theories, it will not be difficult to show that the mutation theory escapes some of the gravest difficulties that the Darwinian theory has encountered. Some of the advantages of the mutation theory may be briefly mentioned here.

I. Since the mutations appear fully formed from the beginning, there is no difficulty in accounting for the incipient stages in the development of an organ, and since the organ may persist, even when it has no value to the race, it may become further developed by later mutations and may come to have finally an important relation to the life of the individual.

2. The new mutations may appear in large numbers, and of the different kinds those will persist that can get a foothold. On account of the large number of times that the same mutations appear, the danger of becoming swampe 1 through crossing with the original form will be lessened in proportion to the number of new individuals that arise.

3. If the time of reaching maturity in the new form is different from that in the parent forms, then the new species will be kept from crossing with the parent form, and since this new character will be present from the beginning, the new form will have much better chances of surviving than if a difference in time of reaching maturity had to be gradually acquired.

4. The new species that appear may be in some cases already adapted to live in a different environment from that occupied by the parent form; and if so, it will be isolated from the beginning, which will be an advantage in avoiding the bad effects of intercrossing.

5. It is well known that the differences between related species consist largely in differences of unimportant organs, and this is in harmony with the mutation theory, but one of the real difficulties of the selection theory.

6. Useless or even slightly injurious characters may appear as mutations, and if they do not seriously affect the perpetuation of the race, they may persist. 


\section{CRITICISMS}

[Oenothera lamarckiana has fallen under suspicion of being of impure stock due to the crossing of two or more original species. The basis for this suspicion is that the type found in Holland is not a truly wild indigenous species, but a domestic type escaped from cultivation. It seems probable that the species was imported from America a great many years ago. B. M. Davis has succeeded in producing by crossing two American wild species a hybrid form distinctly resembling Oenothera lamarckiana in numerous respects, and this hybrirl, like any other hybrid, produces numerous combinations of the parental characters when inbred, and these hybrid progeny sometimes resemble the mutants observed by De Vries. It is also said that the pollen grains of Oenothera lamarckiana exhibit a high degree of sterility, which is a characteristic defect of hybrid plants.

Whether or not, however, the Oenothera situation be taken as valid evidence of the occurrence of mutations, the idea of mutations and their rôle in evolution will stand up on quite independent grounds. Numerous mutations have been observed in all sorts of animals and plants. Professor T. H. Morgan and his able corps of collaborators have observed in their carefully controlled breeding experiments with the fruit fly Drosophila melanogaster hundreds of suddenly appearing new characters which are classed by them as mutants, and whose heredity has been most accurately studied. These mutants involve single characters of the organism which are sometimes of a prominent and readily recognizable sort and sometimes of so slight a degree as to be imperceptible except to the trained eye of the expert student of genetics. It also frequently occurs that two mutants are to the eye practically identical, but may be distinguished by differences in hereditary behavior. The great majority of the mutants discovered in Drosophila are termed "lethals" because they involve the death of the mutants possessing the variation. A further discussion of Drosophila "mutants" appears in a later chapter.-ED.]

\section{CAUSES OF MUTATIONS}

[Various mutations have been produced experimentally by subjecting the germ cells to radically changed environmental conditions. IV. L. Tower claims to have produced at least two new elementary species of potato beetle by suljjecting the already grown and unchangeable parents to radically changed temperature and humidity conditions. Although the parents could lindergo no change themselves they 
produced a small number of offspring with distinctly changed characters. These turned out to be mutants because they bred true to the new characters. Three of Tower's mutants of the potato beetle (Leptinotarsa decemlineata) are shown in Figure 6o.

MacDougal injected into the ovules of various species of plants such foreign materials as solutions of zinc salts, cane sugar, etc. The seeds produced from these plants developed into plants with radically
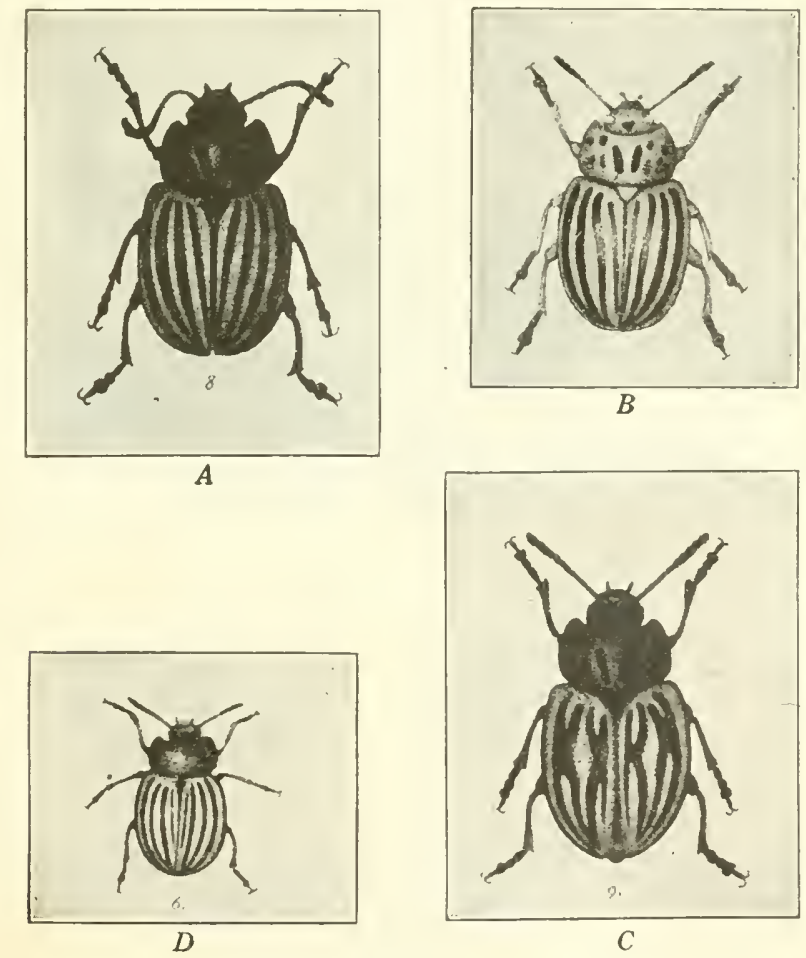

FIG. 60.-Some divergent types (mutations) of beetles produced by subjecting the germ cells to external influences. $A$, normal decomlineata; $B$, the form pallida; C, tortuosa; D, defectopunctata. (From Tower.)

new characters (Fig. 6I) which bred true to type for four or more generations. Whether or not the changes persisted longer we do not know, since MacDougal has not published any further details.

Gager discovered that the action of radium rays on the pollen grains of various plants had a profound effect upon the chromatin. Some of the latter was apparently lost during mitotic cell division. 
The same writer exposed the orules of plants to radium rays and produced marked changes in the germ cells so that they grew into various stunted and otherwise abnormal plants, some of which bred true for several generations. The work was not followed long enough to determine whether the change was one involving a rather prolonged induction or was a permanent mutation.-ED.]
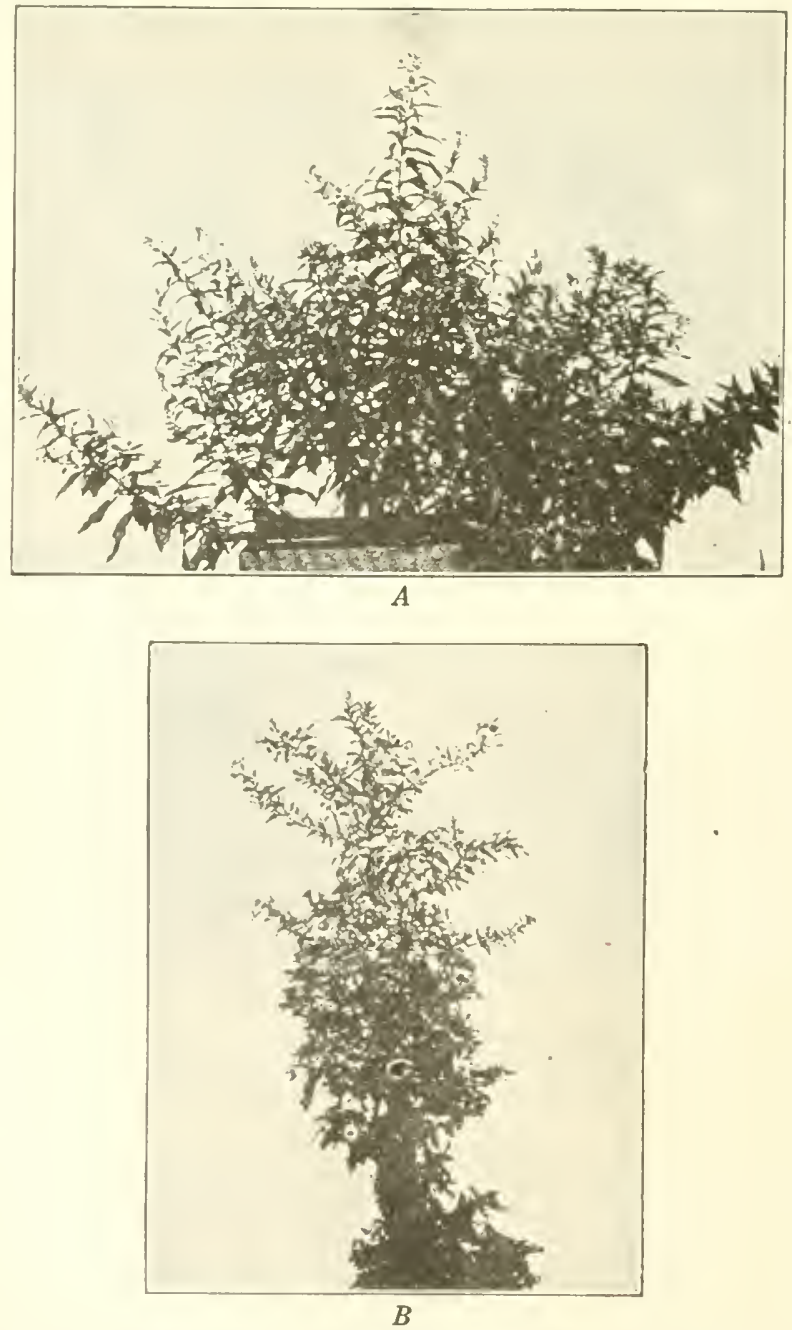

FIG. 6r.-Two plants of Onagra biennis, showing the effect of injections of zinc sulphate into the orule. $A$, normal; $B$, the modified plant, which arose from seeds that had been modified by zinc sulphate. (From MIacDougal.) 
"Baur's third category of variations," say Babcock and Clausen," "comprises all inheritable changes due to causes other than segregation and recombination of genetic factors. Although comparatively little is known concerning the specific causes of mutations, yet it is possible to distinguish between two general classes of such inheritable variations according to the nature of the genetic units involved. These classes are (I) alterations in genetic factors, and (2) deviations in the number of chromosomes. We designate the first group as factor mutations and the second as chromosome aberrations. Since the first group is of vastly greater importance to agriculture than the second, we shall consider the latter very briefly before engaging in discussion of the former, whicn we deem worthy of recognition as mutations in the strict sense.

"Chromosome aberrations.-By the aid of cytology it has been demonstrated that inheritable changes are occasionally induced, in plants at least, by irregularities in the behavior of the chromosomes during mitosis or meiosis, such that certain germ cells contain fewer or more chromosomes than the number typical of the species. Aberrant forms in several plant families are now known to differ from the parent species in chromosome number. Some have only a single chromosome more or less than the parent, while a few are known in which the original number is loubled. It is possible that aberrations occur involving all combinations of numbers between these two extremes. In various forms of Lamarck's evening primrose (Oenothera lamarckiana), whose typical number is $\mathrm{I} 4$, according to Gates the following aberrant numbers have been reported-15, 20, 2I, 22, 23, $27,28,29,30$. Aberrations involving the doubling of the number of chromosomes typical of the species is known as tetraploidy because there are four times the haploid number typical of the parent. Occasionally aberrations or hybridization between diploid and tetraploid forms result in triploidy.

"There is a limited amount of evidence which indicates that groups of species have arisen by progressive alterations in chromosome number. Thus in Drosophila, Metz has found ten species in which the chromosome numbers range from 6 to 12 and the larger numbers appear to have arisen by subdivision of the large dumbbell-shaped chromosomes found in the species having smaller numbers. Evidence that doubling of the chromosome number may occur during somatogenesis has been found by Farmer and Digby in the interesting hybrid,

"From E. B. Babcock and R. E. Clausen, Genetics in Relation to A griculture (copyright I9I8). Used by special permission of the publishers, The MicGrawHill Book Company. 


\section{$3^{6} 4$ REAdINGS IN EVOLUTION, GENETICS, AND EUGENICS}

Primula kewensis. The original plant, which was sterile, 'had I8 and 9 chromosomes in its premeiotic and postmeiotic nuclei respectively,' but in the fertile plants which were propagated asexually from it, as well as in similar fertile hybrids which were produced in later experiments, the diploid and haploid numbers were 36 and 18 respectively. Having found by means of careful measurements of the chromosomes in the two forms that the nuclei in both forms contain the same volume of chromatin, the authors conclude that the increase in number may be attributed to transverse fission of the I8 larger chromosomes and not to the fusion of two riuclei.

"From a study of chromosomal dimensions in relation to phylogeny, Meek 'arrived at the conclusion that the widths of chromosomes are successively greater in higher zoölogical phyla, and that this dimension is constant for very large groups of animals.' But Farmer and Digby have shown that stich a conclusion is without foundation since 'closely related forms may possess chromosomes differing widely in shape and size and character.' Hence they conclude 'that phylogenetic affinity is not, necessarily, correlated with chromosome width.' They also point out that "unfortunately we know practically nothing about the phylogeny of the chromosomes. No convincing hypothesis has been put forward to explain how these remarkable bodies have become organized, nor how their peculiarities have either been brought into existence or are kept so true for a given species.' However, we are reminded by Glaser that chromatin is present in bacteria though not in the form of a nucleus and it may not be too much to hope that cytology may yet discover the principal stages in the development of the chromosomes and establish such correlation as may exist between this development and organic evolution. Certainly extended investigations of chromosome numbers must be made before chromosome aberrations can be considered an important factor in evolution. Except that certain chromosome aberrations, such a tetraploidy causing gigantism, might be of economic value, in general this class of mutations is of minor importance in breeding."

[Conclusion.-In bringing this discussion of the causes of heritable variations (mutations) to a close, we find ourselves in a somewhat pessimistic frame of mind. When all is said, it is found that our knowledge of what actually causes mutations is almost nothing. We think we know something about the mechanism of heredity, but we do not know the mechanism of variation. The really great evolutionary discovery of the future will probably be the finding out of the cause or the causes of mutations. -ED.] 


\title{
CHAPTER XXV
}

\section{BIOMETRY (THE STATISTICAL STUDY OF VARIATION AND HEREDITY)}

\author{
THE STATISTICAL STUDY OF VARIATION
}

H. H. NEWMAN

The pioneer workers in the application of statistical methods to biological study were Sir Francis Galton and his leading disciple, Karl Pearson. The use to which Galton and Pearson put their statistical methods appears later in this chapter. For present purposes we may limit our study of biometry to that part of it which has to do with variation. We have already discussed fluctuating variations, the small plus and minus differences that exist between the different members of the same species or variety. This was the type of variation that Darwin considered the main raw material of evolution. Examples of fluctuating variations are not far to seek. Pearson cites as an illustration of fluctuating variation the number of veins in two sets of beech leaves, each set from a different tree:

\begin{tabular}{|c|c|c|c|c|c|c|c|c|c|}
\hline Number of veins.............. & I3 & I4 & I5 & 16 & 17 & I 8 & 19 & 20 & $\cdots$ \\
\hline Number of leaves................ & $\cdots$ & & & & & & $\cdots$ & $\cdots \cdot$ & $\cdots$ \\
\hline First tree. . . . . . . . . . . . & $\cdots$ & . & I & 4 & 7 & 9 & 4 & I & 26 \\
\hline 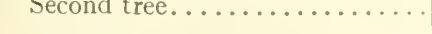 & 3 & 4 & 9 & 8 & 2 & $\cdots \cdot$ & $\cdots \cdots$ & $\cdots$ & 20 \\
\hline Total. & 3 & 4 & IO & 12 & 9 & 9 & 4 & I & . \\
\hline
\end{tabular}

It will be noted that though there were i6-reined leaves on both trees, as well as I5-and I7-veined, the general distribution is quite different in the two trees. In the first tree the most frequently occurring type is the 18 -veined leaf, and the other types may be said to fluctuate about this (the "mode"). In the second tree the mode is the I5-veined type and the other types fluctuate about it. It will be seen also at a glance that the types that differ most from the mode are the least frequent and that those nearest the mode are the most frequent.

Some years ago the writer had occasion to study the heredity of scale numbers in the banded region of the nine-banded armadillo. As a preliminary to this study it was necessary to know the degree and 
extent of rariability present in the species. Consequently 508 individuals were taken at random and their scale or scute number counted. It was found that the total number of scutes in the nine bands ranged from $5 \mathrm{I} 7$ to 625 and that the commonest number was about 557 . In order to get a definite idea of the distribution of the different types,

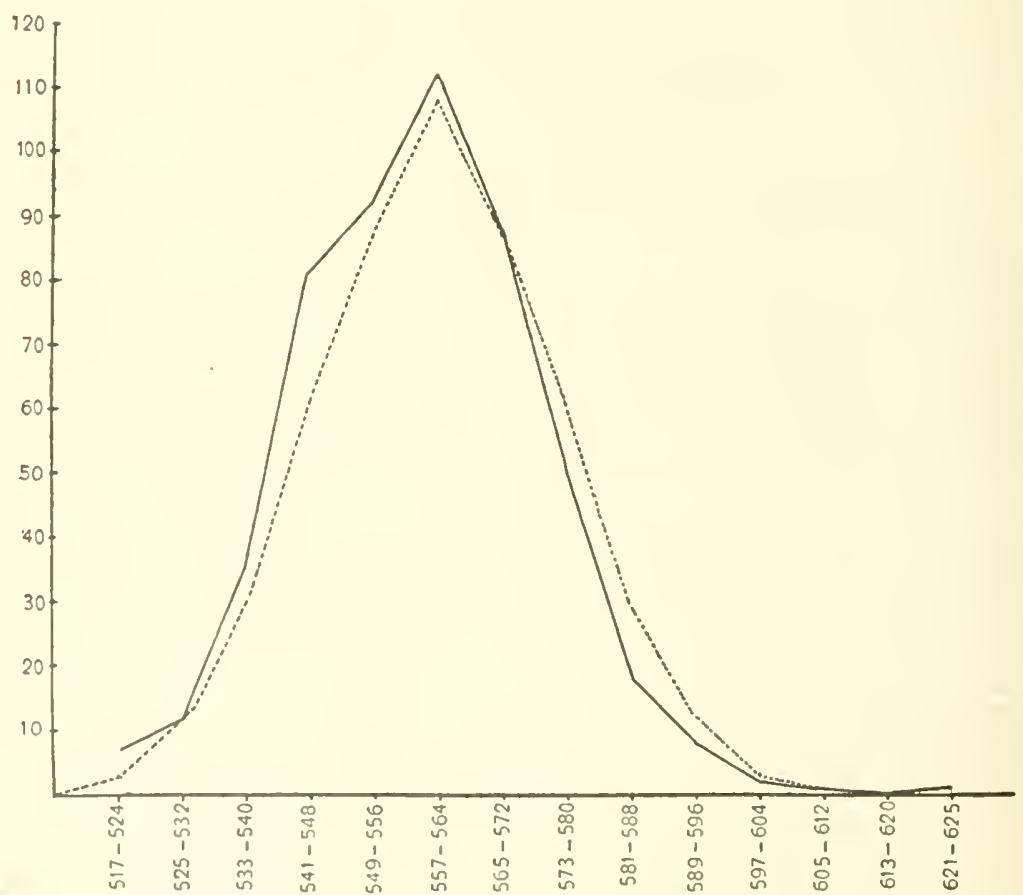

Fig. 62.-Polygon of variation for the total number of scutes in the nine bands of the armadillo (Dusypus novencinctus), as determined by the seriation of 508 individuals. Class range $=8$ scutes. The solid tine represents the observational, and the broken line the theoretical, normal curve. The abscissae refer to the number of scutes, and the ordinates to the number of individuals. (From Iewman.)

they were arranged in a variation polygon as shown in Figure 62. On the abscissa are arranged groups including individuals between $5^{\mathrm{I} 7}$ and 524 scutes inclusive, those between 525 and 532 , those between 533 and 540 , on up to a group of those from 62 I to 625 . All of these except the last included a small class with a range of 8 scutes. This arranging in classes was essential, for without it there would have been 
I 13 classes and a very irregular and meaningless distribution. On the ordinate we find by tens the numbers of individuals in each class. It will be noter that the solid line is one connecting the points of intersection between the class of scute numbers and the number of individuals in these classes. The dotted line represents an ideal fluctuating variation curve, which is practically a mathematical curve of chance. The closeness of fit between the actual and the theoretical curve is very good. The mode is the class including individuals with a scute count of $557^{-6}$, and there is a fairly even balance of individuals in the plus and the minus directions. It seems fairly evident from examination of the curve that the individuals with $6 \mathrm{I}_{3}$ scutes and over are beyond the limits of the theoretical distribution. A further study of these exceptional individuals shows that they are mutations, in which a splitting up of single scutes into paired and twinned scutes has taken place to such an extent as greatly to increase the total numJuer of scutes.

From the data used in constructing this variation polygon several significant constants may be obtained. The "arithmetical mean" (average number of scutes in the entire 508 individuals) is 558.2. The "median" or halfway point between the extremes is $55^{8}$. The "mode" or most frequentlv occurring single type is 557 (the theoretical value being 557.6).

If we wished to compare a large group of parents with a large group of offspring, or if it were necessary to compare the armadillos of Texas with those of Mexico or Brazil, we could compare them as to mean, median, and mode, and also as to the shape of the polygon of variation. This would give us a very good idea as to whether or not the old species present in these three regions is tending to evolve in different directions under different conditions of life.

Instead of having to depend on the visual comparison between the variation polygon of two or more different populations, we can reduce the facts about the distribution of the different types about the mean or mode to a simple arithmetical constant, called the "standard deviation," which is usually given the symbol $\sigma$. This constant is computed as follows:

$$
\sigma=\sqrt{\frac{\Sigma\left(x^{2} \cdot f\right)}{n}} .
$$

In this formula $x$ represents the deviation of each class from the arithmetical mean; $f$, the number of individuals in each separate class; $\Sigma$, the sum of all the classes, and $n$, the total number of individuals. 
By the use of this formula we have calculated the standard deviation $(\sigma)$ of the individuals represented in Figure 62 to be $14.89 \pm$ 0.31 scutes. This means that the average deviation from the mean is about 14.89 scutes.

The $\pm 0.3 \mathrm{I}$ scutes is called the "probable error" and means that the figure $\mathrm{I}_{4} .89$ is inaccurate to the extent of being $0.3 \mathrm{I}$ scutes too high or too low. The probable error is an essential feature of such computations, as, without it, we would not be able to rely on the significance of small differences. Suppose, for example, we should find that the armadillos of Brazil had a standard deviation of $15.43 \pm 0.44$ scutes, we might conclude that the variability of the Brazilian individuals was 0.54 scutes greater than that of the Texas individuals. In view of the fact, however, that the probable error in one case is $\pm 0.3 \mathrm{I}$ scutes and in the other \pm 0.44 scutes we would have to conclude that there was no significant difference. In actual practice it has been decided that unless the actual difference between two constants is about 4.6 times as great as the probable error, the difference is not significant.

The method of determining the probable error of any calculated constant is difficult to understand, but easy to put into practice. For example, the formula for calculating the probable error of the standard deviation is as follows:

$$
E \sigma=\frac{ \pm 0.6745 \sigma}{\sqrt{2 n}}
$$

where $E$ is the probable error, and $n$ the number of individuals. It will be seen that the probability of error diminishes steadily with the increase in number of individuals studied. With very large numbers the error due to what is known as "random sampling" practically disappears.

\section{BIMODAL AND MULTIMODAL CURVES}

If we confine our biometrical studies to homogeneous populations, we get only fairly simple monomodal curves that resemble the normal curve of variation, which is a curve of chance; but when we study ordinary wild populations, we frequently fincl that we are dealing with a complex of several races, each of which has its own mode and standard deviation. Bateson has given us a classic example of this type of phenomenon. In studying the length of pinchers in the common earwig (Forficulata auricularia), he found that he got a two-humped or bimodal curve as shown in Figure 63. It then became evident that there were two distinct varieties as figured above. Such studies have frequently revealed the heterogeneity of supposedly homogeneous 
populations. Opinion differs as to the significance of these findings. The more optimistic evolutionists look upon such instances as that of Bateson's earwigs as visual demonstrations of a species actually splitting up into two or more species. It seems quite likely that one of these types is a successful mutant type that has not fully segregated itself as a true species from the parent-type. Another view of the significance of bimodal curves is that the condition results from hybridization and that the bimodality is the result of the segregation of dominant and recessive types.

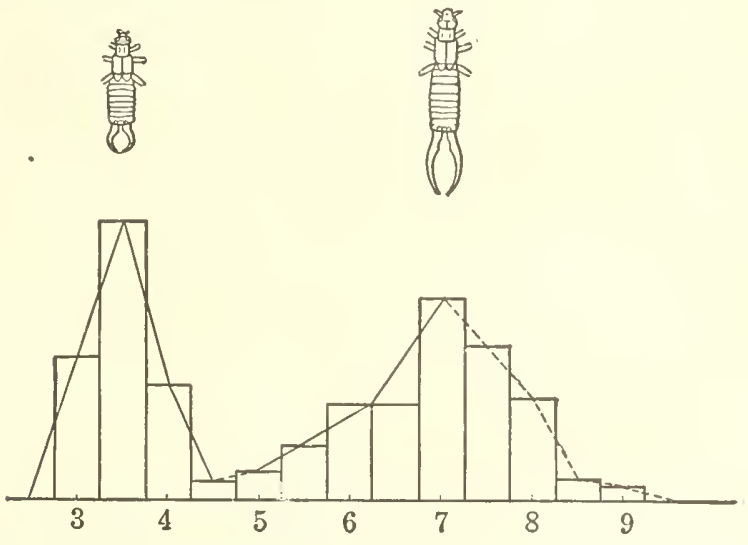

FIG. 63.-Bimodal polygon plotted from data on the earwig. Mean types $\left(\times \frac{3}{4}\right)$ indicated above corresponding modes. Numbers below the base line indicate length of pincers in millimeters. (From Bateson and Johannsen.)

\section{THE COEFFICIENT OF CORRELATION}

Only one more biometrical constant need be mentioned here: the "coefficient of correlation." It is often necessary to discover the exact relation that exists between two sets of variables in order to discover whether they are totally independent or partially correlated with each other. For example, we have found that there is a close correlation between stature and head length in man, also between color of hair and color of eyes; but it is very important to be able to reduce the degree of correlation to a simple arithmetical constant. This is called the "coefficient of correlation" (commonly expressed as $r_{x y}$, where $x$ is one variable and $y$ the other). The formula for computing $r_{x y}$ is as follows:

$$
r_{x y}=\left(\frac{\Sigma\left(d_{x} d_{y}\right)}{n}\right)\left(\frac{\mathrm{I}}{\sigma_{x} \sigma_{y}}\right),
$$


where $d$ represents the actual deviation and $\Sigma$ the sum, $n$ the number of individuals; $\sigma$ the standard deviation.

"Correlation tables" show graphically whether or not there is correlation. If, as in Figure 64, we want to find out what is the relationship between total yield of oats and number of culms to the plant, we may make a table with subject classes arranged perpendicularly, and the relative classes, horizontally. If the individuals tend to group themselves about a diagonal ranging from upper left- to lower righthand corners, the amount of correlation is quite marked. Complete correlation would be represented by a single line of points along this diagonal. No correlation would be shown by random distribution

\begin{tabular}{|c|c|c|c|c|c|c|c|}
\hline & 2 & 3 & 4 & 5 & 6 & 7 & \\
\hline $0-1$ & 3 & & & & & & \\
\hline $1-2$ & 28 & 19 & 3 & & & & 50 \\
\hline $2-3$ & 18 & 66 & 20 & 1 & & I & 106 \\
\hline $3-4$ & 1 & 42 & 58 & $\tau$ & 1 & & 109 \\
\hline $4-5$ & & 7 & 59 & 11 & 3 & & 80 \\
\hline $5-6$ & & & 26 & 14 & 2 & & 42 \\
\hline $6-7$ & & & & 4 & 3 & & 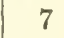 \\
\hline $7-8$ & & & 1 & 1 & & & 2 \\
\hline $8-9$ & & & & & I & & 1 \\
\hline & 50 & 134 & 167 & 38 & 10 & 1 & 400 \\
\hline
\end{tabular}

Fig. 64.-Correlation table of 400 plants of Sixty-Day oats. Total yield of plant in grams, subject. Number of culms per plant, relative. I910. Coefficient of correlation $=0.712 \pm 0.017$. (From Love and Leighty, 1914.)

over the whole rectangle. Inverse correlation would tend to give a grouping about a diagonal ranging from the upper right- to lower left-hand corners.

In the particular corrclation table used for illustration, the coefficient of correlation $\left(r_{x y}\right)$ turns out to be 0.7 I $2 \pm 0.017$. Since complete correlation would be $\mathrm{I}$, the degree of positive correlation is very high, as we might expect. The correlation table was used quite effectively by Galton, as we shall now show.

\section{STATISTICAL STUDY OF INIIERITANCE ${ }^{I}$}

EDWIN GRANT CONKLIN

Francis Galton was one of the first who attempted to reduce the mass of conflicting observations on heredity and variation to some

${ }^{\mathrm{T}}$ From E. Cr. Conklin, II eredity and Environment (copyright I920). Used by special permission of the publishers, The Princeton University Press. 
system and to establish certain principles as a result of statistical study. He was the real founder of the scientific study of inheritance; he studied characters singly and he introduced quantitative measures. Galton's researches, which were published in several volumes, consisted chiefly in a study of certain families with regard to several selected traits, viz., genius or marked intellectual capacity, artistic faculty, stature, eye color and disease. As a result of his very extensive studies two main principles appeared to be established:

1. The Law of Ancestral Inheritance which he stated as follows:

The two parents contribute between them on the average one-half of each inherited faculty, each of them contributing one-quarter of it. The four grandparents contribute between them one-quarter, or each of them one-sixteenth; and so on, the sum of theseries $\frac{1}{2}+\frac{1}{4}+\frac{1}{8}+{ }_{16}^{1}$ being equal to $I$, as it should be. It is a property of this infinite series that each term is equal to the sum of all those that follow: thus $\frac{1}{2}=\frac{1}{4}+\frac{1}{8}+1_{16}^{1} \ldots, \frac{1}{4}=\frac{1}{8}+1_{16}^{1}+\ldots$, and so on. The prepotencies of particular ancestors in any given pedigree are eliminated by a law which deals only with average contributions, and the various prepotencies of sex with respect to different qualities are also presumably eliminated.

The average contribution of each ancestor was thus stated definitely, the contribution dimining with the remoteness of the ancestor. This Law of Ancestral Inheritance is represented graphically in Figure 65. Pearson has somewhat modified the figures given lyy Galton, holding that in horses and dogs the parents contribute $\frac{1}{2}$, the grandparents $\frac{1}{3}$, the great-grandparents

Number of ancestors.-Theoretically the number of ancestors doubles in each ascending generation; there are two parents, four grandparents, eight great grandparents, etc. If this continued to be true indefinitely the number of ancestors in any ascending generation would be $(2)^{n}$, in which $n$ represents the number of generations. There have been about 57 generations since the beginning of the Christian Era, and if this rule held true indefinitely each of us woukl have had at the time of the birth of Christ a number of ancestors represented by (2) ${ }^{57}$ or about I 20 quadrillions - a number far greater than the entire human population of the globe since that time. Is a matter of fact, owing to the intermarriage of cousins of tarious degrees, the actual number of ancestors is much smaller than the thermetical number. For example, Plate says that the late Emperor of (icmany had only 162 ancestors in the roth ascending generation, instead of 
5I 2, the theoretical number. Nevertheless this calculation will serve to show how widespread our ancestral lines are, and how nearly related are all people of the same race.

Davenport concludes that no people of English descent are more distantly related than 3 oth cousins, while most people are much more closely related than that. If we allow three generations to a century, and calculate that the degree of cousinship is determined by the number of generations less two, since first cousins appear only in the third generation, the first being that of the parents and the second that of the sons and daughters, we find that 3 oth cousins at the present time

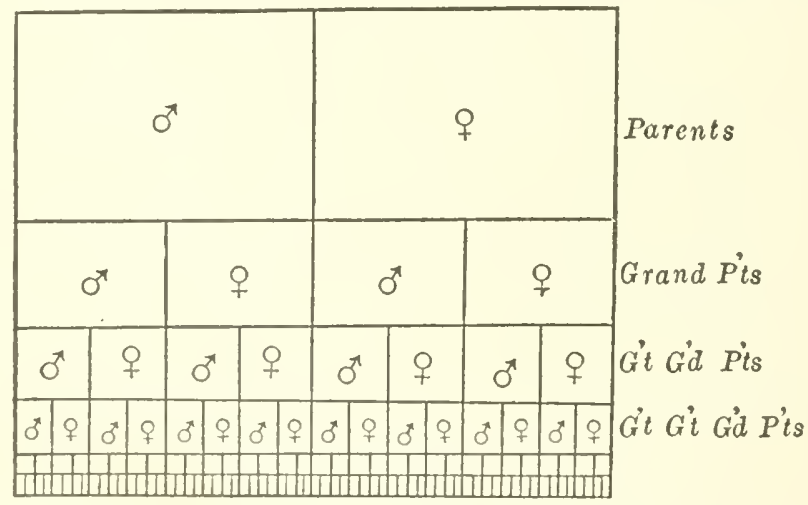

Fig. 65.-Diagram of Galton's "Law of Ancestral Inheritance." The whole heritage is represented by the entire rectangle; that derived from each progenitor by the smaller squares; the number of the latter doubles in each ascending generation while its area is halved. (From Conklin, after Thomson.)

would have had a common ancestor about one thousand years ago or approximately at the time of William the Conqueror. As a matter of fact most persons of the same race are much more closely related than this, and certainly we need not go back to Adam nor even to Shem, Ham, or Japheth to find our common ancestor.

2. The Law of Filial Regression is the second principle which Galton deduced from his statistical studies, or it may be called the tendency to mediocrity. He found that, on the average, extreme peculiarities of parents were less extreme in children. Thus "the stature of adult offspring must on the whole be more mediocre than the stature of their parents, that is to say more near to the mean or mid of the general population"; and again, "the more bountifully a 
parent is gifted by nature, the more rare will be his good fortune if he begets a son who is as richly endowed as himself." This so-called law of filial regression is represented graphically in Figure 66 in which the actual stature of individual parents is shown by the oblique line, the stature of children by the dotted curve, and the mean stature of the race in the horizontal dotted line.

Statistical vs. physiological methods. - One of the chief aims and results of statistical studies is to eliminate individual peculiarities and to obtain general and average results. Such work may be of great importance in the study of heredity, especially where questions of the occurrence or distribution of particular phenomena are concerned; but the causes of heredity are individual and physiological, and averages are of less value in finding the causes of such phenomena than is the intensive study of individual cases.

By observation alone it is usually impossible to distinguish between inherited and environmental resemblances and differences, and yet this distinction is essential to any study of inheritance. If all sorts of likenesses and unlikenesses are lumped together, whether inherited or not, our study of inheritance can only end in confusion. The value of statistics depends upon a proper classification of the things measured and enumerated, and if things which are not commensurable are grouped together the results may be quite misleading and worthless.

Statistical studies insufficient.-Unfortunately Galton and Pearson, as well as some of their followers, have not always carefully distinguished between hereditary and environmental characters. Furthermore much of their material was drawn from a general population in which were many different families and lines not closely related genetically. Consequently their statistical studies are of little value in discovering the physiological principles or laws of heredity. Jennings (1910) well says, "Galton's laws of regression and of ancestral inheritance are the product mainly of a lack of distinction between two absoluteiy diverse things, between non-inheritable fluctuations on the one hand, and permanent genotypic differentiations on the other." In the case of man we have few certain tests to determine whether the differential cause of any claracter is hereditary or environmental, but in the case of animals and plants, where experiments nay be performed on a large scale, it is possible to make such tests by (I) experiments in which the environment is kept as uniform as possible while the hereditary factors differ, and (2) experiments in which, in a 


\section{RE.ADINGS IN EVOLUTION, GENETICS, AND EUGENICS}

series of cases, the hereditary factors are fairly constant while the environment differs. In this way the differential cause or causes of any character may be located in heredity, in environment, or in both.

The observational and statistical study of inheritance helped to outline the problem but did little to solve it. Certain phenomena of

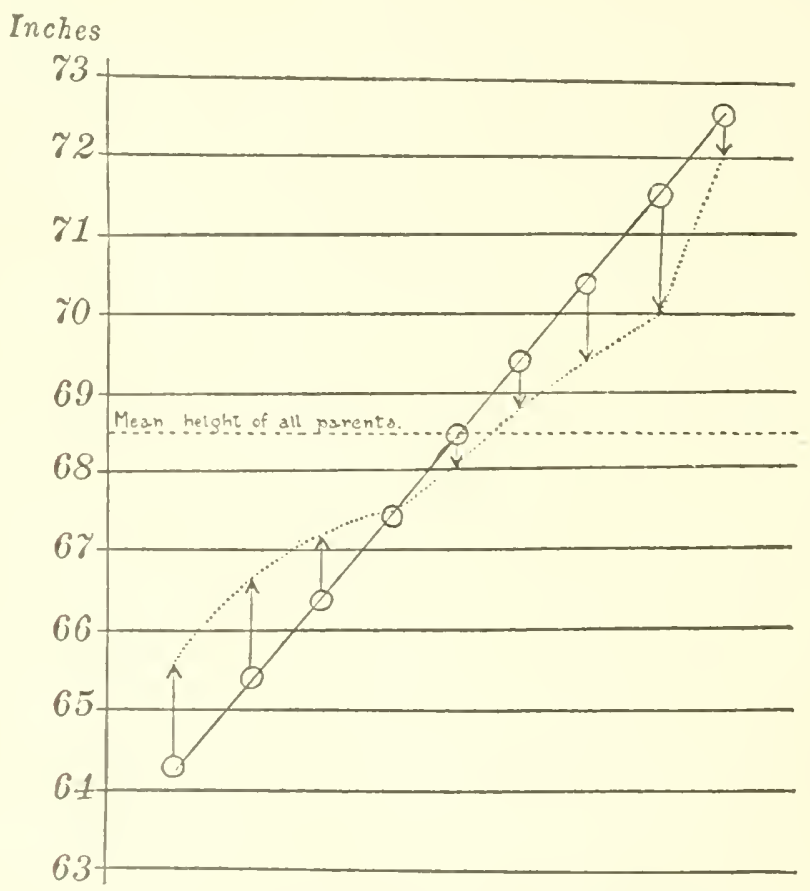

Fig. 66.-Scheme to illustrate Galton's "Law of Filial Regression" as shown in the stature of parents and children. The mean height of all parents is shown by the dotted line between 68 and 69 inches. The circles through which the diagonal line runs represent the heights of graded groups of parents, and the arrowheads indicate the average heights of their children. The offspring of undersized parents are taller and of oversized parents are shorter than their respective parents. (From Conklin, after Walter.)

hereditary resemblances between ascendants and descendants were made intelligible, but there were many peculiar and apparently irregular or lawless phenomena which could not be predicted before they occurred nor explained afterward. For example when Darwin crossed different breeds of domestic pigeons, no one of which had a trace of blue in its plumage, he sometimes obtained offspring with 
more or less of the blue color and markings of the wild rock pigeon from which domestic pigeons are presumably descended. He described many cases of dogs, cattle and swine, as well as many cultivated plants, in which offspring resembled distant ancestors and differed from nearer ones; such cases had long been known and were spoken of as "reversion." He observed many cases in which certain characters of one parent prevailed over corresponding characters of the other parent in the offspring, this being known as "prepotency"; but there was no satisfactory explanation of these curious phenomena. They did not come under either of Galton's laws, and their occurrence was apparently so irregular that every such case seemed to be a law unto itself. 


\section{CHAPTER XXVI}

\section{HEREDITY IN PURE LLNES}

\section{H. H. NEWMAN}

In the last chapter we have seen how Galton formulated his law of filial regression, which means that average parents tend to produce average offspring, but that exceptional parents tend to produce offspring less exceptional than themselves, but nevertheless more exceptional than the average.

In studying this law the Danish botanist Johanssen saw in it a possibility of racial improvement through the instrumentality of controlled selection. He thought that by continually selecting the most exceptional parents in each generation the degree of regression toward the average might be lessened until a pure non-regressing strain might be produced.

In order to simplify the experiment and obviate the complexities inherent in intercrossing, he selected a self-fertilizing type, using the bean Phaseolus. 'Taking a set of nineteen beans from several plants, choosing the largest bean, the smallest bean, and seventeen intermediate types, he planted these, expecting to find that the bean progeny of the large bean would be mainly large, those of the small bean, small. In this he was disappointed, for the bean progeny of the large bean fluctuated about a mean, some being large, some small, but the majority average. Similarly the bean progeny of the smallest bean were of various types, mainly average. Each of these ninetcen purelines had a mean of its own, and irrespective of which one was selected (the largest, the smallest, or the average) the mean and distribution of the progeny was practically the same. 'Thus it was concluded that within a pure line selection had no effect in modifying the character of size of beans. The reason for this rather unexpected result is not far to seek. Johanssen was selecting on the basis of somatic variations, the fluctuating variations of Darwin, that are merely due to more or less favorable growth conditions and are not represented in the germ plasm, i.e., are not hereditary. Each germ cell in a pure line is supposed to have the same hereditary units, and, if that is so, selection would not be expected to effect any modification that would persist. 
Johanssen pointed out that each pure line had a different mean size of bean and a different distribution about the mean. 'This was a real hereditary difference due to differences in the germinal content of the original parent-beans. Two beans of exactly the same size, one an average individual of a larger stock and one a large individual of a smaller stock, were planted and their offspring varied about two distinct means. This leads to the idea that an individual produces offspring not in accord with its somatic appearance, but according to its germinal content. So this idea of the difference between what an individual is somatically, and what it is germinally led Johanssen to introduce the terms "phenotypic" and "genotypic"- "phenotype" and "genotype."

Thus, if one selected all the beans of a given size he would have a group of phenotypes that would be identical pically, but would be very different genotypically; for each might be germinally different and would therefore have different groups of offspring. All of the individuals in one pure line, however, whether they differ somatically (phenotypically) or not, would belong to the same genotype and would be genotypically equivalent.

The appreciation of this distinction at this place, before the treatment of Mendelian heredity, will be of great advantage. Few more useful terms have been deviseil in connection with genetics than genotype and phenotype.

W. L. Tower in a long series of experiments on the potato beetle (Leptinotarsa decemlineata) came to similar conclusions as the result of his attempts to modify a character by selection. Instead of using a self-fertilizing type, he chose a long inbred stock that was probably all identical germinally, but varied considerably in shade of color, etc. He selected for twelve generations the darkest specimens and, instead of getting all dark offspring, he got an array of all shades fluctuating evenly about the average. At the end of twelve generations of selection there was no change in the proportion of light and dark individuals.

Jennings tried another type of pure-line work, using one-celled organisms which reproduce by binary fission, i.e., by the division of the parent into two nearly equal halves, thus forming two offspring. $\mathrm{He}$ chose a considerable number of Paramecia and isolated each in a separate small aquarium where it was allowed to breed for some generations. The original individuals differed quite markedly in size and in other structural characters. The various sets of progeny were 
measured and curves of variability made for each. It was found that a different curve and mean resulted in each set. If the largest and the smallest individual in any pure line is isolated and allowed to produce a set of progeny, the mean and curve of variability will be the same, because both the large and the small inclividual belong to the same genotype, though varying phenotypically.

In conclusion therefore we may say that, according to Johanssen, organisms that appear to be alike, or are alike somatically, are identical phenotypically; but organisms, whether alike somatically or not, that have the same determiners are genotypically identical or belong to the same genotype.

\section{ARE DETFRMINERS (GENES) CONSTANT OR VARIABLE?}

In our study of the causes of mutations we were forced to admit that we are almost wholly ignorant of the causes of mutations. We infer that in the majority of cases the change occurs within the germ cell and in the gene itself. In this pure-line work where the genes are unmixed by intercrossing we should have a splendid opportunity of testing the possibility of genes varying or becoming modified. In none of these experiments in pure lines was there any indication of genes being modified, but some further work by Jennings seems to imply that he has changed his position with reference to the modifiability of genes. Using another protozoan, Diffugia, he found that he did succeed in markedly shifting the mean by selection, and thus seemed to prove that genes were modifiable. This work is open to two comments. First, protozoa are not suitable material for testirig the clistinction between germinal and somatic changes, because the whole individual is but a single cell; therefore any change that is passed on may be merely a somatic change. Second, Jennings, in making his sclections, did so on the basis not so much of an individual itseli as upon the characters of its ancestors for some generations back. He was, therefore, working more with genotypic than with phenotypic considerations. If, as he claims, there was a progressive modification of characters, such as numbers of spines, beyond the limit of variability in the original stock, the results would seem to warrant the conclusion that genes are variable and that selection might be effective in establishing new types within pure lines.

Castle, as the result of a long and elaborate experiment with "hooded rats," at first thought that the gene for the hooded pattern was varialsle and could be enhanced by selection; later, however, he 
says that "the changes in question had not occurred in the gene for the hooded pattern, but in the residual heredity." The situation appears to be this: the hooded pattern is a black marking corering the head and shoulders of the otherwise white body. It varies in the extent to which it covers the body, and, by selecting the plus or minus individuals, a nearly complete black and a nearly complete white race was produced. These were maintained in a pure line for three generations and then were bred with a pure white strain. After six generations "the whitest individuals extracted from the dark hooded race were no darker than the darkest individuals extracted from the white hooded race. In other words repeated crossing with the non-hooded (wild) race had caused the changes in the hooded character, which had been secured by selection, altogether to disappear. . . . Accordingly we are led to conclude that unit-characters or genes are remarkably constant and that when they seem to change as the result of hybridization or of selection unattended by hybridization, the changes are rather in the total complex of factors concerned in heredity than in single genes."

In a mutating race, however, such as Drosophila, changes in genes surely do occur, as has been proved by the work of Morgan and his collaborators. We do not know what causes changes in genes, but we can demonstrate that they do occur. Sclection cannot bring about any change in single genes, 'ut can only' result in isolating certain sets of genes in a single pure line. This once done, selection ceases to be effective in altering the character of the stock under selection.

"The substance of our present knowledge as to changes in genes," concludes Castle, "may be summed up in the statement that such changes come or go suddenly in their entirety, and cannot, so far as we know, be influenced by selection or any other controllable process. Hence we may call changes in genes mutations." 


\section{CHAPTER XXVII}

\section{MENDEL'S LAWS OF HEREDITY}

J. ARTHUR THOMSON

\section{MENDEL'S LIFE AND CHARACTER}

Gregor Johann Mendel was born in I822, the son of well-to-do peasants in Austrian Silesia. He became a priest in 1847 , and studied physics and natural science at Vienna from I85I to I853. Thence he returned to his cloister and became a teacher in the Realschule at Brünn. It was his hobby to make hybridisation experiments with peas and other plants in the garden of the monastery, of which he eventually became abbot. Apart from two papers, one dealing with peas and a shorter one with hawkweeds, and some meteorological observations, he does not seem to have published much. But what he did publish, if small in quantity, was large in quality. He died in I884.

\section{MENDEL'S DISCOVERIES}

In I866 Gregor Johann Mendel, Abbot of Brünn, published what some regard as one of the greatest of biological discoveries. After many years of patient experimenting, chiefly with the edible pea, he reached a very important conclusion in regard to the inbreeding of hybrids, which is often briefly referred to as "Mendel's Law." His publication was practically buried in the Proceedings of the Natural History Society of Brünn; those who knew of it, as Nägeli for instance did, failed to realise its importance: in fact, Mendel's epoch-making work was lost sight of amid the enthusiasm and controversy which the promulgation of Darwinism (I858) had evoked. Mendel's Law seems to have been rediscovered independently in I900 by the botanists, De Vries, Correns, and Tschermak; and to Mr. Bateson we owe much, not only for his recognition of the far-reaching importance of the abbot's work, but also for a notable series of experiments in which he has confirmed and extended it.

"From J. Arthur Thomson, Heredity (copyright 1907). Used by special permission of the publishers, John Murray, London. 
Mendel's experiments. - What Mendel sought to discover was the law of inheritance in hybrid varieties, and he selected for experiment the edible pea (Pisum sativum). The trial plants, he says, must possess constant differentiating characters, and must admit of easy artificial pollination; the hybrids of the plants must be readily fertile, and readily protectable from the influence of foreign pollen. These conditions were afforded by peas, and twenty-two varieties or subspecies of pea were selected, which remained constant during the eight years of the experiments. Whether they were called species, or subspecies, or varieties, is a matter of convenience; the names Pisum quadratum, $P$. saccharatum, $P$. umbellatum, etc., do in any case represent groups of similar individuals which breed true inter se. It should be noted that these peas have the particular advantage, for experimental purposes, that they are habitually self-fertilised-in North Europe, at least.

In studying the different forms of peas, Mendel found that there were seven differentiating characters which could be relied on:

I. The form of the ripe seeds, whether roundish, with shallow wrinkles or none, or angular and deeply wrinkled:

2. The colour of the reserve material in the cotyledons-pale yellow, bright yellow, orange, or green;

3. The colour of the seed-coats, whether white, as in most peas with white flowers, or grey, grey-brown, leather brown, with or without violet spots, and so on;

4. The form of the ripe pods, whether simply inflated, or constricted, or wrinkled;

5. The colour of the unripe pods, whether light or dark green, or vividly yellow, this colour being correlated with that of stalk, leafveins, and blossoms;

6. The position of the flowers, whether axial or terminal; and

7. The length of the stem, whether tall or dwarfish.

Mendel's results; the Law of Dominance.-Having defined the differentiating characteristics of the varieties, Mendel proceeded to make crosses between these, investigating one character at a time. Thus, pollen from a pea of the round-seeded variety was transferred to the stigma of a pea of the angular-seeded variety, the stamens of the artificially pollinated flower being, of course, removed before they were ripe. The same was done all along the line.

What was the result in the hybrid or cross-bred offspring? It was found that they showed one of each pair of contrasted characters, to 


\section{READINGS IN EVOLUTION, GENETICS, AND EUGENICS}

the total, or almost total, exclusion of the other. No intermediate forms appeared.

Mendel called the character that prevailed dominant, and the character that was suppressed, or apparently suppressed, recessive. And the first big result was that crosses between a plant with the dominant character and a plant with the recessive character yielded offspring all resembling the dominant parent as regards the character in question. Let us for shortness call the parents $\mathrm{D}$ and $\mathrm{R}$, and the first result may be expressed thus: $\mathrm{D} \times \mathrm{R}=\mathrm{D}$.

It must be carefully noted that the complete dominance which Mendel observed has been shown in other cases to be the exception rather than the rule. Thus a cross between a "Chinese" primula with wavy crenated petals and a "star" primula with flat simply notched petals is intermediate between the two parents; and yet, as the next generation shows, the case is one of Mendelian inheritance.

In many cases the hybrid, while on the whole dominant, may show some influence of the recessive character but not nearly enough to warrant us in speaking of a blend. Thus, when white (dominant) Leghorn poultry are crossed with brown (recessive) Leghorn, most of the offspring have some "ticks" of colour. When these are inlored they produce a quarter brown (extracted recessives) and threequarters pure white or white with a few ticks. The dominance is not quite perfect.

The Law of Splitting or Segregation.-In the next generation the cross-bred plants (products of $\mathrm{D}$ and $\mathrm{R}$, or $\mathrm{R}$ and $\mathrm{D}$, but all apparently like D) were allowed to fertilise themselves, with the result that their offspring exhibited the two original forms, on the average three dominants to one recessive. Out of $\mathrm{I}, 064$ plants, 787 were tall, 277 were dwarfs.

When these recessive dwarfs were allowed to fertilise themselves they gave rise to recessives only, for any number of generations. The recessive character bred true.

When the dominants, on the other hand, were allowed to fertilise themsclves, one-third of them produced "pure" dominants, which in subsequent generations gave rise to dominants only; and two-thirds of them produced once again the characteristic mixture of dominants and recessives in the proportion of $3: \mathrm{I}$.

The general results may be expressed in the scheme. The result of the hybridisation is a generation $\left(F_{x}\right)$ like the dominant parent. They may be represented by the symbol $D(R)$, for they 


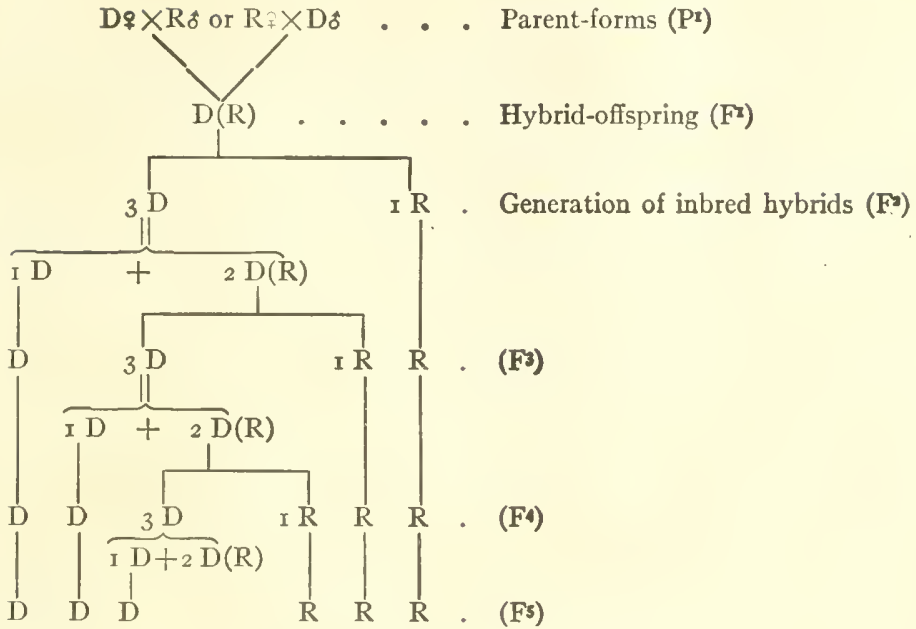

carry with them the possibility of having offspring with the recessive character; that is to say, the recessive character remains latent in the inheritance.

When these $D(R)$ s are inbred (self-fertilised, in the case of peas) they have offspring $\left(\mathrm{F}_{2}\right)$, some of which resemble the recessive parent, while others resemble the dominant parent, and these occur in the proportion of $\mathrm{x}: 3$. When those resembling the recessive parent are inbred, they breed true-i.e., they give rise to a line of pure recessives. Those resembling the dominant parent are all apparently alike, but their subsequent history shows that they may be divided into a set which breed true to the dominant type and a set which behave like the first generation of hybrids-i.e., they go on splitting up into dominantlike forms and pure recessives. These two sets occur in the proportions of $\mathrm{I}: 2$.

A case of peas.-Let us consider a concrete case. Peas with rounded seeds were crossed with peas having angular wrinkled seeds. In the offspring the character of roundness was dominant; the angular wrinkled character had disappeared or receded. It was not lost, as the next generation showed.

The hybrid offspring, all with rounded seeds, were allowed to selffertilise. In their progeny roundish seeds and angular wrinkled seeds occurred in the proportions of $3: 1$. Here were the recessives again, and when they were allowed to self-fertilise they produced pure recessives only, with angular wrinkled seeds. 


\section{READINGS IN EVOLUTION, GENETICS, AND EUGENICS}

The dominants, however, were not all pure dominants, for when they were allowed to self-fertilise they produced one-third pure dominants and two-thirds "impure" dominants, the latter being distinguished by the fact that in their offspring recessives reappeared in the proportion of one recessive to three dominants.

The outstanding facts, taking the case of yellow-seeded and greenseeded peas, may be thus summarised:-
Parental
Generation $\left(\mathrm{PI}_{\mathrm{I}}\right)$
First Filial (hybrid)
Generation (FI)
Yellow-seeded "pure" plant (dominant)
Green-seeded "pure" plant (recessive)
All the offspring were yellow-seeded
Self-fertilised they yielded

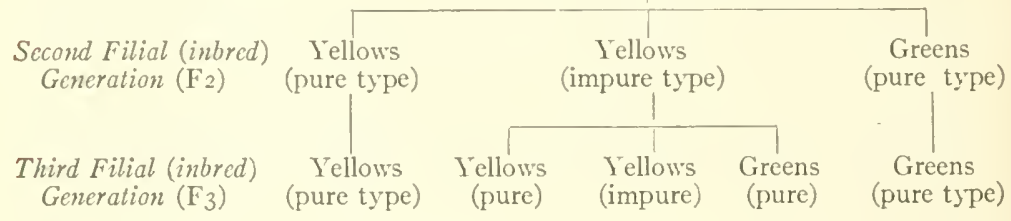

Thus intercrossing of forms with contrasted characters results not in transitional blends, but in the dominance of one character and the recession of another. Self-fertilisation (the extreme of inbreeding) of the hybrids results in a number of pure recessives and a number of dominants in the proportion $\mathrm{I}: 3$; some of these dominants (one-third) are pure, and produce only dominants; some (two-thirds) are apparently pure, but produce dominants and recessives in the old proportion, $3: \mathrm{I}$.

A case of mice.-Let us take a concrete case from among animals. A grey house-mouse is crossed with a white mouse; the offspring are all grey. Greyness is dominant; albinism is recessive.

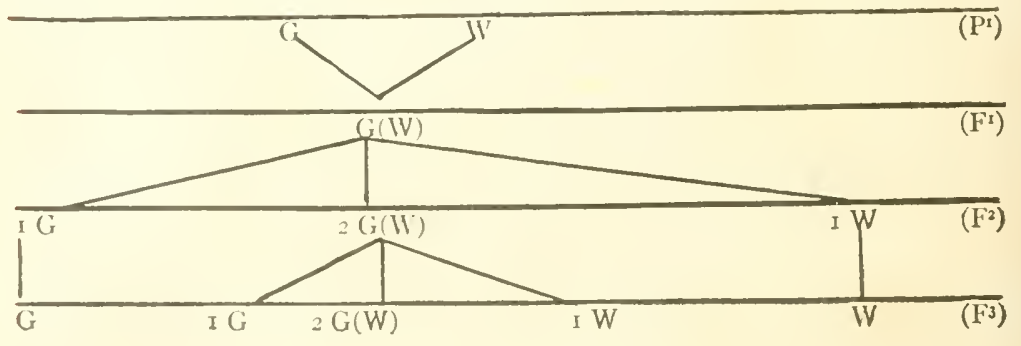


The grey hybrids are inbred; their offspring are grey and white in the proportion 3:I. If these whites are inbred they show themselves "pure," for they produce whites only for subsequent generations. But when the greys are inbred they show themselves of two kinds, for one-third of them produce only greys, which go on producing greys; while the other two-thirds, apparently the same, produce both greys and whites. And so it goes on.

Summary. - In his exceedingly clear exposition of Mendelism (I905) Mr. R. C. Punnett states the result thus: "Wherever there occurs a pair of differentiating characters of which one is dominant to the other, three possibilities exist: there are recessives which always breed true to the recessive character; there are dominants which breed true to the dominant character, and are therefore pure; and thirdly, there are dominants which may be called impure, and which on self-fertilisation (or in-breeding, where the sexes are separate) give both dominant and recessive forms in the fixed proportion of three of the former to one of the latter."

Schematic representation of Mendel's Law.-Following Mr. Punnett's suggestion, with slight modifications, we may use the symbols $\mathrm{P}_{1}, \mathrm{P}_{2}, \mathrm{P}_{3}$ for the parental, grandparental, and great-grandparental generations; $F_{I}$ for the first filial (hybrid) generations, $F_{2}, F_{3} . F_{4}$ for the subsquent inbred ge erations. The symbol $D(R)$ means a dominant with the recessive character unexpressed, but potentially present; DD or RR means pure "extracted" dominants or recessives-i.e., those pure forms which are sifted out from the inbreeding of "impure" dominants.

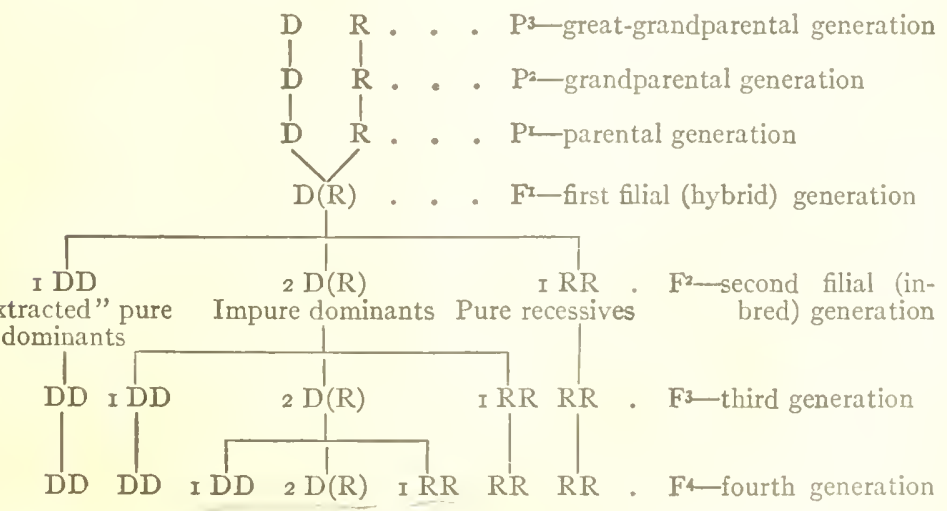




\author{
MENDEI'S EXPLANATIONS \\ JOHN I. COLLTER AND MERLE C. COLLTER
}

Iendel's explanation of this behavior involved three theses which at that time were new to biology. These theses must be kept distinct from one another.

I. Independent unit characters.-This means that an organism, although representing a morphological and physiological unity, from the standpoint of heredity is a complex of a large number of independent heritable units. Thus if one pea plant is tall and another one is dwarf the behavior of the hybrid produced from them with reference to this character will be the same, no matter what other characters the parent plants may have had. In other words, the characters are independent units, unaffected by other characters or units. The character of tallness from a tall plant with wrinkled seeds or purple flowers will act just the same as from a tall plant with smooth seeds or white flowers. Tallness is a unit and its behavior in inheritance is independent of all other units.

2. Dominance.-In the germ plasm there are certain determiners of unit characters which dominate during the development of the body, causing these characters to dominate over others and thus become visible. The characters dominated over and thus not allowed to express themselves are called recessize characters. These recessive characters are present in the germ plasm, but cannot express themselves and become visible as long as the dominant characters are present. When a dominant character is absent, however, its recessive alternate is free to express itself and become visible.

For example, in the case of tall and dwarf peas, tallness is a dominant character and dwariness is its alternative recessive. When a dwarf appears, therefore, there is present no dominant tallness to suppress it. In the $\mathrm{F}_{\mathrm{I}}$ generation all the individuals were tall because, although they had all received the recessive character of dwarfness from one of the parents, they had receired the dominant character of tallness from the other parent, and so dwariness did not appear in any of them. Such pairs of alternative characters are now commonly called allelomor phs. Thus tallness and dwarfness are allelomorphs in the pea, one dominant over the other, which is therefore recessive.

3. Purity of gametes. - A gamete can contain only one of two alternative characters. For example, it may contain the character

${ }^{x}$ From Coulter and Coulter, Plant Genetics (The University of Chicago Press copyright I918). 
for tallness or for dwarfness, but not both. In other words, allelomorphs cannot be represented in the same gamete. If the gamete having the character for tallness unites with one having the character for dwarfness, the resulting zygote will contain both, but will produce a tall individual because tallness is dominant over dwarfness. When this tall hybrid produces gametes, however, one-half of them will contain the character for dwarfness. Thus the alternative characters are "segregated" in gamete formation and no gamete will have both characters.

These three theses, independent unit characters, dominance, and purity of gametes (better called segregation), make up the theoretical explanation of Mendel's law. Independent unit characters was of course a necessary conception. It was original with Mendel, and has also been original with other investigators, but this conception does not represent the essential feature of Mendel's law. The idea of dominance had been somewhat vaguely proposed before Mendel's time. In the old literature on animal breeding one meets theories of prepotency, which were proposed again and again before the discovery of Mendel's work in Igoo. In any event Mendel was the first to formulate definitely the theory of dominance among unit characters. It should be realized also that dominance is not an essential feature of Mendel's theory. Many c ses are known in which dominance fails, but in other regards the Mendelian inheritance is strictly followed.

The essential feature of Mendel's theory is his conception of the purity of gametes, brought about by the segregation of alternative characters. The striking fact is that this conception, purely theoretical with Mendel, has since been confirmed by cytology. In the rnechanism of cell division each chromosome is divided into two equal parts and each daughter-cell receives one of these parts. It is a reasonable inference that chromosomes are bearers of hereditary characters. In the production of gamet es the number of chromosomes, characteristic of the organism is reduced one-half. As a consequence each gamete carries only one-half the characters of the individual that produced it. An application of these statements to an explanation of Mendel's 3: I ratio will illustrate the situation.

For convenience we will assume that the nuclei of Mendel's peas have four chromosomes each (Fig. 67). In the case of a tall plant two of the four chromosomes carry the character for tallness, that is, some thing that determines the prorluction of the tall character in the somatoplasm, which is practically the body builder. This unknown 
something is called by various names in the literature of genetics, the commonest one being determiner. In our illustration, therefore, two of the four chromosomes carry the determiner for tallness. At this point two questions may be asked.

I. Why do just two of the four chromosomes carry the determiner for tallness rather than all of them or only one of them? Just here it would be difficult to explain why no more than two of the four chromosomes are represented as carrying the same determiner. This will be explained later. It is easy to answer, however, why the determiner is being carried by more than one chromosome. When gametes are formed the chromosome number is reduced one-half. Since every gamete from a pure tall plant carries the determiner for tallness there

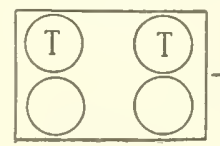

Tall Parent

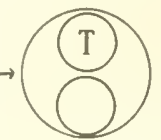

Gametes

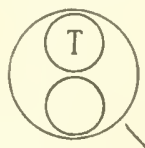

(1)

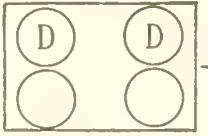

Dwarf Parent

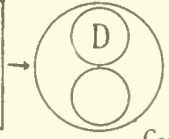

Cametes

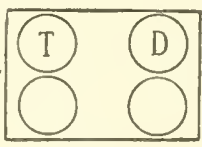

F, Hybrid

FIG. 67.-Diagram illustrating behavior of chromosomes in Mendel's crnss of tall and dwarf peas. Large rectangular figures, nuclei of zygotes or mature individuals; large circles, gametes; small circles within zygotes and gametes, chromosomes; letters on chromosomes, determiners ( $T$, tallness; $D$, dwarfness). (From Coulter and Coulter.)

must have been at least two chromosomes carrying the determiner before the gametes were formed.

2. Do these two chromosomes carry any other determiner than that for tallness? In a tentative way this question may be answered in the affirmative, but a fuller discussion of the situation must be deferred. There is much experimental evidence that indicates that more than one determiner is carried on a single chromosome. In some cases also there are more Mendelian determiners than there are chromosomes.

The situation is represented in Fig. 67. This shows a somatic cell with the cliploid or $2 x$ number of chromosomes. In the formation of gametes this number is reduced to the haploid, or $x$ number, which in this case is two. The diagram shows that the reduction separates 
(segregates) the two chromosomes carrying the character for tallness, so that each gamete contains one. This occurs for the other characters as well as for that of tallness. From the tall plant, therefore, all the gametes will contain the character for tallness, and from a dwarf plant all of the gametes would contain the character for dwarfness. When these two individuals are crossed the zygote will contain both characters, and these two characters will be transmitted together in the succeeding cell generations. The individual from such a zygote of course would be tall, but at the same time it would be carrying a recessive determiner for dwarfness, and this fact would be shown by

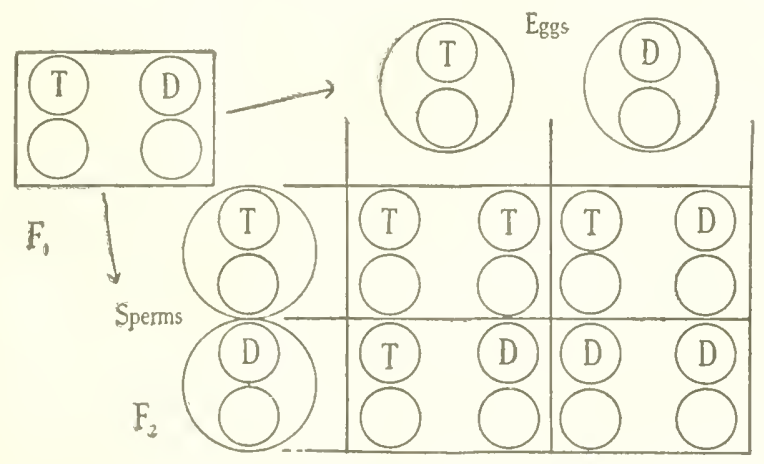

FIG. 68.-Diagram illustrating behavior of first hybrid generation $\left(F_{1}\right)$ when inbred. Illustrates meaning of "segregation" and "purity of gametes" and how chance matings of $F_{I}$ gametes result in $3: \mathrm{I}$ ratio in $F_{z}$ generation; dwarf individual produced only by zygote in lower right-hand corner. (From Coulter and Coulter.)

its behavior in breeding. The result of inbreeding such hybrids is indicated in the accompanying diagram (Fig. 68), which represents the chance matings of two kinds of gametes. The obrious results are three tall individuals and one dwarf. This is the so-called monohybrit ratio, which means the ratio when a single pair of allelomorphs is considered.

Before discussing the further development of Mendel's law it will be necessary to explain some of the terminology of genetics. When each gamete carries the same kind of determiner the zygote is sairl to receive a double dose; when a zygote receives only a single such determiner it is said to receive a single dose. In Fig. 68 one zygote receives a double dose of tallness and two others a single dose. These phrases are more or less common in the literature of the subject, but the more 


\section{READINGS IN EVOLUTION, GENETICS, AND EUGENICS}

frequent terminology is as follows. When two similar gametes-unite to form a zygote it is called a homozigete; when the two pairing gametes are different the zygote is called a heterozygote. Using this terminology it is evident that the $3: 1$ ratio of the $F_{2}$ generation is really a $I: 2:$ I ratio, as follows: I homozygote for the dominant character, 2 heterozygotes, and I homozygote for the recessive character. The $\mathrm{I}: 2:$ I ratio therefore is the significant one and appears as a 3: I ratio only because of dominance.

In the experiment represented in Fig. 68 three tall individuals appear in the $\mathrm{F}_{2}$ generation. Superficially the individuals look alike, but it is realized that I differs from the other 2 in germinal constitution, for I will produce only one kind of gamete, while the other 2 will produce two kinds. To indicate this situation Johannsen has introluced some appropriate terminology. Organisms which seem to be alike, regardless of their germinal constitution, are said to be phenotypically alike, or to belong to the same phenotype. On the other hand, organisms having identical germinal constitution are said to be genotypically alike, or to belong to the same genotype. From the standpoint of phenotypes only, Mendel's $F_{2}$ generation shows the 3: I ratio; but if genotypes are considered, it shows the I: $2:$ I ratio. In other words, this group of forms contains two phenotypes but three genotypes.

Referring again to Fig. 68 several things may be inferred. It can be seen what will happen in the $\mathrm{F}_{3}$ generation when the $\mathrm{F}_{2}$ individuals are inbred. The dominant homozygote will produce only dominant homozygotes in the $\mathrm{F}_{3}$ generation and will continue to produce them as long as it is inbred. The two heterozygotes will split up in the $\mathrm{F}_{3}$ generation in the same $\mathrm{I}: 2$ : I ratio as did their hybrid parents of the $F_{x}$ generation. The recessive homozygote will produce only recessive homozygotes as long as it is kept pure by being inbrerl.

It is interesting to consider what will happen if a heterozygote form is crossed with a homozygous recessive. It should be obvious that one-half of the progeny would be pure recessives, while the other inalf would be heterozygotes, that is, there would be a I : I ratio. A similar result would be obtained by crossing a heterozygote with a dominant homozygote, although all the immediate progeny would show the dominant character. The real situation would be revealed, however, when this progeny was inbred, for one-half would be homozygous (pure breeders) and the other half would be heterozygous (hybrid breeders). 
Thus far we have considered only what is called the monohybrid ratio, that is, the ratio obtained from one pair of contrasting characters, such as tallness and dwarfness. The next step is to consider the dihybrid ratio. Mendel also used contrasting seed characters, finding, for example, that smoothness in seeds is dominant to a wrinkled condition. Introducing this pair of contrasting characters into the situation we have been considering, the dihybrid ratio will be the result. Crossing a tall, smooth-seeded individual with a dwarf wrinkled-seeded individual it is evident that all of the $F_{x}$ or first hybrid generation will be tall, smooth-seeded individuals, since both of these characters are dominant. In the $\mathrm{F}_{2}$ generation, however, the following ratio will appear: 9 tall smooth, 3 dwarf smooth, 3 tall wrinkled, I dwarf wrinkled; which is a $9: 3: 3:$ I ratio. This is the dihybrid ratio, the explanation of which may be indicated in Fig. 69. The question may be raised why the characters for tallness and smoothness are not represented on the same chromosome. If they were, the result would be a simple monohybrid ratio, except that the tall individuals would always be smooth-seeded as well, and dwarfs would be always wrinkled-seeded. The possibility of one chromosome carrying two different determiners will be considered later, but at present we shall assume that these determiners are on different chromosomes.

Fig. 69 shows that we are dealing with two homozygotes, each producing only one kind of gamete, so that all the hybrid progeny will be similar, both genotypically and phenotypically, that is, with the same germinal constitution and the same appearance. By inbreeding these $F_{I}$ individuals, it will be seen that four kinds of gametes are involved. Crossing these four kinds of gametes the resulting combinations are indicated in Fig. 69. The result is four phenotypes, as follows: Nos. I, 2, 3, 4, 5, 7, 9, I0, 13 are tall smooth individuals; Nos. II, I2, I5 are dwarf smooth; Nos. 6, 8, I4 are tall wrinkled; No. I6 is dwarf wrinkled. This is the $9: 3: 3: 1$ ratio.

It will be noticed that Nos. I, 6, I I, I6 are homozygotes and therefore will breed true; but the rest are heterozygotes, either for one pair of characters or for both, and these would split into various types upon further breeding.

The next step is the trihybrid ratio. Mendel found yellow seeds dominant over green seeds, and if this pair of characters is included with those used above the trihybrid result can be observed. The experiment would consist in crossing tall, smooth, yellow individuals with dwarf, wrinkled, green individuals; and it is obvious that the 
hybrid progeny would all be tall, smooth, yellow, since these three characters are dominant. Inbreeding the hybrids gives the following result in the $\mathrm{F}_{2}$ generation: 27 tall smooth yellow, 9 tall smooth green,
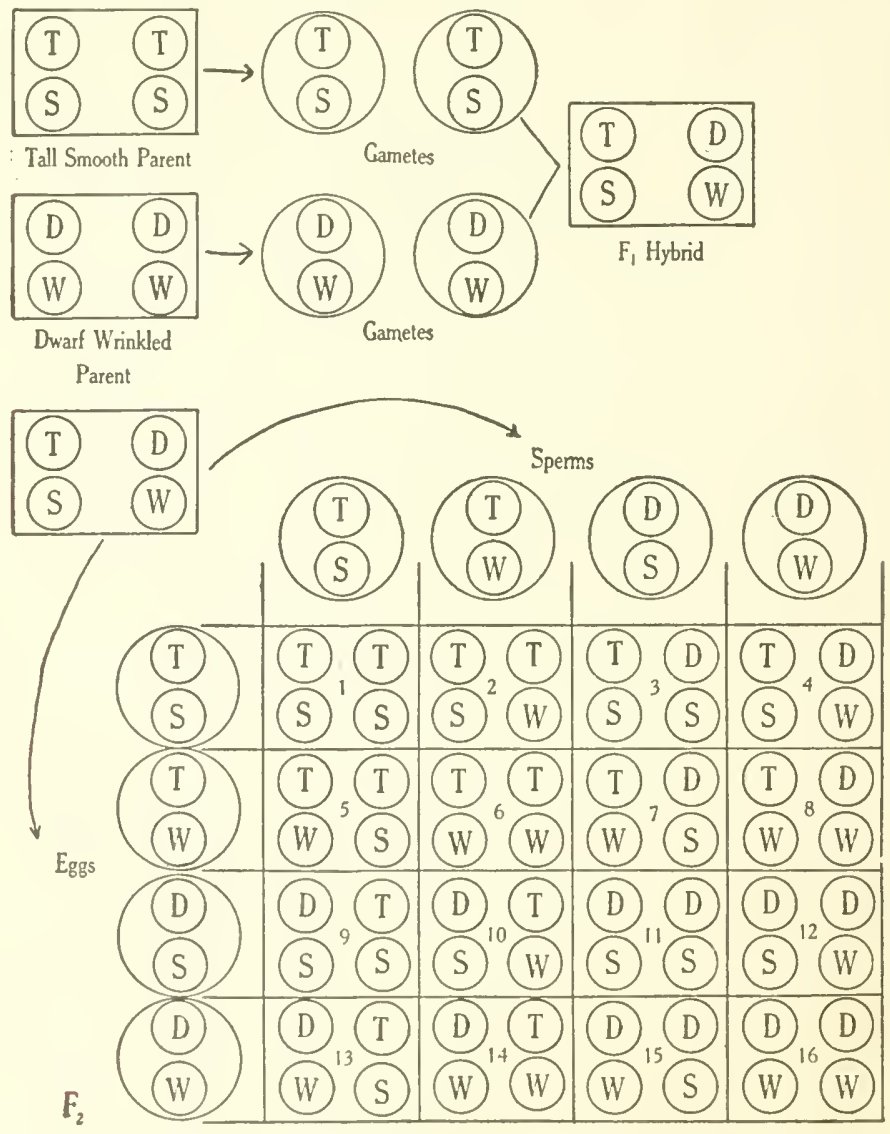

Fig. 69.-Diagram illustrating dihybrid ratio. Upper part shows how original parents were crossed to give $F_{I}$ hybrid; lower part shows $F_{I}$ hybrid producing four kinds of gametes; chance matings among these gametes, when $F_{\mathrm{x}}$ is inbred, result as indicated in the large set of squares and explains the $9: 3: 3: 1$ ratio in the $\mathrm{F}_{2}$ generation. (From Coulter and Coulter.)

9 tall wrinkled yellow, 9 dwarf smooth yellow, 3 tall wrinkled green, 3 dwarf smooth green, 3 dwarf wrinkled yellow, I dwarf wrinkled green. The trihybrid ratio therefore is $27: 9: 9: 9: 3: 3: 3: 1$. This involves 64 individuals and 8 phenotypes. 
ILLUSTRATIONS OF SIMPLE MENDELIAN INIERITANCE IN BOTH ANIMALS AND PLANTS ${ }^{T}$

\section{J. ARTHUR THOMSON}

How far has Mendel's experience been confirmed?-There has been confirmatory work by Correns (on peas, maize, and garclenstock), by Tschermak (on peas), by De Vries (on maize, etc.), by Bateson and his collaborators (on a large variety of organisms), by Darbishire (on mice), by Hurst (on rabbits), by Toyama (on silkmoths), by Davenport (on poultry), and so on. There are some difficulties and not a few cliscrepancies, but, as Bateson says, "the truth of the law enunciated by Mendel is now established for a large number of cases of most dissimilar characters."

In experimenting with Lychnis, Atropa, and Datura, Bateson and Saunders found that the phenomena conformed with Mendel's law "with considerable accuracy, and no exceptions that do not appear to be merely fortuitous were discovered. In the case of Matthiola (garden-stock), the phenomena are much more complex. There are simple cases which follow Mendelian principles, but others of various kinds which apparently do not. The latter cases fall into fairly definite groups, but their nature is obscure."

In experiments with poultry, the phenomena of dominance and recession were detected; interbreeding of the hybrid offspring resulted in a mixed progeny, "some presenting the dominant, others the recessive character, in proportions following Mendel's Law with fair consistency, though in certain cases disturbing factors are to be suspecterl."

The general result, so far, is that Mendel's law has received confirmation in a number of very dissimilar cases.

Dominant and recessive characters. - Let us first of all collect a number of instances of contrasterl characters which behave in relation to one another as dominants and recessives.

\begin{tabular}{|c|c|c|}
\hline \multirow{6}{*}{ Pisum sativum. } & Dominant & Recessive \\
\hline & Tallness & Dwarfness \\
\hline & Round seerls & Wrinkled seeds \\
\hline & Coloured seed-coats & White sced-coats \\
\hline & $\begin{array}{l}\text { Yellow albumen in coty- } \\
\text { ledons }\end{array}$ & $\begin{array}{l}\text { Green albumen in coty- } \\
\text { ledons }\end{array}$ \\
\hline & Purple flowers & White flowers \\
\hline Sweet pea... & Tall ordinary form & $\begin{array}{l}\text { Dwarf or "cupid" vari- } \\
\text { ety }\end{array}$ \\
\hline
\end{tabular}

${ }^{1}$ From J. Arthur Thomson, Heredity (copyright 1907). Used by special permission of the publisher, John Murray, London. 


\section{READINGS IN EVOLUTION, GENETICS, AND EUGENICS}

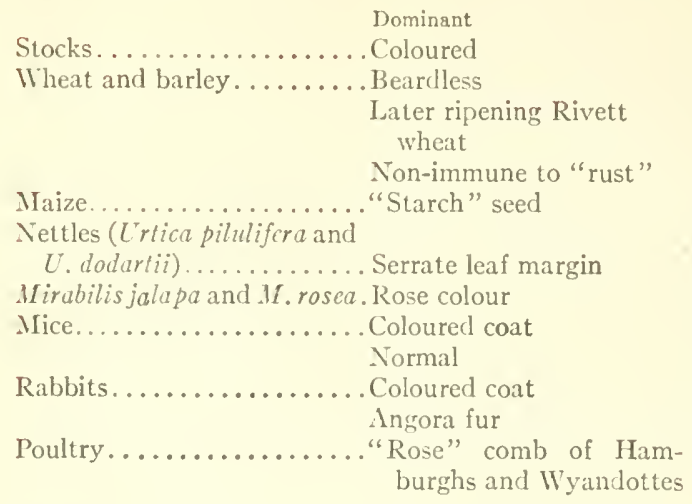

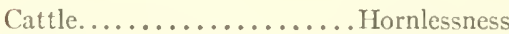

Snails................ Bandless shell
Recessive

White

Bearded

Early ripening Polish wheat

Immune to "rust"

"Sugar" sced

Entire leaf margin

Other colours

Albino coat

"Waltzing" variety

Albino coat

Short fur

High serrated "single" comb of Leghorns and Andalusians

Horns

Banded shell

Other instances in plants. - As is well known, there are two almost equally common forms of wild primrose: (A) thrum-types, with short styles and with anthers at the top of the corolla-tube; and (B) pin-types, with long styles and with anthers half way down the tube. The thrum-type is dominant over the pin-type.

The original species of Chinese primrose (Primula sinensis) has a palmate leaf. About i 860 a sport arose (from seed) which had a pinnate or "fern" leaf. The palmate form is dominant, and the fern leaf is recessive.

The deformed "Snapdragon" variety of sweet pea behaves as a recessive to the normal type.

The 2-row larley has certain lateral flowers which are exclusively staminate; in 6-row barley all the flowers are staminate and pistillate, and all set seed. Mr. Biffen crossed these forms, and found that the more negative character was dominant. The offspring were 2-rowed.

Maize.-When the common or starchy round-seeded maize is crossed with the wrinkled-seeded sugar-maize, the round starchy character dominates. When an egg-cell of the wrinkled sugar-maize stock is fertilised by a pollen-cell of the round starchy stock, the result is a round seed with starchy endosperm. If this seed is sown, it becomes a plant which, on self-fertilisation, forms a cob with a mixture of round starchy and wrinkled sugary seeds in the ratio $3: 1$. The wrinkled seeds yield sugar-maize; the round seeds vield two "impure rounils" to one "pure round.." Correns has observed a very interesting case in which two pairs of contrasted characters are implicated. 
One variety, Zea mays alba, which has smooth white seeds, was crossed with another variety, Zea mays cocruleodulcis, which has wrinkled blue seeds. The hybrids $\left(\mathrm{F}_{\mathrm{r}}\right)$ had smooth blue seeds, one character of each parent being dominant, and one character of each parent being recessive. The hybrids were inbred, and the progeny $\left(\mathrm{F}_{2}\right)$ showerl four combinations-smooth blue, smooth white, wrinkled blue, and wrinkled white (the dominant characters are italicised).

In the next generation $\left(\mathrm{F}_{3}\right)$, the wrinkled white, inbred, yielded wrinkled white-a case of extracted recessives, breeding true. The smooth whites and wrinkled blues, inbred, yielcled partly forms like themselves and partly wrinkled white. The smooth blues, inbred, yielded the same combinations as in $\mathrm{F}_{3}$.

A finer corroboration of Mendelian could hardly be wished.

Nettles.-Correns crossed two "species of stinging-nettle," L'rtica pilulifera $L$. and $U$. dodurtii $L$., which resemble one another except as regards leaf-margin, strongly dentate in the former, almost entire in the latter. The hybricl offspring $\left(\mathrm{F}_{\mathrm{I}}\right)$ have all dentate leaves like the male or the female parent, as the case may be. The dentate character is absolutely dominant. The inbred (self-fertilised) hybrids produce offspring $\left(\mathrm{F}_{2}\right)$ of two kinds, with dentate and with entire margins, on an average in the Mendelian proportion, 3: I.

"Immunity to rust in wheat.--Some kinds of wheat are very susceptible to the fungoid clistase known as 'rust'; others are immune. The quality of immunity to rust is recessive to the quality of predisposition to rust.

"When an immune and a non-immune strain are crossed together the resulting hybrids are all susceptible to 'rust.' On self-fertilisation such hybrids produce seed from which appear dlominant 'rusts' and recessive immune plants in the expected ratio of 3:I. From this simple experiment the phrase 'resistance to disease' has acquired a more precise significance, and the wide fiekl of research here opened up in this connection promises results of the utmost practical as well as theoretical importance. To the question, "Who can bring a clean thing out of an unclean?' we are beginning to find an answer, nor is the answer the same as that once given by Job" ( $R$. C. P'unnett).

Silkworms.-Toyama paired siamese silkmoths with yellow or with white cocoons; the offspring produced only yellow cocoons. When the hylbrids were inbred, the result was two sets, one producing white cocoons, the other producing yellow cocoons, and the proportion was Mendelian-25.037 white and 74.96 yellow. The whites bred 


\section{READINGS IN EVOLUTION, GENETICS, AND EUGENICS}

true; the yellows when inbred showed themselves to be pure dominants or "yellows" and dominant-recessives-i.e., splitting up again into yellows and whites in the usual proportion. More intricate experiments confirmed this general result.

It must be noted, however, that Coutagne has made much more claborate experiments with different results, which in many cases cannot be interpreted on the Mendelian theory. Thus he found (I) that the hybrid forms were sometimes blends of the parents and different from both; (2) that in other cases the brood included some like one parent in a particular character, some like the other parent, and some intermediate; and (3) that in other cases the individuals showed no fusion of characters, but resembled one or other parent. It is likely that the discrepancy may be explained as due to considerable diversity of origin in the domesticated races of silkworm, so that, while they breed true when left to themselves, a disturbance of the usual routine leads to the liberation of latent characters.

Lina lapponica.-Miss McCracken has made a fine study of the hereditary relations in this Californian beetle, which occurs in two types, spotted (dominant) and black (recessive). They are always crossing in natural conditions, but there are no intermediates, and it is easy by isolation to rear a "pure" spotted race and a "pure" black race. When spotted forms are paired they may produce only spotted progeny-a case of extracted dominants. In other cases, however, they yield spotted and black forms (I,02 I spotted, 345 black), i.e., in the Mendelian proportion of $3: \mathrm{I}-\mathrm{a}$ case of dominant-recessives inbred.

Snails.-Lang paired "pure" five-banded forms of the common or garden snail, Helix hortensis, with bandless forms from bandless colonies. The young of the first generation were all bandless, the banded character being recessive. When these were paired the offspring were bandless and banded in the Mendelian ratio, 3: x. Further experiments confirmed this, not only as regards bands, but also as regards colour ( $\mathrm{yellow}$ or red), size, and the form of the umbilicus. It may be said, therefore, that common snails (Itelix hortensis and Helix nemoralis) illustrate Mendclian inheritance.

Poultry.-Numerous breeding experiments with poultry have been made by Bateson, Bateson and Punnett, Hurst, Davenport, and others, many of which show Mendelian phenomena with great clearness, while others are strangely conflicting. One of the reasons for the complicated results is evidently to be found in the difficulty of securing thoroughly "pure" breeds, for many that breed true as long as they 
are inbred tend to liberate latent characters when the ordinary course of breeding is departed from.

Hurst contrasts the following characters, which usually show themselves dominants and recessives; but it has to be admitted that the dominance-always complete for some characters-is for others frequently, or even always incomplete-i.e., showing traces of the corresponding recessives.

Dominant Characters
Rose comb
White plumage
Extra toes
Feathered shanks
Crested head
Brown eggs
Broodiness

Dominant Characters

Rose comb

White plumage

Extra toes

Crested head

Broodiness

\author{
Recessive Characters \\ Leaf comb, single comb \\ Black plumage, butf plumage \\ Normal toes \\ Bare shanks \\ Uncrested head \\ White eggs \\ Non-broodiness
}

Davenport's copiously illustrated work is also of great interest. He shows in case after case that the character dominant in the first hybrids is more or less influenced by the recessive character. Polish fowls with a large hernia of the brain on the top of the head were paired with Minorcas with normal heads. The hybrids showed no hernia, but most of them showed a frontal prominence. When the hybrids were inbred the hernia occurred in 23.5 per cent-a close approximation to the theoretical 25 per cent.

Single-combed black Minorcas were crossed with white-crested black Polish fowls with a very small bifid comb. The hybrids had combs single in front, split behind. When the hybrids were inbred there resulted in a total of IOI offspring, 29.7 per cent with single combs (like Minorcas), 46.5 per cent with $Y$-shaped combs, and 23.8 per cent with no combs or only papillae (like the Polish forms). Here, again, the result is in a general way Mendelian, but the $Y$-like comb is a complication.

Pigeons.-R. Staples-Browne crossed a web-footed pigeon (an occasional discontinuous variation) with a normal form, and got six normal young. In other words, the web-foot character is recessive to the normal foot character. The hybrids were inbred, and in one case produced nine with normal feet and three with webbed-feet-a Mendelian splitting-up. But from another pair of hybrids seventeen normal offspring resulted. Thus, the illustration of Mendelian inheritance is inconclusive. Besides the numbers were too small.

We have noticed elsewhere that crossing different breeds of pigeons often results in forms which more or less resemble the reputed original 


\section{READINGS IN EVOLUTION, GENETICS, AND EUGENICS}

ancestor, the wild rock dove; in other words, reversions occur. Often, however, the results seem quite anomalous, which is probably due to the number of latent characters which different races of pigeons appear to carry.

Mice.-Mendelian phenomena have been carefully studied in mice. Thus, when a grey mouse is paired with an albino, the hybrid offspring are always grey. When these are inbred, they yield greys and albinos, approximately in the proportion of $3: \mathrm{I}$. Thus Cuénot obtained igs grey, and 72 albinos.

Darbishire has obtained many results which harmonise well with Mendelian theory, while others require some ingenuity if they are to be fitted in with this interpretation. As a good case we may cite one where the inbreeding of pigmented mice- derived from crossing pigmented and albino individuals-yielded 159 pigmented young and 55 albinos ( 53.5 being the theoretical anticipation). When similar hybrids were paired with pure albinos, they yielded 69 pigmented and 69 albino forms, precisely as the theory would lead us to expect:

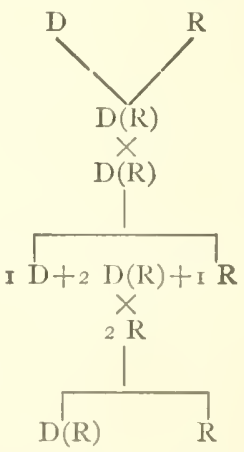

Cuénot crossed an albino $A G$ (with latent grey) with an albino $A B$ (with latent black), and obtained albinos (AGAB). He crossed a black mouse $C B$ with an albino $A Y$ (with latent yellow), and obtained yellow mice $(\mathrm{CBAY})$. He then paired $\mathrm{AGAB}$ (albino) with $\mathrm{CBAY}$ (yellow) and obtained I 5 I young-8I albinos, 34 yellow, 20 black, I6 grey; the theoretical anticipation being -76 albinos, 38 yellow, I9 black, I9 grey. This is an exceedingly striking and convincing case.

Waltzing mice.-The mice of this interesting Japanese breed have among other peculiarities the habit of waltzing round in circles. When waltzing mice are crossed with normal mice, their abnormal quality behaves as a recessive. 
Guinea-pigs.-If a black guinca-pig of pure race be crossed with a white one the offspring will be all black, and if these are mated with each other the recessive white character reappears on the average in one in four of their offspring. These whites mated with each other produce only white offspring, while the black are as usual of two kinds, pure blacks and impure blacks. Similarly, as Professor Castle has shown, a rough coat is dominant over a smooth coat, and a short coat over a long coat.

Rabbits.-Hurst paired white Angora rabbits (with pink eyes and silky hair) with "Belgian hare" rabbits (with pigmented skin, dark eyes, and short yellow fur). The hybrids were pigmented like the "Belgian hares," but the fur was grey like that of the wild rabbit. These hybrids were inbred, and If distinct types resulted-an apparent "epidemic of variation" to which Mendel's theory has supplied the clue, for four pairs of contrasted characters are involved in the hybrid inbreeding-namely, short hair versus long hair, pigmented coat versus albinos, grey versus black coat, uniform versus marked coat (Dutch marking latent in the albinos), and the $\mathrm{I}_{4}$ distinct types illustrate the possible combinations.

As regards short hair versus long hair, Hurst found that when the short-coated hybrids were inbred they produced short-haired forms like the Belgian hare gran 'parent, and long-haired forms like the Angora grandparent. Out of 70 which reached the age of two months or more, 53 were short-haired and $\mathrm{I}_{7}$ long-haired-a close approximation to the Mendelian anticipation, 52.5: I7.5. Similarly, as regards pigmented coat versus albino, the hybrids, when inbred, yielded 132 pignented and 39 albino forms - a close approximation to the Mendelian expectation, I29:43; and so on.

Cats.- There are some interesting results as to colour (Doncaster). Thus, "pure" orange + crossed by "pure" black o gives tortoiseshell females and yellow males, but black crossed by orange gives black males or females, tortoiseshell females, and orange males. It seems that orange usually dominates over black in males, while in females the orange (for some unknown reason) is less dominant and tortoseshell results. Male tortoiseshell cats are very rare. In this case the results are complicated by some peculiarity wrapped up with "sex."

When a male tortoiseshell is paired with a female tortoiseshell the kittens are tortoiseshell, orange, and black-which is what Mendelian theory would lead us to expect.

Man.-Evidence of Mendelian phenomena in man is as yet very scanty. It appears that the condition known as brachydactylism, 
where the fingers are all thumbs with two joints instead of three, is dominant over the normal. In five generations chronicled by Farabee about half of the offspring were of the abnormal type, though the marriages were apparently always with unrelated normal individuals. Moreover, no normal member of the lineage is known to have transmitted the abnormality. Another good case has been recently discussed by Drinkwater.

Of great interest also is Mr. Nettleship's account of the descendants of one Jean Nougaret (born 1637 ), who was afflicted with "nightblindness" - a condition apparently due to loss of visual purple. It seems to behave like a unit character. There are records of over 2,000 individuals; and the night-blindness is dominant over normal eyesight. The notable point is that during two and a half centuries no normal member of the lineage who married another normal, whether related or not, ever transmitted the disease.

Human eye-colour affords another illustration. It is largely determined by the presence or absence of two distinct layers of pigment. In the true blue eye only one of these pigmentary layers is visibly present, the posterior purple pigment of the choroid, which, being reflected through the fibrous structure of the iris, produces the blue colour. In the absence or partial absence of this pigment the eye' appears to be "pink," as in albinos. In the ordinary brown eye two layers of pigment are present, for in addition to the posterior purple layer there is also an anterior brown layer, in front of the iris. Major C.C. Hurst found that the eye with two layers of visible pigment (duplex) is dominant and the eye with one layer of visible pigment (simplex) recessive. Or, putting it in another way, the presence of the brown front layer is dominant to its absence. Practically the same conclusion was reached independently by Professor and Mrs. Davenport.

The Davenports and Major Hurst have also brought forward some evidence illustrating in typical Caucasians the dominance of dark to fair skins, their segregation in the same family, and the apparent purity of the extracted fair individuals. Hurst also gives evidence that "fiery red" hair behaves as a recessive to brown, and that the musical sense or temperament is also recessive. It seems as if an individual is non-musical owing to the presence of an inhibitory factor preventing the expression of musical temperament which is potentially present in everyone (Hurst, I9I2).

It would be interesting to have precise information as to the progeny of Eurasians who intermarry, for here the original hybrids result from the mixture of two very distinct races. 


\section{$\bar{C}$ HAPTER XXVIII}

\section{THE PHYSICAL BASIS OF MENDELISM ${ }^{\mathbb{x}}$}

ERNEST B. BABCOCK AND ROY E. CLAUSEN

Recent investigations in heredity have focused attention upon the chromosome mechanism as the physical basis for the segregation and recombination of the units of Mendelian inheritance. The importance of cytological phenomena to students of genetics is admirably summed up by E. B. Wilson in the brief statement that "heredity is a consequence of the genetic continuity of cells by division, and the germ cells form the vehicle of transmission from one generation to another." It is appropriate, therefore, to introduce the subject of Mendelism with a formal and brief treatment of the chromosome mechanism and its mode of operation, on the one hand, in the building up of the body from the single cell with which the individual begins its existence, and, on the other hand, in the production of germ cells when the individual reaches the reproductive period of its life cycle. It is the purpose of this chapter merely to deal with the fundamental facts of cytology which are necessary to an inderstanding of the connection between cell behavior and Mendelian phenomena. Details unessential to such an understanding, however well established cytologically, will not be dealt with in this treatment to the end that the cardinal points may be presented as simply and as clearly as possible.

The chromosomes. - With few exceptions the number of chromosomes in the cells of any individual is constant and characteristic of the species to which the individual belongs. Thus it is characteristic of Drosophila ampelophila that the cells contain eight chromosomes. In maize the cells contain twenty chromosomes, in wheat sixteen, and in man forty-eight, and so on through the entire plant and animal kingdoms.

Not only is the number of chromosomes in a particular species constant, but the chromosomes themselves possess a definite individuality. Man and tobacco have cells with the same number of chromosomes. It is needless to point out that these chromosomes,

${ }^{2}$ From E. B. Babcock and R. E. Clausen, Genetics in Relation to Agriculture (copyright I9I8). Used by special permission of the publishers, The McGrawHill Book Company. 
however, are qualitatively very different. Similarly within the species the chromosomes are not all alike; on the contrary, especially in certain forms, they exhibit very marked differences in size and shape. This is peculiarly well illustrated in Drosophila as shown in Fig. 70. Here it is possible to recognize in the female two large pairs of curved chromosomes very similar in size and shape. There is also a very small pair of chromosomes, and finally there is a pair of straight ones about two-thirds as long as the large curved chromosomes. In the male the same relations hold except that instead of the pair of straight chromosomes there is a pair consisting of one straight and one somewhat larger hooked chromosome. The significance of this difference in chromosome content in the sexes will be pointed out in a consideration
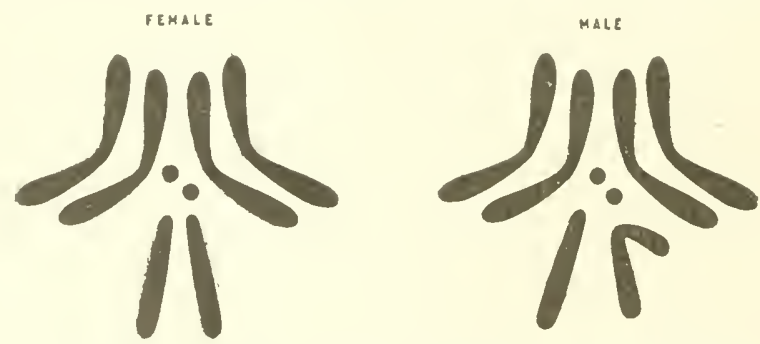

FIG. 70.-Diagram showing the characteristic pairing, size relations, and shapes of the chromosomes of Drosophila ampelophila. In the male an $X$ and a $Y$ chromosome correspond to the $X$ pair of the female. On the basis of $X_{100}$

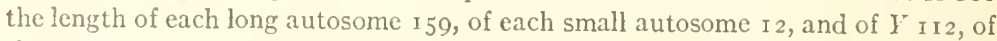
the long arm of $Y_{7} \mathrm{I}$, and of the short arm of $Y_{4}^{r} \mathrm{I}$. (From Babcock and Clausen, after Bridges.)

of the inheritance of sex. The pair of straight chromosomes we call the sex or $\mathrm{X}$-chromosomes, the unequal mate of the $\mathrm{X}$-chromosome in the male of this species is called the $\mathrm{Y}$-chromosome. The other chromosomes are called autosomes when it is desired to distinguish them as a class from the sex chromosomes. Drosophila is not unique in possessing chromosomes of such characteristic shapes and sizes; but more and more as cytology advances it is becoming possible to distinguish chromosomes, and to recognize them at every cell division.

Moreover, the characteristic paired relations which exist among the chromosomes of Drosophila are of general significance. When mature germ cells are formed in an individual, reduction divisions occur by means of which the chromosome number is reduced in the germ cells to one-half that characteristic of the body cells. Thus the 
germ cells of Drosophila contain four chromosomes as the result of a reduction which takes place in such a manner that each germ cell contains one member of each pair of chromosomes. As a consequence, the germ cell of Drosophila contains two large curved autosomes, representing the two pairs of these chromosomes, one small autosome, and one $\mathrm{X}$ - or one $\mathrm{Y}^{\top}$-chromosome. The same thing is true for other species of plants and animals-in the reduction divisions the chromosomes are distributed in such a manner that each germ cell receives one member of each pair of chromosomes. It follows from this that in general a definite number of pairs of chromosomes is characteristic of the body cells of individuals of a given species, and, taking the chromosomes by pairs, one member of each pair is derived from one parent and the other from the other parent.

From the standpoint of interpretation the chromosomes are aggregates of chromatin material which in itself is definitely and highly organized. Our conceptions of this feature of cell organization are based on appearances of the cytological preparations from certain of the more favorable plants and animals and further interpreted by investigations on heredity. Accordingly the entire chromatin content of the nucleus is regarderl as made up of a definite number of individual chromatin elements called chromomeres. The number of chromomeres in a cell of ar species must rum into the thousands. A certain definite group of thase elements make up each chromosome, and at every cell division this chromosome is reformed from the same group of chromomeres, but the chromosome is definitely organized with respect to the position or locus occupied by each chromomere. At certain stages in the history of chromosomes, they are simply lines of chromomeres, very much like single strings of bearls with each bead corresponding to a chromomere. Now it appears probable that all the chromomeres in a chromosome are different, as though our string of beads had no duplicates throughout its length. Noreover, each chromomere has a definite place or locus in the particular chromosome in which it belongs and it is always found at that particular locus. The chromomeres of this discussion are identified with the factors of Mendelian heredity, and how closely this conception of the nature of chromatin and its complex organization corresponds to the modem view of Mendelian phenomena will be pointed out as each new phase of Mendelism is taken up.

Somatic cell division.-The phenomena of cell division (called mitosis) are represented in outline in Fig. $7 \mathrm{I}$, for a species having four 
chromosomes in its body cell. Bearing in mind the description which has just been given of the organization of the chromatin material we may follow the steps involved in mitosis as they are outlined in this figure. In the "resting" cell at $A$ the chromatin is scattered throughout the nucleus in clumps or knots loosely strung together to form an irregular network. As the cell prepares for division the chromatin elements appear in more definite form until at $B$ the chromomeres have
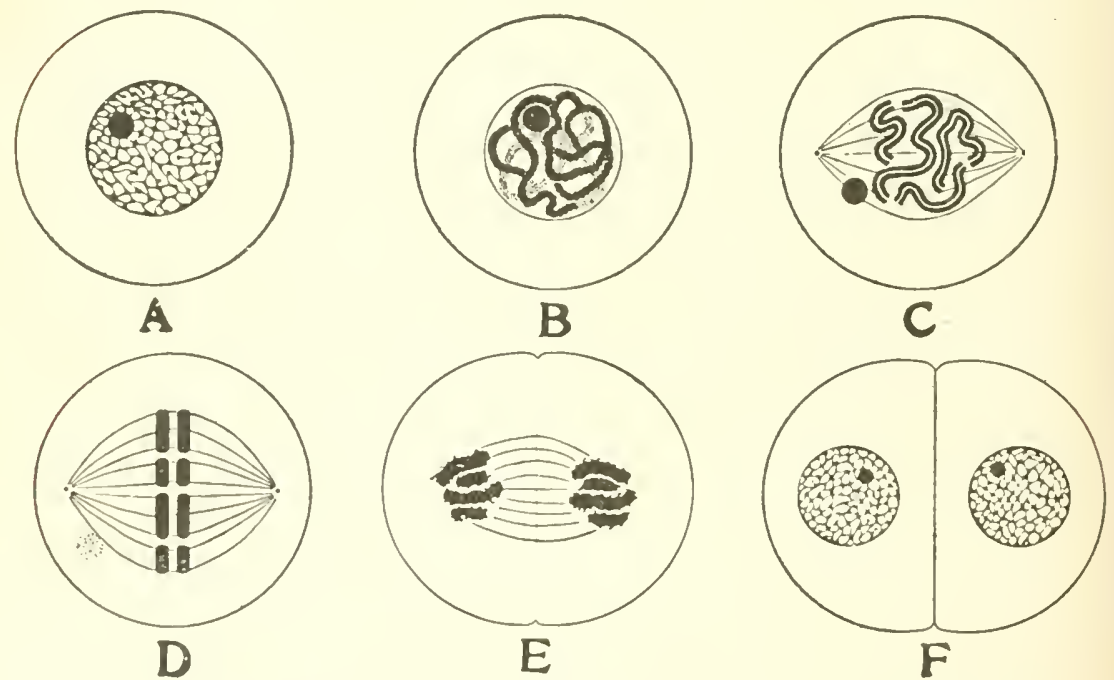

FIG. 7r.-Diagram of mitosis in a species having four chromosomes in its cells. $A$, the "resting" cell; $B$, formation of the spireme thread; $C$, longitudinal division of the spireme thread and transverse segmentation into four chromosomes; $D$, separation of the daughter chromosomes formed by longitudinal splitting of spireme thread; $E$, beginnings of nuclear reconstruction and division of the cell body; $F$, cell division complete and daughter nuclei in the "resting" stage. (From Babcock and Clausen.)

arranged themselves in a single row in a long continuous spiremethread. This spireme-thread may be considered to be made up of the four chromosomes united end to end with the chromomeres arranged in a linear series. As mitosis progresses to the next stage represented at $C$, each chromomere of the spireme-thread divides into two, so that a double spireme-thread results from the longitudinal splitting of the original thread. Both parts of the thread are quantitatively and qualitatively equal, for, by the splitting of all the chromomeres both of the 
threads come to possess all of the individual elements of the original spireme thread. Following the splitting of the chromomeres and the formation of a double spireme, the spireme-thread contracts and segments transversely forming four double chromosomes, the number characteristic of the cells of this indiridual. This is the stage shown at $C$ where also is shown the origin of the spindle, a part of the mechanism in mitosis. The chromosomes now still further contract until they assume their characteristic shapes and sizes. They next appear in an equatorial position on the spindle as shown at $D$, where the two pairs of double chromosomes, one larger and one smaller, are diagrammed and the nucleolus, the large black body of the previous steps, is shown cast out and degenerating. The daughter chromosomes of each pair now separate from each other until at $E$ they have moved nearly to the opposite poles of the spindles and are beginning to fray out and seemingly to lose their identity. At this stage actual division of the cell body has begun. Finally at $F$, the chromosomes have completely lost all appearance of their identity, the chromatin material is distributed thruout the nucleus as in the original cell shown at $A$, and the nucleolus has been reformed in each nucleus. Division of the cell-body has resulted in two daughter cells, each of which, so far as chromomeres are concerned, contains exactly the same chromatin elements as the original cell

There are many variations in this process particularly in the order of occurrence of the steps, but these variations in nowise modify the essential fact of mitosis which is that the chromatin material of the cell is converted into a thread which splits thruout its entire length into two halves so that the daughter nuclei receive exactly equivalent portions of chromatin material. This precise division of the chromatin is brought about by a division of each chromomere so that not only do the daughter nuclei receive equivalent portions of chromatin but these portions are also equivalent qualitatively to the entire chromatin content of the mother cell. By this method then each of the cells of the body finally comes to possess not only the whole number of chromosomes contributed by the two parents, but also the entire set of chromatin elements which it received from them. The extreme care with which the cell mechanism partitions the chromatin material in each successive cell division is in itself eloquent testimony of the fundamental importance of this material.

The production of germ cells.-In the production of germ cells a different set of phenomena occur which result in a reduction of this 


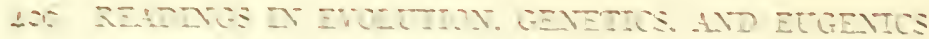

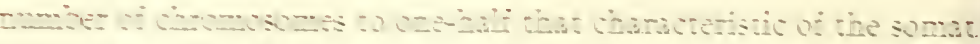

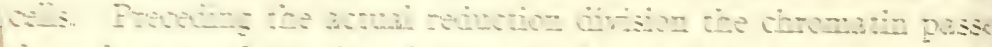

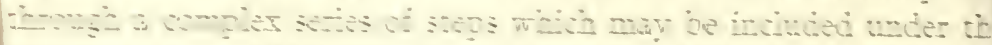

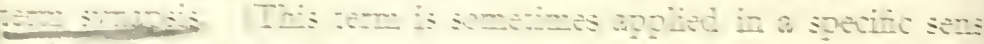

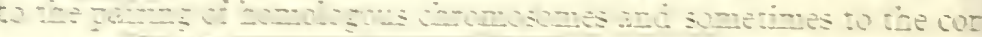

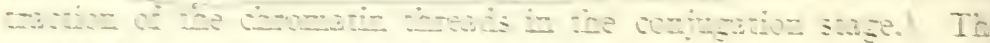
esk

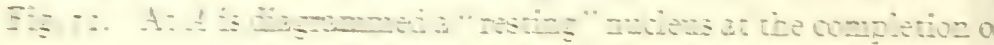
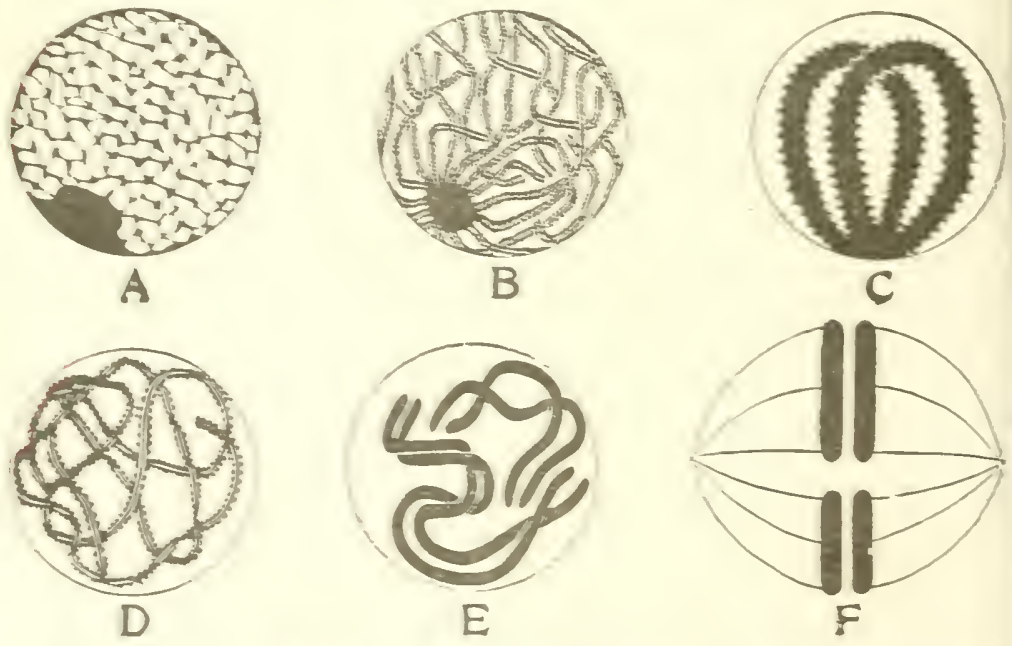

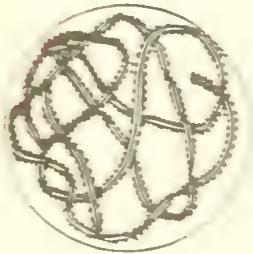

D

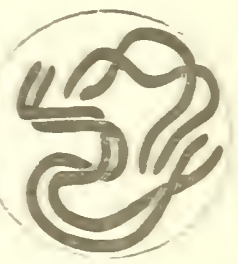

E

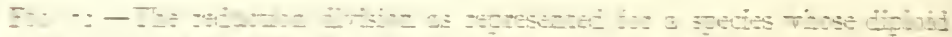

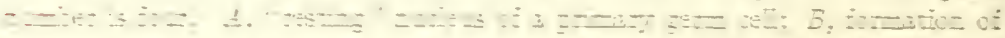
-cu- Y. I-12

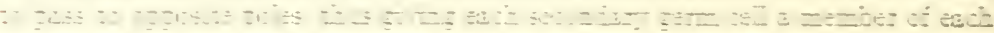

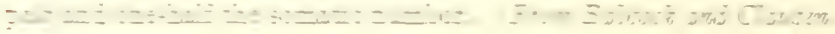

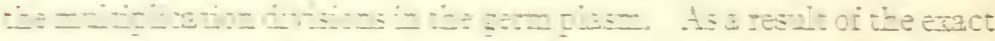

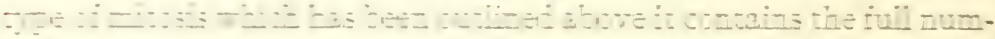
120

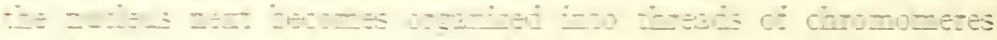

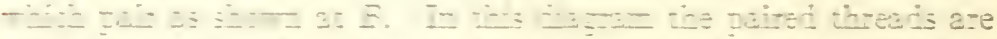

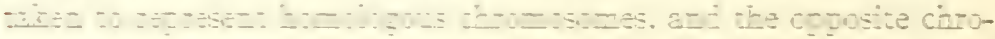

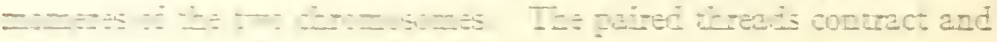




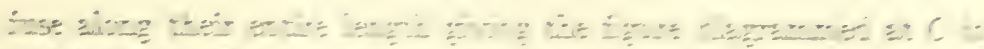

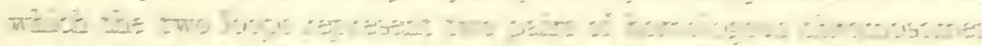

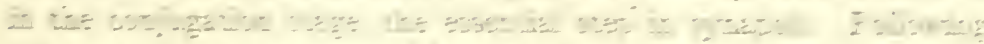

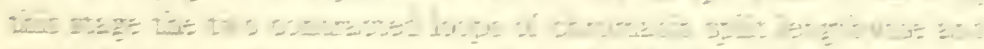

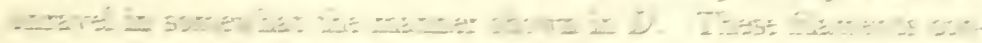

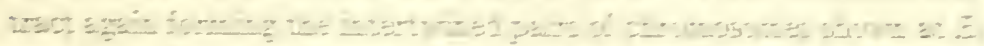

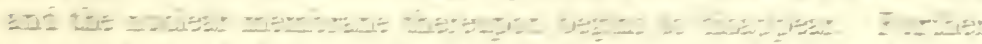
cosms

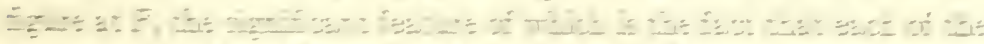
Is э플

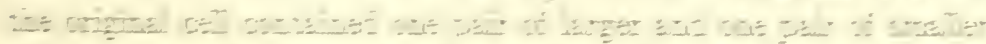

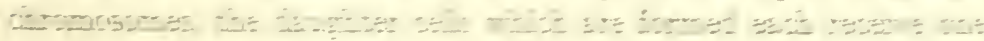

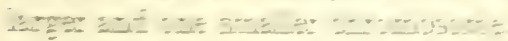

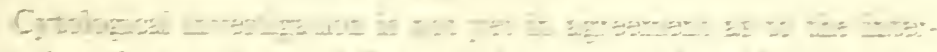
quszind of

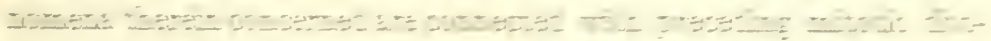

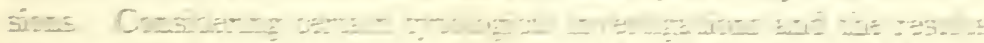

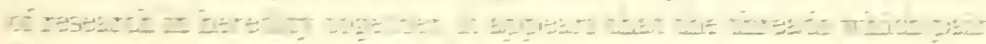

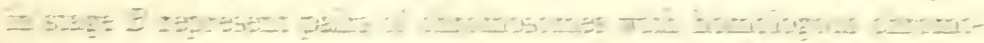

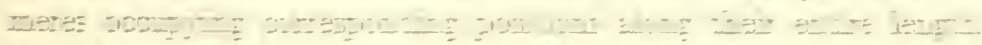
I of $: 2 \div$ -

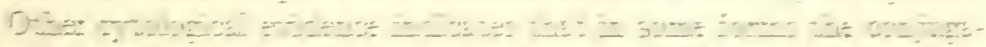

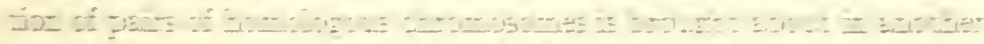

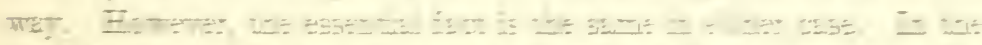

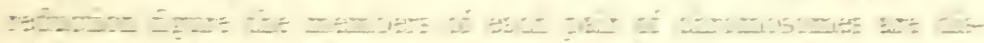

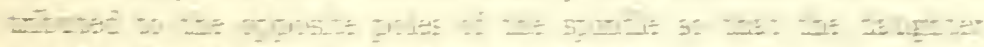

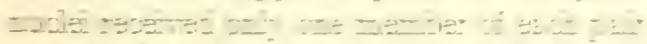

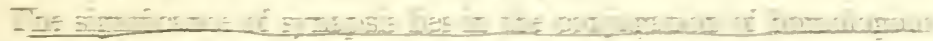

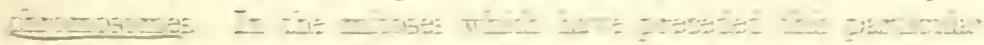

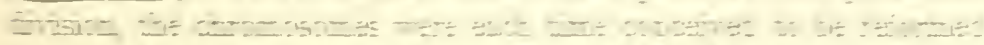

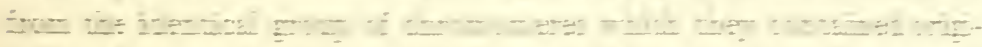

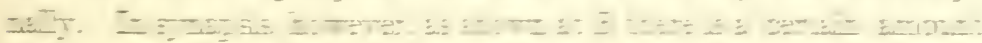

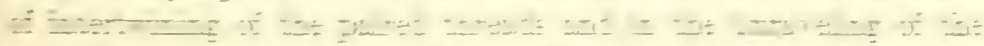

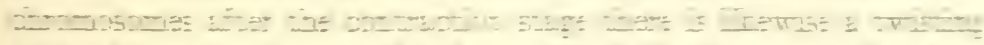

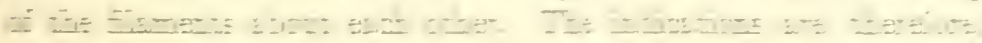

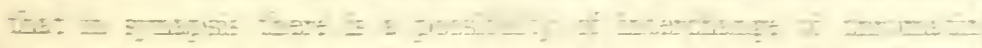
II 
organization of the chromosomes with respect to the chromomeres which they contain, this interchange of material must involve exactly equivalent portions of the two chromosomes. The chromosomes of

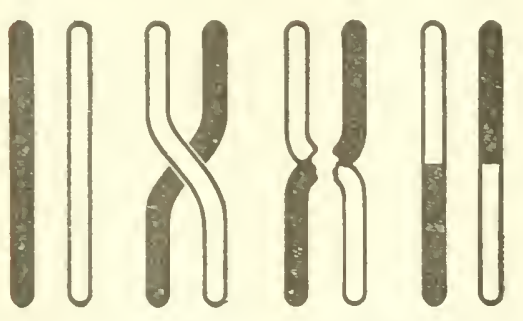

FIG. 73 .-Diagram of chromatin interchange between homologous members of a pair of chromosomes. (From Babcock and Cluusen, after. Miiller.)

the reduction division shown at $F$ may not, therefore, be identical with the four originally present in $A$, but may represent various combinations of portions of both members of a particular pair of chromosomes. The results of such interchange between members of homologous pairs of chromosomes is shown in Fig. 73. At the left is shown a pair of chromosomes, one in outline, the other in full black. In the middle the steps in chromatin interchange are diagrammed and finally at the right this interchange results in a pair of chromosomes each of which is made up of parts of both members of the original pair of chromosomes. Various combinations may result depending on the points at which interchange takes place, but in every case the exchange involves corresponding portions of the two chromosomes.

Independent distribution of chromosomes. - In Fig. 74 are illustrated diagrammatically the chromosomes of Drosophila, with particular reference to their size and form relations and to their characteristic pairing in the cell. One member of each of these pairs of chromosomes was contributed by the female parent and one member by the male parent. In the reduction dirisions these chromosomes are separated so that each germ cell contains one member of each pair of chromosomes. The simplest condition which could obtain is that of independent distribution in each pair of chromosomes such that the particular member of one pair which went to a given pole of the reduction spindle would have no influence on the distribution of the members of any other pair. Such independent distribution of chromosomes appears to be actually the type followed in reduction. As a consequence the germ cells contain various combinations of chromosomes with respect to their original parental derivation. In Fig. 74 the types of combinations of maternal and paternal chromosomes and their mode of derivation in Drosophila are shown diagrammatically. Two germ cells, one from the female with the chromosomes in outline, 


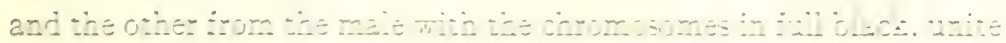

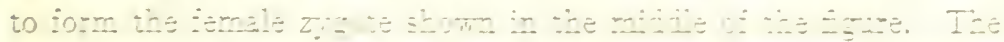

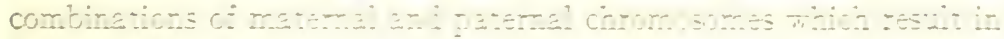

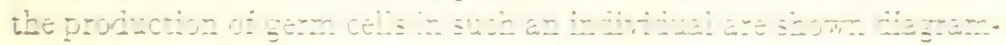
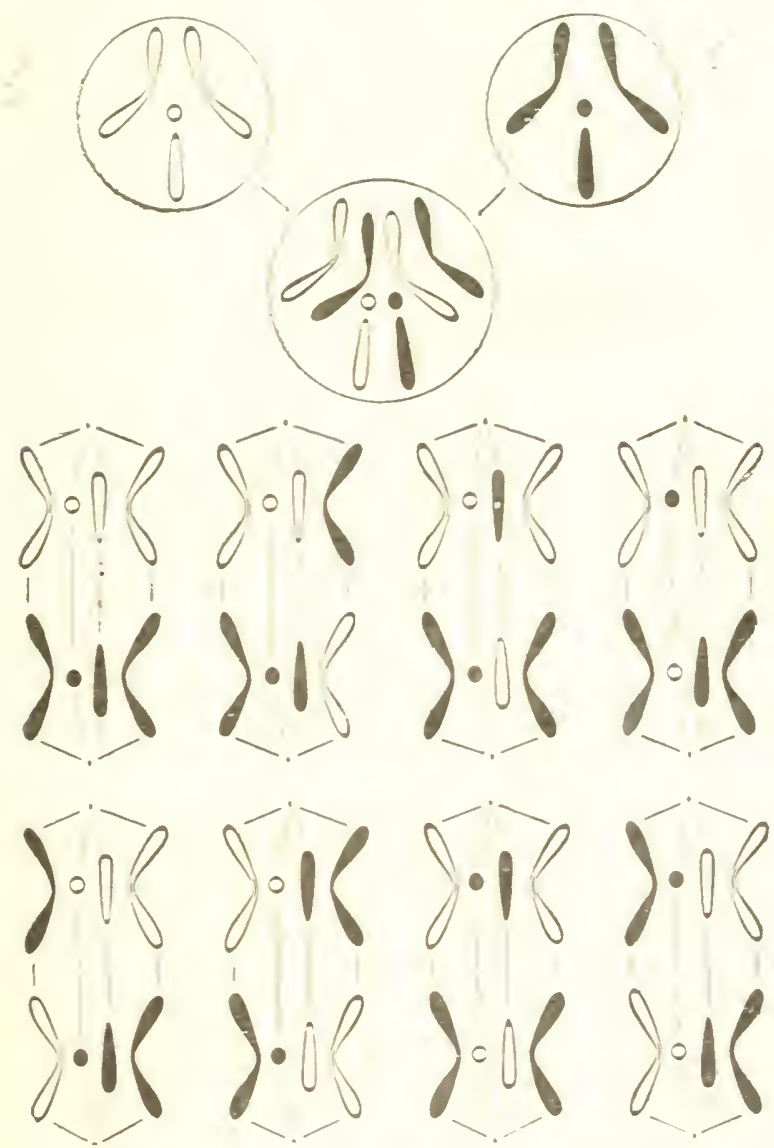

FIG. $-1 .-I: Z z=:=\sum \therefore \div=$

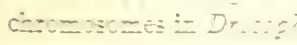

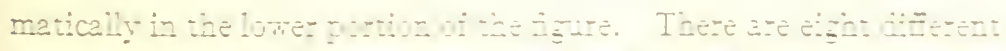

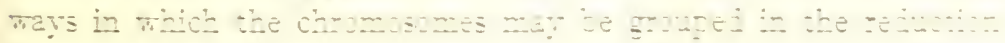

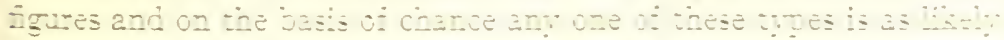

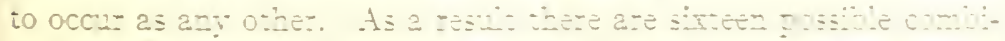
nations o: chromosomes in the zerm cells mith respect to ice justina? 
derivation of the chromosomes, whether from the female or from the male parent. This of course represents only the total number of possible combinations of entire chromosomes. By exchange of chromatin material between homologous chromosomes resulting in the formation of combination-chromosomes the number of actual combinations is greatly increased.

The number of chromosome combinations resulting from independent distribution is that number possible when each pair of chromosomes is considered separately, and every combination has an equal chance of occurrence. With a form having but two pairs of chromosomes there would be only four possible combinations, three pairs would give cight, four pairs sixteen, and in general the number of possible combinations is given by the expression $2^{n}$ in which $n$ is the number of pairs of chromosomes in the individual in question. In tolsacco which has 24 pairs of chromosomes the number of possible combinations in the germ cells reaches the enormous total of $16,777,-$ 216. This means that in the formation of zygotes in a self-fertilized tobacco plant the actual parental combinations, i.e., combinations identical with those of the germ cells which united to form the individual in question, occur only twice in over sixteen million times, and this proportion is still further lessened when the interchange of chromatin material between homologous chromosomes is taken into account. The condition of independent distribution although simple in itself results in a rapid increase in complexity with the increase in the number of pairs of chromosomes involvel.

Chromosomes and sex in Drosophila.-The relation between inheritance and the chromosome mechanism is perhaps most simply displayed in the inheritance of sex in those animal forms in which the sexes occur in approximately equal proportions. Thus in Drosophila as indicated in Fig. 75 there are three pairs of autosomes which are alike in both the male and the female. The remaining pair of chromosomes, however, liffer, for the female possesses two $\mathrm{X}$-chromosomes whereas in the male a single $\mathrm{X}$-chromosome is paired with a $\mathrm{Y}$-chromosome and these differences are characteristic of all normal males and females of this species. The bearing of these differences on the inheritance of sex is shown diagrammatically in Fig. 75. Begimning with the parents, the diploid number is shown in the circles representing the female and the male.

In the female the three pairs of autosomes are outlined and the $\mathrm{X}$-chromosomes only are drawn in black to indicate that they are the ones primarily concerned in the determination of sex. Similarly in 
the male the three pairs of autosomes which are exactly like those in the female are outlined, but the $\mathrm{X}$-chromosome and the $\mathrm{Y}$-chromosome are drawn in black. The reduction division in the female results in a
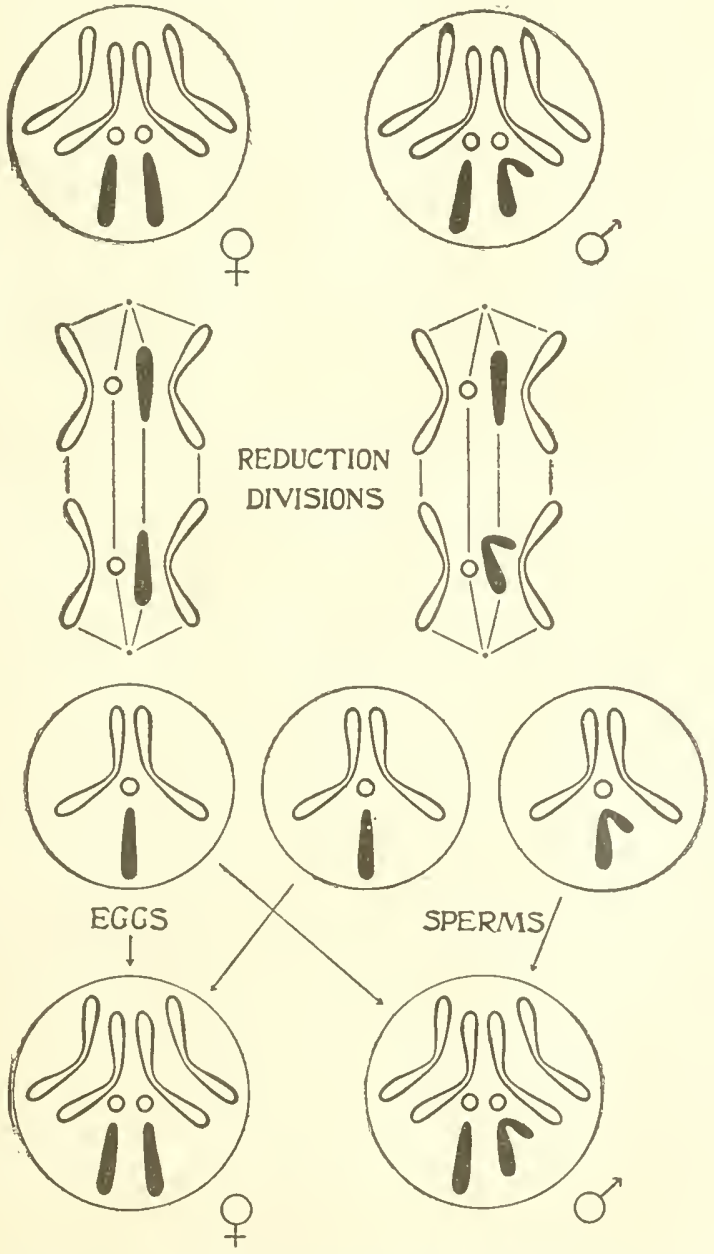

FIG. 75.-Diagram to show chromosome relations in the inheritance of sex in Drosophila ampelophila. (From Babcock and Clausen.)

separation of the members of each pair of chromosomes, so that every secondary germ cell (or egg) contains two large curved autosomes, a small autosome, and an X-chromosome. Consequently as far as chromosome content goes the eggs are all exactly alike. In the male, 
however, the separation of the members of the chromosome pairs results in sperms half of which contain an X-chromosome and half a $Y$-chromosome in addition to the three autosomes. The reduction division in the male insures an equality in numbers for the two kinds of sperm cells and the chances that either kind of sperm will fertilize an egg-cell are equal. By this arrangement the numerical equality of the sexes is maintained. When, later, the egg cells of the female are fertilized by the sperm cells of the male, as shown in the lower portion of the figure, half of them being fertilized by sperm cells which contain an $\mathrm{X}$-chromosome will give females, and half uniting with sperm cells which contain $\mathrm{Y}$-chromosomes will produce males. The inheritance of sex in Drosophila provides a beautiful illustration of the parallel behavior of the chromosome mechanism and a somatic difference, in this case, sex.

To recapitulate, the essential phenomena of cell behavior which furnish the mechanism for the distribution of hereditary factors are these:

I. Every species is characterized by a definitely organized group of chromosomes. The chromosomes occur in pairs, in each of which one member is derived from each parent. In ordinary somatic mitosis the distribution of chromatin is such that each daughter cell receives a full complement of chromosomes which are equivalent qualitatively to those of the mother cell.

2. In germ cell formation the homologous chromosomes conjugate during synapsis, then separate, and pass into a division figure in which entire homologous chromosomes are opposed to each other. The resulting reduction division gives daughter cells with half the number of chromosomes characteristic of the species, the half number being made up of one member of each pair of chromosomes. During synapsis there is an opportunity for the members of a pair of chromosomes to exchange chromatin material. When such interchange takes place equivalent portions of chromosomes both qualitatively and quantitatively are involved. In the reduction division segregation within one pair of chromosomes is entirely independent of that of any other pair so that the combinations of parental chromosomes in the germ cells represent all those to be expected on the basis of chance distribution.

The student should constantly endearor to harmonize this conception of the distributing mechanism of the chromatin material with the Mendelian interpretations of hereditary phemomena which will be presented in what follows, to the end that he may obtain a clear and definite illea of the interrelations between the known facts of heredity and cell behavior. 


\section{CHAPTER XXIX}

\section{NEO-MENDELISM IN PLANTS ${ }^{x}$}

JOHN M. COULTER AND MERLE C. COULTER

Thus far we have been considering Mendel's law in its simple form and have enlarged but little upon Mendel's original statement. The value of the law is apparent. Upon its republication in rgoo it was taken up by biologists and numerous breeders set to work to test it. As a consequence data for and against it began to accumulate. As might be expected, there was much apparent evidence against the law, but as geneticists developed a better conception of the mechanism the contradictory evidence was explained away. Almost every type of inheritance has now been explained according to Mendel's law. Some of the explanations are very complicated and cannot be in cluded in this presentation. A few of the more important cases, however, will be presented.

\section{PRESENCE AND ABSENCE HYPOTHESIS}

This may be regarded as a new method of Mendelian thought. It was first suggested by Correns, but later was worked out in detail by other geneticists, especially Hurst, Bateson, Shull, and East. It is merely a modification of the mechanism involved. For example, in the case of a hybrid obtained by crossing tall and dwarf parents the result had been explained as due to the fact that one chromosome bears a determiner for tallness and the other one of the pair carries the determiner for dwarfness. In other words, each one of a pair of allelomorphs is represented by a determiner, two determiners thus being present. Dwarfness in this case would be the result of the interaction of that determiner and its environment during the development of the body; and the same for tallness. When both were present, however, the conception of the situation was as follows. The determiner for dwarfness, setting up its usual series of reactions, early became paralyzed by the determiner for tallness or its products. This result was called the dominance of the character for tallness. It was as if the determiner for tallness completely prevented the activity of the determiner for dwarfness. This conception was apparently borne out

${ }^{x}$ From Coulter and Coulter, Plant Genetics (The University of Chicago Press. copyright 1918). 


\section{I4 READINGS IN EVOLUTION, GENETICS, AND EUGENICS}

by the facts and was the explanation of the mechanism generally accepted.

According to the presence and absence hypothesis, however, the situation is looked at from an entirely different point of view. Tallness is the result of a determiner, but dwarfness is merely the result of the absence of the determiner for tallness. The dominant character is produced by an inheritable determiner, but the recessive character appears only when the dominant determiner is lacking. This conception has some evident advantages and may modify the previous Mendelian diagram, as shown in Fig. 76. This appears to be a simpler mechanism to account for the phenomenon called dominance. In the case of the dwarf form there is a normal course of development; in the case of the tall parent or hybrid, however, an additional determiner

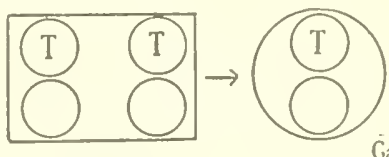

Tall Parent

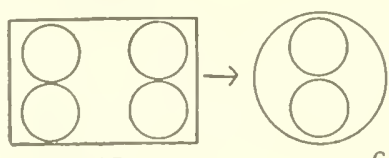

Dwarl Parent

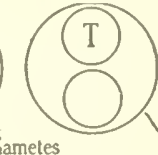

Gametes

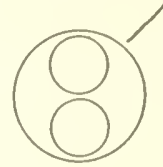

Cametes

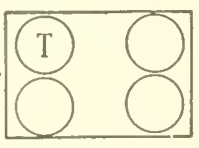

$F_{1}$ Hybrid

FIG. 76.-Diagram showing how the original scheme must be modified to satisfy the presence and absence hypothesis. (From Coulter and Coulter.)

stimulates cell growth, or cell division, or both. It is a simpler and more useful conception, so long as it fits the facts. Some investigators, however, claim that it cannot be applied to all the situations that have been discovered.

This hypothesis introduces some additional terminology suggested by Bateson. In our illustration the tall parent has two determiners for tallness and therefore Bateson calls it $d u p l e x$, having a double dose. For the same reason the $F_{1}$ individuals, having only one determiner for tallness, he calls simplex. According to the same terminology the dwarf parent is mulliplex with respect to its character of tallness.

Additional advantages of the presence and absence hypothesis will appear in connection with a consideration of blending inheritance and of cumulative factors in inheritance. Attention, however, should be called to the fact that those who accept the presence and absence 
hypothesis do not use the form of notation thus far used in explaining Mendelian inheritance. Assume that $T$ is used to express the determiner for tallness, its same letter $(t)$ is used to express the absence. For example, instead of using $D$ for dwarfness, $t$ is used for "lack of tallness" (Fig. 77). It is a matter of convenience to have a symbol to represent the recessive, the absence of something that is present in another individual.

In summary, the essential difference between the presence and absence hypothesis and that of dominant and recessive is that in the former case the recessive determiner has no existence at all, while in the latter case it exists, but is in a latent condition when associated with the dominant.

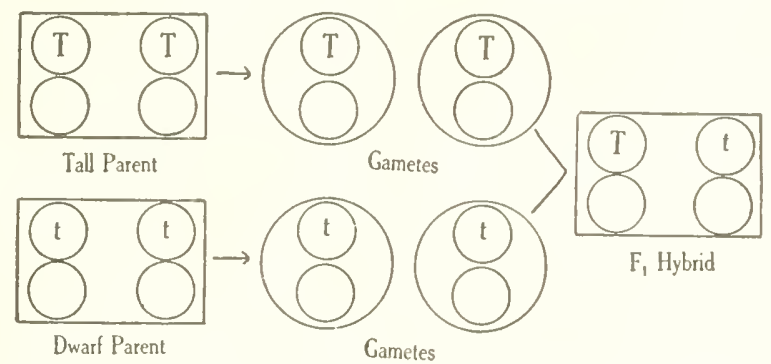

FIG. 77.-Diagram showing how presence and absence scheme is actually used, with small letter representing "absence." (From Coulter and Coulter.)

\section{BLENDS}

This type of inheritance when first discovered was thought to be in direct conflict with Mendel's law. It is a case in which dominance seems to fail, for the two alternative characters both express themselves and the result is an average between them. It is easy to explain this situation in accordance with the presence and absence hypothesis without any violation of Mendel's law.

The classic example of blending inheritance was presented by Correns in breeding work upon Mirabilis Jala.pa, the common fouro'clock. Correns crossed red and white varieties, and all the hybrid progeny had rose pink flowers. This was a color blend, distinctly intermediate between the colors of the two parents. The $F_{I}$ generation, therefore, seemed to contradict Mendel's law in that one color character was not completely dominant over the other. The real situation, however, appeared in the $F_{2}$ generation obtained by inbreeding 


\section{I6 READINGS IN EVOLUTION, GENETICS, AND EUGENICS}

individuals of the $F_{I}$ generation which showed the blend. By inbreeding the pink hybrids Correns obtained the perfect $I: 2:$ I ratio, that is, I red like one grandparent, 2 pink like the hybrid parent, and I white like the other grandparent. Segregation was evidently taking place, the only unusual thing being the appearance of the $\mathrm{F}_{\mathrm{I}}$ individuals, and that was explained immediately as failure of dominance (see Fig. 78).

The question this introduces, therefore, is that of a mechanism which could account for such a result. The easiest explanation offered is that the red parent was a homozygote for redness (double dose) and the hybrid a heterozygote (single dose); the inference is that

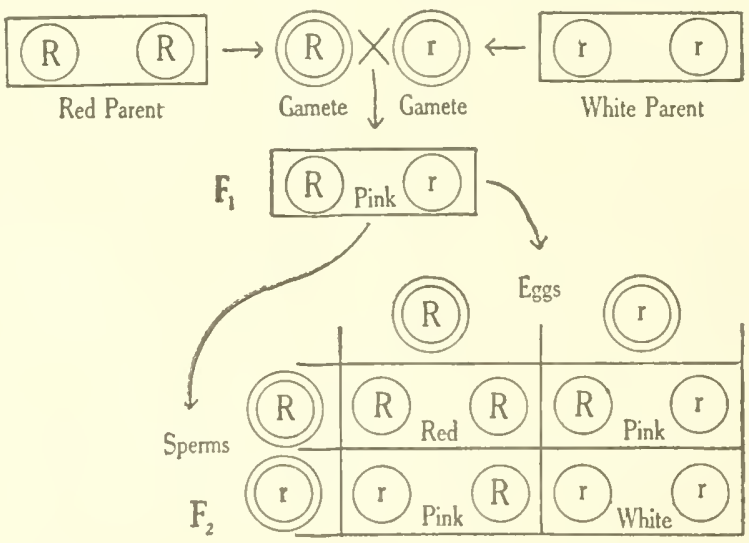

FIG. 78.-Diagram illustrating blending inheritance, discovered by Correns in .Mirabilis Jalapa. (From Coulter and Coulter.)

a single dose produces pink while a double dose produces red. A theoretical explanation of this occasional difference in the result of double and single doses is as follows. Imagine that the body cells of a plant have a certain capacity for expressing hereditary characters. In such a case, just as a given quantity of solvent can dissolve only a given amount of solute, so the body cells can express hereditary characters only to a definite limited extent. In the four-o'clock a single dose of redness may be thought of as half saturating the body cells, while a double dose completely saturates them. In cases showing complete dominance, however, a single dose completely saturates the cells and a double dose can do nothing more. This analogy assists in visualizing on the one hand the necessary mechanism of blends (apparent failure 
of dominance) and on the other hand that for cases of complete dominance.

Another example of simple blending inheritance is the case of Adzuki beans, described by Blakeslee. In this bean the mottling of the seed coat is dominant to the lack of mottling. In the hybrid condition, however, the mottling is lighter than in the pure or homozygous condition. Heterozygous plants, therefore, can be easily distinguished from homozygous plants, so that the $I: 2:$ I ratio is evident on external inspection rather than the usual $3: 1$ ratio.

\section{THE FACTOR HYPOTHESIS}

Mendel concluded that each plant character depends upon a single determiner. Inheritance, however, has proved to be a much more complex phenomenon than indicated by Mendel's peas. Ratios have appeared that were puzzling, and geneticists were forced to the conclusion that there may be a compound determiner for a single character. This conception is called the factor hypothesis, and the growing complexity of genetics has developed in connection with this hypothesis. With the consideration of factors instead of determiners one passes from elementary to advanced genetics. Previously we have used the word determiner, implying Mendel's idea that a single determiner is responsible for the development of a plant character, and this has been true of the examples of inheritance previously considered. It is understood now, however, that a character is frequently determined by the interaction of two or more separately heritable factors, and hence the factor hypothesis. The distinction between factors and determiners should be made clear. In case only one factor is involved in determining a character, there is no distinction between factor and determiner; and in such a case the term factor should not be used.

I. Complementary factors.-This is the simplest expression of the factor hypothesis and it may be illustrated by some of East's work. Crossing red-grained and white-grained corn he obtained all red in the $F_{1}$ generation. . This would suggest that the $F_{2}$ generation would show 3 red to I white; but it showed 9 reds to 7 whites, which did not suggest Mendelian inheritance. It is in accord with Mendel's law, however, if we consider that two complementary factors are necessary to produce the red character, and that each of these factors is inherited separately. Such a situation would give a dihybrid ratio, as indicated in Fig. 79. It will be seen that out of $\mathrm{r} 6$ progeny 9 will be red, for they alone contain the complementary factors; the other 7 will be white. 


\section{I8 READINGS IN EVOLUTION, GENETICS, AND EUGENTCS}

The situation is thus explained by the dihybrid ratio, but although only one character is involved that character depends upon two complementary factors.

Another situation is worth noting. No. 6 of the diagram is white because it contains only one of the necessary factors; No. II is white

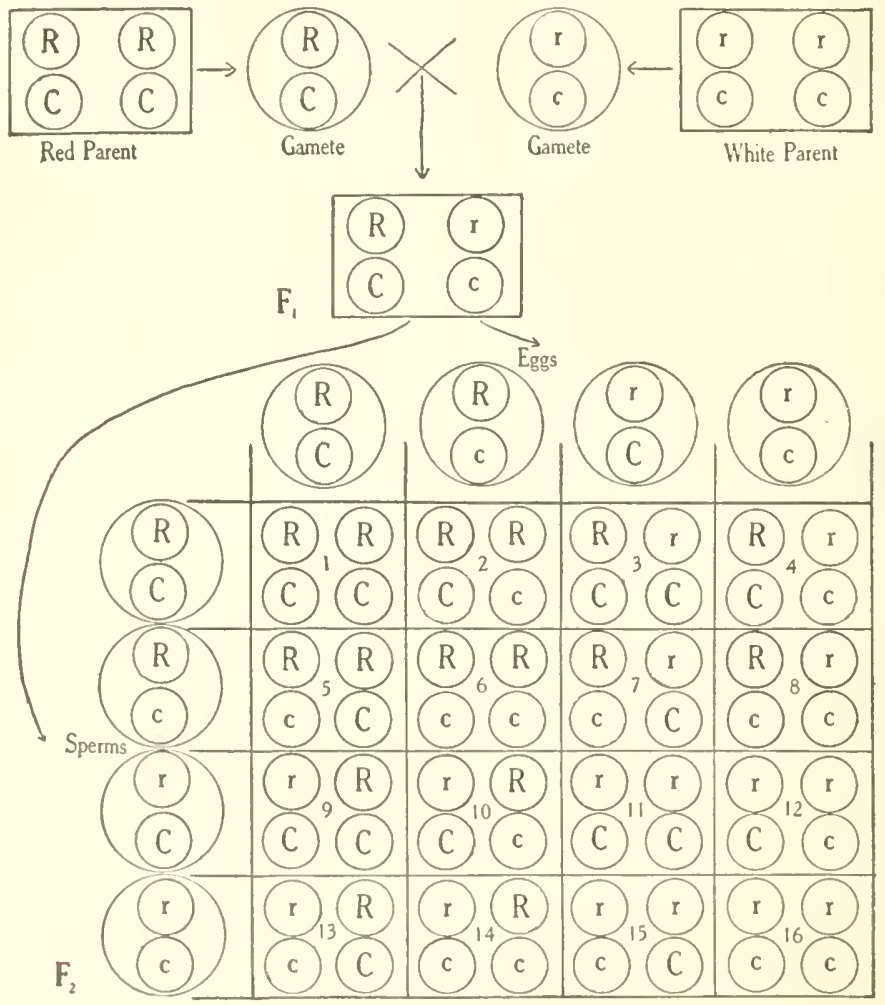

FIG. 79.-Diagram illustrating behavior of complementary factors in cross between red-grained and white-grained corn. $R$ and $C$ must both be present to produce red-grained corn. (From Coulter and Coulter.)

for the same reason, but its germinal constitution is just the opposite. What would happen if these two are crossed? There is only one possibility, since each is a homozygote producing only one kind of gamete. The result would be red, and thus a cross between two whites would produce only reds. What would happen from crossing Nos. 6 and $\mathrm{r}_{5}$, the former being a homozygote and the latter a heterozygote? 
It is obvious that the resulting progeny would be one-half white and one-half red, although both parents are white. The same result would be secured in crossing Nos. I I and I4. A cross between Nos. I4 and I 5 , both of which are heterozygotes, would result in 3 whites and I red, the ordinary $3: 1$ ratio. These illustrations show how differently the same phenotype may behave in inheritance. In each case two whites were crossed. that is, the same phenotypes, but three different ratios were obtained because the genotypes were different.

The striking feature of this situation is that one can cross two whites and get a red. This gives an insight into the so-called phenomenon of reversion. For example, in the course of numerous breeding experiments Bateson obtained two strains of white sweet peas, each of which when normally "selfed" bred true to the white color; but when these two were artificially crossed all the progeny had purple flowers, like the wild Sicilian ancestors of all cultivated varieties of the sweet pea. This appeared to be a typical case of reversion. Further breeding, however, showed that this was just such a case of complementary factors as we have been considering. One of Bateson's white strains had one of the factors for purple and the other strain harl the other factor.

Complementary factors have been defined and the method of their inheritance described, bu is there any mechanism to explain the situation? A suggestion may be obtained from plant chemistry. The most prominent group of pigments in plants is the group of anthocyanins, which are produced as follows. Plants contain compounds called chromogens, which are colorless themselves but which produce pigments when acted upon by certain oxidizing enzymes or oxidases. This is a sufficient mechanism for the behavior of complementary factors. If one of East's white strains of corn contained a chromogeny capable of producing red but lacked the necessary oxidase it would remain colorless. If the other white strain contained the oxidase but no chromogen it would remain colorless. In crossing them, however, chromogen and oxidase would be brought together and a red-grained hybrid would be the result. Inbreeding such red-grained individuals of course would give red and white progeny in a ratio of $2: 7, a$ explained in connection with East's corn. This seems to be the explinattion of the behavior of complementary factors in many cases of color inheritance.

Where other characters are involved the mechanism must be somewhat different. In some cases the two factors may be the enzyme 
and the compound the enzyme attacks, as in the oxidase and chromogen situation just described. On the other hand, we might be dealing with two chemical compounds that are inert when occurring separately but active when brought together, active in such a way as to produce a distinctly new character. Also two active substances might neutralize one another when brought together in a hybrid, and the failure in their activity might result either in a new character or the failure of some parental character to develop. Such are some of the possible mechanisms to explain the behavior of complementary factors.

Hybridızing, therefore, is much like mixing chemicals in a test tube. We know that very wide crosses cannot be made successfully; but the surprising thing is that certain very close crosses are constantly unsuccessful, even though both parents may cross freely with closely related types. We obtain a glimpse of the possibility of such apparcntly inconsistent behavior when we consider the chemical possibilities suggested by the behavior of complementary factors.

The origin of complementary factors is an interesting field of speculation. Did they originate together or separately? A natural inference would be that they originated together, for neither would be of any use without the other. It should be remembered, however, that the idea of use as explaining the occurrence of everything in a plant is being abandoned; one must think rather of a plant as a complex physico-chemical laboratory. No one claims that all chemical reactions are useful; they are simply inevitable; and plant characters are the result of chemical reactions and physical necessities. Even though we assume the simultaneous origin of two complementary factors, they would have to be put on separate chromosomes, for the factors are separately inherited.

The other alternative is to suppose that these factors originated independently in the history of a plant. In this case, of course, the first one to be produced would remain functionless until finally its complement came into existence. This might be an explanation of what are called latent characters. Also they might have not only originated independently but in different varieties or species. In this case if natural hyl,ridizing should bring them together the result would be the appearance of a new character, and this may have been a very important factor in the origin of species.

This may serve as an introduction to the factor hypothesis, with complementary factors as an illustration, simply because it is the simplest situation. There are many other kinds of factors recognized, 
but we shall not attempt to list all of the proposed types. A simple illustration of the better known types is as follows:

a) A complementary factor is added to a dissimilar factor to produce a particular character.

b) An inhibitory factor prevents the action of some other factor.

c) A supplomentary factor is added to a dissimilar factor with the result that the character is modified in some way.

d) A cumulative factor, when added to another similar factor, affects the degree of development of the character.

Some examples of these types will make them clear, those for complementary factors having been given previously.

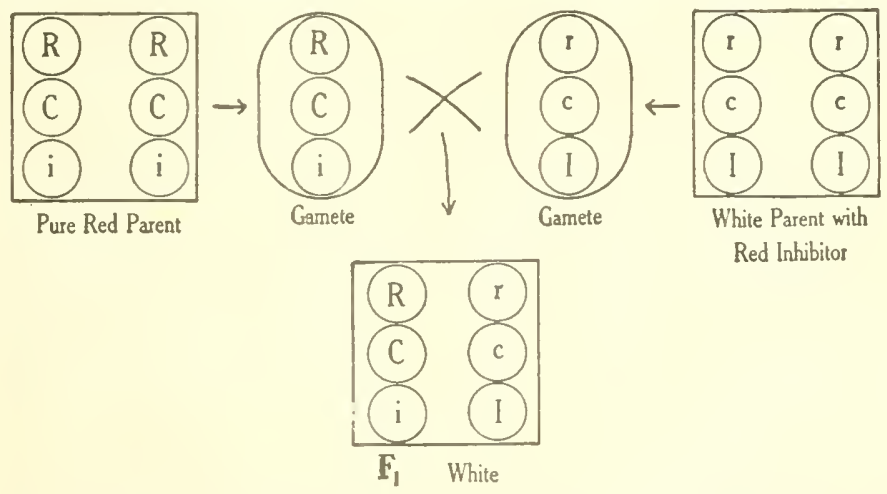

FIg. 80.-Diagram illustrating behavior of inhibitory factor. (From Coulter and Coulter.)

2. Inhibitory factors.-Recalling East's experiment with redgrained corn it will be remembered that when both factors for red were present the grain was red, but when either factor was absent the grain was white. Later he crossed these strains with a new white strain, and the result was surprising. The pure red strain produced gametes carrying both the red factors, and it would be expected that whatever such a gamete mated with would result in red progeny; but when this pure red was crossed with the new strain of white the progeny were all white, although the hybrids certainly contained both factors for red. The explanation which first occurred to East, and which later experiments confirmed, was that the new white strain contained an inhibitory factor, which prevented the development of red even though both the complementary factors for red were present. 


\section{READINGS IN EVOLUTION, GENETICS, AND EUGENICS}

Fig. 8o illustrates the situation and shows why all the individuals of the $F_{I}$ generation are white. It is interesting to note further the possibilities of white and red in the $\mathrm{F}_{2}$ generation. They would be

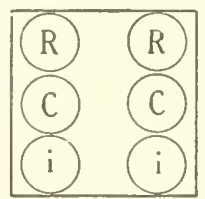

Red

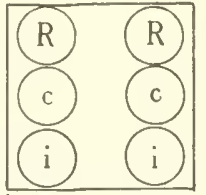

(1)

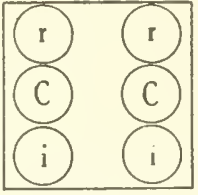

White

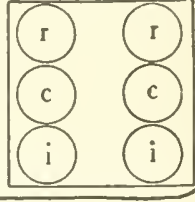

i)

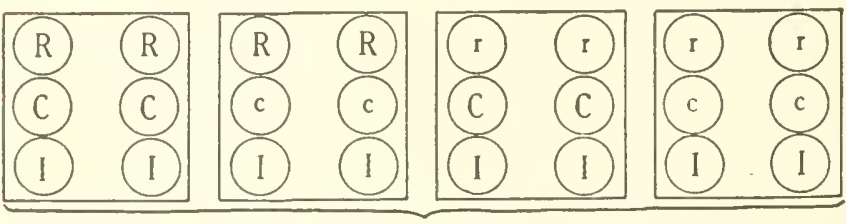

White

FIG. 8I.-Diagram showing some possible combinations in $F_{2}$ when $F_{x}$ of Figure 80 is inbred. Individual on left end of upper set red-grained, because $R$ and $C$ both present and $I$ absent; other individuals in upper set white, because lacking $C$ or $R$ or both; individuals in lower set with inhibitory factor and therefore white, whatever other combinations of factors they may contain. (From Coulter and Coulter.)

numerous, since we are dealing with trihybrid ratios (see Fig. 3r). This does not exhaust the possibilities, for the cases given were

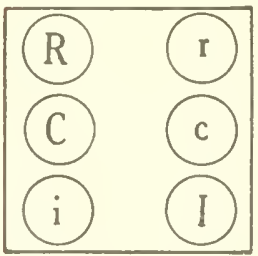

Fig. 82.-(From Coulter and Coulter.) homozygotes, each producing a single kind of gamete. There remains for consideration the heterozygote situation (see Fig. 82).

The possible mechanism of the inhibitory factor is as follows. We have assumed that red is produced only when the enzyme is present to oxidize the chromogen. Enzymes are very sensitive; their activities may be affected or completely checked by various agents. Suppose that $I$ of the diagram be such an agent and the necessary mechanism is apparent. When $I$ is present $R$ is paralyzed, so that it cannot oxidize $C$. NEUTRRIDED

3. Supplementary factors.-A supplementary factor is one that is added to a dissimilar factor, with the result that a character is modified in some way. 
In his work upon red-grained races of corn East found occasionally a few purple grains. His conception of the situation is as follows. The pure red plant contains two complementary factors, one $(C)$ a chromogen, and the other $(R)$ an enzyme, which when brought together produced the red color. The purple grains, however, must be explained by the presence of still another factor $(P)$, the resulting situation being represented in Fig. $8_{3}$. Of course when $C$ is absent no pigment whatsoever can be produced. As a consequence we will assume that the presence of $C$ is constant, and that $P$ and $R$ are variables. For a similar reason we will assume that the absence of $I$ is constant. The figure shows three possibilities, from which the following conclusions may be drawn: (I) when $P$ and $R$ are both present the result is purple grains; (2) red appears only in the absence of $P$; (3) $P$ although present will not develop any color in the absence of $R$.

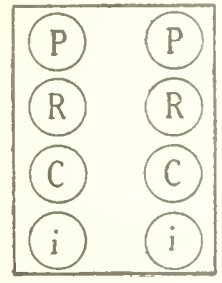

Purple

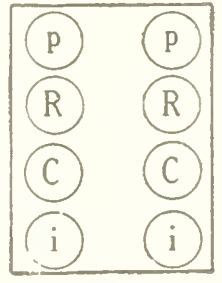

Red

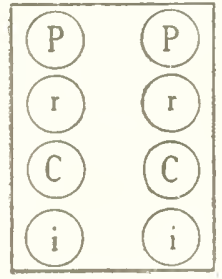

White

FIG. 83.-Diagram illustrating action of supplementary factor. (From Coulter and Coulter.)

This is a typical case of a supplementary factor, that is, one which is added to a dissimilar factor, with the result that the color character is modified. The mechanism of this situation will make clearer the behavior of the supplementary factor. If $C$ is the chromogen and $R$ the enzyme, what is $P$ ? The suggested answer can be obtained from plant chemistry. It is found that the purple pigment is produced by the same substance as the red, but represents a higher state of oxidation. The conclusion is obvious. $C$ is oxidized by $R$ up to a certain point, where red is produced; but if $P$ is also present it represents an additional enzyme, which attacks the red pigment and oxidizes it still further into purple. $P$ is incapable of attacking the original chromogen, but when $R$ carries the attack to a certain point, $P$ can function and carry the oxidation further. As a consequence $P$ without $R$ gives white grains, while $R$ gives red grains only in the absence of $P$. 


\section{READINGS IN EVOLUTION, GENETICS, AND EUGENICS}

4. Cumulative factors. - These will be considered under the next heading, "Inheritance of quantitative characters."

In addition to the four types of factors given, the literature of genetics also contains discussions on intensifying factors, diluting factors, distribution factors, etc. These, however, do not introduce any new mechanisms.

5. Inheritance of quantitative characters.-This phase of the factor hypothesis, if true, is of fundamental importance not only to genetics but to general biology. It is based upon the conception of cumulative factors, and as it is presented it will be realized that it throws light not only upon numerous breeding experiments but also upon variation in general, which means evolution also. A cumulative factor was defined as one which, when added to another similar factor, affects the degree of development of the character.

It will be recalled that Correns crossed red and white strains of Mirabilis and obtained pink hybrids. The suggested explanation of this result was that a single dose of the red determiner gives pink while a double dose gives red. When Correns inbred these pink hybrids, he obtained the result presented in Fig. $7 S$, that is, I red, 2 pink, I white. This result is obvious and the mechanism is plain.

With this cliagram in mind we shall consider some of the experiments of Nilsson-Ehle at the Swedish Experiment Station. He crossed two strains of wheat with red and white kernels. The $F_{\text {I }}$ inclividuals had light red kernels, which of course suggests a repetition of the situation shown by Mirabilis in the experiment of Correns. The $\mathrm{F}_{2}$ generation, however, showed a very different result. The reds and whites appeared in the ratio of $\mathrm{I}_{5}: \mathrm{I}$; but in addition to this, among the 15 reds there could be distinguished varying degrees of redness. Nilsson-Ehle suspected that i $5:$ i meant a dihybrid ratio, I6 indivicluals being necessary to give the ratio, so that he constructed the tentative scheme shown in Fig. 84 .

This shows a regular dihyl)rid ratio, except that the two factors involved are similar. Applying the single dose and double dose conception, as used in the case of Corren's pink Mirabilis, we reach the following conclusions: No. I only has four doses and therefore it only is deep red; Nos. 2, 3, 5, 9 have three doses and are somewhat lighter red; Nos. 4, 6, 7, IO, II, I3 have tyo doses and are still lighter red; Nos. 8, I2, I4, I5 have ene dose and are very light red; while No. I6 alone has no dose and is the only pure white. This accounts for the I5: I ratio, and the different shades of red. This is entirely in 
accord with the conceptions that have been presented, and only two assumptions are necessary: (I) that dominance is absent, and two 2 doses have twice the effect of one: (2) that the independent similar factors are cumulative in their operation, and are paired with their absence in the hybrid. This was Nilsson-Ehle's conception, and of
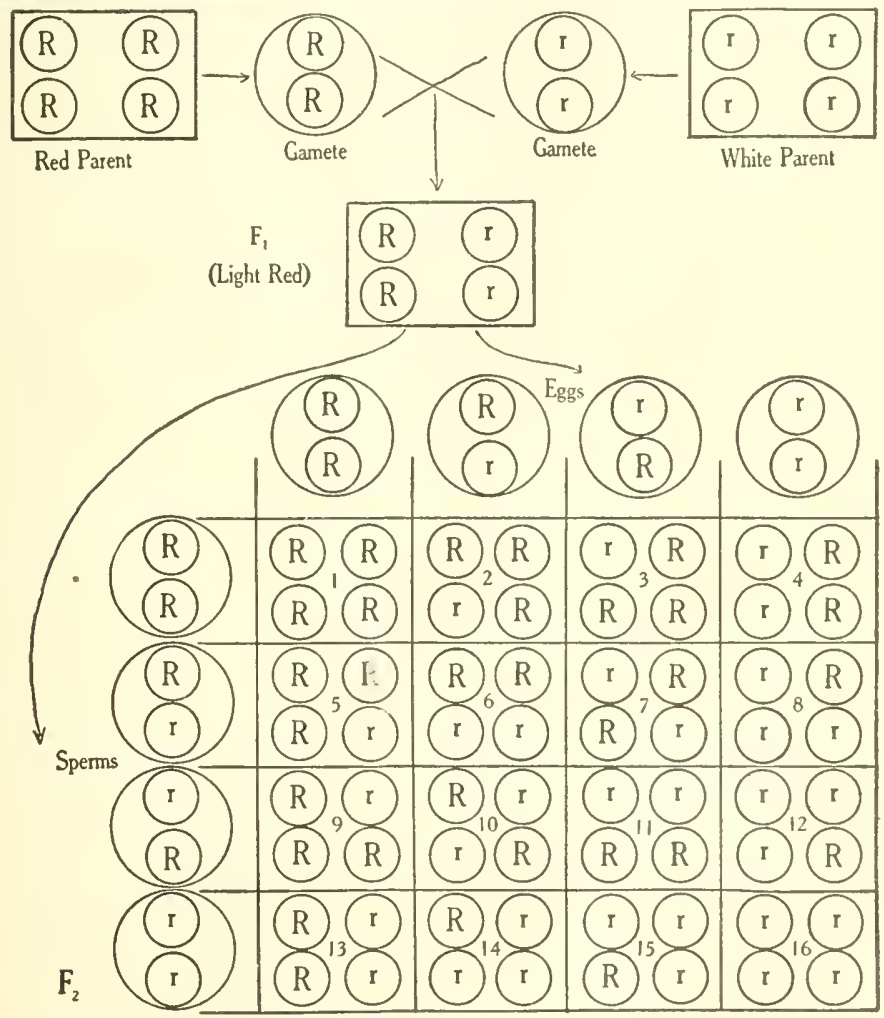

Fig. 84.-Diagram illustrating Nilsson-Ehle's explanation of I5: I ratio obtained in $\mathrm{F}_{2}$ generation from cross between red-grained and white-grained wheat. (From Coulter and Coulter.)

course he tested it by further experimental work, the results consistently confirming the conception.

Since it is important to fix this conception clearly in mind, another type of diagram may represent the facts even more clearly. The proportion of individuals showing the various degrees of redness in the $\mathrm{F}_{2}$ is graphically recorded in Fig. 85 , each dot representing one dose of the factors in question. 
Continuing these investigations, Nilsson-Ehle next discovered a new strain of red-grained wheat, which, when crossed with the pure white strain, yielded $F_{I}$ hybrids of intermediate intensity of red as before. The $\mathrm{F}_{2}$ generation, however, showed a different situation. Reds and whites were obtained in the proportion of $63: 1$; the 63 reds as before falling naturally into different groups on the basis of degree of redness. Applying the same conception as before Nilsson-Ehle

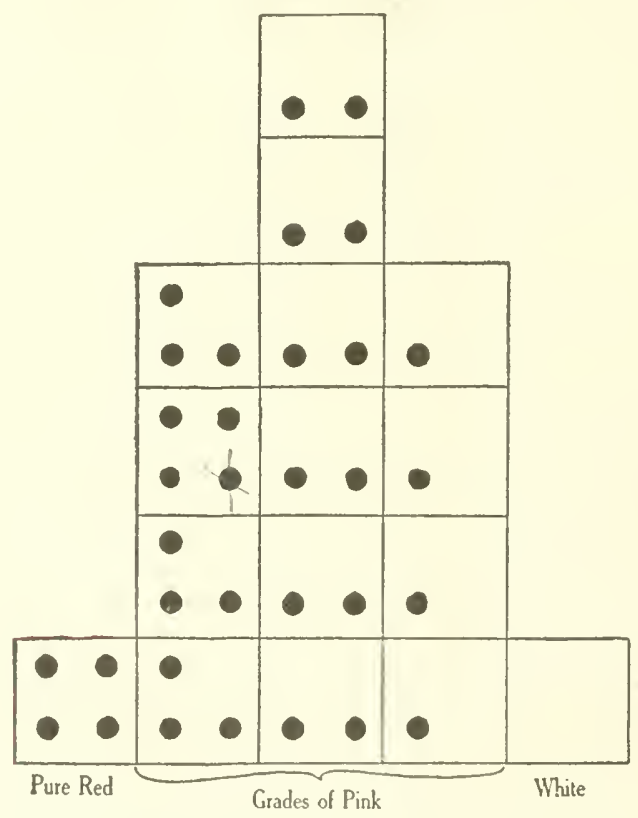

FIG. 85.-Another method of visualizing Nilsson-Ehle's I5: I ratio (see Fig. 84). (From Coulter and Coulter.)

discovered that in this case he was dealing with a trihybrid situation. Without constructing the usual Mendelian diagram, which would have to be extensive enough for 64 individuals, the situation as it appeared in the $\mathrm{F}_{2}$ generation may be represented by Fig. 86. If the graph is surmounted by a curve we recognize the regular "probability curve," exactly the kind of curve biometricians use to represent the fluctuating individuals about a specific type.

This conception of cumulative factors, therefore, has far-reaching significance. For a long time biologists have recognized individual 
variation within the species. Darwin depended upon it as the basis of his theory of natural selection as the origin of species; in fact, ever

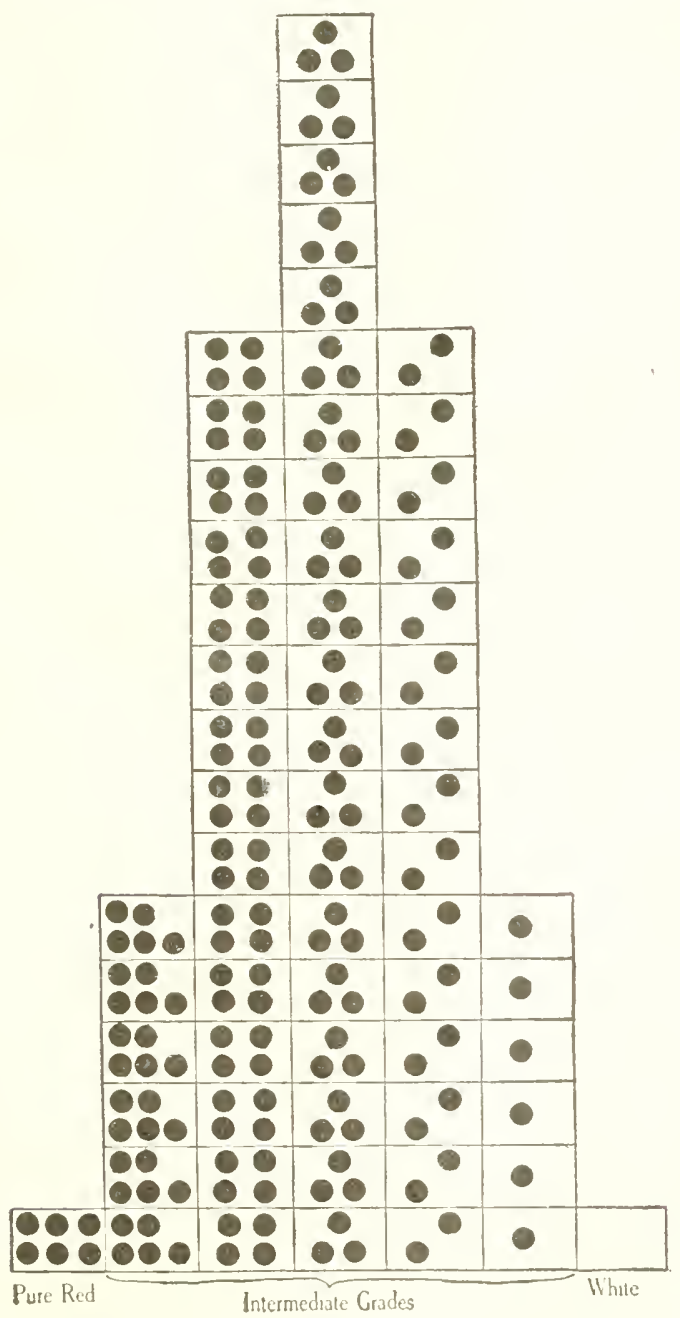

Fic. 86.-Diagram illustrating Nilsson-Ehle's 63: I ratio. (From Coulter and Coulter.)

since Darwin's Origin of Species, individual variation has been fundamental in our conceptions. To account for this universally recognized phenomenon, Darwin proposed his transportation hypothesis as 
a possible explanation, which, as will be recalled, did not long survive. Weismann offered in explanation his germinal selection, which was soon discarded because it was beyond the possibility of experimental testing. Aside from these two attempts to explain individual variation no other comprehensive scheme had been presented. Biologists had simply recognized the fact of individual variation without any conception of the mechanism. They knew that individual variation existed but had even stopped asking why it existed.

The importance of this new theory, therefore, is obvious. It is an ingenious explanation of the inheritance of quantitative characters and of the existence of individual variations. Furthermore, the theory has not been developed through meditation, but has its basis in scientific experiments. It is imaginative to a certain extent, of course, as is every other valuable theory, but unlike most such theories it has a substantial foundation, namely, Mendel's law. 


\section{CHAPTER XXX}

\section{NEO-MENDELIAN HEREDITY IN ANIMALS}

H. H. NEWMAN

Immediately after the announcement by De Vries in I900 of the rediscovery of Mendel's paper, zoölogists in Europe and in America began experiments in animal breeding with the idea of discovering to what extent Mendel's laws were applicable. It was soon found that the principles of unit characters, dominance, segregation, monohybrid, dihybrid, and trihybrid ratios were of practically universal application. A number of instances of Mendelian heredity in animals have already been presented in the preceding chapter and no more simple Mendelian cases need be described. For a considerable period the animal-breeders proceeded no farther in their analysis of the mechanism of heredity than Mendel had done so many years before. In time, however, new facts came to light that needed further analysis, and the older Mendelism was superseded by neo-Mendelism. This new phase in the study of heredity is in the forefront of interest today. Neo-Mendelian heredity in plants has already been discussed. It remains for us to present the data on some phases of neo-Mendelism in animals.

ILLUSTRATIONS OF THE FACTOR HYPOTHESIS

THE FACTORIAL ANALYSIS OF COLOR IN MICE

Miss Durham, after extensive breeding experiments with numerous strains of differently colored mice, has been able to show that the appearance of a particular color in an individual mouse is dependent upon the presence or absence of several independently inherited factors, evidently represented by genes in as many different chromosomes. It seems possible to classify these factors as follows:

$B=$ black pigment, which masks chocolate pigment

$b=$ absence of $B$, which gives chocolate

$I=$ intensity factor

$i=$ absence of intensity, or dilution factor

$C=$ a complementary color factor acting with $P$

$P=$ a complementary pigment factor acting with $C$

If either $C$ or $P$ are absent, albino mice result no matter what other color factors may be present. 
The factorial make-up of the various mice in Miss Durham's experiments would, then, be represented as follows:

$$
\begin{aligned}
& B I C P=\text { black } \\
& B i C P=\text { blue (dilute black) } \\
& \text { bICP }=\text { chocolate (absence of black) } \\
& \text { biCP }=\text { silver fawn (dilute chocolate) }
\end{aligned}
$$

The following experiments indicate the mode of heredity on the factorial basis:

I. $P$ Black $(B I C P) \times$ Silver-fawn $($ biCP $)$

$\mathrm{F}_{\mathrm{I}} \quad$ roo per cent Black $(B I C P-b i C P)$

$\mathrm{F}_{2}$ Black (BICP) Blue (BiCP) Chocolate (bICP) Silver-fawn $(b i C P)$

$$
93
$$

2. $P$ Blue $(B i C P) \times$ Chocolate $(b I C P)$

$\mathrm{F}_{\mathbf{I}} \quad$ Ioo per cent Black $(B i C P-b I C P)$

$\mathrm{F}_{\mathbf{z}}$ Black $(B I C P)$ Blue (BiCP) Chocolate (bICP) Silver-fawn

$$
9
$$
$(b i C P)$

3. $P$ Blue $(B i C P) \times$ Silver-fawn $(b i C P)$

$\mathrm{F}_{\mathrm{I}} \quad$ Ioo per sent Blue $(B i C P-b i C P)$

$\mathrm{F}_{\mathbf{2}}$ Blue $(B i C P)$ Silver-fawn $(b i C P)$

3

I

DIFFERENT KINDS OF ALBINOS

Any one of the color types mentioned, if lacking in the factor $C$, will be an albino, though carrying the other factors for color. For example, there may be a Black-albino (BIcP), a Blue-albino (BicP), a Chocolate-albino (bIcP), or a Silver-fawn-albino (bic $P$ ).

That color factors are present in albinos may be shown by the following experiment. An albino had appeared in a Black stock and was crossed with a Silver-fawn, thus:

4. $P$ Silver-fawn $(b i C P) \times$ Albino extracted from Black $(B I c P)$ $F_{\text {I }} \quad$ Ioo per cent Black (biCP-BIcP)

$\mathrm{F}_{2}\left\{\begin{array}{ccccc}\text { Black } & \text { Blue } & \text { Chocolate } & \text { Albino-Black } & \text { Silver-fawn } \\ (B I C P) & (B i C P) & (b I C P) & (B I c P) & (\text { biCP }) \\ 27 & 9 & 9 & 9 & 3 \\ \text { Albino-Blue } & \text { Albino-Chocolate } & \text { Albino-Silver-fawn } \\ (\text { Bic } P) & (b I c P) & & (\text { biCP }) \\ 3 & 3 & \text { I }\end{array}\right.$


The ratios given are the theoretical ratios for a trihybrid Menrlelian experiment, and the actual results have closely approximated these. As a matter of fact, sixteen allinos appeared, and it is not possible, except by breeding, to tell one kind from another. Breeding each with, for example, Silver-fawn would readily reveal the differences; for the $F_{\mathbf{x}}$ generation would all be of the color that is masked by the lack of $C$ in these albinos. In theLanguage of Johanssen there is only one albino phenotype, but there are four albino genotypes. Similarly in experiments (I) and (4), which have just been described, the individuals are all Black (phenotypically identical), but that they are not genotypically alike is clearly shown by inbreeding them. In experiment (I) we get only individuals of the four color types, while in experiment (4) we get, in addition to the four color types, four albino types.

\section{CASTLE'S GUINEA PIGS}

Professor W. E. Castle was one of the first zoölogists to use Mendel's methods. He soon discovered that in the determination of the coat characteristics of guinea pigs at least three sets of factors were necessary, as follows:

$$
\begin{aligned}
C & =\text { colored fur } \\
C & =\text { albinism (absence of } C \text { ) } \\
S & =\text { short fur } \\
S & =\text { long fur (recessive to } S \text { ) } \\
R & =\text { rosetted fur } \\
r & =\text { smooth fur (absence of } R \text { ) }
\end{aligned}
$$

\begin{tabular}{|c|c|c|c|c|c|}
\hline $\begin{array}{c}\text { Colored } \\
\text { Short }\end{array}$ & $\begin{array}{c}\text { Colored } \\
\text { Long }\end{array}$ & $\begin{array}{c}\text { Colored } \\
\text { Short }\end{array}$ & $\begin{array}{l}\text { Allino } \\
\text { Short }\end{array}$ & $\begin{array}{c}\text { Colored } \\
\text { Long }\end{array}$ & $\begin{array}{l}\text { Albino } \\
\text { Short }\end{array}$ \\
\hline Rosetted & Rosetted & Smooth & Rosctted & Smooth & Smooth \\
\hline 27 & 9 & 9 & 9 & 3 & 3 \\
\hline Albino & Albino & & & & \\
\hline Long & Long & & & & \\
\hline $\begin{array}{c}\text { Rosetted } \\
3\end{array}$ & $\underset{\text { I }}{\text { Smooth }}$ & & & & \\
\hline
\end{tabular}

An example will show how these factors segregate:

$\mathrm{P}$ Colored, Short, Smooth $\times$ Albino, Long, Rosetted

$$
(C S r) \quad(c s R)
$$

$\mathrm{F}_{\mathrm{I}} \quad$ roo per cent Colored, Short, Rosetted (CSr-csR) 


\section{READINGS IN EVOLUTION, GENETICS, AND EUGENICS}

The ratio of $27,9,9,9,3,3,3$, I shows clearly that the three factors independently segregate and are all three concerned in the determination of the characters of the fur. A fourth factor, a pattern factor, is often present that further complicates the factorialanalysis. Usually the self-color dominates the pattern, but certain special patterns are dominant over self-color.

These two examples for animals are sufficient to illustrate the nature of Mendelian factors and their workings. Numerous other factors have been discovered. Castle, for example, found a factor associated with the occurrence of brown pigment in guinea pigs. Some rabbits have the pigment distributed evenly over the body; others have it in the eye only. These conditions are allelomorphic to each other, $E$ (extension) being dominant over $e$ (restriction to eyes).

Inhibiting factors are distinguished, the presence of which prevents the appearance of a char cter represented in the germ plasm. Lethal factors result in the loss of something necessary for the life of the individual. Modifying factors change the expression of a character that depends on another gene. These and various other types of factors have been discovered by the large schoo] of neo-Mendelians now so actively at work. 


\title{
CHAPTER XXYI
}

\section{SEX-LINKED AND OTHER KINDS OF LINKED INHERIT- ANCE IN DROSOPHILA AND OTHER SPECIES}

\author{
WIIIAY E. CASTLE
}

All the facts of ser-linked inheritance in Drosophila harmonize with Morgan's hypothesis that the genes of ser-linked characters lie in a common cell structure ( $\mathrm{I}$-chromosone) which is duplex in females. simplex in males. Accordingly, in a race which breeds true for a sex-linked character, that character may be transmitted by every egy. but byonly kalf the sperms, namely bysuch as possessan X-chromosome and by virtue of that fact determine as iemale all zỹgotes into which they enter. To male zyogotes the sperm will not transmit sex-linked characters. This hypothesis is supported by some curious facts already alluded to but deserving of fuller consideration in this connection, viz.. facts observed in reciprocal crosses involving a sex-linted character. as for example white-eye in Drosophila.

TABLE I

Rectprocal Crosses of Wethe-Eyed mith RED-Eyed DrosophILA

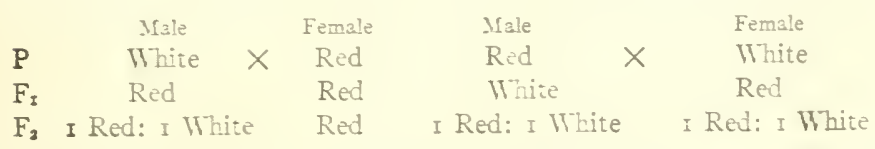

It has already been stated that a white-ered mule Drosophila crossed with normal females has only normal children of both seres. while the white-ered grandchildren are all of the male sex. In the reciprocal cross, between a white-eyed female and a normal male all the daughters are normal. but the sons are white-eyed. and among the grandchildren white-ered individuals occur in both sexes. Diagrams will best explain these facts on the basis of Morgan $s$ hypothesis. (See Figs. S; and SS and Table I.)

To state the foregoing facts in another way, it will be observed that the recessive ser-linked character in Drosophila. when introduced in a cross by the male parent, disappears entirely in $F_{x}$ and reappears in $F_{2}$

IFrom W. E. Castle, Gertics and Eugenies (copyright Io20). L'sed by special permission oi the publishers. The Harrard Lniversity Press. 


\section{READINGS IN EVOLUTION, GENETICS, AND EUGENICS}

only in male individuals. But if the recessive sex-linked character is introduced by the female parent, it appears in $F_{\mathrm{I}}$ in male individuals but in $\mathrm{F}_{2}$ in both sexes.

Suppose now a cross is made between two races, each of which possesses a different sex-linked recessive character, as for example white eye and yellow body. (See Table II, p. 436.) If the white-eyed

Flies
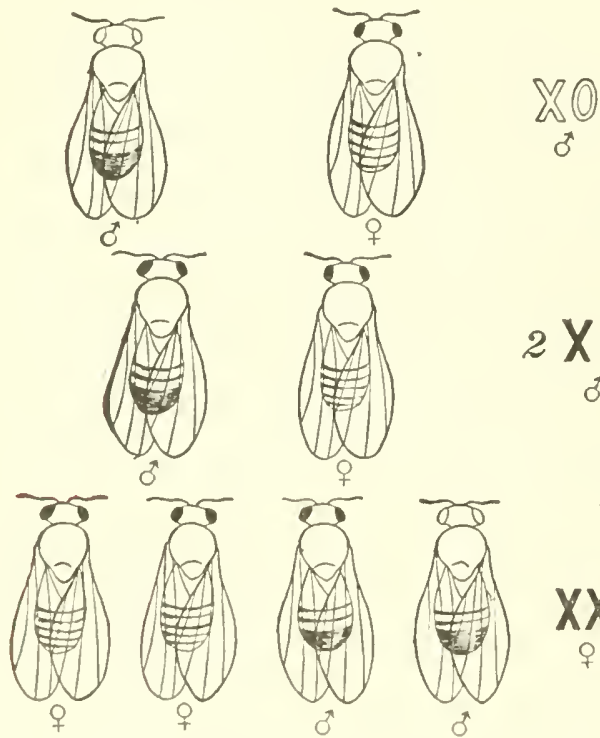

Chromosomes

FIG. 87.-Sex-linked inheritance of white and red eyes in Drosophila. Parents white-eyed male and red-eyed female; $F_{1}$, red-eyed males and females; $F_{2}$, redeyed females and equal numbers of red-eyed and white-eyed males. A black $\mathbf{X}$ indicates an $X$ chromosome bearing the gene for red eye, a white $\mathbf{X}$ bears white eye. () indicates that $X$ is wanting; in recent publications Morgan replaces it by $Y$. (From Conklin, after Morgan.)

parent is a female, there will be produced white-eyed males in $\mathbf{F}_{\mathbf{I}}$ and white-eyed flies of both sexes in $F_{2}$. But the male parent being yellow, there will be no ycllow flies produced in $F_{x}$ and only yellow males in $F_{2}$. In the reciprocal cross (yellow female $\times$ white-eyed male) yellow males will be produced in $F_{x}$ and yellow flies of both sexes in $F_{2}$, while white-eyed flies will not appear until $F_{2}$ and then only in the male sex. In either of the reciprocal crosses we expect the production in $\mathrm{F}_{2}$ both of yellow-bodied males and of white-eyed males. 
Usually no other sort of male is produced throughout the experiment except these two, but occasionally there is produced a male both yellow-bodied and white-eyed, or one which is gray-bodied and redeyed, like wild flies. How do these arise? If in $\mathrm{F}_{\mathrm{I}}$ females the paired X's were to exchange loads in part, so that $\mathrm{G}$ and $\mathrm{R}$ came to be attached to the same $\mathrm{X}$ and $\mathrm{g}$ and $\mathrm{r}$ to the other $\mathrm{X}$, and if each of the

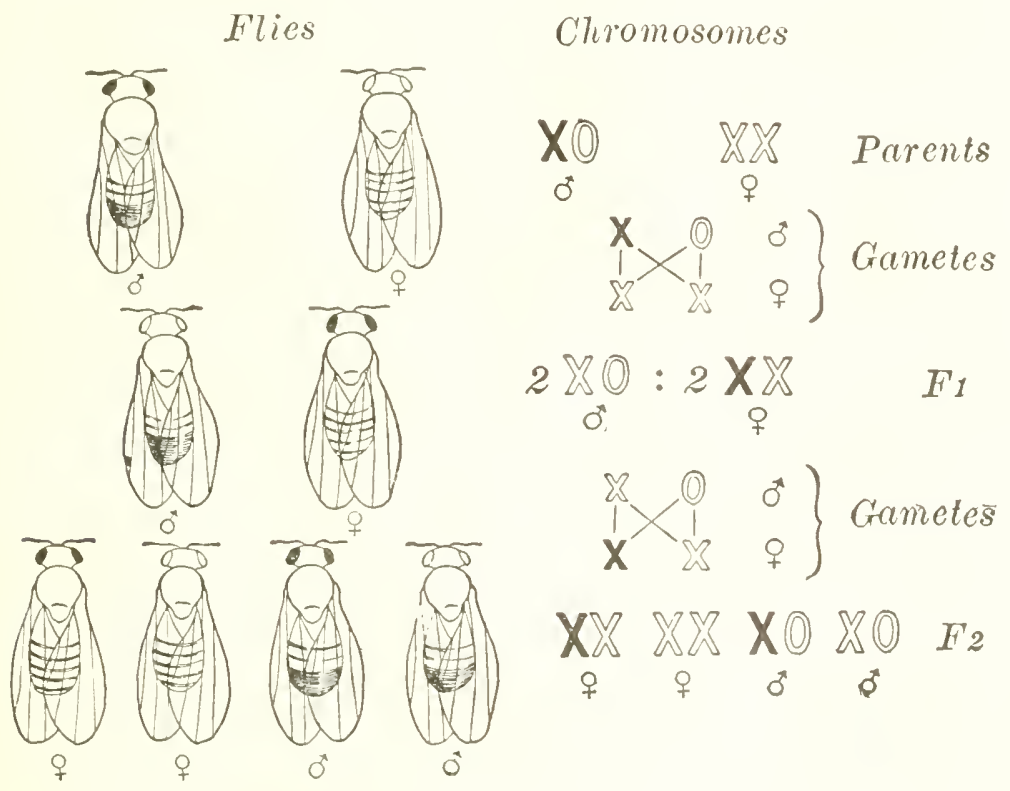

FIG. 88.- Reciprocal cross to that shown in Figure 87. Parents, red-eyed male and white-eyed female; $F_{x}$, white-eyed males and red-eyed females ("crisscross inheritance"-Morgan); $F_{2}$ equal numbers of red-eyed and white-eyed individuals of both sexes. The distribution of the sex chromosomes is shown at the right, as in Figure 87. (From Conklin, after Morgan.)

eggs having such a constitution were to be fertilized with a sperm which lacked $\mathrm{X}$ (male determining sperm), this would make possible the production of $\mathrm{F}_{2}$ males possessing both dominant characters and others possessing both recessive characters or gray-red and yellowwhite respectively, as actually observed in about one case in a hundred by Morgan.

It may add interest to the case to state parenthetically that in man occur a number of sex-linked variations which are inherited in this same curious fashion. Among them may be mentioned color blindness and 


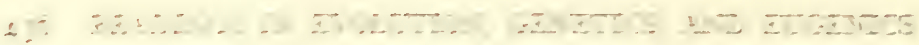

.

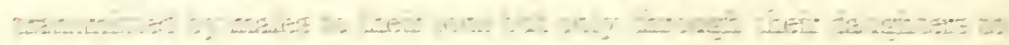

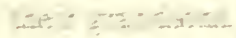

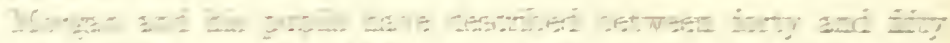

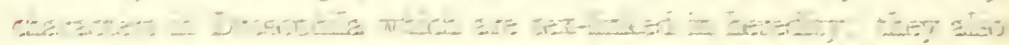

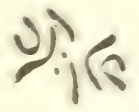

$\sum \therefore-20 \pi+25$

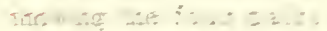

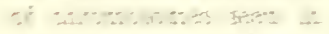

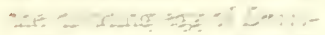

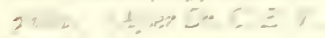
Xr:

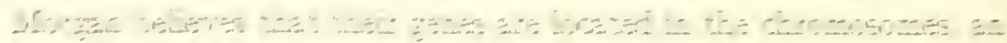

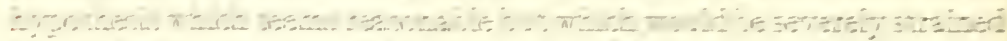
í ㄴ. . If I $x_{1}=\because y_{0}$

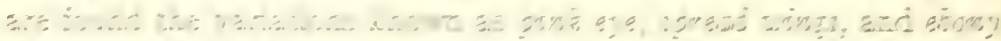

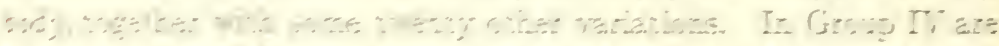

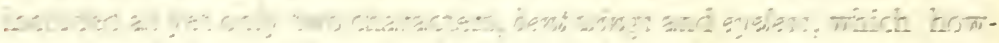

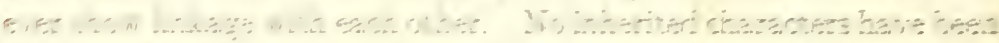

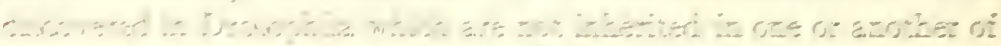
$\because, \ldots \ldots+\ldots, \ldots, \ldots$

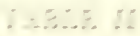

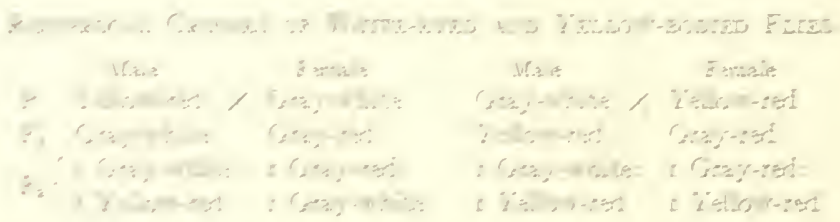

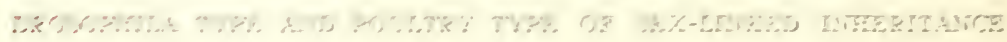

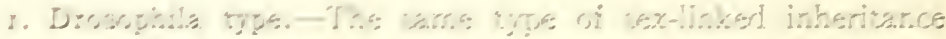

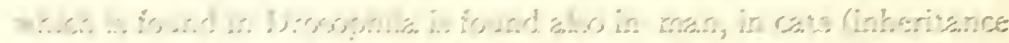

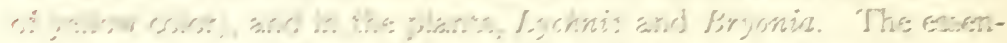

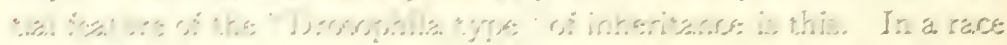




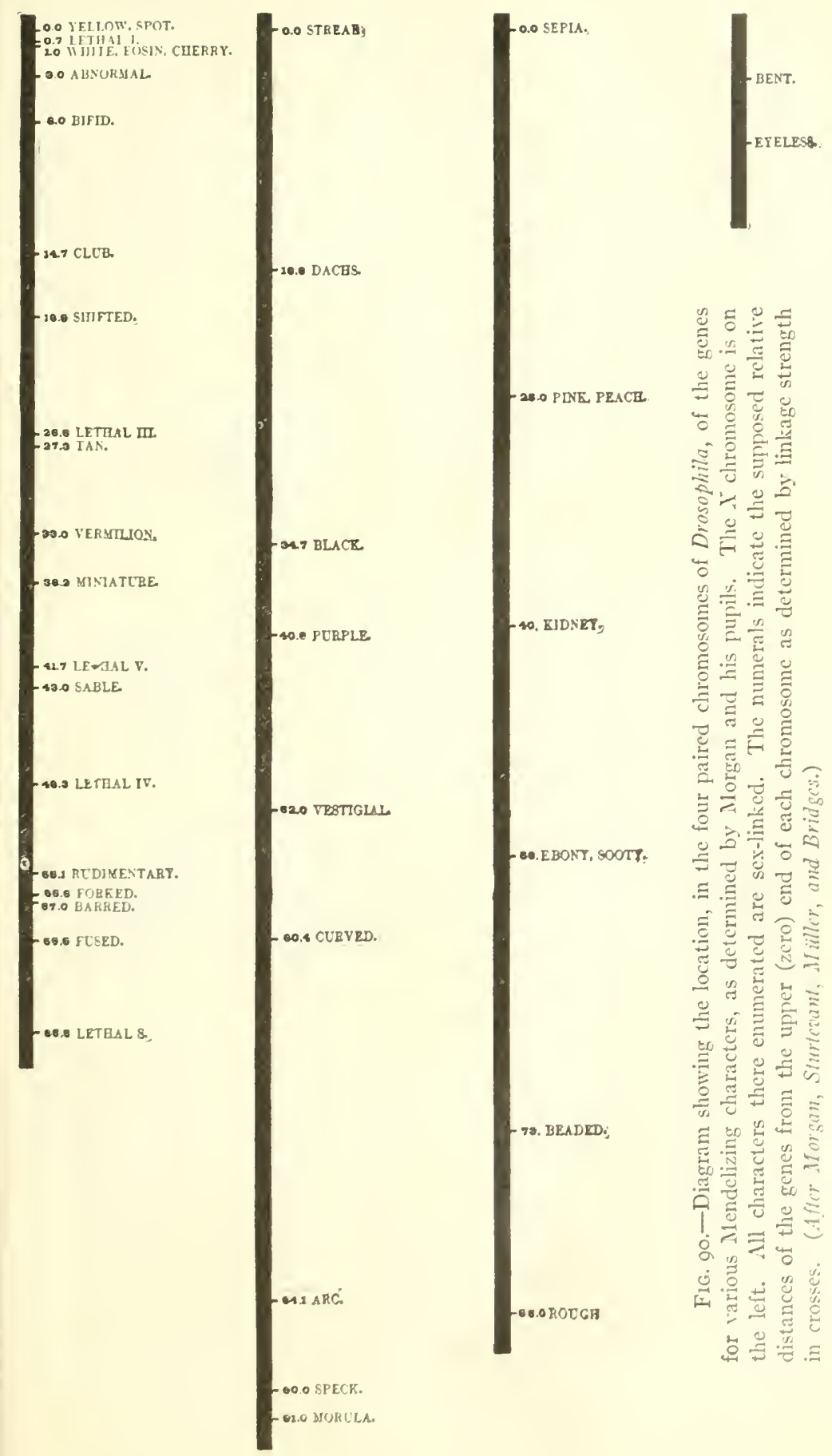




\section{READINGS IN EVOLUTION, GENETICS, AND EUGENICS}

breeding true for a sex-linked character, the female is homozygous for the character in question while the male is heterozygous and incapable of becoming homozygous. Reciprocal crosses with such a race give unlike results, because the female transmits the character to all her offspring, but the male transmits it to only half his offspring, viz., the females.

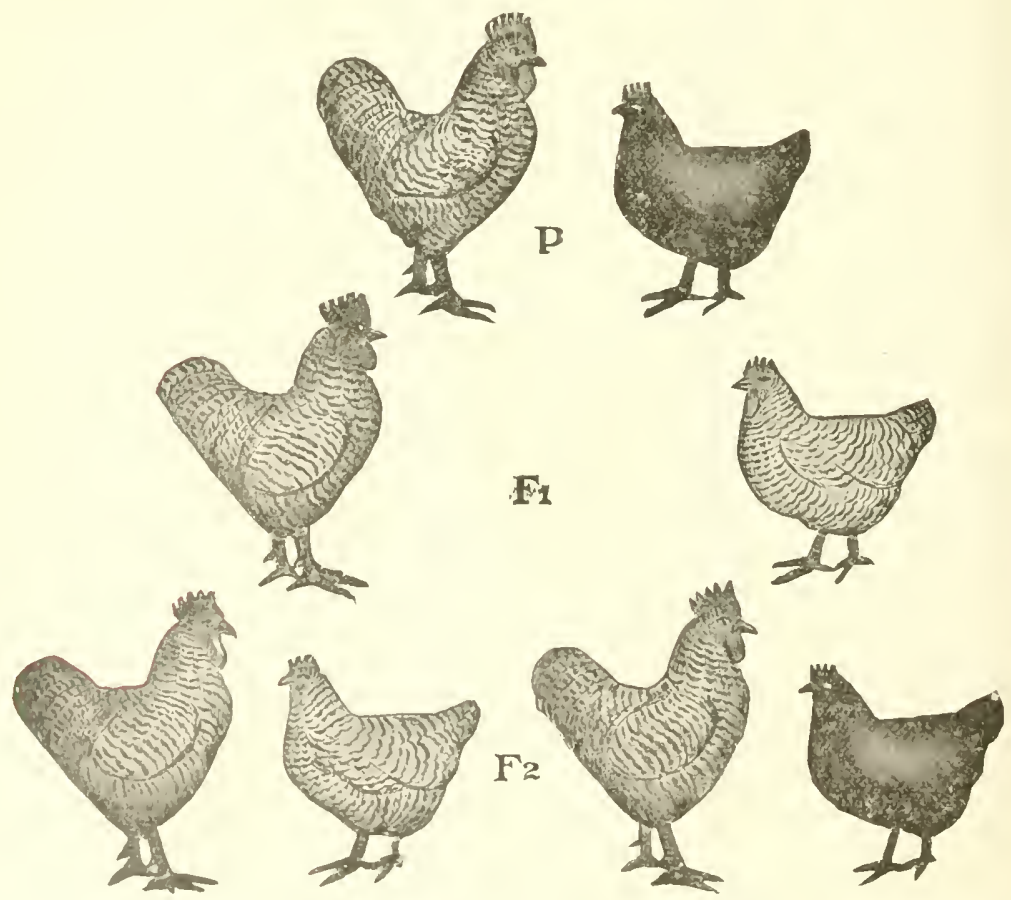

Fig. 9r.-Sex-linked inheritance of barred and unbarred (black) plumage in poultry. P, parents, barred male, unbarred female; $\mathrm{F}_{1}$, barred males and females; $\mathrm{F}_{2}$, males all barred, females in equal numbers barred and unbarred. (After Morgan.)

2. Poultry type.-Another type of sex-linked inheritance exists in which the sex relations are exactly reversed. This was first observed in the moth, Abraxas, but more familiar cases occur in poultry, for which reason it may be called the poultry type of sex-linked inheritance. Here the male is the homozygous sex, the female being heterozygous. This condition is found in moths and in certain birds, viz., 
in domestic fowls, pigeons, ducks, and canaries. As an example we may take the inheritance of the color pattern, barring, in crosses of barred Plymouth Rock fowls. In reciprocal crosses between purebred barred Plymouth Rocks and black Langshans (or another unbarred breed), the results are not identical. If the barred parent is the male (Fig. 9I and Table III), all $F_{1}$ offispring are barred and in $F_{2}$ all males are barred, but half the females are black and half are barrecl. If, however, the barred parent is the female (Fig. $9^{2}$ and Table III),

TABLE III

Reciprocil Crosses of Barred and Black Breeds of Follts

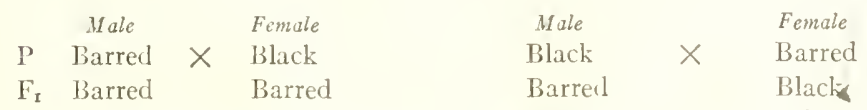

$F_{2}$ Barred I Barred: I Black I Barred: I Black I Barred: I Black (See Fig. 9I) (See Fig. 92)

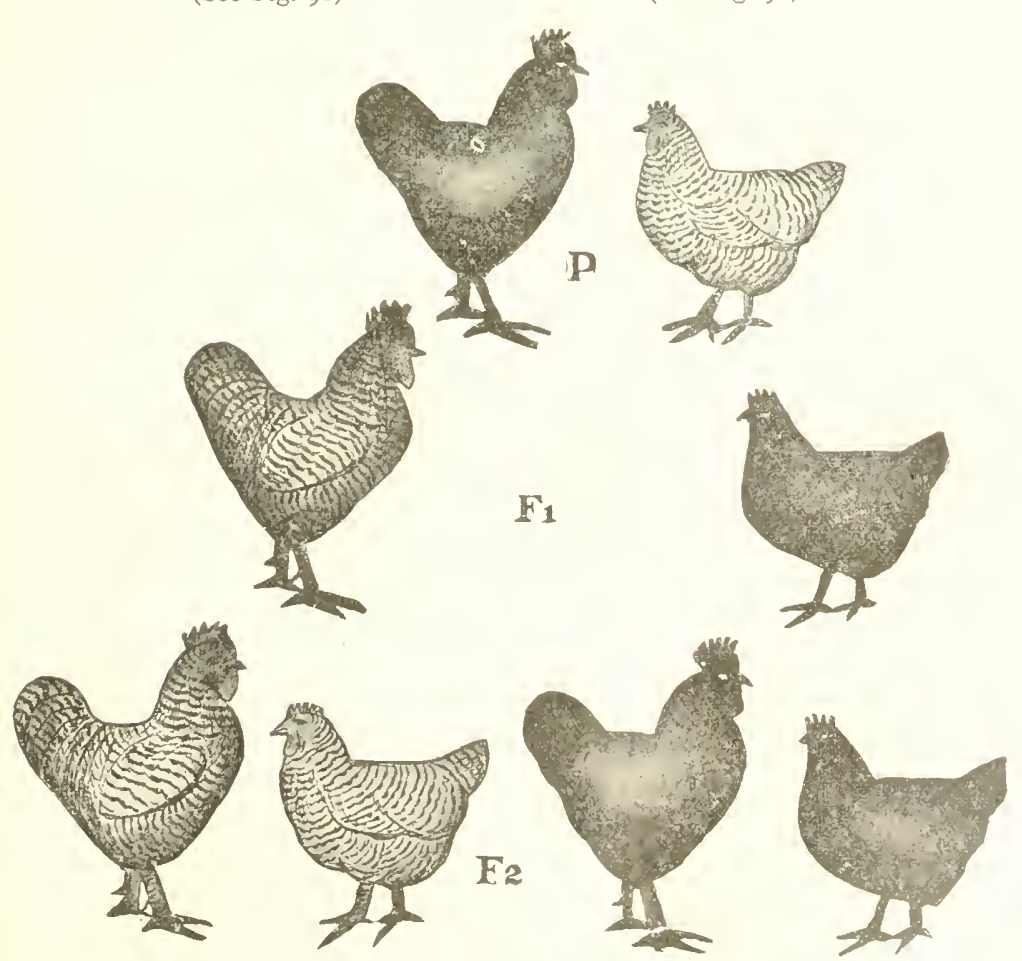

FIG. 92.- Reciprocal cross to that shown in Figure 91. P, parents, unbarred male, barred female; $F_{\mathbf{I}}$, barred males, unbarred females (crisscross inheritance); $\mathrm{F}_{2}$, barred and unbarred birds equally numerous in both sexes. (From Custle.) 
all $F_{1}$ males are barred, but all $F_{1}$ females are black. In $F_{2}$ barred birds and black birds occur in both sexes. These curious facts, which have been repeatedly verified, suggest the occurrence of a vehicle of inheritance which is duplex in males but simplex in females. What this is we do not know. No chromosome has been found which has a distribution of this sort in fowls, but it is possible that some chromosome component, or other cell constituent has such a distribution and may be the actual vehicle of inheritance in such cases. The most important character economically, which appears to be affected by some sexlinked factor in poultry, is fecundity. Pearl has shown that when reciprocal crosses are made between Cornish Indian Games, a poor breed for winter egg production, and barred Plymouth Rocks, a fairly good breed for winter egg production, the $F_{\mathrm{I}}$ females in each case resemble the father's race more strongly than the mother's race as regards egg production. Pearl did not maintain, however, nor do his experiments suggest, that the inheritance of fecundity depends exclusively upon a sex-linked factor. Goodale, however, has not been able to confirm Pearl's observations, in the case of Rhode Island Red fowls. He finds no evidence of superior influence of the sire in the transmission of racial fecundity. 


\section{CHAPTER XXXII}

\section{LTNKAGE AND CROSSING-OVER ${ }^{x}$}

WILLIAM E. CASTLE

In ordinary Mendelian inheritance, if two characters, $A$ and $B$, enter a cross in the same gamete (either egg or sperm), it will be wholly a matter of chance whether they continue together or are found apart in the following generation. If in the formation of gametes by the cross-bred, A and B separate from each other and pass into different gametes, it is evident that one of them has crossed over from the gametic group in which both originally lay to enter the alternative group. This event may be called simply a crossover. Crossovers and non-crossovers will be equally numerous ( 50 per cent each) where no linkage occurs. Also, if A and B enter a cross in different gametes, one in the egg, the other in the sperm, it will in ordinary Mendelian inheritance be a matter of chance whether they emerge from the cross together or apart. If together, it is evident that a crossover has occurred; if apart, a non-crossover, that is a persistence of their previous relations. Again, crossovers and non-crossovers will be equally numerous ( $5^{\circ}$ per cent each) if no linkage occurs.

Linkage may be defined as the tendency sometimes shown by genes to maintain in hereditary transmission their previous relations to each other. Thus if two linked genes, $\mathrm{A}$ and $\mathrm{B}$, enter a cross together in the same gamete, they will oftener than not be found together in the gametes formed by the cross-bred individual. Crossovers in that case will be less than 50 per cent, and non-crossovers more. And if the same two genes enter the cross separately, one in the egg, the other in the sperm, then oftener than not they will be found apart, in different gametes formed by the cross-bred individual. Again crossovers will be less than 50 per cent.

The number of genes in a linkage group varies in known cases from 2 to 50 or more. Howerer many genes there are in a linkage group, each gene shows linkage with every other gene belonging to the same group, but the apparent strength of the linkage varies greatly. Under uniform environmental conditions, $\mathrm{A}$ and $\mathrm{B}$ show a fairly constant

I From W. E. Castle, Genctics and Eugcnics (copyright I920). Used by special permission of the publishers, The Harvard University Press. 
linkage with each other, $\mathrm{A}$ and $\mathrm{C}$ show a different and likewise fairly constant linkage strength, and so on through the entire group. This leads to the conclusion that the genes of a linkage system are bound together, gene with gene, with bonds of definite strength in each case. In order to visualize the matter and get a more objective view of linkage relations, Morgan and his associates have developed the chromosome theory of linkage. Its essential parts are:

I. Genes which show linkage with each other are located in the same pair of chromosomes. It is the substance of the chromosome which binds the genes to each other and causes $\mathrm{A}$ to be inherited when $B$ is.

2. Genes close together in the same chromosome show strong linkage, genes farther apart show less linkage.

3. Homologous chromosomes, those containing corresponding sets of genes, one set derived from the father, one from the mother, lie side by side (in synapsis) previous to the formation of gametes. At this time breaks are likely to occur in the chromosomes and parts of one are likely to replace corresponding parts of the other.

4. Such replacement is called crossing-over.

5. Breaks are commoner in long chromosomes than in short ones, and between distant points than between near points on the same chromosome.

6. The genes occur in a chromosome, like beads on a string, in a single row and in definite order.

The supposed order of the genes in the four linkage groups of Drosophila and their relative distances apart are shown in Fig. 90 (p. 437). In these diagrams or "maps," when the probable order of the genes in a system has once been determined, the supposed end gene of the system is placed at position $\circ$ and the gene next to it is placed at a distance (in centimeters or other units) corresponding to the average cross-over percentage between the two, this process being repeated from gene to gene until the whole chain is plotted. "The "map" is thus based on a summation of the distances (measured in cross-over percentages) from gene to gene. But if we compare the "map distances" between genes not adjacent to each other in the chain with the observed cross-over percentages between the same genes, we find that the map distance is regularly greater than the cross-over percentage, except for very short distances ( 5 or less). Thus if three genes occur in the order $A B C$, it is usually found that $A B+B C$ is greater than $A C$. In other words, the cross-over percentage between $\mathrm{B}$ and $\mathrm{C}$ is commonly 
greater than the cross-over percentage between $\mathrm{A}$ and $\mathrm{C}$, and the discrepancy increases with the magnitude of the values involved. This fact has been accounted for in two different ways. First, it may be supposed that the arrangement of the genes is really not linear, that $\mathrm{B}$ lies out of line with $\mathrm{A}$ and $\mathrm{C}$, so that $\mathrm{AC}$ will be less than the sum of $\mathrm{AB}$ and $\mathrm{BC}$, and that the more distant genes are no farther apart than indicated by the cross-over percentages between them. This explanation has met with more difficulties than it has cleared away. The second explanation is that the map-distances indicate proportionate numbers of breaks in the linkage chain between points, not proportionate numbers of changes of relation between genes at particular points. Thus, suppose genes ABCDE of a linkage system meet their allelomorphs, abcde, in a cross and gametes are later formed by the cross-bred as follows, (I) ABcde, (2) ABcdE, and (3) AbcDe. Assuming that the arrangement is linear, we must suppose that one break in the linkage chain has occurred in (I), two breaks in (2), and three

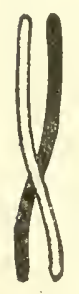

A

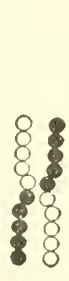

C $a$

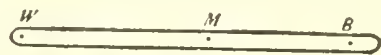

$b$

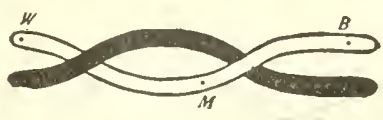

$B$

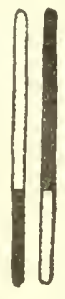

$D$

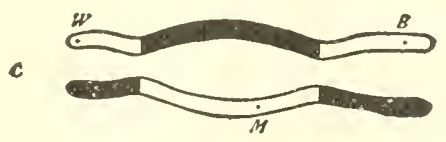

FIG. 93. $-B$ and $C$ illustrate Morgan's idea of the linear arrangement of the genes in the chromosomes. $A$ and $D$ show how the composition of the chromosomes is supposed to change as the result of the crossover. On the right, a pair of chromosomes, $a$, before; $b$, during; and $c$, after a double crossover. (After Morgan.)

breaks in (3). But if we did not have genes BCD under observation, and merely noted the relation of $\mathrm{A}$ to $\mathrm{E}$, we should infer that in case (I) and in case (3) a single crossover had occurred. We should on that basis underestimate the amount of breaking in the linkage chain. 
Accordingly the construction of maps on the basis of short distances summated is justifiable, provided the arrangement is linear, as it seems to be. But it must be borne in mind that the map distances do not correspond with cross-over percentages (although they are based on them) except in the case of very short distances. Map distances often exceed 50, but cross-over percentages cannot do so, as already pointed out. To get a distinctive name for the map units, Haldane has called them units of Morgan or simply "morgans." Haldane has computed a formula for converting cross-over percentages into "morgans" and vice versa. He finds that the two correspond only for very low values ( 5 or less) and diverge more and more as the observed cross-over percentages approach 50. Haldane's formula may be stated thus. If three genes, A, B, and $\mathrm{C}$, occur in a common linkage group, and the cross-over percentages are known between $\mathrm{A}$ and $\mathrm{B}$ and between $\mathrm{B}$ and $\mathrm{C}$, we may predict with a probable error of not over 2 per cent, what cross-over percentage will be found to occur between A and C. Calling the cross-over percentage between $\mathrm{A}$ and $\mathrm{B}, m$, and that between $\mathrm{B}$ and $\mathrm{C}, n$, the cross-over percentage between $\mathrm{A}$ and $\mathrm{C}$ will lie between $(m+n)$ and $(m+n-2 m n)$. It will approach the former for amounts of 5 or less, and the latter for amounts of 45 or over. In a useful table Haldane shows the calculated map distances (morgans) for all crossover percentages between 5 and 50 . This table is based on the relations of the genes observed in the sex-linked group of Drosophila, brit it applies equally well to the second linkage group of Drosophila, and to a group of three genes in the plant, Primula. Provisionally it may be considered to apply generally to linkage systems in animals and plants.

TABLE IV

a Table for Converting Cross-Oyer Percentages into Map Distances ("Morgans") and Vice Virsa (After Haldane)

\begin{tabular}{|c|c|c|c|c|c|c|c|c|c|}
\hline Cross-over percentage & & & 0.0 & 5.0 & 8.0 & I0.0 & II .O & I 2.0 & I 3.0 \\
\hline Map distance...... & $\cdots$ & $\cdots \cdots$ & 0.0 & 5.1 & 8.2 & 10.3 & II . 4 & I 2.5 & I 3.6 \\
\hline & 14.0 & 15.0 & 16.0 & 17.0 & I 8.0 & 19.0 & 20.0 & 21.0 & 22.0 \\
\hline & 14.7 & I 5.9 & 17.0 & 18. I & I 9.3 & 20.5 & $21 \cdot 7$ & 22.9 & 24.1 \\
\hline & 23.0 & 24.0 & 25.0 & 26.0 & 27.0 & 28.0 & 29.0 & 30.0 & 31.0 \\
\hline & $25 \cdot 3$ & 26.6 & 27.9 & 29.2 & 30.5 & $3 x .9$ & $33 \cdot 3$ & $34 \cdot 7$ & 36.2 \\
\hline & 32.0 & 33.0 & 34.0 & 35.0 & 36.0 & 37.0 & 38.0 & 39.0 & 40.0 \\
\hline & $37 \cdot 7$ & $39 \cdot 3$ & 40.9 & 42.6 & $44 \cdot 3$ & $46 . I$ & 48.0 & 50.0 & $5^{2} .2$ \\
\hline & 41.0 & 42.0 & 43.0 & 44.0 & 45.0 & 46.0 & 47.0 & 49.0 & 49.0 \\
\hline & $54 \cdot 4$ & 56.8 & 59.6 & 62.6 & 66.0 & 70.1 & $75 \cdot \mathbf{I}$ & $8 \mathrm{r} .9$ & 93.0 \\
\hline & 49.5 & 49.7 & 49.8 & 49.9 & 50.0 & & & & \\
\hline & 99.2 & 109.4 & 117.7 & I 28. I & & & & & \\
\hline
\end{tabular}

As an example of how the table may be used in predicting undetermined linkage values, suppose that $\mathrm{A}$ is linked with $\mathrm{B}$, and $\mathrm{B}$ with $\mathrm{C}$ 
and that between $A$ and $B$ there are ro per cent of crossovers. What will be the cross-over percentage between $\mathrm{A}$ and $\mathrm{C}$ ? Converting the observed cross-over percentages into map distances with the aid of the table, we find the distance $\mathrm{AB}$ to be 10.3 and the distance $\mathrm{BC}$ to be 15.9. On the linear theory the distance $\mathrm{AC}$ will equal either the sum or the difference of $A B$ and $B C$, that is will be either 26.2 or 5.4. Converting these distances into cross-over percentages by interpolation in the table, we find that the cross-over percentage between $\mathrm{A}$ and $\mathrm{C}$ should be either 23.7 or 5 .I, according as the linear arrangement is $\mathrm{ABC}$ or $\mathrm{ACB}$.

Measurement of linkage.-It will be observed that as the strength of linkage increases, the cross-over percentage decreases. With a cross-over percentage of 50 , there is no linkage. With a cross-over percentage of $o$, the linkage is complete, two characters so related behaving as allelomorphs. Accordingly we depend upon the observed cross-over percentage both for the detection of linkage and for the measurement of its strength. But unfortunately the linkage strength varies inversely as the cross-over percentage. This makes the crossover percentage directly considered, a rather poor measure of linkage strength. It is really the amount by which the cross-over percentage falls below 50 that measures directly the strength of linkage. Thus with cross-over percentages of $50,40,30,20$, IO, and $\circ$, we should have linkage strengths of $\circ, 1 \cap, 20,30,40$, and $5 \circ$. We should then have a standard for measuring linkage strength directly, on a scale of 50 . But as we are more accustomed to grading on a scale of roo, it seems preferable to double the values indicated above. We then have grades of linkage strength on a scale of roo, as follows:

$\begin{array}{lrrrrrr}\text { Cross-over percentage } & 50 & 40 & 30 & 20 & 10 & \circ \\ \text { Linkage strength } & 0 & 20 & 40 & 60 & 80 & 100\end{array}$

Accordingly, to estimate the strength of linkage in a particular case, we multiply by 2 the difference between the observed cross-over percentage and 50 .

But suppose the observed cross-over percentage were greater than 50 , what then? Such an occurrence would not indicate linkage, a tendency of characters to remain grouped as they were, but an opposite tendency, to assume new groupings. No such tendency has been observed. If it should be, it would need a different name and method of measurement.

We may now consider some further examples of linkage. 


\section{READINGS IN EVOLUTION, GENETICS, AND EUGENICS}

In the plant, Primula sinensis, Gregory observed the occurrence of linkage in a group of five characters, viz.,

\begin{tabular}{ll} 
Dominant & \multicolumn{1}{c}{ Recessive } \\
I. Short style & vs. long style (I) \\
2. Magenta corolla & vs. red corolla (r) \\
3. Tinged corolla & vs. full-colored corolla \\
4. Green stigma & vs. red stigma (s) \\
5. Pale stem & vs. full red stem
\end{tabular}

Altenburg later determined the strength of the linkage existing between three of these five pairs of characters, viz., I, 2, and 4 of the above list. His results may be expressed in a linkage map as follows:

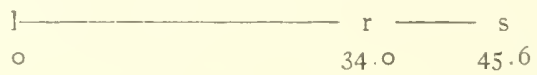

The cross-over percentage letween 1 and $\mathrm{r}$ was found to be 34.02 , between $r$ and s, I1.62. The sum of these two, 45.64, is the total (uncorrected) ma distance. The observed cross-over percentage between 1 and $\mathrm{s}$ was 40.6 , which falls short of the map distance by almost exactly the amount indicated by Haldane's table.

In the sweet pea the earliest discovered examples of linkage are found. Here are known two linkage groups containing each three pairs of characters as follows:

\begin{tabular}{|c|c|c|c|c|}
\hline & Recessive & & Dominant & Recessive \\
\hline & $\begin{array}{l}\text { I. Blue vs, red anwer color } \\
\text { 2. Long vs. round pollen } \\
\text { 3. Erect vs, hooded standard }\end{array}$ & Group 2 & $\begin{array}{l}\text { I. Dark } \\
\text { 2. Fertile } \\
\text { 3. Norma }\end{array}$ & $\begin{array}{l}\text { vs. light leaf-axil } \\
\text { vs. sterile anthers } \\
\text { vs. cretin flowers }\end{array}$ \\
\hline
\end{tabular}

Results described by Bateson and by Punnett indicate that in Group I the map relations of the three genes are:

$$
\begin{array}{ll}
\mathrm{E}-\mathrm{I} \longrightarrow \mathrm{L} \\
0.78 & \mathrm{I} 2.5
\end{array}
$$

The group is a compact one, with $\mathrm{E}$ and $\mathrm{B}$ very closely linked, crossover percentage less than one, with B and L showing between i I and I 2 per cent crossovers, and with $\mathrm{E}$ and L showing about I 2.5 per cent of crossovers.

In Group 2, the cross-over percentage between D and $\mathrm{F}$ is about 6.2, between $\mathrm{F}$ and $\mathrm{N}$ about 25.0. Until the cross-over percentage between $\mathrm{L}$ and $\mathrm{N}$ has been experimentally determined, it cannot be stated whether the "map" order is FDN or FND. In the former case, the total map distance will be 25 , or about double the length of Group I; in the latter case, it will be still longer, or about 3 I.2. 
TABLE V

Cases of Linkage in Piants or in Anmals Other Than Drosophila

\begin{tabular}{|c|c|c|c|c|c|}
\hline Species & 言 & Linked Characters & $\begin{array}{l}\text { Cross-over } \\
\text { Percentage }\end{array}$ & $\begin{array}{l}\text { Linkage } \\
\text { Strength }\end{array}$ & Authority \\
\hline Sweet pea & $\begin{array}{l}\text { I } \\
\text { I } \\
\text { I } \\
2 \\
2 \\
2\end{array}$ & $\begin{array}{l}\text { Purple flowers, long pollen } \\
\text { Purple flowers, erect standard } \\
\text { Long pollen, erect standard } \\
\text { Dark axil, fertile anthers } \\
\text { Dark axil, normal (not cretin) } \\
\text { flower } \\
\text { Fertile anthers, normal (not } \\
\text { cretin) flowers }\end{array}$ & $\begin{array}{c}\text { I I or I } 2 \\
0.78 \\
\text { I2.5 } \\
6.2 \\
? \\
25.0\end{array}$ & $\left.\begin{array}{c}76-78 \\
98.4 \\
75 \\
87.6 \\
\cdots \\
50\end{array}\right\}$ & $\begin{array}{l}\text { Bateson } \\
\text { and } \\
\text { Punnett }\end{array}$ \\
\hline $\begin{array}{l}\text { Primula } \\
\text { sinensis }\end{array}$ & $\begin{array}{l}\text { I } \\
\text { I } \\
\text { I } \\
\text { I } \\
\text { I }\end{array}$ & $\begin{array}{l}\text { Short style, magenta corolla } \\
\text { Short style, green stigma } \\
\text { Magenta corolla, green stigma } \\
\text { Tinged corolla, green stigma } \\
\text { Pale stem, green stigma }\end{array}$ & $\begin{array}{r}34.0 \\
40.6 \\
\text { II. } 6 \\
? \\
?\end{array}$ & 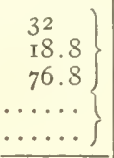 & $\begin{array}{l}\text { Altenburg } \\
\text { Gregory }\end{array}$ \\
\hline Garden pea & $\begin{array}{l}\text { I } \\
2\end{array}$ & $\begin{array}{l}\text { Round seeds, tendrils on } \\
\text { leaves } \\
\text { Late flowering, colored flow- } \\
\text { ers }\end{array}$ & $\begin{array}{r}\mathrm{I} .5 \\
\mathrm{I} 2-\mathrm{I} 6\end{array}$ & $\begin{array}{l}97 \\
68-76\end{array}$ & $\begin{array}{l}\text { Bateson and } \\
\text { Vilmorin } \\
\text { Hoshino }\end{array}$ \\
\hline Antirrhinum & $\mathbf{I}$ & $\begin{array}{l}\text { Red flower color, "pictur- } \\
\text { atum" pattern }\end{array}$ & 20.0 & 60 & Baur \\
\hline Maize & $\begin{array}{l}\text { I } \\
2 \\
2 \\
2 \\
3\end{array}$ & $\begin{array}{l}\text { Waxy endosperm, Aleurone C } \\
\text { Aleurone R, Chlorophyl G } \\
\text { Aleurone R, Chlorophyl L } \\
\text { Chlorophyl G, Chlorophyl L } \\
\text { Starchy endosperm, tunicate } \\
\text { seed }\end{array}$ & $\begin{array}{r}26.7 \\
19.0 \\
0.0 \\
23.0 \\
8.3\end{array}$ & $\left.\begin{array}{c}46.6 \\
62 ? \\
100 \\
54 \\
83.4\end{array}\right\}$ & $\begin{array}{c}\text { Breggar } \\
\text { Lindstrom } \\
\text { Jones }\end{array}$ \\
\hline Tomato & $\begin{array}{l}\text { I } \\
2\end{array}$ & $\begin{array}{l}\text { Vine habit, fruit shape } \\
\text { Green foliage, 2-celled fruit }\end{array}$ & $\begin{array}{c}20.0 \\
0 ?\end{array}$ & $\left.\begin{array}{c}60 \\
100 ?\end{array}\right\}$ & Jones \\
\hline Beans & I & Seed pattern, vine habit & o? & I00? & Surface \\
\hline Silkworm & I & $\begin{array}{l}\text { Pattern } Q \text { of larva, yellow } \\
\text { silk }\end{array}$ & $26 . \mathrm{I}$ & 47.8 & Tanaka \\
\hline Apotettix & $\begin{array}{l}\text { I } \\
\text { I } \\
\text { I } \\
\text { I } \\
\text { I } \\
\text { I } \\
\text { I } \\
\text { I }\end{array}$ & $\begin{array}{l}\text { Patterns } \mathrm{G} \text { and } \mathrm{M} \\
\text { Patterns } \mathrm{M} \text { and } \mathrm{K} \\
\text { Patterns } \mathrm{K} \text { and } \mathrm{Y} \\
\text { Patterns } \mathrm{Y} \text { and } \mathrm{R} \\
\text { Patterns } \mathrm{Y} \text { and } \mathrm{T} \\
\text { Patterns } \mathrm{R} \text { and } \mathrm{T} \\
\text { Patterns } \mathrm{M} \text { and } \mathrm{R} \\
\text { Patterns } \mathrm{Y} \text { and } \mathrm{Z} \\
\end{array}$ & $\begin{array}{r}4 \text { (inf) } \\
\text { I (inf) } \\
6 \text { (inf) } \\
\text { I0 (inf) } \\
\text { I2 (inf) } \\
0 \text { (inf) } \\
\text { IO (inf) } \\
\text { IO (inf) } \\
\end{array}$ & $\begin{array}{r}92 \\
98 \\
88 \\
80 \\
76 \\
100 \\
80 \\
80\end{array}$ & Nabours \\
\hline Pigeon & I & Sex-linked factors I and A & 40 (int) & 20 & $\begin{array}{c}\text { Cole and } \\
\text { Kelley }\end{array}$ \\
\hline Rat & $\begin{array}{l}\text { I } \\
\text { I } \\
\text { I }\end{array}$ & $\begin{array}{l}\text { Albinism, red-eyre } \\
\text { Albinism, pink-eye } \\
\text { Red-eye, pink-eye }\end{array}$ & $\begin{array}{l}\text { I.O? } \\
21.0 \\
18.3\end{array}$ & $\left.\begin{array}{c}98 ? \\
58 \\
63 \cdot 4\end{array}\right\}$ & $\begin{array}{l}\text { Castle and } \\
\text { Dunn } \\
\end{array}$ \\
\hline Mouse & I & Albinism, pink-eye & $\mathrm{I} 4 \cdot 3$ & $7 x \cdot 4$ & $\begin{array}{l}\text { Castle and } \\
\text { Dunn }\end{array}$ \\
\hline
\end{tabular}


In garden peas two independent pairs of linked characters are known and two more are suspected (White). In one of the established cases close linkage is found between round starchy seeds and tendrils on the leaves, with about I.5 per cent of crossing-over. In the other case a gene for late flowering is linked with red flower color with an estimated cross-over percentage of between $\mathrm{I} 2$ and $\mathrm{I} 6$.

In the snapdragon, Antirrhimum, two factors for flower color were found by Baur to be linked, with about 20 per cent of cross-overs occurring.

In maize three linkage groups are known, one of four factors and two of two factors each. Group I includes a factor for waxy endosperm and the factor $\mathrm{C}$ for alcurone color. These show a cross-over percentage of 26.7. Group 2 includes four linked factors, aleurone factor $\mathrm{R}$, chlorophyll factor $\mathrm{G}$, chlorophyll factor $\mathrm{L}$, and aleurone spotting factor, S. No crossovers have been observed between $\mathrm{R}$ and L which behave as if they were allelomorphs, or "completely linked." The cross-over percentage between $\mathrm{L}$ and $\mathrm{G}$ has been determined as 23 , that between $\mathrm{R}$ and $\mathrm{G}$ has been determined less accurately as I 9 , and that between $\mathrm{R}$ and $\mathrm{S}$ as $\mathrm{I} 2.5$. The order of the genes is accordingly $\mathrm{R}-\mathrm{L}-\mathrm{S}-\mathrm{G}$.

Group 3 includes the two characters, starchy endosperm and tunicate ("podded") seeds. The cross-over percentage in this case is 8.3 (Jones and Gallastegui).

In the cultivated tomato two cases of linkage have been reported. A gene for "standlard" vine habit and a gene for "constricted" fruit shape show about 20 per cent of crossing over. In another linkage group, no crossovers have been observed between green foliage color and two-celled fruit, as opposed to yellow foliage color and manycelled fruit, in a total of $24 \mathrm{~F}_{2}$ plants. It scems probable that the linkage in this latter case is close, though the number of observations is too small to do more than establish a probability.

In rats a group of three linked characters has been found, albinism (c), red-eye ( $r$ ) and pink-eye (p), which may be mapped, thus

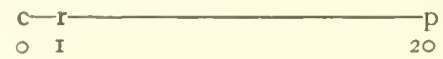

In mice albinism (c) and pink-eye (p) are linked, as they are in rats, but the cross-over percentage is less, viz., I4.3. [Castle cites further examples. $\left.{ }^{\mathrm{I}}\right]$

${ }^{`}$ See Genetics and Eugenics. 


\title{
CHAPTER XXXIII
}

\author{
SEI DETERMINATION \\ VARIOUS THEORIES OF SEX DETERMINATION
}

H. H. NEWMAX

In earlier chapters it has been necessary to introduce a few necessary facts about sex determination and sex-linked heredity. The mechanism of sex determination has been clearly described and illustrated for Drosophila (pp. 4Io ff.), and the close connection that exists between sex-linked heredity and sex determination has been shown in chapters xxxi and xxxii. A more cletailed consideration of sex determination and sex differentiation is now to come.

The question as to what determines whether an animal shall be a male or a female is a very ancient ore, and it is only during the present century that we have solved the puzzle.

A great many theories of sex determination have been proposed, some of which are as follows:

a) Hippocrates and sol.ze subsequent theorists believed that the sex of the offspring depended on the relative vigor of the parents, the more vigorous parent giving his or her sex to the offspring.

b) Thury thought that the sex of the offspring depended on the degree of ripeness of the ovum at the time of fertilization.

c) Various writers claim that statistics show that germ cells from the right ovary produce males and those from the left ovary females.

d) The nutrition theory.-The egg is a much more highly nourished cell than the spermatozoön, and the idea seems natural that high Idegrees of nourishment of the mother produce female offspring and ower degrees of nourishment male offspring. Professor Schenk of Vienna gained a huge reputation by controlling the diet of certain royal prospective mothers and predicting the sex of the offspring accordingly. He was correct in his predictions several times, but his success was short-lived. His early predictions were merely lucky, just as one might be who could guess heads or tails correctly several times in succession.

Some color is lent to the nutrition hypothesis by the fact, if it is a fact, that afier war or famine, when the nutrition of mothers has been 
low, more males than females are born. This is probably a case of differential prenatal mortality. By that we mean that more females die unborn than males, because the latter are hardier and stand prenatal malnutrition better.

e) Sex is determined at the time of fertilization.-Perhaps the best evidence that sex is determined at the very beginning of development is derived from one-egg twins and quadruplets. In the nine-banded armadillo practically every female gives birth to quadruplets, four essentially identical young being produced in each litter. All in a given set of quadruplets are invariably of the same sex, either four males or four females. Newman and Patterson have shown that each set of quadruplets comes from a single egg which at a very early stage divides into four parts to form four foetuses (Fig. 94). The conclusion is that sex was determined before the separation took place. Human identical twins, also always of the same sex, furnish further evidence in favor of very early sex determination. These and numerous other similar facts justify the conclusion that sex is determined at the time of fertilization.

THE CHROMOSOMAL MECHANISM OF SEX DETERMINATION

The well-established case of Drosophila (pp. 4 ro ff.) will serve as a basis for comparison. Many cases similar to that of Drosophila have been worked out. The chief differences have to do with the $\mathrm{X}$ and $\mathrm{Y}$ chromosomes. Sometimes the $\mathrm{X}$ chromosome is distinct and independent during synapsis and maturation, but cases are known in which the $\mathrm{X}$ chromosome is attacherl to the end of one of the ordinary chromosomes, and will, of course, always follow this chromosome in reduction division. The $\mathrm{Y}$ chromosome varies considerably in different species. Sometimes the $\mathrm{Y}$ chromosome and the $\mathrm{X}$ chromosome are optically indistinguishable. Sometimes the $\mathrm{Y}$ element is represented by a group of as many as five small chromosomes which keep together in a group and always go either one way or the other in the reduction division. Again, the $\mathrm{Y}$ element may be very small or vestigial, or, finally, it may be wanting altogether, so that $\mathrm{X}$ is an entirely unpaired chromosome that goes to one cell only at the reduction division.

In spite of all of these various modifications of the $\mathrm{X}-\mathrm{Y}$ type of chromosomal sex-determining mechanism, the method of producing male-forming and female-forming spermatozoa is the same in each case. The female gametes all have one $\mathrm{X}$ chromosome, while half of 
the male gametes have one $\mathrm{X}$ chromosome and the other half have no $\mathrm{X}$, but sometimes $\mathrm{Y}$ and sometimes simply one chromosome less than the first type of male gametes. We can then speak of the two

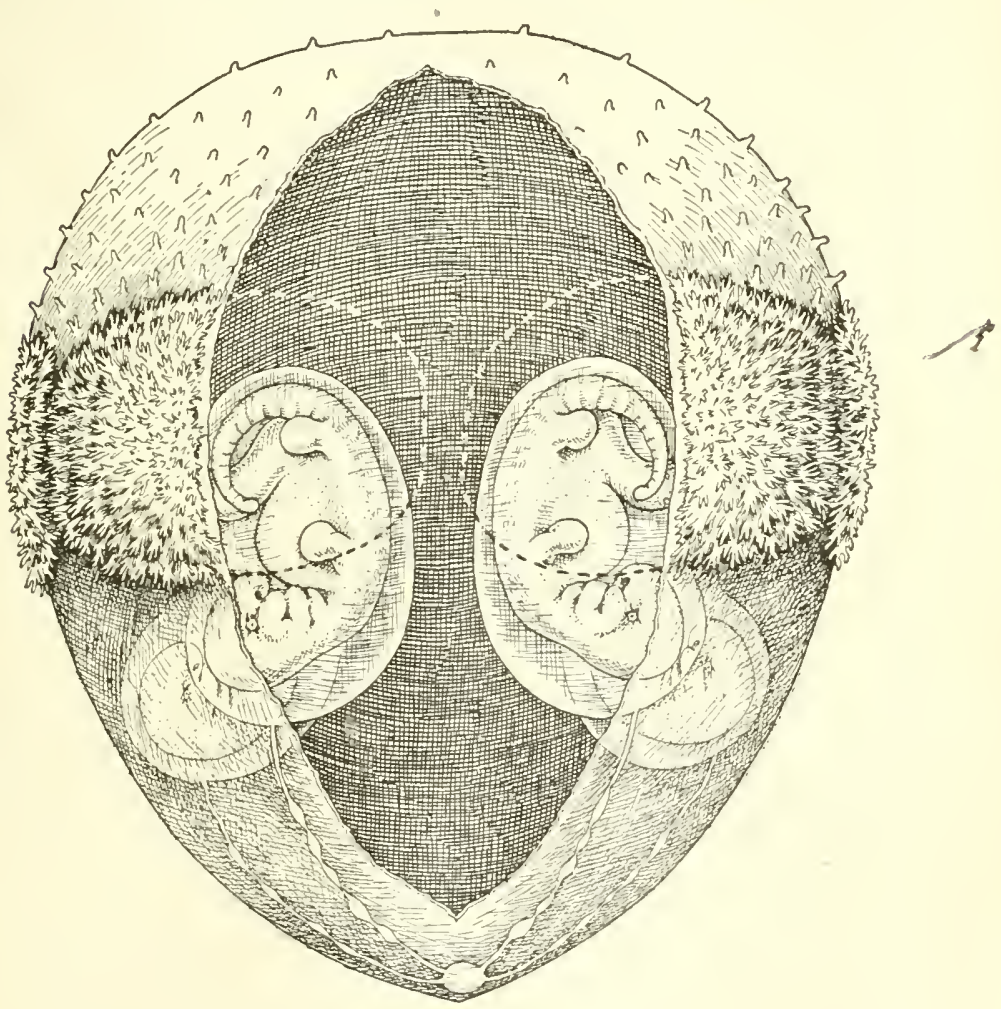

FIG. 94.-An armadillo egg about six weeks after fertilization, showing the quadruplet foetuses derived from the single egg and all destined to be of the same sex. (From Newman.)

sexes produced by union of male and female gametes simply in terms of the $\mathrm{X}$ chromosomes, females being characterized by XX (duplex) and males by $\mathbf{X}$ (simplex).

\section{SEX DETERMINATION IN PARTHENOGENETIC SPECIES}

Although it was at first thought that the facts of parthenogenesis (development of eggs without fertilization) was opposed to the chromosomal mechanism of sex determination, further study of this 
phenomenon only served to line up this category of sex determination with the type already explained.

In the bees and wasps it has long been known that eggs which are extruded without fertilization produce drones (males), while fertilized eggs produce workers or queens (both females). It has now been discovered that the bee egg undergoes the reduction division before fertilization so that all eggs will have only one X chromosome. The eggs that are fertilized always have the $\mathrm{XX}$ condition and will produce only females, while the eggs that are not fertilized keep the $\mathrm{X}$ condition and produce males. These males with only half the normal number of chromosomes cannot carry out the reduction division, but produce spermatozoa always with an $\mathrm{X}$ chromosome.

In aphids parthenogenetic individuals are always females and in this case it has been discovered that the egg develops without undergoing the reduction division, thus retaining the $\mathrm{XX}$ condition.

In all of the cases hitherto mentioned the female is said to be homozygous for sex, because she produces gametes of only one kind, from the sex standpoint, each matured egg having the $\mathrm{X}$ chromosome present. The male, on the contrary, is said to be heterozygous for sex since two kinds of sperms are produced, one with $\mathrm{X}$ and the other without $\mathrm{X}$. The great majority of animals appear to have a similar mechanism, but there are a few groups of animals which are just the reverse of what we have described, since the female is heterozygous for sex and the male homozygous.

THE POULTRY TYPE OF SEX DETERMINATION

There is now evidence both cytological and genetic that in poultry, and probably in all birds, there are two kinds of maturated eggs, one having the $\mathrm{X}$ chromosome and the other with the $\mathrm{Y}$ chromosome, or at least without an $\mathrm{X}$ chromosome. All of the spermatozoa are believed to have the X chromosome. As has already been seen (chapter xxxi), the sex linkage is just the reverse of that seen in the majority of animals when the male is the heterozygous sex. Moths and butterflies are also probably of the same type as poultry. In the classic case of Abraxas, the currant moth, a pale mutant occurred which was female and was sex-linked to females just as white eye color was linked to males in Drosophila. Apart from the fact that the XX condition seems to have shifted from one sex to the other in these two groups (birds and butterflies) the mechanism of sex determination seems to be exactly the same as in the majority of animals studied. 


\section{SEX DIFFERENTIATION}

It now becomes necessary to distinguish clearly between sex determination and sex differentiation. When we say that by means of a chromosomal mechanism sex is determined, exactly what do we mean? We answer that the sex of an individual arising from a fertilized egg (in the case of parthenogenesis, an unfertilized egg) has been settled. Now as a matter of fact only one thing has been set tled irrevocably, and that is that one individual will have the chromosome composition characteristic of a male and another individual that of a female. A male is usually an individual that produces spermatozoa and a female one that produces ova. Is it irrevocably settled beyond possibility of reversal that a zygote with the XX chromosome composition must produce eggs and one with the $\mathrm{X}$ composition, spermatozoa? This question has apparently been answered by Geoffrey Smith in his work on parasitically castrated crabs and by Richard Goldschmidt on Gypsy moths. In the first case, individual crabs whose testes had been infested by the parasitic cirripede, Sacculina, were gradually changed over in their whole metabolism to such an extent that cells destined to produce spermatozoa produced ova. In the second case, when certain varieties of moth were crossed, all of the germ cells produced females with ova, whereas half of the eggs had the XX and half the X chromosome content. This evidently means that some individuals with the male chromosome character produced eggs. From these results we may be justified in concluding that not even this most fundamental difference of sexes, that of the female producing ova and the male spermatozoa, is irrevocably predetermined at fertilization.

Lest the reader be confused, howerer, we hasten to add that under natural conditions of life an individual with the male chromosomal content produces spermatozoa and one with the female chromosomal content produces eggs, and that only rare accidental or umnatural conditions disturl the normal course of events. For purposes of practical genetics we may then define a female as an individual that produces ova and a male as one that produces spermatozoa.

Secondary sexual characters.-- Usually males and females differ from each other in many other characters besides the production of eggs or sperm. Often one sex is larger, stronger, more elaborately ornamented and colored than the other and possesses characteristic accessory sex organs whose function it is to facilitate the bringing together of the eggs and the sperm. All of the differences between the 


\section{4 \\ READINGS IN EVOIUTION, GENETICS, AND EUGENICS}

sexes other than the primary difference of egg or sperm production are called secondary sexual characters. Usually very young animals show only slight differences in secondary sexual characters and the differences increase markedly at sexual maturity. We speak of the gradual divergent development of the two sex types as sex differentiation. The question arises as to whether or not the chromosomal differences are the causes of the differentiation of secondary sexual characters. These secondary sexual characters are all somatic, and, since the soma is the product of cell division of the zygote, the soma cells must have either the male or the female chromosomal character. That the chromosomal mechanism in the somatic cells is not sufficient of itself to bring about, unaided, the differentiation of secondary sexual characters can be shown readily in at least many animals.

In the manmals, for example, it is known that the early removal of the testes or ovaries results in a retention of the juvenile or undifferentiated condition of secondary sexual characters. Evidently some influence is exerted by the tissues of the gonad that is necessary for the full differentiation of sex characters. 'The current theory is that certain glandular cells that form part of the body of ovary or testes excrete materials into the blood that stimulate various tissues in different ways and produce dimorphic results. The specific substances produced by these glands are called "hormones," for want of a better name. To test the efficiency of these hormones the crucial experiment of taking out the gonads of a young rat or guinea pig and implanting the gonad of an individual of the opposite sex has been many times performed. For example, Steinach castrated young male rats and then successfully grafted into them ovaries from young female rats. The result was that these young rats which started to be males became much altered in a female direction, the mammary glands becoming greatly enlarged, their instincts more feminine than masculine, and in a number of other particulars they showed more or less pronounced evidences of feminization. Conversely, spayed females with engrafted testes showed a tendency toward male differentiation, especially in instincts. These experiments have been largely confirmed by C. R. Moore.

Similar experiments with similar results have been performed with fowls and ducks. All indicate that the glandular part of the gonads has a determinative effect on sex differentiation, and this in spite of the chromosome make-up of the somatic cells; for the male differentiation in cells with the male chromosome characters can be 


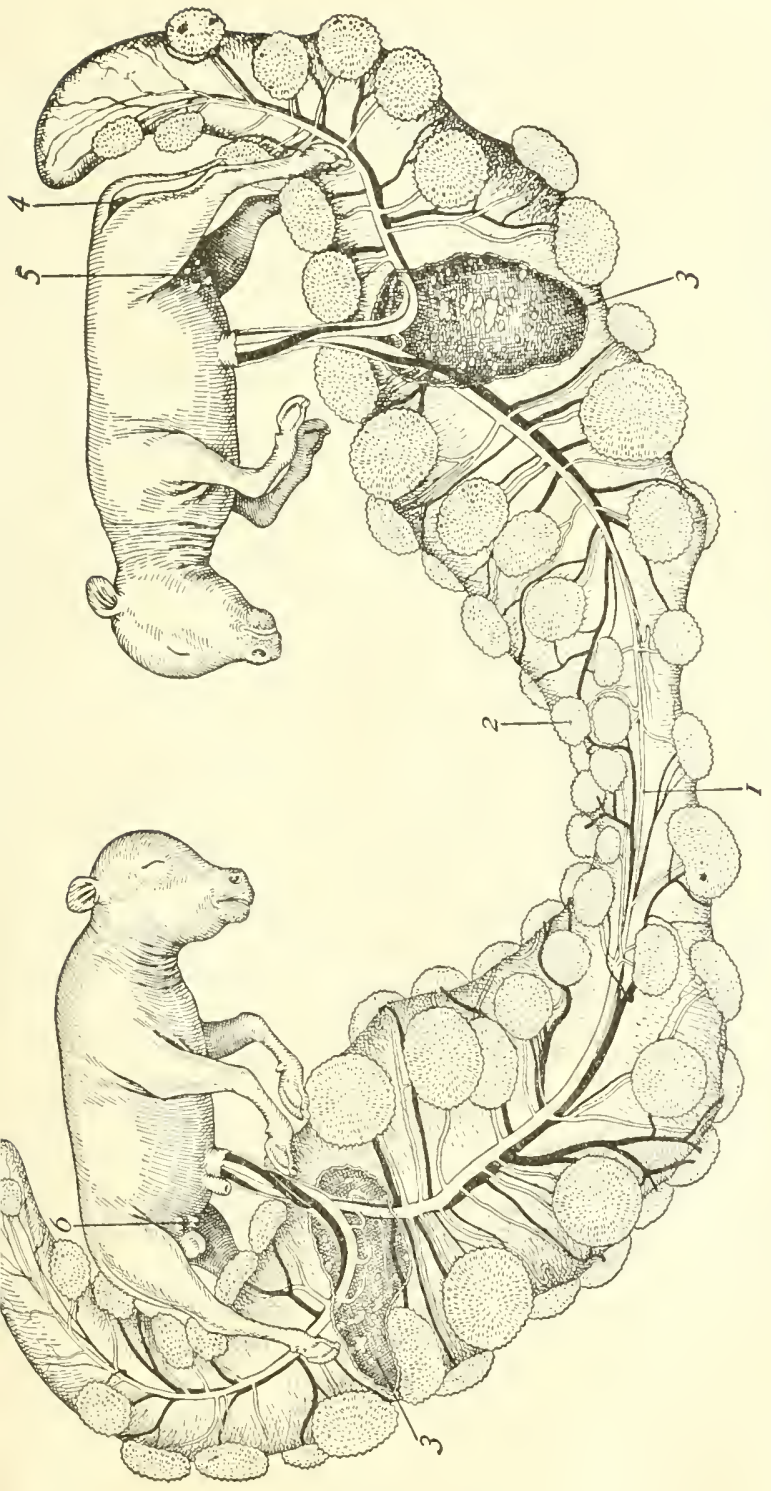

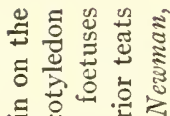

.

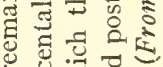

出芯范

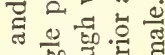

茟

ฮิ โ

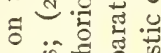

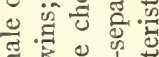

范要焉

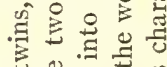

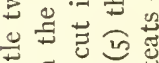

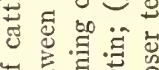

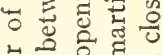

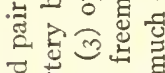

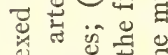

फ़ 날

:

范

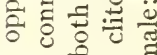

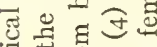

结芯导

广

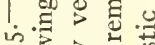

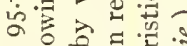

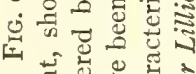

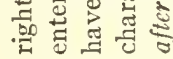


inhibited and female differentiation superimposed if the female gonad is introduced in the absence of the male gonad.

A beautiful experiment conducted by nature herself helps to drive home the hormone theory of sex differentiation. In cattle, as shown recently by $\mathrm{F}$. R. Lillie, twins occur in a small percentage of cases and involve the simultaneous fertilization of two eggs. These eggs lie as a rule in opposite horns of the forked uterus, but owing to the growth of their embryonic membranes the two individuals come to fuse circulations so that there is an admixture of blood (Fig. 95). The result is that if the twins are zygotically of the same sex no untoward effect of blood admixture is apparent, but when the twins are zygotically a male and a female, the female individual is always stopped in its female differentiation and becomes more or less completely transformed in a male direction. It appears, however, that at the time when blood admixture occurs, the female individual has already differentiated so far with respect to the external genitalia and in other respects that, even though subsequent development be entirely male in character, the resultant individual is always a sterile creature, neither fully a female nor a complete male. Such individuals have long been known as "freemartins." As a rare exception to the general rule an occasional case has appeared in which a male and a female pair fail to undergo blood admixture. In such cases both develop into normal animals. It now appears that the reason why the female ser: is the one to suffer is that the male gonads differentiate precociously, before the female, and inhibit the subsequent development of female gonads. Hence the only hormones in the blood of both twins are the male hormones.

In conclusion we may say then that, in mammals, though chromosomes tend to determine the primary sex differences, they have no effect on the differentiation of secondary sexual characters. These are due to substances secreted by the gonads that have been called a hormones. 


\section{PART V}

EUGENICS 



\section{CHAPTER XXXIV}

\section{THE INHERITANCE OF HUMAN CHARACTERS, PHYSICAL AND MENTAL}

ELLIOT R. DOWNING

Anyone who undertakes to trace the ancestry of an individual is soon impressed with the fact that it is a difficult task even to find the names of the persons involved three or four generations back; it is much more difficult to determine with certainty their physical and mental characteristics. One can more surely find the pedigree of a horse or hog that he may own than he can of a child in whom he is interested, for we do have registry books for good stock, but none ordinarily for human family relations (in Illinois not even compulsory birth registrations until very recently), so that a child born in this state may not even legally prove his existence or parentage by official records. It is not an easy matter, therefore, to find human data that illustrate the various phases of heredity concerning which we are reasonably sure in dealing with animals and plants.

Fortunately, there are some studies of the inheritance of physical characters that are quite satisfactory. There is an increasing number of studies of the inheritance of insanity, feeble-mindedness, epilepsy, and alcoholism by the scientific staff of institutions dealing with such cases, and we do have a fairly good mass of material in the lines of descent of the royal families of Europe, where the matings and the characters of the individuals are more or less matters of history. Thanks to the generosity of some men of wealth and foresight, appreciative of the importance of a better knowledge of the laws of human heredity, we have in several countries well-endowed laboratories with expert staffs founded on purpose to study this topic; such as the Galton Laboratory of Eugenics in England and the Eugenics Laboratory of the Carnegie Institution, Cold Springs Harbor, New York.

Occasionally a family is found in which one or more members have five fingers instead of four; such a condition is known as polydactylism. Sometimes a case is recorded in which a person has fingers with

'From E. R. Downing, The Third and Fourth Generation (The University of Chicago Press, copyright I920). 
two joints instead of three and a thumb with one joint in place of two (brachydactylism). Such human abnormalities are inherited. There

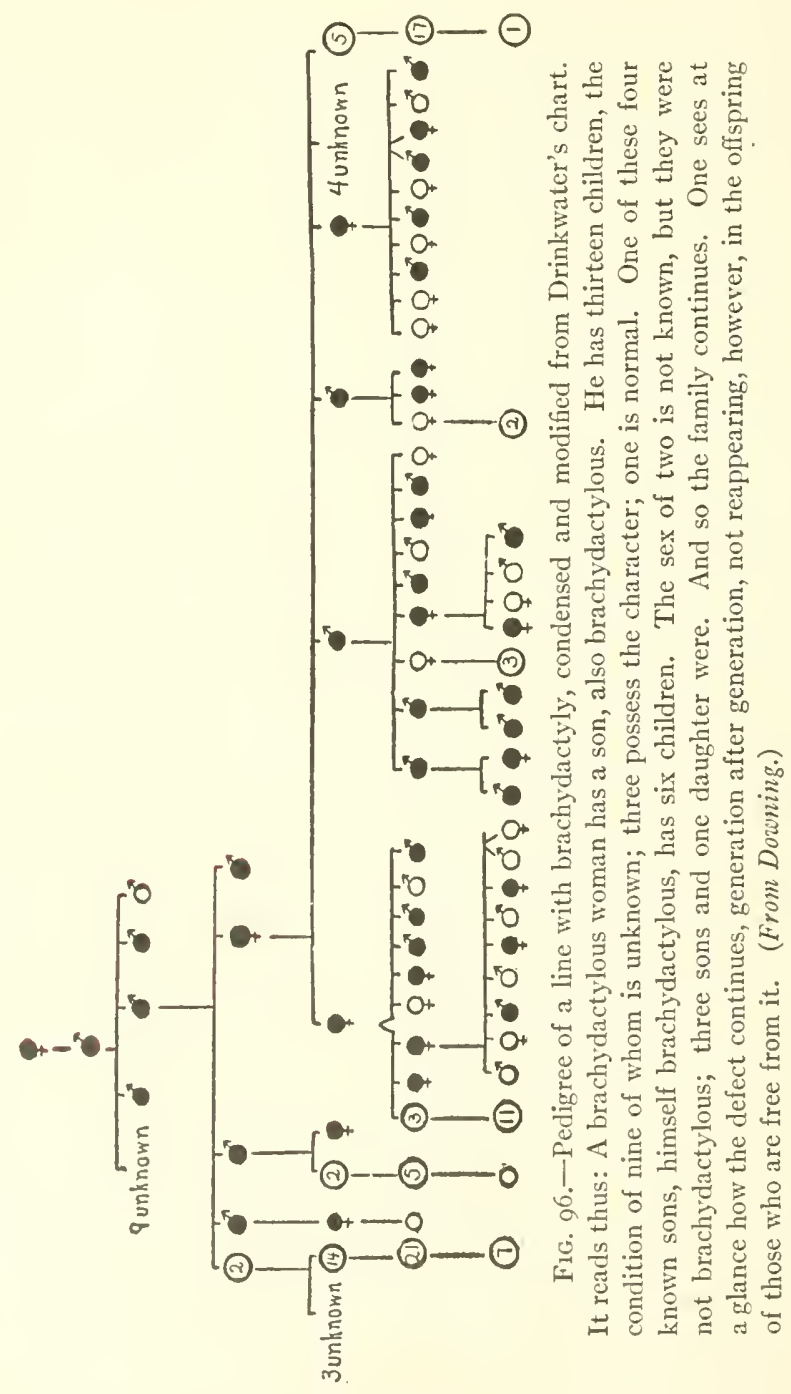

is given on this page a chart (Fig. 96) of a family tree in which brachydactylism is very common; it is based on a study made by Drinkwater. Males in the chart are represented by $\hat{b}$, females by $\hat{q}$, 
matings by $=$. The circles are of solid color in individuals affected with the deformity, open $\bigcirc$ in normal individuals. The character seems to behave like a Mendelian dominant, though one could make no very positive assertion on this point from so few individuals. But it is very evident that such a physical character once in the stock is transmitted generation after generation, reappearing continually in the offspring.

Below there is presented a chart (Fig. 97) of the transmission of cataract. This disease is characterized by the appearance of an opaque area in the usually transparent parts of the eye,

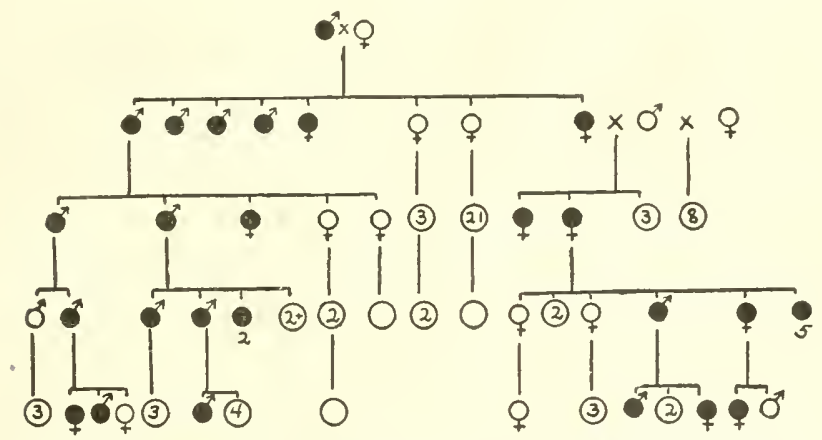

FIG. 97.- Inheritance of one torm of cataract. Modified from Nettleship's chart. The diagram reads thus: A man with cataract married a normal woman; of their eight children six were affected with the disease. One of these married an unafiected man; three of the children of this union were normal, sex unrecorded, two defective. This same man married a second wife who was normal; their eight children were all unaffected. So continue reading through five generations. (From Downing.)

ultimately rendering the person blind. In the particular form of the disease here considered it does not develop until middle life. Clarence Loeb in a study of hereditary blindness published in Igog tabulated the results of a study of 304 families in which such blindness occurs. There were I,OI 2 children, of whom $5^{8}$ per cent were afflicted, which is about the percentage expected when hybrid defectives mate with normal individuals and the defect is a dominant character. Similar extensive studies of congenital deafness and deaf-mutism show that these are similarly heritable, though just how the character behaves is not yet known, for undoubtedly under "deafness" are included a variety of diseased conditions that must be 
studied separately before we shall know how each is inherited. Care must be taken, too, to distinguish between congenital deafness and blindness - that which inheres in the germ plasm-and those forms, due to accident or contagious disease, which are acquired modifications and so not heritable. Thus measles often produces deafness as one of its after effects. Persons so rendered deaf would not transmit the affliction to their children any more than they would transmit blindness if the eyes of the parents were put out by accident.

Feeble-mindedness apparently behaves as a Mendelian recessive. Goddard's studies of the family pedigree of the inmates of the Vineland, New Jersey, institution for the care of the feeble-minded gives us an abundance of material to show the heritability of this defect and its relation to alcoholism, insanity, syphilis, etc. Briefly, syphilitic infection is a fairly common cause of feeble-mindedness in children. There is a higher percentage of feeble-mindedness in the offspring of alcoholic parents than among those of parents not addicted to it. There seems little or no causal relation between feeble-mindedness and insanity. But aside from feeble-mindedness that may be produced by such causes or by occasional accidents such as falls, blows on the head, there is the great mass of feeble-mindedness that is wholly a matter of heredity.

If a feeble-minded individual comes from parents both of whom are congenitally feeble-minded or who both have a great deal of feehlemindedness in their ancestry, such a one is taken to be a pure recessive as far as this character is concerned, and his germ cells have a double dose of the factor for feeble-mindedness (FF). When two such persons mate, their offspring would be expected to be all feeble-minded, for all eggs and sperm contain the factor F, and when any egg is fertilized the person produced is an FF individual. Out of 144 such matings resulting in 482 offspring whose records are known, Goddard found that 476 were feeble-minded. This type of mating as well as others cited below are illustrated in the family pedigrees shown on pages $46_{3}$ and 464 , selected from Goddlard's book.

If a person comes from parents one of whom is entirely normal and one is feeble-minded with many feeble-minded ancestors, it is probable that such an individual is a hybrid with germ cells that, as far as this one character is concerned, can be designated NF. Such a person will pass for normal, since feeble-mindedness is recessive. If such a one mates with the type described above (FF), it would be expected that half the offspring would be normal, half feeble-minded. Out of 


\section{READINGS IN EVOLUTION, GENETICS, AND EUGENICS}

Such cases as those cited are interesting from the standpoint of the student of heredity. They are tremendously significant to the average citizen because there is in the United States a very large feeble-minded population, estimated at 200,000 , nine-tenths of whom are at large, free to reproduce their kind, and very prone to interbreed, because the feeble-minded are seldom sought as legitimate mates by persons of normal mentality. The number of feeble-minded is apparently increasing much more rapidly than the general population. How rapidly, it is impossible to determine, for we have no exact data on the number of feeble-minded; we are not yet awake to the enormity of the problem involved. From these feeble-minded come some

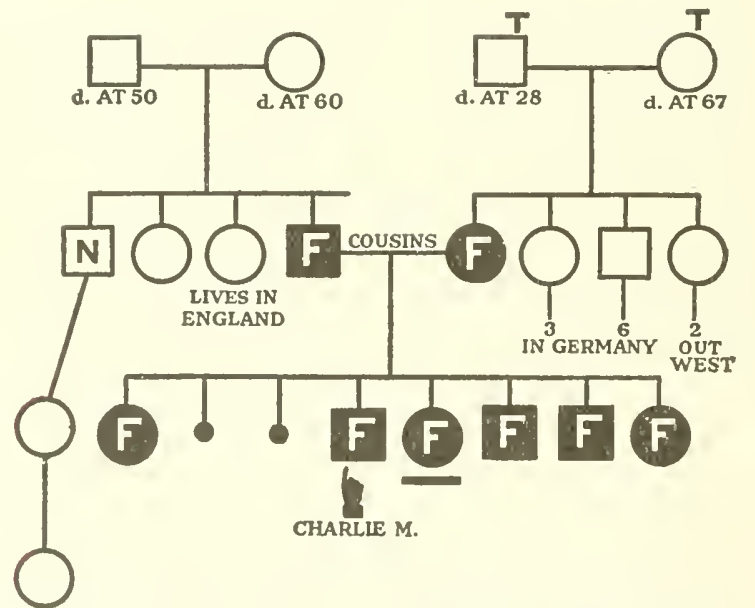

FIG. 99.-Family of Charlie M. (From Downing, after Goddard.)

40 per cent of our prostitutes, a fourth of our criminals, and at least a half of the inmates of our almshouses.

A generation ago the valley of Aosta, in Northern Italy, was overrun with feeble-minded and idiotic individuals of the type known as cretins. It was estimated that fully 60 per cent of the population were affected with this abnormality. A law was passed and enforced segregating the really irresponsible cases and prohibiting the marriage of cretin with cretin. Now the condition has almost disappeared, and it is estimated that only a very small percentage of the population are cretins, these nearly all old, so that this particular form of idiocy will there very soon be a thing of the past. It seems only a rational procedure to accomplish at least a segregation of feeble-minded in this 
country, even if no more drastic action is taken. Otherwise the group is bound to be an increasing burden on the community, adding constantly to the tax needed for their support.

Investigations of competent officials in the employ of insane hospitals have accumulated a mass of evidence demonstrating the heritability of many forms of nervous diseases which most commonly behave as recessives. Rosanoff and Orr, ${ }^{\mathrm{I}}$ in a study of 206 matings between individuals from more or less insane stock, found 1,097 children, I 46 of whom died in childhood. There were $35 \mathrm{I}$ afflicted

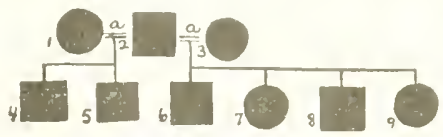

FIG. I00.-(I) Ignorant, "queer"; (2) Insane, was in sanitarium, committed suicide; (3) eccentric, violent temper, ideas of persecution against neighbors; (4) eccentric, not well balancerl; (5) alcoholic, lazy, indolent; (6) dementia praccox, paranoid, in state hospital; (7) violent temper, queer, extreme dolichocephaly; (\$) defective, cranial malformation; (o) inferior, "slow." (From Downing, after Rosanoff and Orr.\} offspring to 586 normal. The theoretical expectations, knowing with more or less certainty the character of the parents, were 359 to 578. There are presented (Figs. IOO, IOI) two typical family pedigrees. In the first an insane man was twicc married, each time to an

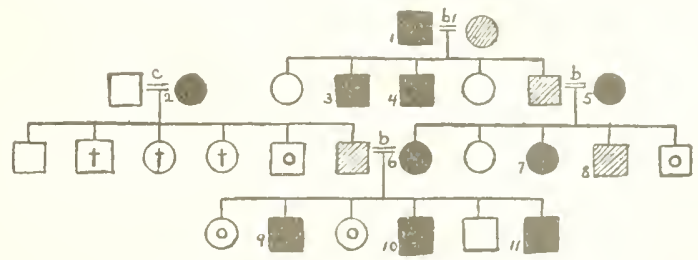

Fig. гог.-(1) epileptic; (2) insane for a time, recovered; (3) epileptic, imbecile; (4) imbecile; (5) melancholy in early married life, recovered; (6) insane five years, was in state hospital, recovered; ( 7 ) insomnia, neuralgial ( $\$$ ) diunghter latal spells of excitement; (0) feeble-minded; (10) demential pracox, katatonic, in state hospital; (II) died of marasmus, had one convulsion. (From Douning, after Rosanoff and Orr.)

eccentric woman, undoubtedly mildly insane. All the offspring were unbalanced. In the second case, those distinctly neurotic are indicated in solid color; those having a neurotic element in the germ material are shaded. It might seem as if insane individuals would scarcely add materially to the general population, since they are commonly in asylums. Often, however, the inherited insanity does not

${ }^{1}$ Eugenics Record Office (Cold Springs Harbor, N.Y.) Bulletin No. 5, IgI I. 
manifest itself until past middle life, when they have already married and started a family. Moreover, those hybrid individuals in whom the insane tendency is present alongside of the normal determiner appear as normal individuals, Frequently they can be detected only by an examination of the perligree. If such individuals mate, onefourth of the offspring would be expected to be insane.

Early modern European history centers about the doings of a few great men and women. Peter the Great of Russia, Ferdinand and Isabella and Charles V of Spain, Frederick the Great of Prussia,Gustavus Adolphus and Charles XII of Sweden, are among the most brilliant of these potent individuals that shaped the destinies of Europe during this period. It is interesting to note how their characters are determined (and through them national destinies are apparently decided in no small measure) by the hereditary concentration of ability due to lucky royal matings, and how their genius is dissipated by unwise matings.

Peter the Great of Russia came as a brilliant type from a good stock, though with a very evident taint of epilepsy and feeblemindedness. He himself was an epileptic. His father, grandfather, and great-grandfather had been men of large ability. They had married peasant girls, as was the custom of the czars. Peter's own brothers and sisters were in no way remarkable. His half-sister Sophia was a woman of marked ability, although two of her brothers were imbeciles, one also an epileptic. As will be seen from the pedigree, the epilepsy, imbecility, and mediocrity appear in both Peter's children and grandchildren, as well as in those of his imbecile half-brother, Ivan. It is interesting to note from the pedigree that the feeble-mindedness and epilepsy seem to cling to the males quite persistently. The females of the family are much more apt to be brilliant and virtuous. Peter the Great's own son Alexis was a poor dissolute specimen, and although he married Charlotte, the angelic daughter of a great line, the house of Brunswick, the son of this mating was Peter II, of unstable mind, while the daughter Natalia was as sweet as she was energetic.

Isabella and Fcrdinand were both descendants from lines of very great individuals, although in each case there is insanity in the family. Isabella herself comes from an insane mother and an imbecile father, but her grandparents and great-grandparents were well-balanced and able. The data for the charts of these royal families were taken largely from F. A. Woods's Mental and Moral Heredity in Royalty, supplemented with information from other sources. He grades the 


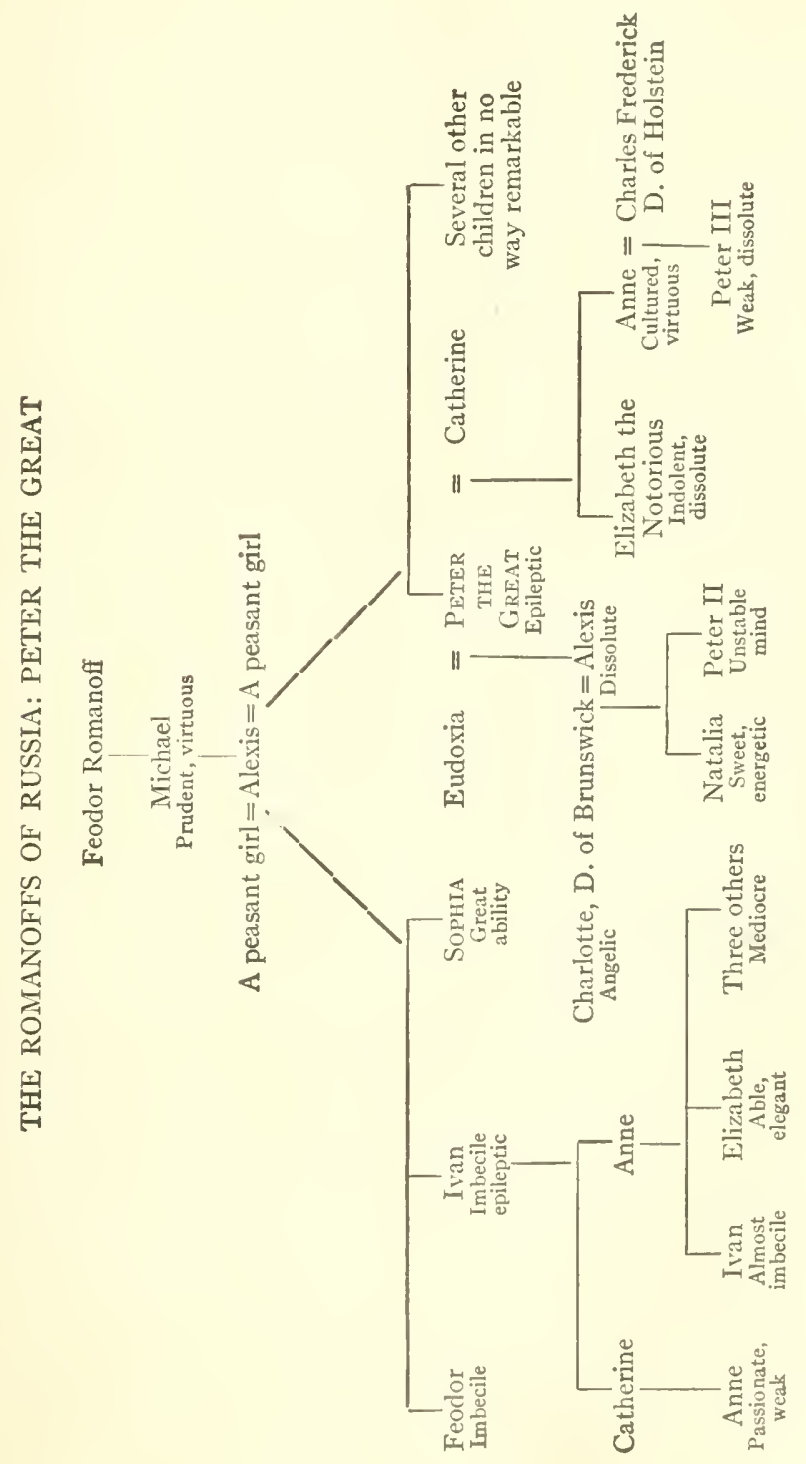


468 READINGS IN EVOLUTION, GENETICS, AND EUGENICS

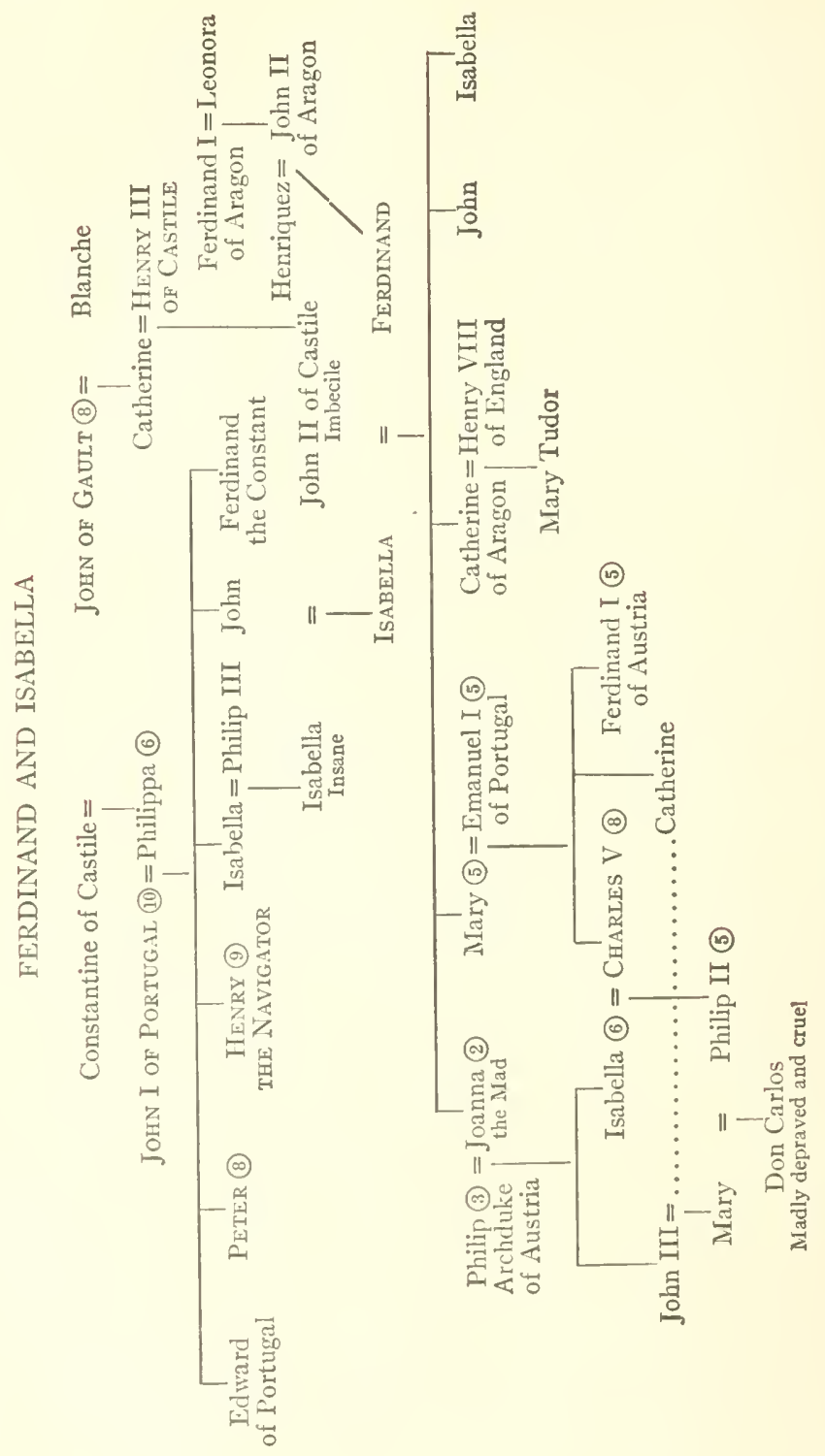


individuals on a scale of Io. Ten represents very high ability, as determined by the comparative amount of space and laudation given to the individual in such standard works as Lippincott's Biographical Dictionary. Five out of eight of Isabella's great-grandparents rank very high. John the Great of Portugal, twice her great-grandfather, has a grade of Io. John of (iault. (wice her great-grandfather, has a grade of $\mathrm{S}$, as does also John of Castile, while Henry III of Castile, one of her grandparents, is designated the model king. Ferdinand I of Aragon, the grandfather of Ferdinand, is a brother of this same Henry III of Castile, and is also an cxceedingly able king. Of the children of Ferdinand and Tsabetla, most were mediocre or distinctly inferior. Joanna was insane. In the next generation, however, appears Charles $V$, whose reign marked the acme of Spain's greatness, partially due to his own ảbility, partially dice to the momentum of those movements that were instituted ly his illustrious grandparents. Charles $\mathrm{V}$ married his own cousin, as did also John HI. Chiklren of these two matings married, and Don Carlos, child of this latter marriage, was madly depraved and cruel.

When insanity and brilliancy are found in the ancestry it seems merely a matter of chance as to whether the determiners for greatness will be thrown together in the union of sperm and egg or those for insanity. We ciln predict with some certainty, that, in a large number of offspring, ability will reappear and insanity will reappear, lout just what individual each will strike it is impossible to prophesy without knowing much more definitely the nature of the germ plasm involved. One may say that the convergence of a number of lines of descent from great ancestors toward one individual makes it probable that he will be exceptionally able.

This is nowhere better illustrated than in the family tree of Frederick the Great of the Prussian house of Hohenzollern, as will be seen from the chart on page 470 . Of his great-grandparents, three scale 10 , one 9 , one 8 , two 7 , and one 6 . Not one is below mediocrity, and the majority are of very high grarle. Of his fourteen ancestors back three generations, only one is distinctly inferior. Of his brothers and sisters, four are distinctly great, three metiocre, and one inferior.

It is interesting to trace the effect of the mating of such splendicl stock with another brilliant line, that of the Swedish royal house. Gustavus I, or Gustavus Vasa, is another instance of the brilliant mutant, with some taint of neurosis. He married a gentle and tactul princess; their son Charles IX was a very able man, although of their 


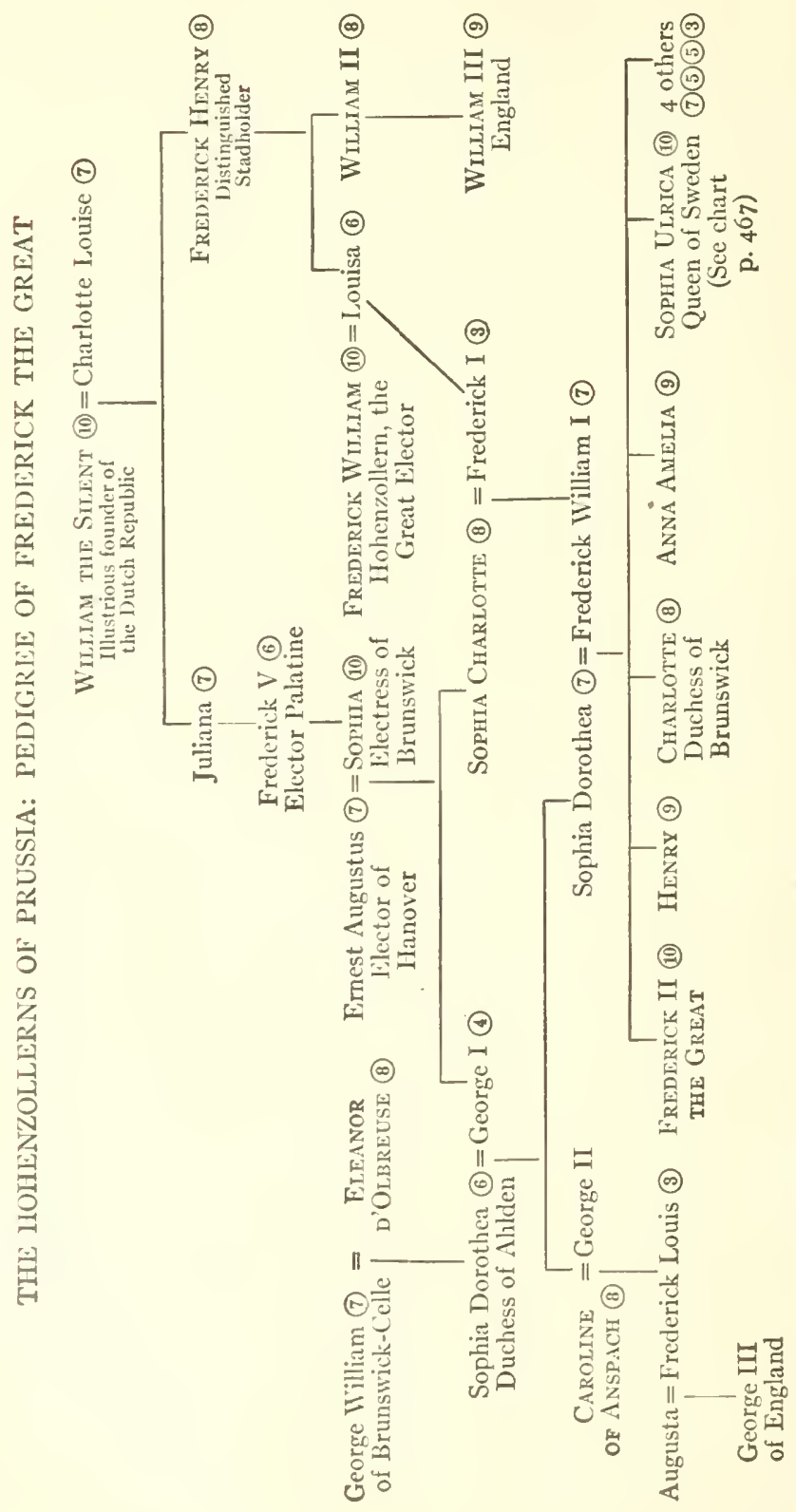




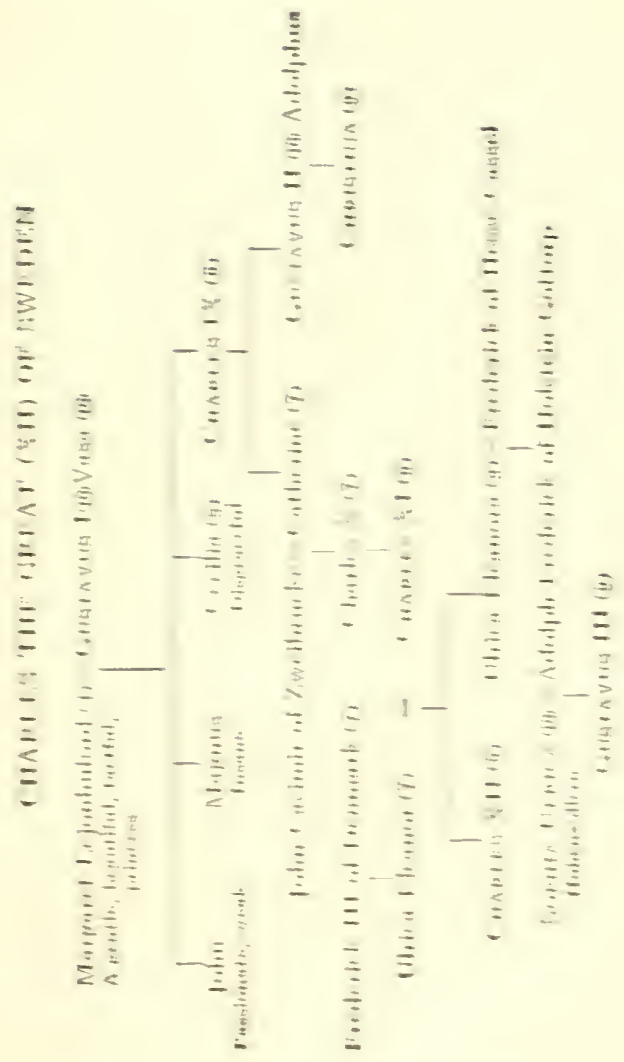


three other children one was insane and two weak. The children of Charles LX were both remarkably able. The daughter Catherine becomes the mother of a later succession of kings. Her son Charles $\mathrm{X}$ and his son Charles XI were rather mediocre; but Charles XI, with this fine stock behind him, married Ulrica Eleanor (7), granddaughter of Christian IV of Denmark, the most brilliant of all Danish sovereigns, and Charles XII, their son, is pronounced by Voltaire the most remarkable man who ever existed. Charles XII had no children: the succession passed to his sister's son, Adolph Frederick of HolsteinGottorp, who married Louisa Ulrica, sister of Frederick the Great of Prussia. The result of this union of two great lines of hereditary ability was Gustavus III, a fit successor of Gustavus Vasa, Gustarus Adolphus, and Charles XII; he was "a prodigy of talents," statesman, poet, dramatist. 


\title{
CHAPTER XXXV
}

\section{HUMAN CONSERVATION ${ }^{x}$}

\author{
HERBERT E. WALTER
}

\section{HOW MANKIND MAY BE IMPROVED}

There are two fundamental ways to bring about human betterment, namely, by improving the individual and by improving the race. The first method consists in making the best of whatever heritage has been received by placing the individual in the most favorable environment and developing his capacities to the utmost through education. The second method consists in seeking a better heritage with which to begin the life of the individual. The first method is immerliate and urgent for the present generation. The second method is concerned with ideals for the future, and consequently does not usually present so strong an appeal to the individual.

The first is the method of euthcuics, or the science of learning to live well. The second is eugenics, which Galton defines as "the science of being well born."

These two aspects of human betterment, however, are inseparalole. Any hereditary characteristic must be regarded, not as an independent entity, but as a reaction between the germplasm and its environment. The biologist who disregards the fields of educational endeavor and environmental influence, is equally at fault with the sociologist who fails sufficiently to realize the fundamental importance of the germplasm.

Without euthenic opportmity the best of heritages would never fully come to its own. Without the eugenic foundation the best opportunity fails of accomplishment. The euthenic point of view, however, must not distract the attention now, for the present chapter is particularly concerned with the program of eugenics.

\section{MORE FACTS NEEDEN}

Since the point of attack in human heredity must be largely statistical, it is of the first importance to collect more facts. Our actual knowledge is confused with a mass of tradition and opinion,

r From H. E. Walter, Genetics (copyright I9I3). Used by special permission of the publishers, The Macmillan Company. 


\section{READINGS IN EVOLUTION, GENETICS, AND EUGENICS}

much of which rests upon questionable foundations. The great present need is to learn more facts; to sift the truth from error in what is already known; and to reduce all these data to workable scientific form. Much progress is being made in this direction, owing to the impetus given by the revival of Mendel's illuminating work, but as yet the science of eugenics is in its infancy.

The most systematic and effective attempt in this country to collect reliable data concerning heredity in man has been initiated by the Eugenics Section of the American Breeders' Association under the secretaryship of Dr. C. B. Davenport. In I910 the Eugenics Record Office, with a staff of expert field and office workers and an adequate equipment of fire-proof vaults, etc., for the preservation of records, was opened at Cold Spring Harbor, Long Island, New York, with Mr. H. H. Laughlin as superintendent. "The main work of this office is investigation into the laws of inheritance of traits in human beings and their application to eugenics. It proffers its services free of charge to persons seeking advice as to the consequences of proposed marriage matings. In a word, it is devoted to the advancement of the science and practice of eugenics." The publication of results from the Eugenics Record Office has already been begun.

The Volta Bureau, founded about twenty-five years ago in Washington by Dr. Alexander Graham Bell, is collecting data with reference to deafness and has now systematically arranged particulars concerning the history of over 20,000 individuals. In England, also, the Galton Laboratory for Eugenics, founded in 1905 , is systematically collecting facts about human pedigrees and publishing the results in a compendious "Treasury of Human Inheritance."

Besides these special bureaus of investigation, innumerable facts about the inheritance of particular traits are being incidentally brought together and made available in various institutions and asylums throughout the world which are immediately concerned with the care of defectives of different types. It is in connection with such institutions for defectives that much of the most successful "field work" of the Eugenics Section of the American Breeders' Association is being accomplished in the United States.

\section{FURTIER APPLICATION OF WTIAT WE KNOW NECESSARY}

Human performance always lags behind human knowledge. Many persons who are fully aware of the right procedure do not put their knowledge into practice. It follows, therefore, that any pro- 
gram of eugenics which does not grip the imagination of the common people in such a way as to become an effective part of their very lives is bound to remain largely an academic affair for utopians to quarrel and theorize over.

It is not enough to collect facts and work out an analysis and interpretation of them, for, important as this preliminary step is, it must be followed by a convincing campaign of education.

The lives of the unborn do not force themselves upon the average man or woman with the same insistency as the lives already begun. In the midst of the overwhelming demands of the present, the appeal of posterity for better blood is vague and remote. If every individual regarded the germplasm he carries as a sacred trust, then it would be the part of an awakened eugenic conscience to restrain that germplasm when it is known to be defective or, when it is not defective, to hand it on to posterity with at least as much foresight as is exercised in breeding domestic animals and cultivated plants.

The eugenic conscience is in need of development, and it is only when this becomes thoroughly aroused in the rank and file of society as well as among the leaders, that a permanent and increasing betterment of mankind can be expected.

\section{THE RESTRICTION OF UNDESIRABLE GERMPLASM}

A negative way to bring about better blood in the world is to follow the clarion call of Davenport, and "dry up the streams that feed the torrent of defective and degenerate protoplasm." This may be partially accomplished, at least in America, by employing the following agencies: control of immigration; more discriminating marriage laws; a quickened eugenic sentiment; sexual segregation of defectives; and finally, drastic measures of asexualization or sterilization when necessary.

a) Control of imMigration

The enforcement of immigration laws tends to debar from the United States not only many undesirable individuals, but also incidentally to keep out much potentially bad germplasm that, if admitted, might play havoc with future generations.

For example, during the year of 1908,65 idiots, I 2 I feeble-minded, I 84 insane, 3,74I paupers, 2,900 individuals having contagious diseases, 53 tuberculous individuals, I 36 criminals, and I 24 prostitutes were caught in the sieve at Ellis Island alone and turned back from this country by the immigration officials. These 7,000 and more 


\section{$47^{6}$ READINGS IN EVOLUTION, GENETICS, AND EUGENICS}

individuals probably were the bearers of very little germplasm that we are nationally not better off without.

Eugenically, the weak point in the present application of immigration laws is that criteria for exclusion are phenotypic in nature rather than genotypic, and consequently much bad germplasm comes through our gates hidden from the view of inspectors because the bearers are heterozygous, wearing a cloak of desirability over undesirable traits.

It is not enough to lift the eyelid of a prospective parent of American citizens to discover whether he has some kind of an eye-disease or to count the contents of his purse to see if he can pay his own way. The official ought to know if eye-disease runs in the immigrant's family and whether he comes from a race of people which, through chronic shiftlessness or lack of initiative, have always carried light purses.

In selecting horses for a stock-farm an expert horseman might rely to a considerable extent upon his judgment of horseflesh based upon inspection alone, but the wise breeder does more than take the chances of an ordinary horse trader. He wants to be assured of the pedigree of his prospective stock. It is to be hoped that the time will come when we, as a nation, will rise above the hazardous methods of the horse trader in selecting from the foreign applicants who knock at our portals, and that we will exercise a more fundamental discrimination than such a haphazard method affords, by demanding a knowledge of the germplasm of these candidates for citizenship, as displayed in their pedigrees.

This may possibly be accomplished by having trained inspectors located abroad in the communities from which our immigrants come, whose duty it shall be to look up the ancestry of prospective applicants and to stamp desirable ones with approval. The national expense of such a program of genealogical inspection would be far less than the maintenance of introduced defectives, in fact it would greatly decrease the number of defectives in the country. At the present time this country is spending over one hundred million dollars a year on defectives alone, and each year sees this amount increased.

The United States Department of Agriculture already has field agents scouring every land for desirable animals and plants to introduce into this country, as well as stringent laws to prevent the importation of dangerous weeds, parasites, and organisms of various kinds. Is the inspection and supervision of human blood less important? 


\section{b) MORE DISCRIMINATING MARRIAGE LAWS}

Every people, including even the more primitive races, make customs or laws that tend to regulate marriage. Of these, the laws which relate to the eugenic aspect of marriage are the only ones that concern us in this connection. "Narriage," says Davenport, "can be looked at from many points of view. In novels as the climax of human courtship; in law largely as two lines of property descent; in society, as fixing a certain status; but in eugenics, which considers its biological aspect, marriage is an experiment in breeding."

Certain of the United States have laws forbidding the marriage of epileptics, the insane, habitual drunkards, paupers, idiots, feebleminded, and those afficted with venereal diseases. It would be well if such laws were not only more uniform and widespread, but also more rigidly enforced.

It is quite true that marriage laws in themselves do not necessarily control human reproduction, for illegitimacy is a factor that must always be reckoned with; nevertheless such laws do have an important influence in regulating marriage and consequent reproduction.

Marriage laws may, however, sometimes bring ahout a deplorable result eugenically, as in the case of forced marriage of sexual offenders in order to legalize the offense and "save the woman's honor." To compel, under the guise of legality, two defective streams of germplasm to combine repeatedly and thereby result in defective offspring just because the unfortunate event happened once illegitimately, is fundamentally a mistake. Darwin says: "Except in the case of man himself hardly any one is so ignorant as to allow his worst animals to breed."

c) AN EDUCATEd SENTIMENT

A far more effective means of restricting bad germplasm than placing elaborate marriage laws upon our statute-books is to educate public sentiment and to foster a popular eugenic conscience, in the absence of which the safeguards of the law must forever be largely without avail.

Such a sentiment already generally exists to a large extent with respect to incest, and the marriage of persons as noticeably defective as idiots or those afflicted with insanity, and also in America with respect to miscegenation, but a cautious and intelligent examination of the more obscure defective traits, exhibited in the somatoplasms of the various members of families in question, is largely an ideal of the 


\section{READINGS IN EVOLUTION, GENETICS, AND EUGENICS}

future. Under existing conditions non-eugenic considerations such as wealth, social position, etc., often enter into the preliminary negotiations of a marriage alliance, but an equally unromantic caution with reference to the physical, moral, and mental characters that make up the biological heritage of contracting parties is less usual.

The scientific attitude is not necessarily opposed to the romantic way of looking at things. Science is simple "organized common sense," and romance, that dispenses with this balance-wheel, although it may be entertaining and always exciting at first, is sure to be disappointing in the end. Marriages may be "made in heaven," but, as a matter of fact, children are born and have to be brought up on earth. It follows without saying that it will be much easier to stamp out bad germplasm when an educated sentiment becomes common among all people everywhere.

\section{d) SEgREgation OF DEFECTIVES}

Persons with hereditary defects, such as epileptics, idiots, and certain criminals, who become wards of the state, should be segregated so that their germplasm may not escape to furnish additional burdens to society. "We have become so used to crime, disease and degeneracy that we take them for necessary evils. That they were in the world's ignorance, is granted. That they must remain so, is denied" (Davenport).

"The great horde of defectives once in the world have the right to live and enjoy as best they may whatever freedom is compatible with the lives and freedom of other members of society," says Kellicott, but society had a right to protect itself against repetitions of hereditary blunders.

There is one grave danger connected with the administration of our humane and commendable philanthropies toward the unfortunate, for it frequently happens that defectives are kept in institutions until they are sexually mature or are partly self-supporting, when they are liberated only to add to the burden of society by reproducing their like.

Furthermore, if defectives of the same sort are collected together in the same institutions, unless sexual segregation is strictly maintained, they may by the very circumstance of proximity tend to reproduce their kind just as defectives in any isolated community tend to multiply.

David Starr Jordan cites the interesting case of cretinism which occurs in the valley of Aosta in northern Italy, to prove the wisdom 
of the sexual segregation of defectives. Cretinism is an hereditary defect connected with an abnormal development of the thyroid gland which results in a peculiar form of idiocy usually associated with goitre.

"In the city of Aosta the goitrous cretin has been for centuries an object of charity. The idiot has received generous support, while the poor farmer or laborer with brains and no goitre has had the severest of struggles. In the competition of life a premium has thus been placed on imbecility and disease. The cretin has mated with cretin, the goitre with goitre, and charity and religion have presided over the union. The result is that idiocy is multiplied and intensified. The cretin of Aosta has been developed as a new species of man. In fair weather the roads about the city are lined with these awful paupershuman beings with less intelligence than a goose, with less decency than the pig."

Whymper, writing in I880, further observes: "It is strange that self-interest does not lead the natives of Aosta to place their cretins under such restrictions as would prevent their illicit intercourse; and it is still more surprising to find the Catholic Church actually legalizing their marriage. There is something horribly grotesque in the idea of solemnizing the union of a brace of idiots, and, since it is well known that the disease is hereditary and develops in successive generations the fact that such marriages are sanctioned is scandalous and infamous."

Since 1890 the cretins have been sexually segregated, and in I9IO Jordan reported that they were nearly all gone.

\section{e) DRASTIC MEASURES}

A fifth method of restricting undesirable germplasm in the case of confirmed criminals, idiots, imbeciles, and rapists may be mentioned, namely, the extreme treatment of either asexualization or vasectomy. The latter is a minor operation corfined to the male which occupies only a few moments and requires at most only the application of a local anaesthetic, such as cocaine. There are no disturbing or even inconvenient after effects from thisoperation. It consists in removing a small section of each sperm duct, and is entirely effectual' in preventing subsequent parenthood.

In the female the corresponding operation, which consists in removing a portion of each Fallopian tube, is much more severe, but not impracticable or dangerous.

Eight states already have sterilization laws providing for certain cases and "could such a law be enforced in the whole United States, 
less than four generations would eliminate nine tenths of the crime, insanity and sickness of the present generation in our land. Asylums, prisons and hospitals would decrease, and the problems of the unemployed, the indigent old and the hopelessly degenerate would cease to trouble civilization."

\section{THE CONSERVATION OF DESIRABLE GERMPLASM}

Not only negatively by the restriction of undesirable germplasm, but also positively by the conservation of desirable germplasm, may the eugenic ideal be approached.

It is possible that if some of the philanthropic endeavor now directed toward alleviating the condition of the unfit should be directed to enlarging the opportunity of the fit, greater good would result in the end. In breeding animals and plants the most notable advances have been made by isolating and developing the best, rather than by attempting to raise the standard of mediocrity through the elimination of the worst.

One leader is worth a score of followers in any community, and the science of genetics surely gives to educators the hint that it is wiser to cultivate the exceptional pupil who is often left to take care of himself than to expend all the energies of the instructor in forcing the indifferent or ordinary one up to a passing standard. The campaign for human betterment in the long run must do more than avoid mistakes. It must become aggressive and take advantage of those human mutations or combinations of traits which appear in the exceptionally endowed.

There are various ways in which this improvement of society may be brought about.

a) BY SUBSIDIZING THE FIT

The following unconfirmed newspaper clipping illustrates the point of what is meant by subsidizing the fit so far as certain physical characteristics are concerned. "Berlin, Dec. II, I9II. The Emperor is reported to be interested in a plan proposed by Professor Otto Hauser for the propagation of a fixed German type of humanitya type which will be as fixed as the Jewish in its characteristics, if the suggestions of the professor can erer be carried out. The fixed type is to be produced as follows:- Only 'typical' couples are to be allowed to mate. The man is to be not more than thirty years old, the woman not over twenty-eight, and each have a perfect healti' certificate. The man should be at least five feet seven inches tall; the woman not under 
five feet six inches. Neither the man nor the woman should have dark hair. Its tint may range from blonde to auburn. The eyes of the pair should be pure blue without any tint of brown. The comjlexion should be fair to ruddy without any suggestion of heariness or 'beefiness.' The nose ought to be strong and narrow, the chin square and powerful, and the skull well developed at the lack. The man and the woman must be of German descent and must bear a German name and speak the language of Germany. These 'mated couples' are to get a wedding gift of $S_{125}$ and an additional grant for each child born. The couples may settle in the "nited States if they prefer." This reported attempt to establish a Prussian type of "Hauser blondes" at least points the way to one sort of a positive eugenic method that might possibly be employed with respect to certain physical characteristics.

It should be remembered, however, that the eugenic ideal is not by any means confined to physical traits alone.

\section{b) BY ENLARGING INDIYIDUAL OPPORTUNITY}

Much good human germplasm goes to waste through ineffectiveness on account of unfavorable environment or lack of a suitable opportunity to develop.

Every agency which cor ributes toward increasing the opportunity. of the individual to attain to a hetter development of his latent possibilities is in harmony with a thoroughly positive eugenic practice. Thus better schools, better homes, better living conclitions, in short, all euthenic endeavor, directly serves the eugenic ideal by making the best out of whatever germinal equipment is present in man.

c) BY PREVENTING GERMINIL WASTE

Nuch good protoplasm fails to find expression in the form of offspring because one or the other of possible parents is cut off either by. preventable death or by social hindrances. To aroid such calamities is a part of the positive program of eugenics.

I. Preventable death. - Ilar, from the eugenic point of view, is the height of folly, since presumably the hrave and the physically fit march away to fight, while in general the unqualified stay at home to reproduce the next generation. When a soldier dies on the hat leficlel or in the hospital, it is not alone a lrave man who is cut off, but it is the termination of a probably de-iratie strain of germplasm. The Thirty Years' War in Germany cost 6,000,000 lives, while Napoleon in his campaigns drained the best blood of France. 


\section{S2 READINGS IN EVOLUTION, GENETICS, AND EUGENICS}

David Starr Jordan has presented the matter very clearly. $\mathrm{He}$ points out that the "man with a hoe" among the European peasantry is not the result of centuries of oppression, as he has been pictured, but rather the dull progeny resulting from generations of the unfit who were left behind when the fit went off to war never to return.

Benjamin Franklin, with characteristic wisdom, sums up the situation in the following epigram: "Wars are not paid for in war time; the bill comes later."

2. Social hindrances.-There are many conditions of modern society which act non-eugenically.

For instance, the increasing demands of professional life prolorig the period necessary for preparation, which, with the "cost of high living," tends toward late marriage. In this way much of the best germplasm is very often withheld from circulation until it is too late to be effective in providing for the succeeding generation.

Certain occupations such as school-teaching and nursing by women are filled by the best blood obtainable, yet this blood is denied a direct part in molding posterity, since marriage is either forbidden or regarded as a serious handicap in such lines of work. Advertisements concerning "unincumbered help" and "childless apartments" tell their own deplorable tale.

One of the darkest features of the dark ages from a eugenic standpoint was the enforced celibacy of the priesthood, since this resulted, as a rule, in withdrawing into monasteries and nunneries much of the best blood of the times, and this uneugenic custom still obtains in many quarters today.

\section{WHO SHALL SIT IN JUDGMENT?}

In the practical application of a program of eugenics there are many difficulties, for who is qualified to sit in judgment and separate the fit from the unfit?

There are certain strongly marked characteristics in mankind which are plainly good or bad, but the principle of the independence of unit characters demonstrates that no person is wholly good or wholly bad. Shall we then throw away the whole bundle of sticks because it contains a few poor or crooked ones?

The list of weakling babies, for instance, who were apparently physically unfit and hardly worth raising upon first judgment, but who afterwards became powerful factors in the world's progress, is a notable one and includes the names of Calvin, Newton, Heine, Voltaire, Herbert Spencer, and Robert Louis Stevenson. 
Or, take another example. Elizabeth Tuttle, the grandmother of Jonathan Edwards whose remarkable progeny was referred to in a preceding chapter, is described as a "woman of great beauty, of tall and commanding appearance, striking carriage, of strong will, extreme intellectual vigor and mental grasp akin to rapacity," but with an extraordinary deficiency in moral sense. She was divorced from her husband "on the ground of adultery and other immoralities. . . . . The evil trait was in the blood, for one of her sisters murdered her own son and a brother murdered his own sister." That Jonathan Edwards owed his remarkable qualities largely to his grandmother rather than to his grandfather is shown by the fact that Richard Edwards, the grandfather, married again after his divorce and had five sons and one daughter, but none of their numerous progeny "rose above mediocrity, and their descendants gained no abiding reputation." As shown by subsequent events, it would have been a great eugenic mistake to have deprived the world of Elizabeth Tuttle's germplasm, although it would have been easy to find judges to condemn her.

Dr. C. V. Chapin recently said with reference to the eugenic regulation of marriage by physician's certificate: "The causes of heredity are many and very conflicting. The subject is a difficult one, and I for one would hesitate to say, in a great many cases where I have a pretty good knowledge of the family, where marriage would, or would not, be desirable."

Desirability and undesirability must always be regarded as relative terms more or less indefinable. In attempting to define them, it makes a great difference whether the interested party holds to a puritan or a cavalier standard. To show how far human judgment may err as well as how radically human opinion changes, there were in England, as recently as I8I9, 233 crimes punishable by death according to law.

One needs only to recall the days of the Spanish Inquisition or of the Salem witchcraft persecution to realize what fearful blunders human judgment is capable of, but it is unlikely that the world will ever see another great religious inquisition, or that in applying to man the newly found laws of heredity there will ever be undertaken an equally deplorable eugenic inquisition.

It is quite apparent, finally, that although great caution and broadness of vision must be exercised in bringing about the fulfilment of the highest eugenic ideals, nevertheless in this direction lies the future path of human achievement. 


\section{CHAPTER XXXVI \\ EUGENICS AND EUTHENICS \\ PAUL POPENOE AND ROSWELL H. JOHNSON}

Emphasis has been given, in several of the foregoing chapters, to the desirability of inheriting a good constitution and a high degree of vigor and diseasc-resistance. It has been asserted that no measures of hygiene and sanitation can take the place of such inheritance. It is now desirable to ascertain the limits within which good inheritance is effective, and this may be conveniently done by a study of the lives of a group of people who inherited exceptionally strong physical constitutions.

The people referred to are taken from a collection of histories of long life made by the Genealogical Record Office of W'ashington. One hundred individuals were picked out at random, each of whom had died at the age of ninety or more, and with the record of each individual were placed those of all his brothers and sisters. Any family was rejected in which there was a record of wholly accidental death (e.g., families of which a member had been killed in the Civil War). The roo families, or more correctly fraternities or sibships, were classified by the number of children per fraternity, as follows:

\begin{tabular}{ccc}
$\begin{array}{c}\text { Number } \\
\text { of } \\
\text { Fraternitics }\end{array}$ & $\begin{array}{c}\text { Number of } \\
\text { Children per } \\
\text { Fraternity }\end{array}$ & $\begin{array}{c}\text { Total Number } \\
\text { of Children } \\
\text { in Group }\end{array}$ \\
I & 2 & 2 \\
II & 3 & 33 \\
8 & 4 & 32 \\
I 7 & 5 & 85 \\
I3 & 6 & 78 \\
I4 & 7 & 98 \\
9 & 8 & 72 \\
II & 9 & 99 \\
I0 & I0 & I00 \\
3 & II & 33 \\
2 & I2 & 24 \\
I & I3 & I3 \\
\hline I00 & & 669
\end{tabular}

× From P. Popenoe and R. H. Johnson, Applicd Eugenics (copyright 1918). Used by special permission of the publishers, The Macmillan Company. 
The average at death of these 669 persons was 64.7 years. The child mortality (first 4 years of life) was 7.5 per cent of the total mortality, 69 families showing no deaths of that kind. The group is as a whole, therefore, long-lived.

The problem was to measure the resemblance between brothers and sisters in respect of longevity - to find whether knowledge of the age at which one died would justify a prediction as to the age at death of the others-or technically, it was to measure the fraternal correlation of longevity. A zero coefficient here would show that there is no association; that from the age at which one dies, nothing whatever can be predicted as to the age at which the others will die. Since it is known that heredity is a large factor in longevity, such a finding would mean that all deaths were due to some accident which made the inheritance of no account.

In an ordinary population it has been found that the age at death of brothers and sisters furnishes a coefficient of correlation of the order of $\cdot 3$, which shows that heredity does determine the age at which one shall die to considerable extent, but not absolutely. ${ }^{\mathrm{T}}$

The index of correlation" between the lengths of life within the fraternity in these roo selected families, furnished a coefficient of $-.0166_{3} \pm .0672$, practically zero. In other words, if the age is known at which a member of one of these families died, whether it be one month or roo years, nothing whatever can be predicted about the age at which his brothers and sisters died.

I Mary Beeton, and Karl Pearson, Biometrika, I, p. 60. The actual correlation varies with the age and sex: the following are the results:

COLLATERAL INHERITANCE

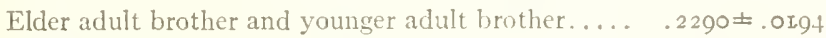

Adult brother and adult brother............. .2\$53 \pm .0 rg 6

Minor brother and minor brother............. 1026 0.0294

Adult brother and minor brother ............0262 \pm .0246

Elder adult sister and younger adult sister........ $3464 \pm .0183$

Adult sister and adult sister..................... . $3322 \pm 5$

Minor sister and minor sister.............. . $748 \pm .0307$

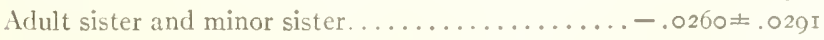

Adult brother and adult sister...............23I9 $\doteq$. OI 45

Minor brother and minor sister............. I435 $\pm .025 \mathrm{I}$

Adult brother and minor sister............... $0062 \pm .0349$

Adult sister and minor brother............. $0277^{ \pm} .023 \mathrm{~S}$

${ }^{2}$ The method used is the ingenious one devised by J. Arthur Harris (Biometrika, IX, p. $46 \mathrm{I}$ ). The probable error is based on $n=100$. 
Remembering that longevity is in general inherited, and that it is found in the families of all the people of this study (since one in each fraternity lived to be 90 or over) how is one to interpret this zero coefficient? Evidently it means that although these people had inherited a high degree of longevity, their deaths were brought about by causes which prevented the heredity from getting full expression. As far as hereditary potentialities are concerned, it can be said that all their deaths were due to accident, using that word in a broad sense to include all non-selective deaths by disease. If they had all been able to get the full benefit of their heredity, it would appear that each of these persons might have lived to 90 or more, as did the one in each family who was recorded by the Genealogical Record Office. Genetically, these other deaths may be spoken of as premature.

In an ordinary population, the age of death is determined to the extent of probably 50 per cent by heredity. In this selected longlived population, heredity appears not to be responsible in any measurable degree whatsoever for the differences in age at death.

The result may be expressed in another, and perhaps more striking, way. Of the 669 individuals studied, a hundred-namely, one child in each family - lived beyond 9o; and there were a few others who did. But some $55^{\circ}$ of the group, though they had inherited the potentiality of reaching the average age of $9 \circ$, actually died somewhere around 60 ; they failed by at least one-third to live up to the promise of their inheritance. If we were to generalize from this single case, we would have to say that five-sixths of the population does not make the most of its physical inheritance.

This is certainly a fact that discourages fatalistic optimism. The man who tells himself that, because of his magnificent inherited constitution, he can safely take any risk, is pretty sure to take too many risks and meet with a non-selective-i.e., genetically, a premature - death, when he might in the nature of things have lived almost a generation longer.

It should be remarked that most of the members of this group seem to have lived in a hard environment. They appear to belong predominantly to the lower strata of society; many of them are immigrants and only a very few of them, to judge by a cursory inspection of the records, possessed more than moderate means. This necessitated a frugal and inclustrious life which in many ways was favorable to longevity but which may often have led to overexposure, overwork, lack of proper medical treatment, or other causes of a non-selective 
death. We would not push the conclusion too far, but we can not doubt that this investigation shows the folly of ignoring the environment-shows that the best inherited constitution must have a fair chance. And what has here been found for a physical character, would probably hold good in even greater degree for a mental character. All that man inherits is the capacity to develop along a certain line under the influence of proper stimuli, food and exercise. The object of eugenics is to see that the inherent capacity is there. Given that, the educational system is next needed to furnish the stimuli. The consistent eugenist is therefore an ardent euthenist. He not only works for a better human stock but, because he does not want to see his efforts wasted, he always works to provide the best possible environment for this better stock.

In so far, then, as euthenics is actually providing man with more favorable surroundings-not with ostensibly more favorable surroundings which, in reality, are unfavorable - there can be no antagonism between it and eugenics. Eugenics is, in fact, a prerequisite of euthenics, for it is only the capable and altruistic man who can contribute to social progress; and such a man can only be produced through eugenics.

Eugenic fatalism, a blind faith in the omnipotence of heredity regardless of the surroundirgs in which it is placed, has been shown by the study of long-lived families to be unjustified. It was found that even those who inherited exceptional longevity usually did not live as long as their inheritance gave them the right to expect. If they had had more euthenics, they should have lived longer.

But this illustration certainly gives no ground for a belief that euthenics is sufficient to prolong one's life beyond the inherited limit. A study of these long-lived families from another point of view will reveal that heredity is the primary factor and that good environment, euthenics, is the secondary one.

For this purpose we augment the roo families of the preçeding section by the addition of 240 more families like them, and we examine each family history to find how many of the children died before completing the fourth year of life. The data are summarized in the table on page 488 .

The addition of the new families (which were not subjected to any different selection than the first Ioo) has brought down the child mortality rate. For the first roo, it was found to be 7.5 per cent. If in the above table the number of child deaths, II9, be divided by the 
total number of children represented, 2,259, the child mortality rate for this population is found to be 5.27 per cent or 53 per I,, 00 .

The smallness of this figure may be seen by comparison with the statistics of the registration area, U.S. Census of 1880 , when the child mortality (o-4 years) was 400 per thousand, as calculated by Alexander Graham Bell. A mortality of 53 for the first four years of life is smaller than any district known in the United States, even to-day, can show for the first year of life alone. If any city could bring the deaths of babies during their first twelve months down to 53 per $\mathrm{x}, \infty 00$, it would think it had achieved the impossible; but here is a population

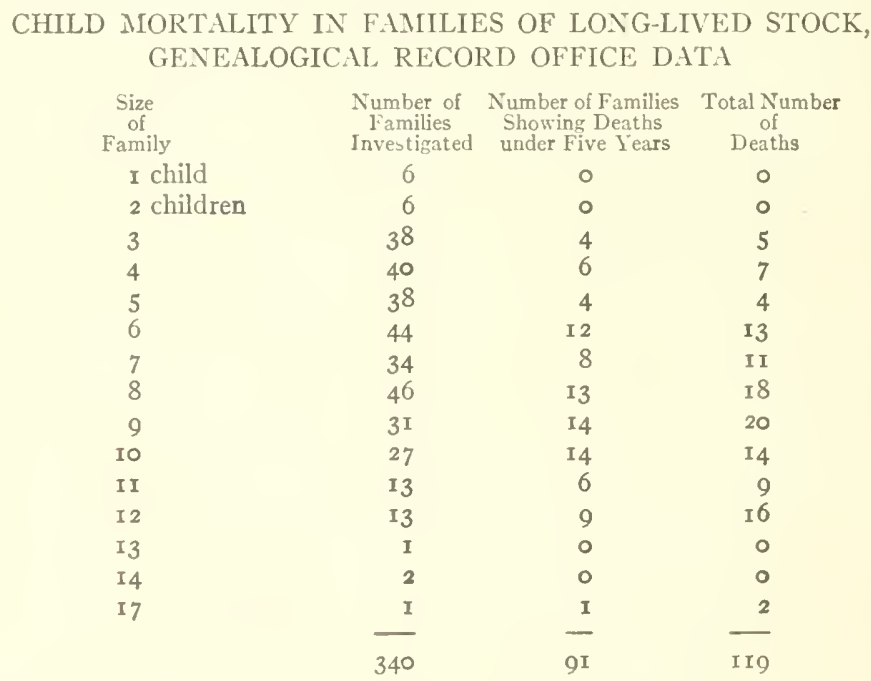

in which 53 per I, 000 covers the deaths, not only of the fatal first I 2 months, but of the following three years in addition.

Now this population with an unprecedentedly low rate of child mortality is not one which had had the benefit of any Baby Saving Campaign, nor even the knowledge of modern science. Its mothers were mostly poor, many of them ignorant; they lived frequently under conditions of hardship; they were peasants and pioneers. Their babies grew up without doctors, without pasteurized milk, without ice, without many sanitary precautions, usually on rough food. But they had one advantage which no amount of applied science can give after birth-namely, good heredity. They had inherited exceptionally good constitutions. 
It is not by accident that inherited longevity in a family is associated with low mortality of its children. The connection between the two facts was first discovered by Mary Beeton and Karl Pearson in their pioneer work on the inheritance of duration of life. They found that high infant mortality was associated with early death of parents, while the offspring of long-lived parents showed few deaths in childhood. The correlation of the two facts was quite regular, as will be evident from a glance at the following tables prepared by A. Ploetz:

LENGTH OF LIFE OF MIOTHERS AND CHILD MIORTALITY OF THEIR DAUGHTERS (ENGLISH QUAKER FAMILIES, DATA OF BEETON AND PEARSON, ARRANGED BY PLOETZ)

\begin{tabular}{|c|c|c|c|c|c|c|}
\hline & \multicolumn{5}{|c|}{ Year of Life in Which Mothers Died } & \multirow{2}{*}{$\begin{array}{c}\mathrm{Ar} \\
\text { ALL } \\
\text { AGES }\end{array}$} \\
\hline & to 38 & $39^{-5} 53$ & $54^{-68}$ & $69-83$ & $8 ;$ up & \\
\hline $\begin{array}{l}\text { Number of daughters.............. } \\
\text { Number of them who died in first five }\end{array}$ & 234 & 304 & 395 & 666 & 247 & $1,8+6$ \\
\hline years $\ldots \ldots \ldots \ldots \ldots \ldots \ldots \ldots \ldots$ & 122 & I I 4 & II 8 & I 31 & 26 & 5 II \\
\hline Per cent of daughters who & $52 . \mathrm{I}$ & 37.5 & 29.9 & 19.7 & 10.5 & $27 \cdot 7$ \\
\hline
\end{tabular}

\section{LENGTH OF LIFE OF FATHERS AND CHILD MORTALITY OF THEIR D.ACGHTERS}

\begin{tabular}{|c|c|c|c|c|c|c|}
\hline & \multicolumn{5}{|c|}{ Year of Life in Which Fathers Died } & \multirow{2}{*}{$\begin{array}{c}\mathrm{AT} \\
\text { ALL } \\
\text { AGES }\end{array}$} \\
\hline & to 38 & $39^{-53}$ & $5+-68$ & $69-83$ & $8 q$ up & \\
\hline $\begin{array}{l}\text { Number of daughters................ } \\
\text { Number of them who died in first five }\end{array}$ & 105 & $28_{4}$ & $5^{S_{5}}$ & 797 & 236 & 2,009 \\
\hline 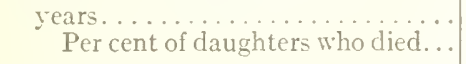 & $\begin{array}{r}51 \\
+8.6\end{array}$ & $\begin{array}{r}98 \\
3+\cdot 5\end{array}$ & $\begin{array}{r}156 \\
26.7\end{array}$ & $\begin{array}{r}177 \\
22.2\end{array}$ & $\begin{array}{r}40 \\
17.0\end{array}$ & $\begin{aligned} 522 \\
26.0\end{aligned}$ \\
\hline
\end{tabular}

To save space, we do not show the relation between parent and son; it is similar to that of parent and daughter which is shown in the preceding tables. In making comparison with the 340 families from the Genealogical Record Office, above studied, it must be noted that Dr. Ploetz's tables include one year longer in the period of child mortality, being computed for the first five years of life instead of the first four. His percentages would therefore be somewhat lower if computed on the basis used in the American work.

These various data demonstrate the existence of a considerable correlation between short life (brachybioty, Karl Pearson calls it) in parent and short life in offspring. Not only is the tendency to live long inherited, but the tendency not to live long is likewise inherited. 
But perhaps the reader may think they show nothing of the sort. He may fancy that the early death of a parent left the child without sufficient care, and that neglect, porerty, or some other factor of euthenics brought about the child's death. Perhaps it lacked a mother's loving attention, or perhaps the father's death removed the wage-earner of the family and the child thenceforth lacked the necessities of life.

Dr. Ploetz has pointed out that this objection is not valid, because the influence of the parent's death is seen to hold good even to the point where the child was too old to require any assistance. If the facts applied only to cases of early death, the supposed objection might be weighty, but the correlation exists from one end of the agescale to the other. It is not credible that a child is going to be deprived of any necessary maternal care when its mother dies at the age of 69 ; the child herself was probably married long before the death of the mother. Nor is it credible that the death of the father takes bread from the child's mouth, leaving it to starve to death in the absence of a pension for widowed mothers, if the father died at 83 , when the "child" herself was getting to be an old woman. The early death of a parent may occasionally bring about the child's death for a reason wholly unconnected with heredity, but the facts just pointed out show that such cases are exceptional. The steady association of the child deathrate and parent death-rate at all ages demonstrates that heredity is a common cause.

But the reader may suspect another fallacy. The cause of this association is really environmental, he may think, and the same poverty or squalor which causes the child to die early may cause the parent to die early. 'They may both be of healthy, long-lived stock; but forced to live in a pestiferous slum which cuts both of them off prematurely and thereby creates a spurious correlation in the statistics.

We can dispose of this oljection most effectively by bringing in new evidence. It will probably be admitter that in the royal families of Europe, the environment is as good as knowledge and wealth can make it. No child dies for lack of plenty of food and the best medical care, even if his father or mother died young. And the members of this caste are not exposed to any such unsanitary conditions, or such economic pressure as could possibly cause both parent and child to die prematurely. If the association between longevity of parent and child mortality holds for the royal families of Europe and their princely 
relatives, it can hardly be regarded as anything but the effect of heredity - of the inheritance of a certain type of constitution.

Dr. Ploetz studied the deaths of 3,2 Io children in European royalty, from this viewpoint. The following table shows the relation between father and child:

LENGTH OF LIFE OF FATHERS AND CHILD MORTALITY OF THEIR CHILDREN IN ROYAL AND PRINCELY

FAMILIES (PLOETZ DATA)

\begin{tabular}{|c|c|c|c|c|c|c|c|c|c|}
\hline \multirow[b]{2}{*}{$\therefore$} & \multicolumn{8}{|c|}{ Year of Life in Which Fathers Died } & \multirow{2}{*}{$\begin{array}{c}\text { AT } \\
\text { ALL } \\
\text { AGES }\end{array}$} \\
\hline & $16-25$ & $26-35$ & $36-45$ & $4^{6-55}$ & $56-65$ & $66-75$ & $76-85$ & 86 up & \\
\hline Number of children. . . . . . . . . . . & 23 & 90 & 367 & 545 & 725 & 983 & 444 & 33 & 3210 \\
\hline Number who died in first five years. & I2 & 29 & I I 5 & $17 \mathrm{I}$ & 200 & 254 & IC5 & $\mathrm{I}$ & 887 \\
\hline Per cent who died........... & 52.2 & 32.2 & $3 I \cdot 3$ & 31.4 & 27.6 & 25.8 & 23.6 & 3.0 & 27.6 \\
\hline
\end{tabular}

Allowing for the smallness of some of the groups, it is evident that the amount of correlation is about the same here as among the English Quakers of the Beeton-Pearson investigation, whose mortality was shown in the two preceding tables. In the healthiest group from the royal families - the cases in which the father lived to old age - the amount of child mortality is about the same as that of the Hyde family in America, which Alexander Graham Bell has studied-namely, somewhere around 250 per I,000. One may infer that the royal families are rather below par in soundness of constitution.

All these studies agree perfectly in showing that the amount of child mortality is determined primarily by the physical constitution of the parents, as measured by their longevity. In the light of these facts, the nature of the extraordinarily low child mortality shown in the 340 families from the Genealogical Record Office, with which we began the study of this point, can hardly be misunderstood. These families have the best inherited constitution possible and the other studies cited would make us certain of finding a low child mortality among them, even if we had not directly investigated the facts.

If the interpretation which we have given is correct, the conclusion is inevitable that child mortality is primarily a problem of eugenics, and that all other factors are secondary. There is found to be no warrant for the statement so often repeated in one form or another, that "the fundamental cause of the excessive rate of infant mortality in industrial communities is poverty, inadequate incomes, and low standards of living." Royalty and its princely relatives are not 
characterized by a low standard of living, and yet the child mortality among them is very high-somewhere around 400 per I,000 in cases where a parent died young. If poverty is responsible in the one case, it must be in the other-which is absurd. Or else the logical absurdity is involved of inventing one cause to explain an effect today and a wholly different cause to explain the same effect tomorrow. This is unjustifiable in any case, and it is particularly so when the single cause that explains both cases is so evident. If weak heredity causes high mortality in the royal families, why, similarly, cannot weak heredity cause high infant mortality in the industrial communities? We believe it does account for much of it, and that the inadequate income and low standard of living are largely the consequence of inferior heredity, mental as well as physical. The parents in the Genealogical Record Office files had, many of them, inadequate incomes and low standards of living under frontier conditions, but their children grew up while those of the royal families were dying in spite of every attention that wealth could command and science could furnish.

If the infant mortality problem is to be solved on the basis of knowledge and reason, it must be recognized that sanitation and hygiene cannot take the place of eugenics any more than eugenics can dispense with sanitation and hygiene. It must be recognized that the death-rate in childhood is largely selected, and that the most effective way to cut it down is to endow the children with better constitutions. This cannot be done solely by any euthenic campaign; it cannot be done by swatting the fly, abolishing the mid-wife, sterilizing the milk, nor by any of the other panaceas sometimes proposed.

But, it may be objected, this discussion ignores the actual facts. Statistics show that infant mortality campaigns have consistently produced reductions in the death-rate. The figures for New lork, which could be matched in dozens of other cities, show that the number of deaths per I,000 births, in the first year of life, has steadily declined since a determined campaign to "Save the Babies" was started:

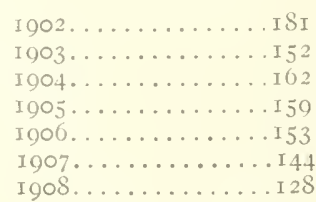

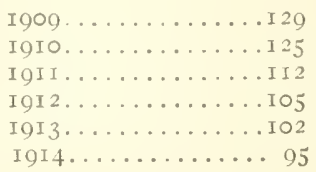


To one who cannot see beyond the immediate consequences of an action, such figures as the above indeed give quite a different idea of the effects of an infant mortality campaign, than that which we have just tried to create. And it is a great misfortune that euthenics so often fails to look beyond the immediate effect, fails to see what may happen next year, or ro years from now, or in the next generation.

We admit that it is possible to keep a lot of children alive who would otherwise have died in the first few months of life. It is being done, as the New York figures, and pages of others that could be cited, prove. The ultimate result is twofold:

I. Some of those who are doomed by heredity to a selective death, but are kept alive through the first year, die in the second or third or fourth year. They must die sooner or later; they have not inherited sufficient resistance to survive more than a limited time. If they are by a great effort carried through the first year, it is only to die in the next. This is a statement which we have nowhere observed in the propaganda of the infant mortality movement; and it is perhaps a disconcerting one. It can only be proved by refined statistical methods, but several indejendent determinations by the English biometricians leave no doubt as to the fact. This work of Karl Pearson, E. C. Snow, and Ethel M. Elderton, was cited in our chapter on natural selection; the reader will recall how they showed that nature is weeding out the weaklings, and in proportion to the stringency with which she weeds them out at the start, there are fewer weaklings left to die in succeeding years.

To put the facts in the form of a truism, part of the children born in any district in a given year are doomed by heredity to an early death; and if they die in one year they will not be alive to die in the succeeding year, and vice versa. Of course there are in addition infant deaths which are not selective and which if prevented would leave the infant with as good chance as any to live.

In the light of these researches, we are forced to conclude that baby-saving campaigns accomplish less than is thought; that the supposed gain is to some extent temporary and illusory.

2. There is still another consequence. If the gain is by great exertions made more than temporary; if the baby who would otherwise have died in the first months is brought to adult life and reproduction, it means in many cases the dissenination of another strain of weak heredity, which natural selection woukd have cut off ruthlesty 


\section{READINGS IN EVOLUTION, GENETICS, AND EUGENICS}

in the interests of race betterment. In so far, then, as the infant mortality movement is not futile it is, from a strict biological viewpoint, often detrimental to the future of the race.

Do we then discourage all attempts to save the babies? Do we leave them all to natural selection? Do we adopt the "better dead" gospel?

Unqualifiedly, no! The sacrifice of the finer human feelings, which would accompany any such course, would be a greater loss to the race than is the eugenic loss from the perpetuation of weak strains of heredity. The abolition of altruistic and humanitarian sentiment for the purpose of race betterment would ultimately defeat its own end by making race betterment impossible.

But race betterment will also be impossible unless a clear distinction is made between measures that really mean race betterment of a fundamental and permanent nature, and measures which do not.

We have chosen the Infant Mortality Movement for analysis in this chapter because it is an excellent example of the kind of social betterment which is taken for granted, by most of its proponents, to be a fundamental piece of race betterment; but which, as a fact, often means race impairment. No matter how abundant and urgent are the reasons for continuing to reduce infant inortality wherever possible, it is dangerous to close the eyes to the fact that the gain from it is of a kind that must be paid for in other ways; that to carry on the movement without adding eugénics to it will be a short-sighted policy, which increases the present happiness of the world at the cost of diminishing the happiness of posterity through the perpetuation of inferior strains.

While some euthenic measures are eugenically evils, even if necessary ones, it must not be inferred that all euthenic measures are dy'sgenic. Many of them, such as the economic and social changes we have suggested in earlier chapters, are an important part of eugenics. Every euthenic measure should be scrutinized from the evolutionary standpoint; if it is eugenic as well as euthenic, it should be wholeheartedly favored; if it is dysgenic but euthenic it should be condemned or adopted, according to whether or not the gain in all ways from its operation will exceed the damage.

In general, euthenics, when not accompanied by some form of selection (i.e., eugenics) ultimately defeats its own end. If it is accompanied by rational selection, it can usually be indorsed. Eugenics, 
on the other hand, is likewise inadequate unless accompanied by constant improvement in the surroundings; and its advocates must demand euthenics as an accompaniment of selection, in order that the opportunity for getting a fair selection may be as free as possible. If the euthenist likewise takes pains not to ignore the existence of the racial factor, then the two schools are standing on the same ground, and it is merely a matter of taste or opportunity, whether one emphasizes one side or the other. Each of the two factions, sometimes thought to be opposing, will be seen to be getting the same end result, namely, human progress.

Not only are the two schools working for the same end, but each must depend in still another way upon the other, in order to make headway. The elgenist cannot see his measures put into effect except through changes in law and custom-i.e., euthenic changes. He must and does appeal to euthenics to secure action. The social reformer, on the other hand, cannot see any improvements made in civilization except through the discoreries and inventions of some citizens who are inherently superior in ability. He in turn must depend on eugenics for every advance that is made.

It may make the situation clearer to state it in the customary terms of biological philosophy. Selection does not necessarily result in progressive evolution. It merely brings about the adaptation of a species or a group to a given environment. The taperrorm is the stock example. In human evolution, the nature of this environment will determine whether adaptation to it means progress or retrogression, whether it leaves a race happier and more productive, or the reverse. All racial progress, or eugenics, therefore, depends on the creation of a good environment, and the fitting of the race to that environment. Every improvement in the environment should bring about a corresponding biological adaptation. The two factors in evolution must go side by side, if the race is to progress in what the human mind considers the direction of advancement. In this sense, euthenics and eugenics bear the same relation to human progress as a man's two legs do to his locomotion.

Social workers in purely euthenic fields have frequently failed to remember this progress of adaptation, in their efforts to change the environment. Eugenists, in centering their attention on adaptation, have sometimes paid too little attention to the kind of environment to which the race was being adapted. The present book holds that the 


\section{READINGS IN EVOLUTION, GENETICS, AND EUGENICS}

second factor is just as important as the first, for racial progress; that one leg is just as important as the other, to a pedestrian. Its only conflict with euthenics appertains to such euthenic measures as impair the adaptability of the race to the better environment they are trying to make.

Some supposedly euthenic measures opposed by eugenics are not truly euthenic, as for instance the limitation of a superior family in order that all may get a college education. For these spurious euthenic measures, something truly euthenic should be substituted.

Measures which show a real conflict may be typified by the infant mortality movement. There can be no doubt but that sanitation and hygiene, prenatal care and intelligent treatment of mothers and babies, are truly euthenic and desirable. At the same time, as has been shown, these euthenic measures result.in the survival of inferior children, who directly or through their posterity will be a drag on the race. Euthenic measures of this type should be accompanied by counterbalancing measures of a more eugenic character.

Barring these two types, euthenics forms a necessary concomitant of the eugenic program; and, as we have tried to emphásize, eugenics is likewise necessary to the complete success of every euthenic program. How foolish, then, is antagonism between the two forces! Both are working toward the same end of human betterment, and neither can succeed without the other. When either attempts to eliminate the other from its work, it ceases to advance toward its goal. In which camp one works is largely a matter of taste. If on a road there is a gradient to be leveled, it will be brought down most quickly by two parties of workmen, one cutting away at the top, and the other filling in the bottom. For the two parties to indulge in mutual scorn and recrimination would be no more absurd than for eugenics and euthenics to be put in opposition to each other. The only reason they have been in opposition is because some of the workers did not clearly understand the nature of their work. With the dissemination of a knowledge of biology, this ground of antagonism will disappear. 


\section{CHAPTER XXXVII}

\section{THE PROMISE OF RACE CULTURE}

CALEB WILLIAMS SALEEBY

The best is yet to be.

In its form of what we have called negative eugenics, the practice of our principle would assuredly reduce to an incalculable extent the amount of human defect, mental and physical, which each generation now exhibits. This alone, as has been said, would be far more than sufficient to justify us. A world without hereditary disease of mind and body would alone warrant the hint of Ruskin that posterity may some day look back upon us with "incredulous disdain." Yet, assuming that this could be accomplished, as it will be accomplished, what more is to be hoped for? Must race-culture cease merely when it has raised the average of the community by reducing to a minimum the proportion of those who are thus grossly defective in mind or body? Such disease apart, are we to be content, must we be content, with the present level of mediocrity in respect of intelligence and temper and moral sentiment? Can we anticipate a London in which the present ratio of musical comedy to great opera will be reversed, in which the works of Mr. George Meredith will sell in hundreds of thousands, whilst some of our popular novelists will have to find other means of earning a living? Can we make for a critical democracy which no political party can fool, and which will choose its best to govern it? Yet more, can we undertake, now or hereafter, to provide every generation with its own Shakespeare and Beethoven and Tintoretto and Newton? What, in a word, is the promise of positive eugenics? It is to this aspect of the question that Mr. Galton has mainly directed himself. Indeed he was led to formulate the principles and ideals of the new science by his study of hereditary genius some four decades ago. Let us now attempt to answer some of these questions.

The production of genius.-And first as to the production of genius. It is this, perhaps, that has been the main butt of the jesters who pass for philosophers with some of us today. It may be said

I From C. W. Saleeby, Parenthood and Race Culture (copyright I909). Used by special permission of the publishers, Moftat, Yard, and Company. 


\section{READINGS IN EVOLUTION, GENETICS, AND EUGENICS}

at once that neither Mr. Galton nor any other responsible person has ever asserted that we can produce genius at will. The difficulties in the way of such a project-at present-are almost innumerable. One or two may be cited.

In the first place, there is the cardinal-but by no means universal-difficulty that the genius is too commonly so occupied with the development and expansion of his own individuality that he has little lime or energy for the purposes of the race. This, of course, is an example of Spencer's great generalization as to the antagonism or inverse ratio between individuation and genesis.

Again, there is the generalization of heredity formulated by Mr. Galton, and named by him the law of regression towards mediocrity. It asserts that the children of those who are above or below the mean of a race, tend to return towards that mean. The children of the born criminal will be probably somewhat less criminal in tendency than he, though more criminal than the arerage citizen. The children of the man of genius, if he has any, will probably be nearer mediocrity than he, though on the average possessing greater talent than the average citizen. It is thus not in the nature of sheer genius to reproduce on its own level. It is only the critics who are totally ignorant of the elementary facts of heredity that attribute to the eugenist an expectation of which no one knows the absurdity so well as he does.

On the other hand, it is impossible to question that the hereditary transmission of genius or great talent does occur. One may cite at random such cases as that of the Bach family, Thomas and Matthew Arnold, James and John Stuart Mill; and the reader who is inclined to believe that there is no law or likelihood in this matter, must certainly make himself acquainted with Mr. Galton's Hereditary Genius, and with such a paper as that which he printed in Sociological Papers, I904, furnishing an "index to achievements of near kinsfolk of some of the Fellows of the Royal Society." There is, of course, the obrious fallacy involved in the possibility that not heredity but environment was really responsible for many of these cases. It must have been a great thing to have such a father as James Mill. But it would be equally idle to imagine that the evidence can be clismissed with this criticism. A Matthew Arnold, a John Stuart Mill, could not be manufactured out of any chance material by an ideal education continued for a thousand years.

The transmission of genius.--One single instance of the transmission of genius or great talent in a family may be cited. We shall 
take the family which produced Charles Darwin, the discoverer of the fundamental principle of eugenics, and his first cousin, Francis Galton. Darwin's grandfather was Erasmus Darwin, physician, poet and philosopher, and independent expounder of the doctrine of organic evolution. Darwin's father was a distinguished physician, described by his son as "the wisest man I ever knew." Darwin's maternal grandfather was Josiah Wedgwood, the famous founder of the pottery works. Amongst his first cousins is Mr. Francis Galton. He has five living sons, each a man of great distinction, including Mr. Francis Darwin and Sir George Darwin, both of them original thinkers, honored by the presidency of the British Association. No one will put such a case as this down to pure chance or to the influence of environment alone. This is evidently, like many others, a greatly distinguished stock. The worth of such families to a nation is wholly beyond any one's powers of estimation. What if Erasmus Darwin had never married!

No student of human heredity can doubt that, however limited our immediate hopes, facts such as those alluded to furnish promise of great things for the future. But let us turn now from genius to what we usually call talent.

The production of talent. - There can be no question that amongst the promises of race-cultrre is the possibility of breeding such things as talent and the mental energy upon which talent so largely depends. In the Inquiries into Human Faculty, Mr. Galton shows the remarkable extent to which energy or the capacity for labor underlies intellectual achievement. He says, of energy:

"It is consistent with all the robust virtues" and makes a large practice of them possible. It is the measure of fullness of life; the more energy the more abundance of it; no energy at all is death; idiots are feeble and listless. In the enquiries I made on the antecedents of men of science no points came out more strongly than that the leaders of scientific thought were generally gifted with remarkable energy, and that they had inherited the gift of it from their parents and grandparents. . . . . It may be objected that if the race were too healthyand energetic there would be insufficient call for the exercise of the pitying and self-denying virtues, and the character of men would grow harder in consequence. But it does not seem reasonable to preserve sickly breeds for the sole purpose of tending them, as the breed of foxes is preserved solely for sport and its attendant advantages. There is little fear that misery will ever cease from the land, or that the 
compassionate will fail to find objects for their compassion; but at present the supply vastly exceeds the demand; the land is over-stocked and over-burdened with the listless and the incapable. In any scheme of eugenics, energy is the most important quality to favor; it is, as we have seen, the basis of living action, and it is eminently transmissible by descent."

Need it be pointed out that any political system which ceases to favor or actively disfavors energy, making it as profitable to be lazy as to be active, is antieugenic, and must incvitably lead to disaster? That, however, by the way. Our present point is that eugenics can reasonably promise, when its principles are recognized, to multiply the human and diminish the vegetable type in the community. In so doing, it will greatly further the production of talent, and therefore of that traditional or acquired progress which men of talent and genius create. Such a result will also further, though indirectly, the production of genius itself. For, as Mr. Galton points out, "men of an order of ability which is now very rare, would become more frequent, because the level out of which they rose would itself have risen."

This is by no means the only fashion in which an effective and practicable race-culture would serve genius, and I shall not be blamed for considering this matter further by any reader who realizes, however faintly, what the man of genius is worth to the world. If it were shown possible to establish such social conditions that genius could never flower in them, we should realize that their establishment would mean the putting of an end to progress and the blasting of all the highest hopes of the highest of all ages.

The immediatc need of this age, as of all ages, is perhaps not so much the birth of babies capable of developing into men and women of genius, as the full exploitation of the possibilities of genius with which, as I fancy, every generation on the average is about as well endowed as any other. There is, of course, the popular doctrine that there are no mute inglorious Miltons, that "genius will out," and that therefore if it does not appear, it is not there to appear. In expressing the compelling power of genius in many cases this doctrine is not without truth. Yet history abounds in instances where genius has been destroyed by environment-and we can only guess how many more instances there are of which history has no record. 'To take the single case of musical genius, it is a lamentable thought that there may be those now living whose natural endowments, in a favorable environment, would have enabled them to write symphonies fit to place 
beside Beethoven's, but whom some environmental factors-conventional, economic, educational, or what not-have silenced; or worse, have persuaded to write such sterile nullities as need not here be instanced. There is surely no waste in all this wasteful world so lamentable as this waste of genius.

If, then, anyone could devise for us a means by which the genius, potentially existing at any time, were realized, he would have performed in effect a service equivalent to that of which eugenics repudiates the present possibility - the actual creation of genius. But if we consider what the conditions are which cause the waste of genius, we realize at once that they mainly inhere in the level of the human environment of the priceless potentiality in question. As we noted elsewhere, in an age like that of Pericles genius springs up on all hands. It is encouraged and welcomed because the average level of the human environment in which it finds itself is so high. But if eugenics can raise the average level of intelligence, in so doing not merely does it render more likely, as Mr. Galton points out, the production of men of the highest ability, but it provides those conditions in which men of genius, now swamped, can swim. We could not undertake to produce a Shakespeare, but we might reasonably hope to produce a generation which would not destroy its Shakespeares. And even if men of genius still found it necessary, as men of genius have found it necessary, to "play to the gallery," they would play, as Mr. Galton says of the demagogue in a eugenic age, "to a more sensible gallery than at present."

Darwin somewhere points out that it is not the scientific, but the unscientific man who denies future possibilities. Thus though an advocate of eugenics may be applauded for his judgment if he declares that the creation of genius will forever be impossible, yet I should not care to assert that the ultimate limitations of eugenics can thus be defined. We have yet to hear the last of Mendelism.

Eugenics and unemployment.-Let us look now at another aspect of the promise of race-culture. When the time comes that quality rather than quantity is the ideal of those who concern themselves with the population question, it is quite evident that not a few of the social problems which we now find utterly insoluble will disappear. In this brief outline, we can only allude to one or two points. Take, for instance, the question of unemployment. Vie know that some by no means small proportion of the unemployed were really destined to be unemployable from the first, as for instance by reason of hereditary 
disease. It were better for them and for us that they had never been born. Nany more of the unemployed have been made unemployable by the influence of over-crowding, to which they were subjected in their years of development. Is there, can there be, any real and permanent remedy for overcrowding, but the erection of parenthood into an act of personal and provident responsibility?

Eugenics and woman.-Take, again, the woman question. No one will deny that in many of its gravest forms, especially in its economic form, and the question of the employment of women, wisely or horribly, this depends (to a degree which few, I think, realize) upon the fact that there are now (I009), for instance, $x, 300,000$ women in excess in this country. Is it then proposed, the reader will say, by means of race-culture to exterminate the superfluous woman? Indeed, no. But is the reader aware that Nature is not responsible for the existence of the superfluous woman? There are more boys than girls born in the ratio of about $\mathrm{IO}_{3}$ or 104 to 100 ; and Nature means them all to live, boyss and girls alike. If they did so live, we should have merely the problem of the superfluous man, which would not be an economic problem at all. But we destroy hosts of all the children that are born, and since male organisms are in general less resistant than female organisms, we destroy a disproportionate number of boys, so that the natural balance of the seres is inverted. Unlike ancient societies we largely practice male infanticide. Can the reader believe that there is any permanent and final means of arresting this wastage of childlife, with its singular and far-reaching consequences, other than the clevation of parenthood, wholly apart from the question of the selection of parents? We shall not succeed in keeping all the children alive (with a trivial number of exceptions), thereby abolishing the superfluous woman by keeping alive the boy who should have grown up to be her partner, until we greatly reduce the birth-rate; as it must and will be reduced when the ideal of race-culture is realized, and no child comes into the world that is not already loved and desired in anticipation.

Eugenics and cruelty to children.-This ideal, also, offers us in its realization the only complete remedy for the present ghastly cruelty under which so many children suffer even in Great Britain, even in the twenticth century. Is the reader aware that the National Society for the Prevention of Cruelty to Children inquired into the ill-treatment or crucl neglect of II 5,000 children in the year beginning April Ist, rgo6? It has been reasonably and carefully estimated that "over 
half a million children are involved in the total of the wastage of childlife and the torture and neglect of child-life in a single year." Surely Mr. G. R. Sims, to whom I would offer a hearty tribute for his recent services to childhood, is justified in saying, "Against the guilt of race suicide our men of science are everywhere preaching their sermons to-day. It is against the guilt of race murder that the cry of the children should ring through the land." As regards race suicide and the men of science, I am not so sure as to the assertion. But the truth of the second sentence quoter is as indisputable as it is horrible.

Now no legislation conceivable will wholly cure this evil nor avert its consequences. At bottom it depends upon human nature, and you can cure it only by curing the defect of human nature. This, in general, is of course bevond the immediate powers of man, but evidently we should gain the same end if only we could confine the advent of children to those parents who desired them-that is to say, those in whom human nature displayed the first, if not indeed almost the only, requisite for the happiness of childhood. To this most beneficent and wholly moral end we shall come, notwithstanding the blind and pitiable guidance of most of our accredited moral teachers today. By no other means than the realization of the ideal defined, that every new baby shall be loved and desired in anticipation-an ideal which is perfectly practicable - car the black stain of child murder and child torture and child neglect be removed from our civilization.

Ruskin and race-culture.-The name of Kuskin, perhaps, would not occur to the reader as likely to afford support to the fair hopes of the eugenist. Consider then, these words from Time and Tide:

"You leave your marriages to be settled by supply and demand, instead of wholesome law. And thus, among your youths and maidens, the improvident, incontinent, selfish, and foolish ones marry, whether you will or not; and beget families of children necessarily inheritors in a great degree of these parental dispositions; and for whom, supposing they had the best dispositions in the world, you have thus provided, ly way of educators, the foolishest fathers and mothers you could find; (the only rational sentence in their letters, usually, is the invariable one, in which they declare themselves "incapable of providing for their children's education '). On the other hand, whosoever is wise, patient, unselfish, and pure among your youth, you keep maid or bachelor; wasting their best days of natural life in painful sacrifice, forbidding them their best help and best reward, and carefully excluding their prudence and tenderness from any offices of 
parental duty. Is not this a beatific and beautifully sagacious system for a Celestial Empire, such as that of these British Isles?"

Apart from the point as to wholesome law rather than the education of opinion as the eugenic means, the foregoing passage must win the assent and respect of every eugenist. It indicates the promise of race-culture as it appeared to John Ruskin. The passage has been quoted in full, not for the benefit of the ordinary thoughtful reader but for that of the professional literary man who, in this remarkable age, 'so far as I can judge, reads nothing but what he writes, and thus qualifies himself for dismissing Spencer or Darwin or Galton by any casual phrase.

Race-culture and human variety.- -Now let us turn to another question. Let it be asserted most emphatically that, if there is anything in the world which eugenics or race-culture does not promise or desire, it is the production of a uniform type of man. This delusion, for which there has never been any warrant at all, possesses many of the critics of eugenics, and they have made pretty play with it, just as they do with their other delusions. Let us note one or two facts which bear upon this most undesirable ideal.

In the first place, it is unattainable because of the existence of what we call variation. No apparatus conceivable would suffice to eliminate from every generation those who varied from the accepted type.

In the second place, this uniformity is supremely undesirable from the purely erolutionary point of view, because its attainment would mean the arrest of all progress. All organic evolution, as we know, depends upon the struggle between creatures possessing various variations and the consequent selection of those variations which constitute their possessors best adapted or fitted to the particular environment. If there is no variation there can be no evolution. To aim at the suppression of variation, therefore, on supposed eugenic grounds (which would be involved in aiming at any uniform type of mankind) would be to aim at destroying the necessary condition of all racial progress. The mere fact that all the critics of race-culture attribute to evolutionists, of all people, the desire to suppress variation, is a pathognomonic symptom of their critical quality.

And, of course, quite independently of the evolutionary function of variation - though this is cardinal and must never be forgotten by the politician of any school, since what we call individuality is variation on the human plane - the value of variation in ordinary life is wholly 
incalculable. It is not merely that, as Mr. Galton says, "There are a vast number of conflicting ideals, of alternative characters, of incompatible civilizations; but they are wanted to give fullness and interest to life. Society would be very dull if every man resembled the highly estimable Marcus Aurelius or Adam Bede." The question is not merely as to the interest of life. Much more important is the fact that it takes all sorts to make a world. What is the development of society but the result of the psychological division of labor in the social organism? And how could such division of labor be carried out if we had not various types of laborers? What would be the good of science if there were no poetry or music to live for? How would poetry and music help us if we had not men of science to protect our shores from plague? Obviously the existence of men of most various types is a necessity for any highly organized society. Even if eugenics were capable - as it is not-of producing a complete and balanced type, fit up to a point to turn out a satisfactory poem, a satisfactory symphony or a satisfactory sofa, the utmost could not be expected of such a man in any of these directions. In a word, as long as their activities are not antisocial, men cannot be of too various types. We require mystic and mathematician, poet and pathologist. Only, we want good specimens of each. "The aim of eugenics," says Mr. Galton, "is to represent each class or sect by its best specimens; that done, to leave them to work out their common civilization in their own way. . . . . Special aptitudes would be assessed highly by those who possessed them, as the artistic faculties by artists, fearlessness of inquiry and veracity by scientists, religious absorption by mystics, and so on. There would be self-sacrificers, self-tormentors, and other exceptional idealists." But at least it is better to have good rather than bad specimens of any kind, whatever that kind may be. Mr. Galton thinks that all except cranks would agree as to including health, energy, ability, manliness, and courteous disposition amongst qualities uniformly desirable-alike in poet and pathologist. We should desire also uniformity as to the absence of the antisocial proclivities of the born criminal. So much uniformity being granted, let us have with it the utmost conceivable variety-more, indeed, than most of us can conceive.

This point, of course, is cardinal from the point of vicw of practice. No progress could be made with eugenics, it would be impossible eren to form a Eugenics Education Society, if each of us were to regard the particular type he belongs to as the ideal, and were to seek merely 
to obtain the best specimens of that type. The doctrine that it takes all sorts to make a world - a doctrine very hard for youth to learn, yet unconsciously learnt by all who are capable of learning at all-must be regarded as cardinal truth for the eugenist. All he asks for, all he is wise in seeking, is good specimens rather than bad. Poets certainly but not poetasters; jesters certainly, but not clever fools.

Time and its treasure.-Taking the modern estimates of the physicists, we are assured that the total period of past human existence is very brief compared with what may reasonably be predicted. Granted, then, practically unlimited time, what inherent limits are there to the upward development of man as a moral and intellectual being? Shall we answer this question by a study of the nature of matter? Plainly not. Shall we answer it by a study of the nature of mind? Surely not, for the sturly of the mind cannot inform us as to what mind might be. One source of guidance alone we have, and this is the amazing contrast which exists between the mind of man at its highest, and mind in its humblest animal forms; or shall we say even between the highest and lowest manifestations of mind within the human species? The measureless height of the ascent thus indicated offers us no warrant for the conclusion that, as we stand on the heights of our life, our "glimpse of a height that is higher" is only a hallucination. On the contrary.

There is no warrant whatever for supposing that the forces which have brought us thus far are yet exhausted; they have their origin in the inexhaustible. Who, gazing on the earth of a hundred million years ago, could have predicted life-could have recognized, in the forces then at work and the matter in which they were displayed, the promise and potency of all terrestrial life? Who, contemplating life at a much later stage, eren later mammalian, could have seen in the simian the prophecy of man? Who, examining the earliest nervous ganglia, could have foreseen the human cerebrum? The fact that we can imagine nothing higher than ourselves, that we make even our gods in our own image, offers no warrant for supposing that nothing higher will ever be. What ape could have predicted man, what reptile the bircl, what amocba the bee? "There are many events in the womb of time which will be delivered" and the fairest of her sons and daughters are yet to be.

But even grant, for the sake of the argument, that the intelligence of a Newton, the musical faculty of a Bach, the moral nature of any good mother anywhere, represent the utmost linits of which the 
evolution of the psychical is capable. There is every reason to deny this, but let us for the moment assume it true. There still remains the thought of Wordsworth, "What one is, why may not millions be?"-a thought to which Spencer has also given utterance. What is shown possible for human nature here and there, he says, is conceivable for human nature at large. It is possible for a human being, whilst still remaining human, to be a Shakespeare or a St. Francis; these things are thus demonstral ly within the possibilities of human nature. It is therefore at the least conceivahle that, in the course of almost infinite time (even assuming, say, that intelligence must ever he limited, as even Newton's intelligence was limited)—some such capacities as his may be common property amongst men of the scientific type; and so with other types. We may answer Wordsworth that there is no bar thrown by Nature in the way of such a hope.

Il'hat is possible.-This of course is speculation and of no, immediate value. I would merely remind the reader that the doctrine of optimism, as regards the future of mankind, which the principles of race-culture assume and which they desire to justify, was definitely shared by the great pioneers to whom we owe our understanding of those principles. Notwithstanding grave nervous disorder, such as makes pessimists of most men, both Darwin and Spencer were compelled by their study of Nature to this rational optimism as regards man's future. The doctrine of organic evolution, and of the age-long ascent of man through the selection of the fittest (who have, on the whole, been the best) for parenthood, is one not of despair but of hope. Exactly half a century ago it struck horror in to the minds of our predecessors. Man, then, is only an erecterl ape, they thoughtas if any historical doctrine, however true, could shorten the dizzy distance to which man has climbed since he was simian; and man being an ape, they thought his high dreams palpably vain. But the measure of the accomplished hints at the measure of the possible, and the value of the historical facts lies not in themselves, all facts as such being as dead as are the individual atoms of the living body, but in the principles which grow out of them. It is of no importance as such that man has simian ancestors; it is of immeasurable importance that he should learn by what processes he has become human, and by what, indeed, they became simian--which would have been a proud adjective for its own day. The principles of organic progress matter for us because they are the principles of race-culture, the only sure means of human progress. Our looking backwards does not turn us 
into pillars of salt, but teaches us that the best is yet to be, and how alone it is to be attained.

Elsewhere the optimistic argument of Wordsworth is quoted. Here also John Ruskin:

"There is as yet no ascertained limit to the nobleness of person and mind which the human creature may attain, by persevering observance of the laws of God respecting its birth and training."

And Herbert Spencer:

"What now characterizes the exceptionally high may be expected eventually to characterize all. For that which the best human nature is capable of, is within the reach of human nature at large."

And Francis Galton:

"There is nothing either in the history of domestic animals or in that of evolution to make us doubt that a race of sane men may be formed, who shall be as much superior, mentally and morally, to the modern European, as the modern European is to the lowest of the Negro races.

"It is earnestly to be hoped that inquiries will be increasingly directed into historical facts, with the view of estimating the possible effects of reasonable political action in the future, in gradually raising the present miserably low standard of the human race to one in which the Utopias in the dreamland of philanthropists may become practical possibilities."

Conclusion-eugenics and religion.-In an early chapter it was attempted to show that eugenics is not merely moral, but is of the very heart of morality. We saw that it involves taking no life, that, rather it desires to make philanthrophy more philanthropic, that, at any rate so far as this eugenist is concerned, it recognizes and bows to the supreme law of love; and claims to serve that law, and the ideal of social morality, which is the making of human worth. Eugenics may or may not be practicable, it may or may not be based upon natural truth, but it is assuredly moral; though I, for one, would proclaim eternal war between this real morality and the damnable sham, which approves the unbridled transmission of the most hideous diseases, rotting body and soul, in the interests of good.

And if religion, whatever its origin and the more questionable chapters in its past, be now "morality touched with emotion," I claim that eugenics is religious, is and will ever be a religion. Elsewhere I have attempted to show that religion has survived and will survive because of its survival-value-its services to the life of the 
societies wherein it flourishes. The religion of the future, it was sought to argue, will be that which "best serves Nature's unswerving desire-fullness of life." The Founder of the Christian religion said, "I am come that ye might have life, and that ye might have it more abundantly." It is higher and more abundant life that is the eugenic ideal. Progress I define as the emergence and increasing dominance of mind. Of progress, thus conceived, man is the highest fruit hitherto. $\mathrm{He}$ is also its appointed agent and eugenics is his instrument.

To this end he must use all the powers which have blossomed in him from the dust. He must claim Art: and indeed in Wagner's great music-drama, at the moment when the prophetic Brünnhilde tells Sieglinde who has just lost her mate that she, the expectant mother, may look for the resurrection of the dead and the life of the world to come in the child Siegfried; and when the heroic theme is pronounced for the first time and followed by that which signifies redemption by love; then, I think, the eugenist may thrill not merely to the music, nor the humanity of the story, but to the spiritual and scientific truth which it symbolizes.

If the struggle towards individual perfection be religious, so, assuredly, is the struggle, less egoistic indeed, towards racial perfection. If the historic meaning and purport of religion are as I conceive them, and if its future evolution may thence be inferred, there can be no doubt in the prophecy that in ages to come those high aspirations and spiritual visions which astronomy has dishoused from amongst the stars, and which, at their best, were ever selfish, will find a place on this human earth of ours. If we have transferred our hopes from heaven to earth and from ourselves to our children, they are not less religious. And they that shail be of us shall build up the old waste places; for we shall raise up the foundations of many generations.

"We feel the high tradition of the world And leave our spirits on our children's breasts." 


\section{BIBI,TOGRAPHY}

LIST OF FIFTY BOOKS FROM WHCH EXCERPTS HAVE BEEN QUOTED

Babcock, Ersest Brown, and Clausen, Roy Elwood. Genetics in

Relation to Agriculture. The McGraw-Hill Book Co., I9I8.

Bateson, Milliar. Problems of Genetics. Yale University Press, r9i3.

Castle, Milliam E. Genetics and Eugenics. Harvard University Press, 2 d ed., I920.

Child, Cilarles Manntag. "Regulatory Processes in Organisms." Jour. Morph., XXII (I9I I).

Conglix, Edwin Graxt. Meredity and Environment. Princeton University T'ress, 3d ed., I920.

Coulter, Join M., and Coulter, Merle C. Plant Genetics. The University of Chicago Press, igis.

Crampton, Henry EDward. The Doctrine of Evolution. The Columbia University I'ress, I9I I.

DARWin, Charles. The Origin of Species. D. Appleton \& Co., with additions from the sixth and last edition, I 893 .

Darwin, Fraicis. Life and Letters of Charles Darwin. John Murray, Iondon, I 888 .

Dendy, Arthur. Ontlines of Erolutionary Biology. D. Appleton \& Co., I 916.

De Vries, Hugo. Species and Varieties. The Open Court Publishing Co., I904.

Downing, Eliot Rowland. The Third and Fourth Generation. The University of Chicago Press, I9IS.

Emier, Theodore. On Orthogenesis. The Open Court Publishing Co., I 898 .

Gadow, Hans. The Wanderings of Animals. Cambridge University Press, I9I3.

Guter, Micilael F. Being Well-Born. The Bobbs-Merrill Co., I9I8.

-. "Immune Sera and Certain Biological Problems." Amer. Natur., LV (I92I).

Henderson, Lawrence J. The Fitness of the Environment. The Macmillan Co., I9r3.

Herbert, S. The First Principles of Evolution. Adam and Charles Black, London, I0I3.

Jordan, David Starr, and Kellogg, Vernon L. Evolution and Animal Life. D. Appleton \& Co., Igos.

Judd, Jown W. The Coming of Eiolution. Cambridge University Press, IOII. 
Kellogg, Vernon L. Darwinism To-Day. Henry Holt \& Co., I907.

Le Conte, Joseph. Evolution. D. Appleton \& Co., 2d ed., I897.

Locy, William A. The Main Currents of Zoölogy. Henry Holt \& Co., I9rS. Lull, Richard Swann. Organic Evolution. The Macmillan Co., igi7.

McFarland, Joseph. Biology, General and Medical. W. B. Saunders Co., 3 d ed., I9I8.

Metcalf, Maynard M. An Oulline of the Theory of Organic Evolution. The Macmillan Co., IgI I.

Morgan, Thomas H. Evolution and Adaptation. The Macmillan Co., I 903.

- A Critique of the Theory of Evolution. Princeton University Press, I9I6.

Newman, Horatio H. "The Limits of Hereditary Control in Armadillo Quadruplets: A Study of Blastogenic Variation." Jour. Morph., XXII (I9II).

- The Biology of Twins. The University of Chicago Press, I9I5.

- Vertcbrate Zoölogy. The Macmillan Co., I920.

Nutrtail, G. H. F. Blood Immunity and Blood Relationship. Cambridge, at the University Press, I904.

Nutring, C. C. "The Relation of Mendelism and the Mutation to Theory Natural Selection." Science, N.S., LIII (Feb. I I, I92I).

Osborn, Henry Fatrfield. From the Greeks to Darwin. The Macnillan Co., Igos.

-_. The Origin and Evolution of Life. Charles Scribner's Sons, I9I8.

Plate, Ludwig. Über die Bedeutung des Durwin'schen Selcctionsprincips und Proleme der Artbildung. Engelmann, 2d ed., I903.

Popenoe, Paul, and Johnson, Roswell H. Applied Eugenics. The Macmillan Co., I9I8.

Romanes, George J. Darwin and after Darwin. The Open Court Publishing Co., I892.

Saleeby, Caleb Williams. The Promise of Race Culture. Moffat, Yard \& Co., I909.

Schuchert, Charles. Text-Book of Geology: Part II, Hislorical Geology. John Wiley, I9I5.

Scott, William Berryman. The Theory of Evolution. The Macmillan Co., IgII.

Shelford, Victor E. Animal Communities in Temperate America. The University of Chicago Press, I9I3.

Shull, A. Franklin. Principles of Animal Biology. The McGraw-Hill Book Co., I920.

Steinmann, Gustav. Die Abstammungslehre. Engeimann, Leipzig, igo8. Tayler, J. L. "The Scope of Natural Selection." Natural Science, Vol. XV., I899. 


\section{I 2 READINGS IN EVOLUTION, GENETICS, AND EUGENICS}

Thomson, J. Arthur. Darwinism and Human Life. Henry Holt \& Co., I909.

-. Heredity. John Murray, London, I907.

Walter, Herbert Eugene. Genetics. The Macmillan Co., rgir.

Whitulan, Cimarles Otis. "The Problem of the Origin of Species."

Proceedings of Congress of Arts and Scicnce, Lniversal Exposition, St. Louis, 1906 .

Wright, Sewalt. Principles of Livestock Breeding. U.S. Dept. Agriculture, Bull. 905 , r 920. 
INDEX 



\section{INDEX}

Abiogenesis, 12

Abraxas, 438, $45^{2}$

Acquired characters, inheritance of, 19 , 20, 273; discussion by E. G. Conklin, $330-36$; lack of evidence for, 332 , 333; misunderstandings concerning, 323-30; other side of the question, 336-38; statement of the problem, $323,33 \mathrm{I}-32$

Adaptation, II, 30, I88-205; classification of adaptations, I95, I96; Osborn's laws of, r92-95

Adaptive radiation, law of, I94, 195

Agassiz, L., I44, 145

Aggressive resemblance, $20 \mathrm{I}$

Albinos, different kinds, of, 4,3I, 432

Allelomorphic, characters in heredity, 433

Alten, E. J., 209

Alluring coloration, $20 \mathrm{I}$

Ameghino, F., 86

Amphioxus, 178

Amphisbaenidae, is

Analogous, versus homologous structures, I 36

Anaxagoras, I2

Anaximander, II

Anaximenes, II, I2

Ancestral inheritance, Galton's law of, $37 \mathrm{I}, 372$

Anti-lens serum, Guyer's experiments with, 338-45

Antirrhinum, 446

Apartness of the germ plasm, 31, 295, 296, 337

Apotetix, 448

Appendix vermiformis, in man and apes, I 54, I 55

Apteryx australis, I42, I43

Aquinas, Thomas, 8, I 5

Archaesthetism, 35

Aristotle, I3, I4, I8

Arithmetical mean, 367

Armadillo quadruplets: and classification, I22, I23; and sex-determination, 45 I
Armadillos, 97

Artificial selection, 25, 26

Aspergillus niger, 327

Atavism, 13

Atropa, 393

Augustine, 8, I5

Azores, fauna of, I03

Babcock, E. B., 287, 307-22, 363, 364, $4 \mathrm{OI}-\mathrm{I} 2$

Bacon, F., I5, 276

Balanoglossus, I 77, I 78

Bascanion anthonyi, II 7

Bat, wing of, I34

Bateson, W., 7, 43, 346, 368, 369, 380, $393,396,414,446$

Bathmism, 35

Bauer, E., 335

"Beagle," Darwin's voyage on the, 23, 25,26

Beebe, W., 316, 317

Beeton, M., 485, 489, 49 I

Begonia, 337, 338

Bell, A. G., 474, 49 I

Bembidium, 109

Bequerel, A. H., 275

Bergson, H., 34

Bermudas, fauna of, 103-5

Bibliography, 5 ro-r3

Biffen, R. H., 394

Bimodal and multimodal curves, 368 , 369

Biometry: discussion of, $3^{6} 5^{-75}$; rise and vogue of, 38,39

Birds: rudimentary teeth of, I8I; wing of, 134

Birgus latro, I38, I39, 140

Bison antiquus, 85

Blakeslee, A. F., 4 I 7

Blastoderm, I 66

Blastula, I66

Blends, in heredity, 4I6-I8

Blood-transfusion tests, evidences from $60,124-28$

Bonnet, R., 16 


\section{I6 READINGS IN EVOLUTION, GENETICS, AND EUGENICS}

Boyd-Dawkins, $\mathrm{I} 62$

Brachydactylism, 399, 400; inheritance of, 460

Bridges, C. B., 402, 437

Brünn, 40, 4I

Bryonia, 436

Buffon, G. L. L., 7, 15, 16, I7

Bullen, G. E., 209

Cameline: forefoot, 75 ; skull, evolution of, 74

Camels, fossil pedigree of, $73-76$

Cape de Verde Islands, fauna of, ro6

Carnivora, $\mathrm{x} 26$

Carnot, S., 277

Carsinas maenas, 256

Castle, W. E., 39, 40, 4I, 43, 26r, 287, $333,334,378,379,399,431,432$, $433-48$

Cataract, inheritance of, $46 \mathrm{I}$

Catastrophism, 22, 23

Cave animals, eyes of, r44, I45

Cebidae, I26

Cell: diagram of typical cell, 29I; division, direct, 290, 29I; division, indirect or mitotic, 29I, 292, 403-5; division, somatic, 403-5; theory, 289

Cenogenetic, I74

Centrosome, 290, 291, 292

Cesnola, 257

Cetacea, I 79

Chamberlin, T. C., 57

Chambers, R., 23, 26

Chapin, C. V., $48_{3}$

Child, C. M., I9I, I92, 337

Child mortality in long-lived families, 488

Chimpanzee, 88

Chromatin, 290; interchange between homologous chromosomes, 408; nucleolus, 290

Chromosomes, 291, 292; conjugation of pairs of, 407; of Drosophila, 297; in heredity, 304, 305; independent distribution of, 408, 409; individuality of, 296; maps to show loci of genes, 437,442 ; of mosquito, 297; number and appearance, 293; pairs of, 297, 407; reduction of, 297-98, 406; and sex in Drosophila, 410-1 2 ; significance of, 292, 293

Circopithecidae, 126
Clark, J. M., 85

Classification: basis of, I I7-19; evidences from, 60 , II 7-23; international code of, II7; method of, I 20-2I

Clausen, R. E., $287,307-22,363,364$, $40 \mathrm{I}-\mathrm{I} 2$

Cleavage of egg, 294

Cocoanut crab, I38, I39, I 40

Coefficient of correlation, 369,370

Coincident selection, 268, 269

Color in animals, 200-204

Coluber anthonyi, II 7

Colubridae, I 7

Colubrinae, 177

Commensalism, as adaptation, 198,199

Communal life, as adaptation, I99, 200

Comparative Anatomy, evidences from, 60, I $29-63$

Confusing coloration, 204

Conklin, E. G., 330-37, 370-75, 434, 435

Conjugation, of homologous chromosomes, 407

Convergence, Osborn's law of, 192-94

Cope, E. D., 35

Correlation: coefficient of, 369,370 ; tables, 370

Correns, C., 40, 43, 380, 393, 394, 4I 5, 416,424

Cossonidae, ro8

Coulter, J. M., 386-92, 4r 3-28

Coulter, M. C., 386-92, 4I $3-28$

Coutagne, G., 396

Crampton, H. E., 5, 32, 27 I

Cretins of Aosta, 464, 465, 478, 479

Crossing-over, in Mendelian heredity, $44^{I-48}$

Cuénot, L., 398

Curic, P., 275

Cuvier, G., I9, 21, 22

Cytoplasm, 290; in inheritance, 304

Dakin, W. J., 209

Daplinia, 335

Darbishire, A. D., 393, 398

Darwin, C., 4, 5, 6, 8, I0, I r, I7, I9, $23,24,25,26,27,28,29,30,3$ I , 45, 6I, $67,97,118,120,121,160,205,210$, $2 \mathrm{II}, 2 \mathrm{I} 3,219-44,259,260,307,330$, $427,477,5$ 이

Darwin, E., 3, 16, I 7, 18, 21 
Darwinism, 7, 8; background of, r882 I6; critique of, $245^{-62}$; defense of, general, 252-56; objections to, 247$5^{2}$

Dasypus novemcinctus, $366,375-78$

Datura, 395

Davenport, C. B., 257, 333, 372, 393, $396,474,475$

Davenport, G. C., 400

Davis, B. M., 360

De Candolle, A., 23, I22

Defectives, segregation of, $479-80$

Democritus, I 2

Dendy, A., 7I, 73

Descartes, R., I5

Determinants (Weismann's), 30, 31, 32, 265

Determination of sex, 449-56

Development: facts of, I64, 165 ; outline of animal development, $165^{-72}$

De Vries, H., $7,36,37,38,39,43,258$, $260,26 \mathrm{I}, 273,335,346-60,380,393$, 429

Difficulties and objections to Natural Selection as seen by Darwin, 236-42.

Difflugia, 378

Digby, L., 363, 364

Dihybrid ratio, 391

Dinornis gravis, $136,137,142$

Dominance, Mendel's Law of, 40-42, $38 \mathrm{I}, 382,386$

Doncaster, L., 399

Downing, E. R., 459-72

Driesch, H., 34

Drinkwater, H., 400, 460

Drosophila ampelophila, 3I8, 321, 380, 444; chromosomes of, $401,402,403$; sex-linked heredity in, $433-38$

Drummond, H., 2 I 4, 2 I 5

Durham, F. M., 429, 430

Ears of man and apes, I55, I56, 157

Earthworms and vergetable mold, 2 if

East, E. M., 43, 419

Eaton, Rev. A. E., I 43

Ectoblast, I 66

Edentates, distribution of, 98

Edwards, J., $48_{3}$

Eimer, T., 34, 35, 26.4

Elderton, E. M., 493

Electric organ, of fishes, 196
Elephants, evolution of, $76-80$

Elephas, 76, 77, 78, 79, 80; E. anliquus, S9; E. columbi, $85 ;$ E. leidyi, $8_{5}$

Embryology, evidences from, 60, I64-72

Empedocles, 12, 13

Endoblast, I66

Engrammes of Rignano, 335

Enteleche, 34

Environment: effects of, on development, 317, 318; effects of, on heredity, 3I2-I6, 318-20; and heredity, 3I2, $3 \mathrm{r} 3$

Eoanthropus daresoni, 93

Epicurus, It

Epigenesis, I3

Epilepsy, inheritance of, 465

Equidae, 70, 71, 72, 73

Equus, 7 I, 72, 73; E. leidyi, 85

Escherich, 2 I 5

Eugenics: Carnerie Laboratory of, 459 ; and cruelty to children, 502,503 ; defined, 473; Education Society, 505; and Euthenics, 48+-96; Galton Laboratory of, 459 ; positive, $480-83$; and religion, 508, 509; restrictive, $475^{-480}$; and unemployment, 501, 502 ; and woman, 502

Eupagurus, 246

Euthenics, 473, 484-96

Evolution, organic: causal factors of, I 85 ; definitions of, $3,4,5$; evidences of, 59,60; experimental, 6o; nature of proof of, 59; proof of , 57, 58, 59; what it is not, 8,9

Fabre, M., 23I

Factor hypothesis, 4I 7-28

Factorial analysis of color in mice, 42930

Factors, in Neo-Mendelian heredity: complementary, 417-20; cumulative, +24 ; inhibitory, $42 \mathrm{I}-23$; lethal, 432 ; in quantitative inheritance, $424-2 \mathrm{~S}$

Farmer, J. B., $36_{3}, 364$

I'arrabee, W. C., 400

Feeble-mindedness, inheritance of, 463 . 464

Fertilization, 30 I, 302

Fierasfer acus, 19\$, 199

Filaria sanguinis hominis, 212

Filial Regression, Galton's Law of, $372-74$

Flower, Professor, i6 2 


\section{I8 READINGS IN EVOLUTION, GENETICS, AND EUGENICS}

Forficulata auricularia, 368,369

Franklin, B., 4Sz

Freemartin, 455, $45^{6}$

Fossils: actual remains, 63 ; Cambrian, 62 ; casts and impressions, 64 ; classification of, 63 ; conditions necessary for, $64,65,66$; Darwin's opinion as to the adequacy of the record, of the, $6 \mathrm{r}, 62$; definition of (by T. H. Huxley), 63; first recognized, I2; general facts revealed by, 69, 70; pedigrees of well-known vertebrates, 70-8o; petrifications, 63

Gadow, H., I I4, I 5

Gager, C. S., 36r

Galapagos Islands, fauna of, 105-7

Gallastegui, 448

Galton Laboratory of Eugenics, 459, 474

Galton, Sir F., 38, 39, 365, 370-75, 376, $473,497-501,505,508$

Gastrula, 166

Gates, R. R., 363

Gazclle-camels, 76

Gegenbaur, I 75

Gemmules, 28, 30

Genealogical Records Office, 484, 49r, 492

Genetics: definitions of, 287 ; evidences from, 6o; importance of cell theory in, 289; methods of study, 288 ; scope and methods of, $287-89$; subject-matter of, 288-89

Genius: hereditary, 498; production of 497,498 ; transmission of, 498, 499

Genotype, 37779

Genotypic, $377-79$

Geographic distribution, evidences from, $60,97^{-1} 16$

Geologic time: lapse of, 67,68 ; scale in millions of years, 68

Germ-cells: carly setting apart of, 295, 200 ; origin of new, 294, 295; production of, $405^{-8}$

Germinal continuity, 3r, 296

Germinal selection, 3o, 3r, 265-68

(icrm-plasm theory, 31, 32

Gickic, Sir A., 69

Gill arches in vertebrates, 176,177

Giraffe-camcls, 76

Glaser, O. C., 365

Glochidia, 2I
Goddard, H. H., 462-64

Goethe, J. W., 21

Goldschmidt, R., 314, 315, 453

Goodale, H. D., 440

Gorilla, 149

Goss, J., 40

Graham-Smith, G. L., I 25

Gray, A., 223

Greek evolutionists, I I-I4

Gregory of Nyssa, I4

Gregory, R. P., 445

Gregory, W. K., 82

Guacanos, 73

Gulick, J. T., 32, 271

Guthrie, C. C., 333

Guyer, M. F., 289, 290-306, 336, 338-45

Habitat: preference, I90, I9I; selection, I90, I91

Haeckel, E., I9, 30, I 72, I73

Hair of man and apes, I 56-6I

Haldane, 443, 444

Hamilton, D. J., 326

Hapalidae, I 26

Harris, J. A., 335, 485

Harrison, R. G., 333

Harte, Bret, 85

Hartmann, C. G., I62

Harvey, IV., I3

Hauser blonds, 48 I

Ifegner, R. II., 295

IIclix hortensis, 396; H. nemoralis, 396

Henderson, L. J., I S9

Heraclitus, I2, 208

Hlerbert, S., 263, 264, 269

Heredity: Galton's Laws of, 371-75; in $\operatorname{man}, 398-400$; in pure lines, 376 , 379 ; statistical study of, $370-75$

Hermit-crabs, I38

IIeron, Sir R., 23r

IIerschel, Sir J., 3

Heterogenesis theory, 36

Heteromcra, Io6

Hetcrozygote, 390

Hialodaphnia, 3 15, 316

Hippocrates, 449

Homo: II. heidelbergensis, 88; II. sapicns, 88, 90, 92, 93; II. neanderthalcusis, So, 90, 91, 92, 93; II. primagcnius, 89 
Homologies, evidences trom. 60

Homozyote. $5 ? 0$

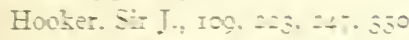

Homone theory of sex cizereztianoy. $45 \div-\Sigma 00$

Homones, 454

Horse: ancestry of. S: feet and teeth in fossil pecigee o: ; 2 : ioss peilinee

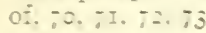

Hozishoe-crab. I27

Hrilicka. A.. : j

Hะd $=0$ ב. Wr. H.. ะ25

Human aniquity, exidences oi, 95.94

Human cozsertation. 4ij-5

Humanity, iuture o: $0 \vdots, 06$

Humerts. periorations oi, in Querrmana. Iñ

Hursi, C. C., $43.395 .306,390,400$

Hutton. J.. 2:. 5 :

Hurley: T. H.. z:. zo. 6z. 63. 9I, zos

Hyz:t. A.. 35

Hybridiestion and the orizin of species. $\div 3$

Hyracothetium. iI

Immigration and etzenics. $45-70$

Immurity coloration. =03

Induction. a temporay change in germ-cells. 335.330

Infant mortalisy morement. 40 :

Inheritance: of acquired chasactes (set Acquired characters: ȫ orachydactylism. tro: of cataract. sor: of feeble-mindedness. $450.40=-4$ : of human characters. fzo-:z: of insanity. ерilepsy, eиc. $150,405.400$ :

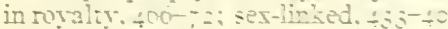

Insanity, inheritance of 40

Intraselection. zos

Isolation: biologic. z;:: generaphic. 200-7z: theories of. 20. 32.53 . 200is: reproducive, 272,273

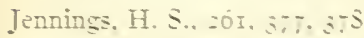

Tohannsen. II... $360.5-0.3 \%$

Johnson. R. H., 4s 400

Tones, D. F.. $4 \div$

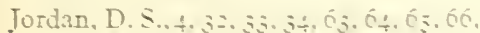

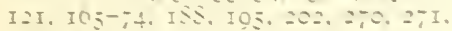
$273.47,470.452$

Toule, J. T.. 2, i

Judd. J. II., IO, 23. 24

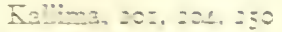

Kammerer. P.. $\$ 35$

Kan: E.. Is. I:

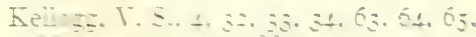

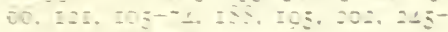

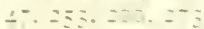

Kelin. Land o- 05. $27 \%$

hinevezen is: 35

Kinz. C.. z

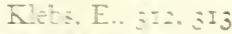

$\bar{\Lambda}-i z=\mathrm{T} . .20$

Eoklreute. T. G. f0. 4 I

Ko=cimity. H. 35

Lamarts. I P.. - zo, II. IS, I0, 20, 2I.

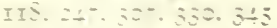

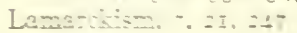

Lar:. A. 505

Leplare. P. S.. इ

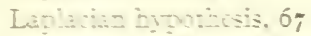

L

Le cins. I.. ‥ $40-53$

Letritan

Le.in. C. E.. :-

Lemunidiza. : :

Lezus metumorhosis o: I; I

Lezicianiren. $=3$

IA

L.m. F. K.. $-5 z-550$

L

Imovin. A. :-

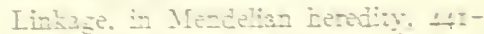

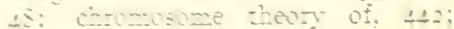
measuremens of. $44+4.45$

Linnaens. Is. - 3 , : :- :

L. II. A.. $11 . \div \div \div \div$

Lueb. C... $\div$ :

Lesz Man. Is

Lo:sy, I. P.. -3

Love. H. H . $\$+0$

Lorre... . . R.. $3: 0$

L.1c:2s. A. H. S.. =-s

Lliterius, It

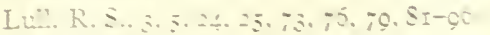

Lyches ic 8 - 50

Lyenker. R.. Its

Lyell. Sir C.. 3. . . :3. 20. 57.5 , c7

Maas. (T. Is

Macderpzl. D. T., 3I0. 320, 301. 352

Mel-actea. I.. 300 
McFarland, J., 28

McGregor, J. H., $9 \circ$

Madagascar, fauna of, I Io, III

Maeterlinck, 200

Mallophaga, 27 I, 272

Malthus, I7, 23, 24, 26, 223

Mammalian dispersal, I I4-I5

Mammary glands, as adaptations, $\mathbf{r} 66$

Man: of Chappelle-aux-Saints, 9I; Crô-Magnon Man, 93, 94; chronological table of fossil man, 87 ; descent from trees, significance of, 84 ; evolution of, $8 \mathrm{I}-96$; evolutionary changes of, 84 ; fossil man, $84-94$; Heidelberg Man, 88, 89, 9I; impelling cause of origin, $8_{3} ;$ Neanderthal Man, $80-92$; origin of, $8_{2}-8_{4}$; Piltdown Man, 92, 93; place of origin, 82,83 ; of Spy, 91 ; stock of, 82 ; time of origin, 83,84

II antis religiosa, 257

Marriage laws and eugenics, 477

Marsh, O. C., 72

Marshall, A. M., 2 I4

Marsupial pouch, as adaptation, ro6, I97

Mastodon, $76,77,78,79,85$

Materialism, the relation of evolution to, 46-53

Matthew, W. T., 8 I

Matthiola, 394

Maturation: of egg-cell, 299, 300, 301; of sperm-cell, 298, 300

Maupertius, I 5

Median, in variation, 367

Meek, 364

Megalonyx jeffersoni, 85

Mendel, G., 40, 260, 346; his conception of purity of gametes, 386,387 ; his conception of unit characters, 386 ; his experiments, 38I; his cxplanations, 386-92; his Law of Dominance, $40-42,381,382,386$; his Law of Segregation, $40-42, \quad 382-385$; his life and character, 380 ; his results, 381,382

Mendelian heredity: in cats, 399; crossing-over in, $44 \mathrm{I}-48$; in guineapigs, 399, 432, 433; in Helix, 396; in Lina lapponica, 396; linkage in, $441-48$; in maize, 394,394 ; in man, 399,400 ; in mice, $384,385,398$; in nettles, 395; in numerous species, 393,394 ; in peas, 384 ; in pigeons,
397,398 ; in poultry, 396,397 ; in rabbits, 399; in silkworms, 395, 396

Mendelism: physical basis of, $40 \mathrm{I}-\mathrm{I} 2$

Mesohippus, 72

Metcalf, M. M., 6, 32, 200-204

Metz, C. E. V., 297, 363, 436

Meyer, L., I55

Miastor americana, 294, 295

Millson, A., 2 I4

Milton, J., I4

Mimicry, 203

Miohippus, 72

Mirabilis jalapa, 394, 4r5, 4r6, 424; M. rosea, 394

Mivart, 135, I36

Mneme theory of Semon, 335

Mode, in variation, 367

Modifications, 308, 309

Moeritherium, $76,77,78$

Monohybrid ratio, 389

Moore, C. R., 454

Morgan, L., 264

Morgan, T. H., 42, 43, 44, 260, 26I, 267, $318,321,355^{-60}, 379,433^{-38}, 442$, 443

Morphology, evidences from, r $29-63$

Moulton, F. R., 57

Miiller, F., I 70, I 72, 239

Müller, H. J., 408, 437

Multiple factor hypothesis, 424-28

Mutation theory, 346-64; advantages over Natural Selection, 359; alternative to Natural Selection, 272; criticism of, 360; De Vries' own account of, 348-55; historical account of, $36-38$; Morgan's summary of, $355^{-59}$

Mysis larva of Peneus, I 70

Nabours, R. K., 448

Nägeli, C. von, $34,35,333,380$

Natural Sclection, 4, 12, 24, 25, 26, 35, $37,38,223-43$; experimental support of, 256-58; present status of, 258 ; relation of Mendelism and mutation to, 258-62

Naudin, C., 4I

Nauplius larva of Peneus, I70

Neanderthal Man, 88-92

Nebular hypothesis, 57

Neo-Lamarckism, 29, 335, 336 
Neo-Mendelism, 43, 44, 45, 413-32

Nest-making instincts, as adaptations, 197

Nettleship, E., 400, 46I

Newman, Colonel, 2 I I

Newton, Sir F., 7, 276, 277, 280, 283

New Zealand, fauna of, I Io, I I I

Nictitating membranes of vertebrates, I46, I47

Nilsson-Ehle, HI., 424-28

Nitsche, Dr., I 55

Nucleolus: chromatin, 290; true, 290

Nutritive chains, 208

Nuttall, G. H. F., I 24 , I 25

Nutting, C. C., 258-62

Oceanic islands, fauna of, roI-ro

Octopus, eye of, I35

Oenothera, 35; O. albida, 355; $O$. bicnnis, 349; 0 . brevistylis, $349 \mathrm{ff}$; O. elliptica, $355 ; \quad 0$. gigas, $353 \mathrm{ff}$.; $O$. lata, $355 ; O$. laevifolia, $349 \mathrm{ft}$; $O$. lamarckiana, 3i, 3+6-6o; $O$. leptocarpa, 358; O. nannella, $310 \mathrm{ff}$; O. rubrineritis, $353 \mathrm{ff}$.; O. scintillans, 355 ; O. spatulata, $35^{8}$

Oglivie, Dr., 326

Oken, 12 , I6

Onagra bicnnis, 362

.Ontogenetic selection, 268

Oöcyte, 300

Oögenesis, 299, 300

Oögonium, 300

Organic selection, 268, 269

Origin of Species, The, 4, 5, 7, 24, 27, $6 \mathrm{I}, 62,67$

Ornithorhynchus, 236

Orohippus, 72, 73

Orr, H. B., $46_{5}$

Orthogenesis, $33,34,35,36,273$

Orthoplasy, 268

Osborn, H. F., 8, IO, II, I3, 20, 2I, 45, $86,87,89,94,05,192-95,273,274^{-83}$

Overspecializations, $3 \mathrm{I}$

Ovum, I64

Owen, R., 121, I50, 240

Pagurus bernhardus, 139

Palaeomastodon, 76, 77, 78

Palaeontology, evidences from, 60 ; opinions as to the adequacy of, 62,63 ; strength and weakness of, 6I, 62
Palingenetic, 174

Pan vetus, 88

Pangenesis, 28, 30

Panmixia, 3 I, 263, 264

Panniculus carnosis, 148,149

Papilio machaon, 35

Paramecium, 377

Parasitism, as adaptation, 197,198

Partlienogenesis: as a method of asexual development, I04; sex determination in connection with, $45 \mathrm{I}, 452$

Pearl, R., $4+0$

Pearson, K., 39, 365, 371, 373, 484, 489, 49I, 493

Pedigree: of bracliydactylism, 460; of cataract, 46r; of Charles the Great of Sweden, 47I; of feeblemindedness, 403,464 ; of Ferdinand and Isabella, 468; of Hohenzollerns of Prussia, 470; of insanity, epilepsy, etc., 465; of Romanoffs of Russia, $4^{6} 7$

Pencus potimiritum, r 70 , I $7 \mathbf{I}$

Phaseolus, 376

Phenotype, 377-79, 390, 43I

Phenotypic, $377-79,390,431$

Phillips, J. C., 333

Phocochaerus, 324,325

Physiological units, 28

Pisum quadratum, $3 \mathrm{~s} \mathrm{r} ; P$. saccharatum, 38r; P. sativum, 393; P. umbellatum, $38 \mathrm{I}$

Pithecanthropus crectus, 86, $87,88,90,93$

Planetesimal hypothesis, 57

Plate, L., 264, 265, 37 I

Pliny, I4

Pliohippus, 72

Ploetz, A., 489, 490, $49 \mathrm{I}$

Podocoryne, $24^{6}$

Poëbrotherium, 74, 75

Polar bodies, 200, 300, 301

Popenoe, P., 484 - 6

Post-Aristotelians, It

Poultun, E. B., 257

Preformation doctrine, ${ }_{7} 6$

Prenatal influences, I3, I4

Presence and aisence hypothesis, 4 I3 15

Primates: geologic record of, $8_{2}$; origin of, SI, S2; place of origin; stock of, $S_{1}$; time of origin, Si 
Primula kiwensis, 364; P. sinensis, 317, 394, 445

Priority, law of, in 7

Probable error, 368

Procamelus, 74, 75

Promise of Race Culture, 497-509

Pronucleus: malc, 301 ; female, 302

Protective rescmblance, 200, 201

Protohippus, 72

Protylopus, 74, 75

Pterodactyl, wing of, I 34

Punnett, R. C., 385, 395, 396, 446

Pure lines, heredity in, 376-79

Purity of gametes, $386,3^{8} 7$

Python, hind limbs of, I4I, I42

Quadrumana, 148

Rabl, C., I 66

Race culture and human variety, 504, 505

Rana sylvatica, 333; R. palustris, 333

Recapitulation, doctrine of, 60 , 171 , I72; critique of, $173-82$

Reduction divisions, in maturation, 405

Reighard, J., 203

Remora, I99

Reversion, I3

Revival of Science, the, ${ }_{5}, 16$

Rhodcus amarus, $2 \mathrm{I} 2$

Rignano, E., 335

Robinson, L., I51, I52

Rodentia, loss of teeth in, I 80

Romancs, G. J., 35, I0I-Io, I 29-63, 263 , 264,329

Roosevelt, T., 2 17

Rosanoff, A. J., 465

Roux, II., 268

Rumford, B. T., 277

Ruminants, collar-bone of, I 80

Ruskin, J., 503, 504, 508

Ruskin and race culture, 503, 504

Rutherford, İ, 275

Sacculina, I7 I, I8 I, 198, 453

Saleeby, C. W., 497-509

Saltatory, variations, 38

Sandwich Islands, fauna of, I09, I Io

Saunders, 393
Scardafella inca, 316, 3I7; S. dialcucos, 316, 317; S. braziliensis, 316, 317; S. ridgwayi, 316,317

Schoetensack, Dr., 89

Schuchert, C., 67, 68, 69

Scott, W. B., 5, 6, 62, 63, 73-6, 82, I $23^{-}$ $28,173-82$

Scrophularia, 319, 320

Scals, comparative anatomy of, 129, I 30

Secondary sexual characters, 453,454

Sedum spectabile, 312-It

Segregation, Mendel's Law of, 40-42, $382-85$

Semon, R., 335

Serology, evidences from, 60

Sex determination, 449-56; chromosome mechanism of, in Drosophila, $410 \mathrm{ff} . ; \quad$ in parthenogenetic species, 45I, 452; nutrition theory of, 449; at time of fertilization, 449, 450; various theories of, $449^{-5}$ I

Sex differentiation, $453^{-56}$

Sex, Heredity and, 44, 305, 306

Sex-linked inheritance, 433,440

Sexual coloration, 204

Sexual Selcction, 26, 230-32

Shelford, V. E., I90

Shull, A. F., 73, 76-80, 100, Ior, I $17-20$

Shull, G. H., 43

Signals and recognition marks, 203, 204

Sims, G. R., 503

Smith, E. A., 339

Smith, G., 453

Snow, E. C., 493

Solidago virguarea, 324

Species, definitions of, I 2 I, I 22

Spencer, H., 4, 19, 28, 29, 264, 325, 508

Spermatid, 298, 299

Spermatocyte, 298, 299

Spermatogenesis, 298, 299

Spermatogonium, 298, 299

Spermatozoön, r6 5, 298, 299

Spontancous generation, I2

Sports, 38

Sprengel, C. K., 2 ro

Standard deviation, 367,368

Staples-Brown, R., 397

Statistical study: of variation, $365-70$; of heredity, 370-75

Stegodon, 76, 77, 78, 79 
Steinach, E., 454

Steinmann, G., 6

Stejneger, II 7

Sterilization laws, 479, 480

Stock on graft, no influence of, 333, 334

Stockard, C. R., 322, 335

St. Helena, fauna of, $107^{-9}$

St. Hilaire, E. G., 2I, 22, 220

Strangeways, T. S. P., I 25

Sturtevant, A. H., +37

Subsidizing the fit, $480-82$

Survival of the Fittest, 223-30

Swainson, I 22

Synapsis, 298, 407

Systema Naturae, of Linnaeus, II 7

Tail, vestigial in man, I $52, I_{53}$

Talent, the production of, 499,500

Tasmanian Wolf, 127

Tayler, J. L., 253-56

Taxonomy, the method of, i i9-20

Teleology, I3

Termites, 2 I4, 2 I 5

Tetrakinetic theory of Osborn, 274, 275$8_{3}$

Thales, II

Theologians, the early Christian, :4, I5

Thompson, A., I 53

Thomson, J. A., 97, I91, 205-18, 323$30,380-85,393-400$

Tibia, flattening of, in man, 162

Tomes, C. S., I6r

Tower, IV. L., 321, 322, 360, 36r, 377

Toyama, K., 393, 395

Trihybrid ratio, 391, 392

Trilophodon, $76,77,78,79$

Tschermak, 40, 43, 380, 393

Turner, Sir W., I6 I

Tuttle, E., 483

Twins, evidences from in support of classification, I 22

Typhlopidae, I 9

Uhrschleim, I2, I6

Uniformitarianism, 22, 23

Unit characters, Mendelian, 386

Urtica dodarti, 394, 395; U. pilulifera, 394,395
Vanessa io, 3I4, 3 I 5

Variation, 307-22; classification of, 308-II; concept of, 308; continuous and discontinuous, 3II, 346; and development, 3 II; and environment, 312; germinal, 308; nature of, 309 , 310 ; polygons of, 366,367 ; somatic, 308 ; statistical study of, $365^{-} 70$; universality of, 307,308

Vasectomy, 479

Vestigial structures, evidences from $60,140-63$

Virchow, R., 91, 240

Volta Bureau, 474

Wagner, M., 269, 270

Walcott, C. W., 62, 64, 67

Wallace, A. R., 17, 26, 27, 36, 97-100, I IO-I3, I22, 239

Walter, H. E., 373, 473-83

IVarning coloration, 202, 203

Weismann, A., 3, 7, 30, 3I, 32, I95, 247, $258,260,263-68,28 \mathrm{I}, 330-3 \mathrm{I}, 428$

Weismannism, 7

Weldon, W. F. R., 256, 257

Whales, comparative anatomy of, I3I33; embryology of, 179, 180

White, G., 206, 2 I 2, 2 I 3

White, T. H., 320

Whitman, C. O., 35

Whitney, D. D., 335

Whymper, 479

Wilberforce, Bishop, 28, 29

Williston, S. W'., 35, 83, 85

Wilson, E. B., 6, +4, tor

Wings, comparative anatomy of, I34

Woltereck, R., 3 I5, 3r6, 335

Woods, F. A., 466-72

Woodward, 88, 92

Woolner, I55

Wordsworth, W., 507

Wright, Sewall, 164, 165

Wyman, Professor, 150

Xenophanes, 12

Zea mays, 395

Ziegler, E., 326

Zoëa larva of Peneus, 170

Zygote, I65, 297 



, 

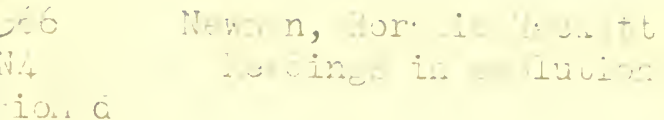

PLEASE DO NOT REMOVE CARDS OR SLIPS FROM THIS POCKET UNIVERSITY OF TORONTO LIBRARY 
